

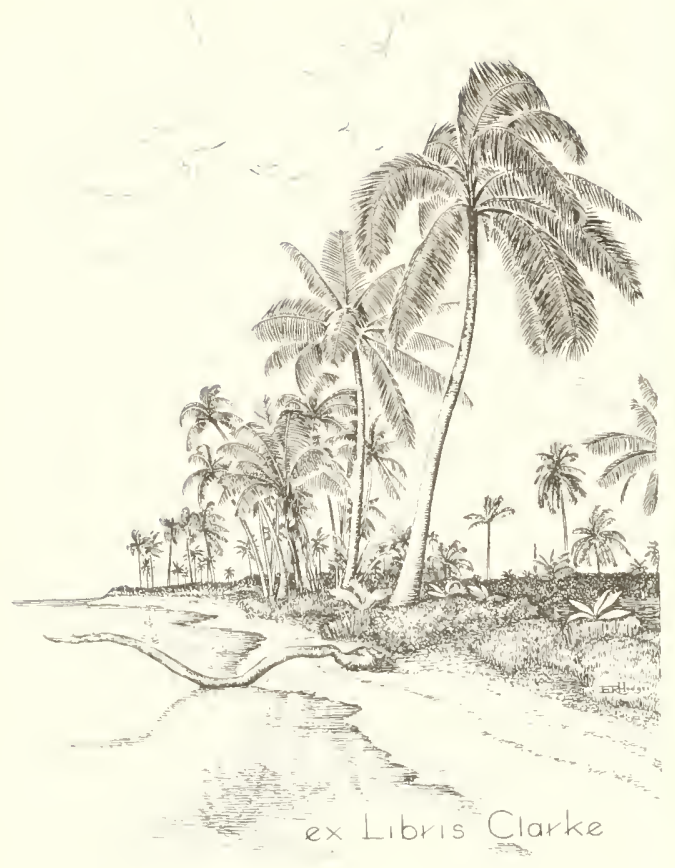




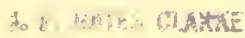







\title{
Beiträge zur Kenntniss
}

\author{
der
}

\section{nordamerikanischen Nachtfalter,}

\author{
besonders der Microlepidopteren. \\ Von \\ Propessor P. C. Zeller \\ in Grünhof bei Stettin.
}

Erste Abtheilung.

(Mit Tafel II und III.)

Vorgelegt in der Sitzung vom 6. März 1872.

J

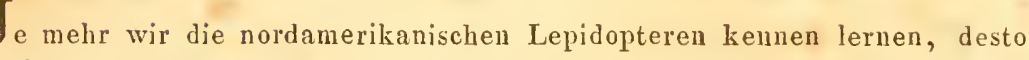
mehr Arten finden wir, die dell europäischen sehr nahe stehen oder sich gar nicht von ihnen unterscheiden lassen. Wenu man also jetzt, und mit Recht, den ganzen Norden Asien's nebst Kleinasien und den Nordrand Afrika's zur europäischen Falterfauna rechnet, so wird diess bestimmt auch nicht bloss mit Island, Grönland und Labrador, deren Producte schon seit längerer Zeit mit unter die europäischen aufgenommen sind, sondern auch mit Canada und einem grossen Theile der Vereinsstaaten geschehen. Es ist auffallend genug, dass diess bisher unterblieben ist, da doch sibirische Producte olne Vergleich schwieriger uach Europa gelangen als amerikanische. Su viel mir bekannt ist, hat Dr. S taudinger die letzteren, mit Ausuahme der hochnordischeu, nur darum aus seinem vortrefflichen Catalog ausgeschlossen, weil er sie und ihre Literatur kemnen zn lemen noch nicht Gelegenheit genug gehabt hat.

Man thut den amerikanischen Lepidopterologen im Allgemeinen wohl ni ht Unrecht, wenn man behauptet, dass sie es sich zu wenig allgelegen sein lassen, die transmarinen Entomologen mit ihrer Fauna bekanut zu macl 'u und dagegen deren Fauna kennen zu lernen. Die Folge davon ist, dass sie ibre eigenen Producte nicht gründlich kennen lernen und 
7. B. ilıre mit den europäischen identischen Arten mit neuen Namen bezeichnen und, wenn sie ökonomische Bedeutung haben, die in Europa gemachten Erfahrungen nicht benutzen, oder die den europäischen Arten zunächst stehenden für identisch halten und also mit denselben Namen versehen.

Einer der grossen Uebelstände ist ferner die Schwierigkeit, sich dio nordamerikanische Literatur zu verschaffen, eine Schwicrigkeit, über die selbst in Amerika geklagt wird, indem auch den dortigen Entomologen bei weitem nicht alle literarischen Hilfsmittel zur Hand oder anch nu: zugänglich sind. Vieles wird dort so publicirt, dass man es nur geschenkt oder zufällig erhalten kann. lrond ein Staat gibt nämlich das Geld zum Druck eines Report her; dann erhalten Senatoren, Abgeordnete und Beamte Freiexemplare; ein bestimmter kleiner Theil wird zum Austausch gegen ahuliche Reports anderer Staaten und zu Geschenken für Gesehlschaften und einige Dutzend Gelehrte aufgehoben. So sind sic für kein feld zu erhalten, ausser etwa antiquarisch, und oft lange nachher, nachdem daron Lätte ein nützlicher Gebrauch gemacht werden können. So ist es mit den Berichten voll Asa Fitch, I, e Barou und Andern; ja man erführt nicht einmal, was erschienen ist. ') Welch' ein Schade das ist, lässt sich leicht einsehen, weun man sich rou dem Eifer überzengt hat, mit welchem man dort in der Biologie der ókonomisch wichtigen Insekten vorwärts zu kommen strebt.

Ucber einen sehr wesentlichen Uebelstand haben ich und Andere bitter zu klagen vielfach Ursache gehabt, so dass ich glaube, ihn hier nicht übergehen zu dürfeu: Es ist die Methode bei der Uebersendung der getrockneten Insekten nach Europa. Zunächst scheinen sich manche do:tige Lepidopterologen nur ron dem zu trennen, was fiir sie gar keinen Werth meln' liat: vou rerflogenen, verstimmelten, verdorbenen Exemplaren. Ter wie Guenée als Sammler der Producte aller Erdtheile nothgedungeu auch das aufuahm, was ihm nach der gewöhnlichen Behand!nug hei Versendungen aus Nordamerika noch mehr verdorben zukam und sich genöthigt sah, bei seinen Pnblicationen auch mit unvollkommenem Material $z u$ arbciten, musste wohl theilweise Darstellungen geben, die niclit nur den Europäern, sondern auch den amerikanischen Lepidopterologen schwer zu lösende Räthsel bieten, gleichsam als Vergeltung fïr die ihm rou dort her gewordene ungenïgende Unterstützung. Zu der gewöhnlich schou bedenklichen Beschaffenheit des Materials kommt die nachlässige Weise

1) Unter diesen Umstiuden ist es ein wahrer Segen, dass Dr. Packard angefangen hat, nach dem Beispiele der Erichson-, Schaum-, Gerstäcker-, Brauerschen Jahresberichte die Records of American Entomology herauszugeben, wodurch man nu wenigstens erfahren wird, was in jedem Jahre erschienen ist. Dabei bleibt noch das sehr tiefe Dunkel zu heben, das über den Erscheinungen ror dem Jalıre 1869 schwebt. 
der Verpackung für den Transport, der zufolge, wenn man endlich erwartungsvoll eine Kiste öfnet, der Anblick eines Trimmerlsaufens oft scluweres Herzleid bereitet. Wie übel die Versendungen nuf dem Trege über Washington, vermittelst der Smithsonian Institution, ganz regeluäss: g gerathen, haben wir, Director Loew und ich, mehr als hinreichend erfahren. Dass aber der Vermittler der Zusendung nu ansmahmsweise die Schuld an dem Unbeil trägt, scheint daraus hervorzugehen, dass die Empfänger der auf demselben Wege ron Europa nach Amerika gaelangten Sendungen regelmässig ihre völlige Zufriedenheit iiber deren Beschaffenheit aussprechen komnten. Es ist nicht zu verwunderm, wenu ein grossel Tlucil der europäischen Sammler, an saubere Haltung der Präparate gowöhnt, sich so lange gegen eine Bereicherung durch verstïnmelte und verdorbene Exemplare völlig gleichgiltig zeigt, bis die Ausgabe eines neuen Staudinger-Catalogs, worin die nordamerilianische Fanna nicht mehr von der europäischen getrennt wird, für die Erwerbung besseren Materials thätiç zu sein nüthigt.

Da ich selbst gegen die Abschliessung auf ein bestimmtes Faunengebiet, die zugleich eiue absichtliche Verschliessung gegen die genane Kenntniss der Producte eben dieses Gebietes ist, ron jeher gewesen bin, so benütze ich die Gelegenheit, die eine reiche fïr das Cambridger lfuseum gewonnene Sammlung Texaner Schmetterlinge bietct, deren Benützung die Herren Agasiz und Hagen mir gestatten, etwas dazu beizutragen, dass der Werth, den die amerikanischen Producte fïl die Kenntniss der europäischen und umgekehrt haben, bessel gewiirdigt werde, dass man diese Producte genauer kennen lerne, und dass ein regerer Verkehr zwischen den Lepidopterologen beider Erdtheile zu Stande komme. Ich habe mich dabei jedoch hauptsächlich anf die niederen Formen der Nachtfaiter beschränkt, weil für diese das Interesse bei den Amerikanern im Allgemeinen erst geweckt werden muss.

Das zur rorlicgenden Arbeit theilweise benïzte Material haben mir verschiedene Zusendungen von seht ungleicher Gïte und Reichloaltigkeit durch die Herren Dr. Packard (den berühmten Verfasser des Guide to the study of Insects), Burgess (den Conservator de. Museums in Cambridge), Edwards in Sin Francisco, Bischoff in Ohio etc. geliefert; das Mciste stammt aus den Einsammlungen, welche die Iferren Boll (aus Bremgarten in der Schweiz) und Belfrage in Texas gemacht luaben. Unbedingt am bcsten erhalten ist das, was Herr Boll im Jabre $1870^{\circ}$ gesammelt und an das Museum in Cambridge abgeg'eben hat. Die von ihm durchforschte Gegend, die wasserleiche Dallas County im uördlichen Texas, liegt $800-1000^{\prime}$ über dem Meere. Die etwas tiefere Niederung. wird rom Trinity river durchlossen und ist bewaldetes Allurium; das Tafelland selbst ist, wo es nicht mit der Post-oak (Quercus obtusifuliu) bewaldet wird, röllige Prärie. Der gelinde Winter dauert hier 2 Monate; 
die schleclsteste Zeit zum Sammeln ist im Juni und Juli; die reichste fällt in die darauf folgenden Monate bis zur Mitte October, in welcher Zeit sich eine zweite Generation entwickelt. Leider hat Boll nur bei den wenigsten Arten die Flugzeit angemerkt, so dass die von Belfrage (durch Stainton und Loew) erhaltenen Exemplare einen wesentlichen Vorzug ror den seinigen haben, inden jedes einen Zettel mit dem Datum des Fanges an der Nadel trägt, ein Vorzug, den sie mit den meisten mir durch Herru Burgess zugeschickten theilen. Dagegen kann au den Belfrage'schen Exemplaren die Art der Conservation nicht genug gerügt werden, denn fast alle haben den grössten Theil der Fransen und folglich auch der Flïgelschuppen, wenigstens auf der hinteren Flügelfäche, eingebiust, was offenbar daher gekommen ist, dass sie stundenlang in der Hitze umhergetragen wurden, ehe man sie tödtete; sie sind daher in den seltensten Fällen zu etwas Anderem als zum völligen Abschuppen und zur Untersuchung des Geäder's zu verwenden.

Meine literarischen Hilfsmittel bestehen ausser den älteren Werken hauptsächlich in den Arbeiten Guenée"s, Walker"s, Lederer"s, Clemens", Grotes und Robinsou"s. Guenée lat in seinen Noctuélites (3 Theile) 1852, Uranides et Phalénites (2 Theile) 1837 und Deltoides et Pyralides (1 Theil) $185^{\prime}$ anf eine Weise gearbeitet, über welche Lederer in der Einleitung zu seinem Pyralidenwerk (Beiträge zur Kenntniss der Pyraliden, im VII. Bande der Wiener entomologischen Monatschrift 1863) ausfibrlich und trefiend spricht.*) Mich gehen hier nur die Genera und Species an; sie sind nach der seichten, leichten, eleganten französischen Weise behandelt, die denjenigen, der seine Exemplare bestimmen will, meist in Verzweiflung zu bringen geeignet ist.

Ueber Fraucis Walker's umfassende Arbeit (List of the specimens of Insects of the British Museum) sind die verdammenden Urtheile Stål's, Auton Dohrn's, Lederer"s, Herrich-Schäffer's zu bekant, als dass sich ohne Wiederholungen viel iiber dieselben Punkte sagen liesse; ich gebe daher nur einige ergänzende Bemerkungen. Zunächst fïge ich zu den Verdammungsurtheilen das von Brunner v. Wattenwyl (Verhllg. d. zoolog.-botiu. Gesellsch. 1870, S. 161 ff) und das roll Grote und Robinson (in den Transactious Amer. Ent. Soc. Philadelphia, Juliheft) ausgesprochene bei. Da ich wohl Derjenige bill, der in der Ueberzeugung, dass cin mit so gewaltigen Material gearbeitetes $W^{r}$ erk, ron einem Manne, der früher, ehe er seine Unglücksarbeit unternalım, Tüchtiges leistete - weil man iln ja sonst die Anfertigung des MuseumsCatalogss nicht übertragen hätte - und der mit den Verdammungsurtheilen

$\left.{ }^{1}\right)$ Auch Herrich-Schäffer urtheilt melurfach ebenso. z. B. im Correspondenzblatt 1868 bei der Bearbeitung der Cubaner Noctuen S. 114, 147 (Leucania), 153 (ror Celaeno). 
nicht unbekannt geblieben sein kann, so dass er wenigstens später eine bessere Art des Arbeitens hätte einschlagen müssen, dass also dieses Werk für meine $Z$ wecke wenigstens einiges Bedeutende gewähren würde, melir Zeit als Andere auf dessen Studium verwendet habe, so halte ich mich für ebenso gut zu einem Urtheile berechtigt, wie die früheren Beurtheiler. Dieses Urtheil fällt dahin aus, dass die Lepidoptern am Ende wo möglich noch schlechter gearbeitet sind als in den frïheren Theilen, weil offenbar der Verfasser sich in seine Weise zu arbeiten so eingewöhnt hat, dass er von ihr nicht mehr zu lassen vermochte, und dass sie, so lange sie nicht bis auf den letzten Rest versehwunden sind, ein trauriges Denknal für ihren Verfasser und eine stehende Warnung für jeden kïnftigen Arbeiter bleiben werden. Diejenigen, die Walker's Vertheidigung übernommen lıaben, künnen uie den Versnch gemacht haben, das Werk auch nur in einem kleinen Theile und für ganz kurze Zeit zu studiren; ihnen wird es zu dauken sein, dass sich immer noch Engländer finden, die ihre ans fernen Gegenden erhaltenen Sendungen von Walker bearbeiten lassen, so dass man imner noch zu oft auf den ominösen Titel: Characters of undescribed etc. by Francis Walker stösst und zum Seufzen über den Zuwachs an dieser Sorte von Literatur veranlasst wird.

Auf eimen Punkt, den man noch nicht genug in's Auge gefasst luat, glaube ich aufmerksan machen zu müssen: Die rou Walker gebildeten Namen für seine sogenannten Genera und Species. Jan hat seinerzeit viel gespottet ïber Artenbenenungen wie: Lapidisaria und Abietisana. Dergleichen und ärgere Missbildungen sind bei Walker in soleher Unzahl vorhanden, dass es den Anschein l,at, als habe er sie mit rölligem Bewusstsein und absichtlich geschaffen, da sich kaum denken lässt, dass Jemand, der sich herausnimnt, griechische und lateinische Wortbildungen aufzustellen, mit den Gesetzen dieser Spracheu ganz unbekanut sein werde. Weil es ihm zu zeitraubend war, sich um einigermassen bezeichnende lateinische Benennungen zu bemühen, so nahm er kurzweg ein Register lateinischer und griechischer Eigennamen, griff blindling's den ersten besten für eine zu taufende Art heraus und ling ihm ohne alle Aenderung die Endung alis etc. an. Es wïrde eine sehr lange Liste werden, wenn man nur alle Züuslernamen von dieser Beschaflenheit — dem sie hauptsächlich sind auf diese Art entstanden - autzählen wollte. Wird man solche Namen, wie: Claudiusalis - Eudoxusalis - Lysippusalis Lycopusalis - Narcissusalis - Ocellusalis - Perseusalis - Orasiusalis und Orasusalis - Ulricusalis - Pyrrhusalis (ausserdem Pyrrhalis) - Eurytusalis (ausserdem Eurytalis) - Thyrisalis - Phyllisalis - Irisalis Niciasalis - Dawoetesalis - Eryxalis - Lelexalis - Caepioalis - Vetusalis etc. etc. etc. in der Wisseuschaft dulden? Die Nordamerikaner, bei denen es Grundsatz ist, dass derjenige, der einer Art ihren I'latz in eincm andern Genus anweist, als in welchem sie bisher stand, damit 
zugleich die Paternitït übernimmt und seinen Namen als Autorität dahinter zu schreiben hat, soliten doch am lieftigsten opponiren. Denn da die Versetzung sehr rielcr Walker'schen Arten ju andere Gattungen nöthig ist, so wïrde Jeler, der nicht seinen Namen als den des Erzeugers eines Inbrexalis, Pelopsalis, Narcissusalis und anderer Noustra ansehen lassen will, eine jede solche Transaction unterlassen müssen. Lederer hat in seinem Pyralidenbuch manche Walker'sche Benenung den Sprachregeln gemäiss berichtigt, und meiner Ansicht nach muss es mit allen geschehen.

Hat Francis W $\mathrm{V}$ lker es sich mit den Artnamen leicht gemacht, so hat er fiir die Benenung dessen, was er neue Gattung nenut, einen andern, aber ebenso bequemen Treg gefunden. Er nahm ein paar Consonanten und ebenso viele. Vocale, wïrtelte sie durcheinander, bis sich etwas wie ein Wort gebildet hattc, und der geforderte Name war da! Welch" eine bewundernswiindige Zahl solcher Geschöpfe, wie Davana, Datana, Nadata, Nachaba, Bardaxima, Rusicada, Orudiza verdankt diesen Verfahren inc Entstehung! Man hat gesagt, solche Namen seien wengstens wohlklingend. Das möchte selbst für ein englisches Ohr bei manchen Namen, z. B. Tiauspa, Chabuata, Phuphena, etwas fraglich seil. Aber welche Ammassung, lrformen zu bilden, die zum Theil wie kindisches Lallen klingen, die dem Gedächtuisse so wenig Anhalt bieteu, dass der Schöpter derselben selbst sie in der nächsten Viertelstunde vergessen haben muss, und den Lepidopterologen zuzumutlen, dass sie dergleichen Unrath sanctioniren solien! Hoffuntich werden die meisten dieser Namen, sobald die danit gemeinten Thiere bekannt geworden sind, durch Zusanmeufallen mit älteren von Andereu gegriindeten Gattungen ihre Existenz und damit ihren Werth fïr die Priorititenhüter verlieren!

Zum Schlusse dieses unerquicklichen Capitels erkläre ich, dass, nachdem ich so viele Stunden meines Lebens mit der Walker'schen Taglöhnerarbeit verloren oder vielmehr vergeudet habe, ich nicht gesonnen bin, diess fernerhin zu thun, sondern bei der Fortsetzung meiner Albeiten iiber nordamerikanische Mikrolepidopteren die Walkerschen Namen für Tickler und Timeinen nur berïcksichtigen werde, wo sie mir von Anderm überzeugend machgewiesen werden.

Clemens hat mit schr mangelhaltem IIaterial grearbeilet und hicr und da, z. B. bei den Craubiden, aut die Unterscheidung ron verwandten Arten so wenig liücksiclit genommcn, dass er in einzelnen l'unliten dunkel und unverständlich bleiben musste, und dass man ïber manche seiner Species nur durch Befragung seiner Sammlung Auskuntt erhalten kann.

Die Aufsätze von Grote und Robinson stehen fast in jeder ILinsicht als Muster da; ilue Beschreibungen sind mit grosser Sorgfialt und fienauigkeit eutworfen, und wenn man auch Diagnosen bei ihnen schmerzhaft vermisst, so haben sie durch Vergleichng mit naliestehenden Arten, sowie durch gute Abbildungen dem Mangel grossentleils abgeholfen. 
Es stände auders und ohne Vergleich besser, weun ihre Vorgänger eben so gewissenhaft gearbeitet hätten. Grote und Robinson haben Mühe und Kosten nicht gescheut, sich persönlich im British Museum Auskunft zu holen, um ihre Arten wit den Walker'schen in Uebereinstimnung zu bringen. Der lesenswerthe Aufsatz, der das Resultat ihrer Pilgerschaft zu Francis Walker mittheilt, ist in den Transactions of the Amer. Ent. Society, Philadelphia 1868 (Sep. pag. 1-22) enthalten. Was aber war das Resultat? Eine Menge Synonyme 'Walker'scher Arten zu einander, die sonderbarsten Plätze der Arten in den Gattungen (wie ja schon andere Entomologen in andern Insektenordnungen fanden), Beschreibungen nach völlig unbrauchbaren Exemplaren, die jeder nur einigermassen gewissenhafte Arbeiter wo nicht weggeworfen, doch unbeachtet gelassen hätte, und Exemplare, die gar nicht zu den Beschreibungen des Catalogs passen! Welcher grosse Nutzen ist also für einen Lepidopterologen von einer Wanderung zum British Museum zu hoffeu? Wenn Grote und Robinson den Wunsch aussprechen, dass eine befähigte Hand das Material des britischen Museums baldigst umarbeiten möchte ("wegen der Nothwendigkeit, welche jetzt die Naturforscher aus allen Theilen der civilisirten Welt zwingt, die Sammlung persönlich zu befragen") und doch der Ansicht bleiben, dass einem gäuzlichen Iguoriren der Walker'schen Publicationen "der Flecken der Ungerechtigkeit auhaften würde", so stimme ich zwar hinsichtlich des ersten Punktes den beiden tüchtigen Forscheru bei; aber ebenso bestimmt schliesse ich mich, ohne Scheu vor dem Vorwurf der Ungerechtigkeit, dem Verdammungsurtheile der andern Richter an.

In der vorliegenden Arbeit, dem ersten Theil dessen, was ich über nordamerikanische Schmetterlinge zu schreiben beabsichtige, gebe ich Beiträge zur genaueren Kenmtniss der schon publicirten Arten und beschreibe unter neuen Namen diejenigen, die mir neu zu sein scheinen; ich bezweifle nicht im mindesten, dass mancher der nenen Namen kïnftig einem älteren wird weichen müssen. Aber das Zeugniss wird man mir wohl nicht versagen, diss ich redliche Mühe angewendet habe, um die Vermehrung der Synonymie zu vermeiden. Ebenso bezweifle ich nicht, dass man mein Bestreben auerkennen werde, meine neuen Arten möglichst kenntlich zu machen. Einen Uebelstand darf ich nicht verschweigen: ich habe melıfach neue Arten nach einzelnen Exemplaren aufgestellt, an denen folglich manches Merkmal, das mir charakteristisch schien, nur untergeordueten Werth haben mag. Es sind aber fast immer nur solche Arten gewesen, gegen deren Elkennbarkeit ich keinen Zweifel hegen kounte. Sobald ich Nachträg*e und Berichtigungen zu solchen Arten liefern kanu, wird diess unverweilt geschehen. 


\section{Sola malama Fitch.}

Major, collari nigro-marginato; alis anterioribus sine tuberculis, canis, venis strigisque 2 vel 3 fulminalibus nigris, macula parva nigra costali strigae secnndae adjacente.

Brachytaenia malana, Fitch: Noxious insects of the state of New York, 1856, p. 244, t. 3, fig. 5 ( 9 , sehr elend).

Diese grosse Art hat ganz den Habitus der gewöhnlichen NolaArten; der Mangel von Schuppenhöckern auf den Vorderflüg*eln nöthig't nicht, ein eigenes Genns aus ihr zu bilden; auch glaube ich nicht, dass Fitch im Geäder einen Grund dazu fand, da er es nicht beschrieben hat. Aber die ganz ungefransten Fühler des $\sigma^{7}$ und der Mangel des Schuppenhöckers am unteru Ende des Wurzelgliedes lassen die Errichtung einer besondern Abtheilung zu. Das $\$$ hat breitere Flügel als das ơ und schärfere Zeichnung, selbst die dritte zackige Querlinie ist bis $2 / 3$ vollständig, während sie bei meinen zwei o kaum in Andeutungen erkannt wird. Beiden Geschlechtern gemeinschaftlich ist, dass der Anfang der zweiten, vor der Mitte des Vorderrandes entspringenden Querlinie verdickt ist und dicht hinter sich ein schwarzes, einwärts gespitztes Fleckchen zeigt. Besonders die Aeste der Medianader sind schwarz beschuppt.

Fitch hat die Zahl der Beine (die sicher die der andern Nola-Arteı ist) der hellgrünen, mit 5 weissen Längshinien gezeichneten, weisspunktirten Raupe anzumerken vergessen. Ich bezweifle, dass die Raupe, wie er angibt, sich zur Verpuppung einfach in ein Blatt einspinnt, sondern glaube, dass sie in dem zusammengezogenen Blatte ebenso ein kahnförmiges Gespinnst anlegt, wie es die andern Arten im Freien thun. Ihre Nahrung sind hauptsächlich die Blätter des Apfelbaumes.

Von meinen 3 Exemplaren wurde das eine o am 25. Juni, das क am 9. August, beide bei Beverly in Massachusetts gefangen.

\section{Tola nigrofasciata n. sp. Tab. II, fig. 1.}

Thorace alisque anterioribus albis, puncto basali atro, macula humerali fasciaque media lata, in costa dilatata, fuscis, intus plumbeo-squamatis. Ђ̆.

Nur so gross wie Cucullatella, der weissen Farbe nach in die Nähe von Albulalis gehörig, doch sehr verschieden ron allen Arten durch die breite, braune, im Innern reichlich mit bleiglänzenden Schuppen bestreute Mittelbinde der Vorderflügel.

Kopf und Rückenschild weiss, wie die Wurzel und der Rücken der dicht, doch nicht lang gefransten Fühler. Taster dick behaart, zusammengedriickt, von doppelter Kopflänge, auswärts gelbbräunlich angelaufen. 
Alle Schienen und Füsse auf der Lichtseite braun, die hintern Schienen am hellsten, alle Schienen mit einem weissen Fleck in der Mitte und am Ende; die Fussglieder mit weissen Enden. Minterleib gelblichweiss, die Segmente an der Wurzellälfte hellbräunlich, das erste mit einem Schuppenhöcker; Bauch gelblich.

Vorderflïgel $4 \frac{1}{4} "$ " lang, etwas gestreckt, am Vorder'rande schwach convex, mit kauru abgerundeter Spitze und sanft convexem Hinterrande. gelblichweiss. Dicht an der Wurzel trägt die Medianader einen starken, tiefschwarzen Punkt. Hinter ilm ist ein brauner, mit bleiglänzenden Schuppen gemischter Costalfleck, an dessen Hinterrand ein weisser Schuppenwulst liegt. Gleich darauf fängt am Vorderrande die breite gegen den Innenrand verengerte, braune Mittelbinde an, welclie mit scliwarzen und noch melır bleiglänzenden Schuppen gemischt ist; in der Mittelzelle ist in ihr ein grosser, kreisförmiger und gleiclı dahinter auf der Querader ein querelliptischer Ring, jeder mit wulstigen, bleiglänzenden Schuppen; in der Falte ist diese Binde fast der ganzen Länge wach, doch sehr fein durchschnitten. In der Mitte zwischen der Binde und dem Hinterrande, vor welchem ein hellgrauer Schatten lierzielıt, ist ein welliger, zwei starke Winkel machender, hellgrauer Querstreif. Die Fransen sind von 2 grauen Schattenstreiten durchzogen.

Hinterflügel weisslich, vor dem Hinterrande breit grau beschattet und neben deru verloschenen Queraderfleckchen mit einem grauen Nebelfleck auf dem Anfange der Verästelung der Medianader.

Unterseite der Vorderflügel bräunlich grau mit verloschenem Costalfleck vor der Spitze, von welchem eill dünuer, noch mehr verloschener, weisslicher Wellenstreif vor den Hinterrande herabzieht. Fransen grau. Hinterflïgel weiss, auf der Costalhälfte bräunlich bestäubt. Der Queraderfleck ist deutlich; vor dem Hinterrande zielıt ein brännlicher Querstreif, der sich gegen den Analwinkel verliert. Die Medianader theilt sich in 3 Aeste. Frausen heller als an den Vorderflügeln, um den Aualwinkel weiss.

Vaterland wahrscheiulich Massachusetts; 1 Männchen durch Packard erhalten.

\section{Nola mimuscula n. sp.}

Antennis $\sigma$ dentatis, triente inferiore longius ciliato-pectinato, prothoracis striga nigra, palpis nigro-fuscis; alis anterioribus acuminstis, dilute cinereis, strigis nigris arcuatis, macula costae mediae nigricante; posteriorum vena mediana bifida.

Grösser als Cicatricalis, steht sie in der Flügelgestalt zwischen dieser und Confusalis; die Vorderflügel sind nämlich spitzer als bei letzterer und weniger spitz als bei ersterer, die Hinterflïgel jedoch mehr zuge- 
spitzt als bei beiden; ron ihmen und allen mir bekannten ist sie durch die Fühler verschieden; diese sind an der obern Hälfte bloss gezähnt, am Basaldrittel aber mit langen, haarig gefiederten Kammzähnen versehen, welche um die Mitte an Länge und Stärke abnehmen. Noch eine Auszeichnung besitzt Minuscula in der dunkelbraunen Farbe der Wurzelhälfte des Bauches uud dem schwarzen Bande des Halskragens.

Das Rückeuschild ist wie der Kopf weissgrau, etwas braun bestäubt, mit der angegebenen Zeichnun,; des Kragens. Die auswärts schwarzbraunen, einwärts grauen Taster sind nicht stark, gegen das Ende des zweiten Gliedes verstärkt, daun zugespitzt. Beine mit braungrauen, an den Endeu der Glieder grauen Füssen. Hinterleib hellgrau, schwach dunkler lestäubt; die 3 oder 4 ersten Bauchsegmente schwarzbraun mit hellem Hinterrand; die folgenden Segmente uur an jeder Seite mit einem braunen, allmälig verkleinerten und verblassten Fleck.

Vorderflingel $3^{3} / 4^{\prime \prime \prime}$ lang, ziemlich schmal und nach hinten sehr sanft erweitert und zugespitzt, mit schwach convexem Vorderrande und gradem, zurückgehenden Hinterrande. Grundfarbe mehlig hellgrau mit den drei gewöhnlichen Schuppenbeulen, am Vorderrande von der Wurzel aus schwarzfleckig, an der Mitte zwischen der zweiten und der dritten Beule mit einem grossen, fast dreieckigen, in der Mitte gelichteten schwärzlichen Fleck (der eigentlich gebildet wird durch einen dicken schwarzen Schrägstrich und einen dahinter folgenden Fleck, mit dem er durch dunklern Staub verbunden ist). Die 2 schwarzen Querlinien sind feil; die erste ist etwas knotig und stark nach aussen gebogen und stösst mit der stärksten Biegung an die zweite Beule; die zweite krümmt sich in einem sehr starken Bogen um eine verdunkelte Stelle hinter der dritten Beule herum und ist unterwärts auf der Wurzelseite von einer mehr verloschenen schwärzlichen Linie begleitet. Näher dem nicht scharf schwarzpunktirten Hinterrande als ihr zieht ein schwärzliches, auf den Aderu verstärktes Gewölk in zwei Krümmungen vom Innenrande bis zu den schwarzen Costalflecken. Frausen grau, sehr verloschen gefleckt.

Hinterflügel zugespitzt, hellgrau, von dem deutlichen braunen Queraderfleck bis zur Spitze brauugrauschattig und auf den Adern verdunkelt. Fransen grau, ungefleckt.

Unterseite der Vorderflügel grau, am Vorder- und Hinterrande schwärzlich umzogen, mit verloschenem Queraderfleck. Hinterflügel weissgrau, am Vorderrande breit und grob braun bestäubt, mit brauner Hinterrandlinie und sehr deutlichem, grossen schwarzbraumen Fleck der Querader.

Vaterlaud: Texas (Boll). 1 ○’ im Cambridger Museum.

Anmerkung. Ich besitze ein 9 aus Texas, welches das schwarze Halsband und ähnlich gebaute und gefärbte Taster und auf den ziemlich 
ïbereinstimmend gefäıbten und gezeichneten Vorderflügeln das schwarze Costaldreieck, endlich auch auf der Unterseite der Hinterflügel den starken Queraderfleck und die gegabelte Mediauader hat. Es ist beträchtlich grösser mit dunkleren Hinterfügelu; sein Bauch weissgrau, grau bestäubt. nur ganz auswärts am Rande der 4 ersten Segmente braun. Alle Flügel sind so stumpf und abgerundet, dass diese Art nicht zu Minuscula gehören kann; wenigstens unterscheiden sich die Geschlechter bei deu europäischen Arten nicht auf diese auffallende Wreise. Belfrage fing das etwas abgeflatterte Exemplar am 19. August. - Ein zweites Belfragesches, noch mehr in der Fangschachtel abgestäubtes Exemplar ist noch grösser und mit spitzern Flügeln. Dass die Taster heller sind, das Costaldreieck der Vorderfliigel und der Queraderfleck auf der Unterseite der Hinterflïgel klein und verloschen, und das Bändchen des Halskragens in Stïcke aufgelöst ist, mag eine Folge der schlechten Behandlung des Thieres sein. Der Bauch ist stark braun bestäubt, am dunkelstel gegen die Wurzel. Dieses Exemplar wurde am 22. Mai gefangen. So viel ich weiss, erscheineu die Nola-Arten nicht zweimal im Jahre, und darum glaube ich nicht, dass beide Exemplare zu einerlei Art gehören, und dass ihre Verschiedenbeit, hauptsächlich die in der Vorderflügelgestalt, eine blosse Folge der Abreibung sei. - Fitch beschreibt in den Noxious insects of New York, l. c. p. 244, eine Brachytaenia triquetrana Fitch, die ,in den Wälderu im Frïhling, elıe die Blätter getrieben haben, gefangen wird. Sie ist aschgrau-weiss mit einem grossen, dreiseitigen, schwarzen Fleck an der Mitte des Vorduraudes der Vorderflügel versehen, wonach sie Brach. triquetrana genannt werden mag. Flïgelspaunung 0.80 [Malana $0 \cdot 80-1 \cdot 15]$. Die Schulter der Vorderflügel ist vou eimem kurzen, breiten, schwarzen Fleck eingenommen, und unmittelbar dahinter ist ein schwarzes, eckiges Querzeichen, gestaltet wie der Buchstabe V, dessen innerer Theil mehr oder weniger zu $2-3$ Fleckchen unterbrochen ist. Der dreieckige schwarze Fleck hinter diesem ist an der Mitte des Vorderrandes; seine vordere Seite ist schräg, seine hintere quer (transverse, d. h. wohl senkrecht). Weiterhin auf dem Vorderrande sind $2-3$ dunkle Flecke, und der Apicaltheil des Flügels zeigt schwach einige wellige Querwolken und Spuren eiler Querreihe schwarzer Punkte." - Diese Beschreibung beziebt sich gewiss nicht auf Minuscula, deren so ganz von der der Malana abweichende Flügelgestalt unmöglich hätte unerwähnt bleiben könneu. Sie mag vielleicht auf meine zweite Texas-Species gehen, ist aber sehr unvollständig, da sie nichts vom Fühlerbau des б’, der Färbung des Bauches • • den Schuppenbeulen der Vorderflügel erwähnt. Jedenfalls wird diese Triquetrana nur sicher wiedererkannt werden, wenn sich, was nicht recht wahrscheinlich ist, im Frühjahre bei New York uur eine Nola-Art vorfindet. 
Nola melanopa n. sp. Tab. II, fig. 2.

Thorace et vertice niveis, fronte palpisque exterius fusco-nigris; alis ant. acuminatis, albidis, costa late fasciaque media retrorsa nigris, strigulis costae tenuissimis obliquis albis; posterioribus cinereis. ot.

Die ungewöhnlich scharf gespitzten Vorderfliigel ohne Schuppenhöcker, der wenig robuste Bau des Thorax, der durchaus nicht eingezogene Kopf, der längere Kragen - lassen es fraglich erscheinen, ob dies's eine echte Nola sei; eine Vergleichung des Geäders ist mir nicht müglich; ich stelle also diese Art, die durch ihre Vorderfligelgestalt, den breit schwarzen Vorderrand und die rückwärts gerichtete Binde sehr kenntlich ist, nur provisorisch in diese Gattung.

Etwas kleiner als die kleinste echte Nola. Riickenschild und Kopf schneeweiss; von der locker beschuppten, schwarzbraunen Stirn geht ein schwarzbrauner Streif am oberu Augenraud hin nach der Fliigelwurzel. Taster von Kopflänge, durch grobe Schuppen sehr verbreitert, zusanmengedrückt, nach oben stark erweitert, mit verstecktem Endgliede, auswärts braun, einwärts heller. Fühler gedrängt kerbzähnig, kurz gefranst, auf dem Rücken schwarzbraun wie das mit einem kurzen Schuppenhöcker versehene Wurzelglied. Brust und Beine grau; Vorderbeine auf der Lichtseite gebräunt; alle Füsse mit weisslichen Enden der Glieder, auf der Lichtseite braun, die hintern bräunlich. Hinterleib ziemlich schlank, weiss, auf den Segmenten 5, 6 und 7 an der Wurzel stark gebräunt; Bauch hellgrau.

Vorderflïgel $3 \frac{1}{2}{ }^{\prime \prime}$ lang, -ziemlich gestreckt, scharfspitzig mit sanft convexem Vorderrande und fast geradlinigem, schräg einwärts gerichteten Hinterrande. Grundfarbe weiss, auf der lintern Hälfte ochergelblich ïberflogen. Der ganze Vorderrand ist breit striemenartig schwarz, auf der Apicallälfte in ziemlich gleichen Abständen mit 6 feinen, schräg nach aussen gelegten, weisslichen Strichelchen. In der Mitte geht eine breite, schwarze Binde zum Innenrande, welche einwärts gerichtet und an den welligen Rändern verdunkelt ist. Aı Hinterrande zieht ein breiter, einwärts welliger, bläulichgrauer Streif, welcher unter der Lupe mit äusserst feinen, dunkeln Querwellen durchzogen und von der schwarzen Randlinie durch eine feine, vom letzten Costalstrichelchen herabkonmende, weissliche Kappenlinie getrenut ist. Fransen weisslich, bräunlich gefleckt, am dunkelsten braun an der Flügelspitze und unter der Mlitte des Hinterrandes.

Hinterflügel hellgrau, gegen die Wurzel gelichtet. Vor dem Hinterrande ist das Grau auch fein querwellig. Hinterrandlinie braun, verloschen, mit einer Verstärkung im Analwinkel. Fransen weisslich, braun bestäubt. 
Unterseite der Vorderflïgel branngrau, auf der Innemrandhälfte in's Weissliche, am Vorderrande schwärzlich; die weisslichen Costalstricbelchen sehr deutlich; in der Flïgelspitze ein schwarzer Punkt. Hinterflügel weisslich, auf der Costalhälfte reichlich brann bestäubt. Medianader dreiästig. Alle Fliigel sind vor dem Hinterrande, besonders in der Spitze hellgrau und wie auf der Oberseite sehr zart dunkel querwellig.

Vaterland: Texas (Boll). $1 \sigma^{\top}$ aus dem Cambridger Museum.

Anmerkung. Folgende echte Nola besitze ich ans dem Berliner Mnseum und beschreibe sie hier zum Beweise, dass diese Gattung auch in Neu-Holland nicht fehlt.

Nola strictalis n sp. Tab. II, fig. 3.

Thorace et capite niveis; alis ant. elongatis, acuminatis, obscure luteogriseis, litura apicali alba in strigam tenuem rectam producta. o’.

Sie ïbertrifft in der Zuspitzung der Vorderfïgel noch $N$. Cicatricalis und zeichnet sich vor allen Arten auf den lehmiggrauen Vorderflïgeln durch den weissen Querstreif aus, der vom Vorderrande vor der Flügelspitze sehr schräg nach dem Innemande lierabzieht.

Grösse der Cicatricalis. Rückensclild und Kopf rein weiss. An den Fithlern ist das Wurzelglied weiss mit ganz kurzeru Schuppenbïschclien, die Geissel borstenfürmig, hellbräunlich mit ziemlich langen Fransenlraaren. Taster fast von Rückenschildslänge, stark bescluppt, stumpf zugespitzt, zusammengedrïckt, weisslich, aussen bräunlich anoeflogeu. Beine grau; die vordern dunkler, die 4 hintern auf der abgewendeten Seite weisslich; die Fussglieder mit weisslichen Spitzen. Hinterleib weissgrau.

Vorderfiügel fast 4"“ lang, ziemlich gestreckt mit verlängerter Spitze, wenig convexem Vorderrande und sehr schräg rïckwärtsgehendem Hinterrande. Grundfarbe lehmgelblichgrau, am dunkelsten vor der Querlinie und vor dem Hinterrande. Ein weisser Streif geht erst von der Wurzel aus am Vorderrande hin, der selbst etwas bräunlichgrau bestäubt ist, und trägt drei wurzelwärts dunkelbräunliche, auswärts weisse Schuppenbenlen: die kleinste nicht weit von der Basis, die grösste weiter vou der ersten. als ron der dritten entfernt, welche in der Flïgelhälfte liegt. Die Flïgelspitze ist wischartig weiss, und von diesem Wisch geht bei $4 / 5$ des Vorderrandes ein weisser, wurzelwärts dunkel beschatteter, grader Streif nach $2 / 3$ des Innenrandes herab, ror welchem er auf der Inuenseite eine kleine Ecke bildet. Hinter ihm sind die Adern, anch in dem Apicalwisch, dunkelbraun. Gegen den Innenwinkel ist ein unregelmässiges weissliches Gewölk. Fransen bräunlich.

Hinterfïgel einfarbig grau mit gabelförniger Medianader. Frausen kaum heller, mit gelblicher Wurzellinie. 
Unterseite einfarbig grau, die Vorderflügel am dunkelsten.

Vaterland: Adelaide.

Thalpochares mmoinla n. sp. Tab. II, fig. 4.

Capite collarique laete cinnamomeis; alis ant. ex basi ultra medium schistaceo-fuscescentibus, striga flavida subrecta fuscedinem terminante, ceterum dilutius schistaceis, macula parva apicali atra interius anguste flavido cincta of.

Diese schöne Art sieht eher einer Hypena als einer der kleinen europäischen Noctuen älnlich und passt nur zwangsweise in eines der Genera derselben. Von Erastria, Photedes, Mesotrosta und Prothymia wird sie durch den Mangel der Nebenzelle auf den Vorderfligeln getrennt (wenigstens konnte ich keine selbst durch theilweise Abreibung der Schuppen auf der Unterseite des liuken Flïgels zur Ansicht bekommen). So bleibt, da auch die Stirn keine blasige Auftreibung hat, Thalpochares. Vou den Adern der Hinterfiügel jedoch, die auf der Unterseite alle dentlich hervortreten, ist die 5. entschieden dïnner ais die andern; die Stirnschuppen stehen als ein ganz kurzer Kegel, der aber in sich nichts Festes hat, also nicht durch eine Erhölung der Stirn entsteht, ïber das ebene, senkrechte Untergesicht etwas hervor; das Eudglied der Taster ist sehr kurz und ragt kaum aus den Haaren des zweiten Gliedes als Zuspitzung lieraus.

Die Art ist leicht zu erkennen durch die feine helle Querlinie, welche die dunkle, grössere Partie der Vorderflïgel von der helleren scheidet, das tiefschwarze Punktfleckchen in der Flïgelspitze und die fast rostgelbe Zimmtfarbe des Kopfes und Kragens.

Rückenschild schieferfarben. Der starke Halskragen und der Kopf in der eben angezeigten Farbe. Der Stimschopf sehr kurz kegeltörmig; das Gesicht darunter senkrecht, ganz fach, in der llitte kahl, an jeder Seite mit einem hellgelblichen Längsstrich unterhalb des Stirnbusches. Die Taster bräunlich zimmtfarben, von doppelter Kopflänge, aufgekrümmt, der Stirn angelegt und über den Schopf wegreichend, zusammengedrückt, an der Lnterseite stark behaart, gegen das Ende des zweiten Gliedes verstärkt; Endglied kaum aus der Behaarnug hervortretend. Sauger klein uud schwächlich. Beine schlank und glatt beschuppt, bräunlich grau, die 4 hinteren Füsse auf der Unterseite bleichgelblich; die Hinterschienen etwas verstärkt, auf der Rückenschneide schwach behaart. Hinterleib schlank, ziemlich weit ïber die Hinterfliggel hinausreichend, duukelgrau, auf dem Rücken des Wurzelsegments mit einem schwachen Schuppenschöpfchen. 
Vorderflïgel 4" lang, nach hinten ziemlich stark erweitert mit fast geradem Vorderrande, wenig scharfer Spitze und sanft couvexem, schwach gekerbtem Hinterrande. Grundfarbe von der Wurzel aus dunkelschieferbraun bis fast $2 / 3$, hier durch eine feine, hellgelbe, fast gerade, über der Mitte schwach winklige Querlinie begrenzt; diese Querlinie ist einwärts dunkelbraun geraudet, welches sanft in das Schieferbraun übergeht. Fast in der Mitte zwischen ihr und der Flügelbasis ist eine verloschene, braune, einwärts hell gerandete, im obersten Drittel stark gebrochene Querlinie. Der Rest des Flügels ist schiefergrau, etwas gelblich bestäubt, von einem verloschenen, zackigen, dunkleru Querstreif durchzogeu und auf dem Vorderrande mit 5 scharfen, gelblichweissen Punkten bezeichnet. Vom vierten Punkte geht eine schwachwellige, feine, gelblichweisse Linie längs des Hinterrandes herab, die mit ihrer stärksten Krïmmung, dicht unter der Spitze eineu tiefschwarzen Punktfleck, mit den übrigeu Krümmungen aber eine schwarze Hinterrandlinie begrenzt. Fransen grau, mit mehreren dunklern Wellenlinien durchzogen.

Hinter@ïgel verbältuissmässig klein, branngrau; die schwärzliche Hinterraullinie ist einwärts von einer gelblichweissen, verloschenen, durch die Adern nnterbrochenen Linie gesäumt. Frauseı dunkelgrau, am Analwinkel beller.

Unterseite der Vordertlügel braungrau; die bellen Costalpunkte deutlich, ebenso die verstärkte, etwas kuotige, auf die Hinterflügel fortgesetzte schwarze Hinterraudlinie. Hinterflügel grau, braunstaubig mit einem braunen Queraderfleckchen und zwischeu ihm und dem Hinterrande mit einem verloschenell, hellen, gekrümmten Querstreif.

Vaterland: Texas (Boll). 1 o aus dem Cambridger Museum.

Agrophila tortricina n. sp. Tab. II, fig. 5.

Alis ant. angustis, flavis, punctis disci duobus nigris, litura dorsali post medium ciliisque cinereis. $0^{*}$.

Da die Stirne ein wenig beulenförmig aufgetrieben ist und die Taster wenig darüber herrorstehen, so scheint mir die Wahl der Gattung nur zwischen Agrophila und Xanthoptera zu schwanken; weil es mir nicht gelang, die Ueberzeugung zu gewinuen, dass die Vorderflügel eine Nebenzelle besitzen, so wähle ich, auch wegen der schmalen Vorderfligel, als wabrscheiulichen Platz fir diese Art Ayrophilu. In keiner der beiden Gattungen fude ich bei Gueuée odel Walker eine Beschreibung, die auf die vorliegende Art passt, womit ich jeduch nicht behaupten will, dass sie uicht bei letzterem an irgend einer unerwarteten Stelle vorkomnen köunte.

A. torticina zeigt eine gewisse Aehnlichkeit mit Janth. niyrofmbria darin, dass sie auf den gelben Yoldertügeln a schwarze Punkte, wenn 
auch in anderer Stellnng, und dunkle Fransen hat. Die schmalen Vorderfügel geben ihr aber ein etwas wicklerartiges Ansehen.

Rückenschild und Kopf liellgelb; der untere Theil der Stirne steht ein wenig beulenförmig hervor, was durch die Schuppenhaare vermehrt wird; das darunter liegende kahle Gesicht ist braun. Fühler bräunlich, mikroskopisch pubescirend; das Turzelglied braun mit weissem Längsstreif. Taster von Kopflänge, gerade, am zweiten zusammengedrïckten Gliede auf der Unterseite abstehend behart; das dritte Glied 1/3 so lang wie das zweite, glatthaarig, dunkler als das zweite hellgelbliche Glied. Beine fahlgelblich, die vorder'n auf der Lichtseite braungrau. Hinterleib gelblichgran, an den Seiten der hintern Segmente mit etwas buschigen Schuppen; Afterbusch ziemlich lang, bleich ochergelb; Bauch gelblichweiss.

Vorderflügel 4" lang, nach hinten wenig erweitert, mit fast geradem Vorderande, ohne scharfe Spitze. Grundfarbe hellgelb, an der Immenrandhälfte gesüttigter. In der Mittelzelle kurz vor der Flügelbälfte liegt ein tiefschwarzer Punkt, und hinter ihm auf der Querader ein kleinerer. Bis zu diesem reicht der schiefergraue, gegen die Flügelwurzel zu verdunkelte, undeutliche T'isch herauf, der auf dem Iuneurande hiuter der Flügelmitte liegt. Der Innenrand träg•t gegen die Wurzel einige lange, etwas abstehende Haarschuppen. Am Hinterrande ist eine Reihe schwarzer Punkte, ron denen das über dem Innenwinkel das grösste und bestumschriebene ist. Fransen lang, schiefergrau, an der Wurzel mit hellgelben Schuppen verdeckt und als Grenze fiir diese Bedeckung mit einer dunkelgrauen Linie durchzogen.

Hinterflïgel einfurbig grau. Fransen weisslich, ganz nahe der Wurm zel mit einer grauen Linie durchzogen.

Uurerseite der Vorderfügel an allen Rändern, am breitesten am Innenrande bleich ochergelb, in der Mitte grau; Fransen gran, von der TVurzel aus mit langen, bleichgelben Schuppen bedeckt. Hinterfliggel bleichgelblich, weisslich gefranst.

Vaterland: Texas (Boll). 1 б ans dem Cambridger Museum.

\section{Colobochila saligua v. sp.}

Alis ant. caesio-cinereis, strigis 3 flaridis, puncto nno ante, duobus post secundam nigris, spatio inter tertian et marginem posticum griseofusco. $0^{x}$.

Der europäischen Col. salicalis ausserordentlich ähnlich und leicht für ein verkümmertes Exemplar derselben zu halteu. Da ich nur eiu Exemplar der $C$. saligna ror mir habe, so gebe ich zunächst die zwei sichern specifischen Unterschiede; diese sind: 1. im Mittelfelde liegt mitten zwischen der ersten und zweiten gelben Querlinie ein schwarzer Punkt, und gleich hinter del zweiten zwei solche Punkte senkrecht uutereinander 
(diese drei Punkte fehlen der Salicalis immer); 2. die schwarzen, scharfen Hinterrandpunkte sind einwärts hellgrau umzogen (bei Salicalis sind sie schwächer und entbehren der Einfassung; bei ganz unrerfogenen Exemplaren scheinen sie ror dem Hinterrande zu liegen, weil die Trurzel der Fransen bis zu der braunen, sie durchziehenden Linie mit schiefergranen Schuppen dicht ïberdeckt ist, gauz wie die angrenzeude Flïgelfäche). Als standhafte Unterschiede bewähren sich vielleicht nicht: 1. Die Querlinien der Saligna sind auswärts nicht roshbraun gesäumt (die erste Querlinie hat gar keine Einfassung; die zweite ist auswärts braunschattig gesäumt, welcher Schatten gegen den Innenland breiter wird; der Raum von der braun gesäunten dritten Querlinie an bis zum Hinterrande ist gleichförmig braungrau, dunkler als es bei Salicalis der Fall ist; da die Richtung: und Stärke der Querlinien bei Salicalis etwas veränderlich ist, so wird diess bei Saligna auch nicht der Fall sein, wesshalb ich nur bemerke, dass die dritte bei dem rorliegenden Exemplare der Saligna weniger gekrimmt und oben mehr rerdickt ist). 2. Saliyna hat den Vorderrand der Torderfügel zwischen der zweiten und dritten Querlinie hellgelb und braun wechselnd gefleckt, Salicalis in einer feinen Linie bloss hellgelb. 3. Obgleich die Kopfharre der Saligna nicht beschädigt scheinen, so nebme ich doch eine Beschädigung an, denn die Stirnliaare sind durchaus nicht zu einem kurzen Kegel rerlängert, sondern liegen ziemlich glatt an und sind im Gesicht lehmgelblich, hinter den Fïhlern gelbbraun. 4. Das Endglied der aussen gelbbraunen Taster ist länger, steht wenigstens freier aus den Schuppen des zweiten Gliedes hervor. b. Der braune Schattenraum am Analwinkel der Hinterfügel ist breiter.

Die Vorderfiügel, so länglich wie bei mancher Salicalis, sind kaum $5^{\prime \prime \prime}$ lang gegen mindestens 6"' der Salicalis.

Vaterland: Texas (Boli). 1 o im Museum rou Cambridge.

Anmerkung. Den Gattungsnamen, der offenbar die grössere Kürze der Taster im Vergleich mit Bomolocha (Hypena) andeuten soll, und der in Hbu. Cat. S. 34 \& Colobochyla lautet, habe ich corrigirt. (Koloßós rerstümmelt, verkürzt; $\chi \varepsilon i$ lios Lippe). Walker hat Calobochyla daraus gemacht (Cat. Pyr. 18). Madopa ist als jünger unanuehmbar, bedeutet auch ("mit kahlem Gesicht"6) etwas in der Gattung nicht Vorhandenes.

\section{Hypena albisignalis n. $\mathrm{sp}$.}

Palpis thorace brevioribus, nigro-fuscis, nucrone apicali albo; alis ant. latis, nigro-fuscis, strigis 3 obsoletis, albidis, subserratis, secunda in dorsi maculam albam exeunte; posterioribus fusco-cinereis, unicoloribus. $\%$.

Mit etwas aufgerichteten Tasterı und ohne rauhe Bescbuppung der breiten Vorderfligel, daber in die Verwandtschaft der Iyp. Baltimoralis 
und crassalis gehörig, sehr ausgezejchnet durch den viereckigen weissen Dorsalfleck der schwarzbraumen Vorderflïgel. Wenn deren Spitzen sich nicht zufïllig so gleichnässig abwärts gebogen haben, so wäre diess auch ein auffallendes Merkmal.

Grösse einer mittleren Baltimoralis. Rïckenschild und Kopf duukelbraun, letzterer in der Mitte mit kammartig aufgerichteten Haaren. Taster etwas aufgerichtet, gerade, schwarzbraun, auf der Unterseite heller und borstig; Endglied aufgerichtet, schwarzschuppig, breit, zusammengedrïckt, mit kahler, weisser, frei hervorstehender Spitze. Brust hellbraunwollig. Beine braun, am Eude der Schienen und der Tarsenglieder punktartig weisslich. Hinterleib bräunlichgrau, auf dem ersten und zweiten Segment mit schwarzbranem Ilaarschuppenbusch; der gleichfalls schwarzbraune des Scutellums schliesst sich dem des ersten Segments an.

Vorderfiigel 61/2" lang, breit, nach linten erweitert, spitz (mit niedergebogener Spitze - ob immer?); der schwach gekerbte Minterrand an der Mitte mit stärkster Convexität, darüber bis zur Spitze fast gerade. Grundfarbe gleichmässig dunkelbraun, auf der Querader mit einer schwarzen Sichel und iu einiger Entfernung daror mit einem starken schwarzen Punkt. Vor diesem ist eine undeutliche, weissliche, etwas hin und hergebogene Querlinie, deren Convexitäten nach aussen gerichtet sind, und die den Inneurand nicht erreicht. Die zweite Querlinie ist vollstäudiger, fein, hinter der Mittelzelle am stärksten nach aussen g'ebogen, ausserdem etwas wellig; sie endigt in einen viereckigen, gelblichweissen, besonders gegen die Fliggelwurzel schwarz eingefassten Fleck. Die dritte weissliche Querlinie ist vielfach durchschnitten und dadurch sehr undeutlich; ihre grosse Courexität ist unterhalb der der zweiten Querlinie. Der Hinterraua trägt schwarze, einwärts weisslich eingefasste Punkte. Die Fransen sind braun, undeutlich schmutzig weisslich gescheckt.

Hinterflügel dunkelbraungrau; die Fransen an der Wurzelhälfte braun, an der Aussenhälfte grau mit ungleichen braunen Stellen.

Unterseite braungrau; die Vorderflügel am Vorder- und Hinterrande hellgrau bestäubt, mit verloschener duukelgraustaubiger Querlinie hinter dem deutlichen, dicken, schwarzen Queraderstrich; Hinterrandlinie schwarz, an den Aderenden durchschnitten. Alle Fransen wie oben.

Taterland: Texas (Boll). 1 \% im Cambridger Museum.

Mypena lacimiosa n. sp. Tab. II, fig. 8.

Alis ant. longiusculis, rufescenti-cinereis, plaga in costa ex basi ad $2 / 3$ perducta, maxima, badio-fusca, albido-marginata, postice producta, in marginibus dentata, litura ex apice fusco-nigra. $0^{\top}$.

Guenée sagt ron seiner Baltimoralis p. 34: très voisine de notre Crassalis. Nun liabe ich aber zwei Arten ror mir, ron denen diess gilt, 
aber gerade von derjeuigen in etwas geringerem Grade, bei welcher er sagt: la grande tache brune est plus laciniée sur ses costours; sonst lassen sich seine oberfächlichen Merkmale auf beide Arten auwenden. Walker macht mit seiner Baltimoralis, Pyr. p. 31, die Sache erst recht duukel. Ich sehe mich also genöthigt, zwei neue Namen aufzustellen.

Laciniosa ist die grössere Art, bei welcher die Flügel gestreckter sind und der grosse, braune Fleck der Vorderflïgel eine viel mehr verlängerte Gestalt und gezähnte und ausgenagte länder hat. Obgleich sie etwas reränderlich ist, zeigt doch das ơ nicht eine dem der europäischen Crassalis entsprechende Verschiedenheit rom $\&$, namentlich nicht eine erhebliche Verdunkelung der Vorderflügel, soudern nur der grosse charakteristische Fleck ist bei ihm gegen den Vorderraud dunkler.

Die Taster, welche fast die Länge des Rückenschildes haben, sind gelbbraun, zweischneidig beschuppt, rorgestreckt; das kurze, etwas aufgerichtete Endglied ist gleichfalls zweischneidig beschuppt, mit kahler, bleichgelblicher Spitze. Fühler bleichgelblich, beim o mit deutlich abgesetzten Gliedern und sehr zart mit kurzer Pubescenz gefranst. Rückenschild und Kopf (dieser mit mässigem Stirubusch) fahlgelblich, braun besprengt. Beine bleich braungelblich; an den rorderu die Schenkel und Schienen auf dem Rücken dunkelbraun; alle Füsse auf der Rückseite braun mit hellen Enden der Glieder. Hinterleib von der Farbe der Beine, auf der Rückenmitte des zweiten und dritten Segmentes mit bräunlichem Schuppenbusch.

Vorderflügel $7^{1} / 2-S^{\prime \prime \prime}$ lang, etwas gestreckt, spitz, beim ot mebr als beim $\$$ und mit schräger rückwärts gehendem Hinterraude, hell röthlichgrau, beim $\$$ am Inuenraude weisslicher als beim $\not$. Der sehr grosse chocoladenbraune Vorderrandfleck reicht von der Wurzel bis über $2 / 3$ des Flügels; an Vorderraude ist er beim $\%$ lichter als beim ó; an seinen andern Rändorı ist er am dunkelsten, fast schwarz, und mit einer weisslichen Liuie eingefasst, welche auf der Iunenrandseite am breitesten und reiusten ist; an seinem hintern Ende ist er unterhalb des Vorderrandes concar, darunter noch weiter gegen den Hinterrand rorgezogen worauf sein Kand mit zwei welligen Zähnen rückwärts und über der Falte schräg aufwärts gegen die Schulter zu verläuft; bei der Flügelhälfte steht aus diesem Rande gegen den Innenrand beim \& ein Zahn, beim $\sigma$ eine bis zum Innenrand selbst reichende, aber durch die Subdorsalader zerschnittene Verlängerung hervor (beides mag veränderlich sein, wie bei Crassalis). Von diesen Erweiterungen an ist der Innenrand bis zur Wurzel gesättigter röthlichgrau. In der Mittelzelle liegt ein wenig bemerkbarer schwarzer Punkt. Mitten zwischen der hintersten Ecke des grossen Flecks und dem Hiuterrande ist eine gebogene Querreihe schwärzlicher, auswärts weisslich umzogener Fleckchen, und ron derselben Ecke aus geht ein brandig schwarzbrauner Wisch etwas gebogen hiuauf in die 
Flügelspitze. Der gekerbte Hinterrand hat in jeder Vertiefung einen schwarzen, dreieckigen, einwärts weisshich gerandeten Punkt. Fransen röthlichgrau, verloschen heller gefleckt.

IJinterfïgel braungran mit verloschenem, schwärzlichen Queraderfleck und bräunlicher Hinterrandlinie, Fransen in jeder der Vertiefungen des Randes mit einer lichten Stelle.

Auf der hell gelblichgraven Unterseite sind die Vorderfügel in Mittelfelde dunkelgrau und am Vorderrande hinter der Mitte mit einem solchen rerloschenen Fleck gezeichnet. Von der Querreihe weisslicher Fleckchen sind Spuren sichtbar; eins macht sich unter dem Torderrande durch seine reinweisse, einwärts schwarz begrenzte Farbe selır benerklich. Auf den Hinterflïgeln läuft hinter dem deutlicheı schwärzlichen Queraderfleck eine gebogene dunkelgrane Schattenlinie. Alle Fransen sind verloschen gelbbräunlich gefleckt, an den Vorderflïgeln etwas deutlicher.

Vaterland wahrscheinlich Massachusetts; beide Geschlechter durch Dir. Packard in meiner Sammlung.

\section{Hypent pallialis n. sp. Tab. II, fig. 9.}

Alis ant. latis, rufescenti-cinereis, plaga in costa ex basi paulo ultra medium perducta, maxima, brunneo-fusca, alhido-marginata, postice subtruncata unidentata, dorso juxta eam rufescente, litura ex apice fusco-nigra. $\$$.

Mit $H$. crassalis hat sie offenbar etwas grössere Aehnlichkeit als H. laciniosa; von letzterer ist sie rerschieden durch beträchtlichere Kürze und Breite des grossen Costalfiecks, ron $I$. crassalis ausser durch die beträchtlichere Kürze desselben auch dadurch, dass sein Hinterrand unterhalb der weniger vorspringenden Ecke keine Wellen macht und auf der Subdorsalader mit der wach der Schulter zurückgehenden Begrenzungslinie einen fast rechten Winkel bildet, der bei Crassalis gewissermassen weggeschnitten ist. Die Querreihe weisshicher, schwarz ausgefüllter Möndchen läuft dem Hinterrande näher als dem grossen Costalfleck; bei Crassalis ist sie diesem näher und besteht aus grössern, weissen, meist aueinander schliessenden Winkeln. Der grosse Costalfleck ist bei Pallialis mit einer weissen Linie gesäunt; bei Crassalis folgt hinter dieser wcissen (beim $\vec{\sigma}$ bräunlichgelben) Linie eine breitere lehmgelbe Linje, die der Pallialis fehlt. Crassalis hat ausser dem schwarzen Discalpunkt auch einen Nierenfleck auf der Querader, der bei Pallialis regelmässig zu fehlen scheint.

Kleiner als Laciniosa. Rïckenschild lehmfarbig grau, Kopf und Taster gelbbraun, diese etwas kïrzer und riel beharter und breiter als bei Laciniosa; das aufsteigende Endglied durch die Beschuppung eiformig mit heller, kahler Spitze. Fühler hell röthlichgran, deutlich geringelt. 
Beine und Hinterleib wie bei Laciniosa gefärbt, letzterer mit braunem Schuppenhöcker auf dem Rückel eines jeden der drei ersten Segmente. Vorderfügel 7"' lang, in der Gestalt wie bei Crassalis, also breiter und kïrzer als bei Laciniosa. Grundfarbe hell röthlichgrau, am lichtesten zwischen dem grossen Costalfleck und der Querleihe heller Mondfleckchen. Der grosse Costalfleck ist tief gelbbraun, längs des Vorderrandes, auf dem er bis etwas über die Hälfte hinreicht, am lichtesten, an den andern Rändern fast schmarz; sein Hinterrand geht der Hauptsache nach senkrecht und ziemlich gerade herab; nur ïber der Mitte hat er eine mehr oder weniger vorspringende Ecke, unter der er ein wenig concar ist; auf der Subdorsalader gelit von ihm ein Streifthen als Fortsetzung bis zum Inmenrande, der bis zur Basis grauröthlich jst. Der dem Immenrande zugewendete Rand dieses Flecks läuft eine Strecke aut der Subdorsalader hin, worauf er unter einem concaren Bogen seine Richtung in die Schulter nimmt. Die Einfassung des Fleckes ist eine weissliche Linie, welche an der Subdorsallinie am dünnsten, in der Concavität am breitesten und reinsten weiss ist. In der Mittelzelle liegt ein nicht sehr auffallender schwarzer Punktfleck. Näher dem Hinterrande als dem grossen Costalflecke zieht eine wellige Querreihe ron mehr oder weniger deutlichen, getreunten, weisslichen Möndchen, welche einwärts schwärzliche Schatten haben. Auf dem Vorderrande liegen 4 -ö weissliche Punkte, deutlicher als bei Laciniosa. Aus der Flïgelspitze geht, dem Hinterrande näher als dem Vorderrande, ein brandig-schwarzbrauner Wisch herab, der sich in der Jöhe der Ecke des grossen Costalflecks plötzlich uach innen wendet und bis zu den Mönd.hen reicht. Der Hinterrand ist nit einer Reihe weit getrennter, dunkelbrauner Strichelchen bezeichnet, deren jedes einwärts weisslich aufgeblickt ist, und von dem ein weisslicher Strich in die graubräunlichen Fransell geht.

Hinterflïgel braungrau ohne Queraderstrich. Hinterraudlinie aus braumen Strichen zusammengesetzt. Fransen einfarbig mit fablgelblicher IT urzellinie.

Unterseite grau, reichlich braun bestäubt; die Vorder"ingel hinter der Mitte mit eineu verloscheneu braunen Costalfeck, hinter welchem der Vorderrand gelichtet ist. Die Hinterfliigel mit schwacbem, bräunlichen Queraderfleckchen. Hinter ihm hat das eine Exemplar eine gebogene schattengraue Querlinie, die dem andern ganz fehlt. Die braune, nur auf deu Adern unterbrochene Hinterrandlinie ist auf den Hinterflügeln schärfer als auf den Fordertiigeln.

Vaterland: Texas (Boil) und Massachusetts. 2 of in der Cambridger und meiner Sammlung. 
Hypena achatinalis n. sp. Tab. II, fig. 7 .

Palpis thorace brevioribus; alis ant. latis, dimidio basali luteo-brunneo ante strigam pallidam, undatam terminantem obscurato, postice cinereo-fuscescentibus cum striga obsoleta dilutiore nebulaque ex apice fusca; posterioribus luteo-fuscescentibus. $\$$.

Aus der Verwandtschaft der Crassulis, ausgezeichnet durch das gelbbräunliche, hinten verdunkelte, mehr als die Flügelhälfte einnehmende Wurzelfeld, das durch eise helle, wenig wellige Querlinie gegen den bräunlichgrauen Flïgelrest scharf begrenzt wird. Das kräftige Rïckenschild und der Kopf graubrännlich; die Stirne mit langem Haarkegel. Fïhler bleichgelblich. Taster kaum ron Rückenschildslänge, rorgestreckt, stark haarschuppig, zusammengedrückt; das dritte Glied etwa $1 / \$$ so lang wie das zweite, aufsteigend, gleichfalls stark bekleidet und zusammengedrückt, mit kaum aus der Beschuppung hervorstehender gelblicher Spitze. Beine gelbbräunlich; an den rordern Schenkelı und Schienen braun, an den mittlem und hintern die Schienen reichlich bloud behaart; alle Fïsse hell und ungefleckt. Hinterleib graugelblichbraun, am Bauche bleich, auf dem Rücken des ersten Segnents mit einem braungrauen Schuppenhücker.

Vorlerflügel $7 \frac{1}{2} "$ " lang, breit, am Vorderrande sehr schwach conrex, mit scharfer Spitze, unterhalb welcher der sanft convexe Hinterrand kaum als eingedrückt angesehen werden kann. Die Grundfarbe ist ron der Wurzel bis über die Mitte hell gelbbraun, vor der die Grenze dieser Färbung bildenden Grenzlinie stark verdunkelt. Nicht weit roll der Wurzel i-t eine verloschene bräunliche Querlinie, welche in 2 Bogen schräg herabgeht und dels Innenrand kaum erreicht. In del Mittelzelle ist hinter ihr ein scliwarzer, wenig deutlicher Puukt, und auf der Querader, nicht weit ror ler Querlinie, eine solche Sichel. Die Querlinie ist diun und blass graugelblich, dem Hinterrande fast parallel, schwach nach aussen gekrümmt mit drei ungleichen, schwachen Wellen. Der Rest des Flügels ist ziemlich dunkel schiefergrau. Am Vordersande mitten zwischen der Fliigelspitze und der hellen Querlinie entspringend, aber ersterem näher laufend und am Innenwinkel endigend, ist eine aus seln verloschenen, lielien, stark getrennten, vach aussen convexen Mondchen gebildete Querlinie, die auf der Wurzelseite durch braune Schatten mehr gehoben wird und uuter der Mitte eiue merkliche Biegung einwärts macht. Aus der Flïgelspitze reicht bis zu ihr ein bräunlicher Schatten, welcher ein zwischen ihm, der verloschenen Querlinie und dem Vorderrande liegendes lichtgranes Dreieck begrenzt. Der Vorderrand der grauen Hinterpartie trägt in gleichen Abständen \&erloschene gelbliche Püuktchen. Die Hinterrandlinie ist aus feimen, braunen, einwärts hell begrenzten Strichelchen zusammengesetzt. Die Fransen sind schwach gekerbt. 
Hinterfliigel hell lehmgelblichbraun mit rerloschenem, schwarzen Queraderstrich. Die braune Randlinie ist dïnn, verloschen, anf den Adern unterbrochen. Fransen dunkelgrau.

Die Unterseite der Vorderflïgel ist braungrau mit gelblich bestäubtem Vorder- und Hinterrande und graubraunen Fransen. Die Hinterflügel sind bleich ochergelb, reichlich bräunlich bestäubt mit braunem Queraderstrich; die braune Hinterrandlinie intermittirt an den Aesten der Medianader und im Analwinkel. Die Fransen sind heller als an den Vorderflïgeln, mit feiner, gelblicher Wurzellinie.

Vaterland: Texas (Boll). 1 \& aus dem Cambridger Museum.

Vielleicht ist diess die nach einer Abbildung beschriebene Made. factalis Guen. Pyr. p. 35; aber so wie die Beschreibung lautet, lässt sich meine Art nicht mit Sicherheit darin erkennen. Unter welchem Namen sie etwa bei Walker vorkommt, erfährt man vielleicht durch Besichtigung des British Museum.

Anmerkung. Ich besitze eine der Achatinalis sehr ähnliche, vielleicht auch aus Nordamerika stammende Art. Sie ist víel kleiner, beträchtlich schmalflügliger, ron röthlichbrauner Färbung; die wie bei Achatinalis gezeichneten Vorderflügel zeigen den wesentlichen Unterschied, dass die helle Querlinie grader ist, keine Wellen macht und äberdiess auf der Wurzelseite mit einer dünnen, braunen Linie gesäumt ist. Der Queraderstrich ist auf der Oberseite kaum zu erkennen, auf der Unterseite dagegen sehr deutlich. Die Taster sind länger als bei Achatinalis. Da das Exemplar nicht gut genug erhalten ist, so unterlasse ich die Benennung und genauere Beschreibung, und erwähne es hier nur, damit es nicht als einerlei mit Achatinalis bestimmt werde.

\section{Hypena trituberalis n. sp. Tab. II, fig. 6 .}

Parva, palpis thoracis longitudine; alis ant. obscure caesio-cinereis, dorso basim versus lutescente, punctis 3 scabris, nigris, oblique ante strigam mediam, undatam, albidam, interius luteo-marginatam collocatis, litura ex apice albicante. ㅇ.

Eine der kleinsten Hypenen, nahe verwandt mit der europäischen Obsitalis, ausgezeichnet durch ihre dunkel schiefergrauen Vorderflügel mit weisslicher Wellenlinie quer über die Mitte, ror welcher drei in schräger Querlinie aufgestellte schwarze Schuppenhöcker gut sichtbar sind.

Grösse noch unter lividalis. Körper braungrau, Kopf dunkler mit starkem, lockeren, kegelförmigen Stirnbusch. Taster ron Rückenschildslänge, stark zusammengedrückt, grade rorgestreckt, dunkelbraungrau, unten an der Basis weisslich; das Eudglied rechtwinkelig aufgerichtet, $1 / 6$ so lang wie das zweite Glied, mit kahler, hleichgelblicher Spitze. 
Fühler hellgrau. Beine hellgrau, die vordern auf der Lichtseite gebräunt; alle Fussglieder auf der Rückenseite dunkelbraungrau mit weissgelblichen Euden. Hinterleib ohne Rückenhöcker, bräunlichgrau mit bleichgelblichen Hiuterrändern, am Bauche weisslich, nach hinten gelblich.

Vorderflügel $4{ }^{1} / 2^{\prime \prime}$ lang, länglich, allmälig erweitert, mit sehr wenig convexem Vorderrande, deutlicher Spitze und gleichmässigem, schwach convexem Hinterrande. Grundfarbe von der Wurzel aus dunkel schiefergrau, an Innenraude bis über die Falte lehmgelblich. Die hintere Begrenzung beider Farben wird in der Flügelmitte durch eine weissliche, einwärts braungelb gesäumte Querlinie hergestellt; diese steht fast senkrecht, biegt sich aber convex uach aussen und bildet erst einen stumpfen Winkel, dann über der Falte zwei kurze Wellen, worauf sie in stärkerem Bogen nach dem Innenrande läuft. In dem Raume vor ihr befindet sich, doppelt so weit von der Flügelbasis als von ihr entfernt, in der Mittelzelle ein schwarzer, rauher Fleck, hinter dem noch zerstreute schwarze Schuppen folgeu; schräg nach aussen unter ihm, noch über der Falte, ist ein stärkerer solcher Fleck, und noch mehr nach hinten hängt unterhalb der Falte ein dritter an der Innenseite der weisslichen Querlinie; alle drei liegen in einer schrägen Querlinie. Der Rest des Flügels ist heller schiefergrau als die Wurzelhälfte, mit einem weisslichen, nebelartigen Wisch in der Flügelspitze, zwischen welchem und dem Hinterrande die Grundfarbe erst dunkler, dann allmälig heller gebräunt ist; diese dunklere Färbung wird durch eine verloschene, hellgraue Kappenlinie begrenzt, welche aus dem weisslichen Apicalwische herabgeht und einwärts fleckartig dunkel schattirt ist. Der Vorderrand trägt auf dunklerem Grunde in ziemlich gleichen Abständen 3-4 weisse Punkte. Die Hinterrandlinie ist schwarz, von den Adern zerschnitten und einwärts verloschen weisslich gesäumt. Die gekerbten Fransen sind braungrau, mit zwei verloschenen dunkleren Linien durchzogen, an der Wurzel mit starker, lehmgelber Linie.

Hinterflügel braungrau mit verloschenem, dunklen Fleck auf der Querader. Fransen mit gekerbtem Ausseurand, heller, mit duuklen Schattenfleckchen durchzogen.

Unterseite der Vorderflïgel bräunlichgrau, am Vorderrande bleichgelblich bestäubt und vor der Spitze mit 4 weisslichen Punkten; Hinterrandlinie schwarz, durch die Aderenden in Strichelchen zerschnitten.

Vaterland: Texas (Boll). 3 ㅇ von ungleicher Güte im Cambridger Museum.

\section{Epizeuxis phaealis $\mathrm{G} \mathrm{n}$.}

- Walker Cat. Pyr. 133. Helia - Guenée Pyr. p. 76.

Mit Recht sagt Guenée, dass sie eine oberflächliche Aehnlichkeit mit Pyralis pinguinalis habe; wirklich ist sie mir auch als diese bestimmt zugeschickt worden. 
Diese Art, von Guenée nach gewöhnlicher Manier oberfächlich, doch ziemlich kenntlich bezeichuet, ändert in der Grösse, Fliigelbreite und Schärfe der Zeichnung ab. Der Raum zwischen der dritten Querlinie und dem Hinterrande der Vorderflügel ist bisweilen ganz hell, bei einem 우 röllig so dunkel wie anderwärts, auch mit einfarbigen Fransen, während sie manchmal fast hell und dankel gescheckt sind.

Vaterland: Texas (Boll), Massachusetts, wo Burgess sie bei Beverly nicht selten den Juli hindurch und 1 을 noch am 24. August gefangen hat, und andere Theile Nordamerika's.

Anmerkung. Da Hübner's Gattungsname Epizeuxis ohne jeden Zweifel die hierher gehörigen Arten bezeichnet, so ist Guenée's jüngere Schöpfung als nuberechtigt zu verwerfen. An eine Spaltung des Genus, um Helia beizubehalten, kann auch nicht gedacht werden.

\section{Epizenais Americalis $\mathrm{G} \mathrm{n}$.}

Helia - Gnen. Pyr. p. 78, tab. 6, fig. 5. Epizeuxis - Walker Cat. Pyr. p. 134.

Guenée's Bild stellt die Art kenntlich, aber nicht in ihrer Schönheit dar. Die tiefschwarze Einfassung der letzten Querlinie auf der Innenseite sollte auf dem Vorderrande fleckartig hervortreten und die Grundfarbe der Wurzelhälfte des Flügels heller sein.

Nach Guenée fliegt sie im Mai, kriecht aber auch schon im März aus. Burgess fing ein schönes 9 im Juli. Die nach Guené e schädliche Art, die jedenfalls in Nordamerika viel häufiger ist als bei uns Calvarialis, besitze ich aus New York und Massachusetts.

\section{Epizeuxis aemula $\mathrm{Hb}$.}

Epiz. aemulalis Hbn. Cat. 346. - Walker Cat. Pyr. p. 134. Helia Gu en. Pyr. p. 78.

Von den vielen Unterschieden dieser in der Flügelbreite gleichfalls wechseluden Art, im Vergleich mit der vorigen, erwähne ich hier nur zwei. Die dritte Querlinie ist bei Aemula auf der Innenseite nur mit etwas dunklerer Grundfarbe schattirt, während sie bei Americalis schwarz, am Vorderrande sogar tiefschwarz eingefasst ist. Ferner ist der gelbe Fleck vor der zweiten Querlinie, der bei Americalis eine oben überhängende Mondsicliel bildet, und durch dunkelgelbe Farbe mit der Querlinie in Verbindung steht, bei Aemula quer elliptisch, ringsum von grauer Grundfarbe eingefasst und im Innern an beiden Enden mit einem schwarzen Punkte oder Fleckchen bezeichnet, welche beiden Punkte öfters durch eine feine Linie in Verbindung steheu.

Sie scheint in Massachusetts und bei New York nicht seiten zu sein; 2 O fing Burgess bei Bererly am 7. Juli und 19. August. 


\section{Zanclogmatha pedipilalis $\mathrm{G}$ u en.}

Herminia - Guenće Pyral. p. 57. ? - Walker Cat. Pyral. p. 103.

Das vorliegende Exemplar stinmt gut zu Guenée's Beschreibung, auch in soferm, als er die Art vor Tarsicrinalis gestellt hat, wohin ich es, ehe ich seimen Namen herausfand, gleichfalls zu stellen geneigt war. Die nubedeutenden Abweichungen sind folgende. Die dritte Querlinie ist fast ganz verloschen (sie nimsnt die Richtung in die Flügelspitze, verschwindet aber in einiger Entferuung davor, so dass sich nicht entscheiden lässt, ob sie davor, nämlich wie bei Tarsicrinalis an Vorderrande, zn endigen bestinmt ist). Die Flïgelspitze entbehrt völlig des point foncé sur la frange. Die feine gelbbraune Hinterrandlinie ist in ihrer obern Hälfte sehr scharf; dann wird sie blass und verschwindet kurz vor dem Innenwinkel. Auf den Hinterflügeln ist die Lunule und die erste Querlinie verloschen, die letztere so, dass nur ïber dem Analwinkel, zu welchem sie die Richtung hin nimmt, so eben zu erkennen ist (auf der Unterseite ist sie ganz deutlich; ebenso die schwarze Mondsichel); dafür ist aber hier die zweite hellbegrenzte Querlinie der Oberseite sehr verloschen. Die feine, gelburaune Hinterrandlinie der Hinterflïgel erreicht weder den Vorder-, noch den Analwinkel. - Auf der Unterseite der Vorderflïgel sind nicht schwarze, sondern nur dunkelblonde Haare vorbanden, und solche, nur mehr anliegende Haare bekleiden auch alle Adern bis zum Hinterrande sehr reichlich. - An den Fühlern befindet sich das Knötchen an der innern Seite und ist mit ein par braunen Börstchen besetzt. Der schwarze, theilweise stahlblauschimmerude, reichliche Haarbusch sitzt auf der Unterseite der Schiene gegen das Ende und lässt sich recht wohl auseinandersträuben; in der Rube ist er zusammengelegt und durch die blonden, langen Schuppen der Oberseite der Schiene meist verdeckt; diese reichen auch ïber das erste Tarsalglied hinweg, welches fast halb so lang ist wie der ganze, dünne Tarsus. - Unter der Wurzel der Taster hïngt ein ziemliclı langer Busch blonder Haare herab. Das Endglied der Taster ist zusanmengedrïckt, aber durch Haare bei weitem nicht so stark fiigelartig erweitert wie bei Tarsicinalis.

Walker's fragliche Varietät scheint doch hierher zu gehören, obgleich an seinem Exemplar die dritte Querlinie auswärts hell gerandet ist. Dass bei ilım über die Beschaffenheit der Taster und des Haarbusches an den Vorderschienen Genaueres angegeben sein sollte, darf man nicht erwarten, weil solche Untersuchungen mehr Mïhe und Zeit erfordern, als ihm in's Geschäft passte.

Vaterland: Texas (Boll). 1 o in Cambridger Museum. 


\section{Zanclognalha lituralis $\mathrm{Hbn}$.}

Antemnis ơ denticulo medio pubescente instructis; alis ant. obscure griseis, areu venae transversae maculisque 3 costae atris, tertia apicali pone strigam lumulis pallidis distantibus compositam. $\sigma^{\top}$ ㅇ.

$$
\text { Epizeuxis - Hbu. Cat. 3ł6. - Walker Cat. Pyr. p. } 134 .
$$
Helia - Guen. Pyr. p. 79.

Guenée hat sie, da er sie nicht in der Natur kannte, zu Helia (Epizeuxis H.) gezogen, und Walker, der wie Hübner Exemplare aus Georgien vor sich hatte, hat diesen Fehler getreulich beibehalteu. Die borstig lang gefransten Fühler des Männchens siud bis gegen die Mitte merklich verdickt; hier machen sie eineu kleinen sanften Bogen, worauf die zahnartige Erweiterung der Innenseite, mit einigen geraden, senkrechten Härchen, folgt; daun sind sie dünner mit kürzeren Fransenhaaren. Die dünnen, behaarten, bogenförmig aufgekrümmten Taster haben die Länge des Rückenschildes; das fein gespitzte, an der Wurzel und am Ende weissliche dritte Glied hat die halbe Länge des Mittelgliedes oder ist auch noch etwas länger. Die Vorderbeine sind dïnn und bleichgelblich; die Fussglieder auf dem Rücken braun ausser an den Enden; der Schenkel hat auf der Unterseite an der Mitte einen aus ungleichen, tiefschwarzen Schuppenhaaren gebildeten Streifen; das Schienbein trägt eine eben so lange Platte mit dicht anliegenden bräulichen Schuppen, die auf dem Rücken an der Basis angeheftet ist und so anliegt, dass sie einen Theil des auf diese Weise verdickten Schienbeines auszumachen scheint; unter dieser Platte sitzt ein lauger, bleichgelber Haarpinsel, der selten ganz hervorragt.

Die dunkel staubgrauen, am wenigsten gegen den Vorderrand dunkler bestäubten Vorderflügel haben, ausser einem schwarzen Querstrich nahe der Wurzel, auf dem Vorderrande 3 tiefschwarze Flecke, die zwei ersten schräg gelegt und unten zugespitzt. Vom ersten, am Anfange des zweiten Drittels liegendeu, geht in hellem Grunde eine nur auf den Adern durch Fleckchen ausgedrückte, wellig geschwungene Querlinie; der zweite, unter welchem sich ein stumpfwinkliger, nach aussen geöffneter schwarzer Querstrich auf dir Querader zeigt, schliesst sich an eine aus schwarzen hell umzogeneu Aderpunkten bestehende Querliuie an, die einen starken Bogen nach aussen macht und hinter der Mitte des Innenrandes endigt; der dritte füllt den Raum zwischen der Flïgelspitze und der wenig gekrümmten Querlinie, welche aus bleichgelben, getreunten Häkchen besteht, die auf der hohlen, der Wurzel zugewendeten Seite dunkel oder braun ausgefüllt sind. Den Hinterrand umzieht eine Linie aus schwarzen Strichen. Die einfarbigen Fransen sind wenig heller als die Grundfarbe. 
Hinterfiügel heller, nit verloschenem Queraderstrich, eiuer deutlichern, schwärzlichen, vollständigen Querlinie in der Mitte und einer weisslichen, aus dem Analwinkel kommenden, den Vorderrand nicht erreichenden Querlinie, die einwärts breit schwärzlich beschattet ist. Die schwärzliche, durch die Adern unterbrochene Hinterrandlinie wird dentlicher als auf den Vorderflïgeln durch eine feine, bleichgelbe Linie von den Fransen gesondert.

Unterseite der Flïgel am Vorderrande gelblich mit brauner Bestäıbung und von zwei vollständigen, deutlichen, braunen Querstreifeu durchzogen, deren äusserer mit einer schwach sägezähnigen, gelblichen Linie eingefasst ist. Die Grundfarbe der Vorderfliggel ist braungrau, der Hinterflïgel hellgrau nit schärferer schwarzer Sichel auf der Querader als an den Vorderflügeln.

Vaterland: New York (Grote), Massachusetts (Packard).

\section{Zanclognatha deceptricalis n. sp.}

Alis ant. obscare cinereis, striga venae transversae maculisque 2 costae fusco-nigris, posteriore in strigam arcuatam, serratam continuata, striga postica dentata pallida, intus fuscomarginata. \$.

Nur ein Exemplar, das ich bisher unter Lituralis stecken hatte. Es nnterscheidet sich aber von dieser sehr sicher durch den Mangel des schwarzen Apicalflecks der Vorderflügel und durch die Vollständigkeit der hintern bleichgelben Querlinie, welche einwärts breiter und dunkler braun schattirt ist; ausserdem sind die Flügel mehr gestreckt, von anderer Grundfarbe, und die Vorderfligel haben auf der Unterseite nur eine Querlinie.

Kleiner als Lituralis. Körper grau, am hellsten am Kopf und an den Tastern; die Stirne mit einem kegelförmigen Haarbusch. Die Taster aussen wenig verdunkelt, von Länge des Rückenschildes, bogenförmig aufgekrümut, ziemlich schlank, zusammengedrückt, schuppenhaarig; das Endglied $1 / 3$ so lang wie das $z$ weite Glied.

Vorderflïgel $5^{\prime \prime}$ lang, mit sanft convexem Hinterrande, grau ohne gelbliche Beimischung. Nicht weit von der Wurzel ist ein schwarzer, auf dem Vorderrande wenig merklicher, welliger Querstrich, der nicht den Innenraud erreicht. Dann folgt auf dem Anfange des zweiten Drittels eiu braunschwarzer Costalfleck, an den sich eine feine, zickzackförmige, bis zum Innenrand reichende, aber nicht deutliche Querlinie auschliesst. Iu der Flügelmitte folgt der zweite Costalfleck, der sich mit seiner schräg nach hinten gerichteten Spitze in eine feine, schwarze Sägelinie fortsetzt, die in einem starken und weiten Bogen nach dem Innenrande beim Innenwiukel läuft. Dicht vor der Spitze konmt eine bleichgelbliche 
vollständige, ziemlich grade, gezälnte Querlinie von Vorderrande herab; sie läuft in den Inmenwinkel und ist einwärts breit duukelbräunlich schattirt, am duukelsten im obersten Drittel und nm Innenwinkel. Den Hinterrand fasst eine aus schwärzlichen Strichen zusammengesetzte Linie ein. Die Franseu lieller grau.

Hinterflügel grau, gegen den Vorderrand weissgrau; der Queraderpunkt und die branne mittlere Querlinie verloschen. Die weissgraue, aus dem Analwinkel herrorgehende, schwach gezähnte Querlinie ist einwärts breit dunkelgrau schattirt und erreicht verloschen den Vorderrand. Die schwärzliche Hinterrandlinie ist durch die Adern unterbrochen.

Unterseite hellgrau, braun bestäubt. Die dunklern Vorderflügel haben hinter den zwei dicken Mittelpunkten eine deutliche, auf dem Vorderrande verstärkte, wach aussen convexe Querlinie und in der Spitze einen bleichgelblichen, einwärts dunkel schattirten Wisch. Auf den Hinterflügeln sind der Mittelfleck und die schwärzliche und die bleichgelbe Querlinie sehr deutlich, letztere aber nur wenig dunkel schattirt, am meisten am Vorderrande.

Vaterland wahrscheinlich Ohio. Ich erhielt mein Exemplar vou Schläger unter dem Namen Bipunctalis.

Coptocnemia n. g. Tab. II, fig. $10 a$ et $b$.

Antennae setaceae, ciliatae, dorso ultra medium setis $\&$ adscendentibns instructo.

Ocelli distincti.

Fasciculus squamis compositus frontalis breviter conicus.

Palpi labiales thorace breviores, subarcuati, articulo secundo compresso, sensim dilatato, articulo terminali brevi filiformi.

Haustellum mediocre.

Pedes elongati, anticorum tibiae femoribus duplo breviores, subtus penicillo instructae; posticorum tibiae postice subarcuatae, superius excisae et villis longiusculis vestitae.

Ventris basis obtecta pilis longis.

Alae latae, anteriores acutae subtus flocco pilorum infra medium.

Das Hauptmerkmal dieser Gattung geben die männlichen Hinterschienen; diese haben die Länge der dünneren Schenkel und sind auf der obern Seite mit einem Ausschnitte versehen, der mehr als 2/3 der Länge einninmt und auf seiner grössern Hälfte, jedoch reichlicher auf seinem Anfange mit langen, zottigen Haaren bekleidet ist; die zwei Paar Dornen sind ron ansehnlicher Länge, jedes Paar aber uugleich. Ferner trägt die kurze Vorderschiene auf der Unterseite beim Anfange einen anliegenden Haarpinsel, der eìn schmales Hormplättchen zu verdecken scheint und bis 
ïber die Hälfte der Schiene reicht. Ausserdem habel die borstenförmigeu, etwas weitläufig und fein gefransten Füller auf dem Rücken hinter der Mitte eine Reihe vol \& zarten, ziemlich langen, etwas nach vorn geneigten (nur durch die Lupe gut sichtbaren) Borsten. Endlich haben die Vorderflïgel auf der Unterseite in der Zelle zwischen dem crsten und zweiten Medianast eine starke, aufgerichtete Haarflocke.

Der Stirnbusch ist kurz. Die Taster sind etwas kürzer als das Rückenschild, sanft aufgebogen, haarig beschuppt; das zweite Glied zusammengedriickt und allmälig erweitert; aus seinen Eudschuppen ragt das dritte Glied hervor, welches glatt und fadeuförmig und kürzer als die Hälfte des zweiten ist. Der Hinterleib ist schlank ohne Schuppenhöcker auf dem Rücken.

\section{Aoccalis n. sp.}

Dilute luteo-fuscescens, collari obscure cinereo; alae anteriores puncto discali nigro, macula venae transversae annulari fusca, nebula fusca ex apice oblique in dorsum directa ibique condensata. $\sigma^{7}$.

Grösse des Pechipogon barbalis. Färbung der Flïgel hell lehmbräunlich, hier und da mit dunklern Wischen; der grosse, schwarze Discalpunkt der Vorderflïgel ist die stärkste Zeichnung; nächst ihm tritt der nierenförmige Ring auf der Querader hervor.

Der Kopf und der breite Kragen ziemlich dunkel schiefergrau. An den Tastern ist das Endglied mit weisslicher Spitze versehen. Die Brust ist (wohl hauptsächlich durch Abreibung der Deckschuppen) seidenglänzend schneeweiss, wie die Vorderhüften, Hinterschenkel und Hinterschienen auf der abgewendeten Seite; die Haare der letztern sind hellblond, die am Anfange des Bauches weiss, ohne Glanz. Afterbusch gelbbraun, zugespitzt.

Vorderfügel '7" lang, etwas gestreckt und zugespitzt mit fast gradem Vorderrande und sanft convexem Hinterrande ohne Einbiegung unterhalb der Spitze. Die Fläche ist bräunlich bestäubt, am Vorderrande mit 4 dunklern Stellen in ziemlich gleichen Abständen. Der starke schwarze Discalpunkt ist etwas weiter von der Flïgelbasis entfernt als vom braunell, in der Mitte hellen, nierenförmigen Queraderfleck. Aus der Fliigelspitze, dem Hinterrande näher, zieht ein dunkler Nebel schräg einwärts herab, verschwindet eine Zeit lang fast ganz und erscheint wieder am Innenrande vor dem Innenwinkel als eil grösserer, duukler Nebelfleck. Dem Hinterrande parallel und ihm näher liegt eine Reihe von 4 weitläufig gestellten schwarzen Punktell, von denen die zwei g'egen dell Vorderrand deutlicher sind, am meisten der im Apicalnebel liegende. Der Hinterrand trägt 7 dunkel gelbbraune verwisclite Punkte vor den braungrauen, gegen die Flügelspitze bräunlichen Fransen. 
Hinterfligel mit verloschenem, braunem Punkt der Querader und einer dem Hinterrande doppelt so nahen Querreihe weitläufig gestellter schwarzer Punkte, you denen der am Analwinkel in einem Nebelfleck lieg.t. Die Hinterrandpunkte deutlicher als auf den Vorderflïgeln.

Unterseite heller mit schärferer Zeichnung. Der Discalpunkt und der Nierenfleck der Vorderfliggel sehr deutlich; letzterem näler als dem Hinterrande eine mehreckige, feine, schwärzliche Querlinie, die am ersten Medianaderast hinter dem röthlichblonden Haarbusch aufhört. Auf den Hinterfligeln geht rom verloschenen Queraderfleckchen eine graue Schattenlinie zum Innemrande; hinter der Mitte ist eine andere, un auf ihrer Costalbälfte deutliche; zwischen ihr und den deutlichen Hinterrandpunkten ist noch eine sehr verloschene Querlinie zu erkennen.

Vaterland: Texas (Boll), 1 ỏ im Cambridger Museum.

\section{Acidalia purata Gu.}

Alis niveis, posterioribus integris rotundatis, puncto venae transverane omnium nigro, striga postica anguloso-undata fusca, maculis duabus in anterioribus strigae adjecta nebulaque fasciata in posterioribus fuscis. 0 .

- Guenée Geom. I. p. 488, pl. 7, fig. 6. - Walker Cat. Geom. p. 720 .

Guenée's Abbildung ist, wenn sie nicht das mir unbekannte o vorstellt, kaum kenntlich, und seine Beschreibung zu kurz. Ich beschreibe also die Art rollständiger.

Diese zwerghafte Vetreterin unserer Paludata, ganz ohne Ausbucl- tung der Hinterflügel, auf allen Flïgeln mit herrorstechendem, schwarzen Mittelpunkt und ohne die kappenförmigen Wellen der hintern braumen Querlinie ist kleiner als die kleinsten Exemplare der Paludata oder Decorata var, congruata. Der ganze Körper schneeweiss, der Kopf bran, im Gesicht sehr dunkel. Fiiller gelbbräunlich. Beine braun angelaufen; die hintern viel kïrzer als die mittlern, die weissen, zusammengedriickten Hiuterschienen ohne hervorstehende Dornen, etwas länger als die Schenket; Hinterfüsse gelblich, ziemlich dïmn fadenförmig, über halb so lang wie die Schienen.

Vorderflïgel $3{ }^{3}{ }^{\prime \prime}$ lang, etwas gestreckt (wie bisweileu bei Paludata), spitz mit sanft und gleichmässig zugerandetem Hinterrande, schneeweiss mit zerstreuten, leicht vergänglichen, schwarzen Schüppchen. Die erste braune Querlinie sehr verloschen, am Innenrande durch schwarze Schüppchen verstärkt. Der Querader- (Mittel-) Punkt sehr deutlich schwarz. Die hintere, feine braune Querlinie bildet keine kappenförmigen Wellen, sondern erst einen spitzen Winkel, darauf einen grössern saufteu 
Bogen der Querader gegenüber, worauf sie concar gekriimmt in den Inuenrand läuft; an der ersten Coucavität ist sie am stärksten durch schwarze Schüppchen verdickt, weniger an ihrem untersten Drittel. In der ersten Concarität, also auswärts, liegt ein brauner Schuppenhaufen, der einen Fleck bildet; ein zweiter länglicher, nebelfürmiger, branner Fleck ist in der zweiten Concavität und reicht bis zum Innenrande; beide Flecke sind durch graue Schatten verbunden. Zwei solche Schattenstreifen zeigen sicb auch, den Concavitäten der Querlinie gegeniiber, dicht ror der aus schwarzen Strichen gebildeten Hinterrandlinie. Die innere Hälfte del Fransen ist braungrau bestäubt, die äussere weiss.

Die weissen Ilinterfligel sind ähnlich gezeichuet; nur macht die lintere Querlinie keine scharfe Fcke, und der sie auswärts begleitende Schatten reicht zusammenhängend vou Vorder- zum Innenrande. Die z.wei Nebelflecke vor den schwarzen Hinterrandstrichen sind schwach; an der Stelle, wo bei Paludata die Einbuchtung ist, liegen statt eines längern schwarzen Strichelcheus zwei kïrzere. Fransen wie bei den Vorderfliigelu.

Unterseite wit sehr deutlichen schwarzen Mittelpunkten und Hinterrandstrichelchen. Die Vorderraudbälfte der Vorderflügel und ein Querschatten zwischen Mittelpunkt und Hinterrand bräunlichgrau. Die Hinterflïgel habel hinter dem Mittelpunkte eine schattengraue, verloschene Querlinie.

Vaterland: Texas (Boll). 1 ○ im Cambridger Museum.

\section{Achalia ferrumimaria n. sp.}

Pedibus posticis ơ mancis, $\$ 4$ calcaratis; alis rufescenti-ochraceis rel ochraceo-rufescentibus, anterioribus fascia media nigricanti strigaque punctorum majusculorum dentata nigra per posteriores continuata. $\sigma^{7} \%$.

Die mehr noch als bei Straminata etc. verkïmmerten ơ Hinterbeine beweisen, dass diess eine echte Acidalia ist, der sich aber, wenn man diesen Umstand und die Färbung berïcksichtigt, in der Gesellschaft der europäischen Arten kaum eiu passender Platz anweisen lässt.

Grösse kaum wie Muricata. Körper röthlich ochergelb oder ochergelbröthlich. Gesicht etwas gebräunt. Taster kurz, spitz, röthlichgelb. Fïhler röthlichgelb, beim $\sigma$ durch feine, brauue, bebaarte Kammzälnne doppelt gefiedert. Hinterleibssegmente am Anfange mehr oder weniger braunstaubig. Beine röthlichgelb; die $\sigma$ Hinterbeine ganz verkümmert, klein und blassgelblich; die Schiene ein wenig länger als der Schenkel, schwach verdickt; der Fuss aus zwei Gliedern bestehend, dessen erstes so lang wie die Schiene, aber etwas dünner, das zweite sebr kurz, diinn und zugespitzt ist. Beim $\$$ sind die Hinterbeine regelmässig ausgebildet mit 2 Paar ausebulicben Voruen, deren oberstes bei $3 / 4$ angesetzt ist. 
Vorderfligel 4-41/2" lang, mit dentlicher Spitze, vor welcher der Vorderrand etwas convex ist. Grundfarbe wie die des Körpers. Dic Mittelbinde wird gebildet durch eine schwarze, wellige, auf der Medianund Subdorsalader winklige, grobe Querlinie, die auf der Aussenseite in ansehnlicher Breite yon einem röthlichbraunen Schatten begleitet ist, dessen Aussenrand auch in einigen scharfeu Ecken hervortritt, Ein schwarzer Mittelpunkt fehlt. In der Mitte zwischen diesel Binde und dem Hinterrande ist eine Querreihe grober, scliwarzer Punkte, die in Inuenwinkel endigt und bei $3 / 4$ und unter ihrer Mitte eineu ausspringenden Winkel bildet; die Punkte sind hier und da durch feine, schwärzliclse Linien verbunden. Den Finterrand entlang zieht eine Reihe schwarzer, strichförmiger Punkte, die nicht so scharf wie jene sind und bei dem einen dunkelröthlichen $\sigma$ in dunklem Staube, der den Hinterrand nebclartig begleitet, fast verschwinden. Fransen wie die Grundfarbe oder etwas violettgrau. Die schwarzen groben l'uukte haben auf allen Flügchu etwas Glanz.

Hinterfliigel mit gerundetem Hinterrande, doch ziemlich deutlichem Analwinkel, und von gleicher Grundfarbe wie die Vorderflügel. Nur auf dem Innemrande zeigen sich vor der Mlitte die Anfänge von zwei schwärzlichen Querstreifen. Die Querreihe schwarzer Punkte der Vordertiigel ist als Fortsetzung vollstäudig vorhauden und bildet in iłrer Vorderhälfte einen einspringenden Winkel. Zeichnung des Hinterrandes weniger deutlich als bei den Vorderflügelı.

Unterseite lebhaft röthlich ochergelb. Alle 4 Flïgel haben schwarze Striche auf den Queradern, das $\boldsymbol{Q}$ die deutlichsten. Die Querreihe schwarzer Punkte ist recht deutlich, ebenso die Hinterrandpunkte.

Vaterland: Texas (Boll). 20,19 in meiner Sanmlung.

\section{Eucrostis ${ }^{1}$ ) phyllinaria. 11. sp.}

Palpis et vertice flavidis, fronte cinnanomea; alis dilute viridibus, subtus magis albidis, anteriorum costa vittae instar flavida, strigis 2 pallide ochraceis, opposite obscurius viridi-adumbratis; posterioribus rotundatis, striga unica, interius riridi-adumbrata. 0 .

Zufolge des zu $2 / 3$ kanmföınigen Fühlers, der kurzen Taster und der zweidornigen Hinterschienen ist sie eine echte Eucrostis, die ebenso gut wie Indigenaria einen kleinen Sangriissel besitzt (den Guenée der Gattung abspricht).

Grösse der Indigenaria. Kopf auf dem Scheitel bleich ochergelb, im Gesichte nach oben scharf abgeschnitten hell zimmtfarben, nach unten

1) Der Name, auf die Färbung der Fransen bei Indigenaria gehend, soll

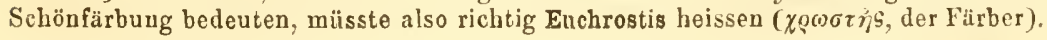


blïsser; die Taster schwach, wenig ïber das flache Gesicht hinansstehend, hellgelb, mit nach unten abstehenden Schuppenharen und kahlem, etwas stumpfem Endgliede. Saugrüssel zusammengerollt, klein, bernsteingelb. Rückenschild (vielleicht entfäıbt) bleich ochergelb. Beine ebenso gefärbt; an den hinteren die Schiene wenig länger als der Schenkel, durch dicht anliegende Haare etwas verdickt, am Ende mit 2 Dornen, von denen der längere durch Haare resdickt ist; der Fuss kaum halb so laug wie die Schiene. Hinterleib dïnn, wenig die Hinterflïgel überragend, bleich ochergelb, am Bauch weisslicher.

Vorderfligel $3^{1} / 4-3^{1} / 2^{\prime \prime}$ lang, spitz mit schwach convexem Hinterrande, hell apfelgriü, längs des Vorderrandes in einer ziemlich schmalen Strieme hell ochergelb. Zwei dünne, so gefärbte, auf den einander zugekehrten Seiten dunkler grïn beschattete Querlinien theilen den Raum iu drei fast gleiche Theile; die erste läuft in einem nach aussen schwach convexen Bogen und ist etwas wellig; die zweite ist grader, mit drei schwachen Wellen. Als ihre Fortsetzung zeigt sich auf den Hinterflügelı, weit hinter der Mitte, eine einwärts grün beschattete, etwas wellige Querlinie, die hinter der halben Flügelbreite einen deutlichen Winkel ibildet und den Innenrand bei $3 / 4$ desselben erreicht. Die Fransen aller Flïgel sind blassgrinlich, an der Wurzel durch eine gelbliche Linie gegen die Flügel begrenzt. Der Hinterrand der Hinterflügel hat keine Ecke, souderu gelıt in sanftem Bogen zum Aualwinkel, wo er mit dem Inneurande den Winkel der Indigenaria bildet.

Unterseite weisslichgrüu, am Vorderrande der Vorderflïgel striemenartig ochergelb und mit sehr verloschen durchscheinender hinterer Querlinie; die Hintertiigel noch weisslicher nit bleichgelber Vorderrandader.

Vaterland: Texas (Boll). 3 o in meiner Sammlung.

Anmerkung. Ich habe ein einzelnes, von Boll in Texas gefangenes o;, das der Phyllinaria sehr wahe steht, aber nicht gut genug. erhalten ist, um eine ausfïhrliche Beschreibung zu gestatten. Es ist auch Eine sichere Eucrostis, etwas grösser (Vorderfligel $4^{3} / 4^{\prime \prime}$ lang), fast von demselben Grïn (das aber mit weissen Sommersprosseu bestrent scheint); uu die Costa del Vorderflügel selbst ist bleichgelb, die zweite Querlinie grade und ohne jede Welle, ganz schmal und verloschen einwärts dunkler gesäumt, während die erste gar nicht gesäumt zu sein scheint, wenigstens nicht auf der zugewendeten Seite. Die Querlinie der Hinterflïgel ist gleichfalls ohme Wellen, in der Nitte z» einem äusserst stumpfen, kanm merklicheu Winkel ausgebogen; der Hinterrand ist zwar gerundet, zeigt aber doch eine Andentung von Erweiterung in der Gegend der Medianaderiste (Eucr. rectilineu Mus. Z.). Dass diese Art nicht gleich Aplodes mbivork Riley (First aunual report on the noxious ins. of Missouri 1869, p. 139, pl. 2, fig. 25) sein kaun, geht aus der Angabe: the wings 
appear sublayline (was sie bei den Eucrostis-Arten gar niclit sind) hervor; auch glaube ich nicht, dass irgend eine Eucrostis-Raupe die Sitten der Gattung Phorodesma hat, zu welcher diese Rubivora aller Wahrscheinlichkeit nach gehört.

\section{Nemoria oporaria s. sp.}

Antennis o brevissime pectinatis, lutescentibus; alis sordide viridibus, costa concolore, ciliis paulu dilutioribus, striga postica pallida, tenui, subtlexuosa, in posterioribus unangula. ơ.

Bedeutend kleiner als Viridata, wenig ïber der Eucr. phyllinaria, kenntlich an den kurzgezähnten Fühlerı, der trüben, braungriinlichen Grundfarbe und dem gleichfarbigen Vorderrande der Vorderflügel.

Körper bleichgrïn; die Segmentränder des düunen, zngespitzten Hinterleibes sowie der Bauch bleich ochergelb. Kopf olivengrüı, am dunkelsten im Gesichte. Taster sehr kurz, gerade, zugespitzt; Saugrüssel lang. Fühler lebmgelblich, am Enddrittel gezähnelt, übrigens mit zwei Reihen kegelförmiger, gefiederter Kammzähne. Beine bleich ochergelb; an den hinterı die Schiene am Ende schwach verdickt mit zwei ungleichen Sporen: der Fuss wenig kïrzer als die Schiene. Das Aftersegment des Hinterleibs endigt mit einem zugespitzten Haarbusch, unter welchem zu jeder Seite ein kïrzerer die Geuitalien verdeckt.

Vorderfliigel $41_{2}^{\prime \prime \prime}$ lang, Hinterflügel mit stumpfer, doch deutlicher Ecke. Grundfarbo bräunlichgrün, trüb, am Vorderrande ungelichtet und ohne Punktirung; die Fransen ein wenig heller, auswärts an den Hinterfiügelı mehr in's Weissliche als an den Vorderflügeln. Die letztern haben au Aufange ilıes letzten Drittels eine verloschene, dünne, eiuwärts kaum etwas dunkler schattirte Querlinie, die in eiu paar schwachen Krümmungen rom Vorderrand zum Innenrand zieht. Die Querlinie der Hiaterflüel ist fast noch verloschener (bein zweiten Exemplar fehlt sie fast ganz) und auf der Hälfte in einen stumpfeu Winkel gebrochen.

Unterseite bleich graugelblichgrïn, am hellsten auf den Hinterflügeln, besonders gegen die Wurzel, läng's des Vorderrandes der Vorderflügel in's Gelbliche, bei dem einen Exemplar fast striemenförmig.

Vaterland: Die nördlichen Staaten Nordamerika's. 2 ơ durch Dr. Packard in weiner Sanmlung.

\section{Epionc mollicularia n. sp.}

Gen. Euchlaenn Hbn. Cat. p. 293.

Alis flaris, puncto disci medii fusco, anteriorum area basali omniumque area limbali latissina rosea. 0 .

Sehr nahe der Vespertaria (parallelaria S. V.), aber mit vielen Verschiedenheiten: Die Hinterflügel haben eine tiefere, ungezähste Aus- 
buchtung; die gelbe Grundfurbe ist ungestrichelt; das rosenfarbige Hillterrandfeld ist breiter, und namentlich auf den hintern fast geradlinig begrenzt, und auf den vordern auch der Raun zwischen der Wurzel und der folgenden Querlinie ganz mit Rosenfarbe ausgefïllt.

Grösse der Vespertaria. Kopf und Taster röthlichgelb. Fühler wie bei Vespertaria doppelt gekämmt mit hellgelbem Stiel. Rückenschild gelb, vorn orangeroth angelaufeu. Beine hellgelb, auf der Lichtseite roth angelaufen; Hinterschienen etwas verdickt, kïrzer als bei Vespertaria, mit zwei Paar Dornen.

Vorderflïgel in der Gestalt wie bei Vespertaria nut hellgelber Grumdfarbe, ohme Querstrichelchen, doch mit sehr verloschen röthlichen, zerstreuten, nur auf dem Vorderrande bemerkbaren Schiippchen. Das Basalfeld ist blass rosenroth, gegen die Wurzel gelb gemischt; die feine, hellbraune Grenzlinie bildet unterhalb des Vorderrandes einen starken Bogen und geht dann sehr schräg rückwärts bis an den Innenrand. Das blassrosenrothe Hinterrandfeld ist breiter als bei Vespertaria, und die braune Grenzlinie läuft olıse die tiefen Buchteu der Vespertaria in schwach concavem Bogen herab und mit einer Welle nach dem Innenrande; an der Flügelspitze ist die Farbe dieses Feldes ohne scharfe Begrenzung hellgelb. Die schwach- und stumpfgezähuten, rosenfarbenen, dunkler gefleckten Fransen werden durch eille bräunliche Linie von der Flügelfäche getrennt.

Hinterflügel nuter der Spitze in einen ziem!ich spitzen Zahn verlängert und unter diesem mit einem flach gebogenen, zahulosen Ausschnit. Grundfurbe wie auf den Vorderfligeln bis an die Wurzel selbst. Der branue Mittelpunkt ist grösser als auf den Vorderflügeln. Das roseufarbene Hinterrandfeld wird durch eine sanft gekrümmte, kaum wellige braune Liıie begrenzt, und an seinem Vorderrand und an Analwinkel tritt in ihm die gelbe Grundfarbe etwas hervor. Fransen wie au den Vorderfügeln.

Auf der Unterseite ist besonders die Grundfarbe reichlich mit rothbräunlicbem Staub bestreut; die Rosenfarbe ist verblasst und lässt die Grundfarbe mehr hervortreten. Die braunen Mittelpunkte und die bramen Grenzlinien sind stärker als auf der Oberseite. Ans der Spitze der Vorderflügel konmt nahe am Hinterrande ein schwal'zes Strichelchen herab, das anf der Oberseite nur ganz schwach angedeutet ist.

Ohne Zweifel ist beim $\$$ wie bei Vespertaria $\$$ das Hinterrandfeld der Vorderfliigel verengt, und seine Begrenzungslinie kommt aus der Flügelspitze oder dicht davor rom Vorderrande.

Vaterland: Texas (Boll). 1 o im Cambridger Museum. 


\section{Gen. Macaria.}

Zur sicheru Unterscheidung der zahlreichen Arten dieser Gattung mïsseu diejenigen, deren $\sigma$ eine Längstinne an der Innenseite der verdickten Hinterschienen baben, von den dieses Merkmal entbehrenden sorgfältig getrennt werden. Jene zeigen hinter der Mitte zwei ungleich lange Dornen und am Ende zwei viel kürzere, gleichfalls ungleiche, und in der Rinne einen langen Haarpinsel, der an der Schienenwurzel entspringt und gewöhnlich in der Rinne versteckt liegt. Bei der audern Abtheilung sind die Hinterschienen viel düuner, ohne Rinne, mit 2 Paaren längerer Dornen, die jedoch an gleicher Stelle wie dort augeheftet sind.

Ich biu so glücklich gewesen, unter meineu 7 nordamerikanischen Arten für 2 die Namen bei Gue née und Walker mit Sicherheit herauszubringen. Sechs dieser Arten gehören in die obenbezeichnete erste Gruppe, deren Repräsentautin in Europa Lilurala ist. Ich beschreibe davon nur 3, weil ich von den andern uur je 1 Exemplar besitze.

\section{Consimilata n. sp.}

Caesio-cinerea, capite collarique ferrugineis; alis ant. acutioribus infra apicem leviter excavatis, maculis costae 4 imparibus cinnamomeofuscis, quarta praecedenti propinqua, inferius in $\sigma^{\star}$ ferrugineo alluta. ơ?

Die nächste Verwandte unserer Liturata, verschieden von ihr durch spitzere Vorderflügel und stärker verlängerte Ecke der Hinterflügel. Beim o ist der eine Sporn des ersteu Paares an den Hinterschienen nur halb so lang wie der andere (bei Liturata 3/4) und das Endpaar kürzer und ungleicher als bei Liturata. Vou den zimmtbraunen Costalflecken der Vorderfliigel stehen die zwei hintersteu einander näher; der äusserste ist schmäler und dunkler als bei Liturata, steht etwas weiter vom Hinterrande $a b$ und hat nur beim ơ unter seinem Ende eine rostgelbliche Lichtung der Gruudfarbe (sonst fehlt alles Rostfarbene auf der Oberseite), und uuterhalb dieser ist, gleichfalls beim $\sigma^{\top}$ eiu sehr undeutlicher, verloscheıer, gelbbräunlicher Fleck; dass der Costalfleck etwas schräger einwärts liegt, mag keine specifische Bedeutuug haben, da Liturata dariu, sowie in der Gestalt und Grösse des Flecks sich veränderlich zeigt. Nur vom zweiten Costalfleck geht ein dunklerer Schatten der Grundfarbe, beim $\boldsymbol{q}$ am entschiedensten, bindenartig durch alle Flïgel; diess mag aber, sowie das Hervortreten von braunen Fleckchen auf den Aderu, welche den oft bei Liturata vorhandenen, aus braunen Punkten gebildeten Querlinien eutsprechen, der Veränderlichkeit unterworfen sein. Die busenförmige Aushöhlung des Hinterrandes unterhalb der Spitze ist 
wie bei Liturata und wird durch die hies rerdickten braunen Striche, mit denen der Hinterrand eingefasst ist, hervorgehoben.

Auf der Unterseite fehlt die breite, helle Rostfarbe durch alle Flügel. Der helle, weissliche Fleck in der Vorderfligelspitze der Liturata ist mit Gelb gemischt und wenig abgegrent, und ebenso wewig aufallend ist auf den Hinterfligeln der Raum vor dem Hinterrande, der bei Liturata ais weissliche Randbinde durch die ocherfarbene Binde scharf abgegrenzt wird. Die braunen Hinterrandpunkte sind besonders beim ơ sehr deutlich.

Vaterland: Wahrscheinlich Massachusetts, Ein gutes durch Dr. Packard erlualtenes Par in meiner Sammlung.

A nmerkung. Guenée nennt seine Praeatomata (Geom. 2 p. 76) voisine de notre Liturata, sondert sie aber vou dieser, der meine Consimilata so äussernt ähnlich ist, durch eine andere Art ab.

\section{Calbineala n. sp.}

Capite collarique ochraceis; alis ant. acutioribus infra apicem leviter excavatis, albidis, griseo-strigulosis, anteriorum costae maculis 4 imparibus, quarta magna ferrugineo-fusca, macula infra eam obsoleta coucolore. ठ’.

Ohne Vergleich der Hinterschienen wird man diese Art in die Nälıe der Notata stellen und sie durch etwas andere Grundfarbe, die spitzeren Vorderfügel, die Verloschenheit des Flecks, der unterhalb des 4. Costalflecks liegt, und die nicht dunkler gefärbten Fransen der Aushöbiung des Hinterrandes unterscheiden. Sie steht aber in Allem der Consimilata sehr nahe, nur dass ihre Grundarbe durch die verwischten bräunlichgrauen Querstrichelchen schmutzig weisslich erscheint.

Kopf, Halskragen und Fühler rostgelb. Rïckenschild wejssgrau. Hinterleib und Unterseite ochergelblich angelaufen, vorziiglich die vies vorderen Beine auf der Aussenseite.

Flügelfarbe weisslich, durch reichliche, blasse, bräunlichgraue Stäubchen verduukelt. Die Vorderflïgel zugespitzt, auf dem bräunlich punktirten Vorderrande mit 4 braumen Flecken in gleichen Entfernungen ron eiuander; der erste und der dritte sind die kleinsten; ron den stärkeren dritten geht ein grauer, blasser Schatten quer ïber den Flïgel, wohl auch oft iiber deu ganzen hintern; der vierte Fleck ist der grösste, länglich, herabhäugend, rostbraun, hinten ziemlich gerade abgeschritten; ron ihm geht auch ein bisweilen deutlicher, immer aber breiter Schatten herunter, in welchem zwischen den zwei untersten Aesten der Medianader ein rostbräunlicher, verwischter (bei 1 Exemplar fehlender) Fleck liegt, der vor sich 1-2 brause undeutliche Punkte hat. Die zu Strichen ausgezogenen braunen Hinterrandpunkte sind nur an der Ausbuchtung 
etwas verstärkt; die Fransen haben die Farbe der Flügel und sehr verloschene oder keine grauen Würfelfleckclsen.

Hinterflügel mit stark hervortretender Ecke, entweder mit breiter, selur verloschener Schattenbinde hinter dem uudeutlichen Mittelpunkte oder auch ganz ohne diese; bei dem tinen Exemplar breitet sich dieser graue Schatten bis an den Hinterrand aus. Hinterrandpunkte sehr undeutlich oder fehlend.

Auf der reinen weissen Unterseite sind der Vorderrand und die Ader'n ochergelb angelaufen; der vierte Fleck der Oberseite ist ochergelb und begrenzt den hellen, weisslichen Raum der Flägelspitze scharf. Die 4 schwärzlichen Queraderpunkte sind deutlich, wem auch nicht scharf. Auf den Hinterflügeln läuft mitten zwischen dem Queraderpunkt und dem Hinterrande eine breite, ochergelbe Binde, die aber dem Punkt gegenüber fast durchbrochen ist and nur verloschen den Analwinkel erreicht. Die verloschemen brauneu Randpunkte sind auf den Vorderflügelu aw deutlichsten.

Vaterland: Massachusetts, woher ich meine $3 \sigma^{\top}$ durch Dr. Packard erhielt.

\section{Succosata n. sp.}

Caesio cinereo albidoque mixta, alis anterioribus acutis, infra apicem leviter excaratis, costae maculis 3 fuscis in strigas repandas continuatis, quarta ferragineo-fusca, infra eam macula prope ad strigam tertiam. o 9 .

Eine hübsche, scharf gezeichnete Art, bei welcher der lostbraune Costalteck und der darunter befindliche schwarzbraune lebhaft hervortreten. Körper schiefergrau mit braunen Stäubchen, die an den weisslich gesäumten Hinteränderu der Hinterleibssegmente zu je zwei Fleckche zusammentreten; der Kopf und der Kragen, wenigsteus des ơ, liat eine blassgelbliche Beimischung. Die gelbbräumlichen Fühler sind an der TTurzelhälfte auf dem Rücken weisslich und braun gefleckt. Die Beine sind bleichgelblich, braun punktirt und gefleckt.

Gruudfarbe der Vorderflügel eigentlich weiss, aber so reichlich mit Schiefergrau ïberzogen, dass sie nur in Mittelfelde und an eimigen andern Stellen hervortritt. Die Vorderflügel sind spitz, nicht so sehr wie bei den zwei vorhergehenden Arten, beim $0^{x}$ aber erheblich mehr als beim $\$$, bei jenem $6 \frac{1}{2}{ }^{\prime \prime \prime}$ lang, bei diesem $5^{3} / 4^{.}$. Auf dem Vorderrande liegeu 3 braume, länglicbe, schräge Flecke, jeder in eine unregelmässige kappenförmige, brauuschieferfarbene, erweiterte Querlinie fortgesetzt; die dritte ist einwärts schmal weissgesäumt und bat, dem untern Ende der Ausbuchtung gegenüber, eine sehr lichtgelbe stelle vor sich aud einen schwarzbraumen, durch die weisse Einfassung rou ilir getrennten Fleck 
hinter sich. Der vierte Costalfleck ist duukel rostbraun, länglich herabhängend und unter- und hinterwärts bis zum Hinterrande von weisslicher Farbe begrenzt. Ein weisser Streif zieht von deu schwarzbranen Fleck bis zum Innenwinkel. Beim o’ befindet sich zwischen der Median- und Subdorsalader nahe der Wurzel eine ziemlich ansehnliche, ovale, schräge glasartige, beulenartige (auf der Unterseite concave) Stelle, die den zwei vorhergehenden Arten ganz fehlt. Bei dem ơ ist der Vorderrand deutlicher als beim $Q$ bellgelb, mit kleinen schwarzen Strichelehen. Die Hiuterrandstrichelchen sind schwarz und scharf ausgedrückt. Fransen hellgrau mit dunklen Wïrfelfecken, die an der Ausbuchtung brau werden.

Auf den etwas hellew Hinterfïgeln läuft eine schiefergraue, wellige Querlinie ror dem deutlichen schwarzen Mittelpunkte. Das o hat eine den $\&$ fehlende solche angefangene Querlinie am Innenrande. Dicht ïber dem Analwinkel fängt eine solche Biude an, die sich gegen den Vorderrand erweitert und ziemlich weit vor ihm eine Ecke bildet. Die braunen Hinterrandpunkte sind dentlich, beim ơ lang gezogen. Die Fliigelecke ist ganz deutlich, doch nicht verlängert. Fransen grau, an den Aderenden bräunlich durchzogen.

Auf der blässern Unterseite sind die Wellen der Vorderflïgel undeutlich, die der heller und reiner weissen Hinterflïgel desto deutlicher. Der Vorderrand der Vordesfliugel ist breit ochergelb angelaufen und der vierte allein vorhandene Fleck ebenso gefärbt oder etwas dunkler. Die Ausbuchtung ist mit einer schwarzbraunen Linie umzogen, und ihre Fransen sind braugrau. Die Binde hinter dem selı scharfen Mittelpunkte ist mehr oder weniger reichlich ochergelb gemischt.

Vaterland: Massacliusetts, woher ich durch Dr. Packard 1 o , 2 우 erliielt.

Meine drei andern zu dieser Abtheilung gebörenden Arten ermaugelu der Aushöhlung des Hinterrandes der Vorderflïgel gänzlich; eine derselben ist

\section{Ocellinata Gn.}

- Guenée Geom. 2, p. 85. - Walker Cat. Geom. XXIII. p. 883.

Die Bandelette subterminale (die vielnehr eine vollständige dunkelgraue Binde ist) hat an ihrem hintern Rande drei hervorstehende Ecken, die mnterste im Innenwinkel, in denen sie schwarz bestäubt ist, am meisten in der mittelsten. Die schwarzen Punkte, die an ihrem Inuenraude auf dell Adern liegen, sind mehr oder weniger vollständig und scharf. Diese Binde setzt sich auf den Hinterflïgelı, nachdem sie einen Winkel gebildet lat, bis zum Innenrande dicht ïber dem Analwinkel fort; sie hat hier und da kleine schwarze Schuppenfleckchen, die stärksten auf den 
Aesten der Medianader, und unter diesen werden sie von einer undeutlichen und wohl selten vollständigen hellgrauen Linie durchzogen. Auf der Unterseite ist sie auf dem weisslichen Grunde überall sehr deutlich begrenzt, und hier ist auch die belle sie durchziehende Linie, nur in ochergelblicher Farbe, gut ausgedrückt.

Vaterland: Massachusetts, von wo ich $3 \sigma^{\top}$ von ungleicher Grösse durch Dr. Packard erhielt.

Aus der zweiten Gruppe dieser Gattung - mit unverdickten Hinterschienen ohue Längsfalte -, zu welcher von Europäern Notata, Alternata, Signaria und Aestimaria gehören, habe ich vor mir:

\section{Aemulataria $\mathrm{W}$ alker.}

\section{- Walker Cat. Geom. p. 884.}

Parra, albida, griseo-obscurata, capite collarique ochraceis; alis ant. infra apicem excaratis, strigis 3 griseis, macula costae ferrugineo-fusca in fasciam cineream continuata, macula intra eam fusca dissecta, margine postico fusco-punctato; posterioribus postice late cinerascentibus. ō.

So ähnlich unserer Notata, dass sie sehr schwer davon zu unterscheiden ist, woriiber Walker kein Wort sagt! Ihre Kleinheit macht sie am besten auf den ersten Blick kenntlicl. Ihre braunen Hinterrandstriche anf den Hinterflïgeln (wofür Notata eine feine, zusammenhängende Linie hat) nähern sie der Alternata, die aber viel reichlicher schiefergrau gefärbt ist, und deren Hinterflïgel auch eine schärfer vortretende Ecke lıaben.

Vorderflügel 5"' lang gegen gewöhnlich $7^{\prime \prime \prime}$ der Notata. Die drei Querlinien, die sich auf der Subcostalader auswärts biegen, sind auf dem Vorderrande nur verdunkelt; die dritte, die eher als aus einem Costalfleck entsprungen angesehen werden kann, läuft dicht an dem grauen Bande, in welches der rostbranne Costalfeck ïbergeht. In diesem liegt der wie bei Notata durch die Adern dreitheilige gelbbraune Fleck, deu sich, gleichfalls wie bei Notata, zwei Punkte der dritten grauen Querlinie zu einer Gruppe anschliessen. Die dunkelbrannen Punkte des Hinterrandes vereinigen sich an der Ausbuchtung zu einer verdickten Linie, und hier sind die Fransen, ausser in einer feinen Basallinie derselben schwärzlich, ohne die hellen Stellen der Notata.

Auf den Hinterflügeln läuft hinter dem Mittelpunkte eine graue, auf den mittlern Adern brann punktirte Querlinie, hinter welcher del Raum bis zum Hinterrande staubgrau ausgefüllt ist, jedoch mit einer liellen, undeutlichen, aus dem Analwinkel entspringenden Querlinie. Fransen hell, hinter der gelblichen Turzel mit einer grauen Linie 
durchzogen, an der Spitze der Ecke ohne den bei Alternata gewöhnlichen braunen Fleck.

Die Unterseite ist wie bei Notata.

Offenbar steht diese Art zwischen Notata und Alternata.

Vaterland: Texas (Boll). 1 o iu meiner Sammlung.

\section{Fidlonia halesaria $\mathrm{n}$. sp.}

Alis supra luteo-fuscescentibus, anteriorum costa vittae instar pallide ochracea, interrupta, ciliis tessulatis; posterioribus subtus pallide ochraceis, fasciis \& ex maculis albis nitidulis, quarta antemarginali maculis ovatis, late discretis composita. o.

Unserer Fasciolaria so ähnlich, dass sie als deren Stellvertreteriu anf dem westlichen Continente anzusehen ist; sie ist etwas grösser als Fasciolariı, mit gestreckteren Vorderflügeln, besonders aber dadurch verschieden, dass sie auf der Unterseite der Hinterf́ügel glänzend weisslich gefleckt ist, und dass die eiförmigen Flecke der vor dem Hinterrande herziebenden Reihe weit von einander getrennt stehen.

Kopf und Riickenschild hellbraun, reichlich hell ochergelb gemischt. Taster kurz, vorn durch Schuppenhaare verdickt, aus denen das sehr kurze Endglied kaum hervorragt. Fühler auf dem Rücken bleichgelb; die Kammzähne länger als bei Fasciolaria, aber gegen die Spitze wie bei dieser an Länge abnehmend. Beine bleich ochergelb; die Hinterschienen am Ende verdickt mit drei (1-2) kurzen, ziemlich feinen Sporen, die nahe an einander gerïckt sind. Hinterleib bleich ochergelb, die Segmente an der Seite weisslich gerandet.

Vorderflügel etwas über $5^{\prime \prime}$ lang, etwas gestreckt, am Vorderende vor dem Enddrittel schwach eingedriickt, mit ziemlich stark convexem Hinterrande (mehr als bei Fasciolaria). Gruudfarbe hell lehmgelbbraun, läug’s des Vorderrandes in einer nach binten erweiterten Strieme hell ochergelb, die auf dem Euddrittel durch verduukelte Gruudfarbe zweimal unterbrochen ist; das dadurch abgeschnittene Ende der Strieme bildet den Anfang einer bald verlöschenden Reihe hell ochergelber Fleckchen vol dem Hinterrande. Fransen blassgelb und braun gescheckt; die braunen Flecke sind umgekehrt dreieckig, gegen den Iunenwinkel hiu verschmälert und strichförmig.

Hinterflügel mit derselben Grundfarbe und mit 2 sehr verloschenen dunkleren Querstreifen durclızogen; auf den Frausen nit 4 Scheckenflecken.

Unterseite der Vorderflügel hellbraun, am Vorderrande und um die Spitze herum bis zur Mitte des Hinterrandes hellochergelb, am Vorderrande vor der Spitze mit einem weissgelben, etwas glänzenden, herabgehenden Streifen uud einer Reihe so gefärbtel Fleckchen vor dem 
Hinterrande. - Hinterflugel bleich ochergelb mit gelblichweisser, etwas glänzender Z ichnung, welche aus Fleeken besteht, die nit bramen Schuppen eingefasst sind und \& nregelmässige Binden bilden. Die an der Wurzel besteht aus 3 Flecken, deren mittelster der grösste, glänzenulste und keilförmig ist. In der zweiten liegt der mittelste Fleck frei. Die dritte besteht aus kleineren und regelmässigeren Flecken; beide Binden sind winklig gekrünmt. Die vierte, ror dem Hinterrande, besteht aus 6 weit von einauder getrenuten, ovalen Fleckchen, welche alle glänzen, und von denen der dritte vou oben der grösste ist.

Vaterland: Texas - Dallas County (Boli). 2 o in meiner Sammlung.

Sudariophora n. g. Tab. II, fig. 11.

Caput exsertum. Frontis fasciculus pilorum conicus.

Palpi longi, porrecti, compressi, acuminati.

Haustellum mediocre, nudum.

Antenuae tenues, $\mathcal{O}$ setaceae, $\sigma$ biseriato-ciliatae, apice nudo.

Mentum appendicibus duabus pendulis, elongatis, piloso-squamatis instructum.

Alae anteriores peracutae, angulo dorsali obsoleto; posteriores margine interuo brevi.

Dass diese Gattung nicht mit Doryorles Guen. (Geom. 2, 233, tab. 17, fig. 6) zusammenfallen kam, ist unzweifelhaft. Sie hat einen kegelförmigen Stirnbusch vor Doryodes voraus (die also schon desswegen nicht mit Ligia zusammenfällt) und an den 2 Anhängseln unter dem Kinn ein sie von allen bekannten Spaunergattungen unterscheidendes Merkmal; es sind 2 ziemiich lange, längliche Hautstreifen, auf der Rückenseite dicht mit anliegenden, die Seiten ïberragenden Haarschuppen bekleidet und neben einander herabhängend '); sie sehen fast aus wie zwei Hüfteu, an denen die übrigen Theile der Beine fehlen. Auch der Saugrüssel ist bei Sudariophora läuger. Ohne Zweifel bietet auch der Aderrerlauf einen Unterschied; ich habe ihn aber an den unabgeschuppten Flïgeln nicht zu erkenneu vermocht. Die Taster sind zwar länger, scheinen mir aber in der Gestalt nicht abweichend. Beide rattungen unterscheiden sich von Ligia durch ihren vorgestreckten Kopf und ihre langen, anders gebauten Taster.

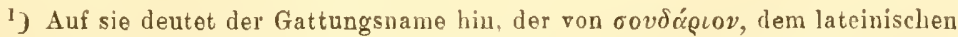
sudarium (Serviette) abgeleitet ist. 


\section{Sual, masutaria Z.}

Alae ant. acuminatae, griseo-ochraceae, prope basim laetiores; strigae binae obliquae albidae, cinereo-marginatae, infra costam refractae, secunda latior et ramum ex angulo in apicem mittens. $\delta$ \%

Doryodes acutalis Walker Cat. Pyr. p. 73.

Wie Jemand Exemplare dieser Art und die beiden guten Abbildungen der Dor. acutaria vor Augen haben und sie doch für einerlei Art ansehen kann, möchte schwer zu erklären sein. Walker bringt nicht allein die Vereinigung zu Stande, sondern erkennt auch, dass der richtige Platz für die Gattung bei den Hypeniden ist, wesshalb er den Artnamen Acutaria HS. Gn. in Acutalis umwandeln zu müssen glaubt.

Da ihm die Hypeniden als Pyraliden gelten, und er in derselben Familie nicbt einerlei Artnamen duldet, so ist es nur ein Versehen, dass er hinterher unter den Pyraliden (in Nascia) noch eine Acutalis vorführt. Auf die Gefahr hin, dass man die Walker'sche specifische Benenuung bevorzugen werde, wage ich es doch, der Art eine neue, die Länge der Taster andeutende zu geben.

Wem nun Walker wach seiner Acutalis die Gattung Doryodes durch lauter uichtssagende Merkmale - nur fasciculus frontalis acutus ist von diesem Prädicat anszunehmen - charakterisirt, so macht er doch ausnahmsweise die vorliegende Art durch seine Beschreibung hinreichend kenutlich.

Die zweite, breite, durch eine bräunliche'Linie grösstentheils der Länge nach halbirte Querlinie geht vom Inneuraude hinter der Mitte aus sanft gebogen und olne Wellen nach der Flügelspitze, die sie aber nicht in ilurel Breite erreicht; sie sendet nämlich in dieselbe eine einfache, verdïnnte Linie von der Stelie aus, wo mnter spitzem Winkel eine etwa dreimal so lange, ebenfalls einfache und dabei einwärts g*ebogeue Liuie nach dem Vorderrande hinter der Mitte abgeht.

Das Vaterland des in Cambridger Museum vorhandenen Paares ist Texas (Boll).

\section{Boarmia psilogramemaria n. sp.}

Tibiis posticis penicillo longo instructis; abdominis segmento primo albido, in basi nigro; alis fuscescenti-cinereis, ant. subelongatis, strigis duabus temuibus nigris, superne valde postice flexis, omnium subtus strigula venae transversae fusca nebulaque fuscescenti ante marginem posticum, anteriorum apice pallido.

Sie hat nur die Grösse der allerkleinsten Cinctaria \%. Die grosse, benlenförmige, kahle Stelle an der Wurzel der Vorderflügel und der Haarpinsel der Hinterbeine beweist, dass diese Art nicht nächst Cinctaria 
stelıen kann, und da ihr ausserdem der helle Ringfleck auf der Queradel der Vorderflïgel fehlt, so ist es nicht glaublich, dass sie mit Guenée's Sublumaria (Geom. 1, 248) zusammenfallen könne. Auch mit der europäischen Secundaria ist ihr eine nähere Verwandtschaft abzusprechen; denn obgleich diese etwas grössere Art gleichfalls auf der Oberseite der Vorderflügel nur einen dunkeln Fleck auf der Querader uud auf der Uuterseite aller Flügel einen solchen zeigt, und ausserdem einen klareu, auf der Unterseite kahlen Fleck an der Wurzel der Vorderflügel besitzt, so fehlt ihr doch ein Harpinsel an den Hinterschienen, und ihre beiden Querlinien sind dick und weniger uach aussen gekrümmt. Etwas mehr stimmt Psilourammaria mit der viel grössern und dunkleru Rhomboidaria in der Richtung der beiden Querlinien; diese hat aber einen kleinerı kahlen Fleck auf den Vorderfligelu und so wenig wie Secundaria einen Schienenpinsel. Dem äussern Ansehen nach lässt sich jedoch Psilogrammaria nebst der in der Anmerkung beschriebenen Fraudulentaria noch am ersten neben Rhomboidaria stellen. Von Fraudulentaria unterscheidet sie sich durch die weniger zugespitzten Vorderfiigel, den gelblichern Tou der Grundfarbe und auf der Unterseite durch die Nebelbinde vor dem Hinterrande, deren auch die vorhin erwähnten drei Arten entbehren.

Das Rïckeuschild ist mit lockern, gelblichgrauen Schuppen reichlich bekleidet, der Halskragen hinten bräuulich gesïumt, und die Flïgeldecken in der Hälfte mit einem Bugenstrich bezeichnet. Hinterkopf grau, Stirne dunkelbraun, am Mundrande schmal weisslich. Taster an der Wurzel licht bräunlich, sonst braun, obenauf schmal weisslich. Sauger mittelmässig. lang, kahl. Fühler mit weniger langen Kammzähnen als bei Rhomboidaria; Geissel gelblichgrau. Beine gelblichstaubgrau, auf der Lichtseite gebräuut; an den hintern sind die Schienen fast dreimal so lang wie die Schenkel, etwas verdickt und zusammengedrückt, an der Wurzel der Innenseite mit einem langen, blouden Haarpiusel, der grössteutheils anliegt und fast bis zur Spitze des Gliedes reicht. Hinterleib etwas ïber die Hintertlïgel hinausragend, grau; das erste Glied weisslich, au Basaldrittel schwarzbraun.

Vorderflïgel $6 \frac{1}{2} \mathbf{2}^{\prime \prime}$ lang, länglich, mit etwas verlängerter Spitze wie bei Cinctaria. Grundfarbe grau mit schwacher, gelblicher Beimischung. Die kahle, auf der Oberseite beulenartig hervortretende Stelle zeigt sich auf der Unterseite als eine Ellipse, wclche ron der Subdorsalader an quer iiber die Falte weg bis an die Medianader reicht. Die zwei schwarzen, feinen Querliuien sind etwas wellig und rom Innenrand aus sehr stark nach hinten gekrümmt; die erste, bei $1 / 3$ des Innenraudes sich erhebend, biegt sich am obern Ende einwärts und erreicht den Vorderrand bei 1/3; die zweite, hinter der Hälfte des Inuenrandes entspringend, biegt sich oben auch etwas rückwärts und geht bei $3 / 4$ in den Vorderrand. Vor dieser zweiteu, ihr ziemlich nahe, ist ein stärkerer, mehrfich unterbro- 
chener, daher sehr wenig auffalleuder Querstreif, welcher oben divergirend, so dass er in der Mitte zwischen der Querlinie und dem schwachen braunen Queraderpunkt zieht, in den Vorderrand ausläuft. Es ist also der Verlauf dieser Linie wie bei Rhomboidaria, nur dass bei dieser der Querstreif deutlicher ist und viel mehr gegen die hintere Querlinie divergirt. Eine helle Zickzacklinie zieht verloschen ungefähr in der Mitte zwischen der Querlinie und dem Hinterraude. In einiger Entfernung von der Spitze geht ein dunkler Schatten iiber die Zickzacklinie hinweg und endigt uıter dem Queraderpunkt. Der Hinterrand hat braune, durch feine braune Linien verbundeue Punkte. Auf den grauen Fransen liegen an den Punkten sehr unmerkliche helle Stellen.

Hinterfligel ron gleicher Grundfarbe, nur mit einer feinen, schwarzen Querlinie hinter der Mitte; sie macht auf der Vorderrandhälfte ein paar Winkel. Vor ilı, doch näher als bei Rhomboidaria, ist vom Innenrand aus ein Querschattenstreif, welcher über dem ganz verloschenen Queraderfleckchen auflört. Gegen die Wurzel zeigt sich am Innenrande ein bräunlicher Fleck, der braunen Basis des ersteu Segments entsprechend. Die lielle Zickzacklinie der Vorderflïgel ist in dem verdunkelten Grunde kaum angedeutet. Der etwas wellige Hinterrand ist wie bei den Vorderflügeln gezeichuet.

Unterseite gelblichstaubgrau, mit spärlichen bräunlichen Querstrichelchen bestreut; die braunen Queraderstriche sind ziemlich verloschen. Die Vorderfliigel sind am Vorderrande lebhafter gelblich und mit branen Strichelchen urgleichmässig bestreut. Vor dem Hinterraude zieht ein breiter, bräunlicher, bindenförniger Nebel, am Vorderrande verbreitert und verdunkelt und einen gelblichen, nicht grosseu, doch recht aufiallender. Raum besonders in der Flïgelspite abschliessend. Auch auf den Hinterflügeln ist diese Nebelbinde vorhanden, doch viel schmäler und gegen den Analwinkel verlöschend. Andere Zeichnungen fehlen.

Vaterlaud: Texas (Boll). 1 o in meiner Sammlung, uach Dr. Hagen's Notiz genau mit den Exemplaren des Cambridger Museums stimmend.

A nmerkung. Nach lavger Prüfung unterscheide ich ron Psilogrammaria als eigene Art Boarmia frandulentaria, von der ich ein o Exemplar des Cambridger Museums vergleiche. Bedenken gegen die Artrechte entstehen vorzüglich dadurch, dass die Hinterschienen ganz gleiche Haarpinsel trageu, und dass auch die kahle Stelle der Vorderflügel fast gleiche Grösse hat und nur mehr kreisrund zu sein scheint; dazu kommt, dass die Querlinien einen gleichen Verlauf haben und nur etwas stärker sind. Was sie unterscheidet ist Folgendes: 1. Die Vurderflïgel siud viel stärker zugespitzt, und ihr Hinterrand ist gerader und geht schräger eiuwärts; 2. die Grundfarbe ist grau, ohne die mindeste gelbliche Beimischung; 
3. der schwärzliche, die zweite Querlinie begleitende Querstreif ist vollständig; 4. ein Queraderpunkt fehlt; 5. die schwarzen Querliuien sind verstärkt, und die zweite macht mehr Ecken und endigt in einen bei Psilogrammaria feblenden Costalfleck; 6. auf den Hinterflügeln geht ein vollständiger, schwarzer Querstreif nahe der Wurzel querïber als Fortsetzung der erstell Querlinie der Vorderfiugel; 7. der am Innenrande anfangende Querstreif vor der Querader ist viel weiter ab von der schwarzen Querlinie; 8. auf der Unterseite fehlt die Wolkenbinde gäuzlich, und nur der gelbliche Rıum in der Vorderflügelspitze ist durch braunen Schatten abgegrenzt; 9. die Hinterfï̈gel sind ganz ohne Queraderstrich.

Voll diesen Unterschieden sind offenbal 1 und 2 die wichtigsten, 8 und 9 von geringer Bedeutung. Ob sie doch nur einer Varietät angehorren, muss der Vergleich mehrerer Exemplare ausweisen. Dass man sowohl Psilogrammaria wie Fraudulentaria wieder orkennen werde, hofte ich mit Bestimmtleit, wenn man nur zunächst auf die Beschaffenlıeit der Hinterschienen uıd die der Vorderflügelbasis achtet.

\section{C'idaria bistriolata $11 . \mathrm{sp}$.}

Alis ant. elongatis, acutis, virescentibus, fascia latissima ante medium, obliqua, fusca, ad dorsun denigrata, litura subfasciata anguli dorsalis fuscescente, striolis ante apicis striolanı duabus atris. 웅.

Die Flügel viel schmäler und die vordern spitzer und mit weniger convexem Hinterrande als bei Literata, wesslialb diese Art der Impluviata entfernter steht und also auch der Guenée'schen Pluviata. Mit den beiden europäischen Arten hat sie die 2 tiefschwarzen, kurzen Läıgslinien gemein, welche vor dem schwarzen Strich der Flügelspitze so übereinander liegen, dass die obere später anfängt und weiter reicht als die untere; letztere ist auch feiner und länger.

Die Grundfarbe ist ein blasses Hellgrün. Die breite, braune Binde vor der Flügelmitte ist wie bei Literata schräger gelegt als bei Impluviata und reicht also am Innenrande weiter gegen den Innenwiukel; sie ist hier schwarz gemischt, und die Innenrandfransen sind an ihrer äussern Hälfte anch schwarz. Die hintere braune Binde ist nur an ihrem Antange, am Innenwinkel dentlich; beim zweiten Ast der Medinnader verschwindet sie in der Grundfarbe, welche unterhalb der ersten schwarzen Längslinie bis zum Hinterrande die Oberhand gewinnt. Der Raum, in welchem die schwarzen Längslinien liegen, ist bis zum Vorderrand hinauf wieder gebräunt.

Die Hinterflügel sind viel dunkler als bei Impluviata (während diese sie nach Guenée dunkler zeigt als seine Pluviata).

Die Unterseite scheint nichts Charakteristisches zu hesitzen. 
Gueuée bemiiht sich die zwei europäischen Arten zu unterscheiden; icl kanl den von ihm hemerkten Unterschied nicht anerkennen, und gebe daher von den Tastern der Bistriolata nur an, dass sie ebenso lang mnd gestaltet sind und am dritten Gliede ein weissliches Ende haben. Die Schnalheit ilırer Fliigel, deren Färbung wahrscheinlich abändert, erlaubt weniger diese Art mit Impluviata zu verhinden als mit Literata. Vaterland: Texas (Boll). 1 \& in nueiner Sammlung, das mit anderu Exemplaren des Cambridger Museums nach Dr. Hagen's Angabe genau iibereinkomint.

\section{Cidaria designata Bkh.}

Covemia propugnata Guenée Geom. 2, p. 412.

Fuenée ist etwas zweifelhaft, ob er niclit sein nordanerikanisches Exemplar für eine von der europäischen verschiedene Art ansehen soll. Obgleich auch meine Exemplare etwas kleiner sind, als Designata bei nus gewöhnlich erscheint, so stehe ich doch keinen Augenblick an, sie fiir dieselbe Art zu erklären. Eine sehr beständige Eigenheit der Designata ist, dass sie im obern Theile des zweiten Zahnes der Mittelbinde eine fleckartige, schwarze Stelle hat, die sich ofter's wischartig einwärts verlänqert. Meine 4 Massachusetts-Exemplare zeigen sie sehr ausgebildet. Der schmale schwarze Innenrand der Mittelbinde ist bei 3 Exemplaren fast gerade (was bei den unsrigen selten ist), beim vierten gebogen, wie gewöhnlich. Alle haben in dieser Mittelbinde ein sehr lichtes Roth, das doch weniger verlosclien ist als bei $\mathrm{Staudinger's} \mathrm{Var.} \mathrm{Islandicaria} \mathrm{(Cat.}$ p. 186). Sie könnten als Verbindungsvarietät zwischen dieser und der Stammart gelten, wenn nicht mein bei Raibl in Kärnten gefangenes (mit Ausnalıme der betıächtlicbern Grösse) ganz mit ihnen stimmite.

Die Flugzeit wird in Nordamerika mit der bei nns gewöhnlichen zusammenfallen; ein unverflogenes ơ fing $B$ urgess bej Beverly am 20. Mai, die zwei andern abgeflogenen $\sigma^{\top}$ am 12. und 16. Tuni.

Cialuria fluciata Hb n. Fig. 280, 281 б̄ var. (schlecht), $283 \%$.

$$
\text { Camptogramma - Guen. Geom. 2, p. } 429 .
$$

Diesen seltenen, aber in Furopa weit verbreiteten Spanner besitze ich nicht nur aus England, soudern auch (durch Christoph) aus Sarepta und (dnrch Lederer) aus dem Caucasus. Guenée zeigt auch Sïd-Frankreich, Italien und Sicilien, Staudinger (im Catalog) Bithynien und Syrien als Vaterländer an; I,ederer kennt ausserdem die fregend vou Wien, Rössler (Nassauer Fama S. 144) zwej Stellen im Nassauischen. Das nördliclıste Vorkommen in Deutschland ist wohl bei Berlin (nach Pfïtz-ner in ler Berliner entom. Zeitschrift, XI, S. 207) und Frankfurt a. d. O., 
wo ich am 16. August 1826 Abends im Gebüsch eines Hohlweges eil schönes ơ fing, dessen Abbildung ich noch besitze. ${ }^{1}$ )

Dass sie aber auch in Nordanerika zu Hause ist, meldet schon Guenée, der sein or als Var. A absondert. Ich selbst habe eiu echtes Fluviata $\&$ aus Texas (Boll), das den schwarzen, weiss umzogenen Queraderstrich auf den Vordereïgeln sehr deutlich zeigt und nur darin eine Auszeichunng hat, dass der Grundfarbe auf Ober- und Unterseite wenig Roth beigemischt ist. Aber ein Sareptaner $\$$ ist gleich schwach geröthet.

Cialuria ferrugata Liun.

\section{Coremia - Gu en. Geom. 2, p. 413.}

Von dieser gemeinen, über den ganzen gemässigten Theil Europa's und Asiens verbreiteten Art besitze ich drei sichere Exemplare (2 б, 1 \%) aus Massachusetts durch Packard und Burgess. Letzterer fing das eine o am 12. Juni, also zu einer Zeit, wo die erste Generation anch bei nns noch fliegt. Sie sind alle klein (doch gibt es bei uns noch kleinere) und gehören zur Stanmart; das $\$$ mit bläulicher, die ơ mit mehr röthlicher Mittelbinde der Vorderflügel.

\section{Cidaria parinotata $11 . \mathrm{sp}$.}

Antennis o breviter ciliatis; alis ant. griseis, nigricanti undulato-strigosis, strigis mediis in fasciam obsoletam compositis, striolis 2 atris geninatis superius ante luarginem posticum jacentibus, punctis marginalibus nigris per paria digestis. 0 .

Offenbar eine Verwandte der Cid. didymata L., von dieser aber im mäunlichen Geschlecht durch die gefrassten, nicht kamuföımigen Fühler, die feineren, schärferen, nicht in einander fliessenden Querlinien der Vorderflïgel, die etwas in's Gelbliche spielende Grundfarbe derselben und die 2 tiefschwarzen Zwillingsstriche vor dem IInterrande verschiedeu. Sie scheint auch eine Verwandtschaft mit Cirl. cummtilis Grote (Annals of the Lyceum of Nat. History. New York VIII, 1867, p. 29, fig. 13) zu haben, welche aber bräunlichgrïne Querlinien der Vorderfïgel hat und der zwei tiefschwarzen Striche entbehrt. Selbst mit Lohophora appensata lässt sie, obgleich auch diese gar nichts von den Doppelstrichen zeigt, eine Vergleichung zu, weil bei selı genauer Betrachtung ganz auf der W'urzel der Hinterflügel

') Rössler hat meine Mittheilung sonderbar missverstanden, weun er a. a. 0. sagt, ich hätte den Spanner zahlreich gefangen; ausser dem einen Exemplar habe Ich bis jetzt keines lebend mehr gesehen. 
ein kleines, helles Schiippchen zu entdecken ist; dieses ist jedoch nicht der Art, dass es als das Auhängsel der Lobophoren gelten und zur Aufnahme der Parinotata unter diese nöthigen könnte; auch scheint das Verhältniss des Unfanges der Vorderflügel zu dem der Hinterflügel ein anderes zu sein als in dieser Gattung.

Riickenschild staubig grau, Schulterdecken vor der Mitte und am Ende schwarz beschuppt. Der starke Schuppenbusch des Schildchens ist schwarz, in der Mitte mit gelbgrauen Schuppen verdeckt. Kopf gelblichgrau beschuppt, im Gesichte dunkler. Taster kïrzer als der Kopf, zugespitzt. Fühler grau mit stark abgesetzten Gliedern, die etwas länger als breit uud mit kulzen Haaren gefranst sind. Beine bleichgelblich, die vier vorderu auf der Lichtseite dunkelbraun mit hellgulblichen Euden der Glieder; die Hinterfüsse auf dem Rücken der Glieder an der Wurzel ganz verloschen bräunlich. Hinterleib fahlgelblich, an den Hinterrändern der Segmente und am Bach weisslich.

Vorderflïgel $3{ }^{1} / 2^{\prime \prime}$ lang, am Vorderrande gegen die scharfe Spitze hin convex, staubgrau, am Vorderrande von der Wurzel aus etwas röthlich. Die vielen schwärzlichen, gezähntwelligen Querlinien, welche die ganze Fläche durchziehen, sind auf den Vorderrande verstärkt und verlöschen zum Theil in Mittelranm. Die gewöhnliche Mittelbinde, welche durch die in ihr etwas verdunkelte Grundfarbe deutlicher wird, enthält an ihrer der Flïgelbasis zugewendeten Seite die kürzesten und vollständigsten Querlinien; in ihrer hellen Mitte liegt auf der Querader ein verloschenes, braunes Strichelchen; ihr verloschener Hinterrand wird durch ein schmales, helles Band begreuzt, das von einer schwärzlichen WVellenlinie durchzogen wird und erkennen lässt, dass die Mittelbiude hinterwärts, wie etwa bei Designata, in 2 stumpfen Ecken hervortritt. Der Aushöhlung zwisclıen diesen zwei Ecken gegeniiber liegen in gleichem Abstande von ihnen und vom Hinterrande die 2 tiefschwarzen Längsstriche nebeneinander, jeder linten mit einem weisslichen Bogeu umzogen; diese Bogen sind ein Theil der gewöhnlichen hellen, bei Parinotrata sehr verloschenen Kappenlinie, welche ror dem Hinterraude berabzieht. Oberhalb der zwei schwarzen Striche ist auf dem Vorderrande der Anfang einer Wellenlinie besonders verstärkt. Der Hinterrand ist mit einer Reihe tiefschwarzer, paarweise geordneter Punkte eingefasst. Die grauen, an der Wurzel hellen Fransen sind an jedem Punktpare mit einem duukelgrauen Längsstrich gezeichuet.

Hinterflügel hell staubgrau mit verloschenem, kaum bemerkbaren, dunkleren Queraderpunkt; einer solchen in der Mitte zu einem Winkel gebogenen Querlinie dahinter und einem schmalen, granen, biudenförmigen Schatten am Hinterrande. Die paarweise stehenden schwarzen Hinterrandpunkte etwas verloschen. Fransen wie bei den Vorderfligeln. Ganz 
an der Wurzel des Innemrandes, unter der Schulterdecke versteckt, liegt ein kleines, weissliches schuppenähnliches Plättchen.

Vaterland: Texas (Boll). 1 б im Cambridger Museum.

\section{Aglossa cuprina n. sp.}

Antennis o pectinato-ciliatis, palporum articulo terminali fusco, apice albo; alis ant. rubido fuscoque mixtis, strigis duabus dilute rubidis, altera fulminali ante, altera argute serrata post maculam disci liberam dilute rubidan; posterioribus cinereis. $\sigma^{\top} \%$.

Guenée erwälnnt bei seiner nach einem $Q$ aufgestellten Aglossa domalis (Pyral. p. 128) nichts von der Färbung der Taster; dagegen spricht er von düsterer Färbung und der Spur einer Querlinie auf der Oberseite der Hinterflügel und einer am Vorderrande geraderen Querlinie auf den Vorderflügelı (im Vergleich mit Cuprealis) - was alles sich bei den vorliegenden Exemplaren nicht findet. Das so betonte: les ailes inférieures ne sont nulleıent prolongées à l'angle interne - nöthigt zur Voraussetzung, dass diese Flügel bei Cuprealis am Analwinkel verlängert seien - sie sind es aber eben so wenig bei den drei Cuprealis meiner Sammlung, wie bei der vorliegenden Cuprina. Ich halte es also bis zur genaueren Kenutniss der Domalis fiir das Sicherste, die Texanischen Exemplare unter einem eigenen Namen aufzustellen. - Walker zieht zu Cuprealis (Cat. Pyr. p. 275) Exemplare aus Nordamerika, die wahrscheinlich so wenig wie meine Cuprina zu ihr gehören.

Diese Art kommt der Cuprealis so nahe, dass ich bloss die Unterschiede angebe:

1. Die ơ Fühler, bei Cuprealis borstenförmig, pubescirend gefranst, haben deutlich abgesetzte Glieder und sind durch längere Haare zweireihig kammartig gefranst. (Die 9 Fühler zeigen keine Verschiedenheit.)

2. Die Taster, in beiden Geschlechtern bei Cuprealis einfarbig, hell röthlichochergelb, am zweiten Gliede auswärts ein wenig gebräunt, sind bei Cuprina auswärts an den zwei letzten Gliedern schwarzbraun, jedes an der Spitze bleich ochergelb.

3. Auf den Vorderfligeln hat Cuprealis in der Mitte des Discus einen grossen, hell röthlichen, zerflossenen, mit einem hellen Vorderrandfleckchen in Verbindung stehenden Fleck; bei Cuprina ist dieser Fleck kleiner, breit am Vorderrande getrennt und vorn und hinten durch braune Färbung scharf' begrenzt.

4. Die zweite (hintere) helle, kappenförmige, aus einem hellen Costalfleck herabkonmende Querlinie nähert sich bei Cuprealis dem Hinterrande so sebr, dass sie ron dem hellen Mittelfleck melır als doppelt so weit entfernt ist; bei Cuprina ist sie nicht kappenförmig, sonderu scharf 
sägezähıig, und dem Hinterrande nur ein wenig näher als dem Mittelfleck, also von ersterem erheblich weiter entfernt als bei Cuproalis.

Bei dem vorliegenden $\sigma$ ist auf Ober- und Unterseite der ganze Raum zwischen der hintern Querlinie und dem Hinterrande mit der Farbe der Qnerlinie ansgefïllt, wodurch die (bein $q$ undeutlichen) schwarzen Randpunkte sehr deutlich hervortreten. Diess mag aber eine Varietät sein. Auf der Unterseite sind die Vorderflïgel beim $\%$ eiufarbig dunkelgran, beim $\sigma^{*}$ aber mit dem oben bemerkten hellen Hinterrande; beide Geschlechter zeigen auf dem Vorderrande an der Mitte 3 helle Punkte und hinter ihnen den hellen Fleck der Obesseite. Auf den Hinterfliigeln ist ein schwacher, grauer, bindenförmiger Querschatten hinter der Mitte, beim ơ zieulich deutlich, beim $\%$ aber nur in seinem Anfange auf dem Vorderrande zu erkenuen.

Vaterland: Texas (Boll). 1 б 1 \& im Cambridger Museum.

\section{Asopia Tr.}

Ich habe drei älnliche nordamerikanische Arten vor nir, die in ihrer Heimat verwechselt zu werden pflegen.

\section{Fimbrialis S. V.}

Capite palpisque ferrugineis; alis purpureis, ciliis cum marginis postici linea tenui anreo-flavis, anteriorum maculis costalibus duabus aureis in strigas pallidas subundatas continuatis; posteriorum strigis undulatis pallidis duabus. ठํㅇ.

Pyral. fimbrialis, purpurfärbiger Zünsler mit goldgelbem Unterraud. Wiener Verzeichn. S. 12́.

Asopia -- Z. Fsis 1847, S. 502. - Guenée Pyr. p. 118. Pyralis Walker Cat. Pyr. p. 261.

Asopia costalis Fabr. Lederer Pyral. S. 53. Staudinger Cat. p. 202 .

Diese von Hübner Fig. 97 roh, voll Duponchel auf Tafel 223 besser (doch mit falsch gestellter zweiter Querlinie der Hinterflïgel) abgebildete Art habe ich in melıeren Exemplaren von New York erhalten (Walker hat sie aus Neu-Schottland). Sie ändert in der Streckung der Vorderflügel und der Deutlichkeit der Querlinien, sowie in der Grösse etwas ab, bleibt aber hinsichtlich der letztern weit unter den zwei folgenden Arten.

Am sichersten ist sie daran zu erkennen, dass alle Flïgel vor den goldgelben Fransen mit einer schmalen, aut der Unterseite feineru und schärfer begrenzten, goldgelben Linie nmzogen sind. Ausserden sind Kopt und Taster hell rostgelb, letztere mauchmal auf der Aussenseite purpur- 
röthlich angeflogen. Die zweite Querlinje der Hinterflïgel entspringt auf dem Vorderrande aus einer Verdickung an der Mitte des Innenrandes der Vorderflïgel, der ersten Querlinie derselben näher als der zweiten.

\section{Olinalis $\mathrm{Gn}$.}

Capite palpisque luteis; alis fuscescenti-purpureis, pallide aureo-ciliatis, anteriorum maculis costalibus duabus in strigas pallidas subrectas contiuuatis; posteriorum strigis duabus undatis pallidis distantibus. ơ 9

Asopia - Guenée Pyral. p. 118.

- Trentonalis Lederer Pyr. S. 166, tab. 7, fig. 2 (mit verfehlter Grundfarbe).

Bedeutend grösser als Fimbrialis (Vorderflügel $4^{3} / 4-3^{\prime \prime \prime}$ gegen höchstens 4), durch Mehreres von ihr zu unterscheiden, hauptsächlich durch den Mangel der hellgelben Miuterrandinie umittelbar an den Fransen, wofiir der Hinterrand selbst in einer feinen, auf der Unterseite sehr deutlichen Linie schwarz ist. Was Guenéc wicht bemerkt, dass nämlich die Querlinien auf ihren zugewendeten Seiten schwärzlich gesäumt sind; gehört auch zu den guten Unterscheidungsmerkmalen; dagegen elwähnt er als solche mit Unrecht die gelben Vorderrandpunkte und ein gebogenes (infléchi) Endglied der Taster. - Die zweite Querlinie macht gleich unter dem Costalfleck einen sanften Bogen, worauf sie gcrade verläuft. Die Costalflecke sind in der Grösse etwas veränderlich; ebenso die Querliuien in der Deutlichkeit und die Grundfarbe in der Dunkelheit. Das $C$ ist gewöhnlich heller als das $\sigma^{*}$.

Von der folgenden Art ist Olinalis durch die weit auseinande. gerïckten Zeichmungen, die zahlreichern gelben Costalpunkte und die Biegung der zweiten Vorderflïgellinie zu unterscheiden.

Da Guenée's Beschreibung selı oberflächlich ist, so hat Lederer die Art mit einem neuen Namen versehen; ich glaube aber doch, dass diess nicht nöthig ist, wenn sich nicht woch mehr ähuliche Arten finden, auf die jene Beschreibung greich gut anwendbar ist. Ich erhielt Exemplare aus Nordamerika als $\boldsymbol{P}_{\boldsymbol{g}} \boldsymbol{r}$. fimbriulis bestimmt.

Die mir vorliegenden Exemplare sind aus Texas (Boll), Ohio (Lederer), Massachusetts und Pennsylvanien (Packard).

Woron Gueuée den specifischen Namen abgeleitet hat, ist mir unbekanut.

A n merkung. In American Entomologist ed. by Walsh and Riley, I. St. Louis 1868 , p. 226 ist eine vermeintliche Asopia costalis F. im Holzschnitt und dazu eine Nachricht über ihre Naturgeschichte gegebell. Die Grösse der beiden abgebildeten Schmetterlinge ist etwas über der von Asop. fimbrialis und cutspricht eher der von As. Olinalis. Auch passen 
die Worte: the moth is one of our prettiest species, being of a reddish brown color nur auf As. Olinalis (ebenso die scharf gesäumten Querlinien in den Bildern), während die folgenden Worte: with golden yellow markings and fringe to its wings sich nur zur Noth auf sie anwenden lassen. Die Raupen wurden hei Galesbury in Michigan in einem Heuschober, der theilweise aus Klee bestand, zwischen dem sie in weissseidenen Gespinnsten lebten, zu Myriaden gefunden. Als clover-worm wurde der Zïnsler schon in den ältern mir unbekanuten Werken: the Practical Fntomologist und the Prairie Farmer ausfülrlich behandelt. Dr. Packard copirt die Abbildungen des American Entomologist in seinem Guide to the Study of Insects p. 328, bezeichnet die Art, gleichfalls unter dem Namen Asopia costalis, als lilac-colored (was auch wieder auf As. fimbrialis gar nicht passt) und erklärt sie für eine Einwanderin aus Europa. Letzteres ist fiir Olinalis allerdings niclit der Fall, weil diese nirgends in Europa rorkoumt; für Fimbrialis wäre es eher möglich, obgleich diese in Norddeutschland eine Seltenheit ist und in England ganz fehlt. Merkwiirdig wäre es, wenn von Fimbrialis die Naturgeschichte in Nordamerika sehr bekannt wäre, während sie in Europa noch zu entdecken bleibt.

\section{Himonialis 1 . sp.}

Capite palpisque cinnamomeis; alis fuscescenti-purpureis, aureo-ciliatis, anteriorum maculis costalibus duabus approximatis aureis iu strigas subrectas pallidas contiuuatis; posterioribus ante medium strigis duabus albidis undatis. 0 .

Wie die grösste Olinalis, auch mit schwarzer, auf der Unterseite sehr deutlicher Hinterrandlinie und zwei auf den zugewendeten Seiten dunkel beschatteten Querlinien; aber diese sind anf beiderlei Flïgeln einander sehr genähert und ehenso auch die 2 Costalflecke, deren hinterer mehr senkrecht gelegt ist und aus welchen die Querlinie ohue Biegung herabläuft. Zwischen den beiden Costalfecken ist nur Raum fïr $2-3$ Costalpunkte (doch wecliselt diese Zahl bei Olinalis, obgleich doppelter Platz dafür ist). Auf den Hinterflügeln sind die beiden weisslichen Wellenlinien eiıander sehr genähert, und die hintere liegt noch diesseits der Flïgelhälfte (bei Olinalis jenseits). Die Grundfarbe füllt also bei Himonialis auf allen Fliigeln zwischen dem Hinterrande und der hintern Querlinie einen viel breitern Raum aus als bei Olinalis. - Die Fransen sind nicht ganz so schön golıgelb wie bei Fimbrialis; an ihrer Wurzel läuft wie bei Olinalis eine gelbbraune Linie um den ganzen Hinterrand der Flügel.

Das schöne Exemplar meiner Sammlung wurde durch Herrn Burgess an 7. Juli bei Beverly in Massachusetts gefangen. Dass es nicht Myllalis Walker Pyr. p. 26ö sein kann: wofïr es bestimmt wurde, 
lehrt das exterior border bright luteous; auch ist das Endglied der Taster nicht elongate-conical und halb so lang wie das zweite Glied, sondern so kurz, dass es kaum aus den Schuppen des zweiten hervorragt. Endlich passt auch die Grundfarbe der Flügel gar nicht.

\section{Binodulalis u. sp.}

Capite palpisque lutescentibus; alis longiusculis, subvirescenti-cinereis, ciliis concoloribus, anteriorum costa rufescente, strigis duabus distantibus, utraque e macula costali demissa. $\$$.

Von den drei vorigen sogleich durch die nicht gelben Fransen verschieden, kommt sie der europäischen Glancinalis in der Flügelstreckung, der Grundfarbe und Zeichnung so nahe, dass sie leicht für einerlei Art mit ilı angeseben werden könute. Obgleich ich aber nur Ein Exemplas vor mir labe, so erkläle ich es doch zuversichtlich für eigene Art, die sich am leichtesten durch die beiden auf dem Vorderrande der Vorderflügel zu Flecken verdickten Querlinien unterscheiden lässt. (Bei Glaucinalis sieht wur die zweite durch eime geringe Erweiterung auf dem Vorderrande fleckartig verstärkt aus, während die der viel dunklern Rubidalis sich wirklich zu einem Costalfleck erweitert.) Das Exemplar hat die mittlere Grösse der in dieser Hinsicht und in der Flügelstreckung sehr veränderlichen Glaucinalis. Die Unterschiede der Binodulalis von dieser sind folgende:

Gesicht und Taster sind rothgelblich, in welcher Färbung ich von Glaucinalis nur 1 \% habe, während bei dieser soust beides nur die rötllichgraue Rückenschildsfarbe zeigt. Die Vorderflügel sind zwar etwas gestreckt, aber doch breiter als bei der breitesten Form der Glaucinalis; ilure Grundfarbe ist etwas licliter, kaum mit grünlicher, auch ohne röthliche Beimischung (welche letztere bei Glaucinalis öfters ziemlich reichlich vorhanden ist); nur längs des ganzen Vorderrandes ist die Farbe bis zur Subcostalader gelblichroth. Die beiden blassgelbeu Querlinien entspringen aus ansehulichen, dreieckigen Costalflecken (bei Glaucinalis sind sie nur auf dem Vorderrande etwas verstärkt und lebhafter gefärbt); die erste steht auf dem Vorderrande entfernter vou der Basis und krümmt sich mebr nach ausseu, worauf sie auf dem Innenrande näher an der Basis endigt; sie hat also eine andere Richtung, inden sie oben mehr nach aussen überhängt. Die zweite ist der ersten näher als bei Glaucinalis, macht über der Mitte einen stärkern Bogen nach aussen, biegt sich aber unten ein wenig, so dass sie ebenso wie bei Glaucinalis nahe am Innenwinkel endigt. Der röthliche Vorderrand ist zwischen den beiden Costalflecken sehr eingeengt und behält nur für 3-4 gelbe Costalpunkte Ram, während Glaucinalis $6-8$ zeigt. 
Die Hinterflügel, die bei Glaucinalis einen sehr vou den Vorderfliigeln abweichenden grauen Ton haben, stimmen in der Farbe mit den Vorderfligehı überein. Die zweite Querlinie geht ohne Wellen (bei Glaucinalis mit mehreren) in sanftem Bogen und entfermter vom Hinterrande in dell Innenrand.

Auf der Unterseite ist die Farbe heller grau; die Vorderflügel zeigen auf dem gerötheten Vorderrande nur den zweiten gelblichen Fleck und $\mathbf{k}$ wine Querlinie; auf den Hinterflügeln ist die zweite in eiuer schwachew Spur zu erkenien.

Vaterland: Texas (Boll). 1 \% in Cambridger Museum.

Sedenia Guен. Tab. III, fig. $14 a, b$.

Abtheilung: B. Cavifrons.

Frons conica, superue cornea, excavata.

Antennae breviusculae (abdominis dimidium vix aequantes).

Alirum posteriorum vena subcostalis trifida, ramo primo prope basim exorto in costam ante apicem exeunte.

\section{Sedlemin (cruifions) bimalulalis n. sp.}

Alis albis, anterioribus sericeis, strigis duabus crassis, undulatis, nigris. $\mathbf{O}$

Diese leicht kemntliche Art bildet, wo nicht eine eigene Gattung, doch eine besondere Abtheilung in Sedenia. Der dicke Stirnkegel ist anf der Oberseite vor seilem Eude mit einer breiten, kablen, tiefeu, hornartigen Grube versehen. Die spitz zulaufenden borstenförnigen Fübler sind wenig länger als der halbe Hinterleib, statt dass sie bei Corvalis $\left(\sigma^{\top}\right)$ fast die ganze Läuge desselben habeu. Auf den Hinterflugeln, wo die Adern auf der Unterseite sehr sichtbar sind, zeichnet sich die Subcostalader dadurch aus, dass ihr erster Ast (8) nicht weit von der Wurzel aus ihr entspringt und daber sehr lang ist; die Gabel, in welche sich darauf die Subcostalader theilt, trennt sich dicht unter der Querader und geht mit dem ubern Ast (7) in die Flïgelspitze. Es ist also wie auf Lederer's Tatel ?, Fig. 3 und 4, nur dass die Ader 8 ganz deutlich aus demselben Stamme, der sich zu 7 und 6 gabelförmig theilt, hervorgeht. Auf dell Vorderflügeln ist der Verlauf der in den Vorderrand auslaufenden Adern nicht kenntlich; ich weiss also nicht, ob er auch von dem der Cervalis abweicht.

Der Kopf ist weisslich beschuppt, im Gesichte gelblich weiss. Die kahle Stirnhöble ist pechschwarz. Taster dünu, um ihre halbe Läıge ïber die Stirne hervorstehend, fast horizontal, gelblichweiss, ant' der Aussenseite oberwärts gelbbraun; Endglied $1 / 3$ so lang wie das zweite Glied diinner, am Ende abgeschnitten; Maxiliartaster klein, auf dem ersten 
Gliede der Lippentaster liegend, braun. Vorder- und Mittelbeine zienlich kräftig (die Hinterbeine fehlen), weisslich, an den Vorderschenkeln und Schienen obenauf so wie an den Füssen gelbbraun. Rückenschild weiss, auf den Schulterdecken etwas glänzend. Hinterleib etwas ïber die Hinterflïgel hervorstehend, gelblichgrauweiss, seidenschimmernd, am Bauche weisslich; der Legestachel kurz, abgeschnittel, fast versteckt.

Vorderflügel 51/2"“ lang; der Hinterrand geht unterhalb der Spitze sehr schwach einwärts, ist dann convex und zieht schräg gegen del Innenwinkel. Grundfarbe weiss, gegen die W'urzel hin allmälig immer lebhafter seidenglänzend. Zwei starke, schwarze, etwas schräge, wellige Querlinien bilden die einzige Zeichnung; die erste ist vor der Mitte, die zweite, mitten zwischen ,jener und der Flïgelspitze vom Vorderrande herabkommend, biegt sich erst schwach nach aussen, dann in grösserer Ausdehunng einwärts und endigt auf dem Anfange der Innenrandfransen.

Hinterflïgel etwas umrein weisslich, seidenglänzend, mit verloschener, gelbgrauer Hinterrandlinie.

Unterseite der Vorderfügel bräunlich grau, gegen den Innenrand lichter mit den matt durchscheinenden zwei Querlinien. Hinterflügel wie obell.

Vaterland: Texas (Boll). 19 in Cambridger Museum.

\section{Botis ${ }^{1}$ ) octomaculata Linu.}

Die in der Preth-Raibler Fauna (Verhawdl. d. zool.-bot. Ges. 1868, 593) erwähnten nordamerikanischen Exemplare (aus Massachusetts, New York, Ohio) gehören ganz sicher zu dieser Art. Walker hat sie als eigene Art: Enmychia glomeralis (Cat. Pyr. 330) abgesondert und, nur mit dem Schreibfehler in der Diagnose: maculis 2 magnis aut parvis nigris statt albis, kenntlich beschriebeu. Er sagt: seems to be quite distinct from Eun. S-maculalis! Man sollte annehmen, dass er Octomaculata L. richtig kenne, da er eine Menge Citate bei derselben anfïlırt. Mabrscheinlich hat er sich aber hinsichtlich des quite distinct nur nach seiner Diagnose der Octomaculata gerichtet, die freilich so verschieden lautet, dass er das seems to be getrost in is luätte verwandeln können. Er definirt sie nämlich: Cupreo-nigra, albo-conspersa; abdomen albo fasciatum;

1) Mit allem Rechte wird in Agassiz Index universalis p. 50 angegeben, dass der Gattungsuame Botis ( $\beta \tilde{\omega} \tau \iota$, Hirtiu) zn schreiben sei, welche Schreibart auch schon Swainson Illustr. 1821 befolgt hat. Latreille hat zwar Botys (180\%). Es ist aber doch zu beleidigend für einen Latreille annehmen zu wollen, er habe die griechischen Buchstaben nicht hinreichend gekannt, um

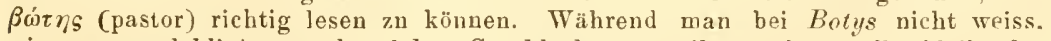
wie man es dekliniren und welches Geschlecht man ihm geben soll, bleibt für Botis in beider Hinsicht nicht der geringste $Z$ weifel. 
alae fascia e maculis quatuor niveis; fimbria nivea. Mit was fiir Augen muss wohl Jemand die sicher in England vorbaudene Octonaculata betrachtet liaber, um an ihr Kupfriges und weissbandirte Flïgel zu sehen und die dottergelben Schulterdecken gar nicht zu bemerken? Oder was fül eine Art hat er aus, England und Europa" in mehr als 20 Exemplaren vor sich gehabt? Sollte er Anguimulis, p. 329, zweimal charakterisirt baben: das erstemal als Ennych. anguinalis richtig, das zweitemal als Octomaculalis? Wo aber die fascia e maculis 4 bei Anguinalis herkommen sollte, bliebe dann noch zu errathen!

\section{Botis laticlavia Grote.}

- Transact. Amer. Soc. Philadelphia 1867, p. 17, t. 2, f. 12.

Diese von Grote vortrefflich beschriebene uud kenntlich abgebildete Art, bei der nur die clarakteristische Färbung der Hinterfligelfrausen unerwähnt geblieben ist, kann als die amerikanische Stellvertreterin unserer europäischen Sanguinalis angesehen werden. Ihre Hinterflügelfransen sind an der kleinerı Anallälfte (bis zum ersten Medianaderast) blassgelb, an der grössern Apicalliälfte hell purpurroth mit verdunkelter Wurzel, - Dass auch bei dieser Art als die Grundfarbe der Vorderflügel eigentlich die gelbe anzunehmen ist, lässt sich wach der südeuropäischen Sommergeneration der Sanguinalis, nämlich Iiaematalis, schliessen.

Nach Grote l. c. 1868, p. 13, ist Walker's fragliche Varietät der Ihhodaria tyralis Cat. Pyr. p. 317 (aus Cuba) zufolge des British Museums dieselbe Art. Aucb enthält die Walker'sche Diaguose nichts Widersprechendes.

Die Art lebt auch in Texas, wo Boll und Belfrage sie sammelten. Ein O wurde von letzterem am 20. August gefangeu.

A umerkung. Von Lederer erhielt ich 3 Exemplare (1 \%, 2 \%) einer sibirischen Art als Virginalis. Obgleich ich ihu auf die Verschiedenheiten aufmerksam maclıte, so liess er doch die Art, die auch hei Guenée, Walker und Bremer nicht vorkommt, in seinem Pyralidenwerk, S. 78, unerwähnt; dagegen bespricht er sie als nicht specifisch voll Viryinalis Dup. verschieden in den Verhaudl. der zool.-bot. Gesellsch. 1853, S. 383 (Sep. S. 33). Ich neune sie als eigene Art.

Bot. Tithonialis. Tab. III, fig. 15.

Capillis et thorace vitellinis; alis ant. acuminatis, in basi etiam in costa vitelliuis, ceterum purpureis, fascia postica costam attingente superius coarctata flava; posterioribus fuscescenti-cinereis, cinereo-ciliatis. $0^{7} \div$. 
Sie lässt sich am kenntlichsten durch den Vergleich mit den Exemplaren der Sunguimalis var. amrorklis machen, bei welchen die Mittelbinde so gut wie gar kein Gelb, nämlich nur einige gelbe Schiippchen, enthält (so dass sie als ganz einfarbig purpurfarben gelten kann). Die Vorderflügel von Tithonialis sind gestreckt wie bei schmalflïgligen Exemplaren der Sanguinalis, aber spitzer als bei jeder Varietät dieser Art. Das Basalfeld ist wie das Rïckenschild gesättigt dottergelb. auf dem Vorderrande ohne eine Spur von Roth; es wird durch die folgende lurpurfarbe scharf und ziemlich gradlinig begrenzt, und die Begrenzung durch querstreifenförmig gelichtetes Gelb noch mehr hervorgehoben. Der bis zu der gelblichen Binde folgende purpnrfarbige Flïgeltheil (die Purpurbinde der Sanyuinalis) enthält nichts Gelbes, ausser dem schmalen Streifchen, das auf dem Vorderrande rom gelben Wurzelfelde hereinreicht. Die darauf folgende gelbe Binde hat das helle Gelb, womit die vorhergehende Purpurbinde gegen das Wurzelfeld abgegrenzt wird; sie rerläuft wie bei Auroralis, ist am Innenrande am breitesten, verdiinnt sich über der Mitte und verstärkt sich wieder gegen den Vorderrand, den sie in aller Vollständigkeit erreicht. Der purpurfarbige Rest des Flïgels hat die doppelte Breite dieser gelben Binde. Die Fransen sind einfarbig grau.

Die bräunlichgrauen, ziemlich dunkeln Hinterflïgel haben gegen den Analwinkel einen hellen, verloschenen Wisch; ilue Fransen sind heller grau. Der Hinterleib ist auf den drei ersten Segmenten ochergelb, dann grau mit gelblichem Afterbusch, beim $q$ fast ganz gelb.

Dass Tithionalis nicht etwa zu Castalis gehört, geht unter anderem daraus hervor, dass bei dieser die schmutzig rothe Farbe des Mittelfeldes gegen die Wurzel hin einen gebogeneu Rand hat, der auf dem Vorderrande bis zur Schulter reicht, und dass der rothe Hinterrandtheil kaum so breit wie die davorliegende gelbe Binde ist.

\section{Botis cinerosa Grote.}

- Transact. Am. Soc. Philad. 1867, p. 18, tab. 2. fig. 13.

Wie Grote richtig bemerkt, gleicht sie der Laticlavia in Allem, nur nicht in der Farbe. Selbst die Hinterflügelfransen haben die dort bemerkte Eigenheit; jedoch tritt weissliche Farbe bei ihr fiir die gelbe ein. Man dïrfte wohl auf die Vermuthung kommen, Cinerosa sei die Früllingsgeneration von jener, die sich freilich noch viel bedeutender ron der Sommergeneration unterscheiden würde, als es im sïdlichen Europa mit Sanguinalis der Fall ist.

Vaterland: Texas. Von den zwei vorliegenden Weibchen wurde das eine durch Belfrage am 24. April gefaugen. 


\section{Botis sigmatalis Walker.}

Capite abdominisque initio vitellinis; alis aut. subelongatis, puniceis, flarido-ciliatis, striga bisinuata antice abrupta ante punctum medium flavum strigaque postica, utrimque crassiore, superne arcuata, in plica acute dentata flavis; posterioribus flavido-cinereis, post strigam utrimque abruptam cinerejs. $0^{7}$ ?

- Grote: Transact. Am. Soc. Philad. 1867, P. 16, t. 2, f. 11. Rhodaria signatalis WV alker Suppl. p. 1282.

Grote's Abbildung ist etwas grob, doch niclit ganz unkenntlich; ich habe sicher seine Alt vor mir, da jch ron ihm selbst ein Exemplar erhielt. Seine Beschreibung ist ïbrigens genau. Guenée's Rhorlaria Tyrulis Pyral. 169 (aus Cuba) scheint riel Uebereinstimmendes mit Signatalis zu habel, kann abes nicht damit vereinigt werdeu, da bei ihr alle Flïgel purpurfarbig und mit solchen Franseu versehen (ailes concolores, d'un rose lie de vin, à frange pareille) und auf der Unterseite fast ganz zeichunungslos und gleichfa!ls geröthet (Dessous d'un rose villeux sali, presque sans aucun òes dessins du dessus) sein solleı. Auch sagt Guenée nicht, dass die erste Querlinie der Vorderfligel unterhalb des Vorderrandes aufhört. Die erste Querlinie der Vorderflügel ist aber bei 5 vor mir befiudlichen Exemplaren nicht nearly straight, sondern wellig gebogen, indem sie sich unter der Subdorsalader einwärts und darüber noch stärker und fast winklig auswärts krïmmt. In der Mittelzelle vor der Querader ist ein gelber, nicht scharf begrenzter Punkt, den die Abbildung richtig zeigt. Die hintere Querlinie macht in ihrem verdickten Dorsaldrittel in der Falte einen scharfen, mit ihrem Scheitel gegen den Hinterrand gerichteten Winkel. Die Fransen sind gelblich, nach aussen in's Graue, an der Flügelspitze schattengrau. Vor ihnen ist am Innenwinkel ein kaum merklicher, kleiner, gelber Wisch.

Auf den Hinterflügelı ist die blasse Querlinie, die sehr schräg gegen den Hinterrand liegt, nicht within the anal angle, sondern, wie in der Abbildung, über die Aeste der Medianader hiuweggezogen.

Beim 9 steht der Legestachel aus dem verdïnuten Hiuterleibsende hervol.

Vaterland: Nach Grote von Massachusetts bis Pennsylvauien. In Texas wurde die Art von Boll und Belfrage gefangen, von letzterem 1 으 2\%. Juni.

Eine Stenia signatalis habe ich in den Lepid. micropt. Caffr. (1852) p. 62 aus dem Caffernlande beschrieben. Lederer stellt sie rermuthungsweise in seine Gattung Aethaloessa (Pyralid. S. 143), ob mit Recht, kann ich nicht sagen, da ich selbst kein Exemplar davon besitze 


\section{Botis morculenta Grote}

Alis ant. pallide flaridis, costa ex basi et thorace saturatioribus, striga priore undulata, puncto disci, strigula venae transversae strigaque postica supra medium foras flexa fusco-cinereis, nebula fasciata cinerea superius divergente ante marginem posticum; posteriorum striga disci obliqua margineque postico cinereis. 57 .

- Grote: Transact. Am. Soc. Philad. 1867, p. 23, t. 2, f. 21.

Ich glaube Grote's Art vor mir zu haben, wenn auch deren Beschreibung in einigen Kleinigkeiten abweicht, und deren viel zu verloschene (vielmeh in der Zeichnung nicht illuminirte) Abbildung sie nicht kenutlich macht, sondern nur eben an sie erinnert. An dem vorliegenden Exemplare sind die zwei Querlinien der Vorderfligel und die dazwischen befindliche Zeichnung (ein Punkt und ein gebogener Strich der Querader) ganz deutlich, sonst genau von der bei Grote angegebenen Beschaffenheit, wie auch, mit dessen Beschreibung stimmend, der Vorderrand von der Wurzel aus eine striemenartige, gesättigtere, ocheröthliche Färbung besitzt. Der graue, fast gerade Schattenstreif, der vor dem gesättigter gelblichen Hinterrand herabzieht, hat dadurch etwas Charakteristisches, dass er vom Innenwinkel aus nach oben gegen ihu divergirt und dem Bogen der Querlinie näher kommt als dem Hinterrande; el endigt unterhalb des Vorderrandes.

Auf den Hinterflügelu ist die Richtung der ziemlich geraden Querlinie bemerkeıswerth; sie fängt weit vom Vorderrande an und verschwindet, sich verdünnend und die Richtung gegen den Hinterrand vor dem Allalwinkel nehmend, am ersten Medianaderast. Der Schatteustreif läuft parallel mit der bräunlichgrauen, verloschenen Hinterrandlinie und ihr gauz nahe.

Die Art steht nebst Citrina Grote am besten neben Ruficostalis Led., obgleich diese auf den Hinterflügeln eine andere Richtung der Querlinie hat und anf der Unterseite zeichnungslos ist.

Vaterland: Texas (Boll). 1 o im Cambridger Museum. Grote hatte die Art aus Pennsylvanieu.

\section{Botis cillina Grote.}

Alis saturatius flavidis, anteriorum costa ex basi et thorace subochraceis, puncto disci, macula venae transversae strigisque duabus fuscescentibus (priore costan non attingente, posteriore supra medium foras flexa), nebula ante marginem posticum nulla; posteriorum striga disci obliqua. $0^{7}$ ㅇ․․

- Grote 1. c. pag. 23, tab. 2, fig. 20 \%. 
Bei Grote gut beschrieben und kenntlich abgebildet. Sie ist meist kleiner als Marculenta, und von dieser durch lebhafter gelbe Färbung und gänzlichen Mangel des Antenarginalschattens zu unterscheiden. Von den zwei ziemlich verloschenen Discaltlecken ist der erste klein und leicht zu ïbersehen. Wo die Grundfarbe abgerieben ist, schimmert die Membran opalisirend. Bei den $\$$, deren eines so gross, wie Marculenta ist, sind die Flïgel gestreckter; als bei den ơ.

Beide Arten sind offenbar nahe mit einander verwandt, und durch die Richtung der (beim $\%$ oberwärts verdickten) Querlinie der Hinterflügel - nämlich ron etwas unterhalb des Vorderraudes, den sie nicht berührt, gegen den Analwinkel, vor dem sie verlöscht - charakterisirt, nach deven sie von den mir bekannten, auf den Vorderflïgeh ähnlichen europäischen Botiden verschieden, aber nit Proceralis Led., Signatalis Gr. und Onythesalis Wkr. zusammen gebört.

Nach Grote l. c. (1868) ist diese Art zufolge des British Museum gleich W alker's Spilodes helvinlis Cat. Pyl. 772 (wohl ganz abgeflogen, da sie alae anticae flavescente- albae und einfarbige [albae] Hinterflïgel haben soll), hinterher auch noch gleich Bolys thycesalis (die ich nicht funde), und die erste seiner 2 Botis apertalis, nämlich die im Supplem. p. 1393 charakterisirte!

Vaterland: New-York (1 o von Grote) und Texas (2 \%, rou Belfrage an 2\%. August und 20. September gefangen).

Botis ventralis Grote.

Botys - Grote 1. c. pag. 21, tab. 2, fig. 23 б.

Von seiner Ventralis theilte mir Grote ein Pärchen mit, welches mit seiner Beschreibung genau stimmt. Da Ventralis, wie er bemerkt, in der Grundfarbe und dem Ausdrucke der Zeichnung veränderlich ist, so hätte er zu der constanten Färbung des Bauches - 2 weisse Längsstreifen, welche einen dunkleren in der Bauchmitte ziehenden begrenzen - hinzufügeu kömmen, dass auf der Unterseite der Vorderflïgel eine gerade, feine weisse Linie vom Hinterrande aus bis zur Querader, auf den Hinterflügeln eine gleichfalls weisse und gerade, aber stärkere vom Hinterrande über die Querader hinweg bis nalse an die Flügelbasis geht. Vielleicht ist auch der ganz schmale, weisse Vorderrand der Hinterhügel eine beständige Eigenthümlichkeit dieser Art.

Eben dieselben Merkmale auf der Unterseite der Hinterfligel hat auch das Pärchen der Bot. argyralis Guen. Pyr. p. 341 meiner Sanmlung. Guenée gibt dieser als Grundfarbe un brun-canelle uni, wie es meine von Grote erhaltenen Ventralis sicher haben; dem $\%$ schreibt er im Vergleiche mit einern $\sigma^{\top}$ ailes supérieures plus conrtes et d'un jaune d'ocre fauve zu. So grefärbt ist mein ơ der Argyralis, während das 
fast dottergelbe Vorderflügel hat mit grösseren, weissen, sollst aber genau übereinstimmenden Zeichuungen. Ich würde Arawalis mit Ventralis als eine Species vereinigen, wenu nicht beide Geschlechter am Bauche nur auf den 3 letzten Segmenten 2 weisse Streifen führten (die beim rerflogenen ơ noch dazu ganz verloschen sind), und beim $\$$ die Spitze der Hinterflügel auffallend weit über den Innenwinkel der Vorderflïgel hiuwegreichtels. Vielleicht ist aber doch die Fliigelgestalt nur eine Monstrosität, und die Färbung des Bauches eine Varietät.

Ein $\sigma^{*}$ der Ventralis aus Texas im Cambridger Museum hat auf den Vorderflügelu sehr kleine und ganz verloschene Punkte, dereu Plätze durch reichlichere schwärzliche Schuppen bezeichnet werden, gerade die 3 dem Innenwinkel nächsten sind undeutlicher und kleiner, als der eiızelne in der Mittelzelle und der auch vereinzelte an der Falte. Aber die oben erwähnten weissen Linien der Unterseite der Flïgel und die 2 weissen Bauchstreifen sind höchst vollständig und scharf.

Eine Eigenthümlichkeit in den Tastern erwähne ich bei der folgenden nächstverwandten Fracturalis.

Bolis fracturalis ч. sp. Tab. III, fig. 16.

Alis ant. elongatis, ciunamomeis, maculis 5 niveis nitidis nigrocinctis (prima arcuata transversa in plica, tertia bidente infra secundam parram, quinta in strigulam mutata); ventris vittis duabus canis $\mathbf{q}$.

In der Grösse und Gestalt der Ventralis, nur mit etwas gestreckteren Vorderflügelı, sehr ausgezeichnet vor dieser und der Argyralis durch die Grösse der glänzeud schneeweisen, überall schwarz eiıgefassten Flecke.

Rückenschild und Kopf heller und melır grau, als die Vorderflïgel. der obere Augenrand mit feiner, weisser Linie umzogen. Taster zimmtbraun, auf der Unterseite vou der Turzel aus bis vor das Ende des Busches des zweiten Gliedes scharf abgeschnitten, schneeweiss; das Eudglied ist wie bei Ventralis und Argyralis aufgerichtet, klein, wach oben rerdickt, mit abgeschnittenem Ende. Beine weisslich, die vorderen auf der Vorderseite, die auderen an deu Schenkeh, und mehr noch an den Fïssen bräunlich-grau angelaufen. Hinterleib ochergelblich-grau, an den hinteren Segmenten mit feinen weissen Hinterräudern; an Bauche mit zwei breiten, weisseu, hinten vereinigten, eine zimmtbräımliche Strieme säumenden Streifen; Afterbusch kegelförmig; abgestutzt, ochergelblich.

Vorderflügel $5^{1 / 4}-51 / 2$ " lang, gestreckt, liuten erweitert, spitz, mit schwach convexem Hinterrande. Gruudfarbe zimmtbraun, am Vorderrande bis zum 4. Flecke und am ganzen Innenrande heller, mehr ochergelblich. Fïnf glänzend schneeweisse, schmal schwarz gesäumte Flecke bilden die Zeichnung. Der erste liegt in der Falte gleichweit rou der Wurzel und 
den 2 nächsten, und bildet einen schräg gelegten, hinten etwas ausgerandeten Bogen. Der zweite ist klein und gerundet, und liegt über der Medianader mitten zwischeu dem 1. und 4. Der 3. gleich unter dem 2. ist nebst dem 4. der grösste von allen, und hat nach hinten 2 lange, divergirende Spitzen. Der 4., gleichweit vom 3. und der Flügelspitze, ist länglich schräg mit dem oberen Ende nahe am Vorderrande, am unteren mehr einwärts liegenden Ende nach hinten in eine Spitze ausgezogen. Der 5. nicht weit. vom Hinterande, bildet ein über die Aeste der Medianader gelegtes Streifclen. Fransen hellgrau, hinter der bleich ochergelben Wurzellinie dunkler.

Hinterflügel braungrau, gegen die Wurzel heller. Fransen weiss mit bleich ochergelber Wurzellinie und hinter dieser mit einer grauen, sehr unterbrochenen, um die Flügelspitze vollstäudigereu Linie durchzogen.

Unterseite der Vorderfügel braungrau, am Vorderrande bleich ochergeblich nit matt durchscheinender, nicht dunkel gerandeter, weisser Zeichnung. Die Aderu vom Hinterrande aus bis Fleck 4 und 5 und eine bis zu Fleck 3 weisslich. Hinterfliigel hellgrau, in der Spitze am dunkelsten; die Aderu weisslich; eine gerade, weisse linie zieht rom Hinterrande durch die Querader bis zur Basis; zwei weniger auffallende gehen ebenso zwischen Inuenrand und Medianader.

Vaterland: 'Texas (Boll). 2 \% in meiner Sammlung:

Die Eigenthümlichkeit des 3. Tastergliedes und die lange weisse Linie auf der Unterseite der Hinterflügel können als Merkmale eine. Gruppe von Botis dienen, zu welcher Ventralis, Argyralis und Fracturalis gehören.

Botis rubigalis $\mathrm{G} \mathrm{n}$.

Scopula - Gueuée Pyr., p. 398. - Walker Cat. Pyr., p. 784.

Meine mänulichen Exemplare aus Californien und Texas zeigen, dass von deu Unterschieden von Ferrugalis, die Guenée und Walker anfïhren, nur die Kürze und Breite sich a!s standhaft und charakteristisch bewähren, und da Ferrugalis bei uns in den Kärntneralpen, bei Triest, im südlichsten Italien, auf Rhodus und Candia (aus welchen allen Gegenden ich Exenılare besitze), stets gleiche Flïgelgestalt zeigt, so zweifle ich nicht an der Artverschiedenheit der Rubigalis, von welcher Walker 4, Guenée 1 und jch 3 hinsichtlich der Kürze der Flügel ïbereinstimmende Exemplare vor uns haben. Die Kürze gilt auch von den Hinterflügeln, die bei weitem nicht so zugespitzt sind, wie bei Ferrugalis. Es ist zwar richtig, dass die Hinterfügel der Rubiyalis auch heller und nur in der Flïgelspitze und zwar schwach verdunkelt sind; doch da Ferrugalis darin etwas abändert, so mag das auch bei Rubigalis der Fall seill. Bei 2 meiner Rubigalis verläuft auf den Hinterflügelu die feinere (allerdings auch verloschenere) Querlinie mit ihren Bogen, statt gleich weit vom Querader- 
punkte und dem Hinterrande abzustehen (wie bei der am deutlichsten gezeichneten Fevrugalis), dem Hinterrande sehr merklich näher; bei dem 3. das doch s̈jcher zu derselben Art gehört, geht diese Linie entschieden dem Punkte näher. - Die Vorderflïgelfransen sind bei Rubigalis heller und von 2 feinen, grauen Schattenlinien durchzogen; bej Ferrugalis sind sie gran und zeigen nur an der Wurzel eine einzelne stärkere, dunkle Linie. - Der aus der Spitze der Vorderflïgel herabkommende, in Hï buer"s Fig. 5́ sehr deutlich ausgedrïckte Schatten, der nach Guenée manchmal bis in die Mittelzelle hinreichen soll, findet sich unter 21 rerglichenen Exemplaren nur bei $2-3$ in schwacher Andeutung; sonst fehlt el völlig, wie bei Rubigalis. Heile Exemplare sind noch heller als Rubigalis.

Die 2 Texas-Exemplare sind viel kleiner, als das californische (Vorderfliigel 4 "' gegen $5-31 / 4$ ).

Botis subjectalis I, ed erer.

- Led. Pyr., S. S4, Taf. 10, Fig. 13. Bot. Euphaesalis (!) Wkr. Cat. Pyr., p. 1008.

Lederer's Abbildung macht sie kenutlich. Die Körperfarbe ist schneeweiss, jedoch auf Kopf- und Rückenschild (auf diesem beim $\subseteq$ röllig) durch grobe, graubraune Schuppen rerdunkelt. Der Hinterleib bleibt in beiden Geschlechtern auf dem 2. Segmente reinweiss mit 3 braungraven Basalfleckchen; die folgenden Segmente sind beim $q$ alle braungrau mit schneeweissen Hinterrändern; beim $\overrightarrow{0}$ sind Segmente 4, 5̆ und 6 reinweiss, und nur auf der Rückenmitte ausser am Hinterrande braungrau, während die anderen Segmente wje beim $Q$ siul, nur mit breiten reinweissen Rändern. Auf der Basis der Vorderflügel tritt der reinweisse Grund etwas hervor.

Da es unmöglich ist, aus Walker's Beschreibung die Art zu erkennen, so muss sich Lederer die Kenntniss des Namens aus dem British Museum selbst geholt haben.

Walkers Benennung Euphaesalis ist eine so kindliche Formation, dass zu wüßscben wäre, ihre Aufuabme würde den Prioritätsjägern durch das Eintreten der Hübner'schen Benenuung Illibalis (die freilich wie lucus a non lucendo ist), abgeschnitten. Grote Transact. Am. Soc. Philad. 1868, p. 14 erklärt sie beide für identisch. Lederer, dem ich zufolge meines schön erhaltenen Exemplares beistimmen muss, hält bejde getrennt.

Botis arlipaloides Grote.

- Grote: Transact. Am. Soc. Philad. 1867. p. 26, tab. 2, fig. 19.

Grote's Abbildung ist zu klein und lässt die dottergelbliche Grundfarbe der Vorderflïgel zu eingeschränkt und die Querlinien der Hinterfliigel nicht richtig erscheinen. Seine Beschreibung dagegen ist sehr genau. 
Un die Art aber von den ähulichen zu unterscheiden, wird man wohl das Hauptgewicht auf die beiden Flecke der Mittelzelle legen müssen; sie sind gross und bis auf die schmalen schwarzbrannen Ränder mit Bleiglanz a usgefüllt. Der erste ist viereckig und häıgt mit einem noch grösseren zusammen, welcher den Raum zwischen der Median- und Subdorsalader einnimmt; der 2., auf der Querader liegende, ist grösser als der erste und queroblong. Die Randbinde aller Flügel ist dunkelschiefergrau, lilafarbig schimmernd, einwärts braungerandet. Die Basis der Vorderflügel ist gänz lich röthlichgrau, wie die Wurzel des Vorderrandes, und es ist hier ein solches Bändchen dicht vor der Flügelbasis.

Auf den Hinterflïgeln sehe ich gar keine basal interrupted line (die auch die Abbildung des $\%$ zeigt). Hinter dem länglichen graubraunen Queraderfleck, tiefer und durch den Raum zwischen 2 Adern davon getrennt, folgt ein dicker Querstrich, der nicht bis zum Innenrande reicht; er ist als die Fortsetzung der tiefer liegeuden, vom Vorderrande ausgehenden, winklich gebrochenen und feinereu Querlinieu anzusehen, obgleich sie sich mit einer Ecke der Marginalbinde vereinigt, und keine rückwärtsgehende Verbindungslinie, wodurch sie sich an jene anschlösse, vorhanden ist. Die Grundfarbe der ganzen Unterseite ist nur blässer, als die der Oberseite. - Unter den Flïgeln liegt längs der weissen Brust ein dïuner, bleichgelber Haarpinsel.

Ungeachtet des Mangels der Basallinie der Hinterlinie der Hinterfiïgel auf beiden Seiten, glanbe ich doch nicht, dass Grote's Art eine andere als die meinige ist.

Vaterland meiner \& 9 Texas. 3 wurden von Belfrage am 23. und 26. August und gleichfalls unversehrt am 24. October (1) gefangen.

Aus Grote's Notizen l. c. 1868. p. 1' erfahren wir, dass zufolge des British Museum Walker diese Art im Cataloge p. 331 zuerst als Samea Elealis (aus Nordamerika), dann als Samea liparalis Guen. p. 353 (aus Brasilien) und zuletzt als Bolys tuedialis p. 732 (aus der Country unknown) aufgestellt hat. Die ekelhafte Arbeit, nachzuweisen, worin die Walker'schen Beschreibungen mit dem Befunde der Sammlnng stimmen oder disharmoniren, ïberlasse ich Anderen; ich begü̈ge mich mit dem Vergleiche der ungewöhnlich sorgfältigen Beschreibung der Samea liparalis Guen. Pyr., p. 19\%, die in der That recht viel Uebereinstimmendes nit Adipaloides, doch auch solche Abweichungen hat, dass ich bei der Wahrscheinlichkeit, dass es in Brasilien äluliche, uächststehende Arten gebe, die Annahme der Identität so lange fiir bedenklich halte, als sie nicht aus der Guenée'schen Sammlung selbst nachgewiesen ist. Die Flügel der Adipaloides haben kein jaune-paille demi-transparent, sondern die vorderen sind bright clear yellow (angenehm hellgelb), welche Farbe auf den limteren nur etwas blässer ist, und gar kein Licht durchlässt. Die 
Discalflecke sollen einfach gran sein, der 2. marquée d'un croissant janne. Bei Adipaloides sind sie, wie oben angegeben, und der 2., d. h. der auf der Querader enthält gar keine gelbe Mondsichel. Dass der erste aus zwei untereinander liegenden und zusammengewachsenen besteht, deren jeder fast die Grösse des Queraderfleckes hat, erwähnt Guenée mit keinem Wrorte. Er sagt von den Fransen, sie seien finement brodées de jaune et de gris, welche vage Bezeichuung doch nur willkïrlich als fringes pales (nämlich als die Randbiude) with a basal line gedeutet werden kann. Walker gibt mit seiner nach Guenée's Worten gebildeten Diaguose - darin macula reniformi flara (!) notata - gar keine Aufklärung. Er fügt dazu eine fragliche Varietät, die immerhin gleich Adipaloides sein mag, aber hinsichtlich des Namens nichts Entscheidendes enthält.

\section{Botis faridalis Guen.}

Botys - Guenée Pyr., p. 329. - Walker Cat. Pyr., p. 562.

Diese grosse Art, die mir Grote als Oxydalis mittheilte, hat, wie Guenée richtig erwähnt, mit ihrer Verwandten, Oxydalis Gn., an den Vorderbeinen die Schienen und Füsse schneeweiss, die ersteren an der Endhälfte, die letzteren an den Enden der Glieder riolettlichschwarz, während die Schenkel auf der Lichtseite, ausser an der Basis, violettbraun gefärbt sind. Hals, Brust und die 4 Hinterbeine sind schneeweiss mit Seidenglanz. Die Taster an den 2 ersten Gliederu schneeweiss, das 2. auswärts, oben scharf abgeschnitten, schwarzbraul; das sehr kurze Endglied gelblichweiss. Vom Auge geht bis zur Flïgelwurzel ein dicker, braumother Streif.

Vorderflügel 7-8" lang, hellgelb, am Vorderrande bis zur Subcostalader nur etwas gesättigter; wo die Farbe abgerieben ist, schillern sie opalartig. Von den welligen, bräunlichen Querlinien entspringen nur 1, 2 und 4 auf dem Vorderrande aus fleckartigen Verdickunger; die 3., vor welcher in der Mittelzelle ein bräunlicher Punkt liegt, kommt aus dem verdickten Queraderstrich und nähert sich gegen den Innenrand bisweilen sehr bedeutend. Die ə̈., aus Möndchen zusammengesetzt, welche durch die Adern getrenut werden, fängt unter dem Vorderrande an, und vereinigt sich durch einen Fleck mit dem 4 .

A n merkung 1. Man hat die 5 Querlinien wohl so zu deuten, dass die 4. eigentlich nur bis zum ersten Medianaderaste reicht, und bier sehr scharf zurïck und aufwärts gegen das untere Ende des Queraderstriches gehen sollte, um sich an die dritte Querliuie als an ihr unteres Drittel anzuschliessen; dadurch würde die gewöhnliche hintere Botiden-Querliuie entstehen; der Schattenfleck am Inıenwinkel würde demnach zu der Antemarginallinie gehören. - So wäre auch auf den Hinterflügeln die abgebrochene rom Innemrande ausgehende Querlinie eine blosse Fortsetzung der 
vom Vorderrande ausgehenden Querlinie, an die sie sich erst anschłösse, nachdem sie am ersten Medianaderaste herabgegangen wïre; die (scheinbare) Fortsetzung der am Vorderrande entspringenden Querlinie, die nämlich bis in den Analwinkel reichende, würde der Wirklichkeit nach nur das Ende der Antemarginallinie sein. Hiernach ergibt sich für Flavidalis und Oxydalis eine Stelle in der Nähe unserer Ruralis.

A nmerkung 2. Wie wir durch Grote erfabren (l.c. 1868, p. 14), sind im British Museum Botis lacorlis Wkr. Cat. Pyr., 733 und Bolis cinclipedalis Wlkr. Pyr. Suppl. 1391 mit Flavidalis (Oxyrlalis Grote) identisch. Wenu Walker Flavidalis Gn. nicht erkannte, so ist das sehr verzeihlich, zumal da Lacoalis ein Mitglied der Walkerschen geographiscben Gruppe Country unknown ist. Wie aber jemand aus den vor seinen Angen befindlichen Exemplaren einer so gar nicht veränderlichen Art drei sollte machen können, wäre etwas schwerer begreiflich. Mag aber Lacoalis der Samulung wirklich einerlej mit Flavidalis sein, so gibt es wichtige Bedenken, ob sie mit der Lacoalis der Beschreibung einerlei ist. Bei Flavidalis sind die Taster oben nicht ferruginei, sondern nigro-fusci; das Abdomeu ist nicht albidum, luteo-fasciatum, sondern einfarbig pallide flavidum und nicht subtus chalybaeum (!), sondern album, subsericeum; die Vorderflïgel nicht lineis tribus rufescentibus, soudern quingue fuscescentibus, die Costa nicht subochracea, sondern uur saturatius flavida. Der allgemene Color ist auch nicht luteus, sondern pallide flavus s. flavidus. Hieruach muss die Lacoalis als eine ganz verschiedene Art gelten! Was nützt da selbst die Besichtigung des British Museum, wem sie etwas ganz Anderes ergibt, als was die im Catalogue of the British Museum gegebene Beschreibung Ferlangt?

Anmerkung*3. Bot. Oxyalalis Guen. Pyr. p. 328, die mir sowie Flavidalis durch Guenée selbst bestimmt wurde, ist viel kleiner (Vorderflügel 5"' lang); ihre Vorderfligel sind gesättigter gelb, am Vorderrande bräunlichroth; dies ist auch die Farbe der dickeren, sonst wie bei Flavidalis lanfenden und gestalteten Querlinien; der Punkt der Mittelzelle liängt an der Farbe des Vorderrandes. Die Unterseite des Körpers ist gelblich, bloss die Hinterschienen md Füsse sind weiss. - Meiue 2 Exemplare sind aus Georgien und von Rio Janeiro.

Botis Thesealis Led. (?).

Major, abbomine $\vec{\sigma}$ elongato, cinerascente, albido-annulato; alis pallidissime flavidis, griseo-mixtis, in disco subiridescentibus, anteriorum maculis 2 discalibus annuliformibus, strigis 3 fuscescenti-ciuereis, secunda repanda cum macula secunda lineis conjuncta, tertia serratissima. $\sigma^{\top} \mathbf{Q}$.

? Botys - Lederer Pyral., S. 83. ? Botys Theseusalis (!) Walker Cat. Pyr., כ̋2.

? Botys pertextalis Led. S. 81 und 174, Taf. 9, Fig. 10. 
Das nearly allied to $B$. verticalis [vuralis] (obgleich bei genauerer Vergleichung die Verwandtschaft nicht so gar gross ist) - abdonen extending far beyond the hindwings - wings iridescent - the orbicular and reniform marks rather large, their disks paler lassen den Schluss zu, dass ich dieselbe Art, wie Walker vor wir habe, wenn auch die Angabe: marginal points brown, wenigstens hinsichtlich der Vordertlïgel, nicht zustimmt. Aber auch, wenn Walker, Lederer und ich wirklich dieselbe Art vor uns haben, so würde doch die Lederer"sche Benennung als eine richtige lateinische Formation den Vorzug erhalten miissen.

Ihre ansehnliche Grösse, die jedoch noch erheblich hinter der ron Flavidalis und Ruralis zurïckbleibt, ihre sehr bleich graugelblichen, etwas opalisirenden Flïgel, die deutliche Ringform der beiden Flecke in der Mittelzelle, die tiefgesägte Antemarginallinie aller Flïgel und der lange, bräunlichgraue Hinterleib mit weisslichen Segmenträndern scheinen sie sicher kenntlich zu machen.

Lederer's Pertextalis wiurde ich ohne Bedenken mit meiner Thesealis vereinigen, wenn 1. in der Abbildung die 2. Querlinie der Vorderflïgel durch verstärkte Adern nit dem Queraderflecke verbunden, und die (dritte) Zickzacklinie ilır nicht viel zu nahe wäre (auf den Hiuterflïgeln ist sie richtig gestellt); 2., wenn Lederer sie nicht für zum Verwechseln ähnlich seiner Multilinealis erklärte; 3. wenn Lederer nicht die Walker'sche Thesensalis gekannt haben müsste, da er dasfror dem corrigirten Namen weglässt.

Es gibt eine andere nordamerikanische Botis von gleicher Grösse (Abdominalis Mus. Z.), die nicht mit Thesealis rerwechselt werden darf. Diese hat einen gelblichern Ton der Flügel. Von den beiden bräunlichen Flecken der Mittelzelle ist nur der der Querader ringförmig (vielleicht ist es bisweilen jedoch auch der erste, was sich nach einem einzelnen Exemplare nicht sicher sagen lässt), und nicht mit der 2. Querlinie durch verdunkelte Längslinien verbunden; die dritte Querlinie ist nur nit kleinen Sägezähnen versehen und liegt der busigen Ausbiegung der 2. Querlinie näher als dem Hinterrande, statt dass sie bei Thesealis genau die Mitte einuimmt; der lange Hinterleib ist auf der ganzen Oberseite ochergelb.

Eine Aelmlichkeit in der Grösse, Gestalt und Färbung hat Thesealis auch mit der europäischen Perlucialulis H. Bei dieser ist aber der Hinterleib weniger verlängert und nur lıellgraugelblich mit weissen Segmentränderı; die Vorderfligel sind breiter und weniger zugespitzt; die 2 Discalflecke der Vorderfliigel sind durchaus nicht hohl oder ringförmig; statt. der 3. Querlinie ist nur ein grauer, auf der Innenseite sägezähniger Schattenstreif vor dem Hinterrande, und was die Art sogleich kenutlich machi, ihr Hinterrand trägt auf allen Flügeln scharfe, weitgetrennte, schwarze Punkte. 
Endlich erwähne ich noch die unten folgende Crociolophor a serratissimalis als der Thesealis ähulich, zumal im \& Geschlechte, weil deren beide Geschlechter, wenn auch das $\mathcal{O}$ viel deutlicher als das o die stark sägenförmige Querlinie vor dem Hinterrande besitzen. Diese Art hat einen durchaus uicht verlängerten, auf der Oberseite eintarbig hellocherfarbenen Hinterleib und keine Ringflecke in der Mittelzelle der Vorderfligel, während doch vou der 2. Querliuie aus gegen den Queraderfleck bräunliche Linien zuriickgeheu. Das kleinere ơ macht sich ausserdem durch die generische Auszeichnung und beide Gesschlechter durch die Kiirze der Mittelzelle der Vorderflïgel sehr keuntlich.

Ich gebe eine neue, vollständigere Beschreibung der Thesealis.

Fühler mikroskopisch pubescirend. Taster aufsteigend nach oben verdickt, nicht vorgestreckt, weiss, am oberen Rande breit, striemenartig braul; das ganz kurze Endglied braun. Beine weiss, die vorderen anf der Lichtseite der Schenkel und Schienen gebräunt, und an letzteren zieht sich die bräunliche Farbe und das verdickte Ende bis auf die andere Seite herum. Der o Hinterleib ist dünn und lang; das zugespitzte Endglied länger als das vorhergehende Segment; die Oberseite braugrau, dunkler als der Banch, mit weissen hinteren Segmenträndern (dem $\%$ fehlt der Hinterleib).

Vorderflügel ơ \%, 우 $6^{\prime \prime \prime}$ lang, beim o gestreckter und spitzer, ringsherum und an der Wurzel sehr blassgelb, im gauzen Raume zwischen der Subcostal- und Subdorsalader bis zur Antemarginallinie noch blässer und schwach opalisirend. Die Zeichuungeu bräunlichgrau. Die Mittelzelle trägt einen kleinen, kleisförmigen Ring nicht weit hinter der ersten welligen Querlinie und eiıen viel grösseren, nierenförmigen auf der Querader; die 2. welliggezälnte Querlinie auf den Aesten der hellgelblichen, bräuแlich gesäumten Medianader einen starken Bogen uach aussen, worauf sie ungezähnt und 2mal verdickt zur Mitte des Iınemrandes geht; die Zähne sind mit dem nierenförmigen Ringe durch bräunlichgraue Linien verbunden. Die 3. Querlinie, in der Mitte zwischen dem Bogen der 2. und dem Hinterrande ist zickzackförmig, beim $\sigma^{7}$ etwas verflossen; hinter ilır ist die Farbe blassgelb, und darin gehen von der feinen Hinterrandlinie aus bräunlichgraue, auf dem Hinterrande verstärkte Läugsstrichelchen, der Zahl nach doppelt so viele, wie die 3. Querlinie Zacken hat (die verdickten, auf dem Hinterrande ruheuden Endeı dieser Strichelchen halte ich fïr die vou Walker gemeinten Randpunkte). Fransen bleichgelblich vou einer stark zerschuittenen, fast in Fleckchen aufgelösten grauen Linie durchzogen.

Hinterfiigel ebenso gelblich, nur auch läng's des Vorderrandes opalisirend. Die bräunlichen Zeichnungen bestehen in einem starkeu Discalfleck nicht weit vou der Basis, in einer gezähnten Querlinie in der Fliigel- 
mitte hinter welcher zwischen dem Aesten der Medianader noch ein drei Wellen bildender Zug liegt, und in der Zickzacklinie ror dem wie ant den Vorderflïgelu gezeichneten Hinterrande.

Vaterland: Texas (Boll) und waluscheinlich Massachusetts, von wo ich durch Dr. Packard 20 , 1 of erhielt.

\section{Eurycreon (spilorles) cereralis n. sp.}

Alis ant. elongatis, griseo-fuscescentibus, nigro-striolatis, macula elongata ante renae transpersar maculam nigram, litura nigro-limitata costae ante apicem fusciaque marginis postici pallide ochraceis. ơ.

Aebulich unserem Sticticalis und wahrscheinlich dessen Stellrertreter in Texas, verschieden durch gestrecktere Vorder- und stumptere Hinterfliggel sowie durch bräunlichere Grundfarbe der ersteren mit schwarzen I.äng:strichelchen, eimen bleichgelben Längs fleck (wofï) Sticticalis einen schräggelegten, viereckigen, kürzeren hat) und einem einwärts schwarzbegrenzten, bleichgelben Costalwisch ror der Fliigelspitze; auch ist dic ganze Unterseite viel heller, weisslich feingezeichuet und auf jedem Flügel ist nur ein einziger, angefangener, brauner Querstreif.

Grösse des Sticticalis. Kopf gelbbraun, oberex Augenuand weiss. Taster mit längerem, feinerem Ende als bei Sticticalis, gelhbrann, innen weisslich, unten breit schneeweiss. Rückenschild braun, Schulterdecken a m Ende bleichgelblich. Hinterleib grau mit weissgrauem Bauche, beim o die 2 letzten Segmente hellgraugelblich, beim \& hellochergelb. Brust wejss. Beine wejssgrau, die rorderen auf der Lichtseite, die mittleren auf dem Rücken der Schiene hellbraun.

Torderfügel $3^{3} / 2-6^{\text {d. }}$ lang, ziemlich gestreckt, wach hinten allmälig erweitert, mit sebr schwach convexem Hinte.rande. Gundfarbe heligranbraun mit mehreren schwarzen Flecken und Längsstrichelchen scheinbar umregemässig bestreut. Nicht weit von der Wurzel ist über der Falte eine ziemlich lange, schwarze, oberwärts liclit eingefasste, vor ihrem Eude verdickte Läugsliuje. Au Ende der Mittelzelle liegt ein bleichochergelber, nicht überall schart gerandeter Längsfleck, der vorn und hinten durch je einen schwarzen Fleck begremzt ist; der vordere schwarze Fleck begrenzt ihn schief und hat unter sich bis zum Inneurande nehrere unregelmässige, dickere oder düınere, schwarze Längsstriche; der hintere, aut der Querader liegende. ist unregelmässig mit mehreren Spitzen, von denen die einwärts gerichtete den bleichochergelben Fleck spaltet, und die auswärts gerichteten sich auf den Adern als Längslinien fortsetzen. Am Vorderrande vor der Flïgelspitze ist ein bleichgelher, wurzelwärts durch einen scluwarzen Schatteu scharf begrenzter $\pi$ isch; dieser schwarze Schatten setzt sich unterwärts bis zur halben Ilügelbreite in eine Zickzacklinie fort, an welcher die schwarzen Adern endigen. Längs des Hinterrandes ist eine bleici 
ochergelbe. nach beiden Enden verdiunte, sinwïnts schwarz schattirte, sehr dentliche Binde ron betächtlicherer Breite als bei den meisten Sticticalis. Frausen braungrau, an der Wurzel von -iner brauneu Linie durchzowen.

Hinterfligel stumpfer, als bei Sticticalis, bräunlichgrau, gegen deu Hint rrand allmälig dunkler und vor diesm mit einer kaum erkenubaren Spur "iner gelblichen Einfassungslinie. Fransen weisslich, an der Wurzel von riner feinen, gelbbräunlichen linie durchzogen.

Tnterseite schmutzig gelblichweiss; die Vorderfügel haben einen schwärzlichen, nach hinten etwas schattirten Queraderstrich; vor demselben liegt in etwas lebhafter gelblicher Färbung der längliche, helle Fleck der Oberseite, den gegen die Wurzel hin rin länglicher, schwärzlicher Fleck begrenzt. Vou dem gleichfalls etwas gelblichen Vorderrande hängt vor der Fliigelspitze rin schmaler, aus schwarzen Fleckeben zusammengesetzter, rebogener Streif bis zur Flïgelhalfte herab. Den Hinterrand fasst einc Linie aus feinen, schwarzen, wertgetrennten Strichelchen ein; Fransen hellgrau.

Die Hinterfligel baben gleichfalls hinter der Mitte einen dümmen, schwärzlichen, sehräg zuı Hinterrande herabreichenden Streifen, der aus Fleckchen auf den Adern besteht, und is der Flïgelhälfte endigt, wo dicht ror dem Hinterrande ein graues (bei einem ơ fehlendes) Schattenfleckchen liegt; von diesem an begleiten den Hinterrand 5-6 zu Querlinien ausgezogene, schwarze Punkte bis zur Spitze. Fransen reiuweiss.

Das 2 ist etwas kleiner als die $\widehat{~}$, mit dickerem, am Eıde gelblichen Hinterleib und schmäleren, dunkler gezeichneten Vorderflügeln.

Vaterland: Texas (Boll). 3 Exemplare in meiner Sammlung.

Anmerkung 1. Zur Unterseheidung ron dem rorhergehenden und dem folgenden Eurycrem stelle ich die Diannose des Sticticalis so:

Alis ant. oblongis, postice ampliatis, luteo-fuscescentibns, macula obliqua, quadrangula, pallide ochracea ante maculam venae transversae subanularem et post maculam ovatam fuscescentes, striga postica fuscescente lituram costae anteapicalem subochraceam terminante, fascia terminali obtuse unidentata ochracea, ciliis unicoloribus. ơ.

A m m rkung. 2. Dem Sticticalis kommt besonders nach der Unterseite noch näher eine Art rom Vorgehirge der guten Hoffunug, Lencostictalis 11. sp. die Lederer auch fïr diese Art erklären wollte, was sie aber sicher 'nicht ist.

Alis ant. oblongis, postice ampliatis, luteo-fuscis, macula quadrangula superue ampliata ante maculan venae transversae fuscam maculaque post eam exalbidis, litura costae postica lineaque marerinis postici semel incrassata pallide ochraceis, ciliorum basi serie punctorum exalbidorum notata. o 9 
Ihre Vorderflïgel sind gegen die Wurzel mehr verschmälert, und haben einen rerarleren Hinterrand, ihre Hinterfligel eine stumpfrre Spitze als bei Sticticalis. Die Grundfarbe der Torderfligel ist dunkler gelbbraun. Der helle Fleck liegt zwar anch scbräg, ist aber oben erwitert, weisslicher und durch die vergrösserten nud verdunkelten daror und dahinter liegenden Flecke scbärfer abgegrenzt. Der Rnum zwischen den Queraderflecke und der schärferen hinteren Querlinie ist durch einen geflichweissen Fleck (der bei sticticulis fehlt), ansgefüllt. Die hintere Querlinie ist schwarz, schärfer gezähnt und gesclıwungen als bei stictrcalis und, aumer dass sie den hellen Costalfleck begrenzt, her und da auswärts mit w snlichen Schuppen eingefasst. Längs des Hinterranden zielit eine dü ur, ochergelbe Linie, die sich in der Gegend, wo Sticticalis den stmmpten Zahn besitzt, in einen Fleck erweitert. Die braunen Fransen laben aut der Wurzelbälfte eine Reihe von etwa 8 weissgelblichen Fltcken. Dir weinsen Fransen der Hinterflïgel sind an der Wurzelbälfte braun und weisslichgellb gescheckt.

Auf der Unterseite sind die dunkeln Zeichmnngen umfangreicher und beengen also die gelblichen mehr. Auf den Hinterfiigeln ist benonders die braune, durch die gelblichen Adern unterbrorh ne Binde durch ihre Breite und Annäherun an den Hinterrand ansgezei,hnet, und die sehr gegen di Basis gerückte Querader hat einen braunen sichelstrich, der dem Sticticalis ganz fehlt.

\section{Eurycreon runtalis $\mathrm{G} n$.}

Nymphula (!) - Guenée Pyr. p. 405. Nymphula (!) - Walker Cat. Pyr.p. 802. Botys - Lederer Pyral., S. 86, Taf. 12, Fig. 3.

Wie die gute Abbildung zeigt, jst Lederer mit der Annalıme, Rantalis könne Varietät seiner Botys crinitalis Fig. 2 (Walker's Crinisalis) sein. im Irithun. Ebenso zeigt sie richtig, dass die 2 Mitt.lltecke braun und sehr ungleich sind und nicht, wie Guenée in seiner sonst richtigen Beschreibung sagt: presque égales, d'un roux-ferrugineux coder sollte das gar eine andere Art sein?) Beide Geschlechter sind gleich, nur das $\widehat{\sigma}$ auf allen Flïgeln etwas dunkler.

Mein \& aus Buenos-Ayres, von Lederer selbst bestimmt, hat ein wenig länger gestreckte Vorderflïgel.

Ausserdem habe ich die Art aus Texas (Boll) und Californien (das o aus letzterem liatte Lederer zur Ansicht).

\section{Eurycreor crinitalis Led.}

$$
\text { Botys - Lederer Pyral. S. 86, Taf, 12, Fig. … }
$$

Lederer's Abbildung macht die Ait kenntlich, nur dass sie den Grund der Torderfiig zu schön rostfarbig und den Punktfleck dem 
Nierenfleck und diesen der Querlinie etwas zu nahe darstellt; auch sollte diese mehr gezahnelt und auswärts mit etwas gelichterer Grundfarbe schattirt suin; endlich sollte der Hinterrand eine Reihe verloschener, dunkler Punkte andeuten.

Die Flïgel dieser Art sind breiter als bei Runtalis und anch in der Färbusg so abweichend, dass schwer zu erklären ist, warum Lederer in beiden Arten nur eine vermuthete.

Lederer hielt seine Art fïr einerlei mit Talker's Scopula crinisalis (1) 'at. Pyr. p. 798. Er hatte sich vermuthlich im British Musem die Thberzeugung ron der Identität geholt; denn Walker's Worte gewähren sie durchaus nicht. Crinitalis ist nicht slender, nicht white beneath (sonderu weisslich ochergelb). hat kein Abdomen ciuereous (es ist lell ochergelh): dit erste Querlini. der Vorderflügel soll dentirulated sein (es ist aber gar keine erste Querlinie bei Crinitalis da), die Hinterflïgel whitixh, tentaceous along the exterior border (bei Crinitalis sind sie gleichmässig blass ochergeib, heller als der Hinterleib, auf den Adern en wenig gesättigter, was man nor durch die Lupe erkennt, und olne Spur der Querlinie der Rantalis).

Crinitalis steht, wenigstens der Diagnose nach, meiner Botys infuscalis Micropt. Caffr. p, 41 sehr nahe; letztere ist aber eine botis mit längern Tastern und gespitztern Flïgeln.

Vaterland: Texas (Boll). 2 0 im Cambridger Museum.

\section{Nesoyraphe stramentalis Н.}

Pyialis - H. 62 (schlecht). Scopula - Dap. t. 216, f. 2 (kenntlich). Pionea - Guenée Pyr. 373.

Sie ändert in der. Breite und dem Ausdruck des braumen Schattens vor der Hi terrande der Vorderfiigel sehr ab; es gibt Exemplare, die dafiir nur eine zweimal gebogene, etwas verflosnene Querlinie habeu.

Ebenso veränderlich ist diese Art in Nordamerika, wo sie stellenweise häufig sein muss. Ich habe sie ans New York, Maine und Massachusetts; in letzterem Staate fing Burgess 2 \& bei Bererly am 16. Juni und 11. Juli.

Eine sehr auffallende Varietät des $\%$ besitze ich aus Königsberg in Preussen. Ihr fehlen anf den Vorderflügeln die zwei gelbbraunen Querlinien und alle Bestäubung gäuzlich; nur die Schattenlinie vor dem Hinterrande ist rorhanden, mit dem sie auf den drei Medianaderästen in Verbindung steht. Das Mittelzeichen ist in ein verdicktes, doch etwas verschwommenes $\mathrm{x}$ umgewandelt. Auf den Hinterflïgeln fehlt die Querlinie vor dem bramgrauen Hinterrande. Die Unterseite entbelst golechlinlls aller Querlinien. 
ICh habe nicht den mindesten Zweifel, dass WV a $1 \mathrm{ker}$, ungeaclitet er ein Dutzend Exemplare der Stramentulis vor Augen hatte und eine Menge Beschreibungen dazu citirte, die 7 nordamerikanischen, im British Museum vorhandenen Exemplare als nene Art: Pioner Enmoselis (!) Cat. Pyı. p. 756 aufgestellt hat; wie el dabei nicht an Stramentalis denkeu und diese also unerwähut lassen konnte, ist ein Rätlısel.

A nmerkung. Da Guenée sich so viel auf die Bildung scines Genus Pioner zu gute thut, so ist es recht zu bedauem. dass der Name Mesoyraphe II übn. als der ïlere und berechtigtere hergestellt werden muss. Hübner charakterisirt das Genus im Cat. S. 33́ gat geuug, und wenn von den 7 hingestellten Arten 3, als nicht dazu gehörig, daraus entfernt werden müssen, so ist fruenće mit seiner Pionea in gleichem Falle. Er stellt in die Gruppe Mesoyraphe H, ausser Forficalis noch drei andere Arten. Sonderbarer Weise nent H. v. Heinemann (Schmett. v. Deutschl. II. S. 93) grerade diese Gruppe, die er zul Gattung macht, von der er ur die eine Art Forficalis kennt, Pione Guen.!

\section{Crocisophora tubercululis Led.}

- Lederer Pyral. S. 93 u. 184. Taf. 2, Fig. 13 u. Taf. 12, Fig. 9.

Das Bild dieses Zïuslers (Taf. 12 ) jst, was Lederer selbst anmerkt, sehr missrathen: auch wïrde das fë̈der nach einem abueschuppten Flügel wohl etwas anders ausfallen, als es auf Tuf. 2 dargestellt ist.

Unter den Botiden zieht diese Art sogleich durch den sehr convexen Vorderrand der Vorderfligen lie dufuerksamkeit auf sich; danu falleu auch die auf der Oberseice kahlen Flecke auf, in welchen di Fliigel wie verschrumpft aussehen. Wegen ter Kürze der Mittelzelle läuft der zweite (geschwngene) Querstreif ungewöhnlich uaht der Flägellälfte, so dass, obgleich der Schattenstreif vor dem Hinterande zar nicht dicht ror diesem himzieht, zwischen ihm und dem Querstreif ein breit. . bindenförmiger Raum der Grundfarbe hleibt. Weder der Schattenstreit, noch die Querlinien erreichen den Vardrrand, der die Grundforbe breit und striemenförmig rein behält. Die frundfarbe vergleicht Lederer richtig mit der unserer (hellsten) B. Pandalis. Wie das O aussicht, ist noch nicht bekanut.

Auscer in Tennesse (Lederer) leht dis Art anch in Texas (Boll), voll wo ich 2 ơ vor nui habe.

\section{C'rocidophora serrulissimalis $11 . \mathrm{sp}$.}

Alis flaridis, anteriorum puncto disci, macula renae transrersae strigisque 3 fuscescenti-cinereis, seeunda arcuata, non dentata, tertia valde serrata. $\partial^{7} \%$. 
Viel gröser als Tuberculalis, von etwas blässerem Gelb, sehr leicht in beiden feschlechtern auf der Unterseite durch die Külze der Mittelzelle als ein. Crocidophora und durch ibre Zickzacklinie ror dem Hinterrande als eigent Art in dieser Gattung charakterisirt. Schon bei oberllächlicher Betrachtung nuterscheidet sie sich von der mit gleich sägezähniger Antemarginallinie bezeichneten Bot. Thesealis durch ihre lebhafter gelbe Farbe und dadurch, dass die zwei Discalflecke nicht ringförmig sind.

Räckenschild hell ochergelb, Kopf heller mit weisser oberer Orbitallinie und ochergelbem Hinterrande der Augen. Taster auswärts ochergelb, auf der Unterseite weisslich. Beine weisslichgelb, die vordern auf der Lichtseite gelblichgrau. Hinterleib (beim ôlange nicht so weit über die Hinterflïgel hinansagend wie bei Tuberculalis) oben blass ochergelb, an der Wurzel und am Bauch in's Weissliche.

Vorderfligel o $5^{1} / 2$, ㅇ $6^{\prime \prime \prime}$ lang, breiter als bei Tuberculalis und mit weniger convexem Vorderrande. blassgelb (ein wenig gesïttigter als bei Ruralis). Die Zeichnungen gelbbräunlich, beim ơ mehr grau. Die erste Querlinie fängt erst bei der Subcostallinie an und sst etwas winklig; beim $\sigma$ ist sie undentlich und geh über ein in der Ecke der Medianund Subdorsalader liegendes Glasfleckchen hinweg. Gleich hinter ihr ist in der Mittelzelle ein dentlicher, grosser dunkler Punkt, hinter welchem in wciteren Abstande, noch diesseits der Flïgelhälfte, der längliche Querfleck der Querader folgt. Ebenso weit, wie dieser Fleck rom Punkt, stelıt die ziemlich dicke Querinie von dem Fleck entfernt; sie verbindet beide Gegenränder, ist etwas hin und her gebogen, dabei ungezälnt und wacht auf den Aesten der Medianader enen starken, nach aussen convexen Bogen, von welchem aus die Aeste der Medianader bis zu dem gelblichen, bräunlich gesäumten Stamm selbst bräunlich und hier durch ein querïber getegtes Gewölk bezejchnet sind; auch aus dem obern Theile dieser Querlinie sind zwei längere Spitzen gerichtet, die sich, ehe sie den Queraderfleck erreichen, vereinigen. Die dritte, sehr scharf sägezahnig gezackte, beiu o etwas verflosene Querlinie liegt auf der reiusten Grundfarbe und erreicht den Vorderant nicht. Von der verloschenen Hinterrandlinie erheben sich schmale, verloschene Kegelstriche, für jede Bucht der Zickzackline einer. Fransen gegen die Fliigelspitze getrübt, ungefleckt, mit feiner, gelblicher Wurzellinie.

Hinterflügel längs de. Vorderrandes breit weisslich, etwas opalisireu. II uter der Mitie ist eine stumpfwinklig gebrochene Querlinie, die weder den Vorder- noch den Innenrand erreicht und gegen den letztern hin auch unterbrochen ist; rom Winkel aus sind die Aeste der Medianader bis zu dieser selbst gebräunt. Die Zickzacklinie wie auf ten Vorderflügeln; die Ilinterrandzeichnung besteht aus kürzern Kegelı mit breiterer Basi:. 
Auf der opalisirenden Unterseite ist der Vorderrand der Vorderfügel bis zur Subcostalader grau, der Queraderfleck, die verdickte zweite Querlinie und die in einen breiteu Schattenstreif verwandelte Zickzacklinie, aus welcher Spitzen nach innen hervorstehen, ziemlich stark verdunkelt. Der Raum zwischen dem Queraderfleck und der zweiten Querlinie ist auch verdunkelt, während der zwischen dieser und dem Antemarginalschatten rein hellgelblich ist. Hinterraudlinie dick, bräunlich. Das o hat auf der Medianader auf dem ersten Aste einen länglichen Schupperuwulst, ron welchem aus eine gebogene, kielförmige Linie zwischen der Subdorsalader und dem ersten Aste der Medianader hinzicht. Zwischen den beiden Mittelflecken ist eine fast kahle, opalisirende Stelle, die sich gegen die Medianader hiı verbreitet. - Auf den Hinterfligelı ist die Miıkellinie deutlich, die Zackenlinie aber in einen aus Fleckchen zusammengesetzten Schatten rerwandelt. Hinterrandlinie fein, bräunlich, nicht den Analwinkel erreichend.

Vaterland: Massachusetts (1 $\sigma^{\top}$ von Packard) und Texas (1 O durch Boll).

\section{Blepharomastian ramalis tr $\mathrm{n} \mathrm{e}$.}

- Lederer Pyr. S. 131. Śtenia - Guenée Pyr. p. 24.3. - Talker Cat. Pyr. p. 417.

Botys grorilis frote: Truwact. Amer. Eut. Soc. Ihi adelph. 186\%, p. 25, tab. 2, fig. 15.

Diese von Schläger als Bot. septrulis in lit. erhaltene Art bestimmte mir Guenée selbst als seine Strnia ranalis, und unter diesem Namen erlielt Lederer sie ron mir; dieselbe Art theilte mir Grote als seine Bot. grocilis mit. Hienach kann kein Irrthum in den vamen stuttfinden.

Guenée's Beschreibung, in welcher die Grundfarbe besser d'un blanc paillé ou ochracé als bei Grot pale brownish tentaceous genant scheint, erwähut nicht, dass die beiden Discalftecke, wie Grote sie richtig angibt, eine ringförmige frestalt haben (wie in seiner Sten. batracalis [?] pl. 9, f. 8) und ebenso hat er Herru Grote den Verlaul' der hintern Querlinie richtig zu beschreiben überlassen.

Auf den Hint refligh sieht man bei unbeschädigten Exemplaren, dass die vom Queraderfleck gegen den Inmenxand laufende Querlinie nur der hiutere Theil der tiefer liegenden und vom Vorderrande ausgehenden ist, iudem von deren gegen den Analwinkel gerichtetem Ende, wic auf den Vorderflïg+hn, eine feine Linie plötzlich unter spitzem Winkel einwälts geht und sich dem Anfange der erstern Linie anschliesst.

Grote's nicht feine Figur macht die Art kenntlich, sollte aber weniger sichelförmige Vorderflügel haben. 
Ausser bei New York und in Penusylvanien lebt die Art auch in Ohio (Schläger) und Texas (Boll).

Anmerkung. Bei l, ederer scheint S. 132 ein Versehen vorgefa]len zu sein. Er zielıt hir Saurialis Gn. zu seiner Stenia praestrictalis, Taf. 18, Fig. 12, die sich doch schlecht mit der Guenée'schen Beschreibung vereinigt.

Gen. Homophysa Gı. Led.

So weit es sich ohne Abschuppung, wämlich bloss durch Anfeuchtung mit Chloroform, erkemmen lässt, bilden bei den 4 mir vorliegenden Arten auf den Vorderfligeln die Adern 10 und 11 (Taf. 2, Fig. 29 bei Lederer) eine in den Vorderrand ror der Spitze mindende Gahel, und da bei allen ie Ocellen deutlich sind, so gelı̈ren sie alle in die Gattung Homophysa.

\section{Glophyratis (Guen.?) Led.}

- Lederer Pyr. S. 163. Taf. 18, Fig. 14.

Bei meinem ciuzeluew, nicht sonderlich schünen Exemplar, das Lederer selhst bestimut lat, sind die Vorderflügel nicht, wie in der Abbildung, scharf gespitzt, und der Hinterrand ist convexer; die Grundfarbe ist zwar d'un jaune d"oere gai, aber nicht presque citrin, und die hintere, gegen deı Innenrand hin schärfer gezähnte und auf der Falte winklige Querlinie ist ganz deutlich auswärts dunkel gesäumt. Ausserdem geht ron jedem der verloschenen, bräunlichen Hinterrandpunkte eine weisse, kurze linie einwärts. Die Hinterflïgel sind völlig so, wie Guenée sie mit einer ihm moewähnlichen fenaugkeit beschreibt. Auf der Unterseite ist aber die Querlinie nicht lavée de noirâtre, sondern einwärts selır verloschen gelbbräunlich gerandet.

Es scheint sich ans diesen Abweichnngen nud denen von luederer's Abbildung zu ergeben, dass die Art etwas abändert. Die Breite ilner Vorderflïgel unterscheidet sie von den drei folgenden Arten.

2. Sesquistrialis (H bu, ?) I, ederer.

Alis ant. oblongis, acutis, vitellino-ochraceis, strigis 2 albis, opposite fuscescenti-marginatis, (priore fulminali, posterior arcuato-repanda), punctis marginis postici nigris; posterioribus albidis, margine postico medio ochraceo-nebuloso. o\%

- Led. Pyr. S. 193, - Guen. Pyr. p. 366.

Ḧ̈bner's Abbildung kann ich nicht vergleichen. Zu Guenée's gut passender Beschreibung füge $i c h$ hinzu, dass mein einzelnes ő grösser i॰t als dic 2 S meiner Sammlung. Die zwei Querlinien der Vorderfiigel 
siud auch auf ihren abgewendeten Seiten, nur nicht so dunkel wie auf den zugewendeten, bräunlich gesïnut, wodurch jhre Zälıne nud Eckcn un so deutlielier hervortreten. Die schwarzen Hinterandpunkte siud nieht immer einwärts weiss eingefasst; sie sind es am meisten an den drei ober-

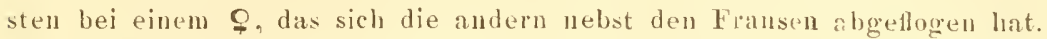
Der weisse Queraderstrich (léger trait cellulaire blanc:), dessen Guenée erwähnt, fehlt meinen drei Exemplaren; das eine @ lat dafür einen hellbräunlichen Fleck. Die Hinterfliigel sind aber, wie truenée sie berchreibt.

Auf der Unterseite sind die schwarzen Randpunkte seh deutlich, ebenso beim 9 auf allen Flügeln das braune Queraderfleckchen. Die verloschene hintere Querlinic (beim ô nur zur obern llälfte vorbanden) ist einwärts beim $\mathcal{O}$ dunkler gosäunt als beiu $\widehat{\sigma}$, und die auf den Hinterfliigeh macht auf der fünften Ader einen einspringenden Winkel. gefangen.

Vaterlaud: Texas (Boll, Belfrage). Die beiden $\%$ sind am 19. Mai

\section{Lentifualis n. sp.}

Alis ant. oblongis, acuminatis, vitellino-ochraceis, strigis 2 pallidis, areuato-undulatis, opposite obscurius marginatis, macula venae transversac obscuriore, punctis marginis postici fuscis; posterioribus pallidis, margine postico ochraceo. 0 .

Sie ist wohl meistens etwas grösser als sesquistrialis und unterscheidet sich ron ihr an den Vorderflïgeln durch schärfere Zuspitzung, weniger convexen Hinterrand, dichte, dunklere Bestäubung, wołurch die Grundfarbe gesättigter ochergelb erscheint, und durch die beiden blassen Querlinien, die durh ihre hell lehmgelbe Einfassung viel weniger hervortreten und der scharfen Ausbnchtungen entbehren; die Hinterflïgel sind nicht weiss, sondern blassgelb, am Hinterrande genättigter.

Rückenschild ron der Farbe der Vorderflügel, also viel lebhafter ochergelb als bei Sesquistrialis, fast lell rostfarbig. Kopf lichter, über den Munde und in einer Linie am obern Angenrande weiss. Fülıler borstenförmig, hellgelblich, an der. Vorderseitw des Wurzelgliedes und darüber weiss. Taster von doppelter Kopflänge, stark behaart, so dass die Haare einen schrägen Endbusch bilden, am Wnrzelgliede und einwärts weiss, auswärts lebhaft ochergelb; das Endglied doruförmig, aufgerichtet, weisslich. Brust und Beine weiss; die vordern rorn ochergelb, ilue Schiene auf der linterseite mit einem anliegenden Haapinsel. Hinterleib blassociergelb mit weissen Segmenträndern nnd solchem Bauch; das eine Excmplar (ein \& zufolge der borstenförmigen, nicht pubescirenden Füller) hat ziemulich starke, auf der Obcrseite fast schwärzliche Seitenbiische. 
Torlerfingel etwas unter " " lang, länglich, mach hinten erweitert, selur schartepitzig mit fast geradem Vorderrande und schwach convexem, unterlall, der Spitze ziemlich geradem Hinterande. Die Grundfarbe ist durch selur reichliche dunklere Stäubchen fast dottergelb. Die beiden blassen Qurlinien haben fast die Lage wie bei Sesquistrialis, sind aber am Vorderande viel, am Imenrande etwas weiter anseinander, auf der zugewendeten Seite verlochen bräunlich gesäumt, auf der aboewendeten f:incr, abel noch weit blässer geramlet; die erste macht die Biegungen wie bei serquistrinlis, mur nicht so stark; die zweite macht in der obem Hialte einen sanftern Bogen und in der Falte nicht den schurfen Winkel der Serrmistrialis und entbehrt der kappenförmigen S.hwingungen. Auf der Querader ist ein verloschenes, bräunliches Fleckchen, fast in der Mitte zwixchen den zwei Querlinion. Die Hinterandinie wird durch branne, fast zusammenhängoude Punktstriche gebildet, von welehen aus die Adern bis inber die zweite Querlinie hinaus hell sind. Fransen grau, auf der Wurzellinie und am Ende hell,

Hinterfliigel viel hlässer als die Vorderfiigel, aber nicht weiss, längs des Hinterrandes dunkler, besonders zwischen dell Aesten der Medianader, ïber welche ein heller, ganz verloschener Querstreif hinzieht Randlinie und Fransen wie bei den Torderlligeln.

Unterseite auf da् Vorderbälte braum bestïuht mit hellen Tängsadern, anf der Dorsalhälfte woisslich, am reinsten anf den Hintertlïgelu. All, Queraderfleckchen und Hinterrandpukte mehr oder weniger deutIich, ehenso die Anfänge einer hellen Querlinie auf dem Vorderrande der Vorderfïgel vor der Spitze und in der Mitte dar Hiuterfligel.

Vaterland: Texas (Boll, Belfrage). 2 Exemplare wurden an 20. und 26. August gefarigen.

\section{Hericulalis n. sp.}

Alis ant. oblongis, acutis, canis, confertim fuscescenti-pulvernlentis, strigis 2 arcuatis, albidis, opposite fuscescenti-marginatis, macula renae transversae biloba majore maculaque minore inferius adjacente albis. $\%$.

Sehr rerschieden von den vorigen, kenntlich an den dicht bräunlich bestäubten Fï̈gein, von denen die vordern auf der Querader mit einem weisseu, nierentörmig zweilappigen und darunter mit einem kleinen weisien Fleck gezeiclmet sind.

Grösse der Serquistrialis. Räeken-chilf und Kopf weisonran, bräunlich bestänbt. Fühler hellgrau, am Wrurelgliede vorn und darïber srhmal weiss. Taster anf'gehogen, weissgrau; zweites Glied anf der Uuterstite sehuppenhaarig, zusammengedrïckt; drittes frlied halh so lang, glatt, dornfömig. Brust und Beine weissgran. Hinterleib hellgrau mit weissen Segmonträudern und weissem Bauch. 


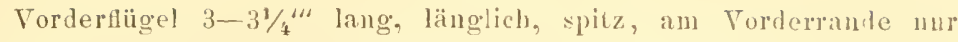
hinten etwas convex, am schwach convexen Hinterande schrioger einwirts gebogen als bei Lentiflualis. Die helle, weissgraue Grundlarbe ist sehr rejchlich mit braunen Schuppen bestecut und erscheint dadureh blanugrau; nur am Vorderande und hinter der ersten (Qucrlinic tritt sie frecer hervor. Die 2 Querlinien sind weiss, auf den zugewendeten seitun fuin braun gerandet; die erste ziemlich senkrecht, in 3 starken Jiogen lerablaufend; die zweite ist an den obern $2 / 3$, in dencn sie in einen stalken Bogen nach aussen gekrümmt ist, kappenförmig gezälnt, macht unterhalb des Nierenfleckes einen starken, einspringenden Winkel und darunter einen nach aussen conrexen Bogen, worauf sie den lmmenand erejelit. Auf der Querader liegt ein anselulicher, weisser, etwas nicrentömiger Fleck, dessen untere Hälfte g'rösser und nach auseen gezogen ist; dicht unter ihm am Winkel der zweiten Querline und in der Filte ist ein kleiner, etwas eckiger, weisser Fleck; beide Flucke sind ungleiclunässig bräunlıch eingelasst. Jängs des Hinterrandes zicht eine lieilh: schwrarel. Punkte, die aber den Inuenwinkel nicht erreicht, und rou deren jeden ein weisslicher Strich einwärts geht. Fransen bräunlich grau, auswärts hell.

Hinterfligel am Torder- und Innemrande breit weissgrau ohne brauen Staub, so dass der bestäulte Theil ungefälr ein schlecht begrenztes Dreieck bildet, das aut dem Hinterande rubt und in der Mitte 2 (oder 1) weisse leckehen und zwichen diesen und dem Hinterrande einen undentlichen Bogen aus meho oler weniger aneinanler schliessenden weissen Fleck chen enthält. Die schwarzen Hinteraudpunkte treten mehr als anf den Vorderflïgeln zu ciner Linie zusilmmen, haben aber auch die weissen Stellen über sich. Fransen wie an den Yorderflïgeln.

Tnterseite der Vorderfligel grau, dunkler bestäubt, an Vorderande breit hell; auf den Hinterfligeln viel heller, besonders an der Wurzel und an Innemrande. Die hintere Querlinie geht deutlich auch über die Hinterflïgel bis zum Analwinkel weg und ist einwiirts stink braun gerandet. Der Nierenfleck ist ziemlich deutlich, das Fleckchen darunter verloschener.

Vaterland: Texas (Boll, Belfuage). Tou den drei rorliegonden Exemplaren wurden zwei am 20. Juli und 2I. August gefangen. 
Chalcoëla ${ }^{1}$ ) n. g. Tab. II, fig. 12, $a$ und $b$.

Antemua ( $\sigma^{\top}$ ?) simplices, setaceae.

Ocelli nulli.

Frons laevis, obtusa.

Palpi labiales longi, tenues, porrecti; maxillares breves, incumbentes. Haustellum brevissimnm, convolutum.

Alne anteriores breves, venis 7 et 8 separatis.

- posteriores latiusculae, margine postico ante apicem inciso, rena mediana pilis longis restita, quadrifida.

Corpus robustum, pedes breviusculi.

Lederer sagt bei Cryplocosma (Pyr. S. 56), dass deren Hinterflügel in der Zeichmung an Crtrecysta lemmalis $q$ erinnern. Wie die Abbildung Taf. 7, Fig. 11 zeigt. haben sie auch am Hinterrande vor der Fliigelspitze einen Einschnitt, dessen Andeutung man bei Cataclysta erkennt. Da beides bei der vorliegenten Texaner Art sehr auffallend ist, so lag der Gedanke nahe, dass sie, zumal da ich sie nur im wejblichen Feschlechte besitze, wie Lederer von der seinigen nur das männliche, mit zn Cryptocosma gehört. Das kam aber durchaus nicht der Fall sein, selbst wenu, was nicht recht wahrscheinlich, das ơ kammförmige Fühler hahen sollte. Denn Lederer"s Gattung hat, wie ihre Stelle gleich hinter Asopia und vor Sinparic beweist, eine vïllig unbelaarte Medianader der Hinterflügel, während sie hier ron der Wurzel an bis zur Theilung lange Haare trägt. Ferner sind bei Cryptocosma , die Palpen ganz kurz und verkïmmert, kanm zu erkenne!"; dagegen haben sie bei Chalcoëla die Länge des Rïckenschildes und ragen, neben eimander ausgestreckt, sehr weit iiber den Kopf hervor. Dass bei Cruptoesma der Sangriissel fehlen soll, mag nicht välig richtig sein, wäre abes auch von keiner Bedeutung, weil er bei Chalcoël $\alpha$ so knrz und versteckt ist, dass er erst nach Abbrechen des einen Tasters zu erkennen war.

Chalcoëla kanu also wegen ihrer behaarten Medianader auf den Hinterflïgeln weder in die Nähe von Cryptocosma, noch in die von Cataclysta gestellt werden, von der sie sich ausserdem durch ihren plumpen Köperbau und ihre kurzen Fiihler und Beine unterscheidet. Sie stimmt mit der folgenden Dirymolomia in der Behaarung der Hinterflügelader iiberein, weicht aber von ihr ab durch das sehr leicht erkennbare Merkmal ihres mur eingeschnittenen Hintermades der Hinterflügel, dann durch den Mangel der Ocellen, durch die Länge und einfache Zuspitzung ihrer Lippentaster und durch ihren sehr kurzen und schwachen Sangriissel.

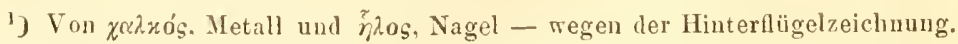


Chalcoëln aurifera n. sp. Tab. II, fig. 12a, b.

Corpus totum ochraceum, alae anteriores in basi et costa late ochraceae, ceterum cinereae nigro confertin pulverulentae; posteriores cinereae, nigro pulverulentae, serie marginali punctorum atrorum metallice aureo mixtorum. 9 .

In der Grösse etwas über Asopia fimbrialis, aber mit kräftiger gebantem Körper. Dieser überall ochergelb. Der obere Augenrand mit feiner, weisser Linie. Taster fast von dreifacher Kopflänge, eng aneinander liegend, so dass der kurze, schwache, zu`ammengerollte Saugriissel ganz versteckt ist, horizontal vorgestreckt, mit 3 dentlich gesonderten Gliederm: das erste mit abstehenden, zum Theil weissen Haaren, die nach vorn einen Busch bilden; das 7 weite etwa doppelt so lang, cylindrisch mit anliegender Beschuppung, aus welcher das dïnnere, etwas kïrzere, cylindrische Endglied frei hervorsteht. Fühler ziemlich kurz mit gedrängten Gliedern, an der Wurzel ziemlich stark, gegen die Spitze merklich verdinnt, hell gelblichgrau mit ochergelbem Wurzelgliede. Brust, Bauch und Beine weisslich, die vordern ochergelb gefleckt, die hintern an der Schiene und dem ersten Fussgliede anf der Lichtseite grau bestäubt. Hinterleib etwa $1 / 3$ iiber die Hinterflïgel himausragend.

Vorderflügel $4-4^{1} / 3$ “ lang. ziemlich kurz, nach hinten allmälig stark erweitert, mit dentlicher Spitze, an Vordermande mach hinten conrex, am Hinterrande sanft convex. Das IT urzelfeld und der ganze Vorderland lebhaft ochergelb; der übrige, dell Innenwinkel in sehr grosser Ausdelnung ausfüllende Ram ist hellgrau, sehr reichlich schwarz bestïnbt, an Hinterande ïber dem Imenwinkel mit einem nchergelbbraunen Wisch. Dieser graue Raum hat gegen sein inneres Ende eine aus schwarzen Schuppen gebildete, hier und da unterbrochene oder auch in wenige Fleckchen aufgelöste Querlinie bis zur ochergelben Färbung. Gegen sein äısseres Ende ist eine sehr gebogene, ganz zusammenhängende, schwarze Querlinie, die in der Falte einen starken, einspringenden, den ocherfarbenen Wisch enthaltenden Tinkel und darïber eimen spitzen Bogen nach aussen macht, der sich sehr schräg einwärts, auf der Anssenseite weisslich gesäumt, bis zum Vorderrande fortsetzt. Auf der Querader, auf hellem Grunde, liegt ein starker, schwärzlicher Fleck. Vor dem Hinterrande ist das Grau etwas rerduskelt. Anf dem Hinterrande liegt oberhalb des Innenwinkels eine Reihe mehr oder weniger zusammenfliessender goldglänzender Punkte, ïber deren oherstem eine weisse, ziemlich deutliche Linie, die vom Hinterrande einwälts biegt, durch den ochergelben Grund bis nahe an den Vorderrand vor der Spitze reicht. Fransen gran, auf der breiteren Wurzelhälfte schwärzlich bestäubt, und bei einem ? mit ziemlich deutlichen, schwïrzlichen Fleckchen gescheckt. 
Hinterflïgel am Torderrande briunlich gran, gegen die Wurzel hell, ïbrigens gran mit schwarzen. sehr reichlichen Stäubchen regelmässig bestreut, mit zwei schwärzlichen Anliafungen um die Mitte und ciner stark gehogenen solchen, auswärts hell gexäumten Querlinie in emiger Entferung vor dem Hintermande. Bieser lat zwischen den Aesten der Medianader eine coldglänzende Wrellenlinie, in deren Vertiefungen und Erhöhungen je ein tiefschwarzer Punkt liegt. Die Fransen sind am Innenrande weisslich, an Hinterrande grau, anf der Wrmelhäfte verdunkelt, längs der Goldzeichung schwarz schillerud. In dem tiefen Ausschnitte unterhalb der Fliigelspitze und nu dieselbe herum sind sie an den Enden deutlicher weisslich als anderwïrts.

Interseite der Vorderfiügel am Vorderrande breit ocherütlılich, sonst grau, in der Mitte reichlich schwar\% bestäubt mit den Andeutungen der beiden Querlinien, von denen die zweite den hellgranen Innemrand erreicht. Die Fransen sind grau, in der Mitte verdunkelt, oberhall, des lnuenwinkels. wo der Hinterrand eine kleine Ansbuchtung hat, mit einem dentlichern weissen Wisch als auf der Oberseite. - Hinterfïgel am Vorderrande schual ochergelb, sonst weissgrau, dicht scl warz bes(äubt, mit zwei gegen die Wurzel gespitzten, schwarzen Wischen diesseits der Mitte und hinterwärts mit einem schwarzen, stark gebogenen Querstreif. Die Randzeichnumg besteht ans einem foldstreifen mit 8 tiefschwarzen Punkten. Fransen seidenschimmernd weisslich mod guan.

Vaterland: Texas. Belfrage fing die drei ausnamsweise gut erhaltenen $O$ meiner Sammlung an 2:3. Angust.

Dicymolomia n. g. Tab. II, fig. 13, $a, b, c$.

Antennae simplices, setaceae.

Ocelli distincti.

Frons laevis, obtusa.

Palpi labiales modici, adscendentes infra pilosi, pilis articuli secundi fasciculum apicalem formntibus, articulo teminali adscendente, laeri, acuto; maxillares longiuseuli, biarticulati, filiformes.

IIaustellum mediocre in dorso squamatum.

Alae oblongae, anteriores rena 7 et 8 separatis: posteriores latiusculae, margine postico bisinusto, rena mediana pilis longis vestita, quadrifida.

Wie der Name anzeigt, hat die rorliegonde Gattung zwei Wellen des Randes, nämliclı des hintern der Hinterflïgel; da aber die unter.ılb des Apicalwinkels befindliche wie bei Chalcoulla ist, und am Hinterrande eine ähnliche Zeichnung liegt', ausserdem der Bau des Körpers ein entsprechender ist, so wäre kein Grund gegen die Aufnahme in Chrysoëla vorhanden, wemn nicht 1. hei ihr sehr deutliche Ocellen wären, 2. der 
Bau der Taster ein ganz anderer, und 3. der Saugrüssel viel ausgebildeter wäre. Statt nämlich, wie bei Chrysoëlı lang. gerade und einfürmig zugespitzt zu sein, haben die Lippentaster nicht die doppelte Kopflänge, sind etwas aufgerichtet, an der ITnterseite der zwei ersten Glieder mit ziemlich reichlichen Haren, welche an Ende dus zweiten Gliedes als ein Epitzer. Busch hervorstelien, welcher mit dem 1/3 so langen, gotat beschuppten, fast aufgerichteten geraden Endgliede eine Gabel bildet; die Maxillartaster sind etwas länger als dienes Endglied der Lippentaster, stielföımig, deutlich zweigliederig, am Ende etwas verdickt. Wenn man den Kopf von oben (Fig. 136 ) betralitet, so erblickt man 4 parweise divergirende, etwas kmre, iber ihn bervorstelende Spitzen, von denen die 2 mittleren die Maxillartaster sind, die 2 insseren dem dritten Lippentastergliede anvehören. - Der Şangrïnsel, bei Chrysoëla ganz verküımert, klein und versteckt, hat bei Dicymolomia eine mittlere Länge und ist gebogen und auf dem Ricken dicht beschuppt.

Die drutlichen Ocellen, die ausgobildeten Taster, die Behanung dw Medinnader der Hinterflïgel und die beim ő nur mikroskopisch pubescirenden Fühler verbieten die Vereiuigung mit Cryptocosma.

\section{Hicymolomill decorn n. sp. Tab. II, fig. $13 a, b, c$.}

Alate anteriores cinnomomeae; strigis 2 arcuatis nigricantibus, exterius albido marginatis, spatio interjecto ad costam late niveo; posteriores ante marginem posticum cinnamome serieque punctorum atrorum metallice aureo cinctorum ormatae. ơ.

In der Grösse der Asopia fimbrialis, aufallend durch die in d m Wurel- und den Hinterrandfelde röthlich zimmtbraunen, am Vorderrande des Mittelfeldes breit weissen Vorderflügel und die tiefschwarzen, goldig eingefassten Randpunkte an der Mitte der Hintertlïgel.

Rïckenschild hell ochergelb, die Schulterdecken einwirts weisslich gerandet. Kopf weisslich mit ziemlich breiter Stirne und grossen Augen. Taster an der Wnrzel weiss, innen und am Endgliede weisslich, an zwciten Gliede answärts ochergelb mit dunkeln Stellen; Maxillartanter weisslich. Beine krätig, schmutzig weisslich, die rordern a uf der Lichtseite an den fichenkeln lehmgelb, an den fiussen verloschen brïunlich gefleckt; die Mittelbeine an den Sihienen durch anliegende Behaarum etwas verdickt, an den Füssen ungefleckt; die Hinterbeine auf der Rückenséite der Schenkel ausser der Spitze, an den Schienen ausser der Wurzel und an den Fussgliedern ausier den Enden dunkelgrau. Hinterleib dunkelgrau uit weisslichen Hinterrändern der Segmente.

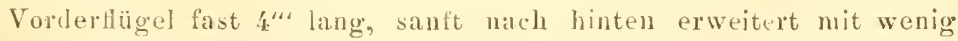
scharfer Spitze und melr als der Hinterrand convexem Vorderrande. Grundfarbe zimmtbraun, am Ende des Wurzelfeldes und in der Flügel- 
spitze gesättigt röthlich zimmtbraun. Das Mittelfeld wird durch zwei nach aussen wellig gebogene weissliche Querlinien begrenzt, die auf der einander zugewendeten Seite in den Vertiefungen schwärzlich ausgefïllt sind (welche schwärzliche Ausfïllung zwei ziemlich vollständige, hier und da verdickte Linien bild(t), und, da die äussere an ihner obern Hälfte einen starken Bogen gegen den Hinterrand macht, auf dem Inneurande halb so weit wie auf dem Vorderrande auseinander stehen. Das Mittelfeld hat weissen Grund, der jedoch ur in einem grossen Costalfleck rein bleibt, unterwärts aber durch schwarze, ungleichmässig vertheilte Stäubchen grauwolkig erscheint. Längs des Hinterrandes zieht eine mehr oder weniger verloschene, feine, weissliche Linie. Fransen hell zimmtfarbig mit verloschenen dunklern Linien durchzogen, oberhalb des Innenwinkels mit einem kleinen weisslichen Wisch.

Hinterflügel an Vorderwinkel zugrerundet, bleich fahlgelbl'ch, an Hinterrande vom Analwinkel aus blässer werdend zimmtbraun und dicht an ihn zwischen den Aesten der Medianader, also in weitell Abstäuden von einander mit 4 tiefschwarzen, blass goldglänzend unzogenen Punkten. In einiger Entferung vom Hinterraude läuft fast vom Analwinkel aus ein zweiwelliger, schwärzlicher Bogenstreif, der auswärts weiss gesäumt ist und weit vor dem Vorderrande verlöscht. Ueber diesem Bogenstreif ist der Innenrand schwarz gefleckt, aber nicht bis zur Basis, und über diese schwarze Farbe legt sich der hellblonde Harstreif der Medianader zum Theil hinweg. Die Fransen des Innenrandes siud weisslich, die des Hinterraudes weissgrau und von einer gelbgrauen Linie durclizogen.

Interseite bleich gelblichgrau; die Vorderflügel in der Mittelzelle mit einem schwarzen Längswisch, der durch die helle Querader plötzlich durchschnitten, dann als tiefer schwarzer Fleck bis zu den schwärzlichen, ausseu liell gesäumten, schon in halber Flügelbreite aufhörenden Querstreif fortsetzt. Hinterflïgel mit einem verloschenen, weisslichen Querstreif hinter der Mitte, auf dessen Innenseite ein jar schwarze Fleckchen liegen. In der Mitte zwischen ilın und der Flügelbasis ist ein schwarzer Fleck nicht weit rom Innenrande. Die \& tiefschwarzen Hintermudpunkte sind vorhanden, doch klein und wenig deutlich; auch zeigt ihre blasse Einfassung nur wenig Metallglanz.

Vaterland: Texas (Boll). 20 , 1 \% in meiner Samulung.

\section{Scirpophongu Jestuliella n. sp.}

Parva, nivea, palpis pedibusque anticis griseo-luteis. $\%$.

Die kleinste bekannte Alt, wie rirginea mit zugespitztem Ende des Hinterleibes und ganz dïnnem Analbusch.

Ueberall schneeweiss, schwach seidenschimmernd auf den Flïgehn; diese (die vordern 31/2" lang) sind weniger gestreckt als bei Viruinca, 
sonst von gleicher Gestalt. Die Taster sind lehmgelb, auswendig dunkler angelaufen; die Vorderbeine bell graulehmgelblich, die Schenkel der mittleren Beine sehr blass; die Hinterbeine ganz reinweiss, auch an den Füssen (die bei Virginea grau sind mit weissen Enden der Glieder).

Vaterland: Texas (Boll, Belfrage). Tou den 3 \% meiner Sammluug wurden 2 am 19. August gefangen.

\section{Schoenobius longirostrellus ${ }^{1}$ ) Clemens.}

- Z. Monogr. p. ๖. - Robinsou: Ammals Lyc. Nat. Hist. IX. p. 31 ?.

Die nahe Verwandtschaft, in der er mit dem europäischen Forficellus steht, zeigt sich auch dariu, dass er ähnlich abändert. Der bräunliche Schattenstrich aus der Spitze der ơ Vorderflïgel, der stets wie bei Forfucellus nur bis zu einem brannen Fleckchen in der Falte, nie bis zum Innenrande herabreicht, ist entweder ganz ohne Unterbrechung, oder es treten, während die Farbe sich lichtet, auf den Adern duukle Stellen als Flecke in ihm herror, oder er löst sich auch gasuz iu gesonderte Flecke auf. Ich halte es auch für wahrscheinlich, dass wie bei Forfucellus bei manchen Exemplaren die Grundfarbe gesättigter oder gar nit Braun ïberflogen wird, und dass sich ein dunkler Streif auf der Subcostalader ausbildet.

Die 6 vor mir befiudlichen $\mathcal{Q}$ ziehe ich alle ohne den geringsten Zweifel zu Lmgirostrellus, nicht bloss wegen ihrer Analogie mit Forficellus 9, sondern auch weil $\ddot{3}$ davon mit einem ö bei Beverly in der ersten Hälfte des Juli gefangen wurden.

Als standhaften Interschied rou Forficellus sebe ich nur den Vorderrand der Voidertiigel bei Longirostrelluts weniger convex. Alles Andere ist, wie mir scheint, ebenso verinderlich. Da alle 6 C Exemplare unter einauder verschieden sind, so muss ich sie einzelı nach ihren Hauptmerkmalen beschreihen:

a) Von New York (von woher auch 1 j). Es stimmt in Farbe und Zeichnung der '5"“ langen Vorderllügel am meisten mit dem gewöhnlichen ơ überein; die Grundfarbe ist aber viel gesätigter; der Apicalstrich reicht nur bis in die Gegend des schwarzen Queraderpunktes.

b) Grösser (am 8. Juli gefangen). Hat die Vorderflügel heller geelb als das $\sigma \overrightarrow{ }$, weil die braunen Stäubchen fast ganz fehlen. Ton dem etwas weiter herabreichenden Apicalstrich an ist der Raum zwischen der Medianader und dem Torderrande sehr dicht gelburaun hestäubt.

1) In Clemen's Contributions steht Lonqirostrallus, welchen Druckfehler auch Robinson verbessert. 
c) Noch grösser (am 11. Juli gefangen). Hat dieselbe Grundfarbe wie $b$. Der dünne, braune Apicalstrich schliesst sich mit seinem Ende unter einem sehr stumpfen Winkel an eine dicke, allmälig verdümute, braune Längslinie an, die unterhalb der Subcostalader bis an die Wurzel zieht.

d) (Am 11. Juli gefangen) hat auf den 7"' langen Vorderfligeln rostgelbliche Grundfarbe; ron dem bis zur Höhe des schwarzen Queraderpunktes reichenden Apicalstriche einwärts ist der Grund gelbbräunlich bestäubt, und in der Mittelzelle liegt ein dunkelbrauner, g*gen die Flügelbasis zu zugespitzter Längsstreif, der weit vor der Elügelbasis aufhört.

e) (Am 3. Juli gefangen) ist anf den $6^{\prime \prime \prime}$ langen Vorderflïgeln hell lehmgelb, dicht bräunlich bestäubt; der Apicalstrich, der Queraderpunkt und ein Längsschatten der Mittelzelle sind verloschen zu erkemnen.

f) (Am 6. Juli gefangen) hat die $71 / 2$ "' langen Vorderflïgel ganz gelbbraun, gegen den Innemrand heller; der Apicalstrich und der breite Längsstreif der Mittelzelle sind brann, wenig hervortretend; letzterer ist aber durch die weissliche Farbe der Medianader, so weit er reicht, begrenzt; der Queraderpunkt ist nicht zu erkennen.

Alle diese $\%$ haben mehr oder weniger deutliche Hinterrandpunkte und ihre Hinterfïgel sind einfarbig weiss mit Seidenschimmer, bisweilen mit schwacher gelblicher Beimischung.

Anmerkung. 1. Ob die von Robinson l. c. aufgestellten Arten: Melimellus, Clemensellıs (!), Dispersellus, Unipunctellus und Tripomctellus sich als gut bewihren werdel, ist mir sehr zweifelhaft. Ich vermutlie, dass die Mehrzabl, wo nicht alle, nichts weiter als $\mathcal{Q}$ des Longirostrellus seien. Wenn ich keine unter den 6 ron mir charakterisirten 2 mit Bestimmtheit heraunfinde, so mag das daher kommen, dass Longirostrellus noch viel mehr abändert. Robinson hätte angeben sollen, mach wie viel Exemplaren er jede seiner Arten aufstellt. So lässt sich nur bei zweien sicher erkennen, dass er mehrere vor sich hatte.

A n merkung 2. Uebrigens gibt es in Texas sicher noch eine dem Longirostrellus nahe Art. Ich habe ein von Belfrage an 7. Juni grefangenes, leider kläglich abgeflogenes $\supset$, das wegen der etwas stumpfern Vorderflïgel, des vor der Flïgelspitze (wie bei Minutellus) herabkommenden braunen Striches und der stumpfern, weisslichern Hinterflügel nicht zu Longirostrellus gehören kann. 


\section{Gen. Crambus.}

Za einer Gruppe, die durch das Fehlen eines woissen Fleckchens zwischen der Vitta und der hintern Querlinie charakterisirt wird, kann man Piafectellus, Pulchellus und Leachellus, nebst dem europäischen Hamellus, allenfalls auch Sutrapellus, zusammenstellen; zu ilır gehört auch der unten beschriebene $C r$. bidens.

1. Profectellus Zinck., durch den breiten Abstand der silberweissen Vitta rom Vorderrande und seine weissen, besonders beim $\mathbf{Q}$ durchscheineuden Hinterfligel ausgezeichnet, kommt bei New York, in Massachusetts bei Beverly (wo Burgess 1 \& am 17. Juni fing), ausserdem in Texas vor ( 1 o von Belfrage mit der bestimmt irrigeu Angabe: 18. März).

2. Leachellıs Zinck., der unserem Pascuellus durch den schmalen Zwischenraum zwischen der Silbervitta und dem Vorderrande am meisten entspricht, aber gleich Praefectellus durch den Mangel des siberweissen Fleckchens ron ilnm abweicht, kommt ausser in lllinois auch in Georgien, bei Philadelphia nud in Texas ror. Ein kleines Exemplar (mit abgebrochenem Hinterleib und sonst beschädigt, aber walıscheinlich C) aus Venezuela (in der Kaden'schen Sammlung) hielt ich ungeachtet seiner ganz weissen, durchsichtigen Hinterflügel doch nur für dieselbe Art.

3. Pulchellıs Z. mit seinen dunkeln Hinterflïgeln ist mir jetzt biusichtlich seines Artrechte verdächtig geworden, da ich noch kein entschieden dazu gehöriges $\&$ gesehen habe, das in der Monogr. p. 18 in der Anmerkung erwähnte @ einen Uebergang zu Leachellus anzudenten scheint, und das o rou Leachellus sowohl in der Dunkelheit der Hinterflügel wie in der Gestalt des braunen Keilstrichs in der Spitze der Vorderfiigoel reränderlich ist. - An den Stellen, wo Leaikellus und Pulchellus zusammenfliegen, werden sich natïrlich die specifischen Rechte selır lejclit entscheiden lassen. - Ein o des Pulchellus erhielt ich durch Dr. Packard, rermuthlich aus Massachusetts.

4. Crumbus bidens n. sp. Tab. III, fig. 17.

Alis ant. uon emarginatis, laete ochraceis, vitta argentea costam longe tangente, valde acuminata, post medium inferius acute dentata, macula inter strigam stanueam marginemque posticum quadrata, nivea; posterioribus oj canis, $f$ albis pellucidis. o 9 .

Diese kleine Art zeichnet sich dadırch aus, dass die silberglänzende Strieme beim $0^{x}$ zwischen der Subcostalader und einer schualen Costallinie von der Wurzel aus bis nahe an ihren Hinterrand dicht gelbbraun bestäubt ist, während sie beim $\subsetneq$ nicht ein dunkles Stäubchen trägt. 
Hiernach, und weil die Strieme in mehr als ihrer halben Länge den Vorderrand berihht, kömnte die Art neben Uliginosellus gestellt werlen: aber die Vitta hat zwischen ihrem Ende und der Querlinie keinen weissen Fleck, und ist dafïr weiter gegen die Querlinie hin verlängert. Tegen dieses Umstandes gehört sie zu den eben aufoeführten Arten, obgleich ihr eine gewisse Verwandtschaft mit Uliginosellus und Agitatellus nicht abzusprechen ist.

Kleiner als die meisten Agitatellus. Kopf und Rïckenschild ochergelb, letzteres lebhafter, Taster kürzer als das Riickenschild, zugespitzt, hell ochergelb, auswärts etwas dunkler. Fühler weisslich ochergelb, be:m o’ pubescirend gefranst. Beine ochergelblich grau, die hintern auf der Innenseite beim $\mathbf{q}$ weisslich. Hinterleib grau ochergelblich mit hellem Afterbusch.

Vorderflïgel 4- $4{ }^{1} / 2^{\prime \prime}$ lang, schmäler als bei Agitatellus, nach hinten erweitert, am Hinterrande unterhalb der Spitze sehr schwach concar. Grundfarbe angenehm ochergelb wie bei Agitutollus, mach hinten rostloraun bestäubt. Die silberglänzende Strieme ist sehr breit, läuft bis über ihre Hälfte dicht am Vorderrande hin, dann in schräger Jinie einwärts, ist fein zugrespitzt nnd trägt auf der untern Seite hinter der Mitte einen scharfen, starken Zahn in der Flïgelfalte; sie ist überall mit einer golbbrannen Linie gerandet, der Raum aber zwischen ihrer Spitze nnd dem Zahne mit dunklem Staube ausgefüllt; ihre Spitze reicht weit in den stnmpfen Winkel der zinnolänzenden Querlinie hinein und liegt in keinem wie bei Prafectellus etc. gelichteten Grunde; zwischen ihr und dem ersten weissen Costalfleck zeigt sich eine sehr feine, kurze, braungesäumte Silberlinie. Der zweite weisse Costalfleck wird durch einen zimmtbraunen, aus der Flïgelspitze bis zur Querlinie schief herabgehenden Streifen von dem weissen dreieckigen Minterrandfleck getrennt. Unter diesem liegt ein grosser, viereckiger, reinweisser Fleck, der vom Hinterrande bis zu der ziemlich weit abstehenden Querlinie reicht. Den Hinterrand begleiten 5-6 schwarze Punkte, vou denen einer am obern Rande des Vierecks, zwei in demselben und einer an seinem untern Ende liegt. Fransen grau, metallglänzend, gegen die Flügelspitze allmälig weisslich.

Hinterflïgel des $\sigma^{\prime}$ hell gelblichgrau, vor der blassgelblichen Flïge:spitze dunkler; des $\$$ weiss und etwas durchscheinend.

Unterseite der Vorderflïgel branngrau, am Hinterrande bleichgelblich mit ક schwarzen Randpunkten; beim $\subseteq$ ist auch der Vorderrand schmal, der Inmenrand sehr breit bleichgelblich, so dass von dej braungrauen Farbe nur eine breite Strieme vorhanden ist. Hinterfliigel an Vorderande dunkler gran als oben.

Vaterland: Massachusetts. ( $\sigma^{\top} \%$, durch Dr. Packard erhalten, in meiner Sammlung.) 


\section{Crambus foridus n. sp.}

Alis ant. emarginatis, latiusculis, pallide ochraceis, vitta argentea snbcostali acuminata, mucronata, non dentata, macula parra nivea inferius inter ejus apicem et strigam stanneam; posterioribus albidis; palpis supra niveis. ơ 9.

Er kommt den hellsten Exemplaren des Pascuellus, dessen mittlere Grösse (Vorderflügel $4^{3} / 4-3^{\prime \prime}$ ) er hat, so nahe, dass man ihn für dieselbe Art halteu möchte, zumal da $C r$. pascuellus (uach Bremer) an der Ostkiiste Sibiriens vorkommt, so dass er sich bis nach Amerika verbreitet haben könnte; aber meine \& Exemplare des Floridus haben ïbereinstimmend kiirzere, breitere Fligel, die hintern mit weniger vorgezogenc' Spitze; der ochergelbe Raum zwischen dem obern Rande der Silberstrieme und dem ersten weissen Costalfleck (dem ror der Querlinie liegenden) ist etwas breiter; der Spiegelfleck (mit 4 tiefschwarzen Punkten in nehr oder weniger meissem Felde) ist etwas schmäler, die Spitze der Silbervitta bleibt etwas weiter entfernt vou der Querlinie, und der weisse Fleck, welcher nuterhalb der Vitta liegt, wird durch eineu breitern gelben Raum von der Querlinie getrennt; die Taster sind verhältnissmässig kürzer und dicker.

Die Grundfarbe der Vorderflügel ist wie bei unserm hellsten Pascuellus. Die HinterAligel sind in beiden Geschlechtern weisslich, gegen die Flügelspitze allmälig schattengrau, am Rande selbst schmal gelblich oder doch hell.

Vaterland: Massachusetts. Beide Geschlechter in frischen Exemplaren fiug Burgess am 20. und 26. Juni bri Beverly.

A nmerkung. Bei Pascnellıs muss in der Diagnose hinter emarginatis eingeschoben werden: elongatis, und statt inter eam muss es wie bei Floridus heissen: inferius inter ejus apicem, damit der Unterschied gegen Uliginosellus besser hervorgehoben wird. Den als fingliche Art aufgestellten Extinctellus, dessen Artrechte Staudiuger nicht bezweifelte (Ent. Zeitung 185\%, S. 272), lat Dr. Wocke wohl mit vollem Recht zu Pascuellus gezogen, da ich Exemplare mit ähulicher, durch Regen bewirkter Färbung auch bei uns gefangen habe. Der im Catalog als Varietät aufgefïhrte Laharpesche Scirpellos (leider nicht diagnosirt), dessen Beschreibung ich nicht vergleichen kann, wird wahrscheinlich zu der auffallenden Varietät von Pascasllus gehörtn, die ich in Graubünden in der Gesellschaft der geröhulichen Exemplare fing, deren Silberstrieme grau angelaufen ist, nnd deren Hinterflügel verdunkelt sind. 


\section{Agitatellus Clemens.}

Ausser den schon angegebenen Lokalitäten lıbe ich die Art auch von Texas, New York und Massachusetts; Burgess fing sie bei Beverly zahlreich zu Ende Juni und in der ersten Hälfte Juli.

Mit Agitatellus ist nothwendig Alboclacellus Schl., Monogr. p. 19, als dunkle Varietät, deren whre Natur ich nach dem einen vorliegenden Exemplare nicht erkannte, zu vereinigen; sie kann charakterisirt werden als Var. b) alis ant. brumneo-obscuratis, praesertim circa vittae apicem pulvere nigro-fusco dense conspersis. ơ 9 .

Die Silberstrieme ist bei 2 Weibchen (das eine etwas, das andere viel grösser als das $\widehat{\sigma}$ ) auf der Subcostalader gauz deutlich gelb und dazu hinterwärts mit braumem Staube bestreut, so dass also die Strieme der Länge nach zerschnitten ist.

Von diesen beiden $\boldsymbol{Q}$ ist das eine aus der Gegend von New York, das andere wahrscheinlich aus Massachusetts.

\section{Laqueatellus $\mathrm{Clemens}$ e}

Ausser von den in der Monographie angezeigten Orten habe ich iln aus Illinois, Texas und Massachusetts. In letzterem Staate scheint er häufig zu sein. Burgess fiıg ihn bei Beverly den ganzen Juni hindurch.

\section{Hecorellus Zinck.}

Nach den rorliegenden Exemplaren, 1 sehr kleinen $\sigma^{*}$ und 2 grossen 9, kann ich den Polyactinellus Kollar Mougr. p. 25, gauz sicher zu Decorellus ziehen, von dem er nicht einmal Varietät ist. Da die Beschreibung des Polyactinellus viel genauer ist, so ergäuze ich bloss die dort vorhandenen Miingel.

Das Rückensehild ist weiss wie der Kopf, die Schulterdecken aber ochergelb angeflogen. Der Hinterleib ist weisslichgelbgrau mit hellem, beim $q$ ochergelblichem, zugespitztem Afterbusch.

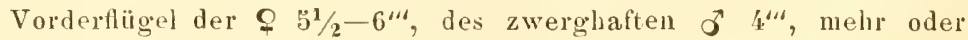
weniger gestreckt. Der Inuenrand ist bis etwas über die Subdorsallinie nur heller als die ïbrige Grundfarbe. Die erste rostfarbene Querlinie ist sehr deutlich bei den 9 , verloschen beim $\sigma^{\star}$, mit dem bei Decorellus angegebeuen Verlauf; sie reiclit aber bis zum Innenrande. Das mattsilberne Strichelchen, wodurch die rostgelbe Hinterrandfarbe oben gespalten sein soll, ist nur bei cinem 9 zu erkennen, bei den audern gar nicht; es bleibt am besten unbeachtet. Die 7 tiefschwarzen Hinterrundpunkte nehmen nach oben an Grösse ab.

Meine Exemplare sind aus Texas (Boll) und Massachusetts, wo Burgess ein $\%$ am 4. August gefangen hat. 


\section{Terrellus Zinck.}

Diese unscheinbare Art, deren Kopf und Oberseite der Taster richtiger als weiss (statt schneeweiss) bezeichuet werden, hat in unverflogenen Exemplaren vor der meist unvollständigen ersten Querlinie der Vorderflïgel braun und gran genischte rauhe Schuppen, die durch die gelblichen Längsadern in zwei oder drei Partien getheilt werdeu und dem Flïgel das Ausehen geben, als ob er durch Feuchtigkeit verdorben wïre. Beim $\subseteq$ scheint der gauze Raum vou der Querlinje bis zur WVurzel mit solchen Schuppen ausgefüllt zu sein; dass sie sich leicht abreiben, ist schon erwähnt.

Das $\mathcal{Q}$ ist etwas grösser als das $\vec{\gamma}$, mit viel stärkerem Hinterleibe.

Ob die Art nicht richtiger bei Cerussellus steht, mnss die Untersuchung des Geäders lehren.

Sie kommt auch in Texas vor, wo Belfrage meine 2 O am 12. und 19. Juli fing.

\section{Elegar.s Clenens.}

\section{Cr. terminellus Z. Monogr. p. 27.}

Durch seine Kleinbeit, die fast gerade abgeschnittenen Vorderflïgel, die zimmtbrane, sichelförmig gekrümmte Querlinie des Innenrandes und die ziemlich gerade, einwärts breit, auswärts fein zimmtbraun gesäunte hintere Querlinie kenntlich.

Vou New York (Grote, der ihn mir als Cr. elegans Cl. witheilte), aus Maryland (Packard) und aus Texas (Boll).

\section{Chalybirostris $Z$.}

Da ich durch frote (der aber den Ruriolellus nicht als eigene Art kannte) ein Exemplar dieser Art als Vulyivayellas Cl. mitgetheilt erhielt, so könnte es scheinen, als ob dieser Name der berechtigtere wäre, obgleich Clemens gar nichts angibt, was iln rechtfertigen könnte; über das so charakteristische Merkmal, die palporum squamae apicales metallice nitentes schweigt Clemens, man mïsste denn dic labial palpi lnteous dark fuscous externally - was sie bei Ruricolellus doch auch sind - dahin deuten wollen.

Noch sicherer mengt Walker in seinem Cr. anrifimbrialis (Cat. Crambites et Tortricites p. 157) die zwei Arten untereinander, wie die Angabe: length of the wings 7-11" lehrt. Von den Tastern weiss er weiter nichts zu bemerken, als dass sie viel länger sind, als der Kopf breit ist. 
Ich erhielt die Art aus Texas (Boll), von New York (Dr. Speyer) und aus Massachusetts, wo Burgess sie nicht selten fing; ein ơ trägt die Notiz: Tuckemuck 29. Angust.

A n merkung. Fs gibt in Nordamerika eine Melırzahl mit Fuscicostellus, Easiccatus, Inquinatellus verwandter Arten, die gehörig zu sonderı und kenntlich zu machen, ein ganz anderes Material erfordern, als das mir vorliegende.

\section{Catharylla $Z$.}

Grote hat Recht, indem er behauptet, dass diese Gattung Argyria Hbn. heissen mïsse (Transact. Am. Soc. Philadelph. 1868, p. 18); Urola Wkr. ist ebenso jïnger als meine Benenuung.

\section{Cuth. conliguellu n. sp.}

Palpis exterius luteis; alis ant. elongato-triangulis, acutis, niveis, stria costali postice evanescente fusco-lntea, punctis 2 fuscis ante medium, striga postica subarcuata fusco-ferruginea, punctis marginis postici fuscis. $\subsetneq$.

Sehr kenntlich an den brännlichen Costalstreifen und der gelbbraunen hintern Querlinie.

Fïhler, Kopf, Rückenschild (beschädigt) und der ziemlich dicke, zugespitzte Hinterleib weiss; die Wurzel der Schulterdecken gelbbraun. Die Taster, un Kopflänge hervorstehend, auswärts dunktllehmbraun, wodurch die schneeweisse Farbe des Kopfes un so mehr hervortritt. Beine bräunlich angelanfen; Hinterschienen weiss.

Vorderflügel etwas über $3^{\prime \prime}$ lang, ziemlich schual, nach hinten erweitert, mit geradem, am letzten Viertel schwach convexem Vorderrande und ziemlich geradem Hinterrande, wodurch die Fliigelspitze scharf hervortritt. Grundfarbe schneeweiss mit etwas Seidenglanz. Der Vorderrand ist von der Wurzel aus in einem schmalen, nämlich nur bis zur Subcostalader reichenden Streifen gelbbraun, der sich allnälig verengert und rostfarbig wird und bei der Querlinie fast ganz verlöscht. Oberhalb des Anfanges des zweiten Innenranddrittels liegt ein dunkel gelbbrauner Punkt, nud schräg answärts über ihm ein zweiter (der anf dem linken Flügel zufällig fehlt). Hinter der Querader ist eine rostbraune, auf den Adern fleckartig gebräunte Querlinie, die einen schwachelı, nach aussen concaven Bogen bildet und kurz ror der Flügelspitze auf dem Vorderrande endigt, während sie auf dem Innenrande rom Innenwinkel ziemlich entfernt bleibt. Der Hinterrand hat eine Linie ron 6-7 dunkel rostbräunlichen Strichelchen; die Fransen sind weiss.

Hinterrand ziemlich schmal, weiss, der Hinterrand an der Apicalhälfte mit verloschenen bräunlichen Punktcn. 
Unterseite weiss, sclwach seidenglänzend; die Vorderflïgel am Vorderrande breiter als die Hinterflügel blass gelbbräunlich angelaufen. Hinterrandpunkte verloschen.

Vaterland: Cuba; ein einzelnes 9 in Herrich-Schäffer's Samm11 lung.

Ich habe bei dieser Art au Walker"s Urola croceivitella - was doch wohl croceivittella heissen soll - l. c. p 182, gedacht; aber unnöglich kann sein interior hardly oblique ochraceous band auf dic. Querlinie der Contigrella gedeutet werden, und wenn die Lage dieser Binde schon räthselhaft ist, so ist es noch mehr die costal line emitting a short oblique streak towards the tip; man denke sich eimual eine Costallinie, ron der ein kurzer, schräger Strich gegen die Flügelspitze geht !

2. Cath. pulchella. Tab. III, fig. 18.

? Urola pulchella Walker, Cat. Cramb. p. 183.

Thorace palpisque superne niveis, nitidis, collari pedibusque \& anticis vitellinis, alis ant. niveis, nitidis, fascia media obliqua lineaque masginali juxta marginem dorsalem conjunctis ferrugineis, ciliis dilutioribus nitidis. ơ?

Es ist nur wahroheinlich, keineswegs sicher, dass ich die Walker"sche Species vor mir habe, da bei dieser die Schulterdecken vorn ochergelb sein sollen und verschwiegen wird, wie die Binde gelegt ist, und ob sie sich am Innenrande bis zum Hinterrande lierumzieht.

Kopf rein weiss. Taster von Rïckenschildslänge, rein weiss, auswärts am ersten und an $2 / 3$ dus zweiten Gliedes rostgelb. Fühler heligelb mit weissem Rïcken. Halskragen rostgelb, Schulterdecken silberweiss. Hinterleib seidenartig weisgrau.

Vorderflïgel $3^{\prime \prime}$ lang, breit, nach binten erwcitert, mit deutlicher Spitze, an Hinterande convex, glinzend schueeweiss. Eine breite, rostgelbe schräge Binde, die auf dem Vorderrande der Flïgelspitze näher ist als auf dem Innenraude, zielit durch die Flïgeluitte so, dass der silberweisse, dahinter liegende Raum grüsser ist als das Basalfeld; sie ist, ausser beim Vorderrande, dunkel rostbraun gesäumt, unten erweitert und setzt sich in einem Streifen am Innenrande bis zum Hinterrande fort; dieser ist von einem schmalen, rostfarbenen, einwärts rostbraun gesänmten Streifen umzogen, an dem sich die hel'er gelben Fransen fast ohne Uebergang anschliessen.

Hinterflïgel weiss, beim o etwas in's Graue, seidenartig schimmernd. Interseite der Vorderfiigel bein ơ braungrau, am Innen- und Hinter rande weisslich; die des $f$ sin I fast ganz weiss. Auch die Hinterfliigel sind bcim $j$ am Vorderande grau angeflogen. 
Das etwas kïrzer geflïgelte und grössere $\sigma^{\top}$ wurde in Massachu-

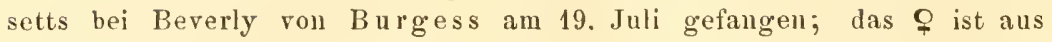
Texas (Boll).

\section{C'ath. Hememulalis Z.}

Nach Grote ist diese Art zufolge des British Musenm einerlei mit Walker's Urolı Michrochrysella (!) (Cramb. p. 181) und Urola subarnescens (ib. p. 182) eine Varietät davon. Ich labe von meiner Nummulalis 17 Exemplare, Walker hatte von seiner Michrochrysella ein Dutzend. Kein einziges weiner Exemplare hat einen ocherfarbenen Kopf; er ist rein weiss, nnd nur sein hintere Rand, wenn er nicht anch rein weiss bleibt, schmal rostgelb; während WValker schreibt: Caput et thoracis margo plus minusve ochracea, was doch uur bedeuten kaun, dass ocluracens die Hauptfarbe ist, die nur mehr oder weniger verdrängt wird. will man aber trotzdem beide Arten als identisch anckennen, so wird der Name wenigstens Microchrusella heissen, wie ihn anch Grote schreibt. Urolt subaenescens mit head and palpi bright ochraceous ist aber sicher eine andere Art, die ich, obg!ejch die Mitte des Kragens und Riickenschildes rostfarbig ist - also gerade das Gegentheil von thorax on each side in front - - tinged with ochraceous - auf meine Fuscipes deuten möchte. Da nun Grote diese für die wahre Nummulalis H. erklärt, so scheint mir, dass er mehrere Arten in eine zusammenzieht.

Meine Nummulalis ist in Norlanerika se!n verbreitet. Ausser ans den in der Monographie angezeigten Gegenden habe ich sie aus Texas (Boll) und Massachusetts, wo Burgess sie in beiden Geschlechtern in der ersten Hälfte des Juli melufach gefangen hat. Sie ist wirklich veränderlich, nicht nur darin, dass auch Jer Hinterkopt rein weiss bleibt, sondern selbst in der Streckung der Flägel, Ein 9 mit recht verlängerten Vorderfligeln, aber auch durch Abfliegen verlslasster Fransen und fast abgewischtem Dorsalffeck, fing Belfrage in Texas (Bosque Connty) am 27. Juli.

\section{Call. r"fisignellı แ. sp.}

Capite palpisque ferrugineis, pedibus anticis ochraceis; alis ant. elongatotriangulis, acutis, niveis, nitidis, costae punctis duobus, dorsi medii uno fermgineis, linea marginali fusca, cilis ferugineis; posterioribus exalbidis, $\vec{j}$.

Diese in die Nähe der Lasella gehörige Art unterscheidet sich von ihr sicher durch die rostbraune Farbe des Kopfes und der ganzen Taster, sowie durch die gelblichen HinterHigel. Das rostfarbige Fleckchen an der Mitte des Innenrandes hat sie mit meiner viel grösseren Nummulalis gemein, von der sie sich durch ihre gelblichen Hinterflïgel und die zwei rostfarbeneu Vorderraudfeckchen unterscheidet. 
Kopf und Taster durchaus rostbraun. Fühler graubrïunlich mit rostbraunem Wurzelghiede. Vorderbeine an den Hüften ocherfarben, an den Schenkeln und Schienen dunkler, an den Fïssen gelbbraun; dle alideren Beine auf der Lichtseite ochergelb, auf der abgewendeten Seite gelblichweiss. Hinterleib hell graugelblich.

Vorderfligel 4" lang, nach hinten stark erweitert, spitz, mit schwach courexem Vorderrande und fast geradem, ziemlich senkrechtem Hinterrande. Grundfarbe silberweiss. Auf dem Vorderrande ist hinter der Mitte ein verloschener, rostfarbener Punkt, und weiter von ihm, als von der Flïgelspitze entfernt, ein rostfarbener, nach hinten etwas schattirter Schrägstrich. Die Mitte des Innerandes trägt ein rostbraunes, gerundetes Punktfleckcheu. Die Hinterrandinie besteht aus gelbbramen, aneinanderstossenden, in der Mitte etwas concar gekrïnmten Strichen. Fransen rostgelb, bis dicht an den Innenwinkel.

Hinterflïgel gelblichweiss, seidenglänzend, vou den Fransen durch eine sehr hlasse ochergelbliche Linie geschieden.

Unterseite der Vorderflïgel dunkelgrau, am Vorderrande striemenartig hellröthlich, am Hinterrande schmal, am Innenrande breit blassochergelblich; der Hinterrand mit einer Reihe verloschener, branner Punkte. Fransen hell grauochergelblich. Hinterfliigel bleichgelblich, am Vorderrande hellgrau, vor der Spitze mit einem dunkleren Schatteu, den Anfange cines Querstreifens. Die feine, ocherfarbene Hinterrandlinie hat vor dem Anslwinkel und bei Ader 5 eine Verdunkelung.

Vaterland: Texas (Boll). Ein $\sigma^{*}$ in meiner Sammlung.

Eromene Texama Robinson.

-- Robinson: Ann. Lyc. Nat. Hist. IX, p. 15̈5, tab. 1, fig. 5.

Ich bezweifle sehr, dass sie von Eromene ocellea wirklich specifisch verschieden ist. Bej der genanesten Untersuchung finde ich nur, dass di., beiden ochergelben, durch ein silberglänzendes Band getrennten Querstreifen ein wenig dïnner sind, als bei meinen 4, der Mittelmeerfauna angelıörigen Exemplaren, und dass die 2 ochergelben Schrägstreifchen des Vorderrandes vor der Flügelspitze schärfer begrenzt sind: geringtïgige Unterschiede, die sicher nicht einmal standhaft sein werden. Die Arten der Gattung Eromene zeigen gerade in der Breite, Gestalt und Richtung der Qnerlinien eine verhältnissmässig bedeutende Veränderlichkeit. Demge-

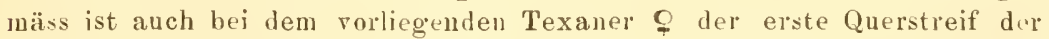
Flügelhälfte muterhalb des Vorderrandes stumpfwinkelig gebogen, beim or gerade. - Uebrigens haben beide auf den Hinterflïgeln weissliche Grundfarbe mit gelblichbrauner, einwärts schmal beschatteter Hinterrandlinie, wie H. S., fig. 144 Cyrilli.

Das o wurde ron Belfrage in Busque County am 17. Mai, das ganz uuversehrte 9 von Boll in Dallas County gefangen. 


\section{I'empelia liynosella Z.}

Isis 1848 S. 883.

Diese kleine Art ist in ö Geschlechte lejcht zn erkenuen an den schualen, ocherfarbenen, an Vorder- und Inuenrand gebräunten Vorderflügeln und den durchsichtigen Hinterflügeln mit 4-theiliger Medianader. Das $\subseteq$ ist weniger leicht kenntlich, weil es mehrere Phycideen wit durchsichtigen Hinterfliigeln und schmalen, fast einfarbig schwärzlichen Vorderflügeln gibt. Um es nicht mit diesen zu verwechseln, hat man die Länge der Taster zu beachten, die zwar kürzer als beim o $\overrightarrow{0}$, aber doch länger als der Kopf und dünn sind, und etwas aufsteigen. Eine solche, eben:o grosse, auch in Texas vorhandene Art ist Turfarella, die sich von Ligmosella O durch kürzere, aufgebogene Taster, durch etwas kürzere Vorderflïgel und durch iluen schwarzgriuen Hinterleib unterscheidet. - Pomp

lencophneolla Z. (Ent. Ztg. 1867, S. 372) aus Ostindien, ist grösser mit 2 verloschenen helleren Querstreifen der Vorderfïgel. - Pemp. Psummenitella Z. (Transact. Ent. Soc. London. 3. Serie, Vol. V, p. 463, pl. 24, fig. 4. Ent. Ztg. 1867 S. 372) aus Aegypten, ist auch grösser, und hat eine tief schwarze Hinterrandlinie der rauchschuppigen Vorderfingel. Gleichgross und sonst wie Lignosella ist fucuntella; diese hat aber dickere, aufgebogene Taster und auf dem Rückenschilde nud dem Basaldrittel der Vorderfligel röthliche Färbung.

Lignosella hat eine weite Verbreitung in Amerika. Ausser Brasilien, Columbien und Carolina lebt sie in Texas (Boll, Belfrage), wo sie nicht selten sein kann. Belfrage fing ein schönes o’ mit einem (wahrscheinlich nach dem Fange sehr beschärligtem), $\subsetneq$ an 15. Juli und zwei $\subseteq$ ron gleicher Beschaffenheit wie das $\sigma^{x}$ am 15 August.

Anmerkung 1. Pempelia (?) Traturella n. sp. palpis breviusculis cum capite et thorace nigricantibus, nitidulis, abdomine nigro-cinereo; alis ant. angustis nigris, posterioribus exalbidis pellucidis. O

Diese Art, die ich nach einem einzelnen Exemplare aufstelle, und die hoffentlich eine Pempelia, jedenfalls aber für den, der Lignosella ? kennt, leicht kenntlich sein wird, ist kleiner als Liynosella $f$, nit nacls hinten fast gar nicht erweiterten Vorderflügeh. Rückenschild, Kopf und Taster sind schwarz, etwas glänzend. Die Taster haben nur etwas über Kopflänge und sind dicker und stärker aufgebogen, als bei Lignosella 9, übrigens wie bei dieser, und so auch an der Wurzel des Endgliedes auf der Innenseite weisslich. Die Beine sind auf der Lichtseite dunkel rauch-briun, und nur die Hinterfïsse haben helle Enden der Glieder. Hinterleib dnukelgran, nach hinten etwas heller, mit ochergelbem After.

Vorderflïgel $3 \frac{1}{2} "$ "lang, schmal, nach hinten sehr wenig erweitert, einfarbig violettlichschwarz, gegen den Hinterrand kaum etwas gelichtet. 
llinterfïgel trïber als bei Lignosella, wenn auch nicht minder durchsichtig. Die gelbliche Medianader sondet ihre 3 Aeste in gleichen Abständon ab. Die feinere, schwärliche Hinterrandlinie ist einwärts schattengrau gexäumt; die Fransen schimmernd, doch weniger rein weisslich als bei Lignosella. - Anf der Unterseite sind die Torderflïgel dunkler braun.

Mein ziemlich gut erhaltenes Exemplar wurde von Belfrage am 21. August gefangen.

A пu erkung.2. Von Incantelln n, sp., deren richtigen Platz bei Liynosella ich nicht bezweifle, habe ich auch nur 1 \&, das sich obendrein die Fransen der Vordertügel ganz abgeflogen hat; ich gebe daher nur die Unterschiede von Lignovella $\%$ an. Das Rückenschild ist röthlich ochergelb. Der branne Stirnbusch ist stark und stumpflegelförmig. Die Taster sind etwas stärker, aufgebogen und an die Stime angelegt, an der WVurzel weis, sonst dunkelgran mit weisslicher Wurzel des Endgliedes. Die Vorderflïgel von der Wurzel ans auf etwa $1 / 3$ des ganzen Raumes, am Torderrande noch viel weiter hin, als an Innenrande röthlich ochergelb von der Farbe des Rückenschildes; diese Farbe geht ohne scharfe Grenze in die braungraue des Flïgelrestes ïber. In der Mittelzelle zieht noch ein röthlicher Streif bis über die Querader hinweg. (Die Hintermndpartie ist sehr abgeflogen und ohne Fransen, wesshalb ich nichts davon erwähne). Die Hinterflïgel sind wie bei Tartarella.

21. August.

B elfrage fing das Exemplar in Texas in Bosque County an

\section{Pempelia pelrella (nus. Berol.) Z.}

lsis 1846, S. 771 und 1848, S. 886.

Ein ganz frisches und unversehrtes $\mathcal{f}$ aus Texas in Cambridger Museum ist sehr viel schöner und leblafter gefärbt, als die Exemplare, die ich zur Beschreibung benutzte. Bei ihm ist der weissliche Vorderrand der Vordertlïgel ron der Wurzel aus abnehmend röthlich bestäubt, was nicht so weit wie bei jenen einwärts reicht, sondern an seiner breitesten Stelle nur so weit, dass es den obersteı Queraderpunkt so eben mit nufasst. Der weisse, stark unterbrochene, mit 2 schwarzen Punkten auswärts bezeichnete Querstreif ist nicht stärker, als der weiter gegen die Wurzel liegende, mit dem er den röthlichen Dorsallec: $\mathrm{k}$ begrenzt. Die schwarzen Hinterrandpunkte sind ziemlich gross, mit un wenigem weisslichen Staube einwärts.

Diese Art scheint eine wahe Verwandte der Subornatella zu sein, von der, wie von den anderen nächsten Verwandten sie sogleich durch dié durchscheinenden Hinterflügel mit viertheiliger Medianader zn unterscheiden ist. Ihre Diaguose möchte ich so stellen: 
Thorace rufescenti-ochraceo; alis ant. rufo-fuscescentibus, costa vittae instar albida, rnfescenti-pulverulenta, strigis 2 distantibus ante medium umaque postica albis, interruptis, punctis venae transversae 2 fuscis; posterioribus ochraceo-griseis, subhyalinis. ơ $\%$.

Tetralopha melanoyrammos n. sp. tab. III, fig. $24 a, b$.

Alis ant. cinereis, strigis duabus, in dorso conrergentibus, priore ante plagam dorsalem al ham posita ntrimque, postica interius nigro-marginata, linea marginis postici distinctissima nigra. ఫౌ

Sehr ähnlich der Tetr. militella Z. (Isis 1848 S. 880), verschieden von ihr durch den hellblonden Pinsel der Maxillartaster, die angenehm gelblichgraue Grundfarbe der Vorderflïgel und die scharfen schwarzen Linien auf denselben, sowie durch die noch mehr abgerundeten Hinterflügel. Die dïmen, langen Lippentaster schienen mir gar nicht geeignet, den Pinsel der Maxillartaster aufuuelimen; erst als ich beobachtete, dass die flache Stirue eine seichte Vertiefung enthält, dass die langen Haarschuppen etwas aufgerichtet und nach hinten ïber gelegt sind, dass die Vorderflïgel in der Mittelzelle eine kahle Längsgrube haben, und auf der Unterseite von der Wurzel aus längs $2 / 3$ des Vorderrandes mit langen Schuppen dicht gepolstert sind, kam ich auf den Gedanken, dass der Haarpinsel doch vorhanden sein könnte, und durch Abbrechen des einen Lippentasters wurde wirkliclı ein langer, blonder Haarpinsel frei, um den sich der Lippentaster eng herum gelegt hatte. Das weitere Merkwiildige ist, dass dieser Pinsel nur einfach ist. Es ist daher fraglich, ob im frischen Zustande wie bei Militella aus jedem Maxillartaster 2 weit auseinander gesperrte Haarpinsel zum Vorscheine gekommen wären, um den Gattungsnamen auch fiir diese Art zn rechtfertigen, oder ob er sich von dem der Gattung Pempelia nicht unterscheidet (bei welcher ich ihn ïbrigens anch schon in zwei Partien auseinander gehend gesehen habe). Niisste man aber den Tasterbau fïr Pempelin und Tetralopha dem Wesen der Sache nach für gleich ansehen, so erlaubt doch der Bau der Fühler, der Beine und der Flïgel weder Tetralopha mit Pempelia, noch mit Gymnancyla, Oncolabis, oder Epicrocis zu verbinden. Denn die Fühler sind eiufach borstenförmig, ohne Krïmmung und ohne Schuppenwulst ïber Jem Wurzelgliede. nnd bis etwa zur Hälfte in 2 Reiheu borstig gefraust, worauf sie in allmälig abnehmender Länge Haarfransen lıaben. Die Beine mit ihrem ganz einfachen Bau und ohne Harrquasten verbieten die Vereinigung mit Oncolabis oder Epicrocis.

Grösse einer mittleren Militella. Rïckenschild gelblichgrau mit starkem, schwarzgemischten Schuppeubusche auf dem Schildchen. Oberkopf mit langen, etwas aufwärts und dann nach hinten gerichteten Schuppen bekleidet, welche hinter jeder Fühlerwurzel einen lingeren Busch bilden. 
Stirn flach, in der Mitte der Länge nach concar ausgehöhlt. Taster lang, dïnn, cylindrisch, aufgebogen, jeder einen langen, blonden (ob sich in 2 auseinanderspreitzenden?), Haarpinsel des entsprechenden Maxillartasters eng umschliessénd. Fühler grau, ron der schon angezeigten Beschaffenheit. Beine weissgrau, die Fïsse auf der einen Seite braun, mit weissen Enden der Glieder; die Vorderschienen und Füsse auffallend weiss, an den Enden der Glieder schwarz gefleckt. Hinterleib gelblichgrau, an den Fnden der Segmente und auf dem ganzen ersten bleichyelblich; Bauch weisslich.

Vorderflïgel etwas iiber 4" lang, mit stark convexem Vorderrande. Grundfarbe angenehm gelblichgrau, am Innenrande bis zur ersten Querlinie mit gröberen und dunkleren Schuppen. Von 1/3 des Vorderrandes geht zur Mitie des Innenrandes eine weisse, anf beiden Seiten tief schwarz gerandete (oder weun man will: eine schwarze, weiss ausgefiillte Doppellinie) fast gerade Linie, die aber gegen den Vorderrand etwas verloschen unl grau ist. An sie stösst auf der der Flügelhasis zugewendeten Seite ein in der Falte liegender, starker, schwarzer Schupponbusch. In der Mittelzelle ist eine längliche, etwas kahle, nicht leicht zu bemerkende Läng'sgrube, ïber deren Vordertheil die helle, schwarz gesäumte Querlinie hinweggeht. Bis zu dieser Grube herauf reicht rom Innenrande aus ein breiter, weisser Raum, der sich einwärts an die erste Querlinie anschliesst und auswärts ungleichmässig und fleckartig mit etwas rauhen, schwarzen Schuppen begrenzt wird. Jeder der 2 Medianaderäste, die rom oberen Rande dieses weissen Raurues ausgehen, bildet eine feine, schwarze, bis nahe an die hintere Querlinie reichende Linie. Die hintere Querlinie verläuft in der Mitte zwischen dem weissen Fleck und dem Hinterrande, ist wellig gezähnt, weisslich, doch nach oben ins Graue, einwärts scharf schwarz gerandet, auswärts von einem röthlichgrauen Gewölk begleitet, das an ihrer schärfsten Ecke (bei $2 / 3$ ) sich am meisten verdünnt. Die Hinterrandlinie wird durch tiefschwarze, einander fast berihrende Strichelchen gebildet. Fransen grau, auf der Endhälfte dunkler.

Hinterflïgel an Vorderwinkel stärker abgerundet als bei Militella, am Inneuranddrittel bleichgelblich, ïbrigens dunkelgrau und reichlich mit braunen, länglichen Schuppen bestreut; die Medianader mit ihren Aesten tritt durch bräunliche Färbung etwas hervor. Hin erraudlinie dunkelbraun fein, den Analwinkel nicht erreichend. Fransen grau.

Unterseite der. Vorderflïgel vraungrau, am Innenrande breit bleichgelblichgrau; längs des, wie bei Militella bis $3 / 4$ der Länge umgebogenen Vorderrandes sitzt ein dicker Polster aus langen, am Ende erweiterten, blonden Schuppen, die sich einwärts überlegen, und die Läıgsgrube völlig verdecke». - Hinterfiugel bleichgelblichgrau, am Vorderrande breit weisslich mit biauner Bestäubuıg; in einiger Eutfernung vom Hinterrande geht vom Vorderrande eine briunliche Querlinie, die aber schon beim ersten 
Aste der Medianader ganz verschwindet. Die Hinterrandlinie ist vorlanden auf allen Fliigeln, am stärksten auf den vorderen, doch auch bier etwas verloncheu.

Vaterland: Texas (Boll). 1 schönes $\sigma$ im Cambridger Museum.

Nephopterya cousobrinelln 11. sp. tab. III, fig. 22.

Fronte palpinque albidis, thorace rufescente; alis ant. elongatis, basi rufescente, ceterum cinereis, strigis 2 duplicatis (priore nebula nigricante transverse obducta) strigulaque venae transversae nigris. $\sigma$.

Diese ansehnliche Art hat am meisten mit unserer Pempelia adelphella Aelunlichkeit, ist aber durch ihre mit keinem Haarpinsel versehenen Maxillartaster generisch verschieden, ausserdem durch den fast fehlenden Schuppenwulst in der Fiihlerbiegung und anf den Vorderflïgeln dadurch ausgezeichnet, dass die erste Doppellinie fast in der Mitte, statt vor derselben liegt, und die Querader statt 2 Punkte eimen starken Strich trïgt. Die kleinere Pempelia formosa, die auch eine gewisse obertächliche Aehnlichkeit mit Consobrinella hat, stimut mit dieser in der Lage der Doppellinie und dem Queraderstrich; sie hat aber ein lebhaferes Roth an Innenrande; das schwarze Gewölk, das ïber die doppelte Qurlinie hinwegzieht, ist dunkler und breitet sich vor ihr am Innenrande viel weniger aus, und die schwarze Hinterraudlinie ist nicht zusammenhängend, sondern durch die Adern in grobe Punkte zerschnitten. Keine dieser 2 europäischen Arten hat ein weissliches Gesicht und weissliche Taster. Beides zeigt die aordamerikanische Nephopt. (?) basiluris. Bei dieser sind aber Rückenschild und Basalfeld der Vorderfligel röthlichweiss, letateres am Innenrande mit groben, schwarzen Schuppen bekleidet; die erste Querlinie erreicht nicht den Vorderrand, die 2. ist ganz verblasst, sägezähnig und weiter von der ersten entfernt. Der Hinterrand ist nur mit einigen Punkten, die Querader statt des Querstriches mit 2 verloschenen Punkten bezeichnet; die Hinterfliggel sind heller und durchsichtig. - Nephopt. rhenellu, neben welche Consobrinella vorliufig gestellt werden mag, hat uur durch die röthliche Vorderflügelbasis eine entfernte Aehnlichkeit mit ihr. Bei Rhenella ist der Fühlerknoten stark, Kopf- und Rückenschild dunkelgrau; die beiden Doppellinien stehen sehr weit auseinander; die Querader hat 2 Punkte, die Hinterrandlinie ist gewöhnlich in Punkte anf'gelöst.

Grösse einer grossen Neph. rhenella. Rückenschild und Hinterkopf röthlich. Gesicht weisslich. Taster weisslich, von doppelter Kopflänçe, durch die Bekleidung stark verdickt. zusammengedriickt und aufgebogen; zweites Glied, ausser an der Wurzel, auswendig dunkelgrau bestïubt; Endglied kaum halb so lang, glattschuppig, etwas plump, aufgerichtet, und fast eine Gabel mit dem Ende des vorhergehenden Gliedes bildend. Maxillartaster an der Stirne anliegend, länger als das 3. Lippentasterglied, 
keulenförmig, grau, dunkler bestäubt. - Fühler mit hellröthlichem, vorn weissem Wurzelgliede; Gejssel bräunlich, kaum pubescirend, über dem Wurzelgliede etwas gebogen und flachgedrückt und auf dem Rïckeı tief schwarz beschuppt, aber ohme Schuppenbusch. - Beine hellgrau, die vorderen auf der Lichtseite gebräunt; die Mittelschienen flachgedriickt und bei $3 / 4$ mit schwarzem Bändchen, die Hinterschienen noch breiter, flach, mit 2 breiten, schwärzlichen Bäudern, alle Füsse schwärzlich mit weissgranen Enden der Glieder. Hinterleib an der Wurzel der Segmente braungrau, auch am Bauche, sonst bleich ochergelb.

Vorderfingel 6" lang, schmal, nach hinten schwach erweitert, am Vorderrande hinter der Mitte etwas convexer als bei Rhenella. Grundfarbe am Basalviertel hellroth, am Vorderrande weisslicher, von da ab grau. Die beiden Querlinien schwarz, doppelt; die erste fast in der Flïgelmitte, oberwärts etwas nach inmen geneigt, mehrere Winkel bildend, am unteren Drittel weisslich ausgefüllt; am oberen Ende ist die Ausfïllung durclı die schwärzliche Wolke verdunkelt, welche vom Innenrande aus schräg über sie hinwegzieht; diese Wolke ist am Imenrande durch die Doppellinie und das röthliche Basalfeld, dessen Breite sie lıat, hegrenzt. Die 2. Doppellinie, ron keinem Scluatten begleitet und nur grau ansgefüllt, zieht fast mitten zwischen dem schwarzen Strich der Querader und dem Hinterande und endigt am Innenwinkel; sie ist etwas gerähnelt und bildet bei $2 / 3$ einen vinspringenden Winkel. Das Mittelfeld, am Dorsaldrittel hell, zeigt auf der weisslichen Subdorsalader cinen schwarzen Längsstrich und den Raum darïber bis zur Falte hellröthlich. Unterhalb des Queraderstriches haben die 3 Aeste der Medianader schwarze Anfänge. Die Hiuterandlinie ist stark, ununterbrochen, titf schwarz, erreicht aber nicht die Flügelspitze und verdünnt sich zum Innenwinkel. Fransen hellgrau, mit dunkler Schattenlinie hinter der gelblichen Wurzel.

Hinterflïgel etwas durchscheinend, bleichgelblich, am Vorderrande und in der Spitze graubräunlich angelaufen. Die braune Hinterrandlinie verschwindet weit vor dem Analwinkel. Fransen grauweisslich, sonst wie an den VorderAügeln.

Unterseite der Vorderflügel dunkelgrau mit schwarzer Hinterrandlinie und verloschener, hinterer Doppellinie, die nur au Vorderraude stärker ausgedrückt ist. Hinterflügel heller, als auf der Oberseite, an Vorderrande schmai gebräunt und gegen die Spitıe mit dem Anfange eines bald verschwindenden, braumen Querstreifens.

Vaterland: Texas (Boli). 1 o im Cambridger Museum

Anmerkung. Von der oben erwälınten, schönen, neuen \eph. (?) basilaris (Taf. III, Fig. 23) besitze ich nur 1 \&, so dass ich über die Gattung in Ungewissheit bin, und eine vollständige Beschreibung unterlasse. Ihre lıauptsächlichen Verschiedenheiten von Consobrinella sind angegeben. Da sie keiner sehr veräıderlichen Art anzugehören scheint, so 
wird sie bei ihrer ausgezeichneten Fïrbung wohl nicht schwer zu erkennen sein. Ihr Flïgelbau ist nicht sehr von dem der Consobrinella abweichend, Riickenschild und Hinterkopf blass ochergelb; Stirn weisslich, wie das Wurzelglied und das unterste Drittel der Füluler. Taster kürzer als bei Consobrinella, weisslich, auswärts grau bestäubt; Endglied sehr kurz, doch hervorstehend. Mittelschienen flach, weisslich mit schwarzen Fleck bei $3 / 4$, Hinterschienen weniger flachgedrïckt, weissgran mit 2 schwärzlichen Flecken. - Vorderflïgel im Wurzelfelde wie das Rückenschild gefürbt, am Innenrande tief schwarzbraun beschuppt. Die erste fast senkrechte, weissliche Querlinie hört weit vor dem Vorderrande anf, und ist zweimal winkelig gebrochen; sie wird auf der Basalseite breit (doch lange nicht so breit, wie bei Consobrinella), auf der Aussenseite schmal schwarz gerandet, welche Farbe sich oberlialb bis zum Vorderrande fortsetzt. Die 2 Mittelpunkte sind weit getrennt und sehr verloschen. Die 2. Querlinie steht sehr weit von der ersten ab, ist dem Hinterraude ungefähr parallel und selır verloschel, gezähnelt, auf der Basalseite in jeder Auszähnung mit einem schwärlichen Punkte auf der Aussenseite von einem schwachen, dunkler grauen Schatten begleitet, der sich ïber dem Innenwinkel in einen röthlichochergelben Fleck verwandelt. Am Hinterrande liegen einige schwarze, weit getrennte Punkte, die auf der einfarbig grauen Luterseite fast nicht zu erkenuen sind.

Vaterlaud: Massachusetts, wo Burgess das schöne Exemplar an 8. Juli fing:

\section{Zophodia Bollii n. sp. Tab. III, fig. $21 a, b$.}

Robusta, antennis breviter pectinatis, thorace griseo, postice nigro; alis ant. elongatis, cinereis, antice albis, strigis 2 nigris (priore semel acute fracta, posteriore geminata serrato-angulata), strigula venae transversae nigra infra incrassata; posterioribus albis, in disco opalizantibus. o $\%$.

Eine der allergrössten Phycideen, von einer gewissen Aehnlichkeit mit Convolutella, ansgezeichnet durch verdickte Taster und wulstige, hinten aufgeblähte Beschuppung der Schulterdecken.

Kopf braungrau, hinten hell. Fiihler bräunlich, auf dem Rïcken weisslich beschuppt, mit kurzen, gedrïngten, allmälig an Länge abnehmenden Kammähnen, die beim 9 nur die halbe Länge haben, aber wie beim ơ am Eude der Fühler in Zähuchen übergehen; das dicke Wurzelglied reicht bis nahe an den Rand des Ilinterkopfes, und der schwer aufzufindende Ocellus steht dicht an der Fühlerwurzel. Die ranhschuppigen, braungrauen, dicken, zusammengedriickten Taster sind kürzer, als das Rïckenschild; die Schuppen des ersten Gliedes längen nach unten buschförnig verlängert, die des 2., läng*eren bilden gleichlalls einen Busch am 
Ende; das 3., weit kiirzere, ragt rom lorizontal, verdickt und abrestumpft liervor. Die Maxillartaster sind kurz, zusammengedrïckt, locker bescliuppt, oben etwas weisslich bestäubt, oberlalb des zweiten Gliedes der Lippentaster an der Stirne liegend. Saugrissel hormgelb, obenauf weissgrau bescluppt. - Rückenschild dick und kräftig, oben mit dunkelbraungrauen Schuppen dicht bekleidet, auf dem Schildchen mit 2 schwarzen, in einanderfliessenden, lockeren Schuppenwiilsten; die starken, hinten lang- und lockerschuppigen Schulterdecken sind vor dem hellgranen Ende bandartig schwarz. Brust dicht weiss schuppenhanig. Die kräftigen Beine mit dunkelbraunen Füssen sind auf der Aussenseite weiss, die Mittelschienen vor der Spitze, die Hinterschienen ïber der Basis mit einem schwarzen Bändehen geziert; die letzteren sind kurz, auf dem Riicken, vor dem Anfange des Bändchens mit einem Haarschupenbusch; die Sporen braum. Hinterleib dick, weit über die Hinterflügel hinausreichend, etwas flach, hellgelblichgrau, an der Wurzel des 2. Segmentes schwarz; Bauch braungrau, gegen die Wrurzel hin schwärzlich.

Vorderfügel 9, bei dem wohl meistens grösseren \%, bis $10^{\prime \prime \prime}$ lang, gestreckt, nach hinten sanft erweitert, am Hinterrande gegen den Innenwinkel sehr convex. Grundfarbe an der schmäleren Costalhälfte wciss, an der breiteren Dorsalhälfte mehr oder weniger dunkel staubgran, welche Farben sich nicht scharf scheiden. Die Zeichmungen sind schwarz und scharf. Die erste, feine Querlinie entspringt bei $1 / 4$ des Vorderrandes, und geht gerade und sehr schräg bis zur Falte, von wo sie unter einem spitzen Winkel in concavem Bogen nach dem Innenrande zielıt; einwärls ist sie weisslich gesäunt, und diese Einfassung von einer schattenartigen Linie begrenzt. Auf der Querader ist ein dicker, unten verdickter, selbst kegelförmiger Strich. Die hintere Querlinie, mitten zwischen dem Queraderstriche nnd dem Hinterrande, ist fein, scharf sägeartig, und erst auf der Höhe des Queraderstriches, dann in der Falte einwärts wiukelig; sie wird hinter einer weisslichen Einfassung von ciner melı verflossenen, schwärzlichen Linie begleitet; letztere nähert sich gegen den Vorderrand der Hauptlinie, und hier wird sie selbst dunkler sihwarz. Den Hinterrand umzieht ejne Reihe starker, schwarzer Punkte, die am Inuenrande mehr zu kurzen Linien werden, und bei einem ox grösstentheils zu einer Randlinie zusammentliessen. Fransen grau.

Hinterflïgel wie bei Convolutella gegen die Spitze verlängert, weiss, im Mittelraume opalisirend, am Vorderrande und gegen die Spitze gebräunt; die bräunliche, mehr oder weniger deutliche Hinterrandlinie verschwindet vor dem Analwinkel.

Unterseite der Vorderfligel branugran, gegen die Wurzel heller; ein vom Vorderrande vor der Spitze herabgehender Strich und die Hinterrandlinie sind dunkelbraun. Hinterflügel weiss, längs des Vorderrandes mit bräunlichem Schatten; beim \& wie aut der Oberseite. 
Vaterland: Texas; beide Geschlechter, die man nach ihrer Unversehrtheit für gezogene halten sollte, wurden wach Hagen's Notizen ron Boll im August und September am Köder in Mehrzahl gefangen.

\section{Gen. Anerastia.}

An hierhergehörigen Arten scheint Nordamerika durchaus uicht arm zu sein; ich habe eine Anzahl Anerastien von Belfrage erhalten, die sicher zu mehreren Arten gehören, leider aber alle kläglich ahgeflogen sind, so dass ich sie nothwendig iibergehen muss. Sichere Arten, die sich kenntlich machen lassen, sind folgende:

\section{An. tedradella $11 . \mathrm{sp}$.}

Alis ant. angustis, ochraceo-griseis, vitta costali postice angustata allida, venis omnibus longitudinalibus albidis, nigricanti-marginatis. के

In der Grösse veränderlich, kleiner als die südeuropäische Vulneratella, das $\sigma^{\lambda}$ meistens viel grösser, als das $\boldsymbol{\Upsilon}$. Sie ist an der weisslichen, gegen die Spitze zwischen den Adern etwas grau bestäubten Costalstrieme, vorzüglich aber an deı dïmen, weisslichen, braunschuppig gesäumten Adern zu erkemen. Da auch bei der ostindischen Sceletella die Adern sehr deutlich und feil hervortreten, so sei hier nur erwähnt, dass diese zu den grössten Arten der Gattung gehört, eine blassrothe Grundfarbe hat, in welcher die Adern in noch weit höberem Grade sichtbar sind, und einer Costalstrieme gänzlich entbehrt. Bei unserer Lotella, die erheblich grösser als Tetradella ist, bilden die brann bestäubten Adern gröbere und weniger weisse Linien.

Kopf- und Rückenschild bleich ochergelb. Stirnkegel kurz und zugerundet. ơ Fühler gekerbt, pubescirend, bleich ochergelb. Taster von mehr als Rückenschildslänge, horizontal vorgestreckt, allmälig zugespitzt, einwärts bleichgelblich, auswärts grau, am unteren Drittel mit einer recht abstechenden, weissen, rou der Wurzel bis zum Ende des 2. Gliedes reichenden Strieme. Saugrïssel auf dem Rücken weisslich beschuppt. Schulterdecken ein wenig dunkler als das Rückenschild. Beine blass grauochergelb, mit helleren Füssen, die vorderen auf der Lichtseite gebräunt, die Hinterschienen zusammengedrückt. Hinterleib obenauf ochergelb, am Bauche weisslich. Der Legestachel steht nur wenig hervor.

Vorderflïgel $4-3 \frac{1}{2}$ " lang, gestreckt, nach hinten schwach erweitert, mit schwach convexem Vorderrande, abgerundeter Spitze nnd sebr convexem Hinterrande. Grundfarbe hell ochergelblichgran, in Dorsalranme bis zur Falte reiner, blass ocherfarbig. Der Vorderrand wird bis zur Subcostalader von einer nach hinten etwas verdïunten, weisslichen Strieme eingenummen, die gegen die Spitze zwischen den Adern mehr oder weni- 
ger deutlich granbestäubt, und auf dem Vorderrande selbst an der Schulter mit einer kurzen, braunen Linie gezeichnet ist; sie hat gegen die Flügelfäche keine dunklere Einfassung. Alle in den Hinterrand miindenden Adern, sowie eine Liuie in der Falte, sind weiss und zu beiden Seiten wit schwarzbraunen, zerstreuten Schuppen gesäumt; die Medianader bildet die stärkste weisse Ader, ist, ausser an ihren Aesten, nicht braun gesäumt, und erreicht nicht als weisse Linie die Flïgelbasis, sondern lıört verdüunt beim Anfange des 2. Viertels der Länge auf. Ebenso reicht auch die weisse Färbuug der Subdorsalader nicht bis zur Wurzel. (Bei dell meisten Belfrage'schen Exemplaren sind die schwärzlichen Schuppen ganz abgeflogen, und auch die weissen, abgeriebeleu Adem wenig sichtbar, und nur unter der Lupe zu erkennen. Die breiten Franseu sind grau und dunkel bestäubt).

Hinterflügel bleichgelblich, in der Spitze in grösserer oder geringerer Ausdehuung schwach grauschattig; die Hinterrandlinie blassbräunlich.

Unterseite der Vorderflïgel bräunlichgrau, mit dünner, gelblicher Costallinie, die nicht bis zur Basis reicht.

Vaterland: Texas (Boll, Belfrage). Mehrere ơ und $O$ fing Belfrage in der ersten Hälfte des Juni, 2 ○ am 8. und 9. Juli.

\section{Aner. glareosella n. sp.}

Alis ant. minus elongatis, caesio-griseis, ubique squamis fuscescentibus adspersis, vitta costali lata albida, postice sensin magis dilatata. $\mathbf{Q}$

Nur 1 9, aber so abweichend vou den anderen wahestehenden, dass ich es zu beschreiben wageu darf. Die Flügel siud kürzer als bei den anderen Anerastien, die vorderen am Vorderrande merklich convex; ihre weissliche Vorderrandstrienue ist auffallend breit, nach hinter sogar erweitert, einwärts ohue scharfe Begrenzung, und wie die ganze Fläche mit bıäunlicheu Stäubchen bestreut.

Kopf und Rückenschild grau, die Schulterdecken, sowie die Aussenseite der 'Taster schiefergrau. (Der Stirnkegel ist abgerieben). Die Taster haben die Länge des Rückeuschildes, und sind horizontal vorgestreckt, zugespitzt, wie die Fühler hell gelblichgrau, am Wrurzelgliede und unterwärts weiss. Saugrüssel sehr versteckt. Beine gelblichstaubgrau. Hinterleib ochergelb mit hellerem Bauche und eingezogenem Legestachel.

Vorderflügel fast 4" $^{\prime \prime}$ lang, kïrzer als gewöhnlich im Genus (wie bei Ematheudes punctella) mit goleichförmig sanft couvexem Vorderrande, zugerundeter Spitze und convexem, in deu abgerundeten Imenwinkel übergehendem Hinterrande. Grundfarbe violettlichgrau, am dunkelsteu ïber der Falte als Einlassung der Yorderrandstrieme von der Wruzel aus. Die sehr breite, weissliche Vorderrandstrieme, die nur von der ITurzel aus gegen die Grundfarbe scharf absticht, wicd allnälig breiter. und erreicht in dop- 
pelter Breite, die fast die halbe Flïgelbreite einnimmt, den Hinterrand. Sie sowohl, wie die ïbrige Fläche ist mit bräunlichen Schuppen bestrent, besouders reichlich nach hinten. Die Adern treten gar nicht herror; auch ist nirgends ein Punkt oder Fleck vorhanden. Fransen grau.

Hinterllïgel mit ziemlich stumpfer Spitze, gelbweisslich, etwas durchsclueinend.

Unterseite der Vorderflügel bränulichgrau, ohne helle Ränder. Hinterflïgel etwas grau, besonders am Vorderande.

Vaterland: Texas, wo Belfrage mein Exemplar am 15. August gefangen hat.

A umerkung. Zwei viel kleinere O mit spitzeren Hinterflügen, von Belfrage im August gefangen, und ein ebenso kleines o mit abgerundeter Hinterfliigelspitze, haben gleichfalls eine sehr breite Custalstrieme der Vorderflïgel, sind aber durch die unglückliche Belfragesche Fangmethode so beschädigt, dass sich von ihnen un sagen lässt, dass sie, wenn nicht zu 3, doch bestimmt zu 2 verschiedenen Arten gehören, von denen keine mit Glareosellu zusammenfällt.

\section{Aner. binotella $\mathrm{n} . \mathrm{sp}$.}

Alis ant. angustis, pallide ochraceo-griseis, vitta costali postice coarctata albida, punctis 2 fuscis venae sublorsalis, altero ante medium, altero ante angulum dorsalem. $\sigma^{7}$.

Auch diese kleine Art wage ich nach einem Belfrage'schen Exemplare aufzustellen, weil die 2 dunkelbraunen Punkte auf der Dorsalader der Vorderflügel so aufiallend sind, dass sie daran wohl stets zu erkennen sein wird.

Kopf und Rückenschild bleich ochergelb. Taster etwas kürzer als das Rückenschild, etwas dick, mit abgestumpltem Endgliede, innen gelblichweiss, aussen gelbbraun, nur ganz an der Wurzel weisslich. Maxillartaster sehr fein, kurz, aufliegend. Füßler borstenförmig, über dem Wrurzelgliede ein wenig gebogen, letzteres gelbbraun, mit weissem Längsstrich am Rande. Beine bleich ochergelb. Hinterleib volergelb; Afterbusch hell, zwei länglichrunde Genitalklappen entlıaltend.

Vorderflïgel $3^{\prime \prime \prime}$ laug, schmal, nach hinten schwach erweitert, mit abgerundeter Spitze und convexem Hinterrande, der in den gerundeten Innenwinkel übergeht. Grundfarbe bleich ochergelb, in der Falte in einem Läugsstreifen und in einer von der Querader bis zum Hinterrande gezogenen Linie, wenn auch nicht besonders hervortietend, am reinsten. Am Vorderrande zieht eine ziemlich breite, gelblichweisse Strieme, die sich von der Querader au verengt, und spitz vor der Fliigelspitze endigt, einwärts aber nirgends dunkel gesäum ist. Die Subdorsalader trägt vor der Hälfte 
und dicht ror dem Innenwinkel je einen starken, auffillenden, schwarzbraunen Punkt. Oberhalb des letzteren ist der Flïgelraum auch am Ende der Costalstrieme, mit einigen feinen, braunen Stätibchen bis zum Hinterrande bestrent. Fransen hellgrau.

Hinterflügel bleich, weisslichgelh, etwas gläızend, olıne dunklere Einfassung.

Unterseite der Vorderflügel hell lehmg*lblichgrau, seidenglänzend.

Vaterland: Texas. Belfrage fing das Exemplar am 12. Juli.

\section{Aner. harmatica n. $\mathrm{sp}$.}

Talpis collarique sordide sanguineis, alis ant. elongatis, postice sensim dilatatis, fuscescenti-sangnineis, dorso pallide ochraceo, ritta costali exalbida, postice acuminata, interius fusco-marginata. ot?

Grösser als die vorigen, kenntlich an der hell blutsothen am Innenrande gelblichen Gruilfarbe der Vorderflügel und an der wach hinten zugespitzten, gelblichweissen, einwärts gerandeten Vorderandstrieme. (Doch gibt es sicher noch mehrere ähuliche Arten, s. die Ammerkung.)

Kopf mit ganz kurzem, abgerundetem Stirnkegel, ochergelblich. Taster etwas kïrzer als das Rückenschild, etwas dick, zusammengedrïckt, mit diinuerem, fast spitzem Endgliede, auf der Aussenseite mehr oder weniger dunkel sclınutzig blutroth, an der Wurzel in veränderlicher Länge hellgelblich, anf der Innenseite gelblich. Saugrüssel vorhanden, aher selır klein und versteckt. Fiihler hellgelblicl, pubescirend gefranst, ïber dem Wurzelgliede anf dem Riicken etwas ausgehöhlt und rauh. Kragen an der Seite röthlich; Rïckenschild heh ochergelb. Beine schiefergrau; Hinterschienen zusammengedrückt, anf dem Rïcken mit einenı Ha)rschuppenkanıme. Hinterleib oclıergelblich, anf der Hinterlı̈̈lfte grau, am Bauche noch dunkler; Afterbusch hell; Legestachel stark, kurz, hervorstelwnd.

Vordertlïgel o $\mathbf{4}^{1} / 4, \quad$ - $4-3^{1} / 2^{\prime \prime}$ lang, schmal, nach hinten erweitert, mit abgerundeter Spitze und convexem Hinterrande, bell blutroth, mely oder weniger rein, gegen den breit hell ochergelben Innenrand hin etwas blässer. Am Vorderrande ist eine ziemlich breite, weishlichgelbe Strieme, die sich allmälig scharf zuspitzt, und in den bräunlichcu Costalfransen vor der Flïgelspitze endigt; sie ist einwärts in gerader Linie scharf schwarzbraun, schmal gesäumt, und dieser Saum bildet eben in seiner etwas verdickten Fortsetzung die dunkle Stelle in den Costalfransen hinter der Spitze der Strieme. Die Schulter ist in einer kurzen Linie, von verïnderlicher Deutlichkeit schwarzbraun. Die Fläche der Flïgel hilt keine stärkereu dunklen Punkte. Fransen gelblichgrau.

Hinterflügel mit herrortretender Spitze, hellgran, in der Flïgelspitze verdunkelt; Eransen lıeller, als an den Vorderfligelı, stark abstechend gegen die Flïgelfarbe. 
Unterseite der Vorderfligel grau, in der Mittelzelle am dunkelsten, mit etwas heller durchscheinender Costalstrieme. Hinterflïgel läıgs des Vorderindes verdunkelt.

Diese Art erhielt ich mit der Benennung Ilithyia carmen von New York und aus Massachusetts; 1 o und 19 find Burgess bei Beverly an 27. Juni.

A umerkung 1. Ein grösseres, schönes ö, von Packard wahrscheinlich aus Massachusetts erhalten, ist der Muematica ganz gleich, hat aber dünnere, längere, anscheinend unversehrte Taster ron bleichgelber Farbe, am 9. Gliede auswärts mit braunem Längsstreif bis ans Ende. Die Costalstrieme ist ziemlich reichlich mit braunen Stäubchen bestreut, und die schwarze Einfassung derselben ist am Ende stärker erweitert. - Ferner habe ich aus Texas ron Belfrage ein an 20. Mai gefangenes ơ und ein sehr kleines Pärchen vom 15. und 25. Angust, die zu 2 besonderen Arten zn gehören scheinen, welche sich vou Hacmatica durch kiirzere Taster unterscheiden, sich aber wegen ihrer unrollkommenen Conservatiou nicht beschreiben lassen.

Anmerkung. 2. Ich mache woch auf beschriebene Arten unter den Anerastien mit ähnlicher Färbung und Zeichnung anfmerksam: Lotricella und Deliquella in Brasilien, Sabuletella im südlichen Africa, Opificella und Laterculella in Ostindien, die wohl alle noch mit reichlicherem Materiale zu untersuchen und fester zu umgrenzen siud. - In anderen Phycideengattungen sind gleichfalls der Haematica ähnliche Färbungen bekannt. Abgesehen vou der Varietit, Sanguinella H. Fig. 65 der Pempelin carmella L., gibt es deren 3 in der Gattung Myelois aus dem südöstlichen Europa, über die ich hier etwas sagen zu nuissen glaube. Die kleine Myel. deserficola Stagr. (mit 3theiliger Medianader der Hinterflügel) ist wegen ihrer graurothen Vorderfiïgel nit einwärts nicht scharf begrenzter Costalstrieme der Haematica etwas weniger älulich, als die grössere Myel. albicostu Stdgr., bei welcher die Strieme durch dunkles, streifenartiges Braun von der röthlichgranen Flägeltïche geschieden ist (die Strieme ist schmal und verschmälert sich gegen ihr Ende, welches die Flügelspitze $n$ i ch t völlig. erreicht. Das Riickenschild ist ganz einfarbig rothgrau, der Kopf etwas heller, im Gesichte und in einer sehr feinen Linie des oberen Angenrandes gelblichweiss. Die Tister von doppelter Kopflänge sind fast gerade, ziemlich stark behaart, stark zusammengedrïckt, mit kurzem, kegelförmigen, glatten Endgliede; hell röthlichgrau, auf der Innenseite bleichgelb. Saugrüssel stark, gelblichweiss beschupt. Fühler in beiden Geschlechtern borstenförmig, beim ơ mikroskopisch pubescirend, hellbräinlich. Die Medianader ist 3 theilig).

lhr nahe stelit: 
Myel. ciliatella n. sp. aus Sarepta.

Antennis of pubescenti-ciliatis, thorace rubescenti alboque mixto; alis ant. angustis, cinereo-rubris, vitta costali alba, ante alae apicem acuminata, dorsi linea basali angusta alba; posterioribus albis, vena mediana trifida. ơ.

Von der Grösse der Albicosta, von dieser durch die angenehm grauröthliche Grundfarbe der Vorderflïgel und die ganz weissen Hinterflïge], vorzïglich aber durch die sehr merklich gefransten o Fühler leicht und sicher zu unterscheiden. - Rïckenschild hellroth, am vorderen Aussenrande der Schulterdecken und unter der Mitte des rothen Halskragens weiss. Kopf röthlichweiss; der obere Augenrand mit reinweisser Linie umzogen. Taster von $1 \frac{1}{2}$ maliger Länge des Kopfes, etwas aufgebogen, zusammengedrïckt, reichlich behaart, weisslich, auswärts röthlich, doch mit weisslichen Haaren an der Unterseite; das glatte Endglied ganz klein, kuosperförmig kaum aus den Schuppen des 2. Gliedes hervorragend. Saugriissel stark, auf dem Rücken weisslich beschuppt. Fübler borstenförmig; hellbräunlich, mit zarten Haaren, von ansehulicher Länge, die aber allmälig kiirzer werden, und das Fühlerende nicht erreichen, in 2 Reilien gefranst; Wurzelglied, stark, weisslich, auf der Rückenseite röthlich. Beine rothgrau bestäubt; Hinterschienen ziemlich dümn, auswärts schwach grau bestäubt; Hinterfüsse gegen das Ende dunkler grau. Hinterleib grauweisslich, das erste Segment weiss und in der Mitte hell bramroth.

Vorderflïgel $5^{\prime \prime ~ l a n g, ~ s c h m a l, ~ n a c h ~ h i n t e n ~ s t a r k ~ e r w e i t e r t, ~ a n ~ d e r ~}$ Spitze zugerundet, mit schwach convexem Hinterrande, grauroth, längs der Vorderrandstrieme am gesättigtsten, gegen den Innenrand gelichtet und mehr ins Graue, besonders gegen den Innenwinkel. Die weisse Costalstrieme ist schmal, über der Querader fast unmerklich erweitert, dann zugespitzt und die Flïgelspitze nicht erreichend. Die Schulter ist in einer äusserst feinen, kurzen Linie bräunlich. Der Innenrand ist von der Wurzel aus bis zu seiner Hälfte in einer dünnen Linie weiss. Auf der Querader ist die Grundfarbe kaum ein wenig rerdunkelt. Hinterrand ohne Punkte. Fransen blassroth.

Hinterflügel weiss, am Vorderrande, in der Flügelspitze und ganz schmal am Hinterrande grau beschattet; auch die Median- und Subcostalader mit ihren Aesten treten durch schattengraue Beschuppung etwas hervor. Fransen weiss, an der Wurzel rou einer grauen Linie durchzogen.

Unterseite der Vorderflügel braungrau, am Hinterrande hellgran. Die bleichgelbliche Costalstrieme ist deutlich und vor ihrem Ende erweitert. Fransen blass rosenfarbig. Hinterflügel weiss, am Vorderrande breit striemenartig grau.

Noch eine ähnliche Art is die folgende: 


\section{Epischmin forvella Curtis.}

Alis ant. angustis, inteo-cinereis, vitta costali ad apicem nsque perducta alba, postice juxta costam cinereo-pulverulenta, puncto venae transversae nigro, vella subdorsali et dorso squamis nigricantibus conspersis. ơㅇ.

Myclois Lafauryella, Constant. Ann. Soc. ent. France 186. Tab. VII, fig. 1.

Diese Art, welche die nördlichen Küsten Mitteleuropas ïberall zu bewohnen scheint, lebt an der pommerschen auf Anthyllis vulneraria; ihre Raupe erhält man an leichtesten, nachdem sie sich zur Ueberwinterung in eine kleine Sandkugel eingesponnen liat, durch Aussieben des Sandes; im Frühjahre spinnt sie sich ein längliches Gervebe, in welchem sie zur Puppe wird. Dass Farella aucl in Nordamerika einheimisch ist, beweist ein schönes $\vec{\sigma}$, das Burgess am 8. Juni bei Beverly in Massachusetts gefangen hat, und das unzweifelhaft dieselbe Art ist; es unterscheidet sich ron meinen europäischen Exemplaren durch nichts, als seine gewaltige Grösse. (Vorderflïgellänge $6 \frac{1}{4}{ }^{\prime \prime}$ gegen $5^{\prime \prime \prime}$ des grössten pommerschen $\sigma^{\circ}$ ).

Ein 9 dieser Art, welches ich durch Lederer als ungarisch erhielt, trug in meiner Sammlung den provisorischen Namen Resectella. Dies ist also die von Sta udinger in der Berliner entomol. Zeitung 1870, S. 203 bei Myel. albicosta erwähnte Art. Der lange, ans Haarschuppen gebildete Stirnkegel, die langen Taster mit dem zusammengedrïckten, baarschuppigen Endgliede, das die Länge des 2. Gliedes hat, und die viertheilige Medianader der Hinter Aligel unterscheiden Favella sehr von Alucosta.

Der Farella ähnlich ist Epischnia leucoloma H. S. (im Staudinger-Wocke'schen Catalog auch dicht davor gestellt), wenigstens hinsichtlich der längs des Vorderrandes selbst grau bestäubten Costalstricme. Diese reicht nicht bis zur Fliigelspitze, oder verliert sich doch ganz in den grauen Schuppen derselben. Die Grundfarbe der anch etwas kïrzern Vorderflügel ist ohne lehmfarbene Beimischung, bräunlichgrau und reichlich mit groben, weisslichen Schuppen, besonders gegen den Hinterrand, bestreut. Das Rürkenschild ist nicht einfarbig nnd rein lehngelb, sondern weisslich, grau bestäuht. Dabei sind die Taster ganz anders, nämlich zwar aufgehogen und an das Gesicht angelegt, aher das verdinnte, zngespitze Endglied ist kürzer als das zweite Glied uud schnabelartig horizontal vorgestreckt. Mein o Hxemplar, von Lederer ans Lydien mitgebracht, hat Vorderfiügel von g"' Läng*e, ist also noch grösser als meiu o der Frorella aus Nordamerika. Ob H. S. Fig. 126 O, etwas fremdartig ansselıend, gut dargestellt ist, weiss ich nicht, die Costalstrieme 
scheint mir aber zu gelblich und die Hinterflügel zu dunkel und zu glejchmässig gefärbt zu sein.

Galleria inimicella n. sp. Tab. I[1, fig. 20.

Alis aut. infra apicem retusis, in basi ochraceis, ceterum griseis, costa late fusco-umbrosa, strigula ante marginem posticum arcuata brunilea. $0^{x}$.

Sie ist sogleich durch den gebogenen gelbbraunen Querstrich vor dem Hinterraude der Vorderflügel von $G$. mellonella zu unterscheiden, aber au sichersten dadurch als eigene Art charakterisirt, dass der Hinterrand dieser Fliigel unterbalb der Spitze nur bis zu seiner llälfte eingedrückt ist und die Hinterflügel viel stumpfer sind.

Grösse einer mittlern Mellonella ơ. Rïckenschild braungrau; Schulterdecken sehr abstechend blass ochergelb. Kopfhare hell ochergelb. Fühler ziemlich stark, zusammengedrückt, gelbbräunlich; das helle Wurzelglied zwar etwas verdickt, aber ohne zahnartige Verdickung. Beine kräftig, hell ocherfarben, die vorderu auf der Lichtseite gebräunt; die stark zusammengedrïckten Mittelschieneu hier mit einem hellen Bändchen; die besonders breiten, zusammengedrückten Hinterschienen auf der Rückenkante mit längerem und dichterem Schuppenkamm als auf der Bauchkante. Hinterleib brangrau (verölt).

Vorderflügel $\ddot{b}^{1} / \mathbf{z}^{\prime \prime \prime}$ lang, breit (kïrzer und dahes breiter als bei Mellonella), am Hinterraude mit einem gleich unterhalb der Spitze anfangenden und nur bis fast zur Hälfte des Flügels reichenden, seichten Eindruck, unter welchem der Hinterraud stark convex hervortritt, worauf er in sanfter Krïmmung und ohne weitere Ausbuchtung jn den zugeruudeten Innenwinkel ïbergelit. Grundfarbe staubgrau, an der Basis bell ocherfarben, über der Falte in Braunroth ïbergehend, am Innenrande schiefergrau, am Vorderrande sehr breit schwarzbraun beschattet; alle diese Farben ohne scharfe Begrenzung. Die Fläche ist am Innenrande und auf den Aderu mit unregelmässigen Reiłen schwarzer, grösserer und kleinerer Punkte bestreut. Auf dem Vorderrande lassen sich in der dunkelı Färbung schräge, hell und schwarz wechselnde Querstrichelchen durch die Lupe erkenuen. Vor der Ausbuchtung des Hinterrandes liegt auf hellem Grunde ein sehr aufiallendes, rothbraunes, gebogenes Querstrichelchen, hinter dessen oberem Ende in den ochergelben Fransen ein braunes Längsstrichelchen liegt: wälıend sein unteres Ende sich iu die Frausen fortsetzt.

Hinterflügel viel breiter und stumpfer als bei Mellonella, ganz wicklerförnig, die Convexität näher gegen die Flügelspitze als gegen den Analwinkel vortretend; Grundfarbe gleichmässig dunkelbraungrau, die Erausen gelblichgrau nit grauer Linie vor der Wurzel. 
Unterseite der Vorder@ügel dunkelbraungrau mit recht deutlichen dunklern und hellern Querstrichelchen wicklerartig gezeichnet; der bogenförmige Strich vor dem Hinterrande dunkelbraun und an jedem Ende mit einem bramuen Strich in den Fransen, die dergleichen noch zwei am Innenwinkel zeigen. - Hinterlligel grau, besonders an dem gelblichen Vorderande mit verloschenen, dicken Querstrichelchen ziemlich reichlich bestreut. Hinsichtlich des Geäder's ist zu bemerken, dass auf den Vorderflügeln die Mittelzelle nicht so weit gegen den Hinterrand reicht und also längere Adern an den Hinterrand abgibt als bei Mellonella, und dass auf den Hinterflügeln die Medianader sich ganz deutlich nur in drei Aeste spaltet, die freie Ader 5 aber nahe an der Endgabel der Medianader zu entspringen scheint.

Vaterland: Texas (Boll), 1 gut erhaltenes ó im Cambridger Mluseum.

Melissoblaptes fulminulis n. sp. Tab. III, fig. 19.

Thorace albido; alis ant. rufescenti-albidis, strigis 2 nigris, priore ex humero oriente serrato-fracta, posteriore profunde serrata, macula interjecta diffusa nigra. $\sigma^{\top}$.

Dem Habitus nach elier eine Aphomia, zu welcher Gattung sie aber nicht gehören kaın, weil die Mittelzelle der Vorderfügel weit vor dem Hinterande endigt und ziemlich lange Adern in denselben sendet; die Art weicht aber dariu auch von Melissobl. bipunctanus ab, dass diese Zelle riel weiter gegen den Hinterrand reicht und spitz endigt.

Grösse eines mittleren Bipunctanus, doch die Vorderflïgel schmäler und die Hinterflïgel breiter.

Kopf und Rïckenschild weisslich. Fühler fein, borstenförnig, nach der Mitte zu mit deutlich abgesetzten Gliedern, am Wurzelgliede ohne Schuppenzalun. Beine weisslich, viel schlanker und länger als bei $B$ punctanus. Hinterleib ochergelblich, am Wurzelsegment weisslich.

Vorderfliigel $5^{1} / 2^{\prime \prime}$ lang, schmal mit stark convexem Hinterrande, röthlich weiss mit sehr feinen, schwarzhraunen Schïppchen bestreut, mit zwei sehr sägeförmigen, schwarzen Querlinien. Die erste zieht aus der Schulter auf dem Vorderrande hin, worauf sie 4 spitzwinklige Zacken macht, ehe sie den Inmenrand erreicht, von denen der zweite und dritte am weitesten gegen die Flïgelmitte reicht; aus dem Winkel des zweiten geht in der Falte ein brauner Staubstreifen gegen die Flügelbasis. Die hintere Querlinie ist mit mehreren, aber nicht so langen Sägezähnen versehen und macht unterhalb des Vorderrandes eime starke Krïmmung gegen den Hinterrand; sie ist hier deutlich auswärts hell gesäumt, weil der Raum bis zu der aus schwarzen Strichen gebildeten Hinterrandlinie in dieser ganzen Ausdehunng gelblichbraun verstäubt ist. Zwischeu beiden 
Querlinien liegt ein beide fast verbindender unregelmässig viereckiger, schräger; verflossener, in der Mitte heller, schwarzbrauner Fleck in der Mittelzelle. Fransen bräunlichgran mit breiter, duıkler Linic durchzogen.

Hiuterflïgel stumpfer und breiter als bei Bipunctanus, braungrau, an der Wurzel heller. Fransen wie bei den Vorderfügeln.

Unterseite der Vorderfiigel längs des Vorderrandes, am breitesten an der Wurzel ochergelblich. Die Mittelzelle ist mit anliegenden grauen Haaren gefülit, an der Wurzel mit einem langen, niedergelegten, sclıwärzlichen Haarstreifen, iiber den die Haare des Vorderrandfeldes etwas hinüberreichen. Hinterflügel wie oben, nur mit dunklem Fransen.

Vaterland: Texas (Boll), 1 sehönes o im Cambridger Museum.

Psecudia semilugens u. sp. Tab. IIf, fig. 25.

Alis ant. minus elongatis, triente dorsalj albo, vitta costali latissima nigra maculam albam apicalem includente, interius bis iucisa, puncto nigro in priore sinu; ventre ferrugineo, tibiis posticis pallide ferrugineis. $\sigma$.

Offenbar in der westlichen Hemisphäre die Stellvertreterin unserer Bipunctella, verschieden von ihr durch eine andere Ausbuchtung der schwarzen Vorderfligelpartie, den schwarzen freiliegenden Punkt in der ersten Ausbuchtung, den nu am Bauche und au den Seitenränderu gelben Hinterleib.

Kleiner als Bipunctella, so gross wie Haemorhoidella.

Kopf und Rückenschild wejss, dieses anf dem Anfange der Schulterdecken mit 1, in seiner Mitte mit 2 grossen und anf dem Schildchen mit 2 kleinern tiefschwarzen Punkten; der Kopf mit einem grossen solchen Punkt auf dem Scheitel und auch über dem Mundrande schwarz. Fühler schwarz; das Wurzelglied auf der Unterseite weiss, auf der Oberseite mit einer weissen Seitenlinie. Taster wie bei Bipunctella grestaltet, am zweiten Gliede schwarz, imen nach oben weissgefleckt, Endglied weiss. Saugrüssel honiggelb, an der Wurzel anf dem Rücken weisslich beschuppt. Beine auf der Lichtseite schwarz, an den Enden der Glieder weiss, auf der Lichtseite der Schenkel und Schienen weisslich; Hinterbeine an den Schenkeln weiss, an den Schienen hell rostgelb, an den Füssen schwarz mit weissen Enden der Glieder. Hinterleib auf dem Rücken schwarzgrau mit hellern Hinteränderu der Segmente; au den hintersten Segmenten sind die Seitenränder nit rostgelben Haaren eingefasst; Analsegment liellgelb; der gauze Bauch rostgelb.

Vorderflügel $41 / 4^{\prime \prime}$ lang, kürzer als bei Bipunctella, zu meh" als $2 / 3$ schwarz, welche Farbe nach imuen gesättigter wird und in der Flügelspitze einen schärfer legrenzten, aber kürzern weissen Fleck einschliesst. Die Dorsalpartie des Flügels ist weiss und greift vor der Flügelhälfte mit einer kürzeru, hinter derselbeu mit eißer längeru, unregrelmässigen 
Einbuchtung in die tiefschwarze Farbe ein. In der ersten Einbuchtung liegt ein starker, schwarzer Punkt frei da. Den Hinterrand fasst eine Reihe starker, schwarzer Punkte ein, welche bis über den weissen Apicalfleck reicht. Fransen weiss, an der Flïgelspitze geschwärzt.

Hinterflïgel weisslich, gegen den Vorderrand grau, am dunkelsten in der Flïgelspitze. Den Hinterrand begleitet eine weit ror dem Analwinkel verlöschende Reilıe kurzer, schwarzer Striche.

Auf der Unterseite sind die Vorderflügel wie auf der Oberseite gefärbt, nur sehr verloschen; die Hinterfligel weisslich, längss des Vorderrandes mit einer vor der Flügelspitze abgebrochenen schwarzgranen Strieme. Die Randpunkte aller Flïgel sind so dunkel wie auf der Oberseite, auf den Hinterfïgehn noch dunkler.

Vaterlaud: Texas (Belfrage). 2 am 19. April gefangene, schön erhaltene $\sigma$ in meiner Sammlung.

\section{Enaemia n. g.}

Capilli laevigati.

Ocelli mulli.

Antennae setaceae, articuli basalis apice anteriore squamis incrassato.

Palpi labiales filiformes, non arcuati, subobtusi; maxillares nulli.

Haustellum breve, nudum.

Alae oblongae, breviter ciliatae; anteriorum area discoidali cellulam c]ausam continente, venarum ramis simplicibus, venae subdorsalis basi breviter furcata, stigmate nullo; posteriores latitudine anteriores superantes, fovea hyalina basali nulla.

Abdomen mediocre. Pedes mediocres; anticorum tarsi tibiis multo longiores; posticorum tibiae laeves, dorso piloso-squamato, 4-calcaratae.

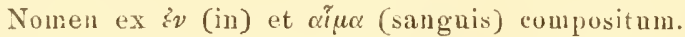

Dass diese Gattung nicht zı Hyponomenta gehört, beweist der Nangel einer verdickten Stelle am Vorderrande der Vorderflügel (Stigma) und der einer kahlen Grube an der Wurzel der Hinterflïgel. Sie mit Psecadia zu vereinigen, verhindert die Kürze des kahlen Sangrüssels und die ganz andere Beschaffenheit der Taster; statt nämlich anfwärts gebogen zu sein mit verdünutem, glattem, zugespitztem Endglied, sind sie gerade, fadenförmig, vorgestreckt, vorn etwas gesenkt, und ihr drittes Glied ist fast dicker als das zweite und nur ganz am Ende ein wenig. zugespitzt. Da.zu kommt auch, dass die ïber der Spitze der Vorderflügel ausgeheude Ader nicht gabelförmig, sondern einfach ist.

1. Enaemia psammitis 11. sp. Tab. III, fig. 26. Ђ’.

Palpis, abdomine alisque posterioribus latericis, alis ant. canis, squamulis elongatis fuscis inspersis. $0^{x} \%$. 
Sehr ansgezeichuet wie die folgende Art durch die ziegelrothe Farbe des Hinterleibes, der ganzen Unterseite aller Flïgel nnd der Oberseite der hintern; ihre hellgranen, braunbestïnbten Vorderflügel unterscheiden sie sehr leicht ron der folgenden.

Kopf und Wurzelglied der einfach borstenförmigen, gelbbräunlichen, beim ơ sehr zart pubescirenden Fühler weissgrau. Taster von Koptlänge, ziemlich dünn, fadenförmig, ziegelroth, auswärts etwas dunkler mnelanfen, besonders am Endgliede; dieses fast so lang wie das zweite Glied, eben so dick, am Ende plötzlich zugespitzt. Rückenschild hellgrau; die Schulterdecken unter dem Halskragen dmkelroth. Beine auf der Lichtseite ziegelroth, auf der abgewendeten Seite hellgrau; die Hinterschienen auf der Rückenkante mit einigen langen, abstehenden Haaren. Hinterleib lebhaft ziegelroth, am Bauche mit einem breiten. weissgranen Lïngsstreif in der Mitte; beim $\sigma^{-}$sind die hintern Segmente am Hinterrande und an der Seite mit langen Schuppenhaaren gefranst, und die Genitalien mit noch läng*ern reichlich eingefasst. Der Legestachel ist eingezogen, mit einem dicken, kurzborstigen Wulst umgeben.

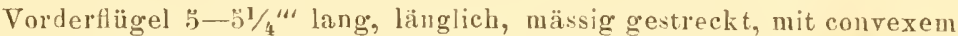
Vorderrande, etwas vortretender Spitze und schrïgem, fast g*eraden Hinterrande. Grundfarbe hellgrau, unregelmässig reichlich mit länglichen, braunen Schuppen bestrent; beim $O$ sind die Schuppen weniger reichlich, und in ganzen Dorsalram gar keine; in diesem Raume hat es zweinal 3 schwarze, zu je eintr geraden Querreihe geordnete Punkte. Die erste so gebildete Querreihe befindet sich beim Anfange des zweiten Flügeldrittels und ist sehr schräg gelegt, oben viel weiter von der Flïgelbasis entfernt als unten; ihr oberster Punkt liegt iiber, die zwei andern unter der k'alte. Die zweite Querreibe ist hinter der Mitte und noch schräger mach aussen gelegt, mit dem Hinterrande parallel; ihr mittelster Punkt liegt in der Falte. Von den 2 joigt das eine beide Punktreihen, aber in zeringerer Grösse und dureh die reichlichern, braunen Schüppchen mehr verderkt, und etwas ïber der zweiten Reihe ist noch ein Punkt anf der Querader. Beim zweiten $\sigma$ ist van beiden Reihen nur der muterste Punkt und auch kaum kennbar rorhandell. Der Vorderrand ist an der Wurzel braunroth. Die ungefleckten Fransen sind heim ö liellgrau, beim Q hellröthlichgran.

Hinterfliigel und ganze Unterseite hellziegelroth, hier nur der Vorderrand der Vorderfïgel in einer feinen Linie weisslicls.

Vaterland: Texas (Boll). 20 , 1 \% in meiner Sammlung.

2. Enathia crassicenella 11. sp. T'ab. 111, fig. 27.

Palpis fuscis, thorace cano, fusco-maculato; abdonine alisque posterioribus latericiis; alis anter. sordide albidis, venis costae et marginis postici incrassaus nigris. 
Etwas grösser als die vorige, durch die strahlenförmigen, schwarzen Aderäste und den Mangel der bräunlichen Schüppchen anf den Vorderflügehn leicht zu erkennen.

Kopf (oben abgerieben) am Hinterrande mit ziegellothen Haarschuppen, im Gesicht weisslich beschuppt. Taster an der Wurzel röthlich, dann, besonders auswärts, dunkelbraun; das Endglied wenigstens so lang wie das Mittelglied. Fühler gelbbräunlich, an der Verdickung des Wurzelgliedes weisslicl. Rückenschild schmutzig weiss; die Schulterdecken am Ende und das Schildchen braun. Beine ziegelroth, die 4 vorderu Schienen und alle Fïsse braun; die Hinterschienen ohne lange Haare. Hinterleib ziegelroth, am Bauch in der Mitte bleichgelblich; der Legestachel in den gelblichen Hornring, den das umgebende Segment bildet, eingezogen.

Vorderflügel $5^{3} / 4^{\prime \prime}$ lang, etwas breiter als bei der vorigen Art, und mit stärker gebogenem Vorderrande. Grundfarbe schmutrig gelbweisslicll. Die Vorderrandwurzel und 5 in den Vorderrand mündende Aderu verdickt schwarz und der Raum von der Wurzel bis zu der dritten grau; die eine in die Flügelspitze und die 4 in den Hinterrand mündenden Adern und das Ende der Falte siud wie die Vorderrandadern verdickt und gefärbt. Auf der Mitte der Subcostalader ist ein schwarzer Längsstrich und auf der Querader ein solcher Punkt. Unterlialb des Anfanges des Subcostaladerstrichs liegt ïber der Falte ein kurzes Läugsstrichelchen, und vor dessen Anfang, von der röthlichen Subdorsalader durchschnitten, ein schwarzes Querfleckchen. Eine Gruppe rou 3 schwarzen Fleckchen zeigt sich noch über dem Iunenrande vor dem Innenwinkel. Fransen weissgrau.

Hinterflügel und ganze Unterseite hellziegelroth; der Vorderrand der Vorderflügel in einer sehr' feinen, vor der Flügelspitze aufhörenden Linie dunkelbraun.

Vaterland: Texas (Boll). Ein schönes $\$$ in Cambridger Museum.

\section{Benennung der Figuren.}

T a fel II.

\begin{tabular}{|c|c|c|c|}
\hline ig. & 1. Nola nigrofasciata & $\begin{array}{r}\text { Seite } \\
. \quad \mathbf{4 5 4}\end{array}$ & Fig. 8. Hypena laciniosa . . \\
\hline "י & 2. Nola melanopa. & .458 & "9. Hypena pallialis. \\
\hline & 3. Nola strictalis. & .459 & 10. Coptocnemia floccalis $a$ Kopf \\
\hline & 4. Thalpochares mundula & .460 & u.Vorderbeine, $b$ Htrbeine 4703 \\
\hline & 5. Agrophila tortricina & .461 & $\leadsto$ 11. a. Sudariophora nasutaria $\$ 90$ \\
\hline & 6. Hypena trituberalis & .469 & $"$ 12. $a, b$. Chalcoëla aurifera . 329 \\
\hline & 7. Mypena achatiualis. & . 468 & "13. reb,r. Dicymolomia decora 331 \\
\hline
\end{tabular}


$\mathrm{T}$ a f e l III.

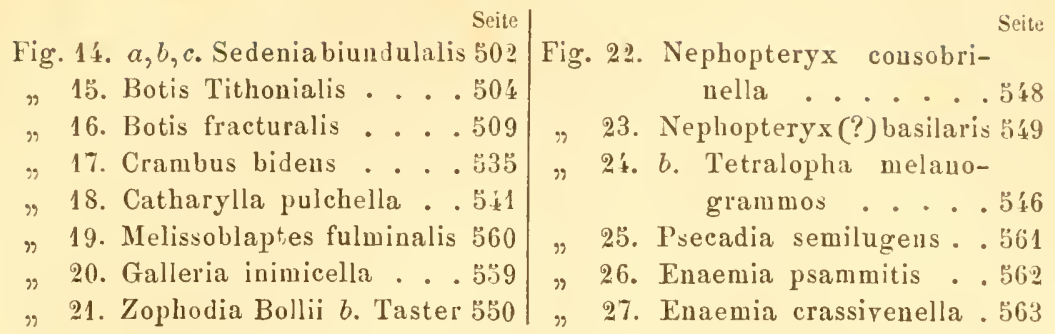

\section{$R$ e g i s t e r.}

\begin{tabular}{|c|c|c|}
\hline Abdominalis Mus. Z. (Botis) & $\begin{array}{r}\text { Seite } \\
. \quad .515\end{array}$ & Costalis F. (Asopia) . . . \\
\hline Achatiualis n. sp. (Hypena) & .468 & Crassivenella n. sp. (Enaemia) . 563 \\
\hline Acutalis Wkr. (Doryodes). & . 490 & Crinitalis Led. (Eurycreon) . \\
\hline Adipaloides Grote (Botis). & .511 & Cuprina n. sp. (Aglossa) . . \\
\hline Aemula Hbn. (Epizeuxis) . & .4 .71 & Deceptricalis u.sp.(Zancloguatha) \\
\hline Aemulataria Wkr. (Macaria) & .487 & Decora n. sp. (Dicymolomia) . . \\
\hline Agitatellus Cl. (Crambus) . & .538 & Decorellus Z ck. (Crambus) . \\
\hline Albicosta Stdgr. (Myelois) & 556 & Deserticola Stdgr. (Myelois). \\
\hline bisigualis n. sp. (Hypena) & . . 463 & Desiguata $\mathbf{B k} \mathbf{h}$. (Cidaria) . . \\
\hline
\end{tabular}
Alboclavellus Z. (Crambus) . .538 Americalis Guen. (Epizeuxis) .4.71 Aurifera n. sp. (Chalcoëla) . . .529 Basilaris n. sp. (Nephopteryx?) . 548 Bidens n. sp. (Crambus) . . . .53ว̈ Binodulalis n. sp. (Asopia) . . .501 Binotella n. sp. (Auerastia) . . 5丂ّ́ Bistriolata n. sp. (Cidaria) . . 493 Biundulalis n. sp. (Sedenia) . .502 Bollii n. sp. (Zophodia) . . . 550 Cereralis n. sp. (Botis) . . .517 Chalcoëla n. g. . . . . 528 Chalybirostris Z. (Crambus) . .539 Ciliatella n. sp. (Myelois) . . .557 Cinerosa Grote (Botis) . . . 505 Citrina Grote (Botis) . . . . .507 Cousimilata n. sp. (Macaria) . 483 Consobrinellan.sp.(Nephopteryx) כ̋ 48 Contiguella n. sp. (Catharylla) • 540 Coptocnemia n. g. . . . . fi:

Dicymolomia n. g. . . . . 530 Elegans Cl. (Crambus). . . . 539 Enaemia n. g. . . . . . 562 Eunusalis Wkr. (Pionea) . . 521 Euphaesalis Wkr. (Botis) . . .511 Farella Curt. (Epischnia) . . 508 Ferrugata L. (Cidaria) . . . 495 Ferruminaria n. sp. (Acidalia) .478 Fimbrialis S. V. (Asopia) . . 498 Flavidalis Guen. (Botis) . . . 513 Floccalis n. sp. (Coptocnemia) . 476 Floridus n. sp. (Crambus) . . .537 Fluviata Hbn. (Cidaria) . . .494 Fracturalis n. sp. (Botis) . . . 009 Frauduleutaria n. sp. (Boarmia) 492 Fulmiualis u.sp. (Melissoblaptes) 560 Galbineata n. sp. (Macaria) . 484 Glaphyralis Led. (Homophysa) . 524 Glareosella n. sp. (Anerastia) . . 553 Gracilis Grote (Botys) . . . 523 
Seite $/$ Seite

Haematica n. sp. (Anerastia) . . 555 Polyactinellus Z. (Crambus) • . . 538

Halesaria n. sp. (Fidonia) . . 488 Praeatomata Guen. (Macaria) . 484

Himonialis n. sp. (Asopia) . . 500 Praefectellus Zck. (Crambus) . . 535

Hyllalis Wkr. (Asopia) . . . 500 Psammitis n. sp. (Enaemia) . .562

Illibalis H. (Botis) . . . . 514 Psilogrammaria n. sp. (Boarmia) 490

Inimicella n. sp. (Galleria) . . 559 Pulchella $\mathrm{Tk}$ r. (Catharylla) . . 5.1

Incautella 1. sp. (Pempelia?) . . 544 Pulchellus Z. (Crambus) . . . 535

Laciniosa n. sp. (Hypena) . . 464 Purata Guen. (Acidalia) . . . 477

Laqueatellus Cl.(Crambus) . .538 Ranalis Guen. (Blepharomastix) 523

Laticlaria Grote (Botis) . . .504 Rantalis Guen. (Eurycreon) . .519

Leachellus Zck. (Crambus) . . 530̈ Rectilinea n. sp. (Eucrostis) . . 480

Lentiflualis n. sp. (Homophysa) . 525 Reniculalis n. sp. (Homophysa) . 526

Lencoloma H. S. (Epischnia) . . $\$ 58$ Rubigalis Guen. (Botis) . . . \$10

Lencostictalis n. sp. (Eurycreon) . 518 Rubirora Riley (Aplodes) . . 480

Lignosella Z. (Pempelia) . . . 544 Rufisignella n. sp. (Catharylla) 542

Lituralis Hbu. (Zanclognatha) . 473 Saligua u. sp. (Colobochila) . . 462

Longirostrellus Cl. (Schoenobius) 533 Semilugens u. sp. (Psecadia) . . 561

Madefactalis Guen. (Iypena) . 469 Serratissimalis n. sp. (Crocido-

Malana Fitcl (Nola) . . . . 4034

Harculenta Grote (Botis) . . . 507

Melanogrammos n. sp. (Tetralopha) ....... . 546

Melanopa n. sp. (Nola). . . . 40̈8

Minuscula n. sp. (Nola) . . . 458

Mlollicularia n. sp. (Epione). . 481

Mundula n. sp. (Thalpochares) .460

Nasutaria Z. (Sudariophora) . . 490

Nigrofasciata 11. sp. (Nola) . . 454

Nummulalis Z. (Catbarylla) . . . 542

Ocellinaria Guen. (Macaria) . .486

Octomaculata L. (Botis) . . . 503

Olinalis Gueı. (Asopia) . . . 499

Oporaria u. sp. (Nemoria) . . 481

Oxydalis Guen. (Botis) . . .514

Pallialis u. sp. (Hypena) . . .466

Parinotata 11. sp. (Cidaria) . . 495

Pedipilalis Guen. (Zanclognatha) 472

Perlucidalis H. (Botis) . . . .515

Pertextalis Led. (Botis) . . . 513

Petrella Z. (Pempelia) . . . 54

Phaealis Guen. (Epizenxis) . .470 Plyyllinaria 4. sp. (Eucrostis) . . $479 /$ Vestaliella 11. sp. (Scirpophaga) . 532 phora) ...... 521

Sesquistrialis Led. (Homopliysa) 324 Siguatalis Grote (Botis) . . .506

Sticticalis L. (Eurycreon) . . .518 Stramentalis Hbu. (Mesographe) 520 Strictalis n. sp. (Nola) . . . 439 Subjectalis Grote (Botis) . . .511 Succsata n. sp. (Macaria) . . 480

Sudariophora n. g. . . . . 489 Tartarella u. sp. (Pempelia?). . 5\$4 Terminellus Z. (Crambus) . . . 539 Terrellus Zinck (Crambus) . .539 Tetradella n. sp. (Anerastia) . .55\% Texana Robinson (Eromene) . 543 Thesealis Led. (Botis). . . .514 Tithonialis n. sp. (Botis) . . . 504 Tortricina n. sp. (Agrophila) . .461 Trentonalis Led. (Asopia) . . 499 Triquetrana Fitch (Brachytaenia) 4.57 Trituberalis n. sp. (Hypella) • .469 Tuberculalis Led. (Crocidophora) 5.2 Tyralis Wkr. (Rhodaria) . . 504 Ventralis Grote (Botis) . . 508 

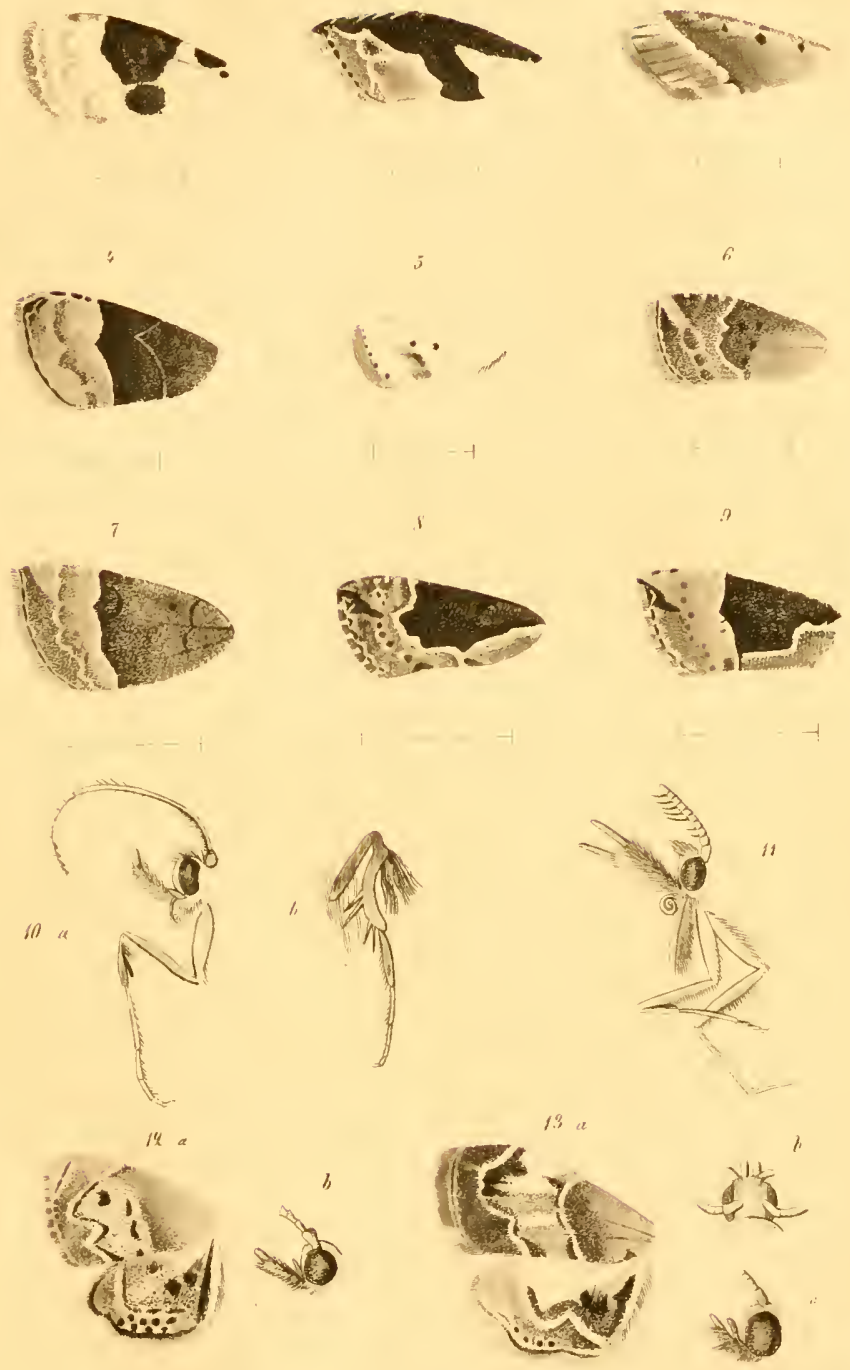

3)
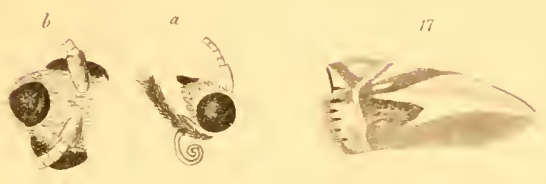

20
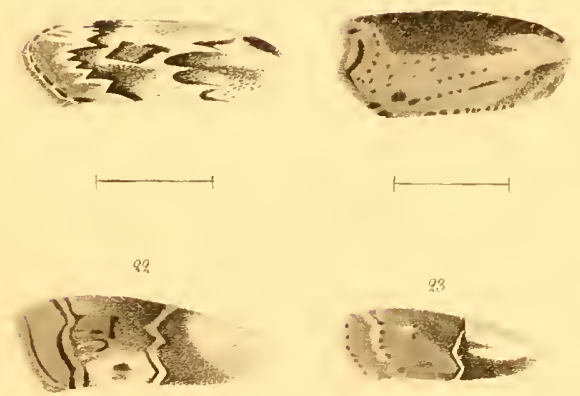

25
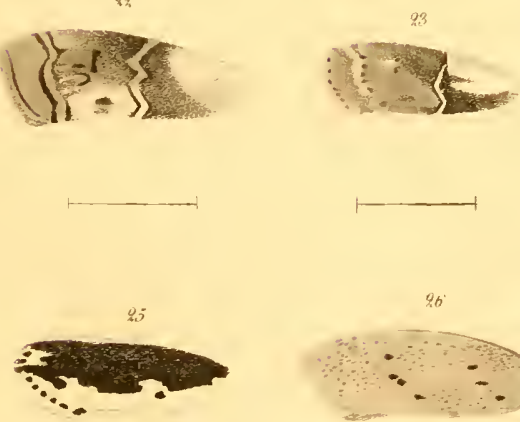

$9 b$

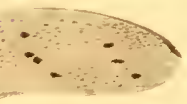

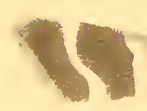
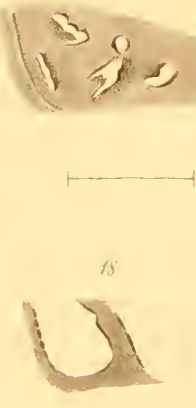
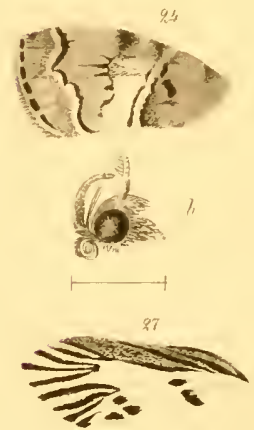



\title{
Beiträge zur Kenntniss
}

der

\section{nordamericanischen Nachtfalter,}

besonders der Microlepidopteren.

\author{
Von \\ Professor P. C. Zeller
}

in Grünhof bei Stettin.

(Aus den Verhandlungen der k. k. zoologisch-botanischen Gesellschaft in Wien.

[Jahrgang 1873] besonders abgedruckt.)

Ziveite Abtheilung.*)

Mit Tafel III und IV.

(Vorgelegt ill der Sitzung am 7. Mai 1873.)

Die vorliegende Abtheilung meiner Arbeit enthält hauptsächlich 'Tincinen und Pteroploriden. Meine Absichi war, in ihr anch dic mir bekannten Tortricinen zu bringen; da ich aber eine Hauptarbeit über diesclben, Grotc's Abhandlnng über nordamericanische Arten der Gattungen Tortrix, Tercts und Conchylis, noch nicht erlangen konnte, so musste diese einer dritten Abtheilung anfgespart bleiben.

Was die Tineinen betrifft, so glaube ich, Nordamerica werde sich ungefähr so artenreich erweisen wie Europa. Nicht nnr ïbergewanderte Arten, sondern auch solche, an deren americanischem Indigenat wenig zu zweifeln ist, sind in beiden Erdtheilen identisch; manche Arten beidel Continente kommen einander so nahe, dass ihre specifische Verschiedenheit noch Zweifeln unterliegt, zumal wenn man die Racentheorie auf sie anwendet; ein grosser Theil, bei dem solche Ansichten nicht stattfinden können, stimmt mit den europäischen Arten wenigstens in den Gattungsmerkmalen überein und ordnet sich daher oft ohnc die mindeste Schwierigkeit zwischen jene. Die Zahl der ächten Gattuugen oder Unterabtheilungen von Gattungen, die in der europäischen Fauna keine Vertretung haben, ist im Vergleich mit der Zahl der identischen olne Zweifel auffallend klein.

Von der grossen nordamericanischen Artenzahl mache ich hier nur einen geringen Bruchtheil bekannt. Ich besitze ungefähr die doppelte Zahl der hier abgehandelten, aber meist in unvollständigen oder einzelnen Exemplaren, deren Wiedererkennen ungeachtet aller Genauigkeit der Beschreibung zu bedenklich ist, wesshalh ich sie lieber übergehe. Von den beschricbenen sind leider auch

*) I. diese Verhandlg. Bd. XXII (1872), p. 447. ft. 
viele unica, und wenn ich anch nach Kräften bemüht war, sie durch Worte und Abbildung kenntlich zu machen, so wird sich mallches Merkmal vielleicht nicht bestätigen oder die Beschreibung sich als unvollständig erweisen. Da dic Mehrzall dieser unicn sich im Cambridger Inseum befindet, so werden nordamericanische Micropteristen sich in zweifehhaften Fällen ohne zu grosse Schwierigkeit Auskunft verschaffen kömnen.

Bej dieser Arbeit habe ich in erster Linie die Clemens'schen Aufsätze über nordamericanische Tineinen zu Rathe gezogen. Ein vorzügliches Hülfsmittel zu deren Studium, welches auch Americaner, denen die Proceedings of the Academy of Natural Sciences of Philadelphia zur Verfügung stehen, schon wegen der Stainton'schen Notizen nicht entbehren künnen, ist Stainton's Buch: The Thineina of North-America by Dr. Brackenridge-Clemens. London 1872 - eine Zusammenstellung aller Clemens'schen Aufsätze über die nordam. Tineinen mit-Anmerkungen über einzelne Arten, systematischer Anordnung und vollständigem Register aller von Clemens beschriebenen, dazu mit biographischen Nachrichten über Clemens and dem Wichtigsten ans der Correspondenz zwischen ilm und Stainton. Gern gestehe ich, dass ich ohne dieses Hïlfsmittel manche Clemens'sche Art ïbersehen oder nicht erkannt hätte. Dass ich demnoch im Ganzen nicht so gar viele Arten mit voller Ueberzengnng wieder erkannte, hat seinen Grund eines Theils in dem Reichthum der nordam. Fauna, aus dem mir gerade die Clemens'schen Arten verborgen blieben, anderen Theils in seinen nicht immer ganz genauen Beschreibungen (er hatte, wie us scheint, noch viel mehr und unvollkommnere unica als ich und ahote nicht, dass es noch mehr ähnliche Arten neben den seinigen gebe), und endlich, weil er weit mehr um Gattungen, als um Arten bemüht war. Letzterer Grund bewog ihn zu einem Verfahren, in welchen ich jhm weder bei fremdem Material nachfolgen durfte, noch bei eignem nachfolgen wollte: er brach bei seinen unicis die Flügel der einen Seite ohne Umstände ab, un sie zu entschuppen und, sobald er im Geäder eine Abweichung fand, ein Genus zu errichten. Vielleicht habe ich deswegen einige seiner Genera nicht erkannt; andere aber glaubte ich, bis auf weiteres - wenn nänlich ein grösseres Material lehren wird, welche Merkmale wesentlich und welche mwesentlich sind - mit den bisher bestehenden wieder vereinigen $\mathrm{zn}$ müssen. Dies betrifft insbesondere die Gattungen Cryptolechia und Gelechia. Von der crsteren zählt Francis Walker 162 Nunmern (um nicht Species zu sagen) anf, von Gelechia 386 ohne andere Unterscheidung als nach den Regionen ihres Vorkommens, kaum jemals mit Hindeutung auf eine verwandte Art! Die Zerlegung dieser Gattungen - denn die von Herrn v. Heinemann versuchte bei den Gelechien halte ich für eine sehr missrathene - überlüsst man wohl billig einem neuen Bearbeiter der Vorräthe des British Musenm.

Ferner habe ich die Reports von Riley und von den Fitch'schen die wenigen, die mir zur Verfügung standen, benutzt. Ich glaube, Hern Fitch nicht Unjecht zu thun, wemn ich ilım die Geschicklichkeit, Arten kenntlich zu beschreiben, in geringem Grade zuspreche. Vielleicht wird ihm das Herbe dieser Erklärung dadurch versüsst, dass ich ihn darin mit Réaumur vergleiche. Nur 
finde ich den Unterschied zwischen beiden, dass Réaumur, weil er lie Classification des Ganzen im Ange hatte, auf die Unterscheidung des Speciellen keinen Werth legte, während Fitch rein die üconomischen Verhältnisse in Betracht zog und darum die Species selbst, die somit recht eigentlich Beachtung verdient hätte, als Nebensache behandelte.

Nieht benutzt habe ich Francis Walker's List of Lepidopterous Insects of the British Museum ans dem schon früher angegebenen Grunde. - Eine vorzügliche Arbeit, die des Professor Frey in Zürich, über nordamerikanische Tineinen in der Entomologischen Zeitnng 1873, S. 201 ff, veranlasste mich, weil ich sie zu spät zur Benntzung erhielt. die von ihm behandelten Tineinen, lauptsächlich Lithoeolletilen, ganz zu ïbergehen, obgleich es wahrscheinlich ist, dass ich ein paar ilm fehlende Texasarten hätte beschreiben mul abbilden kümnen. Nor bei den Gracilarien hatte ich mich überzengt, dass keine der von mir beschriebenen Arten mit den seinigen zusammenfalle, und desshalb führe ich meine nenen Arten auf.

Was sonst über nordamericanische Timeinen nnd Pterophoriden bekannt gemacht worden ist, z. B. Chamber's bei Frey erwähnte Arbeit, habe ich nicht benutzt, weil es mir entweder unbekannt oiler nnerreichbar geblieben ist.

\section{Noctuidae.}

Agrophile truncatula n. sp. Taf. 11. Fig. 1.

Capite et thoraee mfo-fermgineis; alis ant. nigris, squamis filiformibus sulphureis obteetis, basi mfo-fermgineu, upice abrupte exalbido. \&

Von der Grösse einer kleinern Ayr. sulphurulis, mit schmälern Vorlerfligeln und spitzeren Hinterflügeln, durch ihre Fürbung sehr kemntlich.

Rückenschild und Kopf röthlich rostfarben, ersterer nach hinten dunkler mit gebräuntem Wulst des Scntellums. Stirn schwach gewölbt, 'Taster etwas kiirzer als bei Sulplumalis, fast horizontal; das Endglieul nur 1/4 so lang wie las zweite Glied. Saugrüssel ziemlich lang, auf dem Rücken rostbraun beschuppt. Fühler brann, kürzer als bei Sulpluralis, mit hellgelbem Wurzelglied. Beine blassgelb, die vordern auf ler Lichtseite braun mit hellgelben Punliten; die Hinterschienen auf dem Rücken von der Wurzel ans dunkelgrau und vor der Spitze mit einem solchen Fleckchen; alle Füsse dnnkelgran, hellgelb geringelt. Hinterleib dunkelgran mit hellgelbem Afterbusch.

Vorderflügel $4^{\prime \prime \prime}$ lang, etwas gestreckt und nach hinten erweitert. Die Grundfarbe ist schwarz, aber so reichlich mit langen, schmalen, hellgelben Schuppen bestrent, dass sie ilunkelgelblichgrau, etwas gewölkt, aber gegen den Innenwinkel ins Hellgelbe übergehend er'scheint; der Vorderrand selbst ist in einer dünnen Linie blassgelb; die Basis in einem sehrägen, am Innenrant verlïngerten bandförmigen Streifen braunrostfurbig und answärts anf ler obern Hältte hellgelb breit gerandet. Die Flügelspitze ist nebst den anstossenden Franzen als ein Dreieck hellgelb, an der s'pitze selbst rostgelblich. Die darunter folgenden Hinterrandfranzen sind tiefschwarz, auf der Wurzel mit hellgelben schuppen bestreut; die Franzen des Imnenwinkels blassgelb. 
Hinterflügel dunkelgrau. Franzen sehr blassgelb, von einer breiten, grauen Schattenlinie durchzogen, die sich um die Flügelspitze erweitert und hier fast die ganzen Franzen färbt.

Unterseite schwarzgrau; Vorderflügel mit blassrostgelbem, nach hinten erweiterten Costalstreif und sehr breiter, blassgelber Dorsalstrieme. Das Apicaldreieck der Oberseite ist nicht vorhanden.

Vaterland: Texas (Boll.). Ein schön erhaltenes $f$ im Cambridger Museum,

Metoponia obtusula n. sp. Taf. III. Fig. 2.

Antennis crassiusculis; alis ant. flavis, maculis costae 5, dorsi medii unce majoribus, pluribus disci minoribus dispersis rufescenti-cinereis, post. albiclis, obsolete cinereo-bifasciatis.

Verschieden von den übrigen Metoponien durch kürzeren Saugrüssel, dickere, kürzere Eühler, viel weriger gespitzte Vorderflügel und unverdunkelte, durch keine dunkle Hinterrandlinie begrenzte Franzen. Die Stirn läuft aber in eine horizontale, unter deu Schuppen versteckte Homplatte ans, und auf der Unterseite haben die Vorderflïgel wie dort ein helles, einwärts scharf begrenztes Band am Hinterrand, welches sich vor der Spitze in einen Fleck erweitert, und die Hinterflügel an der Spitze einen hellen Fleck, welcher den vor dem Hinterrand herziehenden Schattenstreifen unterbricht.

Rückenschild und Kopf gelb, Schnlterdecken zimmtfarbig bestïubt. Fühler kürzer als bei Vespertina, viel dicker, an Ende auffallend verdünnt, gelbbrännlich mit blassgelbem Rücken. Die schwarze, horizontale Stirnplatte ist kaum von Augenlänge, vorn gerarle abgeschnitten, durch längliche Schuppen bedeckt. Taster aufwärts gekrïmmt, am Gesicht liegend und bis an die Stimplatte reichend, zusammengedrückt cylindrisch, auswärts locker beschuppt, an ersten Glied mit abstehenden Haaren; das Endglied sehr kurz (etwa 1/5 so lang wie das zweite Glied und dünner als dieses), stumpf. Saugrüssel kurz, zusammengerollt. Beine anliegend beschuppt, sehr bleich ochergelb; die vordern, am meisten das erste Paar, braun bestäubt. - Hinterleib um die Hälfte über die Hinterflügel hervorragend, bleich ochergelb; der Legestachel in dem abgestumpften Analbusch verborgen.

Vorderflügel $5^{\prime \prime \prime}$ lang, ziemlich brcit, nach hinten erweitert, mit convexem Hinterrand und deutlicher, doch nicht scharfer Spitze, gelb, längs des Vorlerrandes sehr schwach röthlich angeflogen, mit röthlichgranen Flecken gezeichnet (in Grundfarbe und Zeichnung etwas an Arctia purpurea erinnernd). Der Vorderrand trägt in ziemlich gleichen Abständen fünf Flecke, den ersten an der Schulter, "den letzten etwas vor der Flügelspitze; der zweite und vierte sind kleiner als die andern; vom fünften zieht eine Reihe von fünf Fleckchen parallel dem Hinterrand zum Innenwinkel herab. An der Nitte des Innenrandes, dem dritten Costalfleck gegenüber, ist ein grosser und dicht hinter ihm ein kleiner Fleck. Im Mittelraum sind noch vier Fleckchen sichtbar: das erste unterhalb des zweiten Costalflecks, das zweite grössere unterhalb des dritten Costalflecks; die zwei folgenden bilden mit dem vierten Costalfleck und dem zweiten Dorsalfeckchen eine 
sehr weitläuftige, gebogene Querreihe. Franzen wenig beller als die Grundfarbe mit kaum merklicher dunklerer Mittellinic und etwas verdunkelten Enden.

Hinterflügel weisslich, vor dem etwas gelblichen Hinterrand mit einem unr auf der Apicalhälfte vorhandenen Schattenstreifen und vor diesem in etwas weiterer Entfernung mit einem schnäleren, der über die Mcdianaderïste zieht.

Unterseite gelbweisslich, an den Vorderrändern breit blassochergelb. Die Vorderflügel im Mittelraum gran mit einem dunklern, bindenfürmigen Qnerstreif vor dem oben besprochenen Marginalband und in einiger Entfernung davor mit einem schmäleren. Die Hinterflügel mit einem deutlichern und vollständigern Qnerband vor dem Hinterrand und weiter einwärts mit einem solchen am Vorlerrand anfangenden Schatten. Auf der Querader ist ein erloschener grauer Punkt.

Vaterland: Texas (Boll.). Das schöne $q$ ist im Cambridger Mnseum.

\section{Geometridae.}

\section{Cialuria luscinata n. sp.}

Alis ant. subrufescenti-cinereis, multistrigatis, strigis duabus (altera alba ante medium, altera albida post medium, superius arcuata) interius latius nigro-marginatis, puncto interjecto nigro, albido-cincto, striga ante marginem posticum albida, repunda. o'.

Sie ist die Stellvertreterin nnserer (von Hübner Fig. 277 nicht sonderlich gut abgebildeten) Polygrammata, deren Varietat Conjugata sie so nahe kommt, dass sie leicht damit zu verwechseln ist.

Wenn sie nicht abänilert, so hat sie nur die Grösse der kleineren Exemplare von Polygrammata. Ihre Unterschiede von dieser Art sind folgende: 1. alle Flügel haben eine, wenn auch sehr schwache röthliche Beimischung, die den Polygr: stets fehlt. 2. Die zweite weissliche Querlinie, welche die, wie bei Polygr. gewöhnlich, unvollstïndige Mittelbinde bilden hilft und bei Polygr. am obern einwärts schwarzbeschatteten Drittel eine ganz schwache oder auch gar keine Biegung nach anssen macht, hat bei Luscinat e eine erst nach aussen und dann nach innen gehende, sehr merkliche Krümmung, welche durch die schwarze, bis zum Vorderrand reichende Beschattung hervorgehoben wird. 3. Die weissliche Querlinie vor dem Hinterrand, welche bei Polygrommata schwach wellig ist, hat bei Lascinata einen kappenförmigen Verlauf. 4. Am Vorderrand der Vorderflügel vor der Spitze ist der dunkle Fleck, der das oberste, spitzwinklig abgebrochene Ende der weisslichen Querlinie von beiden Seiten einschliesst, bei Polygrammeta mehr oder weniger dunkelgrau, bei Luscinata schwarz, also anffallend dunkler.

Da Polygrammata nicht wenig veränderlich ist, so lässt sich von ihrer Nebenart auch keine Unveränderlichkeit erwarten. Aber die nnter 2 angegebene Kriimmung der Querlinie und die unter 3 bemerkte kappenfürmige Gestalt der Antemarginallinie werden sich aller Wahrscheinlichkeit nach als standhafte Unterschiede bewähren.

Vaterland: Texas (Boll) und Massachusetts (Burgess). 2 o, von denen eins in meiner Sammlnng, eins im Cambrilger Museum. 


\section{Pyralidae.}

Cordylopesa \%. y. Taf. III. Fig. 3. a-e.

Ocelli mulli.

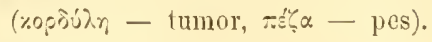

r'apilli sublueviguti.

Antemae mediocres, simpliees, on crussiusculae, mieroscopice ciliatae.

P'ulpi labiales jorrecti, thorace breviores, artienlo terminali brevinsculo, luevi, deflexo.

Haustellum mediocre, in busi squumatum.

Pedes longiores, robusti; mellionm et posticom tibiae el metatarsi squamis modosi.

Abilomen of yracile, deplanutum, 9 subcomvexum, oviluctu retructo.

dlae anteriones in costu media ó bis, f latins semel emarginatae.

C'ellulu media brevis, rumo venre subcostalis anterpricali et ramo venae medianae mimo fureatis.

Alne posteriores lntae, margine postico rotumlato, breviter ciliutne, subtus et in or supre pietue; venu mediuna quadifulu in basi non barbata.

Diese dnreh ihre am Vorderrande busenförmig eingedrüekten Vorderflügel nud die Schuppenknoten der vier hintern Beine leicht kenntliche Gattung wird wohl mit Recht zn den Pyraliden, und zwar in die Nähe von Lederer's Amblynua Tab. 6 Fig. 14 gestellt. Der Mangel der Ocellen, die Länge der vier lintern Beine und der gleichmässig germulete Hinterrand der Hinterflïgel geben vorlïnfig geniigenle Tremmmgsgrïnde* ${ }^{*}$; wahrseheinlich aber zeigt das Geäder einen noclı grössern, da Corlylopezr sich darin von allen mir bekannten Pyraliden unterscheidet. Auf den Vorlerflïgeln hat nämlich die Mittelzelle nur 1/3 der Flügellïnge; die Medianader theilt sich in drei an der Wurzel selır genäherte Aeste, deren erster an seinem Enddrittel eine Gabel bildet; die Snbdorsalader liat an ihrem Anfangsdrittel einen schrägen, gegen den Immenrand gerichteten Furtsatz. Anf den Hinterfügeln ist die Nittelzelle often (wenn nicht eine sehr feine, stark einwärts gekïummte, scheinbar einfache Ader die Begrenzung bildet) umd die freie Ader 1 c fehlt, wenigstens anf dem abgeschuppten männlichen Flügel, so dass zwisehen $1 \mathrm{~b}$ und der Medianader ein breiter Ranm ist.

Habitus nnd Kürze der Franzen würden erlanben, die Gattung in die Nähe von (iyptolechia zn bringen; aber die lorizontalen Taster mit niedergebogenem Endglied entfernen sie gänzlich ans deren Verwandtschaft.

\section{1. migrimolis $\mathrm{n}$. sp.}

Alue unt. rufue, linea costae meliae albu, strigis duabus obsoletis intermulis allidis, murgine postico nigro-punctato. ơ 9 .

*) Der Vorlerrand der Vorlerflügel von Amblyura zeigt Fig. 14 in der Mitte einen merklichen Einlruck, der mich eben auf Verwanctschaft der beiden Gattungen schliessen lässt; dagegen sagt Ledever S. 67: „Vorderrand der Vorderílügel stark convex; an ter Wurel oben mit einer umsehlag«rtigen, mit plattgedrückten Schuppen belegten Haarmähne, 
Grösse wie Asopia costalis. Rüekenschild hellrotlı: das Schildchen und der grösste Theil des Kragens schmutzig weisslicl, wie der Kopf und das Wurzelglied der bräunlichen Fühler; diese beim ơ dicker und kürzer als beim $\subseteq$ und ausserdem gezähnelt und mikroskopisch gefranzt. Stirn durch die etwas lockere Beschuppung fast convex. Taster röthlichbraungrau oder bräunlich, doppelt so lang wie der Kopf, horizontal; das zweite Glied etwas locker beschuppt und allmälig verdickt; das Endglied dümner und $n m-1 / 3$ so lang, zugespitzt und abwärts geneigt. Maxiłlartaster fehlen. Saugrüssel mässig lang, zusammengerollt. Vorderbeine röthlichbraun, an den Enden der Glieder mit je einen weisslichen Punkt. Die vier andern Beine ziemlich lang, granweisslich mit braunrothen Hüften; an den nittlern hat der Schenkel unten vor der Spitze einen schwärzlichen Schuppenbusch, und die Schiene ist an der Mitte und noch mehr am Ende durch schwarze Schuppenhare verdeckt; auch das erste Fussglied hat auf dem Rücken gegen das Ende einen solchen Schuppenbusch. An den Hinterbeinen ist der Schenkel gegen die Spitze schwärzlich bestïubt; ebenso überall die doppelt so lange Schiene, welche am Ende einen schwarzen Schuppenbusch trägt; einen noch stärkern zeigt das erste Fussglied anf den Rücken; die übrigen Fussglieder sind weiss. - Hinterleib des ó schmächtig und etwas flach, dunkelbraungran, an den Endrändern der Segmente mit bleichen Schuppen gefranzt; der Afterbusch ohne Auszeichnung, bleichgelblich. Beim Weibehen ist der Hinterleib kräftiger, länger und convexer, ebenso gefärbt, am Bauch auf den Seiten der vordern Segmente braunroth, sonst wie der Afterbusch bleichgelblich; Legestachel eingezogen.

Vorderflügel $3^{1 / 4}-4^{1} / 2^{\prime \prime}$ lang, länglich, beim $\delta^{7}$ etwas breiter als beim $f$, mit abgerundeter Spitze und schwach convexem Hinterrande; der Vorderrand voll der Wurzel stark aufsteigend, damn schwach gebogen, aber in der Mitte beim $q$ nit einem ziemhich tiefen und langen Eindruck; dieser ist beim $\sigma^{-1}$ seichter, aber an Anfang und Ende vertieft und auf der vordern Hälfte, ansser in den Vertiefungen, mit schwarzen Börstchen gesäumt. Grundfarbe roth, im Wurzeldrittel mehr orangeroth. In der Ausbuchtung ist der Vorderrand bein f in einer starken Linie, beim ơ schniäler und undeutlicher gelblichweiss; an ihr und auf den Convexitäten davor und dahinter sind die Costalschuppen etwas sägezähnig abstehend, und beim ơ schwärzlieh. Vor dem Anfang der weisslichen Costallinie geht eine mehr oder weniger dentliche, mehrfach unterbrochene, ge. zackte, weissliche Linie ziemlich senkrecht zum Inuenrand, und von dem hintern Ende der Costallinie zieht eine zweite, über der Mitte einen starken Winkel bildende und sich dann in weit getrennte Punkte auflösende weisse Querlinie. Den Hinterrand begleitet eine Reihe schwarzer, länglicher Punkte vor den dunkel rüthlichgrauen Franzen.

Hinterflügel beim $\sigma^{\nearrow}$ spitzer als beim $q$, bräunlichgrau, beim $\sigma^{\nearrow}$ am hellsten und gegen die Wurzel gelblich, am dunkelsten grau in der Fligelspitze. Vom Vorderrand konmt in einiger Entfernung voln der Spitze eine verloschene, helle, auf beiden Seiten dunkler gran eingefasste Linie gebogen herab und versclıwindet in den Medianaderästen; beim f fellt sie entweder ganz oder ist 
noclı unvollständiger und verlosehener siclitbar. Den Hinterrand fasst ciné schwarze, durch die bleichgelben Aderenden unterbrochene und vor dem Analwinkel versehwindende Linie ein. Franzen liellgrau, nahe an der Wurzel von einer dunklern Scbattenlinie, welche um die Flïgelspitze am duukelsten ist, durchzogen; die Franzen des Innenrandes sind dunkler und sehimmern besonders beim on purpurfarbig.

Unterseite der Vorderflügel lunkelgran, am Vorderrand geröthet, am Innenrand gelichtet; die hellgelbe Mittellinie des Vorderrandes vorhanden; ebenso die Anfinge der zwei Querlimien, aber weiss und zu beiden Seiten schwärzlich eingefasst; clen Hinterrand fasst, wie auf den Hinterflügeln, eine schwarze, durch die gelblichen Aderenden durchschnittene Linie ein. Hinterflügel hellgrau, beim $0^{7}$ weisslicher, am Vorderrand breit grau mit rother Bestäubung. Nahe an der Basis trägt er ein schwärzliches Fleckchen als Anfang eines Querstreifens; der Querstreifen vor dem Hinterrand ist fast vollständig und bildet einen auf den Aesten der Medianader winklig gebrochenen, cinwärts schwärzlich schattirten Bogen.

Vaterland: Massachusetts. Meine 2 of $3 f$ wurden dureh Burgess bei Beverly in der Endhälfte des Juli gesammelt.

$v$

Botis ribicalis n. sp. Taf. 11I. Fig. 4.

Antennis ciliutis: alis ant. stramineis, roseu-ciliutis, margine dorsuli strigisque duubus (priore obliquissima) obscure roseis; post. cinereis. ot.

Ganz vom Aussehen eines hleinen Spanners, etwa aus dem Genus Sterrh, aber mit dentlichen Ocellen, nicht schlank gebant, mit verlängerten Lippentastern (daher keine Emprepes), ohne Hornfortsatz der Stirn (daher weder zu Anthoplhilodes, noch zu Tegostoma gehörig), sondern nach ihrem Kopfbau eine Botis und nach ilurem sonstigen Aussehen cine Verwandte der Sunguinulis, aber ausser der grössern Spanmerähnlichkeit mit ansehnlichern Franzenhaaren an den Fühlern.

Grösse der kleinsten Sanguinalis. Rïckenschild lehmgrau, mit strohgelben Schulterdecken. Kopf hell lehmgrau mit hellgelber Augenrandlinie, die sich nach vorn verlängert und um das gerade abgeschnittene Gesicht herumzieht. Fühler auf dem Rücken weisslich mit abgesetzten Gliedern und ziemlich langen Franzen. Maxillartaster gelblichweiss, wcit hervorstehend. Lippentaster verlängert, zugespitzt, zusammengedrückt, obenauf gelblichwciss, an den Seiten bräunlichgrau. Beine bräunlichgran; die hintern auswendig am Schenkel längsstreifenartig gelbbraun und an der Schiene mit bräunlicher Mittellinie. Hinterleib bräunlichgrau.

Vorderflïgel $3^{\prime \prime}$ lang, in der Gestalt fast wie bei Sanguinalis, blass dottergelb, auf dem Vorderrand mit einer bis ans Ende des ersten Querstreifs reichenden nnd hinten ein wenig erweiterten bräunlichen Linie. Der erste breite, bandfömmige Querstreif liegt sehr schief, indem er vom Innenrand nahe der Basis bis etwas hinter die Hälfte des Vorderrandes reicht." Der zweite, etwas breitere Querstreif entspringt vor dem Innerwinkel, gelıt den Hinterrande 
parallel bis zum Vorderrand und ist mit dem ersten Querstreif durch eine ziemlich breite Innenrandstrieme verbunden. Beide Querstreifen und die Verbindungsstrieme sind dunkelrosenroth und auf ihren einander zugekehrten Seitell mit lilaglänzenden Schuppen verdeckt. Franzen heller rosenfarbig, in der Mitte mit einer dunkeln Linie durchzogen uud auf der Wurzelhälfte gleichfalls mit etwas Lilaschimmer.

Hinterflügel einfarbig bräunlichgrau. etwas röthlich gemischt, mit braungrauen Franzen.

Unterseite bräunlichgrau, auf den Hinterfiügeln heller; die Franzen der Vorderflügel hell und röthlich gemischt.

Taterland: Texas (Boll.). 1 万 ju Cambridger Museum.

Botis sesquialteralis n. sp. Taf. IlI. Fig. 5.

Alis ant. acutis, gilvis, strigulu ex margine dorsali adscendente ante medium striga postica intra plicum angulatu punctoque renue transrersae grisen-fuscis, striga antemarginali tenui pallida. S.

Kleiner als $B$. vibiealis und ihr verwandt: grösser als $B$. mesonialis und dieser sehr nahe. Inre auffallendsten Unterschiede von Nusoniatis sind bei dieser angegeben.

Rückenschild und Kopf blass dottergelb. Ocellen gross. Taster weit über den Kopf hervorstehend, lang zugespitzt. Fühler dünn, graugelblich. Beine blass vehergelb. Hinterleib grau.

Vorderflïgel $2 \frac{1}{4^{\prime \prime}}$ lang, spitzer als bei Vibicalis und mit gleichmässiger convexem Hinterrand. Grundfarbe blass dottergelb. Aus dem Inmenrande kommt vor der Mitte ein fast senkrechtes, bräunliclıgraues Streifchen, das von der starken, gelblichen Subdorsallinie durchschnitten wirl und nur bis zur Falte reicht. Auf der Querader ist ein starker, gleichfarbiger Punkt. Fast in der Mitte zwischen ihm und dem Hinterrande ist ein vollständiger, starker, unterwärts verengter, bräunlichgrauer Querstreif, weleher in der Falte einen spitzen, einspringenden und auf der Subdorsalader einen fast rechten, ausspringenden Winkel bildet. Etwas vor dem Hinterrande zieht eine Querlinie, welche beller ist als die Grundfarbe. Franzen hellgrau, von einer dunkelgrauen Linie durchschnitten.

Hinterflügel mit ganz abgerundetem Vorderwinkel, grau, am Hinterrand dunkler; Franzen hellgrau mit feiner, gelblicher Wurzellinie.

Unterseite der Vorderflïgel gelbgrau mit verloschenem, granem hintereı Querstreif, hinter welchem ein blasses Gelb den Raum bis zum Hinterrand bandartig ausfüllt. Hinterflügel hellgrau, an Vorderrand gelbgrau bestäubt, längs des Hinterrandes blassgelblich.

Vaterland: Texas (Boll.). Ein schönes $f$ im Cambridger Museum.

Botis masonialis n. sp. Taf. III. Fig. 6.

Minuta, alis ant. acutis, mfo-ochraceis, pallide venosis, fascia obscura ante strigam submarginalem latam pallidam, lumula venae transversae obscura. $f$. 
Var. b. Puncto nigricunti mo lumula, fasciue margine interione in strigam nigricentem mutete $f$.

Die beiden vorliegenden Exemplare sind etwas unter sieh verschieden. Sie kommen (besonders Var. b.) der grösseren Sesquiulteralis so nahe, dass ieh sie anfangs für Varietät derselben hielt; aber sie weichen von ihr ab dureh grössere 7uspitzung aller Flïgel, dureh die ins Rothe übergehende Ocherfarbe der Vorderflügel, durch die grössere Breite, fast bindenartige Gestalt der hellen Antemarginallinie und dureh den gänzlichen Mangel der abgekürzten ersten Querlinie. Vielleieht ist auch ihre beträehtlichere Kleinheit ein beständiges Merkmal.

Einer der allerkleinsten Zünsler. Rüickensehild und Kopf von der röthliehen Grundfarbe der Vorderflügel. Taster wie bei Sesq., aussen etwas verdunkelt, an der Wurzel unten weisslich. Die grauen Fühler so fein wie bei Sesq.

Vorderffügel $2^{\prime \prime}$ lang, am Vorderrand convexer, am Hinterrand weniger convex als bei Sesq., anf hell ochergelbem Grunde sehr dicht röthlich beschuppt; doeh treten die Adern in hellgelber Farbe hervor, am breitesten die Subeostalader, und die ebenso breite Längslinie in der Falte. Auf der Querader ist eine mondsichelartige Verdunkelung, statt deren die übrigens weniger dunkelröthliche Var. b. einen sehr deutlichen sehwarzgrauen Punkt trägt. Hinter dieser Queraderzeichnung folgt eine breite, dunkler röthliche, von keinen Adern durchschnittene Binde; sie ist naeh unten erweitert und auf der der Flïgelwurzel zugekehrten Seite am dunkelsten; bei Var. b. bildet sich aber diese Seite zu einer seharf abstechenden schwärzlichen Querlinie ans, die gegen den Dorsalrand anch zu den Winkeln der Sesquirulterralis gebrochen ist. Statt der hellen Antemarginallinie der Sesq. hat Nasonicalis einen mehr als doppelt so breiten, gegen den Innenwinkel verengerten Querstreifen der hellgelben Grundfarbe, dureh welehen der röthliehe Hinterrandstreifen auf eine ganz dünne Linie eingeengt wird. Franzen gran, von einer dunkeln Linie durchzogen, vor weleher sie röthlich gemischt sind.

Hinterflügel weniger in die Länge gezogen, dagegen mit viel mehr hervortretendem Vorderwinkel als bei Sesquialteralis, grau, vor der breiten gelblichen Hinterrandlinie bindenartig dunkelgrau; die Franzen hell gelbliehgrau.

Unterseite der Vorderflügel hellgrau, am Vorderrand breit striemenartig gelblich. Hinter dem verlosehenen sehwärzlichen Queraderpunkt zieht ein eben suleher Querstreifen bis zur Falte herab; der helle bindenfürmige Raum vor dem Hinterrand ist breiter als auf der Oberseite. Hinterfinggel noeh heller als die Vorderflügel, am Vorderrand grob dunkler bestänbt. Ziemlich weit vor dem Hinterrande zieht ein verloschener, dunkelgraner Streifen, der wohl nieht immer vollständig vorhanden ist.

Vaterland: Texas. Die beiden in meiner Sammlung befindlichen $q$ wurden von Belfrage am 20. August gefangen.

\section{Botis terrealis Tr.}

Fischer v. Rösl. Beitr. Taf. 75 Fig. 4.

Ein $\sigma^{7}$ erhielt ich durch Dr. Speyer aus der Gegend von New-York mit der riehtigen Bemerkung, dass es etwas spitzere Flügel und sehärfere Zeichnung 
habe als unsere Exemplare. Die grössere Schärfe der Zeichnung zeigt sich, im Vergleich mit 20 europäischen Exemplaren, am besten auf der Unterseite ausgedrückt, wo die hintere Querlinie der Vorderflügel mit einem schwarzgrauen Costalfleck anfängt. Die angegebenen Unterschiecle (und andere giebt es nicht) sind aber durchaus keine specifischen, wofür Dr. Speyer sie anch nicht ansehen will; selbst als Zeichen einer Localvarietät möchte ich sie niclıt gelten lassen, da Terrealis trotz ihrer Einfachheit nicht nur in der Dentlichkeit ler Querlinien auf beiden Flügelseiten, sondern auch in der Zuspitzung der männlichen Flügel abändert. Ich habc selbst ein alpines Exemplar, bei welchem wie bei den americanischen der rechte Vorderflügel etwas breiter und weniger zugespitzt ist als der linke, weshalb ich nicht bezweifle, dass bei einer grösseren Zahl americanischer Exemplare sich einige Veränderlichkeit sowohl in der Z/nspitzung der Flügel, wie in der Schärfe der Querlinien heransstellen werde.

Wie diese Art, die mehr bergige Gegenden bewohnt und sich wohl ïberall von der Meeresküste fern hält, nach America gewandert sein sollte, ist schwer amzugeben. Jedenfalls könnte es nur in der zwischen Moos etc. ïiberwinternden Raupe geschehen sein.

\section{Orobena octonalis n. sp. Taf. III. Fig. 7.}

Alis ant. pallide sulplureis, maculis costae aequaliter dispositis intus dilute rufis, nigro-cinctis (tertia orbiculos duos formante) in series punctorum nigrorem contimuatis, litura cilionm apicalium schistaceo-fusca. $0^{3}$.

Eine schüne, leicht kenntliche Art von Botis-ähnlicher Beschaffenheit, nur nicht nach den Tastern und vielleicht nicht nach dem Geäder, dessen Verlanf ich nicht kenne; die Stirn ist zugerundet; die ganz kurzen Taster krümmen sich am Untergesicht aufwärts, und ihr kurzes Endglied reicht nicht ïber die Stirn weg. Hiernach wäre die Art eine Orobena; da ihr aber Maxillartaster ganz zu fehlen scheinen, so ist ihr Platz in Orobenc nur provisorisch.

Grösse einer kleinen $O_{i} \circ b$. praetextalis. Rückenschild blass schwefelgelb, wenigstens auf den Schulterdecken; der Halskragen hellroth, an jeder Seite hellgelb wie der Kopf. Fühler ziemlich dick und kurz, gegen das Ende verdünnt, mit gedrängten Gliedern, ocherbraun. Lippentaster rostroth mit verdunkeltem Ende; Saugrïssel lang. Die Vorderbeine an Schenkeln und Schienen schwarz, an den Fïssen schwarz und weissbunt; die andern Beine weiss; das Knie der mittlern und die Wurzeln der letzten Fussglieder schwärzlich. Hinterleib weiss, um $1 / 4$ über die Hinterflügel hinausreichend.

Vorderflügel $4^{1} / 2{ }^{\prime \prime \prime}$ lang, ziemlich breit, nach hinten erweitert, hell schwefelgelb. Am Vorderrand hängen in ziemlich gleichen Zwischenräumen vier hellrothe, schwarz umzogene Flecke; der erste ist nahe der Basis, eckig und wie der folgende auf dem Vorderrande stark schwarz; der zweite querviereckig und vermittelst einer Reihe ungleicher, schwarzer Punkte mit einem dreieckigen, hellrothen, schwarzbestïubten Innenrandfleck verbunden; der dritte ist der grösste, aus zwei an einander hängenden hellrothen, schwarz eingefassten Scheiben (die ungefähr eine 8 bilden) zusammengesetzt und durch drei schwarze 
Querstriche mit dem Innenrande verbunden; der vierte ist der dunkelste, nach unten zugespitzt, und von ihm geht eine verloschene, aus schwarzen Punkten und Strichelchen bestehende Querlinie nach einem tiefschwarzen Fleckchen des Hinterrandes unmittelbar über dem Innenwinkel. Franzen weissgelb; die des Apicaldrittels schieferbraun und von einer tiefschwarzen Linie des Hinterrandes begleitet.

Hinterflügel mit abgerundeter Spitze, weiss, am Hinterrand blass schwefelgelb. In Aualwinkel ist ein kurzer, tiefschwarzer Strich; ein kleinerer liegt iı einiger Entfernung vou ilnn an Hinterrand, und dieser ist gegen die Flügelspitze in weiten Entfernungen nit vier schwarzen Pünktchen bezeichnet. Franzell weiss.

Unterseite weiss, längs des Vorder- und Hinterrandes blass schwefelgelb. Aul den Vorderflügeln sind die Costalflecke vorhanden, aber der erste nur angedeutet und so wie die andern verloschen und ohne Rotlı. Die Querlinie vou vierten bis zum Hinterrandfleck ist vollständig und viel stärker als anf der Oberseite, und vor ihr ist der Raum bis zum dritten Costalfleck schwärzlich lestäubt. Franzen wie auf der Oberseite. Auf den Hinterflügeln sind die Enden jeder Ader, ausgenommen die am Analwinkel, nit je einem schwarzen Punkt bezeichnet.

Vaterland: Texas (Boll.). Ein schönes ơ im Cambridger Museum.

\section{Aphomia sociella L.}

Aph. colonella, Heinemann Pyr. S. 207. Hübn. Fig. 22. o' (Sociella). 23 ○ (Colonella).

Nach den drei aus America erhaltenen $\bigcirc$ kommt diese Art in genauester Uebereinstimmung mit den europäischen Exemplaren, also auch in gleicher Veränderlichkeit der Grösse und Färbung, in Massachusetts vor. Zwei grosse Exemplare zeichnen sich durch Lebhaftigkeit der grünen Fürbung aus, welche den Vorder- und Hinterand mmzieht. Das eine derselben fing Burgess bei Beverly am 26. Juni; ein kleineres, ohne Grün, also mehr mit Hübners Fig. 23 stimmend, am 7. Juli.

\section{Melissobluptes furellus n. sp.}

Thorace canescente; alis ant. obscure cinereis, litur ex busi orta nigra, limbo fasciue instur dilutius cinereo venis nigris dissecto. ơ 9 .

Etwas grösser und breitflïgliger als Mel. fulminalis (Zool.-bot. Gesellsch.Verhdl. 1872, S. 560, Sep. 114), mit diesem darin übereinstimmend, dass anf den $\sigma$-Vorderflügeln die behaarte Mittelzelle nicht (wie bei Aphomia) bis zum Hinterrand, aber doch weiter als bei Mlol. bipunctunus verlingert ist. Furellus hat ein verrüuchertes Aussehen, auf den Vorderflügeln nit einem starken, schwarzen Längswisch aus der Wurzel und mit schwarzen Längsadern in der helleren Hinterrandpartie.

Beide Geschlechter fast gleich gross. Rückeuschild und Kopf hellgrau. Fühler dünn, borstenförnnig mit deutlich gesonderten Gliedern; das Wurzelglied 
wie bei Mel. bipunctumus länglich, hellgran beschuppt, die Schuppen beim $\sigma^{\top}$ an der Spitze einen kurzen Zahn bildend. Taster des $q$ kaum von Kopflänge, dünn, grau, mit sehr kurzem Endglied. Beine hellgrau, auf der Aussenseite beim ơ dunkler beraucht als bein $\subsetneq$. Hinterleib auf dem Rücken schwach gewölbt, ochergelblich, am Wurzelglied weisslich beschuppt; Bauch des ơ grau, des $q$ weisslich.

Vorderfügel des $\sigma^{7} 6^{\prime \prime \prime}, q 61^{\prime \prime \prime}{ }^{\prime \prime}$, ziemlich schmal, mit stïrker convexem Vorderrand als bei Bipunctanus und Fulminalis, grau, schwärzlich bestäubt wie beraucht. Ein schwarzer Wisch, am Anfang weisslich bestäubt, hinten erweitert, reicht von der Basis oberhalb der Falte bis über $1 / 3$ der Flügellänge (er mag beim $q$ etwas kleiner und blässer sein; bei meinem Exemplar ist der Flïgel hier bedeutend verwischt). Hinter ihm folgt beim $q$ oberhalb der Flügellı̈lfte eine schwarze, mit einer Erweiterung endigende Längslinic. Die schwärzliche hintere Querlinie hat in Allgemeinen gleichen Verlauf wie bei Bipunctanus und Fulminalis, ist aber dem Hinterrande näher und sägezühnig kappenförmig; sie begrenzt den heller grauen Raum, der sich bis zum Hinterrand ausdehnt und von den schwärzlichen Adern, deren jede aus einem Zahn der Kappenlinie kommt, durchschnitten wird. Die schwarze Hinterrandlinie ist an den Enden dieser Iinien fast unterbrochen und an denselbeu auf den grauen Franzen mit je einer kleinen hellgraugelblichen Stelle bezeichnet.

Hinterflügel des $\delta^{\nearrow}$ schmäler als bei Fulminalis, des $q$ fast ebenso breit; sie sind einfarbig grau mit etwas lichteren Franzen.

Unterseite hellgrau, auf allen Flïgeln gegen die Spitze mit einem verloschenen schwärzlichen Fleck als Anfang einer Querlinie. Beim o ist einc längliche, zugespitze, schwefelgelbliche, filzige Stelle, welche von der Wurzel ans $1 / 3$ der Länge des Vorderrandes einuimmt. Die auffallend zart ind diclit beharte Mittelzelle ist breiter als bei Fulminalis und reicht, auch in eine Spitze auslaufend, nälıer an den Hinterrand heran. Beim $q$ sind die verlängerten Vorderandschuppen nach unten umgelegt. - Hinterflitgel heller als die VorderHügel; die Hinterrandlinie an der Apicalhälfte am dunkelsten.

Vaterland: die Gegend von Albany bei New-York. Ein Pärchen, das ich von Dr. Speyer erhielt, in meiner Sammlung.

Anmerkung. Wegen der Uebereinstimmung in Zellenbau der Flïgel fïge ich die Beschreibung einer anstralischen Art bei.

\section{Melissoblaptes latro n. sp.}

Maximus, alis ant. angustis, posticc coarctatis, grisco-carneis, strin disci flavida e basi in apicem ducta, inferius fuscescenti-alumbrata; posterioribus albido-hyalinis, apice cinereo. ơ.

Die grüsste mir bekamnte Galleria, sehr auffallend durch die schmalen, nach hinten zugespitzten Vorderfï̈gel und die zur grǒssern Hälfte durchsichtigen Hinterflügel.

Rückenschild, Kopf mit den Fühlern, Beine und Vorderflügel schmutzigdunkel fleischroth. Die dichten, flach anliegenden Kopfschuppen bilden ein vorn 
abgeschnittenes Stirndach mit parallelen Seiten. Fühler borstenfürmig, dentlich dunkel geringelt mit länglichem, anliegend beschuppten Wurzelglied. Hinterleib fast um seine Hälfte über die Hinterflügel hinansragend, auf dem Rücken convex und glatt, bleichochergelb, mit hellerem Bauch.

Vorderflügel 8"' lang, schmal, nach hinten verengert mit gleichmässig convexem Vorderrand; der Hinterrand convex, sehr schräg rïckwärts gehent, so dass der Innenwinkel ganz verschwindet. Aus der Mitte der Basis entspringt eine ziemlich gerade, breite, hellgelbe, nnterwärts braun beschattete Linie, welche nach der Flïgelspitze hin zieht und sich vor derselben verschmälert und durch röthliche Bestäubung verdunkelt. Unterhalb derselben sind die in den Hinterrand auslaufenden ddern vertieft. Der Hinterrand ist mit kleinen, schwarzen Punkten gezeichnet. Andere Zeichnungen sind nicht vorhanden. Franzen wenig bliisser als dic Grundfarbe.

Hinteıflügel viel schmäler und gestreckter als bei jeder andern Galleria, weisslich durchsichtig, im Apicaldrittel undurchsichtig, gran beschupt, am dunkelsten in der Flügelspitze. Franzen weiss, un die Flügelspitze grau gemischt und röthlich angelaufen.

Unterseite der Vorderflügel bleich, ins Gelbliche, gegen die Spitze mehr röthlich. Die Mittelzelle, welche nach vorn durch die matt durchscheinende gelbliche Linie begrenzt wird, ist schmal und endigt zugespitzt am Anfange des letaten Flïgelviertels; sie ist nicht ïberall behaart, sondern in einem Streifen längs der Medianader mit gewöhnlichen, feinen Schuppen bekleidet. Hinterflügel längs des Vorderrandes und auf den andern beschuppten Theilen hell röthlichgrau.

Vaterland: Adelaide auf Nen-Holland. Ein $\sigma^{\text {万人 }}$ in meiner Sammlung aus dem Besliner Museum.

\section{'Iineacei.}

Anaphora Clemens ed. Stainton p. 56 und 60, Fig. 3. 4.

Durch die Länge seiner männlichen Taster, die über den ganzen Kopt und das Rückenschild hinäber geschlagen sind, während die weiblichen T'aster nur bis zur Stirn heraufreichen, steht dieses Genus unter den Tineinen ver. einzelt da. Bei den Pyraliden giebt es ähnlich gebaute Gattungen, z. B. Deuterollyta, und manche Phycideen zeigen wenigstens in den männlichen Tastern eine viel höhere Ausbildung als in den weiblichen. Zu ihnen lässt sich Ancphora ummöglich stellen, sondern die Gattung scheint eine ächte Tineine zu sein. Clemens will sie in Stainton's Exapatiden unterbringen, was aber nicht anzugehen scheint, weil bei diesen die t'aster in beiden Geschlechtern entweder gleich oder, wie bei Chim. fagella, beim $\subseteq$ ausgebreiteter sind als bein $\sigma^{\top}$. litwas Analoges in der Tasterbildung, nämlich der Kürze oder dem Felılen der T'aster, haben wir bei den Tineaceen, namentlich den ersten derselben (Tuluepmic und Solenobia) und den letzten (Nemotois), und so möchte sich wohl der Schluss rechtfertigen, dass Anephora ihren richtigen Platz unter den Tineaceen liabe. 
Clemens charakterisirt die Gattung ziemlich genan, jedenfalls kenntlich. Dass das Wurzelglied der Taster verengert (arctate) sein soll, kamn sich nur auf dic geringere Verdickung durch Haarschuppen bei einer einzelnen Art (oder vielleicht einigen wenigen) beziehen; da bei einer zweiten dieses kaun der Fall ist, bei den zwei mir bekannten aber das erste Glied - ohne Beschuppung -dicker als die folgenden und dabei von so mngewöhnlicher Länge ist, dass cs sich un das ganze Gesicht bis anf die Mitte der Stirn herum bjegt, so glaube ich, Clemens habe arcuate schreiben wollen. Dieses Glied ist zugleich an das Gesicht angedrückt, wodurch eine Art Rinne für dasselbe entsteht und wenigstens bei einer Art (Scardina) die Haarschuppen zwischen beiden Tastern einen Haarkamm bilden, der oben in die rückwärts gestrichenen Schuppenhaare des Oberkopfes übergeht. - Als Gattungscharakter hebt Clemens die im männlichen Geschlecht auf der Unterseite sägezähnigen Fühler hervor. Hierüber bemerke ich folgendes. Ohne genaue Untersuchung erscheinen sic fast einfach, nur stark zusammengedrückt. Erst bei genauerer mikroskopischer Untersuchung zeigt sich, dass sie anf der Unterseite sehr gedrängt sägezähnig sind und sehr zarte Pubescenz haben. Bei der einen Art sind die Sägezähne, weil sie ziemlich lang und dünn sind und nicht zu dicht stehen, ziemlich leicht zu unterscheiden, bei der andern sind sie kürzer, breiter, am Ende gerade abgestutzt und so dicht zusammengerückt, dass sie nur bei rückwärts gebogenem Fühler auseinander treten, sonst aber dem Fühler das obenerwähnte Ansehen geben, als ob er zusammengedrückt und auf der Unterseite kaum gekerbt ist.

Anf den Vorderflügeln ist die Mittelzelle durch drei Adern in vier Längsfelder zerschnitten. Von der Subcostalader gehen zwei Aeste in den Vorderrand vor der Flügelspitze und einer in diese selbst. Das Enddrittel der Falte ist in eine Ader verwandelt. Auf den Hinterflügeln ist die Mittelzelle durch eine zarte Ader geschlossen, durch welche eine von der Subcostalader herabkonmende und die Zelle durchschneidende Ader unaufgehalten bis zum Hinterrand fortläuft.

$\mathrm{Ob}$ ich die Clemens'schen Arten unter den meinigen vor mir habe, kann ich aus seinen Angaben nicht mit Sicherheit erkennen; ich gebe also letztere unter eigenen Namen.

\section{Scardina.}

? Popernella Clemens 1. c. p. 57.

Antennis of ricte servatis, dentibus gracitibus; alis ant. brunescentibus, juxta dorsum pullescentilus, ceterum fusco-strigulatis, stria pullida plicae per maculam fuscam terminata, macula venae tronsversae fusca. O".

Diese Art ist in Grösse und, da sich ihre gröberen Schuppen leicht abfliegen, in Färbung und Zeichmung veränderlich, und selbst ihre Hinterflügel sind mehr oder weniger zugespitzt. Nebst ihren Fühlern macht der blassgelbliche Streifen in der Vorderflügelfalte sie kenntlich.

Vorderflügel 5-6“" lang, länglich, nach hinten fast gar nicht erweitert, mit schwach convexem Hinterrand und etwas stumpfer Spitze. Grundfarbe graulehmfarben, mchr oder weniger zu Braun verdunkelt vdex - wohl durch längern 
Flug - zu dunklem Schiefergran, das in gewisser Richtung ein wenig hellviolettlich schimmert, abgeändert, reichlich mit groben, braunen Querstrichelchen bestreut, in dem Ramm zwischen Falte und Inneurand heller. In der Falte ist in einiger Entfernung von der Basis ein ziemlich breiter, hellgelblicher Längsstreif, der durch längern Flug um so dentlicher hervortritt, an beiden Rändern theilweise mit einem sehwarzbraunen Streifen eingefasst ist und nach hinten dureh einen starken, unregelmässigen schwarzbraunen Fleck begrenzt wird. Ein kleinerer solcher Fleck liegt auf der Querader, und hinter ihm färbt sich ein grösserer oder kleinerer Raum ohne deutliche Begrenzung hellgelblich. Die Franzen sind heller als die Grundfarbe und sehr verloschen dunkler gescheckt.

Hinterfliigel dunkelbraungrau (bei meinen zwei alten Exemplaren mit gelblicher Beimischung, aber durchaus nicht auf der ganzen Fläche brownish-yellow, wie An. Popeanella sein soll), lichter gefranzt.

Vaterland: Texas (Boll.). (Ein ziemlich gut erhaltenes und drei ganz verflogene aus dem Cambridger Museum); Carolina (nach einem kleinen Exemplar aus dem Berliner Museum; es ist das hellste und am wenigsten querstrichige von allen). Bei einem Exemplar unbekannten Vaterlandes meiner Sammlung, dem grössten von allen, ist der hellgelbliche Faltenstreif fast verdeckt, und der folgende schwarzbraune Fleck halbeiförmig mit abwärts gewendeter Rundung, also ungefähr wie er bei Popeanclla sein soll.

\section{Bombycina n. sp.}

Antennis aretissime scrratis, dentibus truncatis; alis unt. o cinereis, maescrtim al costam latericio tinctis, q cincreis, strigulis fuscis usperis copiose spursis, of 9 macula venue trunsversac fusca; posterioribus ơ fuscescentibus, + cinereis.

Viel kräftiger und plumper als die vorige, spinnerförmig, mit weniger langen, kürzer gezähnten Fïhlern, breiteren, stumpferen Hinterflïgeln und ohne gelblichen Faltenstreif, dagegen mit beim $\sigma^{-7}$ längs des Vorderrandes ziegelroth angelaufenen Vorderffügeln. Etwas grösser als Scardina. Die mänulichen Taster reichen nur bis zur Mitte des Rïckens, sind aber dichter nnd länger and so behaart, dass kein Raum für einen Haarkamm im Gesicht wie bei Scardina zwischen ihnen übrig bleibt; die weiblichen Taster siud gleichmässig langhaarig und reichen bis an die Stirn, deren Haare sich den ihrigen eng anschliessen. An den männlichen Fühlern stehen die Zähne dichter und sind breiter und kürzer als bei Scarlina und am Ende abgestutzt; beim $q$ sind die Fühler etwas kürzer und dïnner und anf der Unterseite mit kurzen, geneigten Querlamellen versehen.

Vorderflügel fast $7 "$ lang, etwas breiter als bei Scardina, beim ơ bellgrau (bei einem Exemplar mehr als bei dem andern), hier und da, am lebhaftesten längs des Vorderrandes, hell ziegelroth angelaufen. Eine ziemliche Anzahl brauner Querstrichelchen (die bei dem einen Exemplar gröber und fast zu Fleckehen geworden sind), ist ohne bestimmte Ordnung über die lintern $2 / 3$ ausgestreut. Sie laufen bei dem einen Exemplar auf der Falte hinter der Mitte (wo Scardina 
ihren dunkelbraunen Fleck hat) zu einem bestimmt begrenzten Fleck zusammen, während das andere Exemplar keine Andeutung davon besitzt. Beiden Exenıplaren fehlt der hellgelbliche Faltenstreif der Seardina gänzlich; dagegen zeigt sich auf der Querader ein brauner, wischförmiger Fleck. Franzen grau hell ziegelroth angelaufen.

Beim Weibchen, das sehr verschieden aussitht, ist die Grundfarbe dunkler aschgran, mit sehr wenig Lilafarbe gemischt, und ohne jedes Rotb, reichlich mit groben, etwas aufgerichteten Schuppen bestreut. Dunkelbranne Schuppen bilden eine Menge fast gitterartig zusammenschliessender Querstriche. Auf der Falte linter der Mitte treten sie zu einem Fleck zusammen, und einen zweiten, der grösser ist als beim o , trägt die Querader. Franzen des Vorderund Hinterrandes verloschen bell und dunkel gescheckt.

Hinterflügel $\sigma^{\nearrow}$ dunkelbraungrau, $q$ sehr hellgrau. Dier Franzen sind nm den Analwinkel bräunlichgrau.

Vaterland des of (nach Lederer): Buenos Ayres; dic zwei $0^{-1}$ : welche ich durch Dr. Packard erhielt, stammen vermuthlich aus Massachusetts.

A umerkung. Das maroon-brown, auf das Clemens bei seiner Plumifrontella p. 57 bedeutendes Gewicht legt, vernisse ich bei meinem Exemplar durchaus; ebenso den brannen Faltenfleck der Vorderfügel gegen die Basis. Die ausserordentlich grobe Beschuppung der Vorderflügel des siidamerica$\mathrm{n}$ ischen Weibchens, der Mangel altes Rothen, die ganz bellen und stumpfern Hinterflügel liessen mich anfangs zweifeln, ob es wirklich mit dem Männchen zu vereinigen sei. Aber das genau übereinstimmende Flügelgeäder, das besonders a uf der Unterseite der Hinterfliigel recht sichtbar hervortritt, hat mein Bedenken gehoben.

\section{Fylesthia Clem.}

Die Gattung ist gut begründet und durch den wollhaarigen Kopf, den fast augendeckelartigen Schuppenbusch am Wurzelglied der Fübler, die Haar bürste an der Unterseite des zweiten und die Kürze des dritten Tastergliedes leicht zu erkennen. Von Ochsenheimeria unterscheidet sie sich durch den dïnnen Hinterleib und den hervorstehenden Legestachel des Weibchens, die reichlich und lang behaarten Hinterschienen, die längern Fühler, den Mangel der Ocellen, das freie Endglied der Taster — von Hapsifer durch den reichlich beharten Wollkopf, die kürzern Fühler mit einem Schuppenbusch am Wurzelglied, das freie Endglied der Taster - von Ateliotum, welcher Gattung sie im Kopfbau nahe kommt, durch den Fühlerbusch und dis nicht verlängerte Bürste des zweiten Tastergliedes - von Setomorilua (Lep. Caffr. p. 93) durch den wolligen (nicht glatten) Kopf, den Fühlerbusch, den ganz andern Tasterbau (indem bei Setomorpha kein Busch am zweiten Gliede vorhanden und das Endglied flach gedriickt ist).

Clemens hat seine $X y l$. pruniramiella aus knotenförmigen Holzauswüchsen an den Aesten der Pflaumenbämme gezogen, muss also vou ihr unversehrte Exemplare vor sich gehabt haben. An diesen sieht er ndie Vorderfiügel schwarzbraun 
oder gelbbraun, etwas weisslich bunt, mit rauhen Schuppenflecken an der Basis und längs der Falte". Ferner sieht er wohl undeutliche, weissliche Binden; aber sie bilden ihm keine Doppellinien, und er zählt weniger als ich an meinen Exemplaren. Obgleich der „schwärzliche Fleck in der Flügelspitze, einwärts weisslich eingefasst", auf diese gut zu passen scheint, so halte ich es doch für sicherer, sie unter einem eigenen Namen aufzuführen.

\section{Xyl. congeminatella 11. sp.?}

Capite et thorace albis, alis ant. elongatis, lutescentibus, squamis asperis fuseis adspersis, strigarum congeminatarum paribus fere quinis albilis obsoletis, macula venae transversae punctoque apicis subocellari fuscis. ơ 9 .

Kopfbekleidung rein weiss. Fülıler mit sehr gedrängten, gezähnelten Gliedern, gelblichbraun, an Wurzelglied weiss, und ebenso auf dem Rücken der Geissel in grössever oder geringerer Ausdehnung. Lippentaster von Kopflänge, weiss; das zweite Glied mit zusammengedrückter, gleichmässiger (nicht nach vorn in einen Busch verlängerter), innen und aussen grau angelaufener Bürste und an der Seite mit einzelnen Borsten; das Endglied kaum halb so lang wie das zweite Glied, glattschuppig, ein wenig aufgerichtet. - Ruickenschild weiss, hinten etwas braun bestäubt. Beine bräunliclı, an den Enden der Glieder weisslich; die Hinterschienen mit zwei Paaren langer Dornen und mit langen, blonden Haaren reichlich bekleidet. - Hinterleib braun, am Bauch weisslich, schmächtig und etwas zusammengedrückt, beim o mit schwachem Afterbusch; heim $Q$ bedeutend länger, zugespitzt, mil lang hervorstehendem Legestachel.

Vordesflügel $2^{1} / 2-3^{\prime \prime \prime}, q 3^{1} / 2^{\prime \prime \prime}$ lang, ziemlich schmal, nach hinten schwach erweitert, dann sanft verengert und an der Spitze abgerundet (in Gestalt und Färbung etwas an Acrolepia granitella erinnernd), hell lehmgelblich mit zerstreuten, groben, schwarzen und weisslichen aufgerichteten Schuppenpunkten. Durch das Spannen werden wohl die meisten niedergedrückt; aber bei keinem meiner fünf Exemplare scheinen sie an der Basis und an der Falte am häufigsten gewesen zu sein. Ziemlich gleichmässig theilt sich der Raum der Länge nach in Bänder der Grundfarbe und fast ebenso breite, paarweise gestellte weissliche, doch mehr oder weniger, besonders hinter der Mitte, undeutliche Querlinien; solcher Paare sind bei den am deutlichsten gezeichneten Exemplaren fünf vollanden; sie sind ein wenig schräg nach hinten gelegt und schwach wellig; ausserdem ist die Flügelwurzel weiss. Die Bänder, welche die Grundfarbe bilden, sind etwas breiter als je ein Paar der Querlinien. Auf der Querader liegt ein grösserer, eckigel, dunkelbrauner Fleck und zuweilen vor ihm in der Mittelzelle ein anderer. In der Flügelspitze ist ein schwarzbrauner Punkt, einwärts weisslich umzogen, wodurch ein unvollständiger Augenpunkt gebildet wird. Vor der weisslichen Einfassung zeigen sich einige schwarzbraune Punkte oder Striche, die eine unvollkommene Querreihe bilden. Die Franzen sind an der Wurzel von einer schwarzbraunen Linie umzogen. Im Innenwinkel ist bisweilen ein undeutliches, weissliches Fleckchen. 
Hinterflïgel kaum so breit wie die Vorderflügel, lanzettförmig zugespitzt, braungrau, beim $\sigma^{-1}$ sehr schwach, beim 9 deutlich purpurschimmernd. Franzen heller, mit bleichgelblicher Wurzellinie.

Unterseite braungran, verloschen purpurschimmernd; die Vorderflügel in den Vorderrandfranzen und in der Worzel der Hinterrandfranzen mit verloschenen, bleichgelblichen Fleckchen.

Vaterland: Nassachusetts; vier $\sigma^{-7}$ an verschiedenen Tagen des Juli, das ㅇ am 13. von Burgess bei Beverly gefangen, in meiner Sammlung.

\section{Amydria effrenatella Clem.}

Alae ant. lutescentes, parte costali ex basi obscurata punctis grossis, fuscis adspersae, parte dorsali puriore, marginibus costali et postico fuscomaculatis, litura fusca venae transversae cum litura plicali cohaerente. $0^{7}$.

Clem. ed. Staint. p. 55 p. 60 Fig. 2. (Kopf, fälschlich mit Borsten auf der Oberscite des zweiten Tastergliedes).

Clemens scheint mir gegen Stainton (Anm. S. 55) Recht zu haben, dass Amydria nicht mit Euplocamus oder Scardia vereinigt werden kann. Letztere Gattung hat zwar gleich kurze, gedrängte Fühlerglieder; aber sie sind im mänılichen Geschlecht doppelt gefranzt, und die deutlichen, fadenförmigen Maxillartaster sind mehrgliedrig. Bei Amydria dagegen sind die Füliler ganz ungefranzt, und ihre Glieder nur gegen die Spitze hin sehr kurz gezähnelt; die Maxillartaster sind sehr kurz und versteckt (nach Clemens zweighiedrig). Euplocamus hat keine Maxillartaster, und die Fühlerglieder zeichnen sich durchaus nicht durch Kürze aus, nnd die männlichen tragen lange, gefiederte Kammzähne. - Bei Sc. boleti kommen auf den Vorderflïgeln die beiden über der Spitze mündenden Aderäste aus einem gemeinschaftlichen Stiel; bei Amydria bleiben sie an der Wurzel getrennt. Die richtige Stelle für die Gattung scheint hinter Scardia zu sein.

Am. effienatella hat das Aussehen einer Tinea, etwa der spretella in vergrössertem Massstabe; sie wird aber durch die Taster sofort von Tiner ausgeschlossen.

Die Vorderflügel sind nicht schmal (narrow, Cl.), soudern nur länglich, nach hinten erweitert, dann zugespitzt, am Vorderrand nur gegen die Spitze gekrümmt, glanzlos, hell lchmgelb nit groben, braunen Fleckchen bestreut, die von der Wurzel aus längs des Vorderrandes auf $1 / 3$ der Länge zusammenfliesseu; nach hinten und gegen den Inmenrand zu sind es eher Punkte von ungleicher Grösse, die deu Grund sehr sichtbar lassen, besonders am Innenrand. (Nach Clemens wird beim $\rho$ das Braune zur Grundfarbe, und das Gelbe tritt nur fleckartig hervor [varied with yellow], an meisten am Innenrand). Auf der Querader ist ein grosser, wischförmiger, Querfleck, der an einen dicken, tiefbraunen Längsstreif der Falte anstösst. Bei einem Exemplar zeigt sich in der Falte vor der Mitte noch ein kürzerer, fleckartiger, tiefbrauner Längsstrich. Am Vorderrand liegen von der Hälfte an grosse, eckige, braune Flecke, welche würfelartig mit helilehmgelben wechseln; sie gehen über in eine am Hinterrand 
hinziehende Reihe brauner, hellerer Flecke. Franzen staubgrau, vom Hinterrand dureh eine branngraue Linie getrennt.

Vaterlaud: Pennsylvanien (Clemens); Massachusetts bei Beverly, wo Burgess meine 5 ơ vom 3-8. Juli fing.

Tinea (Btubophames) arsistrigella Cl.

Capillis esalbidis, thorace allon, scapulis utris; alis ant. atris, vitta dorsuli simuata, macula costae meatice inferius hyalinu punctisque costre ante apicem allis. ơ $\mathrm{O}$.

Tinea dorsistrigella Clemens ed. Staint. p. 49.50.

Obgleich sie unr schwache Farbenunterschiede vour unserer $T$. ferruginella zeigt, so stimme ich doch Stainton bei, sie für eine sicher versehiedene Art $7 u$ halten. Die Diagnose giebt die anffallendsten Unterschiede genügend an; ausser* dem sehe ich bei Dorsistrigella die weisse Dorsalstrieme dem Costalfleck gegenüber tiefer eingedrückt und deren Endtheil mit einer Anzahl ungleich grosser, schwarzer Punkte bestrent, währ'nd bei Fermujinella die rostgelbe Strieme bis zum Ende ganz rein bleibt. Dic Zahl der Costalpunkte ist veränderlich, zwischen Mittelfleck und Flügelbasis sind wenige sehr kleine, oder gar keine vorhanden. In der Grösse scheint Dorsistrigella wenig abzuändern.

Vaterland: Pennsylvanien (Clemens) und Massachusetts; meine vier Exemplare wurden von Burgess an vier verschiedenen Tagen des Juli bei Beverly gefangen.

Anmerkung. Hübner's Mendicelle Fig. 179, im Text S. 63 uffenbar nach der dbbildung beschrieben, stimust zwar hinsichtlich der weissen Vorderflïgelzeichnung mit Dorsistrigella; aber die Grundfarbe soll granbraun sein, mud dabei sind Kopf und Rückenschild braun bemalt. Sicher ist diese Mendicell nichts weiter als in verdorbenes, ganz abgeblasstes Excmplar der Ferruginella.

Timen (Blabophanes) rusticella St.

\section{on Tinea biflavimaculella Clemens 1. c. p. 49. 50.}

Ieh habe ein grosses, am 11. Juli gefangenes $\sigma^{7}$, das mit zwei ebenso grossen livländischen Exemplaren genau ïbcreinstimmt, und drei kleine $q$ (gefangen 7. Juli, 1. und 9. August), die sich gleichfalls von den ebenso grossen europäischen o nicht unterscheiden. Burgess fing die vier Exemplare in Massachusetts. - Nach Clemens fliegt die Art in August und September. Da ich die $\delta^{7}$ am frühesten am 15. Mai fing, so ist eine doppelte Freneration der in alten Vogelnestern lebenien Art ziemlich gewiss.

Tinea refectella n. sp). Taf. III. Fig. 8.

Caprillis, thorace alisque ant. niveis, his rarius inordinate nigropunctatis, striga abrupta mrope basim, striga media acute refracta, dorsum non tangente striaque ante marginem posticum atris, ciliis albo cinereoque tessnlatis. O’.

Die nächste Verwandte der enropäischen Nigralbella (Herr. Schff. Fig. 296), von ihr dadmoh virschieden, dass ihr das zweite Paar schwarzer, envergirender 
Querstriche bei 1/3 der Länge (der cine vom Vorderrand, der andere vom Innenrand ausgehend) ganz fehlt, und dass der lange, spitzwinklig zurïckgebrochene Querstrich der Flügelhälfte sich fast bis znm Innenrand fortsetzt, statt wie bei Nigrullella in der Flügelnitte anfzuhören und in dem eben erwähnten Innenrandstrich gleichsam seine Fortsetzung zu haben. Auch die Zeichnung vor deni Hinterrand ist anders; doch mag sie veränderlich sein.

Grösse der Nigrulbella- $\sigma$. Vorderflügel 31/2" lang, etwas schmäler als dort, rein weiss. Nicht weit von dor Wurzel liegt ein schwarzer Sehrägstrich, der vom Vorderrand alfängt, sich in der Falte verdickt und keine Andentung einer Fortetzung bis zu dem Punkte am Anfang des Innenrandes zeigt. Nach cinigen zerstreuten schwarzen Punliten folgt in der Flügelhälfte die schwarze, schräge Querlinie, welche wie bei Nigrallella ibre Richtnng gegen deu untersten schwarzen verdichten Strich des Hinterrandes nimmt, sich aber gleichfalls unter einem spitzen Winkel bricht und dann sich dem Innenrand zuwendend bis über die Falte hinwegreicht. Hinter zwei Costalpunlten kommt vor der Flügelspitze eine den Hinterrand parallele, unregelmässig verdickte Linie herab. Dun Histerrand begleitet cine Reiho schwarzer Strichelchen, die nach unten an Stärke zunehmen, und von denen das im Lnmenwinkel das grüste ist. In der Flügelspitze ist ein stärkeres Flckchen. Von den Hinterrandstrichelchen aus gehen durch die Franzen droi breite, graue, schwarzbestäubte Schatten, zwischen denen die weisse Farbe cinen schmäleren Raum einninmt.

Hinterflügel, wie bei Nigrallella, beträchtlich schmäler als dis Vorderflïgel, zugespitzt, hellgrau.

Anf der Unterseite sind die Vorderflügel einfarbig branngrau, die Franzen verloschon weisslich gefleckt.

Vaterland: Californien, bei san Francisco, won wo ich durch Loew eiu gutes o erhielt.

Anmerkung. Die Diagnose der Nigralbellu (Linnaea entomol. VI, 131) reicht nun nicht mehr aus, sondern mass hinsichthich der Vorderflitgelzeichnung erweitert werden, etwa so: strigis tribus ex costa (mima et tertia refruetis), unu ex dorso ante medium, muctis enstalibus maryineque postico atris, ciliis albo cinereoque tessulatis.

Tinea grumella n. s]. Taf. III. Fig. y.

Cupillis luteis; alis ant. nitidulis, lutescentibus, moreter dorsum fusecscenti-suffusis, punctis majusculis \& (superiore ante, inferiore post medium) striguluque cence trausversur fuseis, margine postico grosse fusco-punetato, eitiis dilutis. + .

Von Tin. pellionella ist sie sieher versehicden durch die stärke der duskelu Voruerflügelzeichnnng, besonders durch die sehr hervortretenden grossen und vollständigen Puıkte des Hinterandes, welehe bei Pellionell Viel näher kommt sie der Pallescentella, deren Hinterrand gavz ähnlich, nur mit viel vesloscheneren uni kleineren dunkelbraunen Punkten gezeichnet ist. Meine sieben Pallescentella haben gräber bestäubte Vorderflügel (was vielleicht 
daher kommen mag, dass sie etwas verflogen sind); der Qurraderfleck ist nur kleip und gerundet; in der Falte ist nicht ein Punkt, sondern ein dicker Strich, der ziemlich weit gegen die Wurzel verlängert ist und nur bis unter den Anfang des Discalfleckchens reicht, statt diss bei Crumella ein über die Falte hinwegreichend $r$ Fleck, und zwar weit hinter dem Discalfleck, vorhanden ist. Ausserlem liat Pallescentella ein convexen, Grumella einen nor an der Wurzel schwach gebogenen, sonst wie bei Pellionella geraden Vorilerrand. Also sind heide sicher verschiedene Arten.

Grösse einer mittleren Pellionella oder kleinen Pallescentella. Kopfhaare dunkel röthlich lehmgelb, dunkler als bei beiden Arten. Vorderflügel fast $4^{\prime \prime \prime}$ lang, in der Gestalt etwa wie bei Pellionellı, also mit geraden, nur an der Wurzel und ganz am Ende schwach herabgehendem Vorderrand, fett g]änzend, bleich lelımgelb, am Vorderrand von der Wurzel bis zur Hälfte brann unterlaufen, sonst mit braunem Staub bestreut, welcher unterhalb der Falte von der Wurzel ans fast einen Streifen bildet und zwischen dem Queraderfleck und dem Hinterrand an meisten gelıänft ist; am reinsten bleibt übrigens die Innenrandhälfte. Eiı starker, dunkelbrauner Punkt liegt im Mittelraum, etwas näher der Querader als der Basis. Schräg hinter und unter ihm ist ein etwas verflossener, in der Falte am meisten verdunkelter Fleck. Die Querader trägt einen dicken, tiefschwarzen Querstrich, der sich durch die Bestäubung schräg gegen den Hinterrand verlängert. Am ganzen Hinterrand und um die Spitze bis in den Vorderrand hinein sind dicke, schwarze Punktfleckchen; von denen, die der Querader gegenüber liegen, zieht sich dichte, braune Bestäubung, welche helle Längs streifen zwischen sich lässt, bis zum Queraderfleck. Franzen heller als die Grundfarbe.

Hinterflügel, wie es scheint, etwas schmäler als bei Pallescentella; insbesondere an der breitesten Stelle hinter der Mitte.

Vaterland: Massachusetts. Ein gut erhaltenes $Q$, mit mehreren von Burgess an 8. Juli gefangen, in meiner Sammlung.

Tiner spretella (S. V.) Stainton.

- Z. Linnaea entom. VI, S. 154.

Tinea muilipennella Clem. (ed. Stainton) p. 50 und 52.

Wenn nicht Stainton die Clemens'sche Nubilipennella für unsere Spretella (fusci-punctella Haw.) erklärt hätte, so würde ich sie schwerlich aus der Beschreibung erkannt lıaben. Nach Clemens sollen die Hinterflügel „bläulich, grauglänzend, und ihre Franzen von derselben Färbung" sein! Heinemann hat (Tin. p. 53) besser gethan, als ich und Clemens, indem er auf den Vorderflügeln das Gelbliche als Grundfarbe betrachtete.

Das einzelne mir vorliegende $\delta$, von Boll aus Texas mitgebracht, gehört zu meiner Var. b.; doch ist der schwarze, strichförmige Punkt der Flügelfalte ganz deutlich, und die Hinterflügel sind besonders hell und ihre Franzen sehr bleichgelblich. 
Tinea misella Z.

Linnaea ent. VI, S. 151.

Von dieser an ihıen violettschimmernden Hinterflïgeln leicht kenntlichen Art brachte Boll mehrere Exemplare aus Texas mit, von denen ich ein or vor mir habe. Es weicht von den europäischen kaum dadurel etwas ab, dass der Vorderrand der Vorderflügel auf der hintern Hälfte deutlichere, braune, durch breitere gelbliche Färbung getrennte Flecke hat. - Bei Clemens finde ich keine entsprechende Beschreibung.

\section{Tiner (Tineola) biselliella Hummel.}

Tineu lanariella Clem. (ed. Stainton) p. 50 und 52.

Von dieser Art, die als Einwanderin wohl in allen nordamericanischen Städten vorkommt, und deren Naturgeschichte Clemens kurz beschreibt, thielt ich durch Dr. Speyer ein kleines $\subseteq$ aus New-York.

Anmerkung. Bisselliella, wie das Wort Hummel schreibt, habe ich in der Isis und Limnaen stillschweigend in Biselliella corrigirt; Heinemann macht daraus Biseliella, vielleicht durch einen Druckfehler.

\section{Setomorpha Z.}

Lepid. micropt. Caffr. p. 93.

Ueber das Zweifelbafte der Stellung dieser glattköpfigen Gattung habe ich mich a. a. 0. ausgesprochen. Vielleicht lehrt das Geäder und die früheren Stände Sichereres. Für jetzt weiss ich weiter nichts hirzuzufügen, als dass die Arten schwer zu unterscheiden sind, und dass die beiden Geschlechter nicht bloss der africanischen Set. rutella, sondern auch der americanischen Arten in der Grösse sehr verschieden zu sein scheinen.

Die drei mir vorliegenden Exemplare aus Texas sind den Tastern nach wenigstens zwei Arten; sie haben alle eine äussere Aehnlichkeit mit Tinea misella, entbehren aber den dentlichen Purpurschimmer der Hinterflügel.

\section{Set. operosella n. sp.}

Alis ant. oblongis, ditute luteis, fusco-nebulosis, costa fuseo-punctutu et postice maculata. 9 .

In der Grösse der grössten Tin. misella $f$, doch mit kürzeren Vorderflügeln; verschieden von der grösseren Set. vutella $f$ durch viel weniger gestrcckte Vorderflügel und weniger lang zugespitze Hinterflügel; vou len zwei folgenden Arten (von denen Inamoenella mit ihr und mit Rutella in den flachgedrückten Tastern stimmt) und der cubanischen Rupicella (Lep. micr. Caff. p. 95) durch viel beträchtlichere Grösse, von der letzteren Art durch hellere Grundfarbe, von Rulerella durch den Mangel grosser, schwarzbrauner Flecke auf der unteren Hälfte der Vorderflügel.

Rüikenschild bleich lehmgelb mit brauner Bestäubung; die hellen Schulterdecken an der Wurzel braun. Kopf staubgrau, dunkler bestäubt. Fühler mit sehr gedrungenen Gliedern, hellbräunlich, etwas schimmernd; das Wurzelglied 
braun mit bleichgelblicher Spitze. 'Taster stark flachgedrückt, auf der flachen oberen Seite bleichgelblich; das zweite Glied anf der unteren Seitc braun, an den Seiten mit mehreren abstehenden Borsten; das dritte mehr als halb so lang wie das zweite, schmäler, stumpf, fast einfarbig bleichgelblich. - An den Vorderbeinen sind Hüften und Schenkel grau, Schienen und Füsse braun, erstere weissfleckig, letztere mit weisslichen Enden der Glieder. Hinterbenne schmutzig hellgelblichgran; die Schienen auf dem Rücken reichlich grauhaarig, die Füsse schimmernd, aussen hellgrau mit breiten weisslichen Enden. Hinterleib grau mit weisslichem Bauch, kräftig, lang zugespitzt mit langem Legestachel.

Vorderflügel 4"“ lang, länglich, dnrch die Befranzung scheinbar erweitert, an der Spitze abgerundet, bleich lehmgelb mit schwarzbraunen Schuppen bestrent, welche an der Flügelwurzel einen lichten Nebel und in der Falte vor der Mitte einen starken, doch nicht sonderlich scharf begrenzten Längsstrich bilden; im Mittelraum über dem Enddrittel der Falte sind mehrere zusammenfliessende unregelmässige Längsstriche. Anf dem Innenrand liegen wenige Flecke; auf dem Vorderrand in der Wurzelhälfte acht ungleiche, etwas grosse Punkte, in der Endhälfte sechs Flecke in grösseren Zwischenräumen, von denen die vier letzten die Costalfranzen einnehmen und Schräıstreifen bilden. Franzen gelblichgrau, auf der grössern Wurzelhälfte reichlich schivarzbraun bestäubt, auf der kleineren Endhälfte mit verloschenen, dunkelgranen Würfelflecken.

Hinterflügel hellgrau mit gelblichern Franzen. - Unterseite der Vorderflügel dunkel braungrau, einfarbig; nur die Costalfranzen heller.

Ein schön erhaltenes $\subseteq$ im Cambridger Museum.

\section{Set. incmoenella n. sp.}

Parva, alis ant. oblongis, dilute luteis, fusco-maculatis, infra costam muriorizus, coste tota fuscu-maculata, maculis postice sensim majoribus. o’.

Im Bau und in der Körperfärbung stimmt sie mit der vorigen überein, mit der sie jedoch vorläufig noch nicht als das andere Geschlecht verbunden werden kann.

Hinterleib dünn und verhältnissmässig kurz, hell gelblichstaubgrau.

Vorderflügel $2^{\prime \prime}$ lang, nach hinten etwas erweitert, mit derselben Grundfarbe wie bei Operosella, aber mit gröberen und reichlicheren dunkelbraunen Schuppen bestreut, welche grössere Flecke bilden. Am meisten Flecke zeigen sich auf der grösseren Innenrandbälfte; sie sind so verschieden gestaltet und fliessen so verworren in einander, dass sich ohne grosse Umständlichkeit keine genaue Beschreibung davon geben lässt. Der Raum unterhalb des Vorderrandes ist anch bei Inamoenella viel weniger verdunkelt. Die Costalflecke fangen an der Basis an und nehmen nach hinten an Grösse und Abstand von einander zu; sie sind meist nach innen zugespitzt. Der Hint rrand ist mit einer dunkelbraunen, hier und da unterbrochenen Linie umzogen (diese fehlt der Operosella völlig). Di: Franzen sind reichlich braun bestäubt: die Bestäubung bildet verflossene Würfelflecke. 
Hinterflügel verhältnissmässig etwas breiter als bei Opcrosella. Ilıre Färbung, so wie die der Unterseite, hat nichts voll dieser Art Abweichendes.

Ein gut erhaltenes $\sigma^{\pi}$ im Cambridger Musenm.

\section{Set. rulerella n. sp.}

Palpis temioribus; alis unt. dibutc luteis, dimidio dorsali maculis magnis fuscis, portim subangulatis consperso, punctis costulibus fuscis, postice evenescentibus. Oे.

In der Grösse etwas über Inamoenclla. Wenn ilue Taster nicht bebeschädigt sind, was doch nicht der Fall zu sein scheint, so weicht sie von den andern Arten erheblich ab durch die Dünnheit und etwas ansehnlichere Länge der Taster, und durch deren unverdicktes, mit keinen Borsten versehenes zweites Glied; das längere und dünnere Endglied ist aber docl,, den Gattungsmerkmalen gemäss, flachgedrückt. Unter der Wurzel der Taster steht ein Borstenbusch hervor.

Färbung der Körpertheile wie bei den vorigen, die Hinterbeine sehr blass blond, ungefleckt. Hinterleib heller als bei Inamocnella, etwas seidenglänzend.

Vorderflügel $2^{1} / 4^{\prime \prime}$ lang, etwas breiter als bei Inamocnella, anı Vorderrand vor der Spitze convexer, mit bleich lehmgelblicher Grundfarbe, welcher jedoch etwas Röthliches beigemischt ist. Die Innemrandhälfte trägt grosse, schwarzbraune, zum Theil eckige Flecke, in 2-3 sehr unordentlichen Lïngsreihen: der Wittelfleck des Innenrandes ist der grösste und fast viereckig. Die Flecke, welche auf dem Inmenrande liegen, setzen sich bis zu der Reihe grober, strichförmiger Punkte fort, womit der Hinterrand eingefasst ist. Auf der Vorderrandhälfte des Flügels sind zerstrente Punkte, und der Vorderrand selbst ist von de: Wurzel aus mit eben solchen, nur nach hinten weitläuftiger gestellten und vor der Flügelspitze verschwindenden Punkten bestreut. Franzen hellgrau mit dunkleren, von den Hinterrandpankten ausgehenden Schatten.

Hinterflügel breiter und weniger gespitzt als bei Inamoenclla, ebenso gufärbt. Unterseite der Vorderflïgel braungrau, anf der hintern Hälfte mit bleichgelblicher Costallinie und solcher Flügelspitze.

Ein ziemlich gut erhaltenes of in Cambridger Nuseum.

\section{Adela chalybëis n. sp.}

Capillis fermgineis, antennis of corpore quadruplo longioritus, inferius albo nigroque annulatis; pectore inawato; pedibus nigris, tursis albo-anmulatis: alis ant. angustis, violaceo-nigris, dimidio basali cyaneo-chalybeo. of.

Nach den einfarbigen Vorderflügeln und der Fühlerläng๋ scheint sie einige Verwandtschaft mit Violella zu haben; da aber die in den Hinterrand ausgehenden Adern der Vorderflügel tiefschwarz sind, so könnte man sie auch als verwandt mit Sulzeriella ansehen, nur dass sie wegen der gänzlich fehlenden Binde schlecht zwischen diese und Associatella passen wïrde.

Grösse einer ansehnlichen Sulzeriella. Kopfhaare rostgelb. Füller etwa viermal so lang wie der ganze Körper, an den verdickten 8-10 Wurzelgliedern 
riolettschwärzlich, dann in grösserer Länge deutlich weiss und schwarz geringelt, hierauf in $2 / 3$ der ganzen Länge weiss. Taster klein, dünn, spitz, niederhängend, gelblich schimmernd. Rückensehild stahlblau; Brust vergoldet und glänzend. Beine violettschwarz, an den Seheukeln auswärts vergoldet; alle Spitzen der Fussglieder, sowie die der vier vordern Schienen und ein Punkt hinter der Mitte der Vorderschienen reiuweiss; die Hinterschienen glattschuppig, auf der Inuenseite glänzend hellgelb und gegen die Spitze dunkler. Hinterleib dünu, bläulichschwarz.

Vorderflügel schmal, gestreckter als bei Sulzeriella, mit hervortretender, aber abgerundeter Spitze, violettschwarz, in gewisser Richtung etwas golden schimmerud, an mehr als der Hälfte von der Wurzel aus stahlblau, am lebhaftesten am Inuenrand bis zur Falte. Die in die Räuder auslaufenden Adern sind tiefschwarz, doch nur wenn sie in gewisser Richtung betrachtet werden. Franzen schwarz, mit blänlich violettem Glanz.

Hinterflügel weniger spitz als bei Sulzeriella, heller violettschwarz als die Vorderflügel; die Adern erscheinen in gewisser Richtung sehr deutlich schwarz. Frauzen dunkelgrau, violettglänzend.

Unterseite der Vorderflügel schwarz, bläulichviolett übergossen, mit mehr kupferfarbigen Franzen. Hinterflügel wie oben.

Vaterland: Texas (Boll). Ein o im Cambridger Museum.

Adela bivielle n. sp. Taf. III. Fig. 10.

Capillis palpisque infra nigro-ltirsutis, antennis o' longis, albis, basim versus nigro-subannulatis; alis ant. cupreis, strigis ductus allis, interius atromarginatis. $0^{-1}$.

Wegen des rauhen Kopfes gehört sie in die Nähe der Cuprella, sie zeichuet sich aber vor allen Adelen durch die zwei weissen, einwärts tiefschwarz gesäumten Querlinien aus, von denen die hintere überdies einen geschlängelten Lauf hat.

Grösser als Cuprella, am ganzen Körper schwarz. Stirn dicht und lang behaart. Taster länger als der Kopf; ihre dichten und langen Haare reichen etwas über sie hinweg. Saugrüssel unbehaart. Fühler dünn, lang, weiss, an der Wurzelhälfte aut der Unterseite verloschen schwärzlich geringelt. Alle Füsse an den drei ersten Gliedern mit punktähnlich weisser Spitze; die Hintersehienen ziemlich dicht mit langen Haaren bekleidet und mit hellgelben Dornen; das erste Hinterfussglied auf dem Rücken langhaarig.

Vorderflïgel $31 / 2^{\prime \prime \prime}$ lang, viel gestreckter als bei Cuprella, sanft zugespitzt, violett, mit hell kupferglänzenden Schuppen dicht bestreut. Hinter der Mitte geht eine ziemlich gerade, bindenförmige, weisse Querlinie fast seukrecht herab; sie ist nach unten erweitert, einwärts in ihrer ganzen Länge sehmal tiefschwarz gesänmt, auswärts nur durch einen tiefschwarzen Costalfeck begrenzt. Die zweite weisse Querlinie ist viel feiner, aber einwärts gleichfalls schwarz gesäumt; sie fängt auf dem Vorderrande näher der ersten Querlinie als der Flügelspitze 
an, geht S-förmig gekrümmt herab und endigt am Hinterrand über dem Innenwinkel. Franzen schwärzlich, auf der Wurzelhälfte hell kupferfarbig.

Hinterflügel grau, spärlich beschuppt; die Schuppen sind lang und liegen so zerstreut, dass überall die Membran zwischen ihnen frei bleibt. Franzen schwärzlich, auf dem Wurzeldrittel kupferig und messingfarbenschimmernd.

Unterseite aller Flügel mit langen, schwarzen Schuppen spärlich bekleidet, sonst dunkelgrau, violettschimmernd: auf den Vorderfiügeln scheiuen beide Querlinien durch: der Vorderrand und besonders die Flügelspitze tragen kupfer- und messingfarbige, glänzende, kleine Schuppen ziemlich gedrängt.

Vaterland: wahrscheinlich Massachussets. Ein von Dr. Packard erhaltenes $\sigma^{\gamma}$ in meiner Sammlung.

\section{Adela Schlaegeri n. sp. Taf. III. Fig. 11.}

Caprillis palprisque hirsutis brumeis; antennis longis, albis, basim versus nigro-annulatis; alis ant. luteis, striga media stannea, lineis 3 post eam et serie punctorum majusculorum atris metallice intermptis longitudiualibus. of

Diese sonderbare Art, die mit gar keiner europäischen Adela verglichen werden kann, wohl aber der Zeichnung nach mit einem Wickler, nämlich Gropholitha (Roxana) wreuella, scheint mit der, mir nur aus der Beschreibung bekannten Ridingsella Clem. (ed. Stainton p. 250) eine besondere Gruppe zu bilden, die sich zufolge des stark behaarten, dicken Kopfes und des langhaarigen ersten Hinterfussgliedes an Biviella anschliesst.

Grösse der Sulzeriella. Körper schwarz. Kopf auf Scheitel und Stirn, sowie die Taster, dicht mit langen, gelbbraunen Haaren bekleidet. Fühler fast viermal so lang wie der Körper, weiss, an der grösseren Basalhälfte lebhaft schwarz geringelt, doch so, dass die Rückenlinie weiss bleibt. Saugrüssel unbehaart. - Beine hell ochergelb, alle auswärts braun mit weisser Spitze der Fussglieder. Hiuterschienen mit reichlichen, langen, blonden Haaren und hellgelblichen Dornen; auf der Aussenseite ist ein breiter, bandähnlicher, brauner Fleck; das erste Fussglied hat auf dem Rücken lange, blonde Behaarung, die über die zwei folgenden Fussglieder hinwegreicht.

Vorderflügel $3^{\prime \prime \prime}$ lang, gestreckt, hinten zugerundet, lehmgelb ohne Glanz. In der Mitte ist eine zinnfarbene, glänzende, ziemlich gerade und senkrechte Querlinie. Hinter ihr folgt ein vom Vorderrand schräg einwärts herabgehender, gleichfarbiger Strich, dann zwei kurze, fast verloschene, und zuletzt vor der Spitze ein bis zur Mitte des Hinterrandes reichender, der auf seinem Ende eine glänzendere Stelle hat. Der Raum zwischen der ersten (unvollstäudigen) Querlinie und diesem vierten Querstrich ist hellgelb und in seiner oberen Hälfte mit drei aus tiefschwarzen, hier und da unterbrochenen Schuppenhäufchen gebildeten Längslinien gezeichnet. Im untersten Theile dieses Raumes ist eine Längsreihe von vier grossen, tiefschwarzen, durch Silberglanz getrennten Punkten, und unter ihr liegen noch dicht an Innenrand zwei solche Pünktchen. Der Hinterrand ist mit vier silberglänzenden Fleckchen bezeichnet, von denen zwei zu den tief- 
schwarzen Zeichnungen gehören. In der Flügelspitze ist ein mattzinnfarbiges Streifchen, das aber weiter abwärts ebenso glänzt. Franzen lehmgelb.

Hinterflügel deutlich geadert, dicht und fein beschuppt, braungrau. Franzen an der Wurzel mit messingglänzender Linie umzogen.

Unterseite braungrau, violettlich úberzogen; die Vorderflügel an der Endhälfte des Vorderrandes mit vier, am Hinterrand mit fünf verloschenen wcisslichen Fleckchen. An den Hinterflügeln sind die Franzen um die Flügelspitze heruu an der Wurzel weisslich.

Vaterland: Ohio. Ein $\sigma^{7}$, durch Schläger erhalten, in meiner Sammlung.

\section{Hyponomentu multipunctellus Clem.}

Alis ant. minus elongatis, niveis, seriebus puncturum nigromm longitudinalibus subquinque (serie superplicali punctis 8 composita); post. ơ dilute cinereis, albo-ciliatis, of totis albis.

Hyp. multipunctella Clem. ed. Stt. p. 95. - Millepunctutella Packard Guide p. 348.

Von der Grüsse eines mittleren H. Evomymi, unterscheidet er sich von allen Arten durch breitere Vorderflügel; er gehört zu den Arten mit zahlreichern Punkten der Vorderflügel, ohne dass doch die Punkte, wie bei Padi und Rorellus, darum kleiner wären als bei den mit geringerer Punktzahl gezeichneten. Alle Vorderflügelfranzen sind wie bei Evonymi rein weiss. Beide Geschlechter zeigen in den Hinterflügeln und auf ùer Unterseite einen bei den Europäern gar nicht vorkommenden Unterschied. Die Oberseite der Hinterflügel ist nämlich beim $q$ ganz weiss, beim o weisslich, nach hinten allmälig in Weissgrau übergehend, welches in der Flügelspitze am dunkelsten ist, während alle Franzen wie beim $q$ rein weiss bleiben. Auf der Unterseite ist das $q$ ganz weiss. Beim $\sigma^{7}$ ist sie grau, auf den Vorderflügeln an dunkelsten; ihr Vorderrand ist in einer feinen, sich nach hinten erweiternden Linie weiss, welche in die ebenso weissen Franzen übergeht, von denen aus der ganze Innenrand in einem dünnen Streifen gleichfalls weiss ist; die Hinterflügel sind längs des Vorderrandes grau, am breitesten in der spitze; ihre Franzen rein weiss.

Vaterland: Ohio (Schläger); Illinois (Lederer), Die Art muss sich noch wenig bemerklich gemacht haben, weil Cleneus, der nur das on und so oberflächlich beschreibt, dass die Beschreibung auf alle europäischen Arten mit weissen Vorderflügeln passt, nichts über sie mittheilt.

Anmerkung. Walker beschreibt Cat. XXVIII, (1863) p. 530 einen Hyponom. ordinutellus aus Canada, bei welchem in beiden Geschlechtern alue posticae nigricante-cinereae, fimbria alba sein sollen, und der daher nicht Multipunctellus sein kann, falls das British Museuın diese Angabe nicht widerleyt. Wunderbarer Weise hat er nur ein Exemplar vor sich gehabt und doch beide Geschlechter beschrieben!

\section{Oeta punctella Cramer.}

* Phaluem punctella, Cramer Ins. 31 (recte IV, p. 164), tab. 372, Fig. L. (sec. Fabric.). 
Tinea prustulella, Fabr. Ent. syst. 3. 2, p. 292.

Poeciloptera compta, Clemens, Proceed. Acad. Nat. Sc. Philadelphia 1860, p. 546.

Oetu compta, Grote, Proceed. Ent. Soc. Philadelph. V. p. 230.

The Ailanthus Worm, Oeta compta (Cl.), Riley, First annual Report or the State of Missouri (1869) p. 151, pl. 2, f. 22.23.

Oeta compta, Zeller, Entomol. Zeit. 1871, S. 178.

Die sicher in die nächste Nähe von Hyponomevta gehörende Gattung ist wohl begründet. Clemens, der einen schon verbrauchten Gattungsnanien für sie anwendet, beschreibt ihr Flügelgeäder und giebt als ein Hauptmerkmal die dicht und feingesägten Fühler an. Aber ein ebenso wichtiges Kennzeichen geben die männlichen Hinterbeine. (Clemens, der offenbar nur das $q$ kennt. giebt ein Paar Dornen an Ende der Hinterschienen an.) Sie sind nämlich kürzer und dünner als die übrigen Beine: der Schenkel sehr kurz; die Schiene dreimal so lang, sehr dünn, etwas gebogen, auf der Unterseite mit weichen, schräg gelegten Haaren dicht bekleidet, o hne Dornen; der Fuss kürzer, glei chsam ein dünner, fast ungegliederter Faden ohne Krallen. Das längliche, knospenförmige Analglied des $\sigma^{7}$ ist länger als die drei letzten $\mathrm{Ab}$ dominalsegmente zusammengenommen. - Die Flügelfranzen sind noch kürzer als bei Hyponomeuta.

Durch zwei O der Atteva basalis Vollenhoven, Tydschrift VI (1863) p. 140, tab. IX, f. 6 aus Morotai, die auch zu Oeta gehören, wurde ich auf die Walker'sche Lithosidengattung Atteva (Cat. Bombyc. p. 526) hingeführt. Walker giebt davon eine Beschreibung, die nichts wider Oeta Sprechendes enthält, ausser dass er den Hinterschienen (da er nur das ㅇ kannte) zwei ziemlich lange (rather-long) Enddornen ertheilt, während sie mbedingt kurze, und ausserdem bei $3 / 4$ noch zwei besitzen, voll denen der eine sogar der längste von allen ist. Wenn nun der so genaue Clemens an seiner $P$. compta auch nur ein Paar Dornen sieht (vorausgesetzt, dass er nicht falsch sieht, da ich es ihm in Ermangelung eines Comptaweibchens nicht mit voller Bestinmtheit nachweisen kann), so wird dies bei einem Walker noch viel eher zu entschuldigen sein. Da nun Vollenhoven sich wohl volle Gewissheit über den Gattungsnamen verschaft haben wird, ehe er den Namen Atteva dafür annahnı, so hätte statt Oete die Walker'sche Urschöpfung als Gattnngsname einzutreten.

Die vorliegende Art indert in der Grösse und Zeichnung etwas ab; meiı grösstes Exemplar (aus Texas) hat 51/2"“ Vorderflügellänge; zwei andere, vermuthlich durch die Zucht erhalten, aus Missouri (von Riley und Grote) 5“"; das kleinste, aus Columbien, nur $4^{1} / 2^{\prime \prime \prime}$. Die blauschwarzen Binden der Vorderflügel wechseln in der Breite, so dass die orangerothe Grundfarbe mehr oder weniger eingeschränkt wird, und die schwefelgelben Tropfen ändern in der Grösse und Zahl gleichfalls. Bei dem columbischen Exemplar ist das Roth am meisten eingeengt und die schwefelgelben Tropfen am grössten und wenigsten zahlreich; ich trage kein Bedenken mehr, es für einerlei Art mit den Nordamericanern anzusehen. 
Clemens beschreibt die Art hinlänglich genau. Er erwähnt nicht, dass die Vorderhüften auf der Vorderseite orangerotl sind, mit schwarzer Wurzel und Spitze.

Die dunkelolivenbraune, der Länge nach weissliniirte Paupe lebt um St. Louis an Ailanthus zu 5-30 gesellschaftlich innerhalb eines schwachen Seidengewebes im August und September. Sie wird dadurch schädlich, dass sie die Blätter am Stiele abbeisst. Ihre Verpuppung geschieht in dem lockeren Gewebe. Der Schmetterling erscheint nach einer Puppenruhe von zwei Wochen, selbst noch in November, und besucht gern (ob bei Tage?) die Blüthen der Goldruthe and des Eupatorium serotinum. Dass er aber, wie Riley vermuthet, überwintere, möchte wohl wenig Wahrscheinlichkeit für sich haben.

Anmerkung. Die Gattung scheint nicht arm an Arten zu sein. Ausser der schon erwähnten Atteva basalis besitze ich in beiden Geschlechtern Oet a albiguttata n. sp. ablomine fermgineo, alis ant. elongutis, postice truncutis, saturute ferrugineis, postice anguste utris, guttis plurimis niveis sine ordine dispersis; post. nigris, basi aurantiaca. of 9 .

Viel grösser als Punctellı, schlanker und mit länger gestreckten Flügeln. Der ganze Körper rostgelb. Der Kopf mit zwei weissen Flecken hinten ist unter den Augen schneeweiss und hat zwei weisse, breite, nnten vereinigte Linien des Gesichtsrandes. Taster dünn, fadenförmig, etwas aufgebogen, schwarz, am Ende des ersten und zweiten Gliedes mit einem weissen Fleck (beim $q$ ist das erste ganz weiss), am Anfang und Ende des etwas gespitzten dritten weisslich (beim † auch auf dem Rücken). Saugrüssel von Hinterleibslänge, dünn, ochergelb, unbeschuppt. Fühler (wie bei Punctell $t$ ) verhältnissmässig länger als bei Hyponomeuta, sehr gedrängt fein sägezähnig, beim o bräunlich, über dem Wurzelglied auf dem Rücken weiss; beim $q$ hier schwärzlich, dann geringelt, hierauf weisslich; das verdickte Wurzelglied weiss mit schwarzer Spitze. Rückenschild am Kragen mit zwei, auf der Mitte der Schulterdecke mit einem, und vor dem Schildchen mit zwei weissen Flecken; die Brust an der Kehle, so wie zu jeder Seite mit einem weissen Fleck. - Die vier vordern Beine schwarz und weissbunt. Beim $q$ sind die Hinterbeine ebenso stark wie die andern; die Schiene rostbraun, am Ende schwarzbrann mit weisser Spitze, bei $3 / 4$ und an der Spitze mit je einem Paar kurzer, weisser Dornen; der Fuss so lang wie die Schiene, wie gewöhnlich gegliedert, verloschen weissfleckig. Bein $\sigma^{7}$ sind die Hinterbeine ausserordentlich dünn: der Schenkel am stärksten, ochergelb; die Schiene doppelt so lang, dünn fadenförmig, etwas gebogen, ohue Dornen und unbehaart, blassgelblich, innen weisslich; der Fuss ebenso lang, noch dünner, gebogen, mit fast unabgetheilten Gliedern, ohue Krallen, weisslich. Finterleib lang und dünn, am Bauch mit einer Mittelreihe weisser Flecke. Das Aualglied des $\sigma^{\lambda}$ nuch mehr abgesetzt als bei Punctella, länglich eifürmig, so lang wie die drei vorletzten Segmente zusammengenommen; beim $q$ ist dieses Glied viel küızer, nicht abgesetzt, etwas zugespitzt, mit einem Haarbusch, der gegen den Bauch schräg abgeschnitten ist; der Legestachel ist nicht sichtbar. 
Vorderflügel des $\sigma^{7} 5^{1} / 2$, des $7^{\prime \prime}$ lang, schmal, nach hinten allniählich erweitert, an fast geraden Hinterrande wenig schräg, gesättigt rostbraun, anı Hinterrande tiefschwarz. Sehr viele, ungleich grosse, runde oder querovale, reinweisse Tropfen sind über die ganze Fläche ohne erkennbare Ordnung gestreut; die kleinsten liegen auf dem Vorderrande, die grössten als Grenze gegen die schwarze Färbung. Franzen kurz, schneeweiss, an der Wurzelhälfte und über und vor dem Innenwinkel grau.

Hinterflügel des $\sigma^{7}$ etwas breiter, des 9 viel breiter als die Vorderflügel und beim $\sigma^{\nearrow}$ länger zugespitzt als beim $ᄋ$, am Basaldrittel, welches den Analwinkel mit begreift, rostgelb, sonst schwärzlich. Franzen gleichfarbig mit den angrenzenden Flïgelpartien.

Unterseite der Vorderflügel schwärzlich, gegen die Basis nit Rostfarbe gemischt, am Vorderrand vor der Spitze mit zwei schneeweissen Tropfen. Sonst scheinen die Tropfen der Oberseite sehr verloschen durch, am deutlichsten am Innenrand. Die Hinterrandfranzen sind auf der Aussenhälfte schneeweiss. Hinterflügel wie oben.

Vaterland: Australien, Queensland (Masters). $\sigma$ $Q$ in meiner Sammlung.

Walker hat eine Atteva niveiguttata 1. c. p. 526 ans Silhet, die, wenn sie richtig beschrieben ist, nicht meine Art sein kann. Jene soll braune Taster und bräunliche Tarsen und Vorderschienen haben; auch sieht Walker auf den Vorderflügeln fünf Reihen weisser Punkte, die in der Grösse unbedeutend verschieden sind. Die schwarze Spitze der Vorderflizgel und die Farbe der Hinterflügel erwähnt er nicht. Eben so wenig kann meine Art mit Atteva apicalis Vollenh. I. c. p. 139, pl. IX, f. 5 (aus Java) einerlei sein; bei dieser haben die Vorderflügel nur 11-15 weisse Flecke, und ihre ganze Endhälfte ist schwarzbraun.

Eine andere Art sah ich aus Herrich Schäffer's Sammlung; ich nenne sie: Oeta fulviguttata, viridi-nigra, collari scamulisque auratiacis, alis clongatis, anterioribus cyaneo-chalybcis, maculis tribus in disco per longitudinem locatis amontiacis. 0 .

Rïckenschild auf der ganzen Vorderhälfte, sowie am Kragen und auf den Schulterdecken orangegelb, seidenglänzend, auf der Hinterhälfte schwarz mit grünem Schimmer. Kopf (verschimmelt) wahrscheinlich schwarz, an jeder Seite des Gesichtes mit einem weissen Punkt. Fühler schwarz, ziemlich stark, besonders am Basaldrittel, mit sehr zusammengeschobenen, kurzen Gliedern, an der Unterseite schwach gekerbt, gegen die Spitze fein sägezähnig. Taster kürzer als der Kopf, dünn, spitz, mit verlängertem Endglied, schwarz mit einigen weissen Schuppen. Saugrüssel schwarz. - Beine schlank; die vier vordern stahlgrünblau mit schneeweissen Fleckchen und solchen Wurzeln der Glieder. Die Hinterbeine schwarz, am Schenkel weissfleckig; der Fuss sehr verlängert und ausserordentlich dünn, etwas gebogen, mit nicht zu unterscheidenden Gliedern. - Hinterleib lang und dünn, schwarz, hinten und am Bauch stahlblau, letzterer an jeder Seite mit einer Reihe weisser Fleckchen. 
Vordeıflïgel 5"u lang. sehr selımal, mit ziemlich geradem Hinterrand und deutlichem Vorderwinkel, etwas glänzend stahlblau, an der Wurzel des Vorderrandes glänzend orangefarbig und im Mittelraun mit drei grossen, ebenso gefärbten Flecken; der erste ist etwas gestreckt und von der Falte durchschnitten und stelit von der Flügelbasis und dem zweiten gleich weit ab; der zweite, in der Flïgelhälfte ïber der Falte, ist grösser, unregelmässig gerundet und quer; der dritte ist der kleinste, etwas gerundet, dieht über der Falte und mitten zwischen dem zweiten und dem Hinterrand.

Hinterflügel schmal und lang zugespitat, mit haariger, sehwarzer Beschuppung, welche die Membran nicht deckt, sondern halb dnrchsiehtig lässt; die Flügelränder und die Adern sind verdunkelt; die Vorderrandzelle grau beschuppt und undurchsiehtig. Franzen schwarz, violettschimmernd.

Unterseite der Vorderflügel schwarzbraun, an den Pändern blauschimmernd; die Hinterflügel irisiren in der Mittelzelle und zwischen den aus ihr entspringenden Adern.

Vaterland: wahrscheinlich Neuholland.

\section{Tegeticula n. G.}

Capillibreves, hirsuti, ctium in fronte.

Ucelli mulli. - Antennae breves, setaeere, denique attemutae

Palpi labiales breves, tennes, porrecti.

Hanstellum medivere, in dorso squamatum.

Icalum posticurm fomora libiacque robustue, compressue, tibianm dorise viluso.

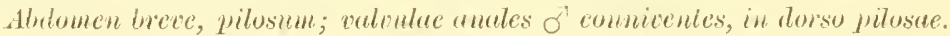

Alae oblongac, brevius ciliatae, posteriores dense piloso-squamutae recuminutue.

Ans der Verwandtschaft der Gattungen I'secudiu, Enuematia und Triehostibus, ron allen durch dic kurzgeschorenen, aufgerichteten Kopfhare, die kräftigen Hinterschenkel und die dicht haarschuppigen Hinterflügel, ausserdem von Psecalia durch die kurzen Fühler und Taster, von Eurcmatit durch die gespitzten, an Hinterrand $v^{\circ}$ der Spitze etwas eingezogenen Hinterflügel untersehieden.

\section{Alba n. sp.}

Alae ant. supra albae, subtus proter cilia fuscescenti-cinereae; post. albae, postice cineraseentes, albo-eiliatce. o'.

Grösse der Pseead. semilugens. Der ganze Körper weiss. Fühler von wenig über halber Vorderflügellänge, borstenförmig. Stirn breit und so wie das ganze Gesicht mit kurzen, aufgerichteten Haaren bekleidet. Maxillartaster halb so lang wie die Lippentaster, diese horizontal, mit kurzem Endglied, unten etwas behaart, aussen ausser am Endgliede braun angelaufen. - Beine kräftig, weiss, mit hellbräunlichen Füssen; die Vorderschenkel und Schienen aussen gebräunt. Die Hinterbeine mit besonders kräftigen, zusammengedrückten Schenkeln 
und Schienen, letztere oben und unten anliegend beliaart, mit zivei Paaren gelblicher Dornen. - Hinterleib ziemlich kurz, gegen die Wurzel hellgrau, an den Hinterrändern der Segmente mit nach hinten immer länger werdenden Schuppenhaaren gesäumt. Die beiden Analklappen löffelfürmig, mit ihrem untern Hinterrand an einander gelegt, auf der Aussenseite kurzhaarig.

Vorderflügel 4-5"“ lang, nach hinten verengert und zugespitzt, mit sehr schrägem Hinterrand, dicht beschuppt, ganz weiss ohne Glanz.

Hinterflügel viel breiter, an der Hinterhälfte zugespitzt, dicht unit weissen Schuppenhaaren bekleidet, die gegen die hellbrüunliche Spitze lileiner werden.

Unterseite der Vorderflügel ranchbram, am Innenrand heller, an Vorderrand in einer nach hinten erweiterten Iinie weiss. Die Mittelzelle hat eine deutliche Nebenzelle. Hinterflügel in der spitze und in einer breiten Costalstrieme hell rauchbraun. Alle Franzen weiss.

Vaterland: Texas (Boll, Belfrage). Ein gut erlaltenes, von Belfrage am 24. Mai gefangenes $\sigma^{-1}$ in meiner Sammlung, ein anderes im Museum Canbridge.

\section{Plutella cruciferimu Z.}

Plut. limbipemella Clem. p. 90. - mollipedella Cl. p. 91.

The Cabbage Moth. Cerostoma brassicella, Fitch. Report. New-lork. 1856, p. $170-175$.

Da die Innenrandstrieme der Vorderflügel des of oft röthlichgrau und auf dem Innenrande selbst schwarzbraun punktirt ist, so brancht Clemens in seiner Hollipedellu nicht gerade das Weibchen dieser Art beschrieben zu haben. Beide Beschreibungen sind nur oberflächliche. - Die Veränderlichkeit der Färbung wird selbst von Fitch angezeigt. Dieser fand die Raupen, zugleich mit den Motten, in den Gärten bei Ottawa in Illinois den October hindurch in schädlicher Menge an den Kohlptlanzen, deren äussere Blätter ganz zerlöchert und zerfressen wurden. Das Puppengespinnst bildet er S. 172 unnatürlich an beiden Enden abgerundet ab, statt dass es wie bei dem der Plut. porrectella nach beiden Seiten zugespitzt ist. (Bei mus hat die Art noch nie Schaden angerichtet).

Ich habe männliche Exemplare aus Ohio (Schläger) und beide Geschlechter aus Texas (Boll) erhalten.

\section{Depressaria.}

Zu den vier von Clemens beschriebenen Arten hat Robinson in den Ammals Nat. Hist. IX, p. 157, pl. 1. Fig. 10 eine Depr. Frotella hinzugefügt. Die mir bekannten sind:

\section{Atrodorsella Cl.}

Thorace atro, eapillis roseo nigroque mixtis, palporum articulo terminali

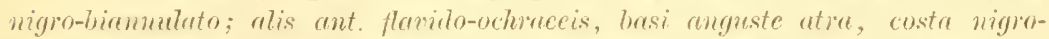
mmetata, punctis postice in lituram corelescentibus, mucto nenae transversae alba liturae brunneae imposita. of 9 . 
Selur leicht zu erkennen an dem schwarzen Thorax und der sehwarzen Vorderfügelbasis - was sic mit Culcitella gemein hat, olne doch dieser Art nabe verwandt $\mathrm{zu}$ sein; dem sic hat cine deutliche Vorderflügelspitze und anders gebaute Taster, so dass sie wohl am besten nach Assimilcllı, deren Durchschnittsgrüsse sie lıat, gestellt wird.

Rückenschild tiefschwarz mit bleichochergelblichem Schildchen. In die schwarzbraunen Haare des Oberkopfes sind zu beiden Seiten aufgerichtete, rosenrothe Schuppen streifenförmig eingemengt: Gesicht bleichgelb wie die Taster und die Schuppen des Rüssels. Taster von gewöhnlichem Bau (also nicbt mit verlängertem Mittelgliede), an zweiten Gliede braun besprengt und mit brannem Schuppenkamm der Schneide; Endglied mit zwei breiten, schwarzen Ringen (an ler Wurzel und vor der Spitze). Fühler graubräunlich. - Beine bleichgelb, aussen braun bestäubt; die vier vordern an den Schienen gebräunt; alle Dornen braungrau mit hellgelblichen Spitzen und alle Füsse auswärts braungrau, an den Enden der Glieder hellgelb; nur die zwei letzten Vorderfussglieder einfarbig schwarzbraun. - Hinterleib bleichgelb, am Bauch mit vier schwarzen Punktreihen, von denen die äussern stark und etwas verflossen, die zwei mittleren fein sind.

Vorderflügel $4 \frac{1}{1} 3^{\prime \prime \prime}$ lang, mit dentlicher, doch nicht scharfer Spitze, blass ocherfarben, hier und da gelbbrïunlich angelanfen und mit einzelnen sehwarzbramnen Schuppen bestreut. Die Basis enthält einen grossen, schwarzen Punkt, der an einen kleineren der Medianaderwurzel stösst. Der Vorderrand ist fast von der Wurzel aus bis zur Spitze mit 8-10 schwarzen Punkten oder Fleckelıen gezeichnet, von denen die vier letrten an ihren untern Ende durch einen schwarzen Längsstreifen verbunden sind. For der Mitte liegt im llittelraum in hellerer Grumlfarbe ein schwarzer Punkt, mul anf der Querader ein weisser in einem gelbbranuen (fast rostbraunen) Längswisch, vou welchem ans dic Adern in gleicher Farbe gegen den schwarzen, die Costalflecke verbindenden Streifen gerichtet sind. (Diesen und den gelbbramnen Wisch betrachtet Clemens als ein nur theilweise unterbrochenes Ganzes). Hinterrand verloschen schwarzbrann punktirt. Franzen von der Grundfarbe oder röthlich angelanfen.

Hinterflïgel hellgelblichgrau, gegen die Spitze verdunkelt. Hinterrand unbezeichnet oder um die Spitze mit ganz verloschenen braumen strichelchen. Franzen weisslich, um die Spitze ins Gelbliche, nahe der Wurzel mit einer verloschenen, granen Linie durchzogen.

Unterseite der Vorderflügel grau, rings herum bleichgelb, auf đem Vorderrand mit schwarzen Punkten bestrent. Hinterflügel bleichgelb, am Vorderrand und in der Spitze in ziemlicher Breite sehwarz bestäubt.

Vaterland der drei von Dr. Hagen erhaltenen ơ die Gegend von Cambridge.

2. Hillrella n. sp.

Palporum articuli terminalis hasi ammuloque medio fuscis, camillis fermgineis; alis ant. ollongis, apice rotundrato, mfescenti-fermgineis, fuscescenti ciebro irroratis, muncto disci ante medium nigro, litura media transecrsa fuscescenti. o 9 . 
Verwandt mit Laterella, kurzflügliger, mit weniger hervortretendem Analwinkel der Hinterflïgel (darin also mehr mit Conterminella stimmend), anf den gesättigt rostrothen Vorderflügeln nur mit einem Discalpunkt vor der Mitte.

Rückenschild hell rostgelb, röthlichfleckig. Kopfhaar rostgelb, Gesicht blassgelb wie alle Taster und die Schuppen des Sangrüssels. Lippentaster am zweiten Ghied answärts lebhafter gelb und brannbestäubt; das Endglied an der Wurzel braun und mit breitem, braunem Ringe vor der hellen spitze, Fühler grambraun. - Beine blassgelb; die Vordersehienen an der Vorderseite rostroth, die 2-3 vorletzten Fussglieder schwarz; die Mittelbeine an den Schienen und Füssen (ausser der Spitze) braungran; die Hinterschienen auswendig sehwach graustaubig mit einfach bleichen Dornen. - Hinterleib des $\sigma^{\nearrow}$ dunkelgran mit hellem, gelbgemischtem Analbusch, des 오 graugelblich. Der Banch ist hellgelblich, jederseits mit einer Reihe schwärzlieher Fleckehen.

Vorderflügel des $\sigma^{7} 4^{1 / 4}$ (bei einem $3 \frac{1}{2}$ ), des $4^{3 / 3}{ }^{\prime \prime}$ lang, breiter und viel weniger gestreckt als bei Latevella, mit fast abgerundeter Spitze, rostgelb, mehr oder weniger roth überlaufen, sehr reichlich mit braungrauen, hier und da zusamnienfliessenden Querstrichelehen bestreut. Vor der Mitte liegt im Mittelraum anf einer gelichteten Stelle ein schwarzer Punkt; etwas hinter und unter ihm ist in der Falte ein sehwarzes Längsstrichelchen, das aber wenig auffällt, weil der grosse, wischförmige, dunkle Quertleck der Flügelmitte bis zu ihm hinreicht. Der Hinterrand ist dureh schwärziiche, meist wenig hervortretende Puukte von den Franzen getrennt. Diese sind heller als die Grundfarbe, blass, mit einer verluschenen, grauen Linie durchzogen.

Hinterflügel grau, beim $q$ heller, in der spitze am dunkelsten.

Unterseite grau, beim $Q$ heller; die Vorderflügel anf der hinteren Hälfte des Vorderrandes hellgelb mit schwärzlichen Fleckchen; beim $\varnothing$ ist das Gelbe breiter und zieht auch um den Hinterrand herum, nnd der Vorderrand ist fast ganz sehwärzlich punktirt. Franzen hell, an den Enden röthlich.

Hinterflügel beim $q$ mehr als beim $\delta$ in der Flügelspitze und von da aus eine Strecke am Hinterrande hin mit sehwärzlichen Punkten bestreut.

Vaterland: Massachusetts bei Beverly; von Burgess erhielt jch fünf Exemplare nit der Angabe: Nahrungspflanze Robinic pseudecaciu; sie krochen ans vom 21. Juni bis 31. Juhi.

\section{Heracliana Deg.}

Linncea Entom. IX, S. 312. Stainton, Nat. Hist. Tin. VI. p. 112, tab. 3, Fig. 2 (Schnetterling unkenntlich). Herrich-Schäffer, Schm. v. Europa V, Fig. 445 (wenig besser).

Zwei durch Dr. Speyer unter der Benennung Depress. Ontariella Betlune erhaltene $q$ (ob also aus der Gegend von New-York?) stimmen nit grossen europäischen Exemplaren auf das Genaueste überein. Das eine trägt einen Zettel nit der Angabe: "14. Aug.". wonach auch die Flugzeit nichts Abweichendes hat. 
Ohne Zweifel ist diese Art dort eingewandert, und die Walnl einer passeuden Futterflanze für ihre Nachkommenschaft hat ihr, sobald sie nach glïcklicher winterlicher Ueberfahit das Land betrat, nicht die mindeste Schwierigkeit geboten.

\section{Scabella n. sp.}

Palpis subattematis, fusco-cinereis, articnlo terminali in medio albido; ulis ant. elongretis, fusco-cinereis, subnebulosis, punctis duobus ante, zno post medium nignis, seubris. 9 .

Eine aberrirende Art, bei welcher das zweite Tasterglied fast gar lieine abstehende, bürstenförmig gesträubte Schuppen hat (also mehr gelechienartig ist), und die Vorderflïgel mit rauhen Schuppenbüischchen bezeichnet sind (was ich noch von keiner Demessaria kenne). Die Färbung der Vorderflügel weist sie zu den Arten ohne helles Wurzelfeldchen.

Grüsse der folgenden Art. Rückenschild und Kopf braungrau, Gesicht ctwas heller. Taster von Rückenschildlänge, braungran, auf der Innenseite etwas lichter; das zweite Glied hier vor der hellgrauen Spitze mit schwärzlichem Bande; dieses Glied ist zusammengedrückt walzenfürmig, nur am Basaldrittel verdïnnt, auf der Schneide mit kaum ein wenig gelockerten Schuppen, doch gegen die Spitze mit einer Lüugsfurche; das Endglied halb so lang wie das zweite Glied; braun mit weisslichem Mittelringe und feiner, weisslicher Spitze. Fühler dünn, bräunlichgrau. - Beine einwärts hell ledergelb, die vier vorderen auswärts braun, am Ende der Schienen und der Fussglieder hell; die zwei vorletzten Fussglieder der Vorderbeine einfarbig braun, wie bei den Depressarien gewöhnlich. Hinterschienen auswärts hell ledergelb mit zwei grauen Längsflecken und blonder Behaarung; die Dornen auswärts mit dunkler Wurzellı̈̈lfte; die Füsse braun, an den Enden der Glieder hell. - Hinterleib bleich gelblichgran mit hellerem, ganz ungeflecktem Bauch.

Vorderflügel 4“" lang, gestreckt, hinteu zugerundet, braungran, dunkel bestäubt, vorziiglich gegen den Hinterrand. A uf der hinteren Hälfte des Vorderrandes lassen sich undeutliche, dunklere Fleckchen unterscheiden. Im Mittelraum liegen vor der Mitte zwei schwarze, rauhe Punkte schrïg untereinander und senkrecht unter dem unteren ist in der Falte ein dritter. Hinter der Mitte, dem zweiten gegenüber ist noch ein solcher Punkt, den ein grösserer, verdunkelter, mit ein paar rauhen, schwarzen Pünktchen bezeichneter Nebelfleck folgt. Zwischen und über diesen zwei Gruppen liegt unterhalb des Vorderrandes eine kleine, schwarze Längslinie. Die dunklere Bestäubung der Fläche reicht in die grauen Franzen hinein.

Hinterfiügel hellgrau, feinschuppig, in der Flügelspitze gröber beschuppt und bräunlich bestäubt. Der obere Ast der Medianader (2) ist von den beiden aus der Ecke der Mittelzelle (3 u. 4) fast aus demselben Punkte kommenden weit abgerückt.

Unterseite der Vorderflügel bräunlichgran, an Hinterrand mit einer Reihe kleiner, schwarzbrauner Punkte. Auch hier ist der dem Innenrande nächste Ast 
der Medianader (wie Limnen entomol. tab. 2, Fig. 6) weit abgerückt. Hinterflügel vor der Spitze mit groben, braunen Schnppen bestrent, in der spitze selbst mit einem schwarzbrannen Raudstrichelchen, dem sich ein paar hellere und verloschenere des Hinterrandes anschliessen. Der Analwinkel tritt nur schwach herror.

Vaterland: Ohio (Schläger). Ein gutes $Q$ in meiner Sammlung.

\section{Nelmotosa n. sp.}

I'ulporum fresciculo subinfundibuliformi; alis ant. elongutis, upice motuduto, cinereis, obscurius donse mermorutis, coshe obsolete maculutr, mueto strislaque albo-murginata nigris ante, prencto ollon nigro-margimeto post medium. ơ 9 .

Eine zienilich kleine Art, die von allen durch den fast trichterformig ansgebreiteten Schnppenbusch an Ende des zweiten Tastergliedes aloweicht. Dass sie trotzdem eine wirkliche Dcpressaria ist, zeigt die fast mit Aplumu stimmende Vorderflïgelzeichumng; doch ist das helle Basalfeld nur so eben angedeutet. Ungeachtet der Tasterbildung ist der beste Platz für diese Art wohl bei Ciniflonella.

Rüekenschild, Kopf und Fülıler gran. Gesicht und Innenseite der Taster weisslich; diese auswärts schwärzlich bestäubt; das zweite Glied von der IVurzel bis znr Hälfte schlank, damn auf der Unterseite mit einem starken, an Länge bis zur. Spitze abnehmenden Sehuppenbusch, der sich fast trichterförmig auseinandersträubt; Endglied an der Wurzel und in einem breiten Ringe vor der weisslichen Spitze schwarz. Sangrïssel weisshich beschuppt. - Beine weissgran, auswärts dunkler grau bestïubt; die Fïsse an den Enden der Glieder gelblichweiss: die drei letzten Vorderfussglieder nur grau, - Hinterleib hellgran mit helleren Hinterrändern der Segmente; der Bauch reisslich, an jeder Seite mit einer Peihe kleiner, schwarzer Punkte, und dazwischen noch 2 wei abgekürzten Pieilıen schwarzer Pünktchen.

Vorderflïgel 4-41/4" lang, gestreckt, nach hinten wenig erweitert, mit abgerundeter Spitze, grau, sehr dicht mit dunkelgranen, melır oder weniger zusammenfliessenden Punkten besprengt. Bei manchen Exemplaren läst sich ein helleres, gegen die Flügelfäche nur durch etwas dunklere Farbe begrenztes Basalfeld erkennen, das sich auch am Vorderrande meln oder weniger verlängert. Der Vorderrand ist anf der Endbälfte meist mit sehr verloschenen, dunkleren Flecken bezeichnet. Im Mittelfelde liegen bei $1 / 3$ sclıräg unter einander zwei schwarze Punkte, der untere meist strichförmig und oberwärts mit einigen weissen Schuppen geraudet und bei deutlichen Exemplaren in eine weissliche Linie fortgesetzt, hinter welcher, etwa in der Flügelhïlfte, auf der Querader ein weisser, theilweise sehwarz umzogener Punkt folgt. Am Hinterrand zieht von ler Flügelspitze aus eine Reihe von sechs schwarzen Punkten, von denen aber bisweilen uur die obersten sichtbar bleiben und bisweilen keiner deutlich ist. Weissliche.

Hinterflügel einfarbig hellgrau; die Franzen ım die Flügelspiłze ins 
Unterseite der Vorderflïgel gran, am Vorderrand schmal weisslich mit dunkelgrauen Flecken und Stïubchen. Den Hinterrand umzieht bis in den Vorderrand eine Reihe schwarzer, kleiner Punkte. - Der erste Ast der Medianader wie bei Liturellu. An den Hinterflügeln ist die Spitze mit schwïrzlichen Strichelchen eingefast. Der erste Ast der Medianader (2) entspringt weit entfernt von dem folgenden.

Vaterland: Massachusetts. $6 \sigma^{7} 4 \mathrm{f}$, wahrscheinlich alle erzogen, durch Dr. Hagen aus der Gegend von Cambridge.

\section{Cryptolechire tentoriferella $\mathrm{Cl}$.}

Pulpis albilis, articuli sccundi dimidio exterius fusco; alis ant. tortriciformibus, costre convexiuscula, apice acuto, mesesenti-osseis, enstue busi, punctis 3 disci (pimo subyemello ante mealinm, secundo in plica matia, tertio venae transversue) nebulaque subfasciata postica nigris. o'

Machimic tentoriferellı Clem. ed. Stainton p. 147.

Sie gehört mit Cr. struminella und castell (Caffr. p. 107) eng zusammen. Ihre Vorderflügel sind nicht so gleichmässig geröthet wie bei letzterer und ausserdem mit Zeichnungen versehen.

Von der Grösse einer ansehnlichen Depr. applana. Die Schuppenhaare des Oberkopfes und die der Stirn sind nicht ganz horizontal gegen einander gestrichen und liegen daher nicht ganz glatt. Der Kopf, sowie das Rückenschild, röthlichweiss; das Gesicht zu jeder Seite am Ange mit einigen braunen Schuppen. Fühler am Wrrzelglied und etwas darüber weisslich, dann verdunkelt, in beiden Geschlechtern gekerbt (doch beim $Q$ schwächer nud nur an der Endhälfte), beim $\sigma^{\gamma}$ mit zwei Reihen Bürstchen gefranzt. Taster lang, zurückgekrümmt; das zweite Glied zusammengedrückt, am Ende wenig breiter als am Anfang, an der untern Schneide etwas locker schuppenhaarig, auswärts von der Wurzel ans in grösserer oder geringerer Länge (bei einem gar nicht) lebhaft brann, übrigens wie das mehr als halb so lange, dünne, feingespitzte Endglied weisshich. Sangrüssel von Rückenschildlänge, halbbeschuppt. - Vorderbeine von den Schenkeln an abwärts immer schwärzer braun; die Mittelbeine gegen die Füsse hin lichter (bei einem $q$ sind lie vier vorderen Beine fast gar nicht verdunkelt); die Hinterbeine bleich ochergelblich; die Schienen ziemlich lick, besonders auf der Rückenschneide mit niederliegenden Borstenhaaren; die Dornen auf der Anssenseite gebrännt, ausser an der Spitze. - Hinterleib ziemlich schlank, bleich gelblichgran, am Bauch etwas dunkel bestäubt nnd oft mit recht dentlicher, hellgelber; breiter Mittelstrieme; die Seiten sind büschelschuppig, der Pü̈cken des $Q$ meist sehr merklich convex; die letzten Segmente des $Q$ verschmälern sich, und der Legestachel steht etwas hervor; der Analbusch des $\sigma^{7}$ ist hell.

Vorderflügel $4^{3 / 4}-5^{\prime \prime}$ lang, von der Schulter aus am Vorderrand convex, dann erst gerade, hierauf gegen die spitze mehr gebogen herabgehend, der Hinterrand sanft convex zurtickgehend. Die Grundfarbe ist ein selrr helles, rüihliches Beingelb, dessen rüthliche Beimischung gewöhnlich am meisten aut den Endlrittel hervortritt; schwarze Stänbchen siud spärlich und angleich anf 
der Fläche zerstreut. Der Schulterpunkt ist tiefschwarz und in eine kurze Linie ausgezogen. Im Mittelraum liegt ein schwarzer, oft zusammengeflossener Doppeljunkt vor der Mitte; in der Hälfte der Falte ein linrzes, von einem mehr oder weniger starken Hof umgebenes Längsstrichelchen, und linter nnd über ilum der schräge Qneraderstrich, der selten einen Schatten nach hinten wirft. Nitten zwischen ihm und dem Hinterrand zieht eine aus Stïnbchen gebildete Nebelbinde, die sich oberwärts nach innen krïmmt und den Vorderrand knuz hinter dem Queraderstrich erreicht. Längs des Hinterrandes sind 6-8 schwarze Pünlitchen, die zwei obersten schon ïber der Flügelspitze. Franzen hell, nngefleckt.

Hinterflügel ohne Ausbuchtung unterhalb der stumpfwinkligen Spitze, einfarbig hellgrau mit lichteren Franzen.

Unterseite der Vorderfligel hellgran, am Vorderrand striemenartig hellochergelb. Hinterflügel viel heller, am Vorderrand gelblich mit brauner Bestäubung. Die schwarzen Hinteraudpunkte der Vorderflügel viel schärfer als auf der Oberseite, auch die Hinterflügel sind um die Spitze herum mit dergleichen versehen.

Vaterland: Massachusetts und die Gegend von New-York; wenigstens nm Cambridge ist die Art nicht selten (ein Exemplar mit der Angabe: September). Nach Clemens lebt die Raupe, die ex beschreibt, bis gegen Anfang September am wilden Kirschbanm, an Eichen und Wallnnssbämmen (hickory) auf der Unterscite der Dlütter in einer kurzen Seidenröhre, nul der Schmetterling erscheint in der Eudliälfte des September.

Anmerkung. Clentens bildet, whe von der Gattung (ryptolechire zut wissen, die zwei Gattungen: Muchimiu und Psilocorsis, welche ich vorläufig nur für Mitglieder von Cryptol'chic ansehen bium. Bei Muchimin legt er auf die oben angegebene Beschaffenheit der Kopfhares rer nennt sie slagey) und auf die des zweiten 'Tastergliedns (second joint roughened with seales) das Hauptgewicht, bei P'silocorsis anf den glattsehuppigen Kopf, die angedrïckte Besclmppung des zweiten Tastergliedes, die wi klerförmige restalt der Vorderflügel (welche Mrachimic doch nicht minder hat) und auf die unbedentendes Entfernung des untersten Astes der Medianader derselben Flügel (the medioposterior vein not remote from the penultimate). Heines Erachtens geht schon daraus, dass er aus seinen zwei Psilocorsisarten zwei Abtheilungen bildet, hervor, lass diese Unterschiede keine generischen sind, oder dass man fast aus jeder Art vou Cryptolechia ein eigenes Genus zn bilden hätte (vgl. Limnec entomol. IX, Taf. 3).

\section{Cryptolechirl piperatell, n. sp.}

Palpis allhidis, articuli secumdi dimidio extcrins fuscescente; alis ant. costr valde comera, anguste flucicante, cetermen exalbidis, sturamis arossis nigris inordinute conspersis. of.

Klein und durch den stark convexen Vorderrand nnd die groben, ziemlich zahlreichen, schwarzen Schuppen der gelblich weissen Vorderflügel selır kenntlich. 
Rückenschild und Kopf mit seinen Theilen gelblichweiss. Taster von liückenschilalünge, aufgekrünmt, am zweiten Gliel mit kaun gelockerter Buschuppung anf der untern Schneide, auswärts bis über die Hälfte gelbbraun; das Endglied von $2 / 3$ Länge des zweiten Gliedes. Samgrüssel klein. Fühler mit rerdicktem Wurzelgliele; die schmutzig ochergelbe Geissel nur gegen die Spitze mit gezähnelten Gliedern, mikroskopisch gefranzt. Beine hell ochergelblich, dio vorderen gebrïunt, die hinteren am hellsten; die dicht beharten Hinterschienen laben die längsten und dichtesten Haare auf der Pückenschneide; die Enddornen ziemlich liurz. Hinterleib von der Farbe der Hinterbeine, gegen die Wurzel weisslich; Analbuseh klein.

Vortlerflügel $3^{3} / 4^{\prime \prime \prime}$ lang, länglich, mit von Aer Wurzel aus gleichmässig und stark convexem Vorderrand, gelblichweiss, reichlich, aber unordentlich mit grossen, runden, schwarzen I'unkten bestreut, am wenigsten gegen die Wurzel und am Innenrant. Der Vorterrand ist von der Wurzel aus in einer feinen, sich allmälich erweiternden Linie bis zur Flügelspitze ochergelb. In der Apicalhälfte des Hinterrandes sind einige verloschene, schwarze Punkte. Franzen etwas länger als bei Tentoriferella.

Hinterflïgel ein wenig breiter und gelblicher als die Vortlerflügel, spritz, ann Hinterrand unterhalb der Spitze etwas eingebogen, seidenglänzend.

Unterseite der Vorderflügel graugelblich mit verdunkelt in den Hinterrand lanfenden Adern, am Vorderrand gelblich, mit bränlicher, vor dem Innenwinkel verlöschender Hinterrandlinie. Hinterflïgel wie oben.

Vaterland: Texas (Boll.). Ein schönes o ${ }^{7}$ in Cambridger Museum.

Anmerkung. Die Schuppen tes Kopfes sind nur im Nacken etwas gesträubt; die Maxillartaster deutlich, über dem Saugrüssel gegen einander geneigt; das Wnrzelglied der Fühler breit und zusammengedrïckt. Die Franzen der Flïgel sind verhältnissmässig länger als bei Tcntoriforellu; dio VorderHügel liaben einen auffallend convexen Vorderrand; die sehr liurze Lndgabel der Subcostalader endigt über der Flügelspitze: der erste Medianalerast steht wie bei Tenturifcrella weit vom zweiten ab.

\section{Cryptotechin quercicella Clem.}

Capillis et thorace friscescentihus, palpis linere longitudinati vigna signatis, aprice pallido; alis ant. subelongatis, costa leviter nrcucuta, pallida, luteis, lense fuscescenti strigulosis, mucto vence tronsversae punctulisque obsoletis marginalibne nigris. $\mathrm{f}$.

Psilocorsis quercicella Clemens, Tin. ed. Staint. p. 159.

Sie ist kleiner und schmalflïgliger aIs Tentoriferella. Rüickensehild und Kopf hellbräunlich. Taster von Rüekensehildlïnge, ziemlich schlank, anfgeliriunmt; das zweite Glied stark zusammengedrückt, am Ende kaum dicker als das Endglied, mit einer Längsfurche in der Schuppenschneide, bleich ochergelblich, in der Furche mit schwarzer Längslinie, die sich his vor die ganz lielle, weissliche spitze des Endgliedes fortsetzt: las Endglied mehr als $2 / 3$ so lang wie das zweite Glied, fein und gespitzt, anf der Innenseite mit einer dümen, 
schwarzen Längsiinie, die hier und da mit der anderen zusammenfliest (daher nemut Clemens das Endglied schwarz, vorn mit zwei gelblichweissen Streifen). An den Fühlern trägt las lïngliche, schwarze Wurzelglied vorn eine hellgelbliche Längslinie und ist auf dem Rücken ebenso hellgelblich; von hier ans zieht eine feine, ebensolche Linie die ganze Geissel entlang, welche übrigens hell ochergelb ist mit allmälich feineren braunen Ringen (Clemens sagt: Antennae ochreous, with a black line above, terminating in black spots; basal joint with two black stripes in front). - Beine bleich ochergelb; an den vorderen die Schienen etwas gebräunt; am Fuss, wie bei den meisten Depressarien, die zwei ersten Glieder mit hellen Enden, die zwei folgenden ganz schwarzbrau, das Endglied ganz hell. An den Hinterbeinen die Schienen reichlich langhaarig. lie Dornen einfarbig, die des ersten Paares fast ibber die Schienenspitze hinwegreichend. - Hinterleib hell gelblichgrau mit hellgelblichem Bauch und an den Seiten mit Schuppenbïschehen; der T,egestachel steht aus dem Analbusch etwas hervor.

Vorderflügel 4"“ lang. etwas gestreckt, nach hinten wenig erweitert, mit schwach convexem Vorderrand, auf bleich ochergelblichem Grunde so dicht, aum dichtesten von der Wurzel aus, mit hellbräunlichen Qnerwellen, dass die Grundfarbe nu wenig sichtbar wird; die Vorderrandader bleibt rein, ebenso ein kurzer Innenrandstreif vou der Wurzel aus. Auf der Queraler ist ein schwarzer, wenig bemerkbarer Puakt, und am Hinterrand eine Reile schwarzer Punkte. Franzen hell: auf die dunklere Wurzel folgt eine brämliche Linie und hinter dieser noch eine verloschencre.

Hinterflügel nur so breit wie die Vorderfliigel, unter lor Spitze mit einer sehr umnerklichen Einhiegung des Hinterrandes, hellgran, nn die Spitze nit vedoschenen braunen Hinterrandstrichelchen. Franzen weisshichgrau, nahe der gelblichen Wurzel mit einer verloschenen, granen Linie durchzogen.

Unterseite der Vorderfügel gran, am Vorderrand schmal. am Hinterand breit gelblich. Hinterflügel heller als auf der Oberseite, am Vorderrand breit grau bestäubt. Alle Hinterandstrichelchen deutlicher als anf der Oberseite.

Vaterland: Ohio (Schläger), Texas (Boll.). Das Texasexemplar hat entschieden kürzere und zartere Taster als die beiden anderen; auch tritt auf den Fühlern die von Clemens bemerkte schwarze, in Punkte übergehende Linie reutlicher hervol. Es gehört aber sicher derselben Art an.

Anmerkung. Quercicell " und die zwei folgenden Arten zeichnen sich durch die zusammengedrückten Lippentaster aus. welche auf der glattschuppigeu Schneide des zweiten Gliedes eine enge Längsfurche haben, in der eine dunkle, bis vor die Spitze des Endgliedes reichende Längslinie hinzieht; die Naxillartaster sind wie bei Piperatella. Die Schuppen des Kopfes liegen glatt. An den länglichen VorderflügeIn ist der Vorderrand schwach, aber gleichmässig convex. Die Gabel der Gabelader ist fast so lang wie der Stiel und mündet mit dem unteren Zinken in die Flügelspitzc. Der orste Ast der Medianader ist dem folgenden ganz nahe. Die drei Arten gehören also zu Psilocorsis Clemens. 


\section{C'mptolerhice obsoletella $11 . \mathrm{sp}$.}

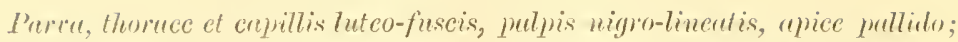
ais and. uequetiter luteo-fusecsecntibus, striolu ante, juncto post medium sericque punctorm muginis postici nigris.

Viel kleiner als Qucrcicella, von weniger wicklerähnlichem Ausschen, nit gleichmässig gelbbramen Vorderflïgeln und einem schwarzen Strichelchen vor deren Mitte, das der Quercicella fehlt: ausserdem füngt der Vorderrand erst hinter der Mitte an, sich gelb zu färben, und die Hinterrandzeichnung besteht aus mehreren und gröberen schwarzen Punkten.

Kopf und Rückenschild ziemlich dunkel gelbbraun. Fïhler heller: das Wurzelglied mit weissgelblicher Längslinie, die sich anf der Geissel fortsetzt und von deren Hälfte an, durch die deutliche Absonderung der Glieder, in gelbliche Punkte oder Ringe aufgelöst scheint. Taster dünn, von mehr als Rückenschildlänge, hell gelbbräunlich; das zweite Glied mit der sehr engen Furche, welche als schwarze Limie erscheint, die auf der Aussenseite von einer sehr feinen, hellgelblichen Linie begleitet wird; die Innenseite dieses Gliedes hellgelblich; das Endglied ïber halb so lang wie das zweite Glied und ohne Absatz aus diesem hervortretend, blassgelb, auf der Vorderseite mit feiner, schwarzer Lüngslinie und mit weisslichgelber Spitze. Sangrïssel von Rückenschildlänge. Beine bleichgelb, die vier vorderen auswärts gebrïnnt; an den Vorderfüssen die zwei vorletzten Glieder schwarz, sonst alle Füsse auswärts bräunlich mit hellen Enden der Glieder. Hinterbeine Iıll; die Schienen zusammengerlrïckt mit langhaariger Rückenschneile und hellen Dornen, deren erstes Paar bis ans Ende der Schienen reicht. - Hinterleib braungran mit bleichgelbem Bauch und ctwas aus dem Analbusch hervorstehendem Legestachel.

Vorderflügel $3^{\prime \prime \prime}$, etwas kürzer als bei Quevcicellu, mit ähnlich gebogenem Vorderrand, doch schrïgerem nnd etwas convexem Hinterrand. Grundfarbe yleichnässig hell lelmigbraun. Die Costalader färbt sich von der Mitte an relblich, und diese Färbung setzt sich durch die Vorderrandfranzen bis zur Flïgelspitze fort. Auf der Querader liegt ein starker, schwarzer Punkt, und nnitten zwischen ihm und der Flügelbasis in Mittelraum ein kurzes, schwarzes Iängsstrichelchen. Ueber deın Innenwinkel ist eine schwärzliche, anch einige Innenrandfranzen färbende Wolke. Den Hinterrand säumt eine Reihe grober, schwarzer Punkte, denen sich über der Flïgelspitze ein paar verloschene Punkte anschliessen. Die ziemlich langen Franzen sind merklich heller als die Grundfarbe der Flügel.

Hinterflügel so breit wie die Vorderflügel mit dentlicher Spitze, unterhalb derselben ohne Eindruck des Hinterrandes, hell brännlichgran, um die Spitzo herum mit schwärzlichen Margiualstrichelchen. Franzen heller als die Grundfarbe.

Unterseite grau, der Vorderrand der Vorderflïgel breiter hellgelb als auf der Oberseite; die Randpunkte deutlich, doch viel blässer als oben. Der Stiel der Gabelader ist länger als die Gabel; der erste Ast der Medianader entspringt dem folgenden sehr nahe und geht anfangs in stärkerem Bogen als bei Quer- 
cicella. - Auf den Hinterflügeln sind die Randpunkte so deutlich mio anf der Oberseite.

Vaterland: Ohio (Schläger). Ein $q$ in meiner Sammlung.

\section{Cryptolechire fierruginosa n. sp.}

Thorace et capillis ferrugineo-vcluaceis, palporum articulo terminati nigno-lineato; alis unt. subelongatis, fermgineo-ochraceis, punct is disci dnotm.. (ultero ante, altero post medium.) nigris, margine postico alsulete punctato. I.

So gross wie Quercicellu, mit gestreckteren Vorderflïgeln, von nicht so wicklerförmigem Aussehen und durch die fast rostgelbliche Ocherfarbe des Vorderkörpers und durch die zwei schwarzen Punkte der Vorderflügel ausgezeichnet.

Kopf, Rückenschild und Vorderflügel gleichfarbig wie angegeben. Fühler hell ochergelb; das Wurzelglied mit schwarzer, auf der Geissel etwas fortgesetzter Längslinie, auf welche dann bräunliche Punkte folgen, wodurch die Fühler deutliche Halbringe erlıalten. - Taster so lang wie das Rückenschild, hell ochergelb; das zweite Glied mit dentlicher, doch so enger Furche, dass keine dunkle Linie darin zu erkennen ist: Endglied von mehr als halber Länge des zweiten Gliedes, dentlich abgesetzt, mit drei schwarzen Längslinien und feiner, heller Spitze. Saugrüssel länger als das Rückenschild, bleich ochergelb beschuppt. - Beine ebenso, fast einfarbig. Hinterschienen schwach zusammengedrückt, auf dem Rücken mit anliegenden, nicht reichlichen Haaren. Der eine Dorn des ersten Paares reicht bis an das Schienenende. - Hinterleib graugelb, am Bauch sehr hellgelblich; der kurze Legestachel ragt aus dem Analbusch hervor.

Vorderflügel $4^{\prime \prime \prime}$ lang, ziemlich gestreckt, mit schrägerem Hinterrand ınd dadurch stärker gespitzt als bei Quercicella. Auf der Querader ist ein schwarzer Punkt; ihm etwas näher als der Flügelbasis in Mittelraume ein anderer solcher Pnnkt. Am Hinterrand entlang liegen von der Flügelspitze aus vier verloschene schwärzliche Strichelchen. Franzen ziemlich lang, etwas heller als die Grundtarbe.

Hinterflügel so breit wie die Vorderflïgel, ohne Einbiegung des Hinterrandes unterhalb der Spitze, hell gelblichgrau, um die mit einer dunklen Stelle gezeichnete Spitze mehr gelblich; Franzen hell gelblichgrau.

Uuterseite der Vorderfiügel grau, längs des Vorderrandes unt dreimal so breit an Hinterrand bleichgelb, mit kaum bemerkbarer Randzeichnung; Hinterflügel gelblichweiss, an Vorderrand und um die Slitze bleichgell. Der erste Ast der Medianader hat einen sehr schwachen, aber bedentend gekrimmntru Aufang, soust einen geraden Verlauf.

Vaterland: Ohio (Schläger). Ein $\subseteq$ in meiner Sammlung.

\section{Cryptolechia eretacen 11. sp.}

Prova, cretrecu, antennis of tongins cilintis, pulpurnm articuli secunde vix dimidio fuscescente, perlibus anticis fuscis; alis ant. oblongis, mometis duolms

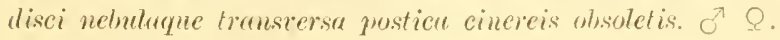


Wenig grösser als Obsoletellı, anf der ganzen Oberscite weiss mit sehr schwacher gelblicher Beimischung, auf den Vorderflügeln beim ersten Aublick zeichnungslos.

Vorderkörper und Vorderflügel gleichfarbig, der Kopf und die Innenseite der Taster reinweiss. Letzterer so lang wie Kopf und Räckenschild zusammengrenommen; das zweite Glieu zusanmengedrüekt, nach oben verdünnt, auf der nugefurchteu Schneide ein wenig locker beschuppt, auf der kleinern Wurzellülfte sraubraun; das Endglied fast so lang wie das zweite Glied und diesem ohne merklichen Absatz aufgesetzt. Maxillartaster weisslich. Saugrüssel brämulich beschupt. -. Fühner hellbräunlich mit weisslichem Wurzelgliede, beim o doppelt gefrumzt, die Franzen an der Wurzelhälfte länger als an der Endhälfte. - Vorderleine auf der Aussenseite dunkelbraun, auf der Inuenseite hellbräunlich wie dio Mittelbeine; Hinterbeine bräunlichweiss, an den Schieven ziemlich reichlich behaart. - Hinterleib hellbraungrau, am Bauch kreideweiss; das o mit starkem Analbusch.

Vorderttügel $2^{3 / 4}-3^{\prime \prime}$ lang, länglich, mit schwach convexem Vorderrand, stumpfer Spitze und convexem Hinterrand. In der Costalbasis in ein sehwarzer, fist unmerklicher Punkt. Die zwei Punkte des Mittelraumes, der eine anf der Querader, der andere ilım ein wenig näber als der Flügelbasis, sind aus ein paar grauen Sehuppen zusammengesetzt und daher lejcht zu übersehen. Noch undeutlicher ist die aus je ein par. Schüppchen zusammengesetzte Punktreihe, welche dem Hinterrand näher als dem Queraderpunkte liegt und, stark nach aussen gebogen, einen kaum merklichen Nebelstreifen bildet.

Hinterflïgel eben so breit wie die Vorderflügel, weniger rein weiss, unterhalb der Spitze ohne Eiubiegung des Hinterrandes.

Unterseite der Vorderflügel dicht grau bestäubt, auch auf den Franzen. Der Stiel der Gabelader ist kürzer als die Gabel. Der erste Ast der Medianader sehr schwach gebogen, etwas abgerïckt von den folgeuden, der mit dem letzten fast aus demselben Punkte kommt. Hinterfiigel weiss, am Vorderrand breit grau bestäubt.

Vaterland: Texas. Ein gutes $\sigma^{\nearrow}$ (durch Boll mitgebracht) in Cambridger Musemm, drei fast franzenlose $Q$, ganz ohue Zeichnung (durch Belfrage am 5 . und 6 . Juni gefangen) in meiner Sammlung.

\section{Cryptolechia lithosina n. sp.}

Pulparum articulo secunto dimidio fusco, thorace pallide ochraceo; alis aut. elongatis, obtusis, osseo-albidis; posterionibus duplo latioribus albidis. O’.

Von der Grösse ler Qucrcicella, nicht wicklerfürmig, mit schmalen, nicht ıach hinten erweiterten Vorderflügeln und doppelt so breiten Hinterfügeln.

Rückenschild in der Mitte blassröthlich ocherfarben, ringsum heller. Kopf glattschuppig, kreideweiss. Taster so lang wie Kopf und Rïckenschild zusammengenummen, aufgekrümmt; das zweite Glied ohne Furche, glattschuppig, zusammengedrückt, am Ende ein wenig verdiinnt, auswärts fast bis zum Ende gellbraun, sonst weiss, wie das feine Endglied, das fast $2 / 3$ so lang wie das 
zweite Glied ist. Maxillartaster bleichgraugelblich, wie die Beschuppung des Sangrüssels. - Fühler fast so lang wie die Vorderflügel, über dem Wurzelglied ziemlich dick, pubeseirend gefranzt, beingelblich, gegen das Ende gebräunt. (Vorderheine fehlen); Mittelbeine hellgelbiichgran. Hinterbeine fast weisslich; die Schenkel and Schienen zusammengedrückt, die letzteren wenig behart (vielleicht nur abgerieben); der eine Dorn jedes Paares lang. -- Hinterleib hellgrau; Analbusch bleichgelb, gross, einen grossen Genitalapparat einschliesend.

Vorderflügel 4"' lang, schmal, nach hinten nicht erweitert; der Vorderrand von der Wurzel aus convex, dann riemlich gerade verlanfend und mit dem convexen Hinterrand die abgerundete Flügredspitze bildend. Grundfarbe weisslich beingelb, am Innenrand lel,hafter beingelb, sonst ganz olne Zeielmung.

Hinterflügel doppelt so breit wie die Vorderfügel, unterhalb der Spitze olıne Eindruck des Hinterrandes, gelblichweiss, weissfranzig.

Unterseite der Vorderfügel hell gelbliclıgran, gegen den Innenrand noch lichter. Soviel sich olme Abschuppnng erkennen lïsst, ist iler Stiel der Gabelaler länger als die Gabel, und der erste Ast der Medianader entspringt nalie an folgenden.

Vaterland: Texas (Boll). Ein mässig gut erhaltenes of im Cambridger Museum.

Cryptolechire mbeculosa n. sp. Taf. III. Fig. 12.

Palpis ante apicem fuscis; ulis ant. postice ungustatis, cinereis, mbeculis obscuris aliquot dispersis, maculis 3 costalibus obsoletis nigricuntibus, striola plicae ante medium punctoque venae transversac nigris; post. paulo latioribus. ठ $\mathrm{O}$.

In der nach hinten verschmälerten Vorderflügelform und also in der Unähnlichkeit mit der Tortricidenformation stimmt diese kleine Art mit $C r$. albicilla Z.

Rückensehild und Kopf grau, Gesicht weisslich. Taster schlank; das zweite Glied etwas zusammengedrückt, am Ende etwas verdünnt, auswärts und an der Schneide gran, innen weisslich; das Endglied nicht fein, mehr als halb so lang wie das zweite Glied, weissgrau, vor der hellen, feinen Spitze gewöhnlich rings herum sehwärzlich, auch auf dem Rücken an der Wurzel schwärzlich. Maxillartaster nnd Rücken des Saugrüssels weissgran. - Fühler $3 / 4$ so lang wie die Vorderflïgel, bein $\sigma^{\nearrow}$ borstenförmig, dieht haarig gefranzt, hellgrau, mit weisslichem Wurzelglied. - Beine weissgrau, die vorderen auf der Lichtseite brann angelaufen, die vier hinteren Schenkel weiss, schiefergrau schimmernd; die Hinterschienen zusammengedrïckt, ziemlich reichlich haarschuppig, besonders auf der Rückenschneide; die Dornen plump, der erste des oberen Paares bis zur Schienenspitze rejchend. Vorderbrust weiss mit einem gegen die Vorderflügel gerichteten Schuppenbäschel. - Hinterleib grau, an den Seiten mit Schuppenbüschen und am Bauch gelblichweiss; der dicke Legestachel des ? stelit kaum hervor. 
Vorderflügel $3-32 / 3^{\prime \prime \prime}$ lang, ziemlich gestreckt, im ersten Drittel am breitesten, danu allmälig verengert und mit ziemlich abgerundeter Spitze, grau mit weisslicheren Stellen und wischförmigen, bräunlichen Nebelflecken, von denen sich drei am Vorderrand und drei längs des Innenrandes am meisten bemerklich machen. Die Costalbasis ist mit einem dunkeln Fleckchen bezeichnet und darunter die Innenrandgegend fleckartig verdunkelt. Ein Nebelstreif geht schräg nach aussen vom Vorderrand bei $1 / 4$ herab und endigt über der Flügelmitte mit einem schwarzen Punkt; unter diesem füngt or mit einem scharfen, scliwarzen, in der Falte liegenden Strichelchen wieder an und setzt sich, dieselbe schrïge Richtung beibehaltend, bis zum Innenrande fort. Vor der Flïgehnitte ist am Vorderrand der zweite Nebelfleck; der dritte, von welchem eine nach aussen gebogene, mehr oder weniger deutliche Linie zum Innenwinkel herabzieht, liegt gegen dic Flügelspitze hinter dem schwarzen Queraderpunkte, unter welchem sich auch ror dem Innenwinkel ein Nebelfleck bildet. Der Hinterrand ist auch um die Spitze herum mit einer Reihe sehwarzer Punkte gezeichnet. Franzen cinfarbig, weissgrau. Bei abgeflatterten Exemplaren, denen die Nebelflecke zum Theil fehlen, hat der schwarze Strich in der Falte und der Punkt anf der Querader sich gut erbalten.

Hinterflügel breiter als die Vorderflügel, mit wenig vortretender Spitze und darunter nicht eingebogen, ziemlich dunkelgran; die weisslichen Franzen nahe der Wurzel mit einer granen Schattenlinie durchzogen.

Unterseite der Vorderflügel grau mit feiner, weisslicher Costallinie. In die Flügelspitze geht, soviel sich ohme Abschuppung erkennen lässt, nur eine einfache Ader; die zwei ersten Aeste der Medianader entspringen dicht beisammen. Hinterflügel weissgrau.

Vaterland: Texas. Mehrere Exemplare im Cambridger Museum; ein ab-

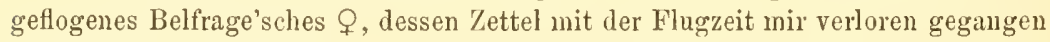
ist, in meiner Sammlung.

Anmerkung. Eine merklich grössere Art (Vorderflügel $4^{\prime \prime \prime}$ ) besitze ich aus Venezuela. Das schlechte, auf der Basalhälfte ganz abgewischte + (Mruscerdella Mns. Z.) hat gestrecktere Flügel und entbehrt den Nebelfleck vor der Flïgelspitze auf dem hier weisslichen Vorderrande gänzlich, und den Hinterrand fasst cine vollstindige Reihe schwarzer Punkte ein. Sehr deutlich zu erkennen ist hier, dass in die Spitze der Vorderftügel nur eine einfache Ader geht.

\section{Cryptolechia Srhlaegeri \%.}

Limnaec entomol. IX, S. 372, Fig. 18. - X, S. 158.

Vatcrland ausser den angegebenen Staaten auch Texas. Von zwei durch Boll gesammelten Weibchen ist das eine von vorzüglicher Grösse (Vorderflügel fast $\left.7^{\prime \prime}\right)$; die blïulichgrauen Nebel der Vorderflïgel sind bei ihm sehr eingeschränlit nnd lassen die weisse Grundfarbe nu so ausgelehnter und reiner hervortreten. Die Hinterflügel sind fast weiss, nu im Mittelranm hellgran angeflogen. Der starke Schuppenbusch des Scutellums enthält eine Menge an der Spitze stahlblan glänzender Schuppen. - Fiu Mämnchen ist ungewöhnlich klein, ıӓm- 


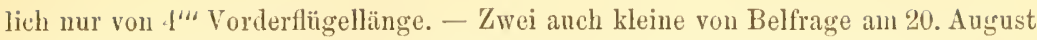
gefangene Mäunchen sind so abgeflogen (sie haben an den Vorderflügeln gar keine Franzen!), dass dem Schuppenbusch des Scutellums die stahlblauen Sclruppen ganz fehlen, und er nuu lehmgelb aussieht.

Die verhältnissmässig kurzen Taster, die im Nacken etwas aufgesträubten und gegen cinander gerichteten Koptschuppen und besonders der starlie Schuppenkuoten auf dem Scutellum, dazu die schmalen Vorderflïgel (die nur die hallue Breite der Hinterflügel haben) und die einfache in die Flügelspitze laufende Ader würden gestatten, ein leicht $\mathrm{zn}$ erkennendes Genus zn errichten, wenn das Bedürfniss dazu vorhanden wäre; die 162 Walker'schen Arten scheinen mir es nicht anzudenten, so lange wicht ein anderer Mann als Francis Walker das in British Museum vorhandene Material von neuem bearbeitet.

\section{Cryptolechia restalis n. sp.}

Antcnnis practer busim palporumque artieulo secundo exterius fuscesecentibus; alis ant. oblongis, postice leviter coarctutis, niveis, uniculoribus; post. latis, albis. $f$.

Zu unterscheiden von C'r. albellu durch viel geringere Grösse, die nach hinten verengerten, anch auf der Unterseite ganz eiufarbigen Vorderflïgel, die schräger zugespitzten Hinterflügel, die kürzeren, reinweissen, nur am zweiten Gliede answärts gebräunten Taster, die anssen an der Wurzel brïunlichen Fühler - von Leucillenc durch die kürzeren Vorderflügel un丸 die anders gefïrbten Taster - von Albieilla durch weniger gespitzte, ganz einfarbige, auf der Unterseite nicht gran angelaufene Vorderflügel und breitere Hinterflïgel.

Grösse einer kleineren Crypt. Schlïgeri. Rïckenschild und Kopf mit seinen Theilen reinweiss, ohne Glanz; das Schildchen ganz glattschupuig. Fühler an Wurzelglied und den folgenden 3-4 Gliedern weiss, dimn hellbran. Taster etwas kïrzer als bei Schlüycri, aber das Enılglied verhältnissmässig länger; sie sind reinweiss, nur am zweiten Gliede answärts bis znr Spitze gellbraun. Beine weiss, auswärts hell ocherbräunlich angelaufen; die Hintersehienen bleiben rein weiss und sind reichlich haarschuppig. Hinterleib ziemlich stark, weiss, mit eingezogenem Legestachel.

Vordenflügel fast 5"' lang, lïnglich, wach hinten ein wenig verengert; der Vorderrand hat vor der Mitte seine meiste Convexitüt und länft dann fast gerade bis zu der beinahe abgerundeten Spitze; der Hinterrand convex. Grundtarbe reinweiss, ein wenig seidenglänzend, obne jede Zeichnung. - Hinterflügel am breitesten vor dem Analwinkel, und zwar doppelt so breit wie die Vorderflïgel, dann gegen den abgerundeten Apicalwinkel zugespitzt, vor diesem mit einem sehr seichten Eindruck des Hinterrandes.

Unterseite der Vorderflügel äusserst blassgelblich angelaufen, mit sehr dentlichem Geäder. Die Medianader verästelt sich wie bei Schlägeri fast aus einem Pnukte. Auch die Hinterflügel sind nicht völlig reinweiss, alle Franzen aber schneeweiss.

Vaterland: Texas (Boll). Ein sehr schön erhaltenes $Q$ im Cambridger Museum. 
Epreorthylis ". g. Taf. III. Fig. 13 a. b.

liopoùros, nois quecedem cupite cristeto.

('apillitium depressum, lecvigutum.

Oeclli nulli.

Antenue eremulutue.

Palpi labiales porrecti, thorace multo longiores, artieulo secund" subureuto, subtus lacvis, supra postice squamis erectis eristato; terminali setreeo, erecto.

IItustellum brevissimum.

Alece anteriorcs ungustue, murginibus oppositis subparallelis; cellula meller simplici, vena apicali fureata; posteriores unterioribus latiores, trepseziformes, mugine postico infra upicem leviter impresso, venu mediana trifidu.

Tilitue posticue in dorso piloso-cristutue.

Vonı Flügelbau, auch von der Fürbung und Zeichnung der Vorderflingel, des Ypsol. juniperellus, aber an dem langen Mittelgliede der Taster auf der Unterseite mit glatt anliegender Beschuppung, wïhrend die Schuppenhaare der Oberseite auf der Endhälfte verlïingert und aufgeriehtet sind und eine längliche Bürste bilden. Bei der ganz verschieden aussehenden Gattung Enicostomu sind die Schuppen der Unterseite des zweiten Gliedes etwas geloekert, und auf der Oberseite liegen sie überall an und sind in der Lïlge cinmuler gleich. Disselbe gilt ron der Gattung Ccuthomudurus, deren Flügelgestalt jedoch meln ler von Elicorthylis entspricht.

Das Flügelgeäder seheint wie bei $Y_{1}$ s. juniperellus zu sein. Ohne Abschuplung lässt sich erkennen, dass die Mittelzelle der Vorderflügel keine Neberrzelle hat, und dass aus ilı eine Ader kommt, die nnit ihrer Gabel die Flügelspitze umfasst. Ocellen konnte ich auch nach Abschuppung des oberen Augunrandes lurch die Doppellupe nicht entdecken.

Eine geeignete Stelle für dieses Genus mag bei Ypsolophus sein, ich betrachte die bei Tachyptilia (Gelechio z. B. Populella) für noch besser.

\section{1. inversella n. $\mathrm{sp}$.}

Alae ant. canae, in diseo albidae; puncta majuscula $4(1,2,1)$ in asco; fascia albida post punctum quartum. $\sigma^{7}$.

Aehnlich theils dem Ypsol. juniperellus, theils der Tachypt. populellu, mit mehr verstärkten Punkten als letztere und mit breiterem, etwas anders verlaufendem hinteren Querstreif.

Kopf etwas heller als das graue Rückenschild. Taster so lang wie beide zusammengenoinmen, etwas aufgebogen, auswärts braungrau, einwärts hellgrau, unten auch braungrau; das Endglied weniger als halb so lang wie das zweite Glied und rechtwinklig von diesem abstehend, tein, hellgrau, mit schwarzem Ringe vor der Spitze. Fühler hellgrau mit feinen, schwarzen Piugen. Die vier vorderen Beine dunkelgrau mit weisslichen Enden der Fussglieder; die Hinterbeine weisslichgrau, nur an den Schenkeln auswärts dunkelgrau; die Schiene 
auf der Rückenschneide nit dichtem, starkem, niederliegendem Haarkamm; die Dornen ebenso hell, ungleich; der äussere des oberen Paares ist der längste und reicht bis ans Eude der Schiene. Hinterleib an den Seiten mit Schuppenbüscheln, bräunlichgrau, am Bauch bis vor den Analbusch sehwärzlich.

Vorderflügel $4^{\prime \prime \prime}$ Iang, nach hinten nicht erweitert, mit rechtwinkliger Spitze und ziemlich gerade herabgehendem Hinterrand, hellgrau mit schwarzen Stäubchelı, am wenigsten im Mittelraum, so dass dieser weisslich bleibt. Die Scbulter ist schwärzlich, ohne einen abgegrenzten Fleck zu bilden. Die schwarzen, fleckähnlichen Punkte liegen folgendermassen: der erste, mehr verwischte in der Falte mitten zwischen der Basis und dem vor der Flügelmitte folgenden Paare, von welchem der oberste Punkt der deutlichste von allen und viel grösser ist als der nahe an ihm in der Falte liegende. Der vierte Punkt, auf der Querader ist ein wenig weiter vom zweiten, als dieser vom ersten entferut. Gleich hinter ihm zieht die breite, weissliche, schwärzlichgran beschattete Binde schräg auswärts voin Vorderrande bis zum Innenwinkel herab; sie ist oben verdünnt und bildet über dem Queraderpunkte einen nach innen gerichteten Winkel. Bis zur Spitze ist der Torderrand mit einigen sehwarzen Fleckchen gezeichnet. Den Hinterrand bildet eine mehrmals unterbrochene schwärzliche Linie. Die Franzen (welche sehr beschädigt sind) scheinen grau oder schwärzlich zu sein; an Innenwinkel sind sie weisslich.

Hinterflügel einfarbig braungran. Franzen heller, gleich hinter der gelblichen Wurzel mit einem dunkeln Sehatten durchzogen.

Unterseite der Vorderflügel dunkelgrau; auf dem Vorderrand vor der Spitze mit weisslichen Punkten; Hinterflügel heller.

Vaterland: Texas (Boll). Ein $\sigma^{\top}$ im Cambridger Museum.

\section{Gelechin (Tachyptilia) innocuella n. sp.}

Pulpis dilute cinereis, articulo secundo exterius excepto apice fusco, antennis fusco-annulatis, tibiis posticis superius pallide ochraceis, inferius abrupte fusco-cinereis; alis ant. fusco-cinereis, punctis 4 nigris $(1,2,1)$ subobsoletis, striga postica canescente bifiacta, maryine postico nigro-punctato; post. subobtusis, fuscescentibus, pallidius ciliutis. 오.

Sie hat mit der auf dem Hiuterleib einfarbig staubgrauen Populella die grösste Aehnlichkeit und unterscheidet sich von ihr nur durch weniges, aber sicher: sie ist beträchtlich grösser und breitflügliger mit stumpferer Spitze der Hinterflügel; auf den Vorderflügeln ist der schwarze Schulterfleek (der bei Populella oft ganz fehlt) gross und sehr deutlich; die vier schwarzen Mittelpankte, namentlich der auf der Querader, sind grösser, die helle lintere Querlinie läuft in ihrem untersten Drittel mehr nach hinten; die Spitze des zweiten Tastergliedes ist breiter hellgrau. - Von der folgendeu Art, die in der Färbung eher mit Scintillelle zu vergleichen ist, lässt sie siel durch ihre beträehtlichere Grüsse, ihre breiteren und stumpferen, graugelblich gefranzten Flügel, die weniger gleichmässig graue Grundfarbe der vorderen und ihre eiuwärts nicht dunkel gesäuınte Querlinie, ferner durch die an der Basis gelichteteu Hinterflügel, sowie 
durch die Zeichnung ihres stärker keulenfürmigen zweiten Tastergliedes und die der Hinterschiene unterscheiden.

Rückenschild und Kopf grau, Gesicht und oberer Augenrand weissgrau. Fühler fein, auf der Unterseite heller gelblichgrau als auf dem Rücken, fein braungeringelt; das Wurzelglied auf dem Rücken bräunlich, am Ende schmal gelblichgrau. Taster lang, gekrlimmt, dürn, hellgrau; die zwei ersten Glieder aussen braun, das zweite nach oben keulenförmig verdickt, am Enddrittel hellgrau; das dritte Glied von fast mehr als halber Länge des ganzen Tasters, einfarbig. Saugrüssel lang, gelblichgrau, kaum an der Wurzel etwas beschuppt. Beine bleichgelb, die vier vorderen auswärts braun; die Hinterschienen, wie bei Populella, anf der Aussenseite an der oberen Hälfte bleich ochergelb, an der unteren streifenförmig braungrau; alle Füsse auf dem Rücken brännlich, an den Enden der Glieder wie die Schienendornen bleichgelb. - Hinterleib flachgedrückt, staubgrau, heller als auf dem Rückenschild; bei dem einen Exemplar ist er (analog der Populella) bräunlichgelb, nur an den drei hintersten Segmenten grau; bei ihm ist auch der Bauch lebhafter ins Gelbliche gefärbt als bei den anderen. Der blassgelbliche Legestachel steht aus dem zugespitzten Analglied ein wenig hervor.

Vorderflügel fast $5^{\prime \prime \prime}$ (bei Populella höchstens $4 \frac{1}{2}{ }^{\prime \prime \prime}$ ), länglich, mit deutlicher, doch nicht scharfer Spitze, auf grauem Grunde ziemlich reichlich und gleichmässig dunkelbraun bestäubt und dadurch bräunlichgrau erscheinend. Der Vorderrand selbst ist bis zur hellen Querlinie bleichgelblich, aber so schwach, dass es nur bei der Betrachtung von vorn zu erkennen ist. An der Schulter ist ein längliches, tiefschwarzes Fleckchen. Die gewöhnlichen vier schwarzen Punkte sind gross, aber ziemlich verloschen: der erste dicht über der Falte bei $1 / 5$ der Länge; die zwei folgenden vor der Mitte sehr schräg unter einander, und zwar der kleinere untere weit vor dem oberen, in der Falte; der vierte näher dem dritten als dieser dem ersten, auf der Querader in etwas hellerer Umgebung. Die darauf folgende Querlinie ist verloschen, bleichgelblich, am Vorderrand etwas erweitert, darunter zu einem einspringenden spitzen Winkel, dann $\mathrm{zu}$ einem kürzeren rechten gebrochen, worauf sie ziemlich gerade und senkrechter als bei Populella in den Innenwinkel läuft; auf der Aussenseite ist sie, besonders oben, etwas dunkelschattig gerandet. Um den Hinterrand zieht eine Reihe schwarzer Punkte bis zu der hellen Querlinie. Franzen bleichgelblich, an der Wurzel und in der Mitte in einer verloschenen Linie grau.

Hinterflügel breiter als die Vorderflügel, viel stumpfer als bei Populella, ganz ohne Ausrandung unterhalb der Spitze, dunkel braungrau, in der Mittelzelle gegen die Wurzel hell. Die bleichgelblichen Franzen haben nahe an der Wurzel eine graue, breite Linie, die weit vor dem Analwinkel verschwindet, und auswärts eine schmälere, verloschenere, die sich um die Flügelspitze herumzieht und nicht bis zur Flügelhälfte reicht.

Unterseite der Vorderflügel schwarzgrau, am Hinterrand breit, an den Gegenrändern schmal bleiclgelb, vor der Spitze mit einem solchen Fleck (dem erweiterten Anfang der helleu Querlinie der Oberseite). Hinterflügel schwarzgrau 
mit groben, dunkleren Schüppchen dicht bestreut, in der Mittelzelle bleichgelb. Alle Franzen heller gelblich als auf der Oberseite, aber ebenso gezeichnet.

Vaterland: Texas (Boll). Ein $q$ in meiner Sanmlung, zwei im Cambridger Museum.

\section{Gelechia (Tachyptilia) consonella n. sp.}

Palpis pallide ochraceis, articulo secundo exterius fusco, antennis distincte fusco-annulatis, tibiis posticis exterius fuscis; ulis ant. angustis, subacutis, fusco-cincreis, vena costali flavida, punctis ordinariis 4 nigris distinctis, striga postica diluta, subbifracta, interius fuscescenti-marginata. $0^{7} Q$.

Kleiner als die vorige, mit schnäleren, gleichmässiger dunkel braungrauen Vorderflügeln ohne schwarzes Schulterfleckchen und mit spitzeren, einfarbig dunkelbraunen Hinterflügeln. - Es giebt von Scintillella eine grössere Varietät (Panormitella Mann in lit.), bei welcher die helle hintere Querlinie der Vorderflügel vollständiger als gewöhnlich ist. Mit dieser lässt sich Consonella, obgleich sie mit der vorigen uäher verwandt ist, hinsichtlich der Färbung vergleichen. Bei der grösseren Consonella sind alle Flügel spitzer, die vorderen gleichmässiger und etwas heller braungrau, mit wenigeren dunklen Schuppen bestrent; ihre helle Querlinie ist deutlicher, feiner und einwärts dunkel eingefasst; ihre Taster sind auf der Aussenseite des zweiten Gliedes braun (bei Scintillella überall bleichgelb).

Grösse einer mittleren Populella. Rückenschild, Kopf und Vorderflügel gleichmässig dunkelgrau; das Gesicht nach unten zu weissgrau gelichtet. Fühler fein, weisslich ochergelb, auf dem Rücken melır grau, sehr deutlich braun geringelt; das Wurzelglied auf der Rückseite grau. Taster von der Gestalt der vorigen, uur gegen das Ende des zweiten Gliedes dünner keulenförmig, bleich ochergelblich, besonders auf der Innenseite; das zweite Glied dunkel braungrau, nach oben kaum etwas lichter. Saugrüssel lang, hell graugelb, kaum etwas beschuppt. Beine graubraun, an den Fussgliedern mit kaum merklicher verloschen gelblichen Enden; die Hinterschieuen innen bleichgelb, auswärts einfarbig graubraun mit bleichgelben Dornen. Hinterleib des $\sigma^{7}$ einfarbig gran, etwas flach, mit dünnem, zugespitztem, länglichem Analbusch.

Vorderflügel $3 \frac{1}{2}-4^{\prime \prime \prime}$ lang, schmal, nach hinten wenig erweitert, mit deutlicher, doch nicht scharfer Spitze und geraderem Aussenrand der Hinterrandfranzen als bei Scintillella. Grundfarbe dunkelgrau. Der Vorderrand ist in deutlicherer, schärferer Linie als bei Innocuella, von der Wurzel aus, wo er bräunlich ist, aber gar keinen Fleck oder Punkt trägt, bis zur hellen Querlinie blassgelb. Au der Wurzel ist die ganze Vorderrandgegend etwas weissgrau. Die vier schwarzen Punkte sind beim $q$ kleiner als bei Innocuella, beim $\sigma^{\pi}$ ebenso gross, und wenigstens die drei letzten sind ganz scharf; ihre Lage ist wie bei Innocuella; der vierte, anf der Querader liegende ist kleiner als die zwei vorhergehenden. Die helle hintere Querlinie, die mit einer lichteren Erweiterung auf dem Vorderrande anfängt, ist dünner als bei Innocuella und Scintillella und auf der inneren Seite vom einem dunklen Schatten begrenzt; 
sie bricht sich in der Mitte zu einem stnmpfen Winkel, dessen oberer Schenkel kürzer als bei Innocuclla eingeknickt ist, und dessen unterer Schenkel gerader und schräger als bei Scintillella einwärts läuft. Längs des Hinterrandes sind einige mehr oder weniger scharfe schwarze Punkte. Franzen ziemlich dunkelgrau, an der Wurzel und vor dem Ende ein wenig dunkler.

Hinterflügel ohne Ausrandung unterhalb der Spitze, einfarbig dunkel braungrau. Franzen heller, an der Wurzel durch eine sehr feine, bleichgelbe Linie von der Flügelfläche getrennt, hinter ihr etwas verdunkelt; sie sind also anders als bei Innocuclla gefärbt.

Die ganze Unterseite ist dunkel braungrau; die ebenso gefärbten Franzen haben eine sehr feine, bleichgelbe Wurzellinie.

Vaterland: Missouri, von wo ich das $q$ durch Riley erhielt; Texas (Boll), von wo das $\sigma^{\nearrow}$ des Cambridger Mnseums stammt.

A n merkung. Die Clemens'sche Gelechia Rhoifructella (ed. Stainton p. 114) würde ich für meine Consonella halten, da sie nach Stainton's Anmerkung nothwendig in diese Nähe gehört, und die freilich etwas dürftige Beschreibung (insbesondere wegen der dark-fuscous dots) fast völlig auf sie anwendbar ist; aber nach ihr sollen die Taster einfach ziemlich dunkelocherfarben (rather dark ochreous) sein, während Consonella sie recht hell ocherfarben und auf der Aussenseite des zweiten Gliedes dunkelbraungrau zeigt, und die Hinterflügel sollen eine schwache Ausrandung haben (hind-wings slightly emarginate beneath the tip.). Dazu kommt, dass Stainton die von Clemens erhaltenen Exemplare von der Popule lla unterscheidet, und zwar durch Merk-

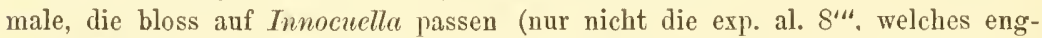
lische Mass für die $10 \frac{1}{2}$ pariser Linien del Innocuclla viel zu klein ist). Ich glaube daher, dass Clemeus mehrere Arten in eine zusammengefasst hat. Da er die Raupe beschreibt, so wird die wahre Rlooifructclla leicht wieder aufzufinden sein.

\section{Gelechir crecella n. sp.}

Abdominis basi ochracea, alis ant. angustis, cinerascentibus, practer costam creberrime nigro-pulvercis et praesertim postice rufescenti-sulpusis, maculis duabus posticis oppositis albidis. ․

Keiner mir bekannten Art recht ähnlich, durch das runde Fleckchen vor der Mitte der Vorderflügel (das wenigstens das eine Exemplar besitzt) in die Nälıe der Gel. atra, muscosella, cuneatclla, Lynccella, versutella gewiesen, vor allen durch die ganz hellgraue Basal- und Costalpartie und den röthlichen Anflug ausgezeichnet, der zwischen der dichten schwarzen Bestänbung, besonders gegen den Hinterrand zum Vorschein kommt.

Von der Grösse der folgenden, mit etwas schmäleren Vorderflügeln. Rückenschild und Kopf hellgrau, wenig dunkelbestäubt und im Gesicht nicht heller. Fühler brännlich, kaum an der Wurzelhälfte auf dem Rücken etwas heller punktirt; die Spitze des Wurzelgliedes hell. An den Tastern ist das zweite Glied mit ziemlich gleichmässiger, reichlicher Bürste versehen und aus- 
wärts braun bestäubt; das Endglied 3/4nal so lang wie das zweite Glied, braun mit hellem Rücken und solchem Fleck an dur Mitte. - Die vicr vorderen Beine aussen braun mit hellen Enden der Fussglieder. An den linteren die Schienen nebst den Dornen und die Füsse auswärts braun, erstere auf der Rückenschneide reichlich blondhaarig und, wie alle Fussglierler, an der Spitze bleichgelblich. Hinterleib zugespitzt, bräunlichgrau, auf den drei ersten Segmenteu ausser am Rande ochergelblich; Bauch blassgelblich, an der Seite reichlich schwarzbestäubt; der Legestachel steht aus dem kegelfürmigen, obenanf braungranen Aualsegment hervor.

Vorderflügel $3^{1 / 2}-4^{\prime \prime \prime}$ lang, schmal, nicht erweitert, hellgran, welche Farbe aber nur an der Basis rein bleibt und am Vorderrand bis zur Mitte fast weisslich ist, während der ganze übrige Raum, doch nicht gleichınässig, dicht schwarz verstänbt ist. Hinter der schwarzen Schulter geht ein sehr kurzes schwarzes Strichelchen etwas schräg unterlalb des Vorderrandes, und nicht weit davon kommt vom Vorderrand ein sehr schräg nach aussen gerichteter, unterbrochener Strich herab. Die Falte zeigt sich als eine feine, hier und da unterbrochene und ausbleibende Längslinie. In ler Mitte des Mittelranmes liegt bei dem einen Exemplar ein gerundetes, weissgraues Fleckchen, rings von dem verdunkelten Grunde umgeben, doch nach dem Vorderrande zu heller begrenzt; es ist bei dem zweiten Exemplar nur in seinem unteren, hakenfürmigen Theile vorhanden. Ein kleineres, eckiges, gleichfarbiges Fleckchen folgt bei dem ersten Exemplare auf der Querader; über ihm ist bis zum Vorderrande die Grundfarbe röthlich angelanfen. Indem die schwarze Bestäubung als Fleck bis zum Vorderrande reicht, wird eine in der Mitte scharfwinklige, helle, hintere Querlinie angedentet, welche sich auf dem Vorderrande zu einen weissgrauen Fleck und im Innenwinkel zn einem solchen Wisch ausbildet; beide Enden der Querlinie liegen schräg unter einander, das obere weiter nach hinten als das antere. Der Raum !bis zum Hinterrande ist geröthet und mehr oder weuiger schwarz bestäubt. Längs des Hinterrandes zieht eine Reihe schwarzer, schlecht ausgedrïckter, mehr oder weniger zusammengeflossener Pnnkte. Franzen grau, auf der Wurzelhälfte dunkel bestänbt.

Hinterflügel merklich breiter als die Vorderflügel, mit schwachem Eindruck des Hinterrandes unterhalb der Spitze, hellbranngrau, gelblicher gefranzt.

Unterseite der Vorderflügel hellbraungrau, am Vorderraud vor der Spitze mit einem verloschenen gelblichen Fleck. Franzen heller mit hellgelblicher Basallinie. Hinterflügel heller als auf der Oberseite, am Vorderrand und in der Spitze bräunlich bestäubt.

Vaterland: Massachusetts. Zwei gut erhaltene $q$, von Burgess bei Beverly, das eine am 20. Juni, gefangen, in meiner Sammlung.

Gelerhir versutella n. sp.

Abdominis basi ochracea, palporum articulo terminuli fusco, apice albido; alis ant. angustis, cinereo nigroque marmoratis, puncto disci ante 
medium, macula parva venae transversae nigro-pupillata, strigaque postica. angulata albidis, linea plicae interrupta nigra, citionum basi lutescente. $f$.

Verwandt mit Gel. nigra Haw. (cautella Z.), doch grösser, auf den etwas kürzeren Vorderflügeln ganz ohne den bläulichen Ton dieser Art, und mit grossfleckiger, schwarzer Marmorirung, in welcher die zwei weisslichen Punkte des Mittelraumes und die dünnere hintere Querlinie am stärksten hervortreten.

Rückenschild gelblichgrau, in der Mitte und vorn braun bestäubt. Kopf gelblichgrau, im Gesicht heller, auf dem Scheitel etwas bestäubt. Fühler braun, in einer sehr dünnen Rückenlinie gelbgrau und bräunlich punktirt, gleichsam geringelt. Taster braun, auf der Innenseite blassochergelb, auf der Aussenseite mit dieser Farbe bestäubt; die Bürste des zweiten Gliedes ist stark, ihre Schuppen werden aber nach oben merklich kürzer; das Endglied fast so lang wie das zweite Glied, braun, mit feiuer, weisslicher Spitze. - Die vier vorderen Beine auswärts dunkelbraun, an den Enden der Fussglieder bleichgelblich; die Hinterschienen bleichgelb, auswärts an der Wurzel braungrau und von der Mitte an mit einem braungrauen Streif, auf der Rückenschneide mit langen, reichlichen, blonden Haaren; die Hinterfüsse auswärts graubraun, an den Enden der Glieder und in einer feinen Linie an der unteren Schneide bleichgelb. - Hinterleib ziemlich lang, zugespitzt, auf dem ersten Drittel und den zwei letzten Segmenten bleichochergelb; der Banch fast weisslich, an der Wurzel der Segmente breit braungrau; der Legestachel steht nicht hervor.

Vorderflügel 4"' lang, ziemlich schmal, nach hinten nicht orweitert, auf weissgrauem Grunde sehr reichlich und grob schwarzbraun marmorirt. Als die schärfsten Flecke lassen sich ansehen: einer an der Schulter, einer an der Mitte des Vorderrandes und einer am Anfang der Costalfranzen, welcher den Anfang der breiten inneren Einfassung der bellen Querlinie bildet. Ferner liegen im Mittelfelde zwei dicke Längsstriche, die durch den weissgrauen, etwas gerundeten Punkt getrennt werden, und von denen der längere zweite durch das grössere helle, mit einem Mittelpunkte versehene Fleckchen begrenzt wird. Aus dem Schulterfleck kommt eine gegen den Vorderrand divergirende und bis zum Mittelfleck des Vorderrandes reichende tiefschwarze Längslinie. In der Falte ist eine tiefschwarze Linie, welche nicht an der Wurzel anfüngt, hinter der Mitte unterbrochen ist und bis zum Innenwinkel reicht. Der Raum zwischen dem hellen Queraderfleckchen und der weisslichen, in der Mitte scharfwinkligen Querlinie ist ganz schwarzbraun, wie aus drei Flecken zusammengesetzt. Der Paum hinter dieser Querlinie bis zum Hinterrand ist auch ganz dunkel und auf den Adern, doch nur in gewisser Beleuchtung, mit kurzen, tiefschwarzen Längslinien gezeichnet. Den Hinterrand fasst eine sich oben und unten an die Enden der Querlinie anschliessende weissliche Linie ein, welche mit groben, schwarzen Punkten bezeichnet ist. Franzen an der Wurzelhälfte hell lehmgelblich, braun bestäubt, an der Aussenhälfte grau.

Hinterflügel breiter als die Vorderfliigel, mit seichtem Eindruck des Hinterrandes unterhalb der Spitze, braungrau, weit heller gefranzt. 
Unterseite der Vorderflïgel braungrau mit einer bleichgelblichen Costalstelle hinter der Mitte und solchen Costalpunkten vor der Spitze. Franzen grau, gegen die Wurzel bleichgelb und dadurch gegen die Flügelfläche scharf abstehend. Hinterflügel hellgrau, gelblich seidenartig schimmernd, längs des Vorderrandes und in der Spitze matt gelblichweiss und bräunlich bestäubt.

Vaterland: Texas (Boll). Ein $q$ im Cambridger Museum.

\section{Gelechia Lymceella n. sp.}

Abdominis basi ochracea; antennis obsolete anmulutis; alis ant. angustis, canescentibus, nigro-pulvereis lituratisque, orbiculo disci ante medium cano, nigro-pupillato; post. canescentibus, subpellucidis. $\sigma^{7}$.

Nahe verwandt mit den beiden bei Herrich-Schäffer ganz unkenntlich abgebildeten Arten Muscosella (welche in der Wirklichkeit eine trüb grünlichgraue Grundfarbe hat) und Cuneatella (die auf den schmäleren Vorderfügeln gelblichgrau ist); sie ist auf den Vorderflügeln sehr hellgrau und deutlicher als beide Arten mit einem gleichfalls helleren, schwarzgekernten Ring versehen, und ilire Hinterflügel scheinen etwas durch.

In der Grösse der Cunecutella, mit nicht ganz so schmalen Vorderflügeln. Rückenschild grau; fein schwärzlich bestäubt; Kopf weissgran, unbestäubt, Fühler braungrau, auf der Rückenseite verloschen grau geringelt, das Wurzelglied braun mit weissgrauem Längsstrich. Zweites Glied der Taster cylindrisch zusammengedrückt, auswärts braun bestäubt, vor der hellen Spitze dunkelbraun; die Schuppenbürste locker, hell, nach oben verdünnt; das Endglied über halb so lang wie das zweite Glied, schwärzlich, auf der Innenseite in der Mitte mit hellem Band. - Beine weissgrau, die Mittelhüften weisslich; die vier vorderen Schienen auswärts schwärzlich mit weissgrauen Flecken, die Füsse schwärzlich mit weisslichen Enden der Glieder; die Hinterschienen auswärts dunkelbraun bestäubt mit hellen Dornen und auf der Rückenschneide mit langen, hellblonden Haaren; die Hinterfüsse grau, an den Enden der Glieder heller. - Hinterleib grau, auf den drei ersten Segmenten hell ochergelb; der Bauch weisslichgrau; der Analbusch lang oval, hell braungrau, auf jeder Seite mit einem hellgelblichen Längsstreifen.

Vorderflügel $31 / 2 "$ lang, schmal (mehr als bei Muscosella, weniger als bei Cuneatella), hinten nicht erweitert, auf weisslichem Grunde reichlich, aber ungleichmässig schwarz bestäubt, am gleichmässigsten in dem schrägbegrenzten Basalraum zwischen der Schulter und dem Innenranddrittel. In Mittelraume liegt vor der Mitte ein rundes, weissgraues Fleckchen mit schwarzem Mittelpunkte. Von ihm reicht ein schwarzer Längsstrich bis zu dem verloschenen, hellen, gleichfalls mit einem schwarzen Punkte bezeichneten Fleckchen der Querader. Ueber beiden Flecken trägt der Vorderrand je einen schwarzen Fleck, und der erste von beiden ist mit dem Discoidalstrich durch eine verdünnte Verlängerung verbunden; hinter dem zweiten ist eine nicht scharf abgegrenzte, dünne, weissgraue, in der Mitte scharfwinklige Querlinie, von deren Enden sich eine Reihe ebenso undeutlich ausgedrückter, weissgrauer Fleckchen um den 
Hinterrand herumzieht; jedes dieser Fleckchen endigt nach anssen in einen schwarzen Punkt. In der Falte lassen sich unter und hinter dem hellen Ringtleck Bruchstücke einer schwarzen Längslinie erkennen. Franzen hellgrau, auf der Wurzellälfte schwarz bestäubt.

Hiuterflügel merklich breiter als die Vordertlügel, mit unterhalb der Spitze sehr schwach eingedrücktem Hinterrand, hellgrau, ein wenig durchscheinend. Franzen mit feiner, bleich ochergelblicher Wurzellinie.

Unterseite der Vorderflïgel gran, an Enddrittel des Vorderrandes, sowie die Wurzel der helleren Franzen bleichgelblich. Hinterflügel am Vorderrand in einem schmalen Streifen matt und bräunlichgrau bestäubt.

Vaterland: Texas (Boll). Ein gutes $\sigma^{7}$ in meiner Sammlnng; nach Dr. Hagen's Angabe sind mehrere genau übereinstimnende im Cambridger Núuseum.

\section{Géchia numatimella n. sp.}

Abdominis besi ochracen; antemnis anmulatis, pulpis griseis, articulo terminali nigro-biammelato; alis ant. oblongis, dilute luteolo-griseis, nigro-pulvereis, muculis olsoletis nigricontibus s 9 in disco dispersis..

Keiner anderen Art ähnlich; wenn auch wit derselben Färbung der ersten Hinterleibsegmente wie die vorigen, doch durch die breiteren Flügel abweichend und besonders ausgezeichnet durch die bleich gelblichgraue, schwarzstaubige Färbung der Vorderflügel und die unregelmässig auf den zwei Basaldritteln im Mittelramı zerstreuten, zerfliessenden, weit von einander getrennten Flecke.

Grösser als die vorigen, anf Rückenschild, líopf und Vorderflügelı hell bleichgelblichgrau mit schwarzen, nicht zusammenhängenden Stïubchen bestreut, so dass der 'l'on der Grundfarbe dadurch nicht oder wenig verändert wird. Das Gesicht ist unterwärts unbestäubt. Fühler bleichgelb mit dentlich abgesetzten und an ihrem Anfang verdunkelten Gliedern, daher geringelt. Taster von ansehnlicher Länge, bleichgelb, auswärts und an der Bürste reichlich braun bestäubt; die Bürste, die in der starken Furche hell ist, wird nach oben kürzer; das Endglied ist 3/4 so lang wie das zweite Glied, auch zusammengedrückt und auf der Schneide etwas locker beschuppt, auswärts mit zwei schwarzen Bündern, an der spitze hell und unbestäubt. - Alle Beine bleichgelb, die vorderen auswärts reichlicher dunkel bestäubt als die Hinterbeine, deren Schienen aussen reichlich behaart sind. - Hinterleib gelblichgrau, auf den zwei oder drei ersten Segmenten blassgelb, am bauch hell mit brauner Bestäubung; Legestachel eingezogen.

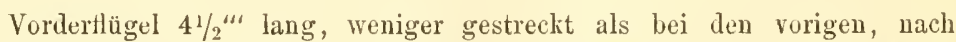
hinten kaum erweitert. Von den nicht scharí begrenzten, verloschenen, schwärzlichen Flecken, die sich nicht wohl zählen lassen, weil die unterhalb des Vorderrandes gegen die Basis liegenden zu undeutlich werden, liegt der unterste unter dem ersten Drittel der Falte, der zweite in der Hälfte derselben. Darüber befinden sich im Mittelrame fünf in einer unregelnüssigen Längsreibe, der erste, dritte und füntte (dieser in der Gegend, wo die völlig nudeutliche Querlinie ihreı Winkel bilden würde) wischförmig, der zweite und vierte etwas höher 
gerïckt und wie der in der Hälfte der Falte kleiner, dunkler und schärfer. Weiter gegen den Vorderrand sind noch 3-4 sehr undeutliche Wischehen, von denen das hinterste, das ziemlich oberhalb des Faltenfleckchens schivebt, am deutlichsten ist. Den Hinterrand entlang und am Ende des Vorderrandes zieht eine Randzeichnung aus schwarzen, undeutlichen Schuppenhäufchen. Die Franzen sind auf der Hälfte von einer schwarzen Schuppenlinie durchzogen und davor etwas bestäubt.

Hinterflügel bedeutend breiter als die Vorderflügel, unterhalb der Spitze ein wenig eingedrückt, grau, gegen den Innenrand heller und weniger grobschuppig.

Unterseite der Vorderflügel dunkelgrau, am Vorderrande bleichgelblich mit bräunlicher Bestäubung, am Hinterrand mit bleichgelblichen, in die Franzen ausstrahlenden Wischpunkten. Hinterflügel hellgrau, am Vorderrand bleichgelblich mit bräunlichen Stäubchen; der Raum in der Flügelspitze bräunlich bestäubt, mit einem bleichgelblichen, in die Franzen verlängerten Wisch aus der Spitze selbst.

Vaterland: Texas (Boll). Ein $Q$ in meiner Sammlung, mehrere nach Dr. Hagen's Angabe im Cambridger Museum.

\section{Gelechic unctulella n. sp.}

Thorace et capite fuscis antemnis palpisque nigerrimis; alis ant. angustulis, nigro-fuscis, nitidulis, punctis disci duobus magnis, nigris (altero ante medium, altero venae transversae). 0 .

Auf allen Flügehn und auch auf dem Hinterleibe etwas fettglänzend, in der Grösse einer mittleren Gallinella (Evicetella), aber schmalfligliger, mit dunkleren Vorderflügeln ohne helle Randpunkte und mit schmäleren, etwas spitzeren Hinterflügeln.

Der ganze Vorderkörper schwärzlichbraun, der Kopf ein wenig schimmernd. Fühler borstenförmig, gegen die Spitze kaum kennbar gekerbt, schwarz. Taster so lang wie Kopf und Rückenschild zusammen, aufgekrümmt, ganz schwarz; das zweite Glied cylindrisch, zusammengedrückt, gegen das Ende ein wenig verengt ohne Furche, auf der Bauchschneide kaum lockerschuppig, indem die Schuppen nur einen kerbigen Rand bilden; das Endglied über halb so lang, düm pfriemenfürmig, feinspitzig. - Beine tiefsclıwarz, nur an den Enden der Fussglieder ein wenig verloschen weisslich; die Vorderschenkel auf der Innenseite etwas kupferig schimmernd; die Hinterschienen auf dem Rücken mit rauchbraunen Haaren. Hinterleib braungrau, fettglänzend: der Bauch schwarzbraun, in der Mitte striemenartig gelbbräunlich; Afterbusch länglich, zugespitzt, hellbrann.

Vorderflügel $3 \frac{1}{2}{ }^{\prime \prime \prime}$ lang, schmal, nach hinten ein wenig erweitert, an der Spitze zugerundet, fettglänzend schwarzbraun, ins Hellviolettliche schimmernd. Die flach liegenden, länglichen Schuppen sind ausser an der Spitze ganz hell ins Graue. In der Mittelzelle liegt vor der Flügelmitte ein dicker, schwarzer Punkt, doppelt so weit von der Basis wie von dem noch grösseren Punkte der Querader; beide Punkte treten aus der Grundfarbe sehr wenig hervor. Andere 
Zeichnungen fehlen. Franzen braungrau, an der Wurzel besonders dicht un die Flügelspitze, mit schwarzen Schuppen bestreut.

Hinterflügel breiter als die Vorderflïgel, spitz, unter der Spitze mit sanft eingebogenem Hinterrande, fettglänzend bräunlichgrau, längs des Vorderrandes und in der Spitze verdunkelt.

Unterseite der Vorderfiügel einfarbig dunkel braungran, heller gefranzt: Hinterflügel wie oben.

Vaterland: Texas (Boll); ein schön erbaltenes ơ im Cambridger Museum.

Anmerknng: Herrich-Schäffer behauptet, doch wohl auf weiter nichts als auf den Namen - der allerdings den Aufenthalt in ericetis richtig andeutet - und auf die Dunkelheit der Färbung gestützt: zu Gallinella Tr. gehöre "Ericetella H. 470 gewiss; doch ist die Form nicht richtig." Auf diese Behauptung hin ist der Name Ericetella allgemein angenommen worden nur von Herrich-Schäffer selbst nicht! Und meines Erachtens hat er daran sehr recht gethan. Das Bild stellt durchaus keine Gullinella dar, wie schon die scbmalen Hinterflïgel, der Mangel heller Randpunkte auf den Vorderflügeln und der weissliche Haken vor der Mitte derselben lehren. Mit mehr Recht liesse sich eine Deutung der Figur auf Gel. cinerosella oder Gel. sevvella versuchen. Man wird sich wohl zur Annahme des kläglichen Haworthschen, von einer schlechten Beschreibung kläglich unterstützten Namens entschliessen müssen.

Gelechia violareo-fusca n. sp.

Antennis crassiusculis, fuscis, fronte flavida; atis ant. oblongis, subtruncatis, violaceo-fuscis, striola plicue mediue punctisque marginalibus nigris; post. dilute cinereis. $\sigma^{7}$.

Sie scheint mit Gel. gallinella Tr. zusammengestellt werden zu künnen, da sie die feste Beschuppung des zweiten Tastergliedes und eine violettlich braune Grundfarbe der Vorderflügel mit ihr gemein hat; durch die Dicke der Fühler und durch die Kürze und den ziemlich gerade abgeschnittenen Hinterrand der Vorderflügel weicht sie aber ganz ab.

Viel kleiner als Gallinell t. Rïckenschild und Oberkopf dunkelbraun, violett schimmernd; Gesicht blassgelb. Fühler dick, borstenfürmig, braun; das kleine Wurzelglied auf der abgewendeten Seite mit gelblicher Spitze. Taster bleichgelb; das zweite Glied aussen braun mit Ausnahme der Spitze, innen etwas dunkler bestäubt; die Bürste nicht lockerschuppig, nach oben kaum verdünnt, mit Längsfurche; das Endglied $2 / 3$ so lang wie das zweite Glied, aussen etwas braun bestäubt. - Vorderbeine auswärts schwarzbraun; die Mittel- und Hinterbeine heller; alle mit bleichgelben Enden aller Glieder; die Hinterschienen an der Mitte und am Ende, wie ihre Dornen, bleichgelb mit blonden Rückenhaaren. - Hinterleib bräunlichgrau, am Bauch mit bleichgelber, am Afterbusch knotenfürmig erweiterter Mittelstrieme.

Vorderflügel $3^{\prime \prime \prime}$ lang, länglich, nach hinten kaum erweitert, mit fast gerade abgeschnittenen, wenig schrïg zurückgehendem Hinterrand, dunkelbraun mit violettem Schimmer, am Innenrand bis zur Falte ein wenig lichter braun. 
In der Falte liegt vor der Hälfte ein wenig auffallender, länglicher, selwwarzer Punkt, an beiden Enden mit einigen weisshichen Sehuppen bezeichnet. Weiter zeigt die ganze Fläche keine Zeichnung. Am Hinterrand zieht eine bis auf den Vorderrand fortgesetzte Reihe sehwarzer, nicht weiss bezeichneter Punkte. Franzen heller als die Grundfarbe, auch violett schimmernd.

Hinterflügel breiter als die Vorderflügel, dicht unter der Spitze mit einem kleinen Eindruck des Hinterrandes, einfarbig grau.

Unterseite der Vorderflügel einfarbig grau; die Franzen durch eine sehr feine, gelbliche Linie von der Flügelfäche gesondert; die Hinterflügel heller.

Vaterland: Texas (Boll). Ein gut erhaltenes $0^{-1}$ in Cambridger Museum.

\section{Gelechia Olympiarlella n. sp. Fig. 15.}

Thorace fusco, cupite exalbilo, palpis prater apiccm allis; alis ant. nigricantilns, maculis tribus costalibus (mima transversa), una dorsali ciliisque allis; post. ditute cinercis. of 9 .

In der Lage der weissen Flecke der Vorderflügel stimmt sie mit der europäischen, etwas kleinern Tessella H. (quadrella F. Scopolella Tr.); sie unterscheidet sich aber schon durch die nur schwärzliche Grundfarbe dieser Flügel, dann durch die schwarze Spitze der Taster, die schwarzbraune (nich1, weissgelbliche) Farbe des Rückenschildes und die hellgrauen Hinterflügel ohne eingedrückten Hinterrand unterhalb der Spitze.

Rückenschild ganz schwarzbraun. Kopf weissgelb. Taster reiner weiss; wweites Glied sehr zusammengedrückt mit lockerer, tief ausgefurchter Bürste, gegen die Spitze verjüngt: Endglied über halb so lang, gekrümmt, schwarz mit weisser Wurzel und heller, feiner Spitze. Maxillartaster und Beschuppung des Saugrüssels weisslich. Ocellen deutlich. Fühler des $\sigma^{\top}$ schwach gekerbt, gegen die Spitze etwas sägezähnig, ganz braun. Vorderschenkel aussen braun; Vorderund Mittelschienen und Füsse braun, weiss punktirt; Hinterbeine bleich ochergelblich, die Schienen reichlich und lang behaart, anf der Aussenseite an der Mitte und vor der Spitze mit einem brännlichen Wisch, die Füsse bräunlich mit weisslichen Enden der Glieder und solcher Wurzel des ersten Gliedes. Hinterleib grau mit weissgelblichem, ungeflecktem Bauch; ठ A Afterbusch bleichochergelb; QAnalsegment zugespitzt mit langem Legestachel.

Vorderflügel $3-31 / 4$ "' lang, nach hinten nicht erweitert, schwärzlichbraun mit vier weissen Flecken. Der erste Costalfleck, nicht weit von der Basis, schräg nach aussen gelegt, etwas eekig, mit der Spitze über die Falte reichend; der zweite an der Mitte des Vorderrandes ist der kleinste und ziemlich gerundet; der dritte, vor der Flügelspitze, ist grösser, aber auch einwärts abgerundet. Ihm gegenüber liegt ein grosser, melır gerundeter Fleck im Innenwinkel und sich am Hinterrande etwas heraufziehend. Vor dem zweiten Costalfleck zeigt sich in der Mitte der Falte ein schwarzes Längsstrichelchen, hinten mit ein paar weisslichen Schuppen begrenzt. Auf der Querader, hinter dem zweiten Costalfleck, ist auch ein schwarzer, undeutlicher Punkt. Längs des Hinterrandes zieht von 
der Flügelspitze aus eine Reihe schwarzer Punkte melır oder weniger weit gegen den Innenrand herab. Hinterrandfranzen weisslich, Costalfranzen schwärzlich.

Hinterflügel breiter als die Vorderflügel, ohne Eindruck des Hinterrandes unterhalb der Spitze, hellgrau, beim $\subseteq$ etwas dunkler. Unterseite der Vorderflïgel dunkelgrau; der zweite und dritte Costalfleck sind in der Färbung der weisslichen Franzen schwach angedeutet, die Hinterrandpunkte sehr verloschen.

Vaterland: Texas (Boll). Ein ziemlich gut erhaltenes Paar in meiner Sammlung; nach Hagen's Angabe befinden sich mehrere im Cambridger Musenm.

Anmerkung 1. Gilvieomella Clem. p. 219 scheint in einiger Verwandtschaft mit Olympiadella zu stehen. Aber schon die Färbung des Kopfes und der Vorderflïgelflecke unterscheidet sie.

Anmerkung 2. Für Gel. tessella Hbn. ist die Diagnose etwa so zu stellen: Thoraee et enpite exulbidis, pulpis albis, articulo terminali nigrobipunctato; alis ant. nigerimis, maculis tribus costae (prima transversa), una dorsi eitisque albis; post. obscure cinereis. $\sigma^{\top} \Omega$.

Gelechia quinella n. sp. Fig. 14.

Thornee nigro, capite palpisque praeter hom apicem exalbidis, alis ant. nigris, striga costae abbreviata binisque macularm paribus oppositis albis, citiis nigris. Q.

Sehr ausgezeichnet durch fünf weisse Flecke auf dem scliwarzen Grunde der Vorderflügel; von ihnen bildet der erste einen schrägen, bis zur Falte reichenden Querstreif, und der untere des Mittelpaares ist eckig und bleibt von Innenrand getrennt.

Kleiner und breitflügliger als Olympiadella, Rückenschild schwarz. Kopf weissgelb; Taster reiner weiss; das zweite Glied sehr zusammengedrückt, mit lockerer, kaum gefurchter Bürste; das Endglied mehr als halb so lang, spitz, am Enddrittel schwärzlich. Maxillartaster sehr dentlich, spitz und weisslich wie die Beschuppung des Saugrïssels. Ocellen deutlich. Vorderbeine an den Schenkein aussen brann, an den Schienen schwarz und am Ende gelblichweiss; alle Füsse schwarz mit bleichgelben Spitzen der Fussglieder; die Hinterschienen auswärts brann mit zwei bleichgelben Flecken und solchen Dornen. Hinterleib braungrau, am Bauch bleichgelb; das ganze Analsegment kegelförmig, grau mit hervorstehendem Legestachel.

Vorderflügel $3^{\prime \prime \prime}$ lang, etwas breit, nach hinten nicht erweitert; mit abgerundeter Spitze, einfarbig schwarz mit weisser Zeichnung. Am Vorderrand ist nicht weit von der Basis ein schmaler Querstreif, der schräg nach aussen liegt und bis zur Falte reicht. An der Mitte des Vorderrandes hängt ein kleiner Fleck, und senkrecht unter ihm ist ein grösserer, fast viereckiger, der nicht den Innenrand berührt. Am Anfang der Costalfranzen trägt der Vorderrand einen kleinen Fleck, und etwas weiter nach hinten liegt über dem Innenwinkel am Hinterrand. eiı eben so grosser. Franzen schwar, am Innenwinkel etwas weisslich. 
Hinterflügel kaum breiter als die Vorderflügel, mit etwas stumpfer Spitze; der Hinterrand unterhalb derselben fast ohne Eindruck: Grundfarbe gleichmässig grau.

Unterseite der Vorderflügel dunkelgrau; nur die zwei letzten Costalflecke scheinen sehr klein und verloschen durch.

Vaterland: Texas (Belfrage). Ein $\Omega$, besser als gewöhnlich erhalten, am 19. August gefangen, in meiner Sammlung.

Gelechir albilovella n. sp. Fig. 16.

Thoruce maeter scrpulus, capite palpisque pweter upicem exalbidis, antemis nigris; alis nigris, strigis tribus albis (prioribus 2 obliquis abbreviatis, tertia angulata), cilie nigris. 9 .

Mit Viduellu F, nnd Luetuella H. (Sauteriella Z.) zu vergleichen, aber kleiner, der Thorax von der Farbe des Kopfes, nur mit schwarzen Schulterdecken, die Fühler ganz schwarz, die zweite Querlinie der Vorderflügel so dünn wie die erste und am Ende lnotenartig erweitert, die dritte wie bei Luctuclla gestellt, aber in der Mitte in einen spitzen Winkel gebrochen.

Rïckenschild weissgelb, zu beiden Seiten (nämlich auf den Schulterdecken) schwarz, so dass das Weissgelbe eine breite, parallelrandige strieme bildet. Kopf weissgelb mit schmalem, schwarzem oberen Augenrand. Taster länger als bei den zwei vorigen Arten, gelblichweiss; das zweite Glied stark zusammengedrückt mit lockerer, deutlich gefurchter Bürste; Endglied von 2/3 Länge des zweiten Gliedes, stark abgesetzt, fein, am Enddrittel schwärzlich. Fühler einfarbig schwarz, ganz ungeringelt. Vorderbeine auswärts schwarz, die Mittelschienen auswärts schwarz mit zwei weisslichen Flecken; die Hinterschienen schwärzlich, an der Wurzel und am Ende weisslich, in der Mitte mit weissem Bande; alle Füsse auswärts braun, am Ende weisslich. - Hinterleib gelbgrau, an den Hinterrändern hell, am Bauch weisslich; Analglied zugespitzt, am Ende gelblich mit hervorstehendem Legestachel.

Vorderfïgel fast $3^{\prime \prime}$ lang, ziemlich schmal obne Erweiterung, schwarz, mit drei weissen, vom Vorderrand ausgehenden Querlinien. Die erste, nicht weit ron der Wurzel, sehr schräg nach aussen gelegt, dünn, etwas über die Falte wegreichend. Die zweite, ihr parallellaufend, entspringt vor der Mitte und erweitert sich an der Falte in einen starken Knoten, der nach hinten zugespitzt ist. Die dritte, weiter von der zweiten als von der Flügelspitze entfernt, divergirt oben gegen den Hinterrand, ist am Vorderrand in einen Fleck erweitert, bildet in der Mitte einen Winkel, dessen scharfe Spitze gegen den Hinterrand gekehrt ist, und endigt im Innenwinkel. Die Franzen scheinen, nach den wenigen, an der Spitze noch übrigen, zu schliessen, schwarz gewesen zn sein.

Hinterflügel so breit wie die Vorderflügel, unterhalb der scharfen Spitze deutlich eingedrückt, einfarbig grau.

Unterseite der Vorderflügel dunkelgrau mit ganz verloschen durchscheinenden Zeichnungen; die Hinterflügel heller grau, gegen die Wurzel noch lichter, in der Spitze mit verloschenem, weisslichem Fleck. 
Vaterland: 'Texas (Belfrage). Ein $\bigcirc$, dessen Zettel mit der Angabe der Flugzeit beim Spannen verloren ging, in meiner Sammlung.

Anmerkung. Herrich-Schäffer's Luctiferclla (neue Beiträge Fig. 46) muss zufolge der Abbildung eine von Viduclla und Lactuella versehiedene Art sein. Die erste Querlinie, die bei beiden nur bis zur Falte reicht, geht hicr bis zum Innenrande selbst und bildet auf der Falte einen scharfen Winkel. Dass die Fortsetzung bis zum Innenrande keine Erdichtung sein kann, scheint daraus hervorzugehen, dass an der Flügelbasis ein gleichfalls bei den beiden audern Arten fehlender weisser Punkt liegt. An der Mitte des Vorderrandes ist, viel weiter von diesem getrennt als bei Luctuclla, nur ein sehr kleiner Punkt (bei Viduella liegt der Fleck auf dem Costalrande selbst); die Franzen sind weiss gefärbt, während sie bei Luctuclla schwarz sind.

\section{Gelechia (? Bryotropha) operrulella n. sp. Fig. 17.}

Capite palpisque exalbidis, horum articulo terminali nigro-bimaculato, at is ant. pallide ochuceo-griseis, cinereo-subncbulosis, punctis tribus tisci striolaque plicae medinc fuscis ( 9 nigris, albido-cinctis); segnento of anali pallide ochraceo, supcrne operculo magno, ovato, pratelliformi obtccto, penicillo pilor um utrimque eminente.

Das Männchen ist an dem oben mit einer grossen ovalen Scheibe bedeckten Analgliede, neben welchem zwei gekrümmte Haarbüsche hervorstehen, leicht zu erkennen. Das etwas hellere Weibchen - wenn es wirklich das Weibchen dazu ist - hat etwas breitere Vorderflïgel und den Queraderpunkt und den vor ihm liegenden Punkt in dunklerer Farbe und auf der dem Innenraude zugekehrten Seite auffallender hell umzogen.

Grösse der kleinsten Terella oder der grössten Senectella. Kojf weisslich, mit ein wenig Ochergelb gemischt, heller als das Pückenschild. Ocellen erkenne ich nicht. Fühler grau, nach unten heller, mit abgesetzten Gliedern, laher fast verloschen geringelt. Taster weisslich; zweites Glied zusammengearückt, mit deutlicher Rinne der Bürste, anssen grau angeflogen ausser am Ende; drittes Glied mehr als halb so lang wie das zweite, pfriemenförmig, feingespitzt, auswärts an der Wurzel und hinter der Mitte mit einem braunen Fleck. - Die vier Vorderbeine hellgrau, aussen braun bestäubt, an den Füssen braun mit weisslichen Enden der Glieder; die Hinterbeine bleich gelblich, an den Schienen mit wenigen hellblonden Haaren, an den Fussgliedern mit hellbrännlicher Wurzel. - Hinterleib gelblich staubgran mit grauweisslichem Bauch. Afterglied des o so lang wie $1 / 3$ des Hinterleibs, hell ochergelb; zwei länglichrunde, etwas ansgehöhlte Scheiben liegen mit ihren Höhlungen aufeinander; die untere ragt überall etwas nnter der oberen hervol und ist auf ihrem (unterseitigen) Rücken reichlich mit ziemlich locker liegenden Haaren bekleidet, während sie auf der oberen angedrïckt sind und nur etwas über die Ründer wegreichen; an beiden Seiten des Ursprungs der oberen Scheibe steht ein fast bis zu ihrem Ende reichender, auswärts gekrïmmter Haarbusch hervor. Beim $q$ hat das Analglied 
die gewöhnliche Länge und ist abgestutzt kegelförmig mit etwas hervorstehendem Legestachel.

Vorderflügel $21_{4}-1 / 2^{\prime \prime \prime}$ lang, beinı $\sigma^{\prime}$ schmäler als beim $q$, hellgrau, gelblichgrau bestäubt, besonders am Innenrand; im Mittelraum reiner ochergelb. In der Mitte der Falte liegt ein schwärzlicher Längsstrich, der an beiden Enden weisslich strichförmig eingefasst ist. Ueber ibm liegen zwei kleine, schwärzliche Punkte, der untere weiter nach hinten als der obere. Auf der Querader ist ein grösserer Punkt, der fast rilıgsum sehr hellgrau eingefasst ist. Am Hinterrande zieht sich eine Reihe verloschener, schwärzlicher, ungleich grosser Punkte hin. Franzen hellgrau, einwärts dunkelbestäubt, besonders um die Flügelspitze.

Hinterflügel kaun so breit wie die Vorderflügel, mit feiner Spitze und unter demselben eingebogenem Hinterrande, hellgrau. Franzen länger als die Flügelbreite, mit gelblich $\in$ m Schimmer an der Wurzel. - Ganze Unterseite cinfarbig grau.

Bei dem fraglichen $Q$ ist der ganze Rücken so gefärbt wie der Kopf, der Hinterleib wie angegeben. Die breitern Vorderflïgel sind am Vorderrand am hellsten, sonst ziemlich gleichförmig grau bestäubt, ohne die ochergelbliche Färbung im Mittelfelde und ohne den gelblichen Ton des Ganzen. In der Falte liegt ein schwarzer Punkt auf einer weisslichen Längslinie. Schräg hinter und iiber dem Punkt ist nicht ein Doppelpunkt, sondern ein einfacher, starker, tiefschwarzer, ringsum hell und auffallend eingefasster Punkt; der Queraderpunkt ist kleiner, aber ebenso schwarz und oben auswärts eben so hell eingefasst. Da die Franzen fast ganz abgeffogen sind, so lässt sich über die Hinterrandzeichnung nichts sagen. - Die Hinterflügel sind merklich breiter als die Vorderflügel und weniger fein gespitzt.

Vaterland: Texas (Boll, Belfrage). Drei $\sigma^{\nearrow}$ im Cambridger Museum; ein von Belfrage am 12. August gefangenes $\sigma^{7}$ in meiner Sammlung, worin auch die zwei fraglichen, am 1. und 26. August gefangenen $Q$.

Anmerkung. Eine kleinere, ähnlich gefärbte Art, ist gleichfalls im männlichen Geschlecht am Genitalienbau sehr leicht zu erkennen:

Gel. glochinella n. sp. (Fig. 18.) capite palpisque exalbilis, horum articulo terminali nigro-bimaculato, antennis albido fuscoque amulatis; alis ant. achroceo-griseis, cinereo - mamoratis; ơ ablominis segmento anali stitis duolus lateralibus clavatis armato. - In der Färbung der Körpertheile stimmt sie mit Operculella; nur ist sie am Kopf und Thorax etwas mehr grau. Fühler deutlich hell und dunkel geringelt. Die Vorderflïgel ochergelblich grau, überall grau bestäubt, so dass nur undeutliche Fleckchen entstehen, unter welchen keiner der gewöhnlichen Discalpunkte oder ein Faltenstrich hervortritt. Die grauen Franzen sind auch auf der Wurzel dunkler bestäubi als bei Operculellu. Hinterflügel ein wenig breiter als die Vorderflügel, spitz, unter der Spitze mit schwach eingebogenem Hinterrand. Hinterleib bräunlichgran, am Bauch sehr hell bleichgelb. Das weibliche Analglied gelblich, länglich kegelförmig mit hervorstehendem Legestachel. Beim $\sigma^{\nearrow}$ ist es kaum su lang wie die zwei vorletzten Segmente zusammengenommen; der untere Theil ist bleich ochergelb behaart, 
einen halben Cylinder bildend, auf dessen Mitte oben ein dünner, spitzer, graner, hellgelbspitziger Kegel (statt des obern Deekels der Operculella) horizontal liegt; zu jeder Seite ragt über ihn ein dünner, Sförmig gebogener Griffel hinweg, dessen gelbliches Ende verdiekt und dann zugespitzt ist und sich hakenförmig seitwärts und einwärts biegt.

Vaterland: Texas (Belfrage). Fin gutes, sicher zusammengehöriges Paar ( $\sigma^{\prime}$ an 18. Septbr., of am 16. Juli gefangen) in meiner Sammlung.

Gelerhia (? Lita) ternariella. n. sp. Fig. 19.

Thorace flarido, antice infuscato, capite flavielo, antennis tot is palpisque exterius fuscis; alis ant. anyustis, nigris, lituru busi pmopinqua, macula tronsversa utrimque libera disci medii strigaque postica anyulatu albis. 오.

Eine der an Caryophyllaceen lebenden Arten, mit ähnlicher Lage der Vorderflïgelzeichnungen, doch beträchtlich grösser, mit weniger rein weissen Flecken, ohne röthliche Färbung der Sehulterdecken, mit schlankeren Tastern, welche nur eine bleichgelbe Rückenlinie des zweiten und eine solche Spitze des dritten Gliedes haben.

Rückensehild bleieh ochergelb, welehe Farbe aber nur in seiner Mitte und in der Endhälfte der Sehulterleeken rein bleibt, indem sie anderwärts braun verstäubt ist. Kopf bleich oehergelb. Fühler schwarzbraun mit hellgelber Spitze les Basalgliedes. Taster fast so lang wie Kopf und Rückenschild zusammen. aufgekrümmt, ziemlich sehlank, braun; das zweite Glied mit bleich ochergelber Rückenlinie; das dritte Glied iiber halb so lang wie das zweite, an der Wurzel auf dem Rüeken hellgelb. Die vier vordern Beine aussen braun, die Mittelschienen heller, die Enden der Glieder bleichgelb; die Hinterschienen bleichgelb, auswärts mit zwei breiten, brüunlichen Bändern und solehen Dornen, auf dem Rücken mit wenigen (vielleicht zum Theil abgeriebenen) blonden Haaren; die Hinterfüsse dunkelbrnun, an den Enden der Glieder bleichgelb. - Hinterleib brännlich grau, am bleielıgelben Baueh auf beiden Seiten mit je einem breiten, braunen Lüngsstreifen; das Analsegment lïnglich kegelföimig, am Enddrittel bleichgelb, mit wenig hervorstehendem Legestaehel.

Vorderflügel $3 \frac{1}{1} 2^{\prime \prime}$ lang, schmal, nach hinten sanft und schwach erweitert, selıwarz. Nieht weit von der Basis, vom Vorderrande getrennt, liegt ein schräger, gelblichweisser Fleek, der in der Falte, wo er an reinsten weiss ist, anflü̈rt. Etwas vor der Mitte ist ein grösserer, fast viereekiger solcher Querfleek, der bis zur Falte reicht und fast gleich weit vom Vorder- wie vom Innenrand entfernt bleibt. Der Raum zwisehen beiden Flecken ist fleckartig tiefschwarz, und hinter dem zweiten zeigt sich noch eine ebenso verdunkelte Stelle. Weiter vom zweiten Fleck entfernt als dieser vom ersten folgt die ziemlich breite, gelblichweisse Querlinie, die senkrecht auf dem Innenwinkel steht und in der Mitte einen mit der Spitze nach hinten gerichteten Winkel bildet. Franzen dunkelbrangrau, auf der Wurzel schwarz beschuppt. 
Hinterflügel breiter als die Vorderflügel, spitz, nit unterhalb der Spitze ziemlich merklich eingedrücktem Hinterrande, grau. Franzen an der Wurzel mit feiner, bleichgelber Linie.

Unterseite der Vorderflügel graubraun, an der Stelle der Querlinie mit verloschenem, blassgelblichem Costalfleckchen. Hinterflügel hellgrau, am Vorderrand striemenartig dunkler grobschuppig.

Vaterland: Texas (Boll). Ein gutes $q$ im Cambridger Museum.

Gelechia (Lita Hum.) lituroselle n. sp.

Alis ant. rufescenti-ochreis, plaga maxima costali nigra, interius oblique alro-terminata, exterins in disco ultra venam transversam contimata, margine postico nigro-punctato. $0^{-7}$.

Sie sieht der Gel. costella HS. Fig. 625 so ähnlich, dass man sie für eine Varietät davon halten möchte, wenn sie nicht entschieden längere Taster hätte. Costella hat auf den Vorderflügeln einen sehr grossen, schwarzen Costalfleck, der weit vor der Mitte anfängt und mit scharfer, tiefschwarzer, schräger Begrenzung bis zur Falte herabreicht, dann sich nach hinten allmählich verengert und lichtet und zugespitzt auf dem Torderrande am Anfange des letzten Drittels endigt. Bei Liturosella ist dieser Fleck an seinem Anfange ganz ebenso; aber nach hinten lässt sich keine eigentliche Zuspitzung erkennen, und unter der Stelle des Vorderrandes, wo er bei Costella endigt, zeigt sich ein längswischartiger, sich als Fortsetzung anschliessender Fleck, welcher etwa $1 / 4$ der Flügelbreite einnimmt und da endigt, wo der Winkel einer (nicht vorhandenen helleren) hinteren Querlinie sein würde. (Diese Querlinie sehe ich übrigens unter den sieben Costella-Exemplaren meiner Sammlung nur bei einem angedeutet.) Bei Costella umziehen den Hinterrand und die Vorderrandspitze helle Fleckchen, die durch dunkle, hie und da verstärkte Bestäubung abgegrenzt werden (Stainton's hinder margin and apex of the costa alternately fuscous and reddish-ochreous). Bei Liturosella umzieht diese Ränder eine Reihe recht scharfer, schwarzer Punkte, von denen der in der Flügelspitze einwärts eiue helle, fleckartige Begrenzung hat, während ihre viel schmäleren Zwischenräume nicht die helle Grundfarbe haben, sondern, so wie die dahinter folgende Eranzenhälfte schwärzliclı bestäubt sind.

Vaterland: Texas (Boll). Ein schün erhaltenes ơ im Cambridger Museum.

\section{Gelechia (Teleiv) sequax, Haw.}

Stainton: Nat. History of the 'Tineina X, 1. 170, t. 12, f. 3. - Var. b capite griseo, non allido.

Meine gut erhaltenen americanischen Exemplare (2 $\sigma^{x} 1$ f $)$ stimmen so genau init den europäischen überein, dass sie sich nur als unbedeutende Varietät, leren Merkmal die graue Kopfbeschuppung, vielleicht nicht eiumal standhaft, ist, ansehen lassen.

Sie sind etwas kleiner als meine in Graubünden gefangenen Exeraplare, doch nicht kleiner als andere bei Wien gesamuelte. Der Kopf hat ziemlich 
dunkel staubgraue Beschuppung, statt dass er bei unserer Sequax weisslich (nach Stainton's Angabe gelblichweiss) und zuweilen in der Mitte grau angelaufen ist. Auch die Taster sind etwas grau statt weiss, und der Ring hinter der Mitte des Endgliedes ist vollständig, während er bei unseren Exemplaren auf dem Rücken offen bleibt. Auf den Vorderflügeln ist die Mittelpartie (vor dem Queraderstrich) dunkler und mit mehr röthlichem Braun gemischt. Die schwarze Längslinie vor der Flügelspitze ist bei einen $\sigma^{\star}$ frei und sehr scharf, bei dem anderen und dem $q$ mit der umgebenden rothbraunen Farbe zu einem dicken Längsstrich zusammengeflossen, während sie bei den europäischen Exemplaren gewöhnlich wie bei jenen $\sigma^{-1}$ anf etwas hellerem Grunde frei schwebt. Andere Verschiedenheiten, noch viel weniger eine als specifisch zu deutende, kann ich nicht entdecken.

Vaterland: wahrscheinlich Massachusetts; meine Exemplare erhielt ich von Dr. Packard.

Anmerkung. Dass dies keine aus Europa eingewanderte Art ist, scheint mir gewiss. Selbst wenn ihre Futterflanze zufällig oder absichtlich hinübergebracht sein sollte, ist die Einfülırung der Motte kaum denkbar, viel weniger ihre so starke Verbreitung, dass sie nun im Freien, wahrscheinlich gar nicht selten, leben sollte.

\section{Gelechiu ('Telein?) gilviscopella n. sp.}

Capillis albis, palporum articulo terminali nigro-bicincto, antennis cras. siusculis, fuscis, obsolete unnulatis; fusciculo pilorum gilvorum ex busi alarum posteriorum nato; alis ant. albidis, fuscescenti-nebulosis obscuriusque maculatis, linea plicue nigia; posterioribus allidis. $\sigma^{\top}$.

Wie bei der folgenden Art kommt bei ihr neben der Wurzel der Hinterflügel ein aus blass ochergelben Haaren gebildeter Pinsel vermittelst eines Stieles hervor and ragt schräg über den Anfang des Hinterleibes hin.

Rückenschild und Kopf weiss. Taster mässig lang und schwach aufgebogen; das zweite Glied cylindrisch, zusammengedrückt, aussen schwärzlich, am Ende breit weiss, innen weiss, vor der Spitze unterwärts nit schwärzlichem Fleck; das Endglied halb so lang wie das zweite Glied, dünn mit zwei breiten, schwarzen Ringen. Ocellen auch nach Abschuppung des Kopfes nicht zu entdecken. Fühler ziemlich dick, am Endviertel merklich verdünnt, mit zusammengedrängten Gliedern, graubräunlich, lell geringelt. Die vier vorderen Beine auswärts weissgrau mit weissen Spitzen der Glieder; Hiuterschieuen ziemlich dünn, auswärts weisslich mit weissen Dornen und langen, fast weisslichen Haaren auf dem Rücken; das erste Fussglied weisslich, die anderen an der Wurzelhälfte auswärts gran. - Hinterleib dünn, bleichgelblich, nach hinten grau, am Bauche weiss.

Vorderflügel $3^{\prime \prime}$ lang, schmal, im Grunde weiss, welche Farbe aber, ausser unterhalb der Falte, durch braungraue Bestäubung, worin mehrere Fleckchen liegen, verdeckt ist; solcher Fleckchen lassen sich auf dem Vorderrand drei annehmen: nabe der Wurzel, vor und hinter der Mitte. In der Falte zieht fast 
aus der Wurzel bis nahe ans Ende eine braune Linie, bei dem einen Exemplar mit einzelnen Verdickungen, bei denı anderen binter der Hälfte unterbrochen und vor der Unterbrechung stark verdunkelt; das Stück hinter der Unterbrechung bildet einen kurzen, dicken, verdunkelten Lüngsstrich. Im Innenwinkel liegt ein dunkles Fleckchen dem dritten Costalfleckchen gegenüber. An den Franzen des Vorderrandes und der oberen Hälfte des Hinterrandes zieht eine Reihe länglicher, schwarzer Punkte auf weisslichem Grunde. Franzen sehr licht grau, gegen den Innenwinkel bei dem einen Exemplar gelblich schimmernd.

Hinterflügel schmäler als die Vorderflügel, nit hervorstehender Spitze, rreisslichgrau. Franzen fast doppelt so lang wie die Breite der Flügel.

Unterseite der Vorderflügel grau; der Hinterflügel weiss. Nach Abreibung der Schuppen zeigt sich die Mittelzelle durch eine feine Ader geschlossen.

Vaterland: Texas (Boll). Zwei o $\mathrm{jm}$ Cambridger Museum (ein drittes. zerbrochenes benutzte ich zur Untersuchung des Kopfes und der Flügeladern).

\section{Gelerhia (Teleia?) domsivittella n. sp. Taf. III. Fig. 20.}

Thorace et capite albidis, antennis crassiusculis, fuscis, subannulatis; fasciculo pilorum gitrorum ex basi alarum posteriorum nato; alis ant. subelongatis, nigris, vitta dorsali acuminata, allida, interius lis atro-emarginata; posterioribus allidis. $\sigma^{7}$.

Vor der vorigen durch die Vorderflügelzeichnung ausgezeichnet, vor der folgenden sehr ähnlichen schon durch das Vorhandensein des gelblichen Haarbusches an der Hinterflügelwurzel.

Rückenschild und Kopf weiss, doch letzterer etwas grau überlaufen; so auch die Schulterdecken. Fühler dick, borstenförmig, schwarzbraun, wegen der deutlich getrennten Glieder gleichsam dunkler geringelt. (Taster fehlen.) Die vier vorderen Beine answärts schwarz mit weissen Enden der Glieder; an den Hinterbeinen die Schenkel weisslich mit dunkelgrauen Flecken, die Schienen ziemlich dünn, auswärts weisslich mit dunkelgrauem Längswisch vor der Mitte und grau vor der Spitze, auf dem Rücken mit langen, hellblonden Haaren, die Dornen schwärzlich mit weisslicher Spitze: die Fussglieder auswärts schwärzlich mit weisser Spitze, die zwei letzten ganz weiss. (Hinterleib fehlt.)

Vorderflügel $2 \frac{1}{2}{ }^{\prime \prime \prime}$ lang, schmal, nicht erweitert, schwarz, in dem Raume zwischen Falte und Innenrand weiss; dieser Raum bildet eine zugespitzte und sehr wenig mit äusserst feinen schwarzen Stäubchen bestreute Dorsalstrieme, deren gerader, schwarzer Innenrand bei $1 / 3$ durch ein tiefscliwarzes, in sie eckig hineinragendes Fleckchen und anf der Mitte durch einen gleichfalls etwas hineinragenden, tiefschwarzen Faltenstrich unterbrochen wird: über ihrem Ende liegt vor dem Innenwinkel auf gelichtetem, schwärzlichem Grunde ein tiefschwarzes Querfleckchen. Der schwarze Grund ist hier und da schwarzfleckig und auf der Vorderrandhälfte mit einem Fleck und dann mit einer noch grösseren solchen Stelle vor dem weisslichen Costaldreieck bezeichnet, welches nebst einem weisslichen dreieckigen Fleck im Innenwinkel den Anfang und das Ende der (nicht vorhandenen) hinteren Querlinie andeutet; zwischen beiden zeigt sich ein tief- 
schwarzes Längsstrichelchen. Am Hinterrand liegen auf hellem Grunde drei schwarze, längliche Punkte. Franzen gelblichweiss, nur ganz an der Flügelspitze dunkelgrau.

Hinterflügel viel schmäler als dic Yorderflügel, mit stark verlängerter Spitze, auf beiden Seiten seidenglänzend grauweisslich mit helleren, etwas gelblich schimmernden Franzen; dicht neben der Flügelwurzel kommt ein bleich ochergelber Haarbusch wie bei Gilviscopella.

Unterseite der Vorderflügel grau, vor der Spitze mit einem weisslichen Costalwisch und ein paar weisslichen verloschenen Punkten in den Costalfranzen.

Vaterland: Texas (Boll). Ein $\sigma^{\pi}$ (ohne Taster und Hinterleib) in Cambridger Museum.

\section{Gelechia (Teleia?) lenconota. n. sp. Taf. III. Fig. 21.}

Capite et thornce albis, scnpulis nigris, palpis allhis, upiee nigro; alis rent. nigricantibus, vittr dorsali alba, interius ter emroiginata; post. dilute eincreis. o'.

Bei flüchtiger Betrachtung so ähnlich der vorigen, dass ich sie anfangs für dieselbe Art hielt. Ansserdem, dass ihr der gelbliche Haarbusch fehlt, sind ihre Schulterdecken schwarz; die weisse Dorsalstrieme der Vorderflügel ist länger nnd gegen die Spitze nicht verengt, und ilır Innenrand anders ausgeschnitten: auch ist das Schwarze heller, ohne dunkle Costalflecke, und die Franzen sind 11 die ganze Spitze herum dunkelgrau.

Etwas kleiner als Dorsivittella. Rückenschild und Kopf reinweiss, dic Schulterdecken tiefschwarz. Fühler (unvollständig) fadenförmig, schwarz, undeutlich geringelt. Taster wenig gebogen, kürzer als das Rückenschild, weiss; das zweite Glied glattschuppig, am Basaldrittel verdünnt, an der Wurzelhälfte ınterwärts schwarz; das Endglied mehr als halb so lang. wie das zweite Glied, nur an der Spitze schwarz. - Beine weiss. Die vier vorderen auswärts schwarz, an den Enden der Glieder weiss; die Hinterschienen auswärts dunkelbraungran, an Anfang, Mitte und Ende weiss, die Dornen und die langen, spärlichen Rückenhaare weisslich; die Fussglieder schwarz, an den Enden weiss. - Hinterleib dunkelgrau; Bauch schwärzlich, an den Seiten weisslich und in der Mitte mit einer Reihe verloschener, weisslicher Flecke.

Vorderfiügel $2^{1} / 4{ }^{\prime \prime}$ lang, schmal, nicht erweitert, schwärzlich, etwas schiefergrau schimmernd, nach hinten weisslich bestäubt, von der Wurzel aus bis zur Hälfte der weissen Dorsalstrieme in einem dicken Striche schwarz. Dic Dorsalstrieme fängt an der Flügelbasis sehr schmal an, erweitert sich damn bis zur Falte, verengert sich alsdann wieder etwas, worauf sie mit einem abgestumpften Zain über die Falte hinwegreicht und zuletzt an der Hälfte des Hinterrandes aufhört. Am Vorderrand ist kein dunklerer Fleck in der Grundfarbe; aber gegen die Flïgelspitze zeigen sich ein paar solche Stellen. Die Costalfranzen, so wie die kleinere obere Hälfte der Hinterrandfranzen, sind schwärzlich bestäubt; der Rest der letzteren, so weit er die Dorsalstrieme begleitet, ist weisslich und unbestäubt. 
Hinterflügel viel schmäler als die Vorderflügel, mit vortretender Spitze, etwas dunkler grau als bei Dorsivittcllu. An ihrer Wurzel ist keine Spur. des gelblichen Haarbusches.

Unterseite der Vorderflügel grau mit sehr verloschener heller Stelle an Vorderrand vor der Spitze. Franzen wie oben.

Vaterland: Texas (Boll). Ein ơ im Cambridger Museum.

Gelechiu (Poecilia?) basifusciella n. sp. Taf. III. Fig. 22.

Capite albo, palpis albis, articulo terminali nigro-bifasciato; alis aut. relbis, fascia obliqua, atre, superius in costa in basim prolucta, iuferins. abrupta, maculis leinde duabus costre atris, macula anguli dorsalis nigricante. ó.

Anscheinend verwandt mit Gel. vigrinotella, doch in Farbe und Keichuung noch ähnlicher der Gel. scalella. Das auffallendste Merkmal giebt ihr auf den weisslichen Vorderflügeln die tiefschwarze, sehr schräge Binde, welche auf dem Vorderrande bis zur Flügelbasis verlängert ist und mit ihrem unteren Ende den Innenrand nicht erreicht. Die folgende kleinere Art hat auf den weissgrauen Vorderflügelı eine schmälere Binde oder vielmehr Querlinie, welche weniger schräg liegt, vollständig ist und keine costale Fortsetzung hat.

Rückenschild weiss, hinter dem Kragen und an der Wurzej der Schulterdecken geschwärzt. Kopf weiss. Fühler schwarz, an der Spitze des Wurzelgliedes mit einem hellen Punkte. Taster weiss; das zweite Glied zusammengedrückt cylindrisch, gegen die Wurzel verdüunt, auswärts schwarz mit weissem Bande vor und an dem Ende, innen weiss mit zwei schwarzen Flecken; das Endglied mehr als halb so lang wie das zweite Glied, schwach gebogen mit schmalem, schwarzem Ping vor der Mitte und breitem vor der Spitze. - Beine schwarz und weissbunt. (Hinterleib fehlt.)

Vorderflügel $3^{\prime \prime \prime}$ lang, ziemlich schmal, weiss mit sehr spärlicher, feiner, schwärzlicher Bestäubung. Nahe der Basis ist ein tiefschwarzes, sehr schräg nach aussen gelegtes Band, das sich auf dem Vorderrande bis dicht an dic Basis verlängert und unterhalb der Falte wje verwischt aufhört, ohne den Innenrand zu erreichen. Vor der Mitte liegt ein kleiner, länglicher, einwärts abgerundeter (also halbeiförmiger) Costalfleck, und über dem schwärzlichen Queraderstrich ein ebenso grosser, viereckiger, von welchem in einem Bogen hinter dem Queraderstrich ein schwärzliches Gewölk bis zu dem schwärzlichen, nebelhaften Innenwinkelfleck hinzieht. Dahinter sind am Vorderrand bis zur Spitze drei graue Nebelfleckchen, und längs des Hinterrandes ein paar undeutliche schwarze Punkte. Die Franzen siud auf der Wurzelhälfte schwärzlich bestäubt, doch nicht die des Innenwinkels.

Hinterflügel fast so breit wie die Vorderflügel, mit stark abgesetzter Spitze, weisslichgrau, an den Pändern und auf den Adern dunkel angelaufen.

Unterseite der Vorderflügel grau mit einem weisslichen Costalfleckchell nicht weit vor der Spitze. Hinterflügel längs des Vorderrandes striemenartig dunkelgrau beschuppt. 
Vaterland: Texas (Boll). Ein bis auf den Mangel des Hinterleibes und der Hinterbeine schön erhaltenes $\sigma^{7}$ im Cambridger Museum.

Anmerkung. Ein zerbrochenes $\sigma^{\nearrow}$ labe ich zur Abschuppung benutzt. Ocellen nach Entfernung der Schuppen deutlich. Auf den Vorderflügeln gehen von der Subcostalader drei einfache Aeste und ein Gabelast in den Vorderrand und ein einfacher in den Hinterrand unterhalb der Spitze. Die Medianader hat vier Aeste; der erste ist vom zweiten ziemlich weit abgerückt und gerade; der zweite, dritte und vierte kommen nicht aus demselben Punkte. Die Mittelzelle ist nicht geschlossen. Auf den Hinterfügeln hat die Mittelzelle eine, wenn auch feine, doch deutliche Schlussader, aus welcher die etwas gebogene Ader fünf zum Hinterrande geht. Die drei Aeste der Medianader sind von einander weit getrenut und der letzte (4) so weit von drei wie von fünf. Die Subcostalader umfasst mit zwei langen Aesten die Flügelspitze. - Das Geschlossensein der Hinterflügelzelle stimmt also nicht mit Heinemann's Angabe über Poecitia (Tin. S. 281); eben so wenig passen die stark vortretende Hinterflügelspitze, die weit gécrennten Adern drei nud vier und die Länge der Franzen zu seiner Gattung Gelechia S. 193.

Gelerhia (Poecilin?) basistrigella n. sp. Taf. IV. Fig. 23.

Capite albido, palpis albis, articulo terminali nigro-bianmulato: alis ant. cinerco-albis, striga oblique subangulate nigra, maculis duabus costalibus unaque dorsali nigricuntibus, striole disci medii obliqua muctisque duobus venac transrersac nigris. o".

Ihr Unterschied von Busifascicllu ist bei dieser angegeben.

Rückenschild und Kopf weissgrau. Fühler schwärzlich und grau geringelt, an der Spitze weissgrau; Wurzelglied schwärzlich, au der Spitze weisslich. Taster länger als clas Rückenschild, gekrümmt; das zweite Glied zusammengedrückt, cylindrisch, auswärts schwärzlich mit zwei bindenartigen schwarzen Flecken; das Endglied mehr als halb so lang wie das zweite Glied, mit breitem schwarzem Ringe vor der Mitte und schmalem vor der Spitze. - Beine gelblich weiss; die vier vorderen auswärts schwärzlich, weisslich gefleckt; die Hinterschienen auf dem Rücken mit langen, nicht sehr reichlichen blonden Haaren, auswärts dunkelgran, an Wurzel, Mitte und Ende mit je einem weisslichen, bindenförmigen Fleck; die Dornen schwärzlich mit weisser Spitze: die Fussglieder auswärts schwärzlich mit weisslichen Enden. (Hinterleib fehlt.)

Vorderflügel $2^{1} / 2^{\prime \prime \prime}$ lang, mässig schmal, nach linten kaum erweitert, weiss, aber durch die feine, reichliche, schwärzliche Bestäubung grauweiss erscheinend und nur an einzelnen Stellen reiner weiss. Die Schulter hat ein schwärzliches Fleckchen, und an der Wurzel der Falte ist ein dentlicher, schwarzer Punkt. Nicht weit von der Basis ist eine schräg nach aussen gelegte, ziemlich starke, etwas gezähnte, ïber der Falte verdickte, vollständige Querlinie, die gegen den Vorderrand auswärts von reiner Grundfarbe begrenzt wird. Vor der Mitte ist ein neblichter, schwärzlicher Costalfleck, und unter ihm ein kurzer, etwas schräger, schwarzer Strich. Hinter der Mitte liegt ein viereckiges, nebelförmiges, schwärz- 
liches Costalfleckchen, welches mit dem Nebelfleck des Innenwinkels durch den schwarzen Doppelpunkt der Querader in Verbindung steht. Eine helle hintere Querlinie ist nicht vorhanden; doch ist nach einer Lichtung der Raun bis zur Flügelspitze schwarz bestäubt. Der Hinterrand zeigt ein paar schwarze Punkte. Die Franzen sind auf der grösseren Wurzelhälfte sehr fein schwärzlich bestänbt und diese Bestäubung ist durch eine ziemlich deutliche Linie nach aussen begrenzt.

Hinterflïgel so breit wie die Vorderflügel, mit stark verlängerter Spitze, hellgrau: die hellen Franzen mit feiner, gelblicher Basallinie.

Unterseite der Vorderflügel grau, in den Costalfranzen init verwischten gelblichen Flecken and mit gelblicher Wurzel der Hinterrandfranzen. Auf den Hinterflïgeln scheint die Mittelzelle durch eine Querader geschlossen zu sein.

Vaterland: Texas (Boll). Ein gnt erhaltenes o im Cambridger Museum.

\section{Gelechir (Poccilia?) frogmentella n. sp.}

Capite dilute cinereo, palporum articulo terminali albido, bis nigrocincto; alis ant. ditute cinereis, fascia subinterruptu, obliqua, dorsum non attingente, nigra, macula costae ante medium nigricante, striola obliqua tisci medii nigra, macula costae post medium cum maculu anguli interni per strigulam migram venae transversue conjuncta nigricante. $q$.

Viel dunkler als Basistrigella, von ihr verschieden schon durch die Binde, welche nicht fern von der Basis herabzieht, und welche, oberwärts fast durchbrochen sich in der Falte stark erweitert und den Inuenrand nicht erreicht.

Rïckenschild grau, Kopf etwas heller. Fühler braun, verloschen heller geringelt. Taster stark gekrümmt; das zweite Glied zusammengedrückt cylindrisch, hellgrau, auswärts an der Wurzel mit einem grossen und vor der Spitze mit einem kleinen schwarzen Fleck, innen gegen die Wurzel mit einem dunkelgranen Fleck gezeichnet; das Endglied mehr als halb so lang wie das zweite Glied, dünn, weisslich mit zwei breiten schwarzen Pingen. - Die vier vorderen Beine sind auswärts schwärzlich mit grauen Enden der Glieder; die Hinterbeine bleichgelblich; die Schenlel auswärts mit grossen, dunkelgranem Fleck; die Schienen mit vier dunkelgrauen Staubflecken, grauen, hellspitzigen Dornen und reichlichen blonden Haaren auf der Rï̌ckenschneide; die Fussglieder an der Wurzel graustanbig. - Hinterleib bräunlichgrau mit bleichen Schuppenbüschchen an allen Rändern; Bauch weisslicl, an den Seiten graustanbig; Legestachel hervorstehend.

Vorderflügel fast $3^{\prime \prime}$ lang, mässig schmal, linten kaum erweitert, hellgran mit dunkleren Stellen. Schulter mit schwärzlichem Fleck; an der Wurzel der Falte ein deutlicher, schwarzer Punkt. Nicht weit von der Wurzel ist eine schräge, winklige, sehwarze Binde; sie verengert sich unterhalb des Vorderrandes, worauf sie sich, besonders in der Falte, erweitert und unterhalb derselben mit einer Spitze endigt. Zwischen ihr und dem folgenden Costalfleck ist die Grundfarbe am hellsten. Der Costalfleck liegt vor der Hälfte und ist länglich und schwärzlich; unter ihm ist ein schräges, schwarzes Strichelchen, und unter 
diesem in der Falte ein schwarzes Längsstrichelchen. Hinter der Flügelmitte folgt ein zweiter schwärzlicher Costalfleck, von welchem ein schwarzer Strich anf der Querader bis zu dem schwärzlichen Schattenfleck des Innenwinkels hinreicht. Eine helle hintere Querlinie, in der Mitte nach aussen gekrümmt, ist angedeutet, nnd hinter ilır ist der Grund bis zur Flügelspitze schwärzlich. Am hellen Hinterrand zieht eine Reihe grober, schwarzer Schuppen, und eine solche Schuppenreihe zieht auch von der Flügelspitze auf der Franzenhälfte herab, um bald zu verschwinden.

Unterseite der Vorderflügel grau mit wie bei Basistrigella gezeichneten Franzen. Ob die Mittelzelle dex Hinterflügel geschlossen ist, lässt sich ohne Abschuppen nicht erkennen.

Vaterland: Texas (Boll). Ein gut erhaltenes $ᄋ$ im Cambridger Museum.

Anmerkung. Eine kleinere Art, eben daher, ohne Hinterleib, mit dicken, kerbig gezälnnten Fühlern (also $\sigma^{7}$ ) unterscheidet sich sogleich von Fragmentella dadurch, dass die Binde der Vorderflügel bis zum Innenrande reicht, dass der schwarze Längsstrich in der Falte fehlt, und dass dafür darunter ein starker, schwarzer Punkt liegt. Sie wird am besten benannt und beschrieben, wenn mehr Exemplare gesammelt sein werden.

Gelechir (Evgrtis) roseosuffusellu. Cl. Taf. IV. Fig. 24.

Pulpis albis, nigro-cingulatis, antemis nigro albidoque anmlutis; alis ant. in parte lorsali laete ochreeis, roseo-mixtis, in parte eostali fasciis alsbreviatis; maculisque ulbis nigrisque quaternis altermutis, maculu apicali allua. o 9 .

Gelechia roscosuffusclla Clemens ed. Stainton 113. 225.

Diese schöne Art kommt in der Grösse breitfügligen Exemplaren der europäischen Subericinella gleich, hat aber mehr die Farbe der viel grösseren Deeurtclla, nnterscheidet sich jedoch von beiden auf den ersten Anblick durch die tiefer schwarzen und breiter reinweissen Costalbinden und den weissen Apicalfleck der Vorderflügel, sowie durch die schwarz- und weissbunten Beine. Von der folgenden, schmalfügligeren Art, die noch mehr Rosenfarbe, aber weniger Ochergelb in die Grundfarbe eingemischt hat, wird sie am leichtesten durch die weisse Costalbinde gegen die Wurzel und durch die zwei weissen Flecke in und vor der Flïgelspitze getrennt, statt deren bei Pullibundella die Grundfarbe blass gelichtet ist.

Clemens beschreibt die Art sehr genau, sieht aber das Schwarz als die Grundfarbe der Vorderflügel an, während als solehe doch wohl nur die lebhafte Ocherfarbe, und das Weiss und Schwarz als Zeichnung anzusehen ist. Die Ocherfarbe fängt an der Basis an, nimmt den ganzen Raum zwischen der Falte und dem Innemrande ein, zieht sich dann über die Querader bis gegen den schwarzen Vorderrandwisch und hinter dem rosenfarbenen Fleck des Innenwinkels mehr oder weniger verdunkelt oder auch in Schwarz übergehend bis gegen die Flügelspitze. Vom Vorderrande gehen zwei breite, schwarze Binden schrïg bis zur Falte herab; die erste spitzt sich zn einen lünglichen Dreieck zn; die zweite 
setzt sich an ilurem unteren Ende nach hinten in eine Spitze fort. Der Raum zwischen beiden bildet eine breite, weisse, auch bis zur Falte reichonde Schrägbinde. Hinter der zweiten schwarzen Binde ist ein weisser, grösstentheils grau bestäubter Raum bis zu dem schwarzen Längswisch oder - strich des Vorderrandes, der über einen schwarzen, weiss anfgeblicktẹn Punkt dej Querader liegt. Auf ihn folgt ein weisser, mit der Spitze einwärts gerichteter Costalfleck, welchem das rosige Dreieck des Innenwinkels gegenüber liegt. Die Costalfranzen sind bis zum weissen Apicalfleck schwarz, und da auch die Franzen hinter ihin schwärzlich sind, so wird sein Weiss gewöhnlich dadurch sehr gehoben. Am unteren Ende des graubestäubten Costalraumes zeigt sich am Innenrand noch eine rosige Stelle. Die Hinterrandfranzen sind am rosigen Innenwinkel weisslich.

Diese Art ist sehr verbreitet. Ich habe sie aus Ohio durch Schläger. aus Massachusetts, wo Burgess sie bei Beverly den ganzen Juli hindurch fing, aus Washington durch Löw. Boll fing sie in Texas.

\section{Gelechia (Evgratis) pudibunatella n. sp.}

Palpis albis nigro-cingulatis. antemis fuscescentibus; alis ant. angustis. obscure cinereis, lutescenti-mixtis, circo margines rosen-maculatis, maculis costae fusco-nigris quatuor, secunda subfrscintr. of 9 .

Von derselben Zeichmungsanlage auf den schmäleren Vorderflügeln wic Roscosuffisella, aber mit dunkleren Grunde, zahlreicheren rosigen Stellen und nhne die drei weissen Costalflecke, statt deren kleinere, rosige Fleckchen vorhanden sind. Von der in der Anmerkung beschriebenen Mfolestello unterscheidet sie sich sogleich durch ren dieser ganz fehlenden röthlichen oder röthlichgefleckten Innenrand.

In der Grösse über oder auch, besonders im weihlichen Gescllecht, unter Roseosuffusellr. Rückenschild und Kopf grau. bisweilen recht hell und gelblich gemischt: die Stirn in der Mitte dunkler als an den Rändern, und das Gesicht am hellsten. Fühler brännlich, kaum verloschen geringelt. Tastcr stark gebogen, rüthlichweiss: zweites Glier cylindrisch, zusammengedrückt. an der Wurzel verdünnt. mit zwei breiten, schwarzen Bändern: Enlglied so lang wie das zweite Glied. vor der Mitte und rer der Spitze mit breitem, schwarzem Ringe. - Beine auswärts schwarz mit weisslichen Bändern und Spitzen der Glieder: an den Hinterbeinen die Schienen wenig. behaart, die Fussglieder auf der Innenseite sehr dunkel grau mit bleichgelben Enden. - Hinterleib braungrau mit weisslichem Bauch: das kegelfürmige Analsegment des $q$ mit bleichgelbem Enddrittel und hervorstehendem Legestachel.

Vorderflügel des $0^{7} 2-2^{1} / 2$, des $q 2^{\prime \prime}$ lang. schmal, heim $q$ etwas weniger: die Grundfarbe selur feinstaubig braungrau. am Innenrand mehr oder weniger mit Ocherfarbe gemischt und an allen Pändern mit rosenfarbigen. nicht dunkelstaubigen Fleckchen von ungleicher Grösse. Die dunkle Zeichnnug des Vorderrandes ist fast wie bej Rosevsuffusella, nänlicb nahe der Wurzel ein schiefgelegter, bindenförmiger Querstrich: dann eine schräge, bis zur Falte 
reichende und hier nach hinten gebogene und stark verdunkelte Binde, welche auf beiden Seiten rosig gesäumt ist; linter der Mitte ein länglicher, gegen die Wurzel rosig gesäumter Fleck, auf welchen nach einem breiten rosigen Zwischenraum ein eben solcher Fleck vor der Flügelspitze folgt. Die Zwischenräume der drei ersten Flecke sind fein punktirt grau, nur an den Rändern hell und rosig. Dem rosenfarbenen Raume zwischen dem dritten und vierten Fleck gegenüber liegt im Innenwinkel ein grösserer, rosenfarbener Fleck, und zwischen beiden zeigt sich ein schwarzes Längsstrichelchen. Der Hinterrand ist rosenfarbig mit schwärzlichen Flecken wechselnd. Anf den hellgrauen Franzen zieht eine dunkelgrane Linie durch die Mitte und eine am Ende, beide vor dem Innenwinkel verschwindend.

Hinterflügel so breit wie die Vorderflügel, mit verlängerter Spitze, einfarbig grau.

Unterseite der Vorderflügel dunkelgrau, auf dem Vorderrande in der Mitte ınit weisslicher Längslinie und weiter nach hinten mit einem solchen Fleckchen, hinter welchem die Vorderrandfranzen fleckartig schwarz sind. Hinterflügel längs des Vorderrandes striemenartig braungrau mit groben Schuppen.

Vaterland: Texas (Boll, Belfrage). Zwei o wurden am 29. Juli gefangen. Massachusetts, wo Burgess mehrere Exemplare im Laufe des Juli bei Beverly sammelte.

Anmerkung. Ein ausnahinsweise gut erhaltenes Belfrage'sches Exemplar weiblichen Geschlechts nenne ich als verschiedene Art Molestella. Es ist stwas grösser und breitflügliger mit dunkler braunen Fühlern und sehr merklich längerem Endglied der Taster. Die Grundfarbe der Vorderflügel ist úberall, also auch längs des Innenrandes, ein violettliches Grau, durch viele schwarze, sehr feine Stäubchen verdunkelt. Die Costalflecke liegen wie bei den zwei anderen Arten; der vierte ist aber so verloschen, lass er kaum dunkler ist als die Grundfarbe. Der zweite, stärkste, gleichfalls nach unten tiefer schwarz, hat nach hinten keine Verlängerung. sondern statt dieser zeigt sich hinter ihm im Mittelfelde ein froi schwebendes, schwarzes Püıltchen, wälırend unter dem abgeschnitteneu Ende des bindenförmigen Flecken auf der entgegengesetzten Seite der Falte ein röthlich ochergelbes Fleckchen liegt. Ein helleres, doch kleineres, rundes Fleckchen befindet sich am unteren Ende des dritten Costalflecks und treunt diesen von einem schwärzlichen, verwischten Fleck des Innenwinkels: man könnte sagen, eine schwärzliche Binde reiche verengert vom Vorderrande bis zum Innenwinkel nnd trage in der Hälfte einen grossen, hell röthlichochergelben Punkt, hinter welchem ein kurzes, tiefschwarzes Längsstrichelchen liegt. Der zweite und der dritte Costalfleck werden am Vorderrande durch einen ganz verloschenen, röthlichochergelben Punkt auf jeder Seite begrenzt, von welchen Punkten der hinter dem dritten Fleck der grösste ist. Die grauen Franzen sind vom Hinterrand lurch einen auswärts undeutlich begrenzten röthlichgelben Raum getrennt, welcher an Hinterrand mit einzelnen schwarzen Schuppen bestrent ist; am Innenwinkel ist dieser Ramm am ansgedelintesten; etwas Geschecktes baben sie gar nicht. 
Da der Zettel mit dem Datum beim Spannen verloren gegangen ist, so ist mir die Flugzeit dieser Art unbekannt.

\section{Gelerhia (Amarrompsis) ayrimomiella Cl.}

Palpis pallide acturaceis; alarum ant. dimilio basali obscure cinereo, apicali nigro, strige flurida posticn, in costre postice producta; subtus costa in strigae loce maculu parra flavida notuta. or 9 .

Gelechia agrimoniella Clemens ed. Stainton p. 112.

Gelechia aduncellı Z. Verh. Zool. bot. Gesellsch. 1868 S. 614.*)

Clemens entdeckte die Raupe in der Agrimonia enpatoria, deren Blätter sie, wie ihre europäischen Verwandten bei den Pupitionuceen, zu Kuäueln zusammenspinnt. Die Schmetterlinge erscheinen sn Encle Juni und Anfang Juli.

Clemens sieht an der Basalhälfte der Vorderfügel des Schmetterlings etwas Grünliches (suffused with a greenish hue); dies mag für das lebende oder eben getödtete Thier, das dann auch wirklich crimson eyes haben wird, richtig sein; an den getrockneten Thieren sieht man auf den Flügeln kein Grüu und an den Augen ebenso wenig Rothes.

Ein $\sigma^{7}$ habe ich aus Greorgien. Da Baron Osten-Sacken die Art bei Washingthon, Clenens in Pennsylvanien fing, so hat sie offenbar in den östlichen Staaten eine beträchtliche Verbreitung.

Gelechin (Anacampsis) glamliferella n. sp. Taf. IV. Fig. 25.

Capite cinereo, palporum articulo terminali nigro-biannulato; alis ant. subelongatis, cinereis, strigula dorsali prope basim angulata, macula trausverse ovata dorsi ante medium punctoque venae transversae niyjis, dilute cinctis. $\sigma^{\top}$.

Sie ist besonders durch den einförmigen, schwarzen, hell umzogenen Dorsalfleck von der Mitte der grauen Vorderflügel sehr ausgezeichnet.

Rückenschild und Kopf grau mit sehr schwacher, röthlicher Beimischung. Fühler grau, beim $\sigma^{7}$ verloschener als beim $q$ dunkler geringelt. Taster lang. aufwärts gekrümmt, hellgrau; das zweite Glied cylindrisch, zusammengedrückt. auf der Schneide etwas locker beschuppt, auswärts braun, am Ende grau; das Endglied fast so lang wie das zweite Glied, mit einem breiten Ring an der Mitte und einem schmälern vor der Spitze. Saugrüssel lang, an der Wurzel wie die aufliegenden Maxillartaster hellgrauschuppig. - Vorderbeine auswärts schwarzbraun, an den Euden der Fussglieder hellgrau; Mittelbeine heller und an den Fussgliedern mit breiten hellen Enden; Hinterbeine hellgrau; die Schienen auswärts grau bestäubt, die Dornen und die langen Haare der Rückenschneide hellgrau; die Füsse dunkelgrau, an den Euden der Glieder hell. - Hinterleib bräunlichgrau, an den Seiten mit Schuppenbüscheln, am Bauch heller mit dunkelgrauen Seiten: der weibliche Analkegel an der Spitze melı oder weniger breit hellochergelb mit etwas hervorstehenden Legestachel.

*) In der Beschreibung lege man statt Vorrande: Vorderrande und statt ferven Unterschied: ferneren Unterschied. 
Vorderflügel $\sigma^{\prime} 2 \frac{1}{2}$, $q 2$ " lang, zientich scbmal, von der Farbe des Rückenschildes, dunkelbraun bestäubt, wodureh aber die Grundfarbe nur in der Spitze verulunkelt wird. Die Schulter ist geschwärzt, der Vorderrand bis zu einem über der Querader liegenden Querwisch mit einer grössern oder geringern Zahl schwacher, punktförmiger Striche, zwisehen denen der Grund weisslich ist, bestrent. Am Innenrand ist nicht weit von der Wurzel ein schräg nach aussen aufisteigender und bis über die Falte reichender, umregelmässiger, sehwarzer Strich, dessen Anfang auf lem Inmenrande sich leicht zu verwisehen scheint. In gleicher Entferuung von ihm, wie er von der Flügelwurzel, ist ein grosser, sehr wenig nach hinten übergeneigter, nach inmen zugespitzter und über $2 / 3$ der Flügelbreite hinwegreichender, schwarzer Dorsalfleck. Anf der Querader liegt ein kleines, schwarzes, strichfürmiges Fleckchen, dessen Spitze der Basis zugewendet ist. Alle drei schwarze Zeichnungen sind manchnal sehr dentlich gelblich oder doch heller als die Grundfarbe ringförmig eingefasst. Hinter dem sehwärzliehen Costalwisch, dem ein noch weniger scharf ausgedrüekter im Innenwinkel gegenüber liegt, folgt eine weissliche Stelle am Vorderrande. Die grauen Franzen sind an der Flügelspitze am dichtesten schwärzlich bestäubt; bei einem $\sigma^{\top}$ geht von der Spitze eine aus schwarzen Schuppen gebildete Linie in der Hälfte der Franzell weit herunter.

Hinterflügel so breit wie die Vorderflügel, mit stark verlängerter Spitze, hellgrau. Franzen heller, gegen die Wurzel gelblich schimmernd. Unterseite der Vorderflügel mit hellem Fleckchen am Anfang der Costalfranzen, und blassgelblicher Basallinie aller Franzen.

Vaterland: Texas (Bull, Belfrage). Vier Weibchen, welche, als sie gefangen wurden, ganz unverflogen waren, tragen die Data: 27. Juli, 7. und 27. Angust. Diese Art hat also eine lange Flugzeit.

Anmerkung. Oeellen entdecke ich durch Absehuppung des Augenrandes. Auf den Vorderflügeln geht von der Subcostalader eine Gabelader in den Vorderrand vor der Spitze. Die Medianader hat vier getrennte Aeste, deren längster, der zweite, ron dem folgenden weit entfernt und fast gerade ist. Die Mittelzelle ist nicht oder doch nur änsserst fein geschlossen; aber Ader sechs kommt aus einer deutlichen Verlängerung der Subcostalader hervor, welehe fast die Hälfte der Zelle begrenzt. Auf den Hinterflügelı scheint die Mittelzelle offen zu seiu. - Welcher Heinemannsehen Gattung ieh diese Art zuweisen soll, ist mir ein Räthsel.

\section{Gelechia (Ceratophora?) fullonella n. sp.}

Thorace et capite osseis, antennis allido nigroque unnulatis, palpis albidis;

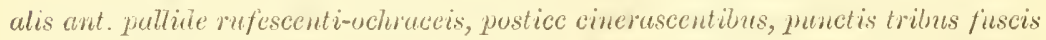
(primo clongato in plica media, secusedo in disco medio, lerlio venue transversue), striga postica firucta, pallida. P.

Obgleich die Vorderflügel sich nach hinten nieht erweiteru und die Adern zwei und drei nicht aus einem Punkt kommen (wenigstens seheinen sie mir es nicht), so stimnt sie doch uach der Flügelgestalt, der Kürze der Hinterflügel- 
franzen und den Palpen mit den vou Heinemann zu seiner Gattung Ceratophora gerechneten Arten, und die Zeichnung der Vorderflügel ist die der Inornatella.

Grösse der Gerronella. Räckeuschild und Kopf beinfarbig gelblich, im Gesicht am weissesten. Fühler dünn, schwarz und weisslich geringelt. Taster stark aufwärts gebogen; das zweite Glied cylindrisch, zusammengedrückt, weisslich, auswärts an der Wurzelhälfte braun; das Endglied länger als das zweite Glied, pfrienenförmig, feingespitzt, am Ende etwas verdunkelt. Maxillartaster kaum vorbanden. Saugrüssel bräunlich, von Rückenschildslänge. - Die vier vordern Beine graubraun mit hellen Enden der Fussglieder; die Hinterbeine auf der Innenseite weisslichgrau, auswärts dunkel; die Schienen mit blonden Haaren ziemlich spärlich bekleidet. - Hinterleib braungrau mit hellgelblichgrauem Bauch; das Analglied abgestutzt kegelförmig mit hervorstehendem Legestachel.

Vorderflügel $2 \frac{1}{2} "$ lang, ziemlich schmal, nach hinten nicht erweitert, zugespitzt mit sehr schrägem, schwach convexem Hinterrand, hell röthlich ochergelb, am hellsten an der Wurzel, vor dem Hinterrand grau. Der Vorderrand ist ron der Wurzel aus in einer feinen, kaum merklichen, an der Wurzel punktförmig verstärkten Linie schwarz. In der Mitte der Falte ist ein länglicber, braumer Punkt; hinter und über ihm in Mittelraum ein kleiner, brauuer Punkt (bei dem einen Exemplar verloschen) und anf der Querader eiu wenig grösserer. Hinter diesem verdunkelt sich die Grundfarbe zu einer grau und roströthlich gemischten bindenförmigen Wolke, welche nach aussen durch eine verloschene, gebrochene, oben erweiterte Querlinie der Grundfarbe begrenzt wird, hinter welcher die Grundfarbe bis zum Hinterrand dunkler grau ist. Die gelblichgrauen, um die Flügelspitze und am Innenwinkel dunkler grauen Franzen sind durch eine feine, gelbliche Wurzellinie vom Hinterrand getrenut.

Hinterflügel $1 \frac{1}{2}$ mal so breit wie die Vorderflügel, am Hinterand unterhalb der kurzen, abgerundeteu Spitze schwach eingedrückt, einfarbig dunkelgrau; die Franzeu der Ajpicalhälfte kürzer als die halbe Breite der Flügrelfäche.

Unierseite einfarbig braungrau.

Vaterland: Texas (Belfrage). Zwei f, an 20. und 21. August gefungen, in meiner Sammlung.

\section{Gelechire (Dor!lphon'r) piscipellis n. sp.}

Capillis palpisque ulbulis, antennis albo nigroque amulatis: alis ant. angustis, dilute griseis, squanis nigricunti-albidis creberrime adspersis, plicu partim gullide ochracen maculam obsoletum fuscescentem vel striolum nigrum continente. of $\bigcirc$.

Sehr ähnlich der Gelech. tenuiellu Munn, wesshalb jch sie in das dieser (Tin. S. 191) durch Heinemann angewiesene neve*) Genus stelle; sie ist etwas kleiner, mit dickerem zweiten Tasterglied, auf den Vorderflügeln mir grübern Schuppen bestreut, welche schwärzlich sind, mit hellgrauen Enden.

Rückenschild und Oberkopf heller staubyelb als dic Vorderflügel; die Schulterdecken beim $q$ mit solchen Schuppen wie diese bestrent; Stirn weisslich. Taster 
so lang wie das Rückenschild, innen weisslich, aussen am locker beschuppten und dadurch verdickten zweiten Glied ein wenig dunkler; das Endglied fein, spitz, kaum $2 / 3$ so lang wie das zweite Glied, wenig gebogen; vorgestreckt. Sangrüssel ziemlich lang, an der Wurzel obenauf wciss. Fühler weisslich und schwärzliclı vollständig geringelt. Beine schlank, weissgrau, auswärts bräunlich angeflogen; die Hinterschienen dünn, auf dem Rücken mit dümner, weisslicher Bebaarung; die Hinterfüsse answärts am dnnkelsten brännlichgran mit weisslichen Enden der Glieder. - Hinterleib verhältnissmässig lang, hell gelb]ichstaubgrau, an Bauch heller, beim ơ stark gerandet, mit bleichgell,lichem, kurzkegelförmigem, sehr dichtem Analbusch: beim $O$ ist der Hinterleib lang kegelfürmig zugespitzt mit etwas hervorstehendem Legestachel.

Vorderflügel $3^{\prime \prime \prime}$ lang, schmal, nach hinten wenig erweitert, dann länglich zugespitzt, mit schwach convexem Hinterrand und ganz stumpfem Innenwinkel. Grundfarbe sehr bleich ochergelb, aber sehr reichlich mit schwarzen, an ihren Enden weisslichen schuppen bestreut, so dass die Grundfarbe nur hier und da, am meisten beim $q$, zam Vorschein kommt. Als ein solcher, doch ziemlich undertlicher, bleichgelblicher Längsstreif tritt beim $q$ die Falte hervor; sie wird anf ihrer Mitte durch einen schwärzlichen, wenig scharfen Fleck unterbrochen, während das $\sigma$ an derselben Stelle durch einen schärfern, länglichen Längsstrich bezeichnet ist. Bei dem ol zeigt sich auch im Mittelfelde schräg hinter diesem Strich eine feine, ganz kurze, schwärzliche Längslinie, von der beim $q$ keine Spur sichtbar ist. Den Hinterrand sondert eine ziemlich deutliche, aus den angegebenen Schuppen gebildete Linie von den grauen Franzen $\mathrm{ab}$, welche am meisten um die Flügelspitze mit schwärzlichen Schuppen bestreut sind.

Hinterflügel sclmmäler als die Vorderflügel, mit fast parallelen Gegenrändern und stark verlängerter, feiner Spitze, unter welcher der Hinterrand einen tiefen Ausschnitt hat. Ihre bleigraue Farbe sticht von den heller grauen, gegen den Analwinkel gelblicheren Franzen dadurch besonders ab, dass diese eine ziemlich scharfe, blass ochergelbliche Wurzellinie haben; sie sind, so weit sie die Innenhälfte des Flügels einfassen, doppelt so lang wie dieser breit ist.

Unterseite der Vorderflügel einfarbig, hell bräunlichgrau; die Hinterflügel bleigrau mit einem gröber beschuppten Streifen von der Farbe der Vorderflügel längs des Vorderrandes.

Vaterland: Texas (Belfrage). Ein ausnahmsweise ziemlich gut erhaltenes Paar (das $\sigma^{\top}$ am 7. Juli, das $q$ an 6. August gefangen) in meiner Sammlung.

Anmerkung. Gel. tenuiella ist in der Wiener Monatsschrift 1864, tab. 4, Fig. 16 wenig kenntlich abgebildet. Die Vorderflügel sind etwas zu kurz, der Ausschnitt des Hinterrandes der Hinterflügel zu seicht; auf dem erstern ist vor dem hellern Hinterrand ein dunkler Querstreif, den keines meiner beiden von Mann erbaltenen Männchen zeigt, anf den Hinterflügeln ist die Oberseite viel zu dunkel. Man muss freilich zugeben, dass sich die unscheinbare Art weder in der Abbildung, noch in Worten leicht kenntlich darstellen lässt. 
Gelechir (Trichotuphe) Havocostella Clem. Fig. 26.

Palpis pallide ochrocis, antcnuis fuseescentibus: alis ant. nigris, vittu costuli pallide fluva, unte upicen coarctatum dentem longum udversus angulum internum exserente or o.

Gelechiu (?) - Clemens ed. Stt. p. 113. Tirchotıphe - ib. p. 180.

Die Taster, welche Clemens nicht beschreiben konnte, sind so lang wie Kopf and Rückenschild zusammengenommen, sehr schwach gebogen, einfarbig bleich ochergelb; das zweite Glied stark zusammengedrückt, nach beiden Enden hin verdünnt, sowohl auf dem Rücken wie an der convexen Schneide glattschuppig; das Endglied fast so lang wie das zweite Glied, diinn und feingespitzt.

Grösse einer kleinen Gel. (Brachycross.) cinerella, von $4^{\prime \prime \prime}$ Vorderflügellänge; das $Q$ etwas grösser als das $\sigma$.

Vaterland Haine (nach Clemens). Meine zwei Exemplare wurden von Burgess in Massachusetts bei Beverly, und zwar das bis auf die abgebrochenen Taster gut erhaltene $0^{\top}$ am 20. Juli, gefangen.

Anmerkung. Die Zeichnung lässt sich auf die von Fel. bilohella zurückführen; selbst die Franzen sind dicht am Hinterrand ähnlich mit gelblichen Punkten gezeichnet. Wahrscheinlich haben die Ialacotrichen gleichen Aderverlauf. Die Hleine Verschiedenheit in der Behaarumg der Taster zwischen Malucotricha und Trichotaphe hat Clemens sicher mit Recht nicht als Gattungsmerkmal betrachtet (bei seiner Setosella zeigt er sie so all, wie ich sie als Merkmal meiner Abtheilung Malacotricha ansehe). Welche Heinemann'sche sogenannte Gattung auf Trichotaphe (und Malacotricha) zurückzuführen ist, vermag ich nicht zu sagell.

\section{Gelerhia (Trichotaphe) orhripalpella is.}

Épistomio pulpisque fermgincis schaeeisve, antennis fuscescentibus; alis ant. nigris, vitta costae metallicn eoerulescente, unte medium ampliata, postice puncto ferrugineo costali terminata et in angulum intermum coarctata, striga coerulescente ante marginem posticum. of $q$.

Trichotuphe alacella Clem. (ed. Stt.) p. 180.

Kleiner als die vorige. Vorderflügel $2 \frac{3}{4} "$ "lang. Das Schwarz ist, soweit es die hellbläulich metallische Partie begrenzt, in ungleicher Breite sehr gesättigt; am Innenrand geht es in tiefes Gelbbraun ïber. Der Vorderrand ist striemenartig bis zum Anfang der Costalfranzen metallglänzend hellbläulich; sie erweitert sich vor der Mitte zu einem sehr breiten, bis zur Falte reichenden, dreieckigen Zalın, hinter welchem sie ihre geringste Breite hat; dann wird sie wieder sehr breit und endigt mit einem hellrostfarbigen Punkt anf dem Vorderrand, während sie sich einwärts zu einer Linie verengert, welche schräg bis zum Innenwinkel hinzieht. Vor der tiefschwarzen Hinterrandlinie ist ein breiter metallisch hellblauer Streif, von den schwarzen Adern in Fleckchen (Clemens nennt sie blos (lots) zerschnitten.

Vaterland: Die Gegend von Washington, wo Baron Osten-Sacken meine drei Exemplare fing. Clemens fing das seinige in Pensylvanien am 17. Juli, 
Anmerkung. Da es schon eine Gelechia (Acanthophila Heinemann) rlucella giebt, so musste der Name der Clemens'schen Art geändert werden.

Gelechia (Trichotrphe?) servativittella n. sp. Fig. 27.

Capite fuscesconti-cinereo, ortitis, epistomio prolpisque pallide fravis; alis ant. violaceo-nigris, vitta costali latissimu, pullide flavo, postice acuminata, interius dentrita. of $q$.

Mit auffallend gefärlten nnd gezeichneten Vorderflügeh, naeh denen sie keiner europäischen Art ähnlich sieht. Ihr Flügelgeäder kann ich ohne Abschuppung nicht genau erkenuen, wesshalb ich unsieher bin, ob sie zu Trichotriphe gehört.

Grösse der Gel. luculella. Rückenschild braungrau mit hellgelben Schulterdecken; Kolf heller braungrau, an den Augen ins Hellgelbe, im Gesicht hellgelb. Fühler bräunlich, beim $\sigma^{\nearrow}$ fein gezähnelt, am Wurzelglied blassgelb. Ocellen erkenne ich nicht. Maxillartaster blassgelb, fadenförmig, gegen einander gelegt. Lippentaster so lang wie Kopf und Rückenschild zusammengenonmen, aufwärts gekrïmmt, hellgelb: das zweite Glied kräftig, zusammengedrückt, glatt, am Ende kaum verdünnt; das Englied ein wenig kürzer als das zweite Glied, borstenförmig, spitz, Saugrüssel länger ałs das Rückenschild. - Die vier vordern Beine graubraun, an den Enden der Glieder verloschen gelblich; die Hinterschienen gelblichgran, auf dem Rüicken schwach behaart; die Hinterfïsse graugelblich, an den Wurzeln der Glieder bräunlich. - Hinterleib braungrau mit kaum hervorragendem Legestachel des 0 .

Vorderflügel $3^{\prime \prime \prime}$ lang, länglich, hinten kaum erweitert, violettschwar", an der Strieme hin ticfschwarz und ebenso in der Falte und in der Hinterrand linie. Am Vorderrand zieht eine breite naeh hinten verscbmälerte und zugespitzte, vor der Flägelspitze endigende, hellgelbe Strieme; sie verbreitet sich an der Wurzel bis zur Falte; ihr Imnenrand ist bis fast zur Hälfte geradlinig; dann hat er einen schrägen Einschnitt und vor der Zuspitzung einen kleinern, so dass er in zwei scharfen und einem abgerundeten Zahn hervorsteht. Franzen etwas heller als die Grundfarbe, an der Wurzel mit gelblichen Schnppen.

Hinterflügel ein wenig breiter als die Vorderflügel, am Hinterraud nnterhalb der Spitze ein wenig eingezogen, dunkelgrau.

Unterseite dunkelgrau. Auf den Vorderfin̈geln kommt von der Medianader eine langstielige Gabel (Ader zwei und drei); auf den Hinterflügeln scheint die Mittelzelle offen zu sein.

Vaterland: Texas. Ein o im Cambridger Museum; ein Paar in meiner Sammlung, wie gewöhnlich, mit gänzlich abgeschliffenen Franzen, durch Belfrage am 28. Juli und 15. Angust gefangen.

Gelechir (Malarotricha Z.) bitobella n. s. Fig. 28.

Palpis pallide ochaccis, antemis fuscescentilus; alis ant. pallide ochroceis, plaga magna bitoba nigra, ad dorsum schistacen, ante zuncto duo venae transversue nigra, fascia marginis postici schistacea, nigro-marginata. $\sigma^{\top}$. 
Ausserordentlich ähnlich der Nothis tolabella, aber sogleich durch die ganz anders beschaffenen Taster zu unterscheiden; auch ist der zweilappige Fleck anders gestaltet; die Hinterrandbinde ist schmäler mit schwach convexem Innenrande, und díe Querader trägt nicht einen Strich, sondern zwei weit getrennte Punkte.

In der Grösse etwas über der vorigen. - Rückenschild und Kopf gelblichgrau; Schulterdecken, Seiten der Stirn und an entschiedensten das Gesicht gelblich. Fühler bräunlich, zahuartig fein gekerbt und dadurch scheinbar heller geringelt. Taster hell ochergelb, anf der Innenseite an hellsten, am zweiten Glied auswärts bis $2 / 3$ lehmgelb; dieses Glied ist gebogen, stark zusammengeUrïckt, gegen die Wurzel verdünnt, mit glatter Schneide, auf der Endhälfte des Pückens mit lockeren, aufsteigenden Schuppenhaaren; das Endglied nur $3 / 4$ so lang wie das zweite Glied, dünn, gebogen, einfarbig. Maxillartaster und Rücken des ziemlich langen Saugrüssels bleichgelb beschuppt. - Die vier vorderen Beine gebräunt mit bleichgelben Enden der Fussglieder; die Hinterschienen ziemlich lang, dünn, answärts lehmfarbigbraun wie die hellspitzigen Dornen, auf dem fast baarlosen Rücken und der Innenseite bleichgelb; die Hinterfüsse aussen blassbraun, an den Enden der Glieder hell. - Hinterleib grau; der Bauch blassgelb, an den Seiten bräunlich. Analbusch ziemlich lang, mit langen, fast anliegenden Haarschnppen.

Vorderflügel $3^{1} / 4^{\prime \prime}$ lang, recht merklich gestreckt, hinten wenig erweitert, mit schwach convexem Hinterrand, an de1 Wurzelhälfte hellgrau, etwas bestäubt, dann dunkler, und zuletzt von der Querader an bis zur Hinterrandbinde ochergelblich. In der Falte liegt nicht weit von der Basis ein tiefschwarzer, sich verdünnt hinziehender Fleck, der sich einem viel grösseren, nach vorn zugerundeten anschliesst und mit ihm die zweilappige, schwarze Zeichnung bildet, von welcher aus die Farbe bis zum Innenrand dunkel schiefergran ist. Auf der Querader liegt ein schwarzer Punkt, und ein zweiter, davon getrennt, von Ocherfarbe eingefasst, darunter. Den Hinterrand nimmt ein breiter, ovaler, bindenförmiger Fleck ein; er ist dunkel violettschwärzlich, und seinen Innenrand bildet eine dicke, schwarze Linie, durch welche er um so mehr von dem lebhaft ochergelben Grunde absticht. Von den dunkelgrauen, nur am Innenwinkel ganz hellen Franzen ist er durch sechs in gleichen Abständen aufgestellte, hellgelbe, scharfe, ziemlich grosse Punkte getrennt.

Hinterflügel etwas breiter als die Vorderflügel, unterhalb der nicht verlängerten, aber deutlichen Spitze mit eingezogenem Hinterrand, grau; die grauen Franzen mit feiner, gelblicher Wurzellinie.

Unterseite der Vorderflügel grau, mit einem kleinen, gelblichen Costalwisch dicht vor der Spitze und mit verloschenen, gelblichen Punkten an der Franzenwurzel.

Vaterland: die Gegend von Washington, wo Baron Osten-Sacken mein schönes $\sigma^{\top}$ fing, und Ohio, von wo ich ein sehr verflogenes $\sigma^{7}$ durch Schlïger erhielt. 
Anmerkung. Diese Art gehört nach Flïgel- nnd Tasterbau nit Gel. internella Z. (Lep. Caffr. p. 109) zu einerlei Abtheilung, welche Malacotriche heissen kann. Bei Intermella, von der ich ein $Q$ besitze, ist, was in der Beschreibung nicht erwähnt wurde, der Rïcken des zweiten Tastergliedes gleichfalls mit einem Haarbusche versehen; (das Endglied ist verhältnissmässig länger als bei Bilobella). Ocellen kunnte ich nicht entdecken. Vielleicht gchört auch Gel. septella Caftr. p. 108 in dieselbe Abtheilung (in der Diagnose muss es statt interne heissen; interins). Die mir sonst unbekannte Trichot. setosella $\mathrm{Cl}$. ist zufölge der p. 121 angegebenen Merkmale gleichfalls eine Malucotricha.

Enchrysa $\boldsymbol{n}$. y. Fig. 29. a. b.

Capilli laevigati, nitidi. Ocelli mulli.

Antennae breviores, subdenticulatce.

Palpi labiales longi, tenues, arcuati, laevigati.

Hustellum nediocre, lorso squamato.

Alce anteriores acuminatce, margine costali postice subexcavatae, margine postico longo.

Alce posteriores angustae, infra apicem productum profunde excisae.

Der Vorderflügelfärbung und Zeichnung nach an Tinagma transversellum, nach den Fühlern allenfalls an Chrysoclista erimnerud, ist diese Gattung zufolge der Hinterflügel eine ächte Gelechide. Den Glanz des Rückenschildes und Kopfes hat sie nur mit Gelechia (Nannodiu) Hermannella gemein; aber ihre dünnen Taster sind so lang wie Kopf und Rückenschild zusammengenommen und stark nach oben gekrümmt. Was. sie vor allen auszeichnet, ist die Gestalt der Vorderflügel, deren Vorderrand sich von der Wurzel aus schwach convex krümmt, von der Mitte an aber sanft concav bis gegen die Spitze hin verläuft; der Hinterrand ist sehr schräg und lang, schwach convex und geht, ohne einen Innenwinkel zu bilden, in den Innenrand über. Daher sind die Vorderflügel lang zugespitzt. Die Hinterflügel haben etwas über halbe Breite derselben und sind unter der verlängerten Spitze tief ausgerandet und langgefranzt.

Auf den Vorderflügeln gehen aus dem Vorderrande der langen, schmalen Mittelzelle drei einfache Aeste parallel schräg zum Vorderrande und zuletzt eine Gabelader, die sich vor der Flügelspitze endigt, und deren Zinken länger sind als der Stiel. Aus der Querader gehen zwei Aeste in den Hinterand, ans der Medianader drei mit ihnen parallele, deren zwei oberste doppelt so lang sind wie der unterste. Die Subdorsalader, der Medianader parallel, scheint an der Basis gabelartig gespalten zu sein.

Anf den Hinterflügeln theilt sich die Subcostalader in eine Gabel, von welcher der obere Zinken in die lange Flügelspitze, der untere in den Scheitel des fast rechten Winkels, in welchen der Hinterrand gebrochen ist, ausläuft. Der fast gerade untere Schenkel des Hinterrandwinkels nimmt eine von der Mittelzelle konumende Ader an seiner Hälfte und eine andere an seinem untern 
Ende anf. Der übrige Theil des Hinterrandes läuft mit dem Vorderrande fast parallel. Die Franzen baben mindestens die Breite der Hinterfiügclfäche.

\section{1. dissertella n. sp.}

Antenuae nigrae, apice allo; thorax et caput metallice aurea. Alamm area basalis cumea, postiee nigro-terminatu et exalbido-marginata; press reliqua andentirea, litum costali nigra. o'.

Grösse der Chrysoctista Scluranliellu. Das Pückenschild upd dex hervorstehende Kopf sehr glatt und glänzend röthlichgoldig; die Stirn messinggelb. Fühler kürzer als die Vorderflügel, etwas stark, fadenförmig, gegen das Ende ctwas verdünnt, schwarz, an Endviertel weiss. Taster dünn, stark aufwärts gebogen, innen metallisch hellgelb, auswärts brauu; das zweite Glied cylindrisch. glattschuppig, gegen die Wurzel schwach verdünnt; das Endglied fast ebenso lang, feingespitzt. - Vorderbeine glänzend braun, an den Enden der Fussglieder ein wonig heller (die übrigen Beine und der Hinterleib fehlen).

Vorderflügel $2^{1 / 2}{ }^{\prime \prime}$ lang, ziemliclı schmal; das bis fast zur Mitte reichende Wurzelfeld ist kupfergläuzend, an Vorderrand in einer nach hinten erweiterten Linie schwarz und hinten in fast gerader, etwas schräger Linie breit schwarz begrenzt und mit einer hellgoldgelben Querlinie eingefasst. Der Rest der Flügel ist weniger glänzend, hell orangegelb. am Vorderrand mit einem breiten, schwarzen Streifen, der nicht weit vom Wurzelfeld anfängt und verdünnt in der Flügelspitze endigt. Die schwärzlichen Franzen ziehen sich am Innenrande bis über das Ende des Wurzelfeldes hin.

Hinterflügel schwarzgrau. - Untcrseite aller Flügel einfarbig graubraun, kupferig schimmernd.

Vaterland: Ohio (Schläger). Ein ơ in meiner Sammlung (das zweite abgeschuppt).

\section{Yjsolophus prurigutlellus Clemens.}

Antennis fuscis, rurius subanmulis; alis ant. anyustis, acutis, mie colorutis; posterioribus hyulinis, irielesecutibus, fusco-venosis.

Var. a) alis ont. dilute luteis, fusco monctutis liturutisque.

Ypsol. poucigutt. Clemens (ed. Stainton) p. 229.

Var. b) alis cut. colore fuscescenti inluctis.

Var. c) alis ant. obscure brunneis, vitte costuli ussea distinctissima.

Y'sol. flavivittellus Clem. 1. c. p. 254.

Eine höchst veränderliche Art, die sich in dieser Hinsicht mit Cerost. rudintellı vergleichen lässt, aber in allen Varietäten viel leichter an den durchsichtigen, irisirenden Hinterflügelu mit aller Bestimmtheit zu erkeunen ist.

Rïckenschild und Kopf hellbraun, bei Var. c. ersteres vorn gelichtet und ge]blich gemischt und der Kopf gelblich, in der Mitte der Länge nach braungrau; die Fühler bräuulich, doch bei hellen Exemplaren bisweilen ganz vollständig bell und dunkelgeringelt, während soust nur anf der Unterseite bellere Pinge zu erkennen sind. Ocellen deutlich. Der starke Busch des zweiten 
Tastergliedes ist braun, nur am oberen Encle in einem mchr oder weniger verlängerten Streifen hellgrau; das feine, borstenfürmige Endglied braun mit heller Iïickenlinie, die nicht bis zur Spitze reicht, die Spitze selbst hell. - Die vier Vorderbeine 'aussen brann mit hellen Gliederspitzen. Die Hinterbeine bleich. gelb; die Sehienen am oberen nnd unteren Rande braungrau oder auch ohne diese Färbung, auf der Rückenschneide mit dichtem, auf der unteren Seite mit dünnerem, hellblondem Haarkamm; die Dornen an der Seite gebräunt; die Fussglieder gran mit hellen Spitzen. Hinterleib hellbraun, ain Bauch hellgelblich und zu jeder Seite, bisweilen auch in der Mitte, mit einer Reihe dunkelgraner Fleckchen.

Vorderflügel $3^{1 / 2}-3^{3} / 4$ "' lang, schmal, spitz, doch nicht scharfspitzig, mit sehr schräg zurückgehendem Hinterrande. Grundfarbe lehmgelb, mehr oder weniger lebhaft und gesättigt, mit dunkelbraunen St:iubchen bestreut. Bei den am vollständigsten gezeichneten Exemplaren liegen zwei sehwarze Punkte nahe der Basis (einer auf dem Vorderrande, eincr unter der Falte), dann ein einzelner dicht iiber der Falte, hierauf zwei schräg unter einander (der vordere über, der hintere in der Falte), beide dureh einen braunen Nebelfleck verbunden, endlich im Mittelfelde hinter der Mitte noch ein Paar schräg gestellter und durch einen grösseren Nebelfleck oder Wisch verbundener Punkte. Oefters fehlt der eine oder andere oder mehrere dieser Punkte, und bei der dunkleren Varietät b ist fast gar keiner zn erkennen. Fin Exemplar ist hell mit sehr kleinen Punkten und olıne Nebelflecke, nnd die Fläche ist vom Vorderrande aus rosig angelaufen. Bei Var. c ist die grössere Innenrandhälfte dunkelbraun; die kleinere Costalhälfte bilklet eine beingelbe, sich hinten zuspitzende und vor der Flügelspitze endigende Strieme. Auf der Grenze beider Färbungen liegen drei tiefschwarze Punkte, dem dritten, vierten und sechsten der oben angegebenen entsprechend. Eine Reihe schwarzer Punkte zieht am Hinterrande hin bis in den Vorderrand, und liegt öfters in gelblichem Grunde. Bei Var. a zieht eine bräunliche Wolke davor her. Franzen heller als die Grundfarbe, an der Wurzel meist gelblich.

Hinterflügel ein wenig breiter als die Vorderflügel, unter der vortretenden Spitze mit einem schwachen Eindruck des Hinterrandes, durchsichtig glasartig und irisirend, nur gegen die Spitze braun angelaufen, sonst mit starken, brannen Adern, unter denen sich vorzüglich der Hauptast der Medianader auszeichnet. Franzen braungrau.

Unterseite der Vorderflügel braungrau, bei Var. $e^{\cdot}$ an Vorderrande vor der Spitze etwas gelblich.

Vaterland: Ohio (wo die Art nieht selten zu scin seheint) und Texas (Boll); zwei $f$ der Var. a in meiner Sammlung und dem Cambridger Musenm.

Anmerkung 1. Es ist auffallend, dass Clemens bei seinen beiden Arten die Durchsichtigkeit der Hinterflügel unorwïhnt lässt nnd dieselben bei P'unciguttcllus nur als brownish with a bluish iridescent hue, bei Flaviviticllus gar nur kurzweg als fuscous bezeichnet. Aber die Identität seiner Arten mit der meinigen unterliegt darnm keinem Zweifel. 
Anmerkung 2. In Fitch: First and second Report on the Insects of the State of New-York 1856 findet sich S. 221-234 ein sehr ansführlicher Bericht iiber die Verwüstungen, welche das Räupchen Palmer-Worm im ästlichen Theile des Staates New-York und in allen Nen-Englandstaaten am Laube der Garten- und Waldbäume, namentlich der Apfelbänme und Eichen, von Zeit zu Zeit anrichtet. Die sich daraus entwickelnde, in Fürbung und Zeichnung sehr variirende Motte nonnt er Chaetochilus pometellus Harr. Aus der von einer höchst elenden Abbildung (T. 4, Fig. 4) begleiteten Beschreibung derselben (S. 229) scheinen mir die Worte: the hind wings above and beneath are dusky with a glossy azure blue reflection and blackish veins - ologleich die Durchsichtigkeit dieser Flügel ebenso wie bei Clemens nnerwähnt bleibt - auf den Yls. panciguttellus hinzudeuten. Fitch beschrciot S. 232 einen Chactochilus malifoliellus n. sp., den ich mit Yps. punctiliscellus Clem. vercinigen würde, wenn nur das Mindeste über den so wesentlichen Unterschied in den Hinterflïgeln zwischen ihm und Pomctcllus gesagt wäre! Den Chactochilus contubernalellus Fitch, the Comrade Palmer-Worm, S. 233 bin ich geneigt, für den Clemens'schen Yps. flrvivittellus (oder meine Var. c des Pauciguttcllus) zu halten; Fitch glaubt, in einem Räupchen, das mit dem seines Pometellus zusammenlebt, aber sich von diesem durch die Farbe des Kopfes und Prothorax unterscheidet, das von Contubernalellus zu erkennen, obgleich ilım dessen Erziehnng nicht gelungen ist. Die Beschreibungen seiner zwei breitflügligen Chaetochilus-Arten weiss ich auf keinen mir bekannten Y psolophus anzuwenden. Die specifische Benennung Punctellus wird wahrscheinlich für die Clemens'sche eintreten müssen; da aber Clemens sie nicht kennt, so begnüge ich mich, auf sie hier wenigstens aufmerksam zu machen.

\section{Fpsolophus pumrtiliscellus Clem.}

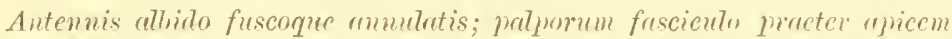
fusco, articulo terminati allon: alis aut. prollide lutcolis, fuscesecnti inoratis,

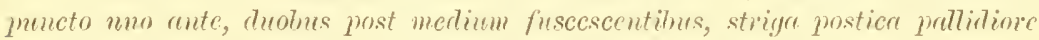

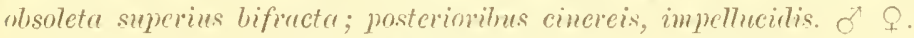

\section{Ypsol. punetid. Clemens 1. c. 1. 228.}

Von der vorigen Art sogleich durch die mulurchsichtigen Hinterfïgel zu unterscheiden, aber auch mit etwas kiirzeren, stumpferen Vorderflïgeln und selır deutlich geringelten Fïhlern. Ocellen. die bei manchen Exemplaren des Pruciguttellus schr sichtbar sind, kann ich nicht erkennen.

Riückenschild und Kopf blass lehmgelblich. Fülıler ebenso mit braunen Ringen, nur am Wurzeldrittel auf einer Seite einfarbig hell. Tasterbusch lang und zugespitzt, aussen gelbbraun, innen brännlichgrau, auf dem Rücken und am Endrande mit einem bleichgelblichen Streif und an der Wurzel des Endgliedes weiss; das Endglied tein, lang, braun mit bleichgelblicher Rückenlinie. Die vier vorderen Beine aussen braun; die Hinterschienen aussen an der untern Schneide bräunlich, an der oberen mit langen, hellblonden Haaren; alle Fussglieder braun 
mit bleichen Spitzen. - Hinterleib schmal, grau; der Bauch und der ungefleckte Analbusch bleichgclb.

Vorderflügel $3^{1} / 3^{\prime \prime}$ lang, schmal, nach hinten etwas erweitert, mit convexerem Hinterande als bei Puncignttellus, sehr blass lehngelb, an Vorderrande gegen die Basis am hellsten, von $1 / 3$ an nach und nach reichlicher mit blassbräunlichen Schuppen bestreut. In einiger Entfernnug von der Basis liegt in der Falte ein solchar verloschener Punkt; ebenso weit von diesem ab folgen zwei Punkte: der obere im Mittelfelds, der untere sehr wenig weiter nach hinten gerückte in der Falte; ebenso weit ab folgen zwei auf der Querader, nahe bei einander oder zusammenfliessend, der untere etwas gegen die Basis gerückt. Wieder in gleicher Entfernung kommt dic sehr verloschene helle Querlinie, die nur dadurch gebildet wird, dass auf ihr die Grundfarbe rein bleiltt; sie ist dünn, ïber der Mitte mit zwei Winkeln und hinterwärts etwas dunkel eingefasst. Fine schwärzliche Punktreihe umzicht den Hinter- und Vorderrand bis zur Qucrlinie; jeder Punkt hat eine hellgelbliche Stelle anf den Franzen hinter sich. Franzen hellgrau, hinter den hellgelblichen Stellen mit einer dunkleren Schattenlinie durchrogen.

Hinterflügel sehr wenig breiter als die Vorderflügel, am Hinterrande unterhalb der Spitze schwach eingedrückt, einfarbig hellgrau, doch gegen die Wurzel zarter beschuppt; die Flïgelspitze ist anf den lichteren Franzen mit einer verloschenen Schattenlinie umzogen.

Unterseite der Vorderflügel grau, auf den Franzen mit verloschenen, hellgelblichen Flecken. Die Hinterflügel ausser am Vorderrande sehr zart hellgrau heschuppt und ins Bläuliche schimmernd.

Vaterland: Ohio (Schläger), New-York ('Tengström). Ein gut erhaltenes I'aar in meiner Sammlung.

Anmerkung. Von Clemens wird der erste Punkt der Vorderflügel als at the base of the fold liegend bezeichnet: er liegt aber ebenso weit von der Basis ab wie vom folgenden Punktpaar.

\section{rysolophus uniripunctellus $\mathrm{Cl}$.}

Anteunis fuscescenti-annulutis; palporum fusciculo exterins moeter apicem fuseo, artieulo tcrminati longu, palliclo; alis ant. pallide luteolis, squamis fuscis erebro alspersis, costu ipse pollidn, muctis duobus nigris exterins allwo terminatis ante malium, uno vonue transversae nigro interius albo-signato. ơ $?$.

Ypsol. unicip. Clemens 1. c. p. 229.

Man muss gewöhnlich sebr genau und bai giustigem Lichte nachsehen, um auf den Vorderflügeln unter den vielen schwä!zlichen Stäubchen die drei charakteristischen schwarzen Punkte, deren jeder auf einer Seite mit einem oder ein paar weissen Schüppchen bezeichnet ist, zu entlecken; sie liegen wie bei Nothris verbascella, nämlich zwei im Mittelraume in der Flügelmitte, der hintere auf der Querader; sie sind auf den einander zugewandten Seiten mit den weissen Schüppchen versehen; der dritte ist in der Falte, ungefähr in deren Hälfte, 
etwas vor dem ersten Discalpunkt, und trägt seine weisse Auszeichnung am hinteren Ende.

Diese Art hat die Grösse der N. verbascelle und ist in der Helligkeit und Mischung der Grundfarbe (blasslehıngelblich, blassochergelblich, blassröthlichochergelb), sowie in der Reichlichkeit der aufgestreuten braunen und schwarzen Stäubchen veränderlich. Immer bleibt der äusserste Vorderrand dieser Flügel von der Wurzel aus bis über die Mitte oder auch bis zum Anfange der Franzen hell und ungefleckt. Von den drei Punkten, die bestänlig grösser als die Stäubchen sind, ist der hinterste der grösste; der vor ilım im Mittelraume liegende ist zuweilen nicht kleiner als der in der Falte. Die schwärzlichen kleinen Punkte, nit denen der Hinterrand und das hintere Ende des Vorderrandes umzggen ist, werden durch die gelblichen Stellen in der Wurzel der Franzen gehoben.

Die Vorderflügel, 4-41/2" lang (bei einem Texaner nur $3^{1 / 3}$ ), sind breiter als bei Punctidiscellus, nach hinten sehr unbedeutend erweitert, mit deutlicher Spitze. Die Hinterflügel sind ansehnlich breiter, ohne Eindruck des Hinterrandes unter der Spitze, grau, in der Mittelzelle ein wenig durchscheinend, sehr zart beschuppt, welche Beschuppung sich in einem breiten Streif bis zum Hinterrande fortsetzt; nur ein breiter Vorderrandstreif ist gröber beschuppt und braunstaubig. Bei dem grössten Exenıllare, eiuen recht dunkeln, röthlich angelanfenen Weibchen aus Missouri, zeigt sich sogar auf dem linken Vorderflügel eine helle Querlinie, die dem Hinterrande näher als dem Queraderpunkt, ziemlich senkrecht steht und in der Mitte einen stumpfen Winkel bildet. Hier hat der erste Discalpunkt kein weisses Schüppchen an sich und ist etwas grösser als der Queraderpunkt.

Die Nebenaugen sind (durch Abreiben vermittolst einer Pinselspitze) am oberen Augenrande ganz deutlich. Die Fühler sind beim $Q$ feiner und dabei weniger deutlich geringelt als beim $\sigma^{\top}$. Die Hinterschienen sind auf der Aussenseite unterwärts braun, oberwärts und auf dem Rücken blondhaarig; die Dornen und Füsse braun. Der Bauch hat einen breiten, blassgelben Mittelstreif, der in der Mitte eine Rieihe schwärzlicher Fleckchen von verschiedener Deutlichkeit trägt.

\section{Vaterland: Ohio (Schläger), Texas (Boll), Missouri (Riley).}

A nmerkung 1. Clemens giebt den Vorderflügelu einen purpurfarbenen Anflug (pale brownish-ochreous with a purplish hue) und schwacher Bestïubung (slightly dusted with blackish). Ich habe unter sieben Exemplaren nur zwei $q$, auf welche Letzteres passt, und nur ein $\delta$ mit etwas röthlicher Beimischung. Clemens bat den ersten Discalpunkt ganz übersehen und bemerkt bloss an dritten Punkt Weisses (two or thre white scals on its interior margin).

Anmerknng 2. Dagegen habe ich zwei grüssere, wohl erhaltene $\sigma^{7}$ aus Ohio, auf welche das purplish hue vortrefflich passt. Die Vorderflügel (5'“ lang) sind etwas breiter und nach hinten mehr erweitert, dichter bestäubt. Bei dem einen ist die Falte fast in ihrer ganzen Länge als eine feine, weissliche, sehr auffallende Linie ausgezeichnet; bei dem zweiten ist vou ihr nur 
gegen die Mitte der Falte ein trïber gefärbtes Bruchstïck auf dem rothen Flügel zu entdecken. Die drei charakteristischen Punkte und mit ihnen die weissen Schüppchen fehlen sämmtlich; hüchstens lässt sich bei dem einen Exemplare auf der Querader in ler zusammenftiessenden dunkeln Bestäubung ein weissliches Pünlitchen auffinden, bei dem andern aucb dieses nicht. Obgleich der Banch ebenso gezeichnet und die Beschuppung der Hinterflügel nicht anders ist als bei Unicinunctellus, so scheint doch eine verschiedene, wenn auch sehr älnnliche Art vorzuliegen, für welche vielleicht, ausser dem Mangel der drei P'unkte, der Innenrand, der von der Hälfte an bis zu den Franzen in einer insserst feinen Linie blassröthlich ist, ein unteıscheidendes Merkmal abgiebt.

Nothris dolabella n. sp. Fig. 30.

Palporm articulo secumlo exterius praeter apricem fusco; alis ant. lutescentibus, inferius schistaceis, macula dolabriformi plicae superposita ante medium punctoque venae transversae nigris, fusciu marginis postici fusca interius vigro-marginata. $\sigma^{7}$.

Ohne Beachtung der Taster ist sie sehr leicht mit der etwas grösseren Gelechio (Malacotricha) bilobella zu verwechseln; im Falle, dass die Taster abgebrochen sein sollten, macht die Unterseite der Vorderflügel sie gegen diese kenntlich.

Rückenschild graugelblich, Kopf gran. Fühler weisslich und gran geringelt. Taster: zweites Glied durch seine Behaarung ein etwas schräggestutztes, zusammengedrïcktes Dreieck darstellend, aussen dunkelbraun mit Ausnalnme des hellgrauen Endes, imnen hellgrau, doch unterwärts schwarzgrau; Endglied ebenso lang, dünn, aufgerichtet, etwas gebogen, hellgelbgrau, an der Spitze und der Vorderseite der Wurzel schwarz. Beine gelbbraun mit bleichgelblichen Spitzen der Glieder; die Hinterschienen auf dem Rücken gelblichweiss und ebenso behaart. Hinterleib lehmgelblich, in der Mitte gebrännt; Banch mit schmalem, bleichgelblichem Mittelstreif, zu jeder Seite desselben braun. Afterbusch riemlich lang, fahlgelblich.

Vorderfingel $2 \%^{3}$ " lang, ziemlich schmal, hinten nicht erweitert, mit ziemlich abgerundeter Spitze. Die Grundfarbe ist in der Vorderrandhälfte, doch hinter der hobelfürmigen Zeichnung in geringerer Breite, bleich lehmgelb, übrigens hell schiefergran. Der Vorderrand ist mit braunen Punkten bestreut. Vor der Mitte lieg't auf der Falte die schwarze Hobelzeichnung; sie fängt nicht weit von der Wurzel an als eine sich zu einem ganz flachen Dreieck verstärkende Linie, die sich an ein transversales, oben etwas übergeneigtes und hinten concaves Dreieck anschliesst. Auf der Querlinie liegt ein schwarzer Querpunkt, an dessen Mitte vorn urd hinten je ein gelbes Pünktchen hängt. Den ganzen Endtheil des Flügels nimmt ein bindenförmiger, dunkel schieferbrauner Fleck ein, der einwärts einen in der Mitte etwas convexen, schwarzen Rand hat und durch eine feine, gelbliche Einfassung noch mehr von der hell schiefergrauen Grundfarbe absticht. Die grauen Hinterrandfranzen sind einwärts verdunkelt und mit einer verloschenen lieihe gelber Punkte gezeichnet. 
Hinterflügel breiter als die Vorderflügel, einfarbig grau; die Franzen mit einer sehr feinen, gelblichen Wurzellinie.

Unterseite der Vorderflïgel grau, am Vorderrande von der Mitte bis vor die Spitze mit einem hellgelben Wisch. Ast zwei nud drei sind weit von einancler getrennt. - Hinterflügel beller grau. am Vorderrande striemenartig loraun bestäubt.

Vaterland: Texas; ein ungewühnlich gut erhaltenes, von Belfrage am 24. Juni gefangenes $\sigma^{\nearrow}$ in meiner Sammlung.

\section{Dasycera Newmanella Clem.}

Thorace et capite cupreis, nitidis, yalpis vitellinis, antennis riolacenmigris, apice attenuato allo; alis ant. elongatis, nitidulis, nigro-violaeeis, vitha anrantiuce ex Insi ad medium prodncta, acrminuta, oblique nigro dissecta. o"

Das. Newmanellu Clem. ed. Staint. p. 252.

Clemens giebt unter den Gattungsmerkmalen die Vorderflügel als lanzettförmig an; sie sind es aber grade bei dieser einen Art in etwas höherem Grade als bei $D$. sulplurella, und da sie bei $D$. imitatrix etc. ganz abgerundet sind, so haben sie für die Charakterisirung der Gattung keinen Werth.

An lebhaftesten glänzen bei Newmanella der Kopf und die Schulterdecken. Die Taster sind fast so lang wie bei Sulphurellu und gegen die Spitze verdunkelt. Die Hinterbeine sind auf der Imnenseite glänzend ochergelb, auswärts nur an den Füssen. Der dünne Hinterleib ist dunkelgraubraun nit ochergelben. braun behaarten Genitalien.

Vorderflügel 4"' lang, ziemlich gestreckt, allmählich erweitert, vom Innenwinkel aus zugespitzt, ohne scharfe Spitze, etwas glänzend scbwarzviolett. Ton der Wurzel aus geht unterhaib der Subcostalader eine orangegelbe, sich zuspitzende Strieme bis wenig über die Flügelhälfte; von ihrer Hälfte an ist sie durch eine sehr schräge, am Anfang und Ende verdickte Linie der Grundfarbe durchschnitten, so dass Clemens zwei Streifen sieht (an orange-colonred stripe in the dist and a shorter one at the base of the wing in the fold and nearly joiviny the former); von ihrer Spitze aus sind bis gegen den Hinterrand einzelne orangefarbene Schuppen auf kupferigem Grunde gestrent. Franzen schwarz. Auf der Unterseite dieser Flügel ist keine Zeichnnng sichtbar.

Die schwarzen, etwas messingfarbig schimmernden Hinterflïgel haben, wo sie am breitesten sind, die Breite der Vorderflügel, verengern sich sanft nach linten und endigen in eine abgerundete Spitze.

Clemens hatte sein Exemplar aus Virginien. Das meinige erhielt ich durch Sclılïger ans Ohio, von wo er noch eins besass.

Oecophora determimatella n. sp. Fig. 31.

Alis ant. litacino-nigricantibus, fascia latissima ante medium maculaque costae postica inferius rotundata pullide aureis, niyro-terminatis. $0^{\lambda}$.

Nahe verwandt unit der folgenden nnd von der Grösse der kleinsten Exemplare derselben, auf den schwärzlichen Vorderfligeln mit einer sehr breiten 
hellgoldgelben Binde und einem grossen gleichfarbigen Fleck, der vom Vorderrand schräg einwärts herabhängt und unten zugerundet ist.

Rückenschild und Kopf brann. Fühler ebenso, nach oben sehr verloschen heller geringelt. Die. langen. dünnen Taster sind über den ganzen Kopf hinweggebogen; das zweite Glied answärts braun, innen ochergelb, das Endglied an der Wurzel und Spitze weiss. Vorderbeine braun, an den Fussgliedern mit heller spitze; die vier hintern Beine einwärts bleich ochergelb; die Hinterschienen auswärts am Enłle braun; die Fussglieder weisslich mit brïunlichen Enden. Hinterleib schwächlich, grau, mit ochergelblichem Analbusch.

Vorlerflügel 2"' lang, länglich, an der Wurzel verengert, hinten zugespitzt, violettschwärzlich. Vor der Mitte ist eine sehr breite, an Vorderrand etwas verschmälerte, blassgoldgelbe, anf beiden Seiten tiefschwarz gesänmte Binde, deren Innenraud ganz grade und deren Hinterrand convex ist. Der Flügelspitze etwas nüher als dieser Binde hängt vom Vorderrand ein einwärts erweiterter nnd zngerundeter Fleck bis in die Gegend des Innenwinkels herab; er ist gleichfalls hell goldgelb, auf dem Vorderrand selbst weisslich, und rings, ausser auf dem Vorderrand, tiefschwarz eingefasst. Die schwärzlichen Franzen haben an ter Flügelspitze einen kleinen, an Innenwinkel einen grössern gelblichen Wisch.

Hinterflügel etwas ïber halb so breit wie die Vorderflügel, lünglich eiförmig, zugespitzt, grau mit schwärzlichen Franzen.

Unterseite dunkelgrau; auf den Vorderflügeln scheint das untere Ende der Binde und das Costalende des grossen Flecks sehr verloschen durch.

Vaterland: Texas (Boll.) Ein $\sigma^{7}$ in Cambridger Museum. Da es nicht ganz frisch ist, so mag die Färbung des Vorderkörpers und seiner Theile etwas bunter sein, als sie beschrieben ist.

\section{Decophover Borlihausenii 7.}

Alis ant. lilucino-nigris, grosse squamatis, maculis 4 maximis (prima

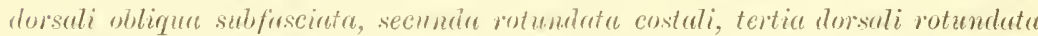
unte angulum. dorsalem, quarta posticu eacosta pendcute) ciliasque pallide aureis.

Herrich-achäfer Fig. $40 t^{\circ}$ (pessima). Heinemann Tin. S. 382.

Heinemanns Beschreibung genügt so wenig wie H.-Schäffer's Abbildung. Die Vorderflügel sind, wie Herrich-Schäffer richtig sagt, violettgrau, welche Farbe aber durch die grobe, schwarze Beschuppung fast ganz verleckt wird und einen geringern Raum einnimmt, als die vier grossen, hoclgoldgelben Flecke, deren Lage mul Gestalt Heinemann richtig angiebt; sie sind theilweise sehr fein weiss umzogen. Die blassgoldgelbe Farbe der Franzen ist nicht scharf vom Hinterrand abgeschnitten, und die des Vordsrandes sind fast bis zur Flïgelspitze braun. Die Grüsse der vier Flecke ändert etwas ab; wenigstens sind die des $\subseteq$ grösser, und der erste Costalfleck, (ler beim $\sigma^{\top}$ wohl immer vom Vorderrand getrennt ist, verbreitet sich bei diesem mehr oder weniger auf dem Vorderrand hin. Die stärkere Verbreitung gilt besonders von dem vorliegenden amerikanischen Exemplar, bei welchen anch durch die Breite des hintern Costalflecks die Grundfarbe 
zwischen den beiden Costalflecken ungewähnlich eingeschränkt wird. Uebrigens stimmt es so sehr mit den europẳischen Exemplaren, dass an Artverschiedenheit durchaus nicht gedacht werden kaun.

Vaterland: Die Gegend von Washington, wo Baron Osten-Sacken das in meiner Sammlung befindliche $q$ gefangen hat.

Anmerknng. Diese im nordöstlichen Europa sehr verbreitete, aber wohl äberall seltene Art sammelte ich bei Berlin (in der Nähe von Tegel im J. 1829), Frankfurt a. d. Oder, Glogan ${ }^{*}$ ) und Meseritz; Herr Büttuer bei Stettin, Schläger in Jena selbst, Erschoff bei Petersburg. Sie fliegt hauptsächlich im Juli; am frïhsten fing ich ein $O^{7}$ am 14. Juni, am spätesten Schläger das seinige am 19. Angust. Ihr Wohnort sind Kieferwälder, in denen sie an den dicken Stämmen unten sitzt oder von den dünnem aus der Höhe abgeklopft wird. Sehr wahrscheinlich lebt ilıe Raupe unter Kieferrinde. Die Erklärung des Vorkommens derselben Art in Nordamerika scheint etwas schwierig zu sein.

Oerophonu ronstrictella n. sp. Fig. 32.

Iutennis albo fuscoque rmmlatis; ulis ant.vehruceis, fascir ante medinm cinmmomen, exterizes albido-maiginatr, mucula costue postica ante lituram. exrlbillum eustalem apiceque cinnamomein; post. ungustrtis, ditute cinereis. or fo.

Keiwer europäischen Art ähnlich, wenn anch allenfalls neben Formosell. zu stellen, noch kleiner als Bonklunenenii und alle Oecophonen durch Schmalheit der Hinterflïgel ïbertreffend, doch wohl nicht, wenn das Geäder keine bedeutende Verschiedenheit nachweist, von ihnen abzusondern.

Rückenschild und Kopf hellochergelb. Fühler mit länglichem, dünnem, cylindrischem, hellochergelbem Wurzelglied und scharf weiss und braun geringelter Geissel. Taster so lang wie Kopf nud Rückenschild zusammengenommen, aufgebogen, diünn, ganz hell: das spitze Endglied etwas kürzer als die Hälfte des zweiten Gliedes. Beine sehr bleich ochergelb; an den vordern die Schienen nnd Füsse auswärts blassbräunlich gefleckt; an den hintern die Schienen durch lange Haare etwas verdickt und nebst den Fïssen verloschen gefleckt. Hinterleib grau ochergelblich, beim q zngespitzt ohne vorstehenden Legestachel.

Vorderflügel $13 / 4-2^{\prime \prime \prime}$ lang, ziemlich schmal, durch die Franzen scheinbar erweitert, zugespitzt, hell ochergelb. Nicht weit von der Wurzel ist ein fast senkrechtes, unter der Falte etwas auswärts gebogenes, schmales, zimmtbraunes Band; es ist gegen die Basis nicht schart abgegrenzt, nach aussen verdunkelt und scharf abgeschnitten nnd mit einer gelblichweissen Linie gerandet, welche sich auf dem Vorderrand bis zum Costalfeck verlängert. Dieser liegt hinter der Mitte, ist etwas dunkler als die Binde nnd einwärts nicht scharf begrenzt: ihm schliest sich ein weisshichgelber Costalwisch an, der sich schräg einwärts verdïnnt nnd, meln oder woniger verlöschend, fortsetzt und bisweilen bis zum

*) Was Heinemann's -Schwaitz" bedeuten soll, ist mir räthselhaft, da es in Schlesien, so viel ich weiss, keinen Ort dieses Namens gieht, und die Schweiz nicht als Vaterlaud der Art bekannt ist. 
Innenrand am Anfang der Dorsalfranzen verfolgt werden kann, wo cr dann basalwärts cinen dunkeln Schatten wirft. In Miltelram ist, wenigstens beim $\Omega$, unterhalb des dunkeln Costalflecks ein braunes Pünktchen sichtbas. Längs des Hinterrandes ist die Grundfarbe verdunkelt, melır noch in der Flügelspitze, und anf den Costalfranzen am meisten. Franzen gelblichgran, an der Flügelspitzc mit einem verwischten weissgelblichen Lüngsstrich.

Hinterflügel weniger als halb so breit wie dic Vorderflügel, lang zngespitzt mit gradem Hinterrand, seidenglänzend hellgrau nit gelblichgrauen Franzen.

Unterseite der Vorderflügel hellgrau ochergelblich, in der Spitze verdunkelt und mit verkleinertem, verloschen durchscheinendem Costalfleck.

Vaterland: Texas (Boll.). Ein $f$ in meiner Samminng, cin $f$ und $\delta$ (nebst noch mehrercn nach Dr. Hagens Angabe) in Cambridger Musenm.

\section{Butalis.}

Mit Stainton glaube ich, dass Matutella Clem. 1. 127 mit meiner Imposilellı (Linnaea ent. X, 1. 241) znsammenfällt. Mein bedeutend abgeriebencs Exemplar hat die Flecke in weisslicher, Bretulella in grünlich weisser Farbe. Der hintere Fleck - an Hinterrand oberhalb des Innenwinkcls - hat die Lage, die unter den bekannten Arten nur bei manchen Varietäten der Chenupodiella vorkommt (bei Cuspidellı Var. d ist er höher gegen đlie Flügelspitze hinaufgerückt). Clemens' Angabe on the inner margin kann nur ein Versehen statt on the hinder margin sein, wie das beigefügte near the apex -- was doch auch nicht in strengsten Sinne zu nehmen ist - beweist.

Flavifrontella Clem. p. 126 würde ich mit Stainton für meine Basilaris halten, weil die Flügelbeschreibung sehr gut zutrifft. Aber bei meinem Exemplare der Basilaris hat der Kopf eine fast so alunkle, nur in Gesicht nach unten hell schimmernde, Farbe wie das Rückenschild. Bei Flavifiontclla, die sogar den Namen nach der Gesichtsfarbe erhalten hat, sind head and face pale brownish-ochreous. Es ist aber wohl möglich, dass die Färbung des Kopfes bei Basilaris ebenso abändert wie bej Cuspidella. Clemens scheint jedoch, ungeachtet er mehrere Exemplare vor sich hatte, keine Veränderlichkeit wahrgenommen zu haben.

Fuscicomella Clem. p. 126 kann nicht mit meiner Eboracensis l. c. p. 205 einerlei sein, wie das tinted somewhat with yellowish der Vorderflügel bei jener lehrt. Da es in Norlanerica ohne ¿̈weifel nehrere einfarbige Arten giebt, so wird der Mangel genaner Angaben über Grösse, Hinterflügelbreite und Zuspiłzung, Beschaffenkeit des männlichen Hinterleibs dem Wiellererkennen dieser Fuscicomella manche Schwierigkeit bereiten.

\section{Trivinctella n. sp. Fig. 33 a. b.}

Minur, palpis breciusculis; alis unt. brunneis, busi pallide ochuecu, strign

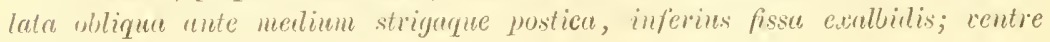
c.calbido, fasciculo anuli acuminato. $\sigma^{\top}$. 
Sie zeichnet sich vor allen Butaliden. durch dic trei hellen Bänder der Vorderfliggel aus, deren hinterstes die Besonderheit hat, dass es am unteren Fule gespalten ist und mit dessen vorderem Theil nur bis zur Falte reicht.

Grösse wie $B$. impositellu, neben welche die Art auch am besten gestellt wird. Rïckenschild hellgelbbramn, anf den Schulterdecken und dem Kragen leller schimmernd. Kopf hell-gelbbraun. Taster kaum von Rïckenschilllänge, schwach aufgekrümmt, dünn, spitz, anssen gelbbrüunlich, imnen weisslich. Fühler braun. Beine hell gelbbräunlich; Hinterschienen weisslich ochergelb. Hinterleil, mässig stark, braungrau, an len Seiten mit bellen Schmppenhöckerchen, am Bauch schmutzig weiss. Analbusch pyramidenförmig, gelblichgrau, anf der Unterseite bleichochergelb.

Vorderflügel etwas äber $2^{1} / 2^{\prime \prime \prime}$ lang, ziemlich schmal, spitz, gelbbraun mit drei hellen Querstreifen. Die Wurzel nimmt ein bindenartiger, hell ochergelber Fleck ein, der answärts convex und etwas eckig ist. Von 1/4 des Vorderrandes geht eine schwach nach aussen gebogene, weissgelbliche Qnerlinie nach dem Innenrande vor der Mitte. Mit ilı unterwärts stark convergirenıl läuft von $2 / 3$ des Vorderrandes ein fast weisser Querstreif herab, ler sich unterwärts sehr erweitert und unten so spaltet, dass das innere Ende auf der Falte ruht, das äussere aber in den Innenwinlel reicht, wo von ihm aus einige weissliche Iraarschuppen über die braungranen Franzen gebreitet sind.

Hinterfügel riel schmïler als die Vorderflügel, lang zugespitzt, dunkelbraun.

Von gleicher dunkelbrauner Farbe ist die ganze Unterseite; nur die VorderHïgel haben die Endhälfte des Vorderrandes in einer feinen Linie bleichgelb.

Vaterlaud: Texas (Boll). Ein $\sigma^{\top}$ in meiner Sammlnng, meluere übereinstimmende nach Dr. Hagen s Angabe im Cambridger Museum.

\section{Pilosella n. sp.}

Minor, alis ant. elongatis, hrumeis, triente postion pilis longis, flavidis dense obsito; pust. ungustioribus, sensim renminatis; ublomine non erusso, fiseo-cincreo, rentre flavescenti-nitidulo, fasciculo rnerli brevi, bipartito. ó.

Wegen der reichlich mit gelblichen Haarschuppen bestrenten Vorderflügel nit der gleichgrossen But. senescens zn vergleichen, aber mit viel gestreckteren Vorderflügeln. schmäleren Hinterflïgeln, dünnerem Hinterleib und in zwei Büsche getheiltem Analbusch. So wenig wie Senescens hat irgend eine kleinere oder grössere Butalis die letztere Beschaffenheit des Analbnsches. Piloscllu kamn, da sie nichts Violettrbrannes, ansser auf ler Unterseite der Flügel, an sich bat, nicht Fuscieumella Clem. sein. selbst wenn bei dieser der münnliche Analbusch ähnlich sein sollte, oder die beiden Geschlechter miissten sich ungewühnlich unterscheiden.

Rïckenschild und Kopf gelbbraun. Fühler borstenförnig, einfach, dunkelbraun. Taster von Rückenschildlänge, stark aufwärts gebogen, dünı, spitz, gelbbraun. Beine gelbbram; die Hintersehienen unbehaart, gelbiichschimmernı. Hinterleib ziemlich schmal, flach convex, dunkel braungrau, am Bauch mit langen, 
licht anliegenden, braungelblichen, schimmernden Schuppen bekleislet. Analbusch knrz, nicht reichlich, in zwei Büsche gespalten.

Vorderflügel $2^{1 / 2}{ }^{\prime \prime \prime}$ lang, schmal, braunerzfarben, mit nach hinten immer lïngeren, haarförmigen, bleichgelben Schnppen gedrängt bekleidet: unterhalb der Falte sind die Schmppen am gedrängtesten und weniger hell gefärbt. Franzen bramgrau.

Hinterflügel riel schmäler als die Vorderflügel, lang zugespitzt, branngran, wie die ganze, nur etwas violettschimmernde Unterseite.

Vaterland: Massachusetts, von woher ich durch Dr. Packard das einzelne of meiner Sammlung erhielt.

Anmerknng. Ich habe ein einzelnes $Q$ des Cambridger Mnseuns ans Texas vor mir. Es ist kleiner als Pilosella, mit noch schmäleren Hinterflügeh und kïrzeren, geraden, dïnnen, zngespitzten Tastern. Die Vorderflügel sind erzfarbig und hamptsächlich in der Falte mit bleichgelblichen Haarschuppen bestrent; da aber solche Haarschuppen auch am Innenwinkel und in der Flügelspitze vorhanden sinul, so ist es leicht möglich, dass bei noch besser conservirten Exemplaren sich anch anderwärts dergleichen finden. In der vertieften Falte zeigen sich übrigens ein paar durkle, fast schwarze Längsstreifen, die aber bei verändertem Lichteinfall gänzlich verschwinden milg folglich nichts als tiefer im Schatten liegende Stellen sind. Das abgestumpft kegelförmige Analglied, aus dem der Legestachel weit hervorsteht, ist schmäler als das vorhergehende Hinterleibssegment nind dunkelbraun; am Banch ist das letztere Segment trib und blassochergelb, und von ihm ans geht ein noch trüberer, sich alhmählig verengernder Streifen in der Banchmitte gegen die Basis. - Eine von Pilosella verschiedene Art ist diess gewiss: sie aber ohne Kenntniss des of $\mathrm{z}$ benennen, halte ich uicht für rathsam.

\section{Bululis Eborrerensis $1 / 1$.}

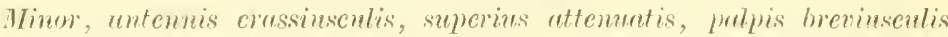
fere rectis; atis unt. snhelongatis, obsenre vinlaceo-fuscis; pusteriovibus angustionibus, sensim aenminatis; ablomine ơ cressinsculo, ntrimene violuceo-nigno, fascicnto anali atro, miloso, rotumitato, apice subemarginato; $\subseteq$ -

Limaer Entomol. X, S. 205.

Ein zweites gutes Exemplar nöthigt mich, die Diagnose darlurch etwas zu erweitern, dass ich die gegen das Ende verdiunnten Fühler und den kurzen. kräftigen Hinterleib mit seinem reichlichen, zngerundeten, am Ende in der Mitte schwach ansgerandeten Analbusch hervorhebe. Der etwas flache Hinterleib hat auch die Auszeichnung, dass an den zwei vorletzten Segmenten die Seitenschuppen etwas verlängert sind und zahnartig hervorstehen. Der Analbusch bildet bei diesem Exemplare nicht vier Partien, sondern ein Ganzes, das durch einen seichten Einschnitt in der Mitte, der auch bei dem andern vorhanden ist, eine tambenschwanzartige Gestalt erhält. Dasselbe Exemplar hat vor dem anderen entschieden dickere Fühler (also gegen das Ende mit noch auffallenderer Verdïnnung) voraus. 
Vaterland: ausser New-York auch Texas, von wo Boll nach Hagen's Angabe mehrere gleiche Exemplare mitbrachte.

Blastobasis Z. (1855. Linnaea ent. X, S. 171.)

Holcocer ${ }^{\circ}$ Clem. 1863 (ed. Staint. p. 225).

Clemens bebt, indem er die Gattung ausführlich charakterisirt, das Hauptmerkmal: die Krümmung und den Ausschnitt der männlichen Fülller ïber dem Wurzelgliede, mit Recht hervor. Er sagt: no ocelli, Heinemann: mit Neluenaugen; ich kann selbst bei der allergrössten, bei Bogotá durch Herru v. Nolcken entdeckten Art keine entdecken. Clemens vier Arten, deren Grösse nirgends angezeigt wird, sind nicht so beschrieben, dass ich sie wieder erkenne. Seine Chalcofrontella soll eine verïderliche Art sein; er scheint mir aber mehrere zusammenzufassen, die meiner Quisquitiella nahe kommen. Gilbociliella (?) liesse sich auf meine Livorella, Hodestella auf Nubilella deuten, wenn sie nur auf der Querader (welche über dem Innenwinkel liegt, und welche Cl. mit deu Worten: above the end of the fold bezeichnet) eine Zeichnung hätten. Obgleich ich viel Zeit und Mühe auf die Auseinandersetzung und Charakterisirung der mir vorliegenden Arten verwendet babe, so bezweille ich doch, überall das Richtige getroffen und das, was mir als Art erschien, unverkembar bezeichnet zu haben.

\section{1. sciaplitella n. sp. Fig. 34 .}

Alis unt. cinereis, area busuli postice abrupta maculaque costue triungula interius albido-marginata nigricantibus, pari punctorum supre anyulum internum nigro. $\sigma^{\top}$.

So gross wie die allergrösste $\boldsymbol{B l}$. phycidella H.-S. Fig. $\left.358^{*}\right)$, aber in Bau verschieden durch die breiteren Vorderflügel und durch die kürzer und eiförmig zugespitzten und daher weniger feinspitzigen Hinterflügel, dann auch von ihr und der in der Anmerkung erwähnten Art durch den dreieckigen, schwärzlichen Fleck abweichend, der am Vorderrand der Vorderflïgel häugt und mit der Spitze bis zur Falte herabreicht.

Rückenschild und Kopf gran, etwas fettglänzend. Fühler grau, ganz vom Bau der Phycidella, nämlich über dem verläugerten Wurzelgliede, welches vorn unterwärts einen Borstenkanm trägt, nit einer kurzen Biegung, und in dieser auf den Riücken mit einem Ausschnitt, in welchem ein nach vorn abgeschnittenes S'chuppenwulstchen liegt. Taster von Pückenschildlänge, dünn, etwas aufgerichtet; das zweite Glied anliegend beschuppt, braungrau, an der Spitze weisslich; das dünne, spitze Endglied halb so lang, gegen das Ende hell. - Brust weisshich. Beine braungrau, an den Spitzen der Schienen nnd Fussglieder weisslich; die Hinterschienen zusammengedrückt, auf bciden schneiden bräun-

*) Eine ganz ungenügenie AJbildung, in ler die Vorilerflügitl nicht schual und spitz genng sind, und the weissliche Binde einen scharften, ausspringenden Winkel bilden sollte, wodurch sie ler unten folgenden Segnella ähnich wird; für diese sind aber die Hintertïngel viel zu sthr zugespitat largestellt; aber dalurch zeigen sie eben, dass ll.-S. wirklich Playcidella vor sich hatte. 
lich behaart, aussen an der Spitze, auch an der Mitte auswärts mit einem bindenförmigen weissen Fleck; die Dornen weisslich. - Hinterleib kurz, staubgrau. ctwas schinmernd mit knrzem, gerundetem, weisslichem Analbusch.

Torderflügel $3^{1} / 2^{\prime \prime}$ lang, zwar ziemlich schmal, aber bis zum Innenwinkel fast gleichbreit bleibend und dann kürzer zugespitzt als bei Phycidclla, anf hellgranem Grunde reichlich mit feinen, schwärzlichen stäubchen bestreut. An der Wurzel ist ein schwärzliches Feld, das etwa $1 / 5$ der Flügellïnge einnimmt und hinten ziemlich gerade, wenn auch nicht scharf abgeschnitten ist. Etwas vor der Mitte des Vorderrandes hängt ein schwärzliches Dreicck, das auf der der Basis zugekehrten Seite verdunkelt, geradlinig und weisslich gesänunt, anf der hinteren Seite dagegen verloschen uud schlecht begrenzt ist; es erreicht mit seiner Spitze die Falte. Ihm gegenüber liegt am Innenrand ein schwärzlicher Nebelfleck, so dass das Ganze als eine in der Falte winklig gebrochene und unterbrochene, nach unten verengerte und verlöschende Binde angeseluen werden kann, die in ihrem oberen Theile anf der der Flïgelbasis zugewendeten Seite weisslich gerandet ist. Mitten zwischen dem Costaldreieck ond der Flïgelspitze zeigen sich über dem mit einem kleinen, dunklen Nebelfleck versehenen Innenwinkel zwei tiefschwarze Punkte dicht übereinander. Der Hinterrand ist kaum durch ein paar verloschene dunklere Schuppen (so dass also die schwarzen Punkte der Phycilella ganz fehlen) von den grauen Franzen geschieden.

Hinterflügel schnîler als die Vorderflügel, aber lange nicht so sehr wie bei Phycidella, nur am Endviertel zugespitzt, ohne scharfe Spitze, grau, etwas glänzend, gegen die Spitze dunkler. Franzen mehr staubgelbliclı und durch die gelbliche Wurzellinie scharf von der Fläche abstechend.

Unterseite einfarbig, auf den Vorderflügeln braungrau, auf den Hinterflügeln heller und glänzender als auf der Oberseite.

Vaterland: Texas (Boll). Ein gut erhaltenes ơ im Cambridger Museum.

Anmerkang 1. Wit dieser Bl. sciaphilella stimmt in Grösse und Ban ziemlich überein: Blastop. segnellu n. sp. ans dem südöstliclien Russland.

Bl. segmella: Alis ant. cinereis, fuscia ante modium fere vecta, albida, exterias frescia multo latione nigricante terminata, jari junctonum nigrorum supre angulum dorsalem in nebula albida transverse posito. . . (Fig. 35.)

Sie hat kürzere Flügel als Phycidella, aber nicht so kurze wie Sciaphilellı, mnd die hintern sind zwar auch etwas breiter nnd viel kürzer zugespitzt als bei Phycilclla, aber doch mit schärferer Spitze versehen als bei Sciupleilella. Was sie von der crsteren leicht nuterscheidet, ist die weissliche Binde vor ler Mitte der Vorderflügel; sie ist bei Segnella auf der dem Hinterrande zugervendeten Seite schwach conrex, fast geradlinig, statt einen scharfen Winkel zu bilden, und hiuter ihr folgt ein melır als doppelt so breites schwäıliches, hinterwärts gelichtetes und nicht deutlich begrenztes Band, wofür Phycidella nur ein schmales, aus Flecken zusammengesetztes hat. Nach diesen Bande folgt bei Segnella über dem Innenwinkel ein weisslicher, bindenförmiger Nebel; in ihın stehen zwei tiefschwarze Punkte ïbereinander, und über diesen trägt der Vorderrand ebenso wie unter ihnen der Innenrand ein schwärzliches, unbestimmt begrenztes 
Fleckchen. Der Hinterrand entbehrt der dicken schwarzen Punkte völlig, welche Phycidella hier zeigt. Das $q$ hat ein kegelförmiges Analsegment mit ochergelber Spitze und lang bervorstehendem Legestachel. Es wurde nebst mehreren von Christoph bei Sarepta am 10. August gefangen.

Anmerkung 2. Dieser Segnella sehr nahe kommt Bl. mbitella n. sp.

Alis ant. obscurius cinereis, striga obsoleta albida ante medium posita, in plica fracta, spatio post eam fusciae instar olscurato punctumque majusculum superius continente, pari punctorum nigrorum supra angulum dorsalem (Fig. 36). Ein $q$ ans Texas im Cambridger Nuseum.

Vorderflügel 4" lang; sie ist etwas grösser, mit breiteren Vorderflügelu und dünner zugespitzten Hinterflügeln. Bei ihr ist nicht sowohl eine weissliche Binde vor der Vorderflügelmitte, als eine weissliche Querlinie, die sich in der Falte in einen stumpfen Winkel mit ziemlich graden Schenkeln bricht; diese Querlinie ist auf der der Flügelbasis zugewendeten Seite nicht sonderlich scharf begrenzt, desto schärfer aber auf der abgewendeten; die dunkelgraue Grundfarbe verdunkelt sich nämlich an dieser am stärksten, indem sie fast eine Binde bildet, die sich jedoch nach hiuten lichtet und obne die mindeste scharfe Begrenzung in die Grundfarbe übergeht; in diesem dunkeln Faum ist ein bei Segnella ganz fehlender grosser, schwarzer, doch wenig auffallender Punkt in der Flügelhälfte mitten zwischen der Falte und dem Vorderrande. In der Gegend des Innenwinkels sind der Grundfarbe weissliche Schuppen beigemischt, und in diesem gelichteten Raum liegen über einer dunkeln Stelle des völlig obliteriıten Dorsalwinkels zwei scliwarze Punkte dicht über einander. Am Hinterrand sind keine lunkeln Punkte; die Franzen sind heller als die Grundfarbe.

Hinterflügel kaum halb so breit wie die Vorderflügel, messerförmig zugespitzt, doch ohme scharfe Spitze. - Das Analsegment des Hinterleibes ist gespitzt, der Legestachel verborgen.

Anmerkung 3. Ein kleineres amerikanisches 우 (Vorderflïgel $3^{\prime \prime \prime}$ lang) lïsst sich weder mit Nubilella, noch mit Segnelka vereinigen, weil die Hinterflügel noch schmäler und feiner zugespitzt sind als bei ersterer. Die VorderHügel dieser Bl. retertella $\boldsymbol{n}$. $3 \%$. sind nicht so dunkel wie bei Nulvillu (doch wohl etwas rerflogen, wie die schlechte Beschaffenheit der Frauzen andentet); der weisse Querstreif ist nur nach aussen convex, etwas wellig, breiter, gegen die Wurzel durch einen aus schwarzen Schuppen gebildeten Nebelfleck begrenzt. Der schwarze, starke Punkt in der Flïgelınitte ist vorhanden. Statt der zwei schwarzen Punkte ïber dem Innenwinkel zeigt sich nur ein dickes Querstrichelchen. Der Hinterrand ist nur verdunkelt, ohne schwarze Punkte. - Der lange Legestachel ist pfriemenförmig und platt gedriickt. - Belfrage fing das in meiner Sammlung befindliche Exemplar am 29. August.

Ein ron Boll ans Texas mitgebrachtes unverflogenes Exemplar von fast gleicher Grösse, aber verstümmelten Fühlern und ohne Taster und Hinterleib, scheint uicht zu derselben Art zu gehüren, weil die Hinterflïgel breiter und stumpfer endigen. Statt der weisslichen Querlinie ist hier auf den Vorderflügelı eine wirkliche Binde, nur auf der Basalseite ohne scliarfe Grenze, auf der ab- 
gewendeten Seite wie bei Retectellu begrenzt. An diese Seite stösst, wie bei Phycidella, ein schwarzer Längsstrich in der Flügelfalte, der aber aus der dunkeln Färbung wenig hervortritt, während der schwarze Punkt in der Flügelhälfte dick und deutlich ist. Im Immenwinkel, doch etwas von ihm entfernt, ist ein schwarzes Fleckchen, und darüber, mehr einwärts, ein dicker, tiefschwarzer Querpunkt, beide ziemlich uahe an einander reichend, und über diesem Punkt, doch etwas linterwärts, zeigt sich auf dem Vorderand eine dunkle Stelle.

\section{Fractiliner n. sp. Fig. 37.}

Parva, alis ant. breviusculis, canis, striga ante medium albida, in angulum fracta, postice nigricunti-maryinuta, juncto disci prosteum striguluque venae transversae inferius incrassata niyris. o'.

Die zwei ziemlich gut erhaltenen ठ Exemplare meiner Sammlung sind so gross wie Roscidella, mit kürzeren Vordeıflügeln und viel hellerer Grundfarbe als die vorigen Arten und mit scharfem Winkel der weisslichen Querlinie.

Die Taster sind fast wie bei Retectella, doch etwas kürzer, auswärts schwarzbraun, am Ende des zweiten Gliedes bleichgelblich; das Endghied ist nicht so fein gespitzt wie dort, pfriemenförmig, an der spitze weniger bell. Der Hinterleib breit wie dort, daher plumper als bei Phycidella, bleich gelbgrau mit hellerem Bauch.

Vorderflügel $2 \frac{1}{2}{ }^{\prime \prime \prime}$ lang, breit und stampf wie bei Sciaphilella, weisslichgran, mit schwärzlichen Stäubchen mässig bestreut, an dichtesten an der Basis, an der Endhälfte des Vorderrandes und un die Flügelspitze herum längs des Hinterrandes. Die weissliche Querlinie bildet bei dem einen Exemplar den sehr antfallenden Winkel in der Falte, bei dem andern etwas darüber, so dass bei jenew der abere, bei diesem der untere Schenkel des Winkels der längere ist; sie wird gegen die Flügelbasis zu durch schwärzliche Stäubchen, die sich vorzüglich dem Winkel gecenüber zu einem Nebelfleck verdichten, unvollkommen begrenzt, während sie nach aussen schwärzlich gesäunit ist; der breiteste schwarze Saum ist am obern Schenkel. Hinter der Spitze des Winkels, doch etwas höher, liegt in hellerem Grunde ein schwarzer Punkt. Anf der Querader sind zwei schwarze Punkte zu einem schwarzen, unten verdickten Querstrich zusammengeflossen, der bis nahe an den Innenwinkel reicht.

Hinterflïgel kaum halb so breit wie die Vorderfligel, gleichmässig zugespitzt, mit scharfer Spitze und ziemlich gradem Hinterrand, braungran; die bellen Franzen sind durch eine feine, gelbliche Basallinie vou der Flügelfläche getrennt.

Beide ơ wurden durch Belfrage in Bosque County in Texas am 1. und 19. August gefangen.

\section{Quisquiliella n. sp.}

Alis ant. unicoloribus, yriseo-fuscescentibus, atomis nigris frequentibus inspersis, mucto disci ante medinm parique punctorum disci postici nigris. of \&. 
Ohue Beachtung der generischen Auszeichnung der of Fühler und der messerfürmigen Hinterflügel würde man diese unscheinbare Art allenfalls für eine Gelechio ans der Verwandtschaft der Notatella halten; sie weicht aber nebst der folgenden Livorella nicht nur durch den Mangel der typischen helleu Binde $a b$, sondern auch durch die in $q$ Geschlecht merklich breitern und stumpfern Hinterflügel. Letzteres ist so auffallend, dass die Frage aufgeworfen werden kann, ob die beiden Geschlechter wirklich znsammen gebören; aber sie stimmen im übrigen zu sehr überein, als dass ich sie nicht für einerlei Art halten sollte.

Grösse der Sciaphilella. Rückenschild bräunlichgrau, mehr oder weniger ins Bleichochergelbliche, was entschieden die Farbe des Kopfes ist. Fübler braungrau; Wurzelglied und die Schuppen auf dem gebogenen Theil der Geissel ganz lıllgelblich. Taster stark anfwärts gekrümmt und bis über die Stirn reichend, ziemlich dünn, gleichmässig zugespitzt mit feiner Spitze, bleichgelblich, auswärts braun. Saugrüssel zusammengerollt, bleichbeschuppt. Beine bleichgelb, auswärts gebräunt; Hinterschienen kräftig, zusammengedrückt, auf dem Rücken mit langen, blonden Haaren, auswärts vor der Mitte mit einem dunkelbrannen Bändchen ror einem hellgelblichen Fleckchen, von da ab dunkelbrann bis zur hellgelblichen Spitze; die Füsse auf dem Rücken braun mit hellen Enden der Glieder. Hinterleib staubgran, am Bauch hell in; Gelbliche mit braunen Seiten; Analbusch des $\sigma^{7}$ bleichgelblich, Analsegment des $q$ kegelförmig, an der Endhälfte ochergelb, mit etwas bervorstehendem Legestachel.

Vorderflügel 4"“ lang, von der kurzen Gestalt der Sciaphilella, gelblichstaubgrau, sehr reichlich braun bestänbt und dadurch etwas wolkig, mit mehr oder weniger hervortretenden gelblichen Stellen. Im Mittelraum ist vor der Mitte, der Querader näher als der Flügelwurzel, ein schwarzer Punkt, und über ihm trägt der Vorderrand gewöhulich einen dunkeln Nebelfleck. Auf der Querarer sind zwei eben so deutliche, von einander getrennte Punkte, der untere etwas grösssr als der obere. Franzen grau mit gelblicher Wurzellinie, von welcher ans, mehr oder weniger dentlich, sehr kleine, gelbliche Ecken, die nach innen dunkel begrenzt werden, in den Hinterrand hineinreichen; hinter dieser Wurzellinie sind sie von eiver dunkler grauen Schattenlinie durchzogen.

Hinterflügel etwas über halb so breit wie die Vorderflïgel (beim o noch unehr) zugespitzt, mit sanft convexem Hinterrand; beim $f$ enden sie in eine breitere Spitze. Grundfarbe gran, beim $\&$ bräunlichgrau. Franzen mit feiner hellgelblicher Wurzellinie.

Unterseite braungran; Hinterflügel gegen den Analwinkel gelichtet.

Vaterland: Texas (Boll). Zwei $\sigma^{\top}$ in meiner Sammlung, ein $\sigma^{\top}$ zwei $f$ im Cambridger Museum.

\section{Tivorella n. sp.}

Alis ant. angustis, osseo-griseis, puneto parvo infra basim costalem, majore disci ante medium marique punctormn venae transversae nigris; post minus longe acuminatis. $\sigma$. 
Viel heller als die andern Arten, anf' dem ganzen Vorderkörper und den Vorderflügeln sehr blass, beingelblichgrau, auf den letzteren olme helleren Querstreifen.

Kleiner als Phycidella. Der Vorderkörper und das dünne, verlängerte Wurzelglied der Fülller nebst dem Schuppenbusch im Ausschnitt derselben schmntzig beingelb, mit Grau gemischt. Gesicht in gewisser Pichtung weisslich. Fühlergeissel dünn, borstenfürmig, grau. Taster selır hell, von Rückenschildlänge, aufwärts gebogen, dünn, gleichmässig zugespitzt; das Endglied etwa halb so lang wie das zweite Glied. Beine wie das Pïckensclitd gefärbt, mur die vordern anf der Vorderseite etwas gebrännt; die Hinterschienen dünn, schwach behaart; die Füsse ungefleckt. - Hinterleib kurz nnd schwäclllich, grau, mit hellerem Analbusch.

Vorderflügel $3^{\prime \prime \prime}$ lang, schmal, nicht erweitert, am verdünnten Ende etwas abgerundet, von der bleichen Farbe des Rïckenschildes. Nahe der Basis liegt unterhalb des Vorderrandes ein wenig deutlicher, schwärzlicher Punkt. Fin viel grösserer, selır dentlicher, länglicher schwarzer Punkt ist im Mittelraum vor der Flïgelhälfte, der Falte viel näher als dem Vorderrande. In der Mitte zwischen ihm und der Flügelspitze zeigt sich auf der Querader ein Paar schwarzer Punkte dicht bei einander, und über dem obern bilden schwarze Schüppchen eine wenig merkliche kurze Längslinie. Franzen hellgrau.

Hinterflügel bis zur Hälfte nur wenig schmäler als die Vorderflügel, dann sanft verengert und in eine deutliche, doch nicht lange Spitze auslaufend, sehr hell staubgrau, etwas glänzend, gegen die Wurzel gelichtet. Franzen hell, ins Gelbliche.

Unterseite der Vorderflügel einfarbig grau, am Innenrand hell; Hinterflïgel wie oben, doch längs des Vorderrandes verdunkelt.

Vaterland: Texas (Boll). Ein $\sigma^{\nearrow}$ in meiner Sammlung, mehrere mit ihm übereinstinmende nach Dr. Hagens Angabe im Cambridger Museum.

\section{Blastobasis (?) rufugella n. sp.}

Minuta, antennis crassiusculis, supm articulum basalem squamis ampliatum non excisis; alis ant. cinereis, fascire obscura post strigam albidam leviter fractam, puncto nigro grosso in fascia punctisque lluobus geminatis vonae transversae nigris; post. lineari-lanceolatis. $\sigma^{7}$.

Nicht grösser als Roscidella*) und Fluxella, hat sie so wenig wie diese über dem Wurzelgliede der Fülrler einen Einschnitt und entbehrt also des charakteristischen Merkmals der Gattung Blastobasis, wälırend sie in Habitus, Färbung und Zeichnung ganz mit Phycidella, Sciaphilella ete. ïbereinstimnt. Es wird wohl erst durch eine genaue Untersuchung des Geäders entschieden werden, ob die drei Arten ungeachtet ihres Aussehens zu Hypatima zu stellen, oder ob

*) In H.-S. Fig. 985 ist der helle Querstreifen zu rein weiss, und auf der Querader fehlt der duukle Strich. Auch sollte der Hinterflügel gegen die Wurzel zu etwas breiter werden und einen stumpfen, doch deutlichen Analwinkel zeigen. 
ïberhaupt Blustolsasis und Iypatima zu einem Genus zu vereinigen sind. Einstweilen betrachte ich sie lieber als eine Abtheilung von Rlastobasis mit uneingeschnittenen Fühlern, die dicker sind als sonst in beiden nächstverwandten Gattungen.

Von Roscidella unterscheilet sich Aufugella sogleich durch ihre viel schmälern Hinterflügel, ausserdem durch den starkeu, schwarzen Pmit anf ren Vorderflügeln gleich hinter dem weisslichen Querstreif ïber der Falte; vou Fluxella gleichfalls durch die Hinterflügel und auf den Vorderflügeln durch den sehr stumpfwinklig gebrochenen hellen Querstreif und die Stärke des schwarzen Punktes dahinter.

An den starken, mikroskopisch flaumbaarigen, braungranen Fühlern ist das Wurzelglied durch hell gelblichgraue Schuppen zu einer runden Scheibe erweitert; der Vorderrand dieser auf der ausgehöhlten Unterseite gelblichern Scheibe ist mit abstehenden Haaren besetzt. Die Taster sind sehr kurz, nur yon halber Kopflänge, bleichgelblich, verdickt, mit feinem Endgliede. Beine aussen braun, an den Spitzen der Fussglieder bleichgelblich; die Hinterbeine auf der Innenseite bleichgelblich. Hinterleib hell braungrau, etwas schlanker als bei Roscidella.

Vorderflügel $2 \frac{1}{4}{ }^{\prime \prime}$ lang, schmal, hellgrau mit dunkler Bestäubung, am dunkelsten in der Binde hinter dem weisslichen, weniger als halb so breiten, schwach winkelförmig gebrochenen, unten etwas erweiterten, weisslichen Querstreif. Der undentliche, schwarze Doppelpunkt der Querader liegt in einem schmalen, dunkeln Quernebel, vor und hinter dem der Grund fast weisslich gelichtet ist.

Hinterflügel linear lanzettlich, auf dem Basaldrittel am breitesten, von da ab gleichmässig lang- und fein zngespitzt; der Analwinkel sehr undeutlich. Vaterland: Texas (Boll). Ein ơ im Cambridger Museum.

\section{Blastobusis (?) Auxella n. sp.}

Minuta, antennis crassiusculis, supro articulum basalem squamis ampliatum non excisis; wis ant. cinereis, strigu ante medium fracta, albida, exterius nigricanti-marginala, puncto disci punctisque duobus geminatis venue trunsversae coalescentibus nigis; post. lanceolatis. ${ }^{7}$.

Ton der vorigen leicht durch die breitern Hinterflügel und die drei bis viermal so langen Taster zu unterscheiden, kommt sie der Rl. fiactilinen in der Zeichnung nahe; sie ist aber kleimer, mit schmäleren Hinterflïgeln und dïnnerem Hinterleib und hat ausserdem in den Fühlern keinen Einschnitt.

Die Fühler sind etwas dicker und heller als die der Aufagella, übrigens gleich gebaut. Die Taster, schlanker als bei Fractilinea, haben Rïickenschildlänge und sind aufwärts gebogen, innen lichtgrau, auswärts bräunlich angeflogen; das Endglied weniger als halb so lang wie das zweite Glied, dünner und zugespitzt. Beine viel heller als bei Aufugella, weisslichochergelb; die hintern an den Schienen reichlich langbehaart, auswärts wenig verdunkelt; die Hinterfüsse auswärts hellbräunlich mit weisslichen Enden der Glieder. Hinterleib schmal, 
gran, an den Seiten der hintern Segmente bleichgelhtich behart Anabusch bleichgelblich.

Vorderflügel 2\%" " lang, sehr wenig breiter als loei Anfugellı, grau an len Rïndern an dmbelsten. Der weissliche Querstreifen bricht sich über der Falte in einen dentlichen Winkel und ist nach aussen schwärzlich gerandet.

Vor ihm liegen in der Falte ein schwärliches Fleckchen und dicht darunter ein solches längsstrichelchen, und hinter ihm, gleich ïber der Spitse des Winkels im hellen Grunde ein scharfer, sehwanzer Punlit. Anf der Querader sind zwei schwarze, zusammenfliessende Punkte, unter denen im Innenwinkel ein sehwärzliches Fleckehen liegt. Den Hinterrand trennen sehwarze, unregelmässige, aber nicht zusammentiessende Punkte von den Franzen.

Hinterflïgel etwa halb so breit wie die Vorderfügel, lanzettförmig. seharf zugespitzt, mit deutlichem Analwinkel.

Vaterland: Texas (Boll). Ein gut erhaltenes of im Cambridger Masemm.

\section{Hylutima subsenella n. sp.}

Alis ant. canis, postice obscurioribus, striola plicae, puncto disci ante medium, puncto venne transversae striolaque his interjecta nigris, maculis dualus oppositis ante medium nigricantimes. o'.

Diese Art bat einigermassen das Aussehen einer Blastolusis, aber an den nännlichen Fühlern keine Spur eines Ausschnittes. Sie stimmt mit Hyp. linotell in der Lage der sehwarzen Costalpnnkte und Striche anfiallend; nur ihre Hinterflïgel sind weniger breit und stumpf und dabei Iänger gefranzt; auch seheint der Haarpinsel an der Tasterwurzel zn fehlen.

Rüekenschild und Kopf weisslichgrau. Fühler grau, stark; das Wurzelglied oblong, ganz flach, weisslichgran, vorn mit Borstenkamm. Taster von Rüekenschildlänge, stark aufwärts gekrümmt, ziemlich sehlank; das zweite Glied answärts braun, am Ende weisslich; das Endglied ïber $2 / 3$ so lang, spitz, weisslich, in der Nitte mit brännlichem Fleck. Saugrüssel von Hinterleibslänge. Beine innen weisslieh, answärts braungrau angelanfen, an den Enden der Fussglieder hell; die Hinterschienen kräftig, stark zusammengedrückt. an der Mitte und am Fnde auswärts mit einer hellen Stelle, auf dem Rücken blondhaarig, auf der Innenseite bleiehgelblich. Mittelbrust weisslich. - Hinterleib klein, dunkelgrau, an Bauch bleichgelblich wie der kleine Analbusch.

Vorderflïgel $3^{\prime \prime}$ lang, ziemlich schmal, hinten zngespitzt, weissgran, in der Spitze verdunkelt. Die Schulter fleckartig dunkelgran. Der Vorderrand trägt hei $1 / 3$ cinen rerloschenen, sehwärzliehen Fleck; ihm gegenüber der Immenrand cinen grösseren, blässcren, etwas weiter gegen die Basis reichenden, der auf dieser Seite sehräg abgeschnitten ist nnd an den schwarzen Längsstrich der Falte stösst. Schräg über unl hinter dem Ende dieses Strichs ist im Mittelfelde ein schwarzer Punkt. (Diese zwei Gegenflecke, der Discalpunkt und der Faltenstri,h, bieten eine der bej Blastobusis gewöhnlichen entsprechende Zeichnnng, indem eine sie verbindende Qnerlinis eine gebrochene Qucrlinie bilden würde, deren Seheitelpnnkt in dem Discalpunkt läge.) Hinter dem sehwarzen Punkt folgt in 
gleicher Höhe ein schwarzes Längsstrichelchen und auf der Querader ein kleiner schwarzer (auf dem linken Flügel verdoppelter) Punkt, über und miter welchem die Grundfarbe etwas verdunkelt ist. Am Vorderrande sind schwarze Schuppen deutlicher als am oberen 'Theile des Hinterrandes zu unregelmässigen Punkten angehäuft. Franzen grau, un die Flïgelspitze mit hellen und dunkeln Stäubchen bestreut.

Hinterflügel vor der Mitte etwas schmäler als die Vorderflügel, von da ab alhnälig zugespitzt, mit sanft convexem Hinderrand, grau; die wie bei Blastol,asis langen, staubgrauen Franzen haben eine feine, bleichgelbe Basallinie.

Unterseite einfarbig, auf den Vorderflïgeln bräunlichgrau, auf den Hinterflügeln grau.

Vaterland: Texas (Boll). Ein $\sigma^{\top}$ im Cambridger Museum, bei welchem ein Theil des Vorderrandes der Hinterfügel umgeschlagen ist, wodurch sie schmäler zuzulaufen scheinen, als es in der Wirklichkeit der Fall ist.

A umerkung 1 . Ein etwas verwischtes kleineres $q$ (Vorderflügel $2^{2} / 3^{\prime \prime}$ lang) aus Texas - Confectella n. sp.? - seheint gar nicht dazu zu gehören wegen seiner ganz schmalen Hinterflügel, die nirgends die halbe Breite der Vorderflügel haben und in eine schärtere spitze auslaufen. Sollte das Exemplar doch zu Subsenella gehören, so wäre die Verschiedenheit in der Hinterflügelbreite eine Abweichung in diesem Geuus, indem beide Geschleehter darin sonst keinen merkliehen Unterschied zeigen. Die Vorderflügel haben einen gelbliehern Ton des Hellgrauen. Die Basis des Vorderrandes ist ganz unverdunkelt. Statt des trsten Costalfleks ist eine sehr dünne Costallinie sichtbar; das Faltenstriehelchen über dem weiter gegen die Wurzel reichenden Dorsalwisch fehlt, während weiter gegen die Wurzel ein längerer, schwarzer Streifen vorhanden ist, von dem Subsenella keine Spur zeigt. Dafür fehlt der Längsstrich vor dem Punkte der Querader gänziich, und der Queraderpunkt hat noch einen kleineren ganz deutlich über sich. Einzelne dieser Abweichungen mögen durch Abreiben t.ntstanden sein; aber die Hinterflügelgestalt und die Grundfarbe der Vorderflügel ist so auffallend, dass ich das Exemplar benenne, obgleich ich im Ban ler Taster und Fühler nichts Abweichendes von Subsenella sehe.

Anmerkung 2. Zwei o aus Texas stimmen in der Grundfarbe der Vorderflügel ınit dem eben eliarakterisirten $Q$, aber in der Hinterflügelform mit Subsenella, und da beider Zeichnung unter sich etwas verschieden ist, so künnten sie wohl alle drei zusammen einer veränderlichen Art angehüren. Bei den einen der beiden Exemplare ist die Schulter und zugleich die Basis der Vorderflügel verdunkelt. Der Discalpunkt, der zu den vier eine winklige Querreilıe bildenden Zeichnungen gehürt, ist zu einen Längsstrich ausgezogen. Näher der Flïgelbasis sind noch zwei schwarze Längsstriche: einer nahe am Ymenrande, einer in der Falte, und bei dem einen Kxemplare liegt sogar noch ein kürzerer dielit über der Falte. Der sehwarze Disealstrich vor den zwei sehr deutlichen Queraderpunkten ist bei dem cimen Exemplare kürzer als bei Subsenella, aber auch tiefschwarz; dagegen bei dem zweiten ist er in ein schwaches Pïuktchen verwandelt. Gleichsam als Ersatz dafür ist gleieh hinter den Queraderpunkten ein 
recht dunkler Costalfleck, von dessen unterem :Fnde ein schwärzlicher Staubstreifen bis über den ersten Discalstreifen zieht.

\section{Argyresthia Anderegyiella F. R.}

- F. v. R. Beiträge S. 209. Taf. 74, Fig. 2.

Argyr. Oreasellı (!) Clemens 1. c. p. 93.

Mein einzelnes americanisches Exemplar ist etwas kleiner als die aus der Schweiz und steiermark (wo ich ein $\subseteq$ zu Ende Juli bei Bruck a. d. Mur fing) und weicht von ihnen, in Uebereinstimmung mit der Clemens'schen Angabe, darin ab, dass ein hell goldbräunlicher Schattenstreif, der aus der Schulter konmt, unterhalb des Vorderrandes bis zur Binde hinzieht, während bei jenen die weisse Farbe entweder rein bleibt oder sehr blass gelblich angelaufen ist. Die Mittelbinde ist wie bei jenen, verdünnt sich also nicht gegen den Vorderrand (tapering to the costa, sagt Clemens). Die Zeichnung der Flügelspitze ist in Clemens' Beschreibung (in welcher olnedies statt behind which wie anderwärts before which zu denkt'n ist.) nicht recht verständlich; sie ist in F. R.'s Bild auf Taf. 74 recht gut gegeben.

Vaterland: Pennsylvanien (Clemens), Ohio (Schläger).

\section{Argyresthia quadristrigella n. sp.}

Thorace nitido capillisque flavidis; alis ant. nitidis, exalbidis, basi fasciisque angust is distinctissimis quatuor ferrugineis. $\sigma^{7}$.

Eine kleine Art, keiner europäischen ähnlich, an den vier rostfarbigen Binden der gelblichweissen, glänzenden Vorderflügel leicht kenntlich. Ihr Platz ist wohl am besten bei Goedartella und Pygmäiella.

Grösse der drei folgenden Arten. Rückenschild hell goldfarben, glänzend. Kopf anch im Gesicht blassgelb. Die dünnen Taster mehr weisslieh, so wie das Wurzelglied der schwarz unil weisslich geringelten Fühler. Die vier vorderen Beine brïunlich angelanfen, an den Füssen dunkler; die Hinterbeine weisslich, an den Enden der Fussglieder bräunlichgrau. Hinterleib lehmgelb, hier und da mit glänzenden, weisslichen Schuppen; Bauch blassgelblich, Analbusch weisslich.

Vorderflügel 2"' lang, ziemlich schmal, nicht erweitert, an Ende wenig verengert mit abgerundeter Spitze, glänzend, mit gelblichweisser Grundfarbe, an der Wurzel ohne scharfe Begrenzung rostfarbig, darauf mit viel sehr scharfen, streifenförmigen Binden von gleicher Farbe in ziemlich gleichen Abständen von einander: die erste bei $1 / 4$ der Iänge, über der Falte zu einem schwachen Winkel nach anssen gebogen; die zweite vor der Mitte, gerade; die dritte in der Flügelhälfte, nicht ganz gerade; die vicrte vom Anfang der Costalfranzen lierabkommend. Vor der Flügelspitze ist noch ein ganz verloschenes, kaum kenntliches, rostfarbenes Querstreifchen. Franzen lieller als die Grundtarbe.

Hinterflügel hellgran. Unterseite der Vorderflügel gelblichgrau: die vier

Binden scheinen etwas breiter und in verdunkelter Farbe sehr verloschen durch. Vaterland: Texas (Boll). Ein schönes of im Cambridger Musenm. 


\section{Argyresthia deletella n. sp.}

Capillis allis; alis ant. luteolis, dorso lutius pallide flavido, strigulis dispersis maculaque angustata dorsali post medizm brunneis. OT $\$$.

Von verloschenem, lehmgelblichem Aussehen, etwa bei Curvella zu stellen.

Kopf fast weiss, Gesicht gelblich. Taster dünn, weisslich. Eühler schwarz und weisslich geringelt. Rückenschild bleich lehmgelblich. Hinterbeine schnnutzig weiss, die Schienen und Fussglieder an den Enden mit je einem brannen Punkt. Hinterleib bräunlichgrau mit hellerem Analbusch.

Vorderflügel 2"' lang, wach hinten rerengert, schwach schimmernd, an Vorderrande hin, nach hinten in zunehmender Breite und Dunkelheit hell lehnıgelb, längs des Innenrandes bis über die Falte hinweg, ohne scharfe Grenze gegen die lehmgelbe Farbe, sehr blass, weissgelblich oder gelblich, auf der ganzeu Fläche, am meisten an den Gegenrändern, mit gelbbräunlichen, etwas verloschenen Querstrichelchen bestreut. Am Anfang der Innenrandfranzen, also an der Flügelhälfte, steht auf dem Innenrand ein schmalbindenfürniges, in der Breite etwas wechselndes, gelbbraunes Fleckchen, dessen oberes Ende in dem Lehmgelblichen, weit unterhalb des Vorderrandes verschwindet, und das sich überhaupt beim Fangen leicht verwischt. Vor der Flügelspitze trägt der Vorderrand bisweilen 2-3 ganz verloschene, helle Häkchen. Die Flügelspitze ist mit einer gelbbraumen, gekrümmten Linie umzogen, hinter welcher die sonst bleichgelblichen Franzen gleichfalls verdunkelt sind.

Hinterflügel grau mit gelblich schimmernden Frauzen.

Unterseite der Vordenflügel etwas dunkel gelblichgrau, in der spitze und deren Franzeu graubraun.

Vaterland: Texas (Boll). Hier scheint die Art nicht gerade selten zu sein. Mehrere Exemplare in meiner Sammlung und im Cambridger Museum.

\section{Argyresthia austerella n. sp. Fig. 38.}

Capite, thorace alisque ant. niveis, harum costa nigro-conspersa, fascia abbreviatu unte medium, fasciu integra media oblique retroversis apiceque albido-maculato nigris. ơ 9 .

Völlig ohne Glanz, durch ihre oben schräg überhängenden anderthalb schwarzen Binden auf den schneeweissen Vordertlügelı sehr ausgezeichnet. sie ist schwer unter die Europäer einzuordnen, vielleicht noch an ersten bei Retinella.

Grüsse der Deletella. Rückenschild und Kopf schneeweiss. Taster dünn, weiss, am Endglied aussen dunkelgrau. Fühler schwarz, sehr fein weisslich geringelt nit rein weissem Wurzelglied. Beine weisslich mit schwarzen Flecken. Hinterleib grau mit weisslichem Analglied; Bauch weisslich mit weissen Hinterräudern der Segmente.

Vorderflügel 2"“ lang, ziemlich schmal mit convexem Vorderrand, ohne Glanz, schueeweiss mit schwarzer oder schwarzbrauner Zeichnung. Der Vorderrand ist von der. Wurzel aus in zunehnender Breite mit groben, schwarzen, 
mehr oder weniger zusammenfliessenden Querstrichen bestreut, zwischen welchen die weisse Grundfarbe als Punkte oder schräg rückwärts gerichtete Querstrichelchen hervortritt, letzteres am meisten gegen die Flügelspitze. Vor der Mitte kommt vom Vorderraude ein dicker, schwarzer Querstreifen herab, welcher etwas schräg rückwärts gerichtet ist und an der Falte endigt oder ein wenig über sie wegreicht. Eine breitere, jenem parallele Binde zieht vom Vorderrande hinter der Mitte herab, verdünnt sich meistens nach unten und endigt auf dem Innenrande am Anfange der Franzen; sie ist auf dem Vorderrande mit ein paar weissen Punkten bezeichnet. Der Raum hinter ihr in der grösseren Costalhälfte schwarz und wie oben angegeben weiss gestrichelt; zwischen dem Hinterrande und dem unteren Theile der Binde bildet die weisse Farbe ungefähr ein Dreieck, welches auf der Mitte des Hinterrandes durch ein schwarzes Fleckchen unterbrochen wird. Franzen um den Innenwinkel hellgrau, höher hinauf am Hinterrande weiss, um die Flügelspitze schwarz.

Hinterflügel grau, heller gefranzt. Unterseite der Vorderflügel dunkel braungrau; die Franzen wie auf der Oberseite.

Vaterland: Texas (Boll). Sechs Exemplare in meiner Sammlung und im Cambridger Museum.

\section{Argyresthia abdominalis $\mathrm{Z}$.}

- Linnaea Entomol. II, S. 270.

Diese Art ist in der Zeichnung der Vorderflügel veränderlich. Die drei von Boll aus Texas mitgebrachten Exemplare zeigen die charakteristischen zwei goldfarbenen Basalstreifen, den grösseren, schief nach oben verlängerten Innenrandfleck, die zerstreuten Fleckchen dahinter und die tiefschwarzen Schïppchen in der Flügelspitze - alles wie die europäische A. abdominalis. Der Innenrandfleck ist anch wie bei diesen entweder mit dem darüberliegenden Costalfleck zusammengeflossen oder deutlich von ihm getrennt. Kurz, ich vermag die beiderlei Exemplare durch kein einziges Merkmal als verschiedene Arten zu unterscheiden.

\section{Gracilaria.}

Die Gattung scheint in Nordamcrika viele, aber nicht an Individnen reiche Arten zu enthalten. Fünf vorliegende Exemplare muss ich für eben so viele Arten erklären, von denen nur eine mit einer der sieben Clemens'schen zusammenfällt.

Sehr auffallend wäre es, wenn unsere so verbreitete Syringella noch nicht nach America verpflanzt sein sollte; aber eine solche Verderberin der Blätter des Flieders wie in uuseren Gärten ist sie dort bis jetzt auf keinen Fall, selbst wenn Clemens sie als seine Venustella (1. 92 und 216), wie ich vermuthe, beschrieben hat; er hat so wenig Exemplare vor sich gehabt, dass das Zweifelhafte in seinen beiden Beschreibungen recht gut von del mangelhaften Beschaffenheit seines Materials hergeleitet werden kann. 
1. Grec. Burgessielle n. sp. Fig. 39.

Capite exalbito, palpis ulbis, apice fusco; alis ant. schistaceis, purpureonitentibus, triangulo obliquo ante, striola costuli post medium pallide flavis. $\sigma$.

Die nir in natura mbekannte $G r$ coroniella Clem. p. 243 muss dieser Art nahe verwandt sein; ich kann sie aber, da die Gracilarien nicht anf diese Weise abzuänderu pflegen, nicht für einerlei mit der vorliegenden halten. Coroniella hat die Vorderfligel dunkel gelblich, mit Purpur überzogen (dark yellowish, overlaid with purple), Burgessiella ohne alles Gelbliche, schiefergran, lebhaft purpurschimmernd; Coroniella hat hinter dem hellgelben Costaldreieck ein hellgelbes Costalfleckchen (a little posterior a small costal pale yellow spot), Burgessiella einen rom Dreieck durch einen ziemlich breiten Zwischenraum getrennten, scharf begrenzten hellgelben Costalstreifen von 11/2 maliger Länge des Dreiecks; Coroniella hat das Endtheil des Flügels gelblich mit gelblichen Franzen (apical portion of the wing yellowish; cilia yellowish), Burgessiella eben so gefärbt wie den Flügelrest mit grauen Franzen.

Verwandt mit Stigmatella, deren kleineren Exemplaren sie in der Grösse gleichkommt.

Rückenschild von der Farbe der Vorderflügel. Kopf glänzend, gelblichweiss, hinten ius Röthlichgrame. Fühler einfarbig bräunlich. Taster länger und dünner als bei Stigmatella, weiss, an der Spitze des Endgliedes braun. Die vier vorderen Beine schwarzbraun mit weissen Füssen; die Hinterbeine an den schwarzbramen Hüften mit rein weissem Enddrittel, übrigens weisslich mit wenigen verloschenen, grauen Stellen. Hinterleib grau, am Banch weisslich.

Vorderflügel $3^{\prime \prime}$ lang, etwas schinäier als bei Stigmatella, dunkel violettgran, am Innenrande etwas lichter, überall lebhaft purpurschimmernd. Von der Nitte hängt am Vorderrand ein heligelbes, mit der nach hinten gebogenen Spitze ein wenig über die Falte hinwegreichendes Dreieck; seine der Basis zugekehrte Seite ist schräg, etwas convex; seine abgewendete Seite tief concav; auf dem Vorderraude trägt es hinterwärts zwei braune Punkte. In einem Abstande, der etwas kïuzer ist als die Costalseite des Dreiecks, liegt ein ringsum scharf begrenzter, hellgelber Streif, der etwas länger als das Dreieck und dreimal so lang wie breit ist. Die Franzen der Flügelspitze sind so dunkel wie die Flügelfläche; die übrigen des Hinter- und Innenrandes grau.

Hinterflügel etwas glänzend gran, heller gefranzt. Unterseite der Vorderfiügel dunkelbraungrau; die zwei bellen Flecke scheinen sehr verloschen durch, sind aber in einer dünnen Linie anf deın Vorderrande hellgelb.

Vaterland: Massachusetts. Mein gut erhaltenes o wurde von Burgess bei Beverly mit mehreren am 20. August gefangen.

2. Gracilaria falconipennella Hübn. 317.

Zeller Linnaea entomol. Il, S. 323.

Diese Art ist sehr veränderlich und erlangt besonders durch die Uuberwinterung, duch auch durch längeren Flug eine helle, röthliche Färbung, in welcher sich das Custaldreieck fast immer ziemlich gut darstellt. 
Ein solches kleines, doch wohl nicht überwintertes Exemplar ist das mir aus 'T'exas vorliegende $\sigma^{\nearrow}$. Ich finde gar keinen haltbaren Unterschied: selbst. der, dass bei ihm die Fühler nicht hell und dunkel geringelt, sondern einfarbig brïunlich erscheinen, bewährt sich nicht, weil sie, von unten besehen, zwar verloschener als sonst, aber doch deutlich geringelt sind.

\section{Gracilaria resmortifoliella Clem. Fig. 40.}

- Clem. ed. Staint. p. 239. - violacella ib. p. 93.

Fronte alba, nitidula, palpis albis, nigro maculatis, rntenuis cinereis: alis ant. costa vittae instar latissimae postice coarctatae pullide flara munctuTisque nigris notata, cetemu ochaceis, mormureo-nitentibus, muctis disci ruobus nigris. $\sigma^{\top}$.

Kleiner als Alchimiella, durch die selur breite, einwärts nicht scharf begrenzte, vor der Flügelspitze endigende blassgelbe Costalstrieme und die zwei schwarzen, an ihrem Iunenrande liegenden Punkte kenntlich.

Rückenschild bleich ochergelb wie der Hinterkopf; das Gesicht weisslich, etwas glänzend. Alle vier Taster weiss, an den Enden der Glieder schwärzlich. Fühler gelblichgrau, ungeringelt, mit weisslicher Spitze und rerdunkeltem Wurzelgliede. Die vier vorderen Beine sclwarz nit weissen Füssen; die Mittelbeine an den Schenkeln und besonders an der Unterseite der Schienen durch die Bèschuppnng stark verdickt und dabei zusammengedrückt: die Hinterbcine schmutzig gelblichweiss, auch an den Hüften, an der Spitze der Schienen verloschen grau. - Hinterleib grau mit gelblichweissem Bauch.

Vorderflïgel wenig über $2^{\prime \prime}$ lang, ziemlich schmal. Die Grundfarbe isi eigentlich bleich röthlich ocherfarben, nach hinten, besonders an der Spitze dunkler, überall blass purpurfarbig schimmernd; sie wird aber durch die blassgelbliche Färbung der Costalpartie auf einen geringeren Raum besclıränkt, als diese einninmt. Dieses blasse Gelb ist an_der Wurzel schmäler als weiter lin. verengert sich aber von der Flügelhälfte an, bis wohin es bis zur Falte reichte, und endigt in den Costalfranzen etwas vor der Flügelspitze; seine Begrenzung gegen die Grundfarbe ist nirgends recht dentlich, wird aber in der Flïgelmitte durch einen länglichen und weiterhin durch einen kleineren, runden, tiefschwarzen Punkt bezeichnet. Der Vorderrand trägt an der Basis einen schwarzen Punkt und vor dem Anfange der Costalfranzen fünf schwarze Pünktchen in ziemlich gleichen Abständen. Die Costalfranzen sind anfangs bleichgelblich und werden bis zur Flägelspitze rötlllichochergelb; die Hinterrandfranzen sind nm die Flügelspitze schwärlich bestäubt nnd violettschimmernd, weiter herab grau.

Hinterflügel gran schimmernd mit gelblichgranen Franzen.

Unterseite der Vorderflügel sclıwärzlichgrau, nach hinten gelblich genischt und heller, auf dem Vorderrande von der Hälfte an bleich ochergelblich. Franzen unter der Flügelspitze schwärzlich.

Vaterland: Texas (Boll), Ein gutes ơ im Cambridger Musenm. 
Anmerkung. Ich halte eine vollständige Besclireibung dieser Art, anf die ich anfangs Clemens' Worte nicht vollständig anwenden konnte, für keinen Ueberfluss. Den späteren Namen glanbe ich mit Recht angenoumen zn haben.

\section{Gracillerin atomosella n. sp.}

Capillis albihlis, in occipite hirsutulis, palpis nigricantibus, albido-maculatis; alis ant. pallide ochraceis, squemis nigricantibus creberimis nebulosis, striga obsoleta ante medium pallide ochracea. ‥

Eine unscheinbare Art, wohl neben Syringella zu stellen, deren kleinen Exemplaren sie in der Grösse gleicht, mit zwei Haarwülsten am Hinterkopf. die, wenn sie nicht zufällig entstanden sind, das auffallendste Artmerkmal geben wïrden.

Rückenschild mit bleich ochergelblicher Grundfarbe, dicht schwarz bestänbt. Kopf weiss; die Haare des Hinterkopfes als zwei starke Knäuel aufgerichtet. Fühler schwarz und bleichgelblich geringelt mit schwarzem Wurzelgliede. Lippentaster nur von Rïckenschildlänge, nicht schlank, doch fein gespitzt; das zweite Glied schwarz mit zwei weissen Ringen; das Endglied schwarz, an der Wurzel weiss. Die Maxillartaster fein, schwärzlich mit weissen Fleckchen. Vorderbeine schwarz; die Füsse weiss; aussen grau angelaufen, an den Enden der Glieder schwarz. (Mittelbeine fehlen.) Hinterbeine weisslich, an den Schienen auswärts grau angelaufen, mit reinweissem Rücken und solchem Punkte an der schwarzen Spitze; die Füsse wie oben. - Hinterleib grau, am Bauche weisslich.

Vorderflügel $3^{\prime \prime \prime}$ lang, nicht ganz schmal, lurch die Beschuppung der Franzen anscheinend hinten erweitert, anf bleich ochergelblichem Grunde sehr raichlich mit schwarzen Schnplen bestreut, welche die Grundfarbe nur in wenigen Fleckchen frei lassen und hier und da am Vorder- und Innenrand zn unregelmässigen, nicht scharf begrenzten, kurzen Querstrichelchen oder sclımalen Fleckchen zusammenfliessen. Am dunkelsten ist der Basalrann, den vor der Flügellälfte ein auf dem Vorderrande erweiterter Querstreif der Grundfarbe ziemlich scharf begrenzt, welcher etwas schräg nach aussen bis zum Innenrand herabzieht. Die. Franzen um die ganze Flügelspitze und his zur Hälfte des Hinterrandes herah sind ziemlich dicht schwarz beschuppt; dis tiefer abwärts folgenden Franzen sind bleiclıgelblicligran.

Hinterflügel grau, mit helleren, etwas gelblich gemischten Franzen.

Unterseite der Vorierflïgel dunkel braungran; die Costalfranzen bis um die Flügelspitze weisslichgran.

Vaterland: Texas (Boll). Ein gut erhaltenes $q$ im Cambridger Museum.

Coleopleovel n. sp. oreidentis? an nigrirella Haw?

Col. coracipennella Limnaen entomol. IV, 379.

Unter der Benennung Col. pruniella Cl. erhielt ich ron Herrn Burgess eine Art in mehreren Exemplaren nach beiden Geschlechtern and mit Säcken. Clemens hat den Schmetterhing seiner Col. pruniella nicht beschrieben, sondern 
S. 167 nur die Lebensweise der Rampe, ibr Futter und die Beschaffenheit ihres Gehänses angegeben. Offenbar hat Burgess sich bei seiner Bestimmung hauptsächlich nach der Futterpflanze, wild cherry, gerichtet. Die lebhaft grünen, glatten, unbehaarten Blattstücke, an denen die von ihm erhaltenen säcke sitzen, können keiner anderen Prunusart, als cerasus angehört haben. Die Motten krochen ihm zu Anfang Juli ans, also zu einer Zeit, in der sich Col. nigricuns entwickelt, mit deren Säcken anch die ilrigen grosse Uebereinstimmung laben. Nur fand Clemens seine Raupen in mehr als halb erwaclsenem Zustande (moro than half grown) zu Anfang October, um welche Zeit die Raupen der Nigricell und ihrer nächsten Verwandten ganz klein sind, wenn sie ja schon ihre Eier verlassen haben. Den Sack beschreibt er als abgeflacht (flattened) und (nebst geringeren Abweichungen) auf der unteren Kante an Enddrittel tief gekerbt und gegen die obere Kante gekrïmmt, wodurch eın schwanzähnliches Anhängsel gebildet wird (deeply notched and curved towards the upper edge, thus forming a tail-like appendage). Ein solches Anhängsel haben die Säcke bei manchen Arten in der frübsten Jugend (vgl. Fischer v. Röslerstamm, Beitr. S. 112 ff.). Ob ałso Clemens' Angabe, dass seine Raupen meln als halb erwachsen waren, richtig ist, bleibt noch zu untersuchen. Bei den von Burgess crhaltenen, die sicher im Sommer gesammelt wurden, ist keine Spur einer schwanzähnlichen Krümmung vorhanden, sondern sie endigen mit einer kurz pyramidenförmigen Klappe, wie bei unserer im Sommer gesammelten Nigricella, und haben eine ebensolche cylindrische Form.

Die nordamericanischen Schmetterlinge stimnen aufs Genaneste mit unsrer Nigricella übereiu, ausser dass ihre Taster ein wenig schlanker, und ihre Vorderflügel nach hinten etwas mehr zngespitzt sind, beides so unbedentend, dass, wenn man die Motten ohne die Säcke und ans gleicher Gegend mit den unsrigen vor sich hätte, man darauf gar kein Gewicht legen würde. Aber die Säcke, ans lenen sie stammen, sind anders als die von Nigricella, die ich in rer Sammlung habe. Jene sind braunroth, etwas kürzer, ganz kahl, glatt, nur hier und da mit einer kurzen, rippenförmig vortretenden, unregelıässigen Längslinie, auf dem Banche und dem Rücken wit einem hantartigen Längskiel; der des Banches ist ganz niedrig, der les Rückens entweder anch einfach oder aus einen gekerbten (offenbar aus einem Blattrand gebildeten) flïgelartigen, höheren Hautrand bestehend; das kurz pyramidentölmige Ende ist dreiklappig; die Klappen eben, indem eine untere zur horizontalen Gruudfäche dient, oder eine obere den horizontalen Deckel bildet; der Hals des cylindrischen Sackes ist sehr wenig verengert und schwach abwärts gebogen, so dass die kreisrunde Oeffunng schrïg liegt.

Von Nigricella habe ich viele auf Pflaumenblättern gesammelte Säcke vor mir; sie sind länger und daher schlanker, kurz bchaart, hell graugelbbrä unlich, ohne Rücken- und Bauchkiel (bei einem Exemplare jedoch auf dem Rücken mit einem Flügelansatz), dagegen mit zahlreichen, unregeluässigen, welligen Längsrippen von verschiedener Länge und Richtung; der Hals ist kürzer als dort und noch weniger gebogen; die Analpyramide ist länglicher, die Ḱlappen 
sind auf der Aussenseite etwas concav. - Vier von Mann erhaltene Säcke (von Prunus) sind ebenso, nur röthlicher.

Hieraus ergiebt sich also, dass der Sack der nordamericanischen Coleophore kürzer ist, braunroth, kahl, fast ohwe Längsrippen, dafür mit zwei Kielen, mit gebogenem, engerem Halse, mit kürzerer Analpyramide und ebeneu Kilappen.

Von Nigricella kennt Dr. Rüssler den Kirschbaum als Futterpflanze (Nassauer Fauna S. 265 [365]). Frey giebt in den Tineinen der Schweiz S. 220 ausdrücklich an, dass ${ }_{n}$ die Säcke von Kirschbäumen einen gezackten Rückenkanm (den Rand des Kirschblattes) haben und glatt sind". Wahrscheinlich werden beim Nebeneinanderhalten solcher und nordamericanischer Säcke die Unterschiede noch mehr verschwinden, so dass die specifische Verschiedenheit noch unsicherer wird.

Ich zweifle übrigens nicht im geringsten, dass unsere Nigricella in der überwinternden Raupe vielfach nach America hinübergewandert ist uud sich dort ansässig gemacht hat.

\section{Coleophora Fabriciella Vill.}

Col. Mayrella H. Linnaea entomol. IV. 200.

Col. coruscipennella Clemeus (ed. Stainton) p. 88.

Nach Stainton's Anmerkung zu Coruscipennella ist diese mit der ebenso grossen Fabriciella sehr nahe verwandt, jedoch ein wenig branner. Die mir vorliegenden drei $\sigma^{\lambda}$ fünf $q$ stimmen aber so genau mit Fabriciellu, dass ich sie durchaus nicht von einander trennen kann und nicht recht begreife, wie Clemens, der doch Stainton's Insecta Britannica besass, für seine Exemplare einen neuen Namen wählen konnte. Die Verdickung der Fülıler reicht so weit herauf wie bei unserer Falviciellu; die Endhälfte ist scharf schwarz und weiss geringelt, nur bisweilen auf dem Rücken der letzten Ringe weiss (bei einem $Q$ am Endsechstel ohne ganz schwarze Ringe). Die Farbe der Vorderflügel ist, wie bei Fabriciella, beim $\sigma^{\nearrow}$ metallisch grün, in der Spitze kupferglänzend, beim $O$ gold- oder messiugfarben, nach hinten in grösserer Ausdelınung violett oder stahlblau.

Meine Exemplare sind von New-York und aus Massachusetts. Burgess fing die Art bei Beverly vom 10. Juni bis 4. Juli. (In Deutschland Hiegt sie bis gegen Fnde Juli; bei Zürich fing ich am Uetliberg ein ganz frisches ox am 29. Mai.)

\section{Laverna definitella n. sp. Fig. 41.}

Thorace, capite cum palpis alisque ant. albis, horum macula magnu costali ante, fascia latissima post medium et margine posticn fuscis. o $q$.

Grösser und breitflügliger als die folgende Art, ihr übrigens ähnlich gefärbt und gezeichnet, drch leicht dadurch zu erkennen, lass bei ilır vor dem Hinterrand der Vorderflügel noch ein bindenfürmiger Ramı der weissen Grundfarbe vorhanden ist, der dort gäızlich fehit. 
Rückenschild und Kopf weiss. Fühler bräunlich mit länglichem, weissen Wurzelgliede; Taster von Rückenschildlänge, ziemlich schlank, aufwärts gekrümmt, weiss; das zweite Glied an der verdünnten Wurzel gebräunt; das Endglied wenig lürzer, feingespitzt. Brust mit wischfürmigen, weissen Flecken. Vorderbeine nnd Mittelschienen auswärts braun; die Hinterschienen zusammengedrückt, auswärts branngrau, an der Wurzel, Mitte und Spitze fleckartig weiss; alle Füsse bräunlich mit weissen Spitzen der Glieder. - Hinterleib beim or grau mit weissen Banch und kegelförmigem Analbusch, beim $q$ ziemlich lang und stark, grau, nach hinten weisslich; das Analglied kegelförmig, am Enddrittel bleichgelb mit hervorstehendem Legestachel.

Vorderflügel des $\delta^{7} 3$, 오 $3 \frac{1}{1} 2^{\prime \prime \prime}$, ziemlich gestreckt, zugespitzt, weiss ohue Glanz. Weit vor der Mitte bängt am Vorderrand ein dreieckiger, brauner Fleck mit der schwarzen Spitze bis über die Falte herab; er ist beim ơ grösser als beim $q$ und verlängert sich auf dem Vorderrande bis zur Basis, während er beim $O$ frei ist, und der Vorderrand bis zur Basis rein weiss bleibt. Unter der Spitze des Dreiccks liegt am Inuenrand ein schwarzbrauner Punkt. Hinter der Mitte ist eine sehr breite, gegen den Innenrand verengte Binde; ilır Innenrand ist nur beim $\sigma^{7}$ concav, ihr Aussenrand schwach gezähnelt in beiden Geschlechtern. Der darauf folgende weisse, bindenförmige Raum ist nur schmal, nach dem Innewwinkel hin sebr verschmälert. Vor dem Hinterrand ist die Farbe wolkig duukelbraun unit einem weisslichen Wisch an der Mitte des Hinterrandes selbst. Franzen branugrau, an der Flügelspitze weisslich gemischt.

Hinterflïgel lanzettförmig, fein zugespitzt, braungrau.

Unterseite braungrau; die Franzen der Vorderflügel an der Wurzel bleichgelblich. Das Geäder ist ganz verdeckt.

Vaterland: Texas (Boll, Belfrage), Ein abgeflogenes $q$ in Cambridger Museum; ein an den Vorderflügelspitzen beschädigtes $\sigma^{\top}$, das Belfrage am 15. August fing, in meiner Sammlung.

Laterua ciremmscriptell в. sp. Fig. 42.

Thorace, coprite palpisque albis; alis ant. niveis, macula triangula costae ante medium brunnea, dimidio alae posteriore luteo-brunnco per lineam. areuatam tenuem allidam oblique dissecto. on $q$.

Vielleicht neben Lav. decorella und mopinquella zu stcllen, doch mit sehr verschiedenen Tastern, im Aussehen am meisten mit Definitella übereinstimmend.

Grösse der Decorellı. Wenn das verülte Rückenschild in der Mitte nieht weiss ist, so sind es wenigstens die Schulterdecken. Kopf weiss. Fühler ziemlich kurz, dınkelgran, sehr fein heller geringelt, mit länglichem, weisslichem Wurzelglied. Taster von Rückenschildlänge, anfwärts gekrünunt, weiss; das zweite Glied dünn, bis ans Enddrittel auswärts braun angelanf'en, an Enddrittel durch lockere, einen Trichter bildende Schuppen stark verdickt; das Endglied fast su lang wie das zweite Glied, zusammengedrückt, auf der Bauchschneide locker 
beschuppt, feiuspitzig. - Vorder- und Mittelbeine braun; Hinterbeine innen weisslich, auswärts an den Schienen und Füssen etwas bunt. (Hinterleib des $\sigma^{\prime}$ fehlt, des \& verölt, mit kaum sichtbarem Legestachel.)

Vorderflügel $2 \frac{1}{2}-2^{3} / 4^{\prime \prime \prime}$ lang, schmal, sanft zugespitzt, bloss auf der Wurzelhälfte, bis zum Anfang der Innenrandfranzen weiss, welche Farbe durch Jas dunkelgelbbraune Costaldreieck noch mehr eingeschränkt wird. Dieses hängt vom Vorderrande weit vor der Flügelmitte his sur: Falte herab, ist stmmpf und breit und hat auf dem Vorderrande eime Verläıgerung bis zur Fiügelbasis und stösst auswärts mit der dunkeln Flügelpartie zusammen; seine der Flügelbasis zugewendete Seite ist schmal tiefscliwar", und unterhalb seiner Spitze liegt nahe ann Innenrand ein tiefschwarzer Punkt. Die Begrenzung der lehmgelbbräunlichen hinteren Flügelhälfte bildet auf der der Flügelbasis zugewendeten Seite eine concave Linie, die über der Mitte mit einem schwarzen Schuppenpunkt und an Innenrande mit einem solchen Fleck bezeichnet ist. Z/wischen diesen beiden schwarzen Stellen fängt eine feine weisse oder weissliche, mehr oder weniger verloschene Limie an, welche gekrümmt nach dem Vorderrande hinaufzieht und ibn weit vor der Spitze erreicht, indem sie so ein längliches, lıllovales Stück abschneidet. In der Flügelspitze und weiter abwärts am Hinterrande ist nicht immer eine lichte Stelle in der gelbbraunen Farbe, und noch tiefer, gleichfalls am Hinterrande, ein schwarzes Fleckchen. Franzeu braungelblichgrau, an der Flïgelspitze dicht beschuppt.

Hinterflügel linearlanzettlich, feiı gespitzt, bränulichgrau.

Unterseite braungran; die Mitte des Innenrandes der Vorderflügel in einer sehr feinen Linie weiss.

Vaterland: Texas (Boll). Zwei zerbrochene $\sigma^{-1}$ mid ein $q$ in meiner Sanmlung; melırere Exemplare nach Dr. Hagen's Angabe in Cambridger Museum.

\section{Batrachedra striolate u. sp.}

Alis ant canis, finsco-pulverulentis prasertim juxta ciliu custalia, striolis disci duabus longitudinalibus (altera unte medium, altera postica) nigris.

Var. b) striolu tertia paulo ante striolam posteriorem.

Obgleich diese Art, die kleiner als Batr. praeangusta ist, sich etwas veränderlich zeigt, so vermag ich doch nicht, die Salicipomonella Clem. p. 265 anf sie anzuwenden. Bei Sulicip. sollen die Vorderflügel bräunlich sein nit -inem weisslichen, reichlich bräunlich bestäubten Streifen, der von der Basis durch die Flügelmitte his zur Flügelspitze läuft. Ein solcher lässt sich bei den vorliegenden Exemplaren durchaus nicht erkennen, da die Costalpartie nicht heller als die Dorsalpartie und sugar im Apicalviertel mehr als anderwärts ver1unhelt ist, so dass hier noch viel weniger von einem hellen Längsstreifen die Rede sein kann.

Rückenschild und Kopf lellgrau, mit brauner Bestäubung, ausser in Gesicht (das aber nicht weiss ist, wie Clemens von Salicip. angiebt). Taster dünn, gebogen, imnen weisslich, anssen braun gefieckt. Fühler hellbräunlich, dureh die Einschnittc ler Glieder auf der Riückseite sehr verloschen geringelt 
erscheinend, anf dem dunkeln Endserbstel mit eimen breiten Ringe, dann vor der Spitze mit 2-3 schmäleren Ringen von weissgrauer Farbe. Beine gran, an den Füssen auswärts schwärzlich, mit breiten, weisslichen Enden der Glieder; die Hinterschicnen an der Mitte mit einem weisslichen, beiderseits schwärzlich begrenzten Bändchen und an der Spitze erst schwarz, dann mit weisslichen Endhaaren. Hinterleib grau, auch Bauch mit weisslichen Hinterrändern der Segmente.

Vorderflïgel $2 \frac{1}{4}{ }^{\prime \prime}$ lang, weissgran, lurch brannen Staub verdunkelt, am meisten am Torderrand bis zur Spitze. In Mittelraum vor der Mitte liegt ein kurzer, schwarzer Längsstrich in der Falte, der Basis etwas näher als dem folgenden, eben so langen Strich, welcher dem Hinterraul ziemlich nahe kommt und sich dem Vorderrand mehr nähert als dem Innenrand. In gleicher Richtung und Höhe mit ihm bildet sich vor demselben bei Var. b eine liunnere, längere, anch wohl unterbrochene Längslinie melır oder weniger ans. F'ranzen grau, an der Flïgelspitze weisslichschinmernd.

Hinterflügel und Unterseite grau mit solchen Franzelı.

Vaterland: Texas (Boll). Beide Geschlechter in meiner Sammlung und in Cambridger Museum.

\section{Heliozela gracilis n. sp.}

Alis ant. subelongatis, aeneis, subviolucen-nitidulis, guttis dorsalibus duabus argenteis, miore obliqua, posteriore triangula majore. $\sigma^{7}$.

Schwer von den europäischen Arten zu unterscheiden, am sichersten durch die gestrecktern und zugespitztern Vorderflügel und die länger und feiner zugespitzten Hinterflügel. In der Grösse steht sie zwischen Sericiella und Resplendella.

Die Vorderflügel sind erzglänzend mit sehr wenig beigemischtem Vinlettschimmer, wie bei den genannten zwei Arten. Von den zwei reinsilberweissen, glanzenden Dorsaltröpfchen ist das zweite, am Innenwinkel liegende dreieckig, mit feiner, gegen den Vorderrand gerichteter Spitze und scharf mugrenzt (wie bei Saltatricella [Tinagma], docl kleiner). Das erste, näher an der Wurzel als an dem zweiten liegende, ist ein schmaler, oben nach hinten übergeneigter Strich. Die Franzen sind, ausser gegen die Flïgelspitze, riemlich hellgran und sondern sich von der Flügelfläche gut ab, so dass die Zuspitzung der letztem auffällt.

Hinterflügel von mehr als der Hälfte an dümn zugespitzt, gran. Die Hinterrandfranzen lieller, gegen die Wurzel heller nud von der Flïgelfläche sehr dentlich abgesonilert.

Vaterland: T'exas (Boll). Ein gntes ơ in Cambridger Mnseum.

\section{Phyllocuistis.}

1. Vitigenella Cl. pag. 82 .

Die zwei vorliegenden Exemplare stimmen darin unter einander, dass sie kleiner sind als die kleinsten Suffusella und Saligna und das eine hat alle Verknıle, welche Clemens von seiner Vitigenclla angiebt, nach welchen sic treilich nicht von unserer Saligna zu unterscheiden ist. Es hat nämlich wie 
diese einen bräunlichen, von der Schulter herabliommenden, am obern Rande der Falte hinziehenden und etwas vor der Flügelhälfte endigenden Schattenstreifen. Der Unterschied scheint zu sein, dass, da er sich der Länge nach spaltet, der obere Theil bei Vitigenella der stärkere ist, bei Saligna dagegen der untere, und dass überhaupt der Streifen bei Vitigenella feiner anfängt. Aber das zweite Exemplar entbehrt diesen Streifen völlig! Dennoch können beide Exemplare nicht wohl zu verschiedenen Arten gehören, da sie in den übrigen, sie von den Europäerinnen unterscheidenden Merkmalen übereinstimmen. Diese bestehen in den Vorderrandstrichen auf der hintern Flügelhälfte. Sie sind nämlich bei Vitigenella feiner, schärfer und dunkler und, während sie bei jenen beideu in ziemlich gleichen Abständen von einander liegen, ist bei Vitigenella zwischen dem zweiten und dritten ein solcher Abstand, dass noch ein Strich dazwischen liegen müsste, um gleiche Abstände hervorzubringen. Der zweite Strich setat sich bei allen drei Arten als ein Bogen oder als eine winklig gebroclıene Querlinie bis zum Innenrand fort; bei Vitigenella ist der Winkel weit über der Mitte, bei den beiden andern in der Mitte, wo auch die stärkste Convexität ist, wenn sich bloss ein Bogen gebildet hat. - Clemens giebt für Vitigenella au, dass sie a blackish lorsal patch on the inner margin near the base habe, und diesen Fleck žeigen meine beiden Exemplare sehr stark. Keins meiner zehn Saligna-Exemplare besitzt eine Spur davon; aber bei Suffusella ist er eine ganz gewöhnliche Erscheinung und manchmal nach beiden Seiten des Innenrandes hin verlängert. In der Flügelbreite stimmt Vitigenella mit Suffusella.

Diese, wie es scheint, so auffallend abändernde Art verdient genauer beubachtet zu werden. Erst wenn dies geschehen ist, lassen sich sichere Diagnosen fiï die drei Arten anfertigen.

Vaterland meiner zwei Exemplare Massachusetts bei Cambridge.

\section{Magnatella n. sp. Fig. 43.}

Maxima, alis ant. candulatis, niveis, postice fermgineis, puncto buseos subdorsali atro, macula ante marginem posticum longitudinali, nivea, nitida, tuberculum nigricans et superius lineolum atram continente. $0^{7}$.

Die beiden vor mir befindlichen Exemplare sind nicht nur in der Grösse, sondern auch in der Zeichnung bedeutend verschieden, gehören aber zu einerlei Art, wie der glänzendweisse, durch einen lialb grauen, halb schwarzen Schuppen. wulst unterbrochene Längsstreif in der gelben hintern Partie beweist. Das grüssere Exemplar übertrifft die grüsste Lyonetia! Obgleich den Fühlern und der Kopfbildung zufolge die Art eine Phyllocnistis ist, so scheint doch das ausgezeichnete Franzenschwänzchen und die Abweichung in Aussehen anzudeuten, dass auch das Geäder ein verschiedenes sein, und dass man für sie ein besonderes Genus zu errichten haben werde.

Rückenschild und Kopf reinweiss. Fühler ziemlich stark, kürzer als die Vorderflügel, hellbrüunlich; das weisse Wurzelglied lüıglich, an Ende etwas verdickt. - Beine weiss, schwarzbnnt, besonders an den Füssen; die Hinterschieuen dünu, answärts weisslich, vor der sjuitze mit schwürzlichem Fleck, aut 
dem Rücken mit langen, hellblonden Haaren dicht bekleidet; der eine Dorn des ersten Paares ist doppelt so lang wie der andere md der längste von allen. Hinterleib dünn, grau mit kleinem, hellem Analbusch; Bauch weiss, an den Seiten schwärzlich gefleckt.

Vorderflügel ohne Schwänzchen bei dem einen Exemplar $2^{1 / 2}$, bei dem andern nur $13 / 4$ “" lang, schmal (bei dem kleinerı etwas breiter), weiss, ohne Glanz, in der hintern Hälfte ausser am Vorderrand rostgelb. Tnterhalb der Falte an der Basis ist ein tiefschwarzer, echiger Punkt (beim kleinern Exemplar verloschen und kleiner). Ebenso unterhalb der Falte ist weit vor der Mitte bei dem kleinern ein ziemlich grosser, schwärzlicher Punkt, und weiter nach hinten dicht an Vorderrand ein ebensolcher; statt beider hat das grössere Exemplar reclit undeutliche, kurze Längsstreifchen. Die Rostfarbe fängt beim grössern in der Flögelhälfte dicht an der Falte mit einem starken, schwarzen Punkt an; beim kleinern fehlt er fast, während bei ihm von dieser Stelle aus ein dnnkelbräunlicher, sehr schräg aufwärts nach hinten gerichteter Strich die Rostfarbe begrenat und mit seinem Ende mit dem bei beiden Exemplaren rorhandenen, sehr schräg herabkommenden, schwärzlichen Costalstrich zusammenstüsst. Untrrhalb der Spitze des dadurch gebildeten Winkels ist der gestreckt eiförmige. etwas silberweisse Längsstreifen, der bis zum Hinterrand hinreicht und in seiner Mitte einen verdickten, granen, linten sclwwarzen Fleck trägt, von dessen oberen Fnde eine kurze, schwarze Länglinie gegen das Schwänzchen gerichtet ist. Hinter dem angegebenen schwärzlichen Costalstrich folgen vier weisse, lurrh Rostgelb schlecht begrenzte Costalflecke und Striche, derei letzter vor den abgestutzten, hier schwarzen Eranzen liegt. Das zienlich lange, frei hervorstelıenl Franzenschwänzchen ist schwarz. Die Franzen unter ihn enthalten einen am Hinterrande hinziehenden sehwärzlich punktirten Fleck: sonst sind sie blass ochergelb.

Hinterflügel schmal messerförmig, gran; die sehr langen Franzen holler mul gelblich gemischt.

Unterseite der Vorderflïgel brämnlichgrau, bei dem grössern Fxemplar vor dem schwarzen Franzenschwänzchen mit einer sehr lentlichen, wrisshcheu, wischförmigen Stelle. Hinterflügtl wie oben.

Vaterłand: Massachusetts. Beide Fxemplare wurden von Purgess gefangen, las grössere bei Beverly am 8. Juli.

\section{Trifurcula obrutella n. sy.}

Capite et alis ant. pallide lutescentibus, his mulvere grosso, crelmo, fusen conspersis, costa e luasi lineae instar nigra. o $q$.

In der Grösse zunächst der Pallidella, etwas schmalfüglicher, von den enropäischen Arten ziemlich leicht $7 u$ unterscheiden Aurch lickere Fühler, bleich lehmgelbe, reichlich (wie bei Pulverosella) mit groben, bramen Sichuppen bestrente Vorderflïgel mil hesonders dureh den schwarzen Costalrand an der Schulter. 
Rückenschild und Kopf bleich lehngelblich, noch heller die auf der Unterseite weissen Augendeckel der dicken, staubgrauen Fühler. Beine einfarbig hell ochergelb. Hinterleib grau mit gelbweissem, seidenglïnzendem Bauch.

Vorderflügel kaum 2"“ lang, bleich lehmgelb, auf der ganzen Fläche seh» schwach opalisirend, beim $Q$ weniger reichlich als beim $\sigma^{\pi}$ mit groben, braunen Schuppen, besonders hinterwärts, bestrent. Der Vorderrand ist von iler Wurzel aus als eine kmze, beim of feinere und weniger weit als beim of reichende Linie scliwarz. Am wenigsten und mit feineren Schuppen ist die Iunenranlgegend nach der Wurzel bestreut. Die hellgelblichgranen Franzen sind nu den Hinterrand herum mit einer Schuppenreihe durchzogen.

Hinterflïgel hell bleigran; die helleren Franzen mit gelblichem Seidenschimmer. - Auf der glänzenden Unterseite sind die Vorderflïgel viel dunkler grau als die Hinterflïgel und stechen von den helhn, gelblichschimmernden Franzen selır ab.

Vaterland: Texas (Boll). Twei of ein $Q$ in meiner Sammlung und im Cambridger Museum.

\section{Pterophoridae.}

Ans dieser Familie loat Fabricins eine einzige americanische Art beschrieben (Pter. lencodactylus), jedoch nicht so, lass sie leicht wieder qu erliennen sein möchte. Darauf stelite Asa Fitch in Rejurt of the noxious Inserts uf the State of New-York 1856 S. 139-145 mehrere Arten anf, von denen num die erste, Perisceliductylus, nach ihrer ganzen Naturgeschichte und auch sonst hinreichend genau abgehandelt ist. Itie folgenden: Lobidactylus, Tenuidactylus, Gineviluctylus, Marginiductylus, Nebulaeductylus, Nuevosidactylus und Cretidectylus sind nur nach den Schmetterlingen and nicht einmal zur Unterscheidong von andern nordanericanischen Arten ausreichend beschrieben und tragen sämmtlich Bastardnamen, die nicht geduldet werden kömnen. Ob er noch audere Arten beschrieben hat, ist mir gäuzlich unbekannt. Hierauf charakterisirte ich in der Futomol. Keitung 1867 S. 389 einen Platyptilus Bischofï ans Nordamerica. K/u diesen Arteu fügte Riley im Anmual Report of the noxions etc. insects of the State of Missomri 1869 einen Pterophorus curduiduetylus hinzu. Dif mir in natura bekamnten Arten Nordamerica's sind folgende:

\section{Platyptilin Bischoffii Z.}

Platyptilus B. Entom. Ztg. 1867, S. 333.

Sie steht der Plat. Bertrami nicht mur nach der Zeichnnng der Hinterschicnen, sondern auch in ler Flügelfärbung an näclısten, unterscheidet sich aber ausser den ctwas weniger gespitzten Vorderzipfel der Vorderflïgei vorziiglich inreh die einfarbig weisslichen Hinterfüsse (bei Dertrami ist das erste Hinterfussglied an der Silntze ocherfarbig in verschiedenen Abstufungen nnd Mischnngen), - Meine ersten Exemplare thielt ich ans (Tho. Furgess schichte mir of $Q$, die er bei Beverly in arsten Drittel des Juli gefangen hatte. Ihr 
verflogener Zustand zeigt, wie bei Ochrolactyla und Bertrami, die Entwicklung vor und in die Mitte des Juni fällt.

\section{Platypt. corelui Z.}

Pterophorus carduidactylus Riley 1. c. p. 180, tab. 2, Fig. 13, 14.

In der Grösse der ansehnlichsten Ylat. Zetterstedtii, aber mit dunklerer, fast etwas röthlicher Färbung, so dass sie dadurch der $P l$. isoductyla (De Graaf) nalse kommt. Die Hinterrandiranzen der Vorderfïgelziplel sind aber auswärts so weisslich wie bei Zetterstedtii (bei jener Isodectyla schmutzig und bleich ochergelblich). Die mit einem weissen verlängerten Costalpunkt anfangende helle Liufassung des dunkelbrauneı Costaldreiecks erweitert sich cinwärts bei weitem nicht so wie bei Zetterstedtii, sondern bildet eine etwas breite Linie, die answärts durch die dunkeIröthlichzimnitbraune Farbe ziemlich deutlich begreuzt wird. Die helle Querlinie, welche über die beiden Zipfel vor dem Hinterrande hinwegzieht, ist ziemlich verloschen, nicht scharf begrenzt, und auf dem zweiten Zipfel verlöscht sie weit vor dem Innenrande. (In der Abbildung Fig. 13 ist sie so fein, scharf und vollständig wie bei Zetterstedtii gegeben, womit meine drei Exemplare gar nicht übereinstimmen.) Das Hauptmerkmal giebt das schwarzc Schuppendreieck in den Franzen der dritten Hinterflügelfeder; dieses ist so gross, wie es keine unserer Arten mit Ausnahme der Pl. nemoralis besitzt; es liegt ein wenig vor der Mitte der Feder und hat vor sich eine weissliche Stelle, von weleher aus bis zur Basis eine einfache Reihe schwarzer Schuppen auf den Franzenhaaren liegt. (In Riley's Figur ist das Dreieck ganz ausgelassen, oder vielmehr ist die Feder selbst hier unnatürlich erweitert; auch die zweite Feder, die wie bei Zetterstedtii gestaltet ist, zeigt einen falschen Umriss.) Auf der Unterseite hat der erste Hinterfügel die Andeutung einer verloschenen Querlinie. - Der stirnkegel ist kleiner als bei Zetterstedtii, wesshalb die Taster auch weiter über ihn hinausreichen. Der Hinterleib ist ocherbraun, auf den zwei ersten Segmenten ins Weissliche; am Ende des zweiten liegt in der Mitte ein mit der Spitze nach vorm gerichtetes, dunkles, kleines Dreieck; der hintere Seitenrand des dritten Segments ist weisslich; der des vierten mit einem dunkelbraunen Fleck gezeichnet. - An den Hinterbeinen sind Schienen und Füsse weiss; die erstern vor dem oberu Dornenpaar mit einem dunkelzimntbraunen Ringe; der darauf folgende Theil ist an den ganzen zwei Enddritteln ebenso gefärbt. Auch das erste Fussglied ist an der grössern Endhälfte von derselben Farbe, and die folgenden liaben hellbräunliche Spitzen.

Vaterland: Missouri; ich erhielt von Riley ein ơ zwei ㅇ. Die Ranpe lebt nach seiner Beobachtung den Monat Mai hindurch an der gemeinen Distel (('irsium lanceulatum - Cersium lanceulata ist wohl nur Druckfehler), an der man häufig die Köpfe durch Seidengespinnst zusammengezogen sehen kanu; üfters sind einzelne abgestonbene Blitter mit darin enthalten. Zieht man solche Ciespinnstwulste auseinander, so triftt man 8-12 dicke, glatte, wurmähnliche Raupen darin an. Sie sind licht strohgelb, in der Jugend melı grïn, mit Reihen schwarzer Punktwärzchen; der Kopt und die durch eine helle Längslinie halbirte 
Hornplatte des Prothorax schwar\%. (Ril 'y beschreibt dies ausführlich.) Gegen Ende Mai verwandeln sic sich innerhalb des Nestes in glatte, glanzlose, schmutzig gelbe Puppen mit kurzem Stirnkegel und m jeder Seite mit drei dnnkeln Längsstreifen. (Fig. 14.) Genan in einer Woche nach der Verpuppung kriechen die Schmetterlinge aus. (Von keinem enropäischen Pterophoriden leht. so viel man weiss, eine Art gesellig; die Puppe der Pt. cardui stimmt aber mit den verwandten europäischen Platyptitien).

Anmerkung. Ein durch Boll ans Texas mitgebrachtes $c^{2}$ ist von so heller Grundfarbe auf den Vorderflïgeln wie Zetterstedtii. Da cs sehr verflogen ist, so könnte dic helle Farbe eine Folge des längern Fluges sein. Aber die Vorderflugel sind etwas gestreeliter als bei Cardui, und die helle Querlinie iiber die Vorderflügelzipfel ist vollständiger und breites. Das schwarze Schuppendreieck der dritten Feder ist so vollständig wie bei dieser. Aber - was einen sichern specifischen Unterschied anzudeuten scheint - an der Hinterschienenspitze nimmt bei diesem Texaner Fxemplar die branne Farbe weniger als den halben Raum zwischen den zwei Sporenpaaren ein, bei Crudui $2 / 3$. Der ungenügende Zustand des Exemplars verhindert eine genaue Beschreibung und Benennung der Art. Es giebt also aus der Gonorlactyla-Gruppe in Nordamerica wenigstens zwei Arten.

\section{Oxymtitus periscelidartylus Fitch.}

Fitch 1. e. p. 138. The gartered or grape-vine Plume.

Riley 1. c. p. 137. tah. 2. Fig. 15. 16 the grape-vine Plume.

Er gehärt - zufolge der dritten Hinterfügelfeder, die vor dem starken. schwarzbeschappten Ende nicht bloss in den Franzen weisse Schuppen fïhrt, sondern auf der Fläche selbst weissbeschuppt ist - in die Verwandtschaft des Didactylus und Obscurus, mit denen er auch darin ïbereinstimmt, dass die Puppe auf dem Rïcken dornig ist. Von allen bekannten Artell unterseheidet or sich durch das branne, gestreckte Dreieck. Welches auf dem zweiten Vorderflügelzipfel auswärts von der weissen Querlinie, an seiner Spitze von einem weissen Wisch begrenzt wird.

Er hat die Grösse und den Ban des Didnctylus; die Fürlung des Körpers und der Vorderflügel ist aber wie bei keinem enropäischen Oryntilus (bei Lrretus zwar heller, aber bleich ochergelb): hellzimmtfarben, wenimer schön als bei Plat. rhododactyla. Die Zeichnung der Vorderflïgel ist wie bei Didactylus; aber die weisse Querlinie des zweiten Zipfels steht weiter vom Hinterrand ab und dient als Basis des gelbbraunen, diesem ganz felılenden Dreieckso Der Vorderrand dieses Zipfels ist von der Spalte bis zur Qnerlinie und rifters iiber diese hinans auf den hellen Franzen mit tiefschwarzen Schuppen bekleidet (die bei Didactylus, dessen Vorderrandfranzen schwarz sind, ganz fehlen). Die Zeichnung der Franzen ist sonst wie bei Dirlactylus.

Der starke schwarze Schuppenbusch am Ende der dritten Feder ist kürzer und breiter als bei Didactylus, weil die Schuppen, besonders am Hinterrande, länger sind, und sticht gegen die weissen Schuppen der Franzen sehr ab; er 
ist hinten gerade alogesehnitten, und die linter ihn folgenden Franzen sind rein weiss, wie auch die weisslich gelranzte Flügelfäche vor ihm; die Basalhälfte dieser Feder ist blass ochergelb, mit hinfälligen dunkleren Schuppen bestreut.

Die Fühler sind auf dem Rïcken weiss, anf der Unterseite sclnwarz und weiss wechselnd. Anf dem Rücken des in der Färbung mit den Vorderflügehn stimmenden Hinterleibes sind die weissen Zeichnungen durch dickere Linien gebildet als bei Didactylus. Die weissen Hinterbeine sind wie bei Didactylus. gefärbt, nu in den dunklen Stellen nicht schwarzbraun, soudern zimintbraun.

Mein einzelnes Exemplar aus Olio biłdet eine Varietät. Alle dunkle Färbung an Flügeln und Körper ist dunkler, und das Weiše, besonders anf dem Hinterleibe, ist verloschener und weniger ausgedehnt. Die erste fleckähnliche Querlinie des Vorderflïgelzipfels ist, statt schräg nach aussen gelegt zu sein, fast senkrecht: die zweite weisse Querlinie ist vorhanden, aber die des Hinterzipfels (die Fortsetzung der ersten des Vorderzipfels) fehlt völlig, um da die Farbe dieses Zipfels dunkel ist, so tritt das charakteristische Dreieck nicht aus der Grundfarbe hervor. Die Franzenzeichnung ist nicht verschieden, nur weniger hell weiss. Auch die Haarknoten an den Hinterschieuen sind dunkler braun.

Meine anderen sechs Exemplare, alle weiblich, und von verschiedener Güte der Couservation, stammen von New-York, ans Missouri und Texas. Die Art hat in Nordamerica gewiss eine grosse Verbreitung. Ihre Raupe lebt zu Ende Mai und Anfang Juni in einem oder zwei durch Seide zusammengezogenen Blättern des Weinstocks und verpuppt sich an der Unterseite eines Blattes oder Stengels. Fitch glaubt, dass es zwei Generationen gebe, deren zweite aus den im Juli (nach Riley schon in etwa acht Tagen nach der Verpupjung) auskriechenden Schmetterlingen erscheine, nnd da diese Art schädlich werden könne, so müsse man die Raupe in Juni absuchen und törten. Mir scheint dì Möglichkeit der Schädlichkeit wenig glaubhaft, wenn anch Riley die Raupe in vielen Theilen von Missouri recht häufig fand.

\section{Oxymtilus Delawaricus n. sp.}

Antennis albo nigroque anmulatis; alis ant. minus querm ad medium fissis, cinnamomeis, lacinia anteriove albido-bistrigata, ante apicem latius niveociliata, citiis laciniae posterionis in basi linerm albam gerentibns; digiti tertit medio albido, apice utrimque retrosquamuto. o'.

Auch bei ilım, sowie bei dem folgenden ist die Spitze der dritten Hinterfliigelfeder schwarz beschuppt. Vom vorigen unterscheidet er sich durch viel geringere Grösse, vollständig schwarz und weiss geringelte Fühler, ganz andere Grundfarbe der Vorderflügel, den rein weissen Costalstreifen an der Spitze des Vorderzipfels, den Mangel des braunen Dreiecks anf dem hintern Zipfel, die anders gezeichneten Franzen dieser Zipfel, den hinten nicht gerade abgeschnittenen Schuppenfleck an der Spitze der dritten Feder. - Die folgende Art über. 
trifft er so sehr in der Grösse, wie ihn der Periscelidactylus tibertriftit; seine Vorderflïgel sind viel heller, und wenigstens die zwei weissen Querlinien des ersten Zipfels sind vollständig, und von der zweiten an sind die Vorderrandfranzen in einem breiten Streifen weiss, statt schwarzbraun; auch ist die Franzenzeichnung eine andere. - In der Färbung kommt Delawaricus dem Pilosellae nahe, von dem ihn aber die Zeichnung der dritten Feder weit entfernt. Von den dunkler und schöner gefärbten $O$. ericetorum mul $O$. tencrii unterscheidet ihn der grössere Umfang des schwarzen Schuppenfleckes der dritten Feder.

Fühler weiss und schwarz scharfgeringelt, nur an den ersten 6-7 Gliedern auf der Unterseite bloss weisslich. Kopf, Rückenschild und Vorderflügel hellzimmtbraun wie beim gewöhnlichsten Pilosellae.

Vorderflügel $3 \frac{1}{2} "$ lang nnd von der sewihnlichen Oxyptilus-Gestalt, ziemlich hellzimmitfarben, auf der verdunkelten Vorderrandader von der Wurzel aus weisspunktirt, und mit ein paar dunkeln Fleckchen im Mittelraune; vor der Spalte mit einem kleinen weisslichen Fleckchen. Die zwei weissen Querlinien des Vorderzipfels deutlich und gut begrenzt; die Costalfranzen vor der ersten, schräg liegenden Querlinie und hinter ihr bis zur zweiten schwarz; die zweite ist weniger schräg nnd geht in den breiten rein weissen Streifen über, deı die Franzen von ihr an bis zur Spitze bilden. Die Innenrandfranzen dieses Zipfels sind von der spalte aus blund, daun hinter der ersten Querlinie schwarz, hierauf wieder blond, gegen die spitze an ilner Wurzel streifenartig weiss, welche Farbe erst durch einen schwarzen Längsstrich, damm bis zur Flügelspitze durch verdunkelte Grundfarbe begrenzt wird. Aut dem zweiten Zipfel ist an der gewöhnlichen Stelle ein weissliches Fleckchen, und von der Fortsetzung der zweiten Querlinie eine Spur zu sehen (dies mag veränderlich nnd bei anderen Exemplaren deutlicher sein). Die Vurderranzfranzen dieses Zipfels sind erst hellblond, dann bis fast zur Spitze dunkelgrau mit einzelnen noch dunkleren Haaren gemischt und mit einzelnen sehr kleinen schwarzen Schüppchen bestreut; die Innenrandfranzen sind lellblond, an der Spitze aber schwarz und einen auffallenden solchen Fleck bildend; die Hinterrandfranzen sind wieder sehr hell blond, an der Wurzel weisslich, so dass hier eine weisse Bogenlinie (wie bei Ericetorum) gebildet wird, welche einwärts durch die Grundfarbe und einerseits durcl den schwarzen Franzenfleck, andererseits durcin elnen schwarzeu, ans der Spitze des Zipfels hervorkommenden Franzenstrich begrenzt wird. An diesen schwarzen Längsstrich der Spitze stossen auf der anderen Seite einige an der Wurzel weisse Franzenhaare.

Dic zwei ersten Federn sind dunkelgrau; die dritte ist in Anfangs- und Enddrittel hellzimmtfarbig, im nittelsten Drittel, so wie die es begrenzenden Franzen weisslich. Um das Enddrittel bildet die schwarze Färbung der Franzen einen länglichrunden Fleck, der besonders auf dem Vorderrande nnit tiefschwarzen Schuppen bekleidet ist. Die Franzen an der Spitze der Feder sind in ansehnlicher Ausdehnnng weiss, nit ein paar tiefschwarzen Schuppen.

Auf der Unterseite der Flügel ist das Schwarze weniger tief, das Weisse aher anf den Vorderflügeln in den ausgeprägteren Zeichnungen reiner; hier ist 
auch die (zweite) Querlinie des Hinterzipfels ganz deutlich, doch nicht bis an beide Ränder ausgedehnt.

An den weissen Hinterschienen sind die Haarbäsehchen (bei den Dornen) gelbliehbraun; diese Farbe nimmt die Endhälfte des Raumes bis zu dem ersten Dornenpaare ein. An den Füssen sind die braunen Endringe der beiden ersten Glieder halb so breit wie der weisse Rest. Sammlung.

Vaterland: am Delawarefluss. Ein $\sigma^{\top}$ (durch Schläger erhalten) in meiner

Anmerkung. Tenuidactylus Fitch, der in Dornbüschen (brakes) und auf Sümpfen Mitte Juli gemein sein soll, mag einerlei nit meiner Art sein, ist aber durehaus nicht so beschrieben, dass ich ihn ohne Ansicht eines Originals dafür annehmen könnte. Dass der schwarze Fleck der dritten Hinterflügelfeder nahe an der Spitze gelegt wird, ist vielleicht nur Ungenauigkeit der Bezeichnung (the inner lobe $[\alpha . h$. die dritte Feder] threadlike, white, its fringes white, with a broad black band wear the tip).

\section{Oxyptilus nigrociliutus 11 . sp.}

Parvus, antennis albo nigroque cunulatis; alis ant. minus quam ad medium fissis, bmneo-fuscis, lacinia anteriore obsolete albido-bistrigata, ciliis costalibus nigris; ciliis laciniae posterioris in basi lineam albam gerentibus; digiti tertii medio albido, apice utrimque atro-squamato. ‥

Von der Grösse des kleinsten Oxypt. obscurus und von noch dunklerer Farbe als dieser. Sein geruudeter schwarzer Schuppenbusch am Ende der dritten Feder weist ihn wie die zwei vorigen Arten zwisehen Didactylus und Obscurus. Was ihn vor allen Oxyptilus-Arten kenntlieh macht, ist die schwarze Farbe aller Vorderrandfranzen am ganzen ersten Zipfel entlang.

Die Fühler sind lebhaft weiss und schwarz geringelt. Die Vorderflügel, 3"“ lang, sind dunkel gelbbraun, ohne lichte Stelle an der Spalte. Die zwei weissen Querlinien der Zipfel sind undeutlich; am deutlichsten und reinsten ist der Anfang des ersten auf dem Vorderzipfel. Nur im Anfange der Spalte sind die Franzen weisslich, sonst am Vorderzipfel überall schwarz, ausgenommen unterhalb der spitze, wo sie in einem spitzen Dreieek hell blond sind. Am Hinterzipfel haben sie den ganzen Vorderrand entlang, mit Ausnahme des Winkels der Spalte, schwarze Farbe; am Innenrande sind sie in grosser Ausdehnung hellblond mit ein paar tief'schwarzen Schuppen, dann bis zum Hinterrande in geringerer Ausảehnung sehwarz; an Hinterrande sind sie bis zur Spitze, wo ihre Farbe tiefschwarz ist, mit einer hellen stelle darüber, hellblond, an der Wurzel aber ganz weiss in einem Bogen, der einwärts durch die schwarze Hinterrandlinie scharf begrenzt wird, auswärts aber keine scharfe Grenze hat.

Hinterflügel dunkelbraun. Die dritte Feder in der Mitte weiss und hier auch weisslich gefranzt; un die Spitze bilden die auf den Franzen liegenden tiefschwarzen Schuppen einen kurzen, eiförmigen Fleck, hinter welchem, also an der Spitze der Feder, die Franzen hellblond sind. 
An den Hinterbeinen sind die Schienen und Füsse reinweiss, die erstern mit braunschwarzer Farbe der Verdickungen (wie bei Obscurus). Die Fussglieder sind an der Spitze wenigstens auf einer Seite schwarz, und das erste Glied ist es auch an der Wurzel, so dass hier anf der Aussenseite der weisse Ring etwas schmäler ist als der schwarze Endring.

Vaterland: am Delawarefluss. Ein $q$ (durch Schläger erhalten) in meiner Sammlung.

Anmerkung. Lobidactylus Fitch soll grösser sein als Tenuidactylus (Flügelspannung 0,80 gegen 0,60 : bei Periscelidact, 0,85), und kann also schon darum nicht einerlei mit Nigrocitiatus sein. - Ohne Zweifel giebt es in Nordamerica mehr Oxyptilus-Arten, als Fitch unterscheiden zu künnen glaubte.

\section{Mimeseoptilus semicostutus n. sp.}

Parvus, alis cut. fuscescenti-cinereis, dorso gilvescente, vcnae costulis dimidio posteriore albo, puncto fusco ante fissuram posito, ciliis laciniae utriusque nigro-bipunctutis, punctis anterioris ante angulum dorsalem.

Die zwei vorliegenden Exemplare lassen sich nicht als verschiedene Irten ansehen. Es ist fraglich, ob sie nicht zu dem europäischen Zophodactylus (Loewii), dessen ganzen Ban und Färbung sie haben, gehören, indem die Stellung der beiden Punkte in den Franzen des Vorderzipfels, die olnedies nur bei dem einen Exemplar unversehrt sind, vielleicht nur die Bedeutung einer Varietät liaben mag. Aber bei der Verschiedenheit des Vaterlandes ist es rathsamer, eine eigene Art anzunehmen und die Entscheidung von der Erforschung der Naturgeschichte (Zophodactylus lebt an Erythraea centaurium) und von der Untersuchung mehrerer Exemplare abhängig zu machen.

Der Kopf ist grau, am obern Augenrande mit einer feinen weissen Linie. Fühler grau, angeringelt, gegen die Wurzel weiss. Rückenschild etwas bräunlich bestäubt. Hinterleib schlank, bleich gelblich, an Ende eines jeden der drei vorletzten Segmente mit zwei schwarzen Punkten. Beine weisslich.

Vorderflügel $3^{3} /{ }^{\prime \prime \prime}$ lang, bräunlichgrau, längs des Innenrandes und in den beiden Zipfeln, übrigens ohne scharfe Grenze, in bleiches Ocherröthlich übergehend. An der Grenze des Bräunlichgranen ist im Mittelraum mitten zwischen der Wurzel und der Spalte ein schwarzer, in die Länge gezogener: Punkt. An der Spalte liegt am Anfang des untern Zipfels ein anderer solcher Punkt, und iiber ihm bei dem einen Exemplar ein grösserer, wischförmiger, doch sehr undeutlicher. Eben dieses Exemplar hat in der Mitte eines jeden Zipfels einen feinen, braunen Längsstrich, auf dem vordern kurz und in der Mitte, auf dem hintern lang und fast bis zum Hinterrande reichend. Nur von dem erstern hat das zweite Exemplar eine Andentung. - Die Costalader ist von der Gegend des ersten Discalflecks an weiss, nach hinten breiter, bei dem ersten Exemplar blos vor der Spitze des Zipfels (wo die weisse Farbe die Franzen einnimmt) ein wenig getrübt; bei dem zweiten Exemplar hört aber die weisse Farbe bei $2 / 3$ des Zipfels ganz auf (doch sind hier die Franzen beschädigt). - Die Franzen am Innenrand des Vorderzipfels sind weisslich, aussen grau, um den Innen- 
winkel fleckartig schwärzlich; darüber liegen in den reinweissen Finterrandfrauzen zwei schwarze Punkte hinter einander. Die Franzen des Hinterzipfels: sind grau, aussen dunkel; an der Spitze des Zipfels sind sie weiss mit zwei schwarzen Punkten.

Hinterflügel braungrau; die Franzen dunkelgrau, an der Wurzel in feiner Linie hell, besonders um die Spitzen der zwei erstern Federn.

Vaterland: Texas (Boll). Zwei $0^{\pi}$ im Museum Cambridge.

\section{Mimeseoptilus pmomilio n. sp.}

I'usillus; atis unt. latioribus, ditute cervinis, parle venue costalis pusteriore alba, punctis alisci nigris 3 , ciliis laciniae postcrioris apicalibus allis, nigro-punctatis. C'.

So klein wie Leiopt. microdactylus, von allen Mimeseoptilen durch die Kiirze und Breite der hell hirschfarbenen, mit drei sehr deutlichen, schwarzen Punkten gezeichneten Vorderflügel abweichend.

liückenschild und Oberkoj,f röthlichgran, Gesicht weisslich. 'Taster ganz dünı, fadenförmig, von Kopflänge, horizontal, weisslich. Fühler hellgran, gegen die Wurzel aussen weiss. Beine fein, weiss; das erste Dornenpaar der Hinterschienen ungewölmlich lang, indem es fast bis zum Endpaar reicht. Hinterleib an Anfang und Ende gelblichweiss.

Vorderflügel $2 \frac{1}{2}{ }^{\prime \prime}$ lang, für eine Mimcs. ungewühnlich kưz und breit, sehr hell hirschbraum, an dunkelsten im Vorderzipfel, und zwar an Hinterrande am meisten. Der Vorderrand fast gar nicht verdunkelt; die Vorderrandader von (ler Flïgelhälfte an bis zu $2 / 3$ des Vorderzijfels weiss. Bei ${ }_{1}^{1}$ der Flïgellänge licgt in der Falte ein schwarzes Lüngsstrichelchen; ein lïnglicher, ansehnlicher Punkt in der Mitte zwischen ihm und der Spalte, und vor dieser ein aus zwei Längsstrichelchen zusammengellossenes Fleckchen. Die Franzen des Vorderzipfels sind an Vorderrande wie angegchen, sonst gran mit zerstrenten tiefschwarzen Schujpen, am Hinterrand mit zwei schwarzen, etwas znsammenfliessenden Punkten mahe dem untern Ende. Die Franzen des hintern Zijofels grau, reichlich nit tiefschwarzen Selüppehen bestrent, die an seinen Innemande zn drei schwarzen Flecken vereinigt sind; mu die Spitze sind sie weisslich und mit einer licilic nngleicher, etwas zusammenflicssender Punkte gezeichnet, welehe nicht bis zur Franzenwurzel reichen.

Hinterflïgel bräunlichgrau, vicl heller gefranzt. In der Spitze der ersten und zweiten Feder lässt sich in gewisser Richtung eill schwarzes Pünktchen erkemen, anf der Unterseite am deutlichsten, und hier ist auch die Spitze der dritten Feder dunkelbraun.

Vaterland: Texas (Boll). Ein ơ im Cambridger Musemm.

Anmerkung. Die Mrmescoptilus-Gruppe lässt sich im gespannten Z/nstande von Leioptilus mit Sicherheit dadurch unterscheiden, dass iln Vorrand nie mit dunkeln Flecken gezcichnet ist. 


\section{Oerlematophoms inquinatus n. sp.}

Panvus, pedibus albidis, tibiarum fasciculis exiguis, cinereis; alis ant. griseis, albulo fuscoquc lituratis, macule ante fissuram maculisque laciniac renterioris costalibus duabus menetoque his interjecto fuscis, ciliis marginis postici nigricanti-albidoque alternantibus. $0^{\pi}$ 오.

Var. b) alis cut. ulbidis, ceterum ut var. a. $q$.

Er stimmt in der Zeichnung des vordern Zipfels der Vorderflïgel geuau mit Oed. lithodactylus, luat aber keine aufgekrümmten, sondern horizontale, zxgespitzte Taster, und seine längern Mittelschieneu sind nur mit selıwachen, durch dunkle Färbung ein wenig gehobenen Haarbüsehen versehen.

Grösse etwas über der des Mimes. semicostutus. Kopf und Rïckenselìld grau, weissliclı bestäub斤. Taster klein, vorgestreckit, zugespitzt, weisslich, aussen gebräunt. Fühler weisslich, verloschen brännlich geringelt, an der Wurzel auf ler Unterseite weiss.

Vorderflïgel $4^{\prime \prime}$ lang, etwas kürzer als bei Lithodactylus, staubgrau, reichlich mit weissen und brannen Schmpen bestrent, welche hicr und da Flecke oder Wisehe bilden. Ein solcher ist gewöhnlich im Mittelraum zwischen der Flügelwurzel und der Spalte zu sehen; ein grüsserer liegt vor der Spalte, durch eine weissliche Stelle von ilı getrennt, gegen welche sein schräger Hinterrand ausgehühlt ist. Unter ihm ist ein grosser, länglieher, breiter Schuppenstreif, der vor sich (gegen die Wurzel bin) einen weissen Fleek als Begrenznng hat und gegen den Spaltenfleck durch einen weisslichen Ram getremnt wird. Auf dem Vorderrande des Vorderzipfels, dessen Franzen weiss sind, liegen zwei schwarze, strichförmige Flecke, der erste grüsser als der zweite, und zwischen beiden ein schwarzer Punkt. Die übrigen Franzen sind, besonders in der Spalte, schwärzlich srau; an der Spitze des Vorderzipfels sind sie weiss, und an dessen Hinterwinkel enthalten sie einen weisslicheu Wisch; die des Hinterziplels tragen vor' der Spitze und am Hinterwinkel emen solchen Wisch. An jeden dieser drei Wische liegt anf der Flügelflüche ein braunes Püultchen.

Hinterflügel braungran, lueller gefranzt, in der Spitze jeder Feder, viler duch der ersten, ein verloschenes brames Pünktelıen.

Die ganze Unterseite ist braungran, nud des Vorderrand der Vorterfligel ist von der Wurzel an ungeschlagen, mit etwas abstehenden weisslichen und granen Schuppen. Das Weiss zwischen den sehwarzen Custalzeichnungen an Vorderzipfel, das weisse Fleckehen an der Spalte nnd die Wische in den Franzen sind noch auffallender als anf der Oberseite.

Bei Var. b ist die ganze Grundfarbe der Vorderfiügel und des liückenschildes weisslich; die sonstigen weisshichen Stellen zeichnen sich dureh grössere Reinheit ans; die zerstreuten schwarzbraunen Schuppen sind weniger zahlreich, die Flecke aber in der Zahl und Lage nicht perschieden.

Vaterland: Texas (Boll, Belfrage). Ein ơ nebst der Vir. b im Museum Cambridge (worin sich noch mehrere befinden), drei $q$, von denen cines am ¿ə̀. Juli gefangen warde, in meiner Sammlnng. 


\section{Pterophorus monodactylus Linn.}

Alucita pterodactyla Hbn.

Zuverlässig identisch mit der europäischen Art. Ein hell rüthlich granes $\sigma^{7}$ aus Texas (Boll) im Museum Cambridge, ein mehr staubgraues $\sigma^{7}$ aus Ohio (Schläger) in meiner Sammlung, beide in gewöhnlicher Grösse und ohne jede Abweichung von den Europäischen. Schwerlich ist diese Art in neuerer Zeit aus Europa eingewandert: eine Aufklärung über den Grund ihres gleichzeitigen Vorhandenscins in Europa und Nordamerica wird wohl zugleich mit der über solche Arten wie Van. Antiopa und Atalanta erlangt werden.

\section{Leioptilus palencens n. sp.}

Major, oceipite cinnamomeo; corpore alisque anterioribus cxalbido-ochroceis, puncto ante fissuram fusco; al. post. cinereis, griseo-ciliatis. o 7 .

Er gelı̈̈rt zn der Abtheilung, bei welcher sich am Hinterzipfel gar kein Hinterrand unterscheiden lässt, indem nämlich der Innenrand in schwach concaver Linie verläuft und sich in der Spitze des Zipfels mit dem convexeren Vorderrande vereinigt. Er ist, da ihm alle Randzeichnung fehlt, mit Rhypodactylus (in Staudingers Katalog unrichtig in Mimeseoptilus gestellt), und Trimmatodactylus Christoph Hor. IX. 1872, p. 38 zusammenzustellen. Auf den Vorderflügeln hat er die hellere Farbe des Rhypodactylus; er ist aber kleiner, mit ungeringelten Fühlern, zimmtbraunem Hinterkopf, mit braunem Punkt vor der Spalte der Vorderflügel etc. Dagegen ist er bedeutend grüsser als Trimmotodactylus, mit dem er in der Farbe der Fühlex stimmt, von dem er aber als sehr versehieden erscheint durch die Glätte, grössere Helligkeit und Einförmigkeit der Vorderflügel; auch bat Trimmatodact. ein so verloschenes Pünktchen vor der Spalte, dass man (wie Christoph) es leicht ganz übersieht.

Körper und Vorderflügel sehr licht ochergelb, ohne dunklere Stäubchen. Hinterkopf dunkel zimmtbraun. Fühler in beiden Geschlechtern nikroskopisch pubescirend gefranzt, eintarbig, hell. Taster kurz und dünn, etwas aufgekrümmt und vorgestreckt. Beine weisslich; an den mittlcrn die Schenke] auswärts zimmtbrauı, die Schienen auswärts in einer feinen Linie gelbbraun. - Bauch mit drei sehr blass zimmtbräunlichen Lïngslinien. Beim $\sigma^{x}$ ist das Endglied sehr lang und zugespitzt, auf der Unterseite mit einer langen, schmalen zugespitzten, hellzimmtbraumen, weissgesäumten, in eil weissliches Schuppenbiischchen aus* laufenden Klappe, Vorderflügel $4^{\mathrm{J}} / 2-5^{\prime \prime \prime}$ lang. Der Hinterzipfel ist breiter und kürzer als der Vorderzipfel, welcher mit seiner feinen Spitze sichelförmig über ihn hinwegreicht. Grundfarbe ein sehr verschossenes, weissliches Oehergelb, an dunkelsten in Vorderzipfel, ohne dunklere Bestäubung, am Vorderraude von der Wurzel aus bis zur halben Länge weisslich, doch ohne Begrenzung und nach hiuten in die Grundfarbe übergehend. Kurz vor der Spalte ist ein etwas verlosehener brauner Funkt. Franzen von der Grundfarbe, höchstens am Hinterrande etwas dumkler.

Hinterflügel bräunlichgrau, lichter gefranzt. - Unterseite einfarbig hellbräunlichgrau. 
Durch Einwirkung des Wetters und längern Fluges wird die Farbe überall fast weisslich, sogar am Hinterkopf. Doch scheint der Punlt vor der Spalte sich standhaft zu behaupten.

Vaterland: Ohio (zwei $\sigma^{7}$ durch Schläger in meiner Sammlung) und Texas (zwei $\sigma^{\nearrow}$ ein $ᄋ$ im Museum Cambridge).

Anmerkung. Ein ganz abgeflogenes $\sigma^{\prime}$ atus New-York in weiner Sammlung ist viel grösser. Seine $6^{\prime \prime}$ langen Vorderflügel sinả ganz weiss geworden, ausser dicht an der Wurzel des Innenrandes, wo sie noch etwas Gelbes haben. Es fehlt aber der Punkt vor der Spalte völlig; die Franzen sind in der Spalte rein weiss. Der Bau der Zipfel ist derselbe wie bei Paleaceus. Die Hinterflügel sind fast weissgrau. Die untere Analklappe ist schmäler, länger, auf der Fläche beschuppt und einfarbig weisslich. - Hiernach scheint das Exemplar eine verschiedene Art zu bilden. Gewiss giebt es aber in Nordamerica noch melır Arten ans dieser Gruppe.

\section{Ścoptomoma 11. gg. oxẃrs sty irridere - vou.os lex.}

Char. cssent: Antenuae alis anterioribus longiores; alcue integrae, anteriores sine plica heteronoma, angulo dorsali prominente; tibiae sine nodis. Antenuare filiformes. - Ocelli rlistineti.

Palpi labiales mediocres, porrecti, squamosi, acuminuti.

Haustellum longum, crassum, convolutum, squamulatum.

Pedes longi, graciles, tibiis posticis breviter calcaratis.

Abdomen nodutis squamatis exiguis marginutum.

Alcue integrae, clongatae; anteriores acutac, postice dilatatae, angulo dorsali distincto, plica heteronoma nulla; posteriores elongato-ovatae, subacutae.

Diese Gattung zeichnet sich durch den Mangel des kleinschuppigen Feldes auf den Vorderflügeln aus; obgleich ich aber kein ungespanntes Exemplar gesehen habe, so halte ich es doch nicht für ausgemacht, dass die Flügel in der Ruhe nicht der Länge nach getaltet getragen werden. Dass die Gattung nicht etwa zu den Pyraliden gehört, beweisen die Hinterschienen, welche über doppelt so lang wie die Schenkel sind. Ausser durch den Mangel des heteronom beschuppten Feldes unterscheidet sie sich von Agdistis und Stenoptycha (Ent. Ztg. 1863 p. 154) noch durch die Länge der Fühler, und von Stenoptycha, der sie durch die ausgebildete Flügelzeichnung am vächsten steht, durch die knotenlosen Beine, von Agdistis durch den stärker hervortretenden Innenwinkel der Vorderflügel und die Breite der Hinterflügel.

Das Geäder ist folgendermassen beschaffen. Auf den Vorderflügeln ist die Costalader bis zum ersten Ast der Subcostalader stark verdickt. Von der vordern Basis der Subcostalader geht keine Ader in den Vorderrand (12 fehlt also), sondern der erste Ast kommt aus der Mitte und verläuft mit den zwei folgenden parallel, von denen der letzte in eine Gabel getheilt ist. Die Mittelzelle ist durch keine Querader, sondern durch eine kaum bemerkbare concave Hantfalte geschlussen, aus welcher drei Adern zum Hinterrande gehen. Die Medianader 
theilt sich in drei Aeste, deren erster vom folgenden weit entfernt entspringt und ganz gerade ist. Die Subdorsalader, die an der Wurzel keine oder eine selsr kurze Gabel bildet, mündet in den Innenwinkel. - Auf den Hinterflügeln theilt sich die Subcostalader in drei Aeste, deren oberster in den Vorderrand mündet, während der folgende in die Flügelspitze, der dritte in den Hinterrand auslänft. Die Mittelzelle ist durch eine sehr schräge, rückwärts nach oben ziehende und

- dann sich zum ersten Subcostalaste zurückliümmende, schwache Falte geschlossen, aus deren hinterstem Ende eine Ader zum Hinterrande läuft. Dic Medianader theilt sich in drei Aeste, von denen der erste vom zweiten weit absteht und in die Mitte des Hinterrandes mündet. Zwisehen ihm und dem Innemrande sind drei freie Adern, und zwischen je zwoi derselben eine zarte Falte.

\section{Futegrue 11. sp. Fig. 44.}

Alis ant. griseis, macule magna costce ante apicem fusco-cinnamomea, fascia dilute cinnamomea ex dorso ante medium usque prope costam post medium curvata, deinde deflexa, denique adversus apicem coarctata alboque temiter marginata. or 9 .

Sehr ähnlich der folgenden, aber durch den geschlängelten, nnunterbrochenen Lanf des bindenförmigen, zimmtbrannen Streifs sicher zu unterscheiden, und wie diese schwierig. zu beschreiben.

Kopf vorstehend, gelbbrännlichgrau nit einer weissen Linie, die sich am obern Augenrande entlang und um den Unterrand des Gesichts herumzieht und sich in rein weisser Farbe bis ans obere Ende des Wurzelgliedes der Fühler verlängert. Ocellen sehr deutlich. Fühler viel länger als die Vordertlügel, fadenförmig, dünn, mit ganz feiner, weisser Rückenlinie, sonst weisslich und verloschen gelbbräunlich geringelt, gegen die Wurzel nit verlüschenden weisslichen Ringen. Taster ziemlich weit vorstehend, reichlich und lang beschuppt, stark zusammengedrückt; das Endglied schmaldreieckig, dünn, zugespitzt. Saugrüssel stark und lang, auf dem Rücken weisslich feinbeschuppt. - Rückenschild gelbbräunlich grau. Beine dünn und lang, weissgrau, die vier vordern aussen braun bestäubt; die Hinterschienen mit zwei Paaren sehr kurzer, feiner Dornen versehen und am Ende etwas gebräunt, ohne Schuppenbüsche. Hinterleib des $\sigma^{\prime}$ dümn, hellgrau, am Bauch weisslich, auf jedem der hintern Segmente über dem seitlichen Schuppenbüschchen mit braunem Längsstrich; Afterbusch länglich, langschuppig (Hinterleib des $q$ fehlt).

Vorderflügel $4^{\prime \prime \prime}$, schmal, nach hinten stark erweitert, dann deutlich zugespitzt, am Innenrand concav, am Hinterrande ziemlich grade, weisslich and bräunlichgrau schattirt, auf den Enddrittel des Vorderrandes mit vier ungleichgrossen, zimmtbraunen Fleckchen; dem zweiten, grössten schliesst sich unterhalb ein grosser, nach hinten gespitzter zimmtbrauuer, mit mehreren schwarzen Linieu durchzogener und unterwärts verdunkelter Fleck an, den fast ringsum eine feine, scharfe, weisse Linie einfasst. Ein hellerer bindenförmiger Streif entspringt breit anf dem Innenrand vor der Mitte, zieht gebogen bis nahe zum Vorderrand hinauf, biegt sich dann wieder abwärts, worauf er, mit der Richtung gegen die Flügel- 
spitze, sich zu einer Linie verdiinnt, die einwärts von der weissen Begrenzungslinie des grossen Flecks, auswärts lureh eine eben so stharte, weisse Linie gesäumt wird. Genau genornmen hürt dieser streif schon viel früher auf, und es ist nur der hellzimmtfarbene Grund vor dem Hinterrande, der die Fortsetzung zu bilden scheint; auch die weisse äussere Einfassungslinie setzt sich zu einem verloschenerm Ziekzack fort, welches bis zur Mitte des Innemrandes verlängert ist. Der bindenförmige streif ist bis zu seinem wirklichen Ende innen saumwärts dunkelbraun schattirt und ausserden! von weisslicher" Grundfarbe begrenzt. In einiger Entfernung vor dem Hinterrande zieht eine feine, weisse Querlinie, die weder die Flügelspitze, noch den Innenwinkel erreicht; aut ihr ruhen einwärts zwei helle Stellen in der zimmtbräunlichen Grundfarbe. Franzen auf der Wurzelhälfte zimmtbrïunlich, auf der Endhälfte mit ein paar weisslichen Wischen gegen die Flügelspitze und einer grossen weissen Stelle über dem Innenwinkel, an dem sie verdunkelt sind.

Hinterflügel gelblichgran, an Hinterrande verduukelt und mit einem weisslichen Wisch auf dem Ende der Medianader. Den Hinterrand fasst eine branne, einwärts weisslich gesäumte Linie ein, welche aber weit vor deın Analwinkel verschwindet. Die fast weisslichen Franzen sind von einer bräunlichen Linie durehzogen.

Auf der Unterseite der Vorderflügel scheint die Zeichnung der Oberseite verlosehen durch; nur die weissen Linien vor der Flügelspitze und die des Hinterrandes sind eben so seharf, und die Franzenzeichnung ist fast eben so deutlich. - Hintertlügel weisslich, in der Spitze dunkelgrau mit einer weissliehen, braungesäumten Querlinie davor am Vorderrand. Dieser ist in einem schmalen Streif braungrau bestäubt, nnd ein solcher staubfleck zieht vor dem Analwinkel von Hinterrand aus zugespitzt gegen die Wurzel; die Randlinie und die Franzenzeiehnung sind verlosehener als oben.

Vaterland: Texis (Boll). Ein Paar in meiner Sanmlung, mehrere nach Hagens Angabe in Canbridger Museun.

\section{Interrupta и. sp.}

Alis ant. griseis, maculu magna costae ante apicem cinnamomea, fascia cancolore prope dorsum medium. oricnte, oblique udscendente, infra costam intermpta, deinde deflexa, denique adversus apicm coarctatu exalbidoque tenuiter marginata. or 9 .

Bei ihn ist der breitere, zimmtbraune Streif (wirkliche Bincle) an seinem Ursprung vom Inuenrand breit getrennt, hat nicht den sanftgebogenen Verlauf, sondern bilket an seiner höchsten Erhebung einen Winkel, in welehem er unterbrochen ist und wird an stinem zugespitzten Ende von schmutzig gelblichen Linien eingefasst. Auch sind die Hintertiuggel breiter und stumpfer.

So gross oder anch ein wenig grösser als Sc. integru. Fühler bräunlichgrau, ganz ohne Ringe. Der weibliche Fiinterleib viel krälitiger als beim $\sigma^{-1}$, um die Mitte herum verdickt, dann sanft zugespitzt, lehngelblichgrau, an der Wurzel schmatzig weisslicin. 
Auf den Vorderfligeln ist alles Weisse durch brïunliche Beimischung getrült und undeutlicher. Statt des Querstreifs der Integra ist eine breite, weniger nach hinten geneigte, an ihrem Aussenrande gradlinige Binde vorhanden, die an ihrem Ursprunge durch einen hellen Raum rom Innemrand breit getremnt bleibt und etwas höher linauf durch die helle Medianader durchischnitten wird; nahe an Vorderrand ist sie ganz unterbrochen, worauf sie sehr verengt abwärts geht, nachdem sie mit dem ersten Arm einen fast rechten Winkel gebildet hat; hierauf stimmt sie in Gestalt und Richtung mit Integra. Die Costalflecke sind blässer als bei dieser. - Die Hinterfügel sind viel breiter und stumpfer, etwas dunkler, einfarbig: am Analwinlel sind sie, wie in einiger Entfernung vom Hinterrand an der Medianader, braunschuppig. Auf der Unterseite ist zwischen den Aesten der Subcostalader in der Flügelspitze eine dunkelbraune Schuppenwolke und der Stanbfleck vor dem Analwinkel ist anch dunkelbrann.

Vaterland: Texas (Boll). Ein o zwei $Q$ in meiner Sammlung, nach Hagen mehrere im Cambridger Museum. Diese Art scheint früher aufzutreten als Sc. integra, da meine Exemplare, besonders an den Franzen, durch den Flug beschädigt sind. 


\section{Benennung der Figuren.}

Taf. III.

Fig. 1. Agrophilu truncetule S. 203.

๓ 2. Metoponiu outusula S. 204.

"3. Cordylopeza niyninodis S. 206 .

Ł. weiblicher Vorderfügel.

c. Mittel- und Hinterbein.

d. e. Flügelgeäder.

4. Bot is vibiculis S. 20 S.

5. - sesquiulteralis S. 209.

6. - nesonialis S. 209.

7. Oroberu octunutis S. 211.

8. Tiner defectellı s. 220.

9. - grumelle S. 221.

10. Adelu biviella \$. 226.

"11. - Schlcueyeri s. 227.

n 12. Cryptolechiu mabeculosa S. 245.

"13. Enicorthylis inversella \$. 248.

b. Lippentaster.

. 14. Gelechia quinglle S. 260.

15. - Olympiudella S. 25!.

16. - albitorella S. 261.

17. - operculella ( $\sigma$ Hinterleibs. ende) S. 262.

"18. - glochinelle (o Hinterleibsende) S. 263.

^19. - ternariella S. 264.

ᄁ20. - dorsivittelles S. 267.

"21. - Tenconota S. 268.

.22. - busifusciella S. 262 .
Taf. IV.

Fig. 23. Gelechia basistrigella S. 270.

724 - roseosufjuselle S. 272.

.25. - glantiferella S. 275.

"26. - flarveustella S. 279.

"27. - serrativittelles S. 2 SO.

28. - bilobella s. 280 .

b. Taster.

n 29. Enchrysu dissectella S. $28 \%$.

b. Geäder des Vorderfügels.

* 30. Nothris dulubella S. 285.

b. Lippentaster.

31. Oecophora determinatella 289.

" 32. - cunstrictella S. 291.

- 33. Bututis trivinctellu S. 292.

b. Hinterleil.

- 34. Blustobrisis sciaphilella \$. 295.

$\rightarrow 35$. - segrella S. 290.

^ 36. - mubilella S. 297.

. 37. - fractilinea S. 298.

b. unterer 'Theil des Fühlers.

. 38. Argyresthice uusterella s. 305.

`39. Gracilaria Burgessielle S. 307.

40. - desmorlifutielle S. 308.

. 41. Laremu affinitella S. 311.

b. Lippentaster.

" 42. - circumscriptella s. 312 .

b. Lippentaster.

43. Plyliacnistis maynatella S.315.

- 44. Scoptonoma integra s. 328. 


\section{Register.}

\begin{tabular}{|c|c|c|c|}
\hline & Seite & & Seite \\
\hline Abdominatis 7. (Argyresthia). & 306 & Clurlybeis n. sp. (Adelu). . & \\
\hline Aduncelle Z. (Gelccleie) . . & 275 & Circumseriptella n. sp. (Laverna) & 312 \\
\hline Agrimoniella Cl. (Gelechio) & 275 & Colonella Hein. (Aphom.) . . . & 212 \\
\hline Alucella Cl. (Trichatuphe) . & 279 & Compta Grote (Octa) . . . & 29 \\
\hline Alha n. sp. (T'egeticula). . & 232 & Confectclla n. sp. (Hypatima). & 303 \\
\hline Albigmettate n. sp. (Octa) . & 230 & Congeminutella n. sp. (Xylesthia) & 18 \\
\hline Albitorelle n. sp. (Gelechia) & 261 & Consonella n. sp. (Gelechia). . & 51 \\
\hline Anapteora Clem. .... & 214 & Consirvictelle n. sp. (Oecophen'u) & 291 \\
\hline Andereggiella F. P. (Argyresthia) & 304 & Conetubervalellus Fitch (Chacto- & \\
\hline Apicalis Vollenh. (Attera) . . & 231 & chilus) . . . . . . & 285 \\
\hline Atomosella n. sp. (Gracileria) & 309 & Correcipenella H. (Coleophorer). & 09 \\
\hline Atrodorsella Cl. (Depressaria) & 233 & Covelytopnace m. \%. . . . . & 96 \\
\hline Atteva Walker . . . . . & 229 & Coroniella CI. (Grracilarin). . & 307 \\
\hline Aufuggella n. s!̣. (Blerstoluasis?). & 300 & Comecipennelle Cl. (Coleophora) & 11 \\
\hline Arsterella n. sp. (Argyresthia). & 305 & Cretacere n. sp. (Cryptolechie). & 243 \\
\hline Busatis Tollenh. (Atteva). . & 229 & Crucifurarum \%. (Plutellu). & 233 \\
\hline Busifresciellu n. spr. (Gelechior) & & Defectella n. sp. (Timere). & 220 \\
\hline Brtsilaris 7. (IButulis) , . . & 292 & Definitelle n. sp-(Lewerve) . & 311 \\
\hline trigella n. sp. (Grelechior) & & Delaurarieus 11. sp. (Oxyptilus). & \\
\hline Biflavimaculella Cl. (Tinea). & 220 & Deletellu ". sł. (Argyresthio). & 305 \\
\hline Bilobclle n. s]). (Gelechia) & 280 & Depressurie . . . . . & \\
\hline Bischoffii \%. (Plutymtitiu) & 317 & Desmoulifaliella Cl. (Gracilaria). & 308 \\
\hline Bisclliellu Humm. (Tinea) & 223 & erminutelle n. sp. (Oecophora) & 289 \\
\hline Biviclles แ. sj!. (Ailcle). & 226 & Dissectellı и. sp. (Enchrysa). . & 283 \\
\hline Tilestobasis Z. . . . . . & 295 & Dolribella n. sp. (Nothris) . & 288 \\
\hline Bombincina n. s]. (Anequhorel) & 216 & Dorsistrigelle Cl. (Tinea) & 220 \\
\hline Bortilertusenii Z. (Occophore). & 290 & Dersivittelle n. sp. (Gelechire) & 267 \\
\hline Bressicella Fitch (Cerostoma). . & 233 & Eboraccusis Z. (Butulis) . . & 244 \\
\hline Burgessiclle n. sp. (Giocilurir) . & 307 & Efiremetell Cl. (Amydria). & 219 \\
\hline 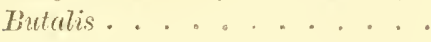 & 292 & Enchrgasu n. g. . . . . & 282 \\
\hline Caecella n. sp. (Gelechia) . . & 252 & Epriconthylis n. \% . . . & 248 \\
\hline Cardui Z. (I'latyntilia) . . . & 318 & Ericetellu Hibn. (Gelechire) & 258 \\
\hline Cavlucilactylus Ril y (Pterophomes & s) 318 & Fuloriciella Vill. (Colcophor a) . . & 311 \\
\hline
\end{tabular}


Seite

Falconipemellu H. (Gracilaria) . 307

Ferruginosa n. sp. (Cryptotechia) 243 Flavifiontella Cl. (Butalis) . . 292 Flavivittellus Cl. (Ypsolophus) . 283 Flavocostella Cl. (Gelechia) . . 279 Fluxclla n. sp. (Blastobasis?) . 301 Fractilinea n. sp. (Blastobusis?) 298 Fragmentella n. sp. (Gelechia) , 271 Fullonella n. sp. (Gelechiu) . . 276 Fulviguttata n. sp. (Oeta) . . 231 Furellus n. sp. (Melissolulruptes) 212 Fuscicomella Cl. (Butalis) . . 292 Gullinella Tr. (Gelechia) . . . . 258 Gitvicomella Cl. (Gelechica) . . 260 Gilviscopella n. sp. (Gelechia) • 266 Glandiferellu n. sp. (Gelechia) . 275 Glochinella n. sp. (Gelechio). . 263 Graciluria . . . . . 306 Gracilis n. sp. (Heliozela) . . 314 Grumellu n. sp. (Tiner) . . . 221 Heracliana Deg. (Depressuria) . 235 Hitarella n. sp. (Depressurice) . 234 Holcucera Clem. . . . . 295 Impositella Z. (Butulis) . . . 292 Inumoenella. n. sp. (Setomonplua) 224 Invocuella n. sp. (Celecliri) . 249 Inquinatusn.sp.(Oalematophoms. 325 Integra n. sp. (Seoptonomre) . . 328 Intervepta n. sp). (Seonstonuma). 329 Inversellu n. sp. (Epricorthylis) . 248 Lanariella Cl. (Tinea) . . . . . 223 Lutro n. sp. (Melissollaptes) . 213 Leaconota n. sp. (Gelechia) . . 268 Limbipennella Cl. (Plutellu) . 233 Lithosina n. sp. (Cryptolechia) . 244 Liturosella n. sp. (Gelechici) . 265 Livorcllu 11. sp. (Blrustobusis) . 299 Lobirlactylus Fitch (Pterophons) 323 Luctiferella H. S. (Gelechiu) . 262 Luscinutu n. sp. (Cidaria) . . 205 Lynceella n. sp. (Gelechia) . . 255 Muchimia Cl. . . . . . 238 Magnatella в. sp. (Phyllocnistis) 315
TI al acotivichate

Malacotricha Z. . . . . 280 Malifuliellus Fitch (Chuctochilus) 285 MIatutellu Cl. (Butalis) . . . 202

Mayrella H. (Coleophora) . . . 311

Mendicella H. (Tinea) . . . . 220

Misella 7. (Tinea) . . . . . 223

Mulestella n. sp. (Gelechia) . 274

Mollipeilella Cl. (Plitella) . . 233

Monodactylus L. (Pterophorus) 326,

Multipunetellus Cl. (IIyponomeuta)

228

Muscertella is. sp. (Cryytulechia) 246

Nasonialis n. sp. (Botis) . . 209

Nebulosa n. sp. (Depressaria) , 237

Newmanella Cl. (Dusycerti) . 289

Nigialbella Z. (Tiner) . . . . 221

Nignicella Haw. (Coleopleon'c) . . 309

Niyninodis n. sp. (Cordylopeza) . 206

Nigrocitiatus n. sp. (Oxyptitus) 322

Niveiguttata W. Kr. (Attena) . 231

Nubeculosa n. sp. (Ciyptolechia) 215

Nutuileller n. sp. (Blustoluasis) . 297

Nubilipennellic Cl. (Tinea) . . 222

Numelinelle n. ș!r. (Gelechir) . 256

Otwutelle 11. sp. (Trifureula) . 316

Obsoletelli n. sp. ('iryptolechior) 242

Obtusula n. sp. (Metopomiri) . . 204

Uccidentis n. sp. (Coleophorre) . 309

Ochripalpella Z. (Ǵelectiru) . . 279

Octonulis n. sp. (Orolonure). . 211

Olympiudellu n. sp. (Gelechic) . 259

Ontariella Bethune (Depressaria) 235

Operculella n. sp. (Gelechiu) . 262

Operosella n. sp. (Setomorpha) . 223

Orcasella Cl. (Argyrestlia) . . 304

Paleuceus n. sp. (Leioptitus) . 326

Punciguttellus Cl. (Ypsolopihus) . 283

Periscelidactylus Fitch (Oxy), tilus) 319 Phyllocnist is . . : . . . . . 314

Pilusella n. sp. (Butulis) . . . 298

Piperutella n. sp. (Cryptolechiu) 239

Piscivellis n. sp. (Gelechice) , 277

Plumifrontella C.. (Anuphora) 217 
Ponctellus Harr. (Chaetochitus). $\begin{array}{r}\text { Seite } \\ 285\end{array}$ Popernella Cl. (Amuphora) . . 215 Pruniella Cl. (Coleophora) . . 309 Pruniramiella CI. (Xylesthia). . 217 Psilocorsis Cl. . . . . 239 Pterodactyla H. (Alucita) . . . 326 Pudibundella n. sp. (Gelectia) . 273 Pumilio 11. sp. (Mimeseoptilins) . 324 Punctella Cram. (Oeta) . . . 228 Punctidiscellus Cl. (Ypsoloplurs) 285 Pustulella Fabr. (Tinea) . . . . 228 Quadristrigellan.sp. (Argyresthia) 304 Quercieella Cl. (Cryptolechia) . . 240 Quinella n. sp. (Gelechia) . . 260 Quisquilielle n. sp. (Blastobusis) 298 Retectella n. sp. (Blistobasis) . . 297 Rhoifructella Cl. (Gelechia) . . 252 Roseo-suffusella C1. (Gelechia) . 272 Rudevella n. sp. (Setomorpha) . 225 Rusticella H. (Tinea) . . . . . 220 Salicipomonella Cl. (Batrachedra) 313 Scabella n. sp. (Depressaria) . . 236 Scardina n. sp. (Anupliora) . 214 Selduegeri n. sp. (Adela) . . . 227 Schluegeri Z. (Cryptolechia) • 246 Sciantilella n. sp. (Blastobasis) . 295 Scoptonomere t. g. . . . 327 Segnella n. sp. (Blustubusis) . 296 Semicostatus n.sp.(Mimeseoptilus) 323
Sequax Haw. (Gelechiu) - - nete

Serrativittella n. sp. (Gelechia) , 280 Sesquialteralis n. sp. (Botis) . . 209 Setomorpha Z. . . . . 223 Sociella Linn. (Aphomia) . . 212 Spretella S. V. (Tinea) . . . . : 222 Striolata n. sp. (Batracledra) . 313 Subsenella n. sp. (Hyputima) . . 302 Syringella Fabr. (Grocilaria) . . 306 regeticula $\boldsymbol{n} . \boldsymbol{y}$. . . . . . 232 Tentoriferella Cl. (Cryptolectia) . 238 Temiilactylus Fitch (Pteroplonus) 322 Tenuiella Mann (Gelechia) . 277 Termariella n. sp. (Gelccliu) . . 264 Terrealis Tr. (Botis) . . . . . 210 T'essella Hbn. (Gelechia) . . . . 260 Trivinctella n. sp. (Butalis) • . 292 Truncatula n. sp. (Agroplita) . 203 Unctulella n. sp. (Gelechice) . . 257 Unicipunctellus Cl. (Ypsolopluus) 286 Venustella Cl. (Gracilaria) . . . 306 Versutella n. sp. (Gelechici) . . 253 Vestalis n. sp. (Cryptoleclia) . 247 Vitricalis n. sp. (Botis) . . . 208 Violucellet Cl. (Gracilaria) . . . 308 Violuceofusca n. sp. (Gelechia) . 258 Titigenella Cl. (Ployllocnistis) . 314 Xylesthia Clem. . . . . 217 

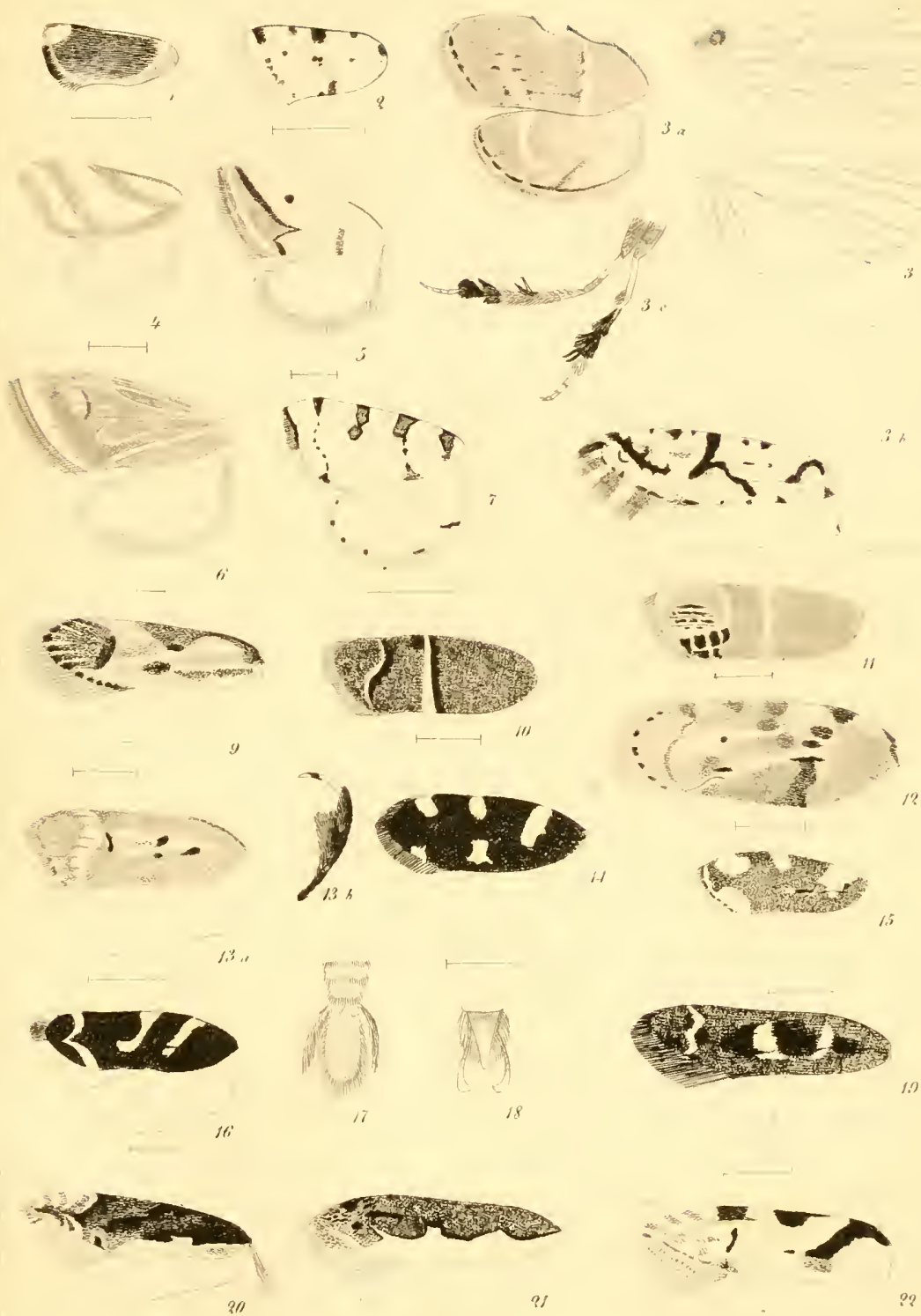



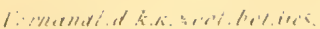

Bund $1 \mathrm{X} / \mathrm{II}$ औ?.

Taf.II.

$P i$

9.3

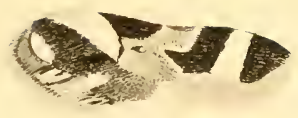

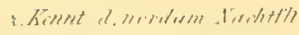

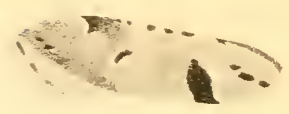

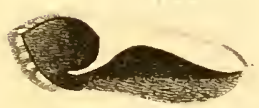
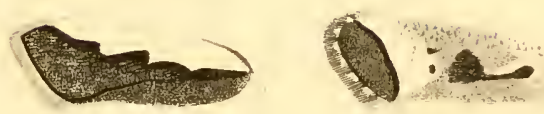

27
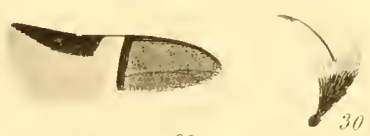

$1-$

998

29 a<smiles>C=CCC#CC(C)=CCC</smiles>

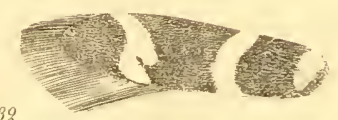

$33 \mathrm{re}$

$V^{33}$

$\therefore:$

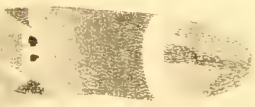

$3-2$

$37 \pi$

\section{and \\ $3 i 1$}

"n

整
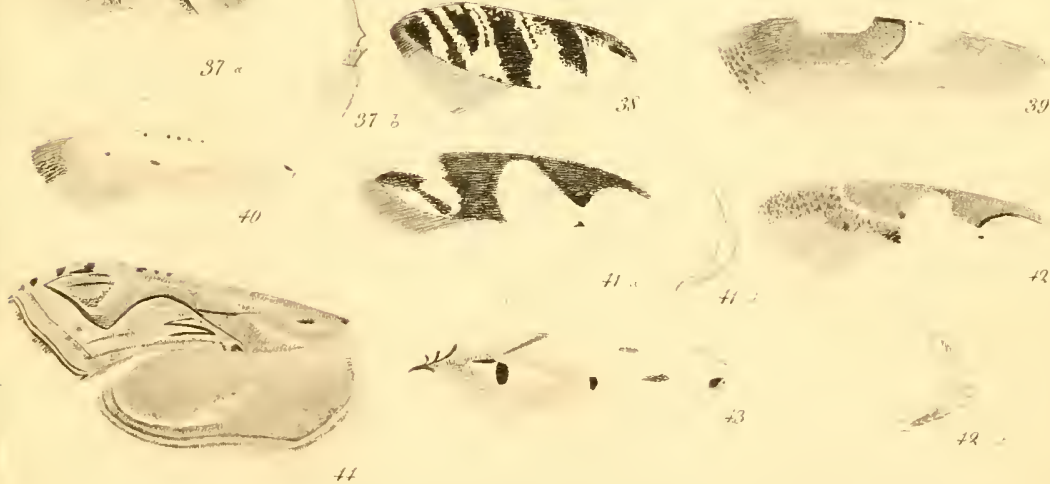

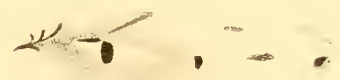





\section{Beitrïge zur Kenntniss}

\section{nordamericanischen Nachtfalter}

\section{besonders der Microlepidopteren}

\section{Professor P. C. Zeller}

in Grünhof bei Stenttin.

D $r i t t e A b t h$ e $i l u n g$.

Mit Tafel VIII-X.

Wien, 1875.

Druck vun Adolf II 0 l $\%$ hansen. 



\author{
Beiträge zur Kenntniss
}

\title{
der \\ nordamericanischen Nachtfalter
}

besonders der Microlepidopteren

von

Professor P. C. Zeller

in Grünhof bei Stettin.

Dritte A b t h e i l u $\mathrm{ng}$.

Mit Tafel VIII-X.

( $A$ us den Verhandlungen der k. k. zoologisch-botanischen Gesellschatt in Wien

[.Jahrgang is75] hesonders abgedruckt.)

Wien, 1875.

Druck von $A$ d n $1 \mathrm{f} H$ ol z hans $n$. 



\title{
Beiträge zur Kenntniss
}

der

\section{nordamericanischen Nachtfalter,}

\author{
besonders der Microlepidopteren \\ von \\ Professor P. C. Zeller \\ in Grünhof bei Stettin. \\ Dritte Abtheilung. \\ Mit Tafel VIII-X.
}

(Vorgelegt in der Jabressitzung vom 7. April 1875.)

(Aus den Verhandlungen der k. k. zoologisch-botanischen Gesellschaft in Wien

[Jahrgang 1875] besonders abgedruckt.)

Das vorliegende dritte und wahrscheinlich letzte Heft meiner Beiträge zur Nachtfalter-Fauna Nordamericas enthält einen grossen Theil der in meiner Sammlung und in Cambridger Museum vorhandenen Tortricinen und einen Nachtrag von Berichtigungen und Ergänzungen zu den zwei ersten Heften.

Ueber die Tortricinen sind die zwei wichtigsten von Americanern gelieferten Arbeiten die von Brackenridge-Clemens und Coleman Robinson. Ausserdem sind mehrere Arten, zum Theil mit ihrer Naturgeschichte von Harris, Fitch, Riley, Grote u. A. bekannt gemacht worden.

Clemens' Aufsätze sind in den Proceedings of the Academy of Natural Sciences of Philadelphia und in den Proceedings of the Entomological Society of Philadelphia erschienen. In dell ersteren (Jahrgang 1860. S. 345-62) sind 40 Arten, in den letzteren in Vol. I (1862), S. 137 eine Art, in Vol. II (1863), S. 417-18 3, in Vol. III (1864), S. 510-20 25, in Vol. V (1865), S. 133-142 22, also im Ganzen etwa 90 Arten beschrieben.

Clemens erklärt (1860, S. 360. W. Stainton S. 154) die Wickler für die wahrscheinlich schwierigste Falterfanilie in systematischer Hinsicht, zugleich aber auch für die uninteressanteste von allen. Ich finde in dieser Behauptung einen Widerspruch, in den er nicht verfallen wäre, wenn er sich länger mit dem Gegenstand beschäftigt und ein reichhaltigeres Material gehabt hätte. Dass er hinsichtlich der Schwierigkeit, die Gattungen scharf und naturgemäss abzugrenzen, Recht hatte, kann nicht geläugnet werden. Wir sind noch so fern von einer guten Classification der Wickler, das Wocke im Staudinger-Wocke Catalog die neueste, die Heinemann'sche, nur theilweise angenommen hat. Eine befriedigendere aufzufinden, als die Guenée-Wilkin s on'sche, die Clemens allein zur Verfügung hatte, wäre doch gewiss keine uninteressante Beschäftigung gewesen. 
Ungeachtet des Widerwillens, den er offenbar gegen die Wickler empfand, der sich aber sicher gelegt hätte, wenn ihm ein längeres Leben beschieden gewesen wïre, hat er sich doch gewissenhaft bemübt, seine Arten kenntlich zu beschreiben. Nun besitzt aber Nordamerica eine recht bedeutende Zahl, und viele derselben sind, wie die europäischen, entweder einander sehr ähnlich oder grosser Abänderung unterworfen. Bei aller Sorgfalt kann es daher nicht ausbleiben, wenn das Material zu mangelhaft ist, dass manche Beschreibungen an Dunkelheit leiden und erst richtig zu verstehen sind, wenn man die Originale vergleichen kann.

Dieser Schwierigkeit abzubelfen hat Robinson angefangen, indem er die Clemens'sche Sammlung zur Bestimmung der Arten benutzte und jede neu beschrieb und durch gute Abbildungen erläuterte. Leider hat ihn ein plötzlicher Tod gehindert, mehr als die drei Genera des Staudinger-Wocke Catalogs: Tortrix, Teras und Conchylis zu bearbeiten. Die Arbeit ist in den Transactions of the American Entomological Society 1869, S. 261-288 (Tafel 1. 4-8) enthalten. Mit einem sehr beträchtlichen Material ausgerüstet, hat er nicht blos die Clemens'schen, sondern eine Anzahl neuer Arten geliefert auf eine Weise, die fast nichts zu wünschen übrig lässt und wohl als Muster für künftige Arbeiter auf diesem Felde aufgestellt werden kann.

In meiner vorliegenden Arbeit habe ich es also bei den drei von Robinson behandelten Gattungen leicht gehabt, und ich darf wenig befürchten, eine dahin gehörige ältere Art verkannt oder eine Art unrecht als neu aufgestellt zu haben, vorausgesetzt, dass sie nicht in einer mir verborgen gebliebenen nordamericanischen Schrift vorkommt. Ganz anders steht es mit den Arten der übrigen Gattungen. Bei diesen werde ich manches Synonym geliefert haben! Da es aber jedenfalls weniger schädich ist, eine Art unter zwei Namen, als zwei Arten unter einem vor sich zu haben, so habe ich, wo ich nicht völlig sicher zu sein glaubte, eine neue Beschreibung unter einem neuen Namen verfasst und meine Bedenken gegen die Annahme einer älteren Benennung erwähnt. Weun ich nun auch eine ganze Anzahl Arten überging, weil sie zu den schwer kenutlich zu machenden oder zu den in der Zeichnung veränderlichen gehören, so blieben doch viele, die ich nicht unerwähnt lassen wollte, die ich aber nur in einzelnen oder wenigen Exemplaren vor mir hatte. Um die Wahrscheinlichkeit, treffende Beschreibungen zu geben, zu erhöhen, bemühte ich mich bei nordamericanischen Lepidopterologen um Vermehrung meines Materials; aber ungeachtet der mir bereitwillig gegebenen Versprechungen erhielt ich - ausser 5 Exemplaren, die als zu hinreichend sichern Arten gehörig mir überflüssig waren - rein gar nichts. Da ein längerer Aufschub der Publication meiner Arbeit aus mehreren Gründen nicht angeht, so muss ich also die vielen auf unicis beruhenden Species ihr Heil versuchen lassen. Einigermassen ist dem Verkennen dadurch vorgebeugt, dass ich von mancher Art die genaue Abbildung eines Flügels gebe; aber gerade bei den schwierigsten Arten, für welche diese Hilfe recht am Orte wäre, musste ich dies unterlassen, weil bei ihnen blos Schwarz und Weiss nicht hinreicht, sondern Illumination erforderlich ist. Meine 
Beschreibungen werden zum Theil für europäische Lepidopterologtn verständlicher sein als für nordanericanische, weil ich die Arten meist mit allgemein bekannten europäischcn verglichen habe. Die Norlamericaner künnen, wenn sie ihre Arten richtig ktmmen wollen, die Kenntniss der curopäischen nicht entbehren, und so mag ihnen meine IVicklerarbeit mit Veranlassung sein, mit den europäischen Lepidopteristen mehr als bisher in Verkehr zu treten.

Nachträge und Berichtigungen, namentlich in der Synonymie, hätte ich zu den zwei früheren Arbeiten zahlreicher liefern köunen, als geschehen ist; ich unterliess sie aber, wo mir die Mittel feblten, mich zu überzengen, dass ich eine wirkliche Berichtigung brächte. Ueberhaupt sind es aber schon mehr, als ich in so kurzer Zeit für möglich gehalten bätte.

Als Ablürzungen habe ich angewendet: Våfl. für Vorderflügel, Htfl. für Hinterflügel, VJrd. und Itrd. für Vorder- und Hinterrand, R. und K. für Rückenschild und Kopf, Ex. für Exemplar.

\section{Teras Tr. $\left.{ }^{1}\right)$}

Betrachtet man die Bilder der 7. Robinson'schen Tafel, so scheint es leicht, fast in allen europäische Arten wieder zu erkennen. So sehen z. B. ansser Fig. 63, die Robinson selbst für Hastiana var. divisana erklärt, Fig. 60, 61, 62, 73 wie Abänderungen unserer so veränderlichen Hastiana aus. Vergleicht man sie aber mit europäischen Ex, so wollen sie nicht in allen Punkten damit übereinstimmen, und das gilt auch von den Beschreibungen, die zum Theil wieder tetwas von den Bildern abweichen. Robinson's Verfahren, solche Aiten, die europäischen ähnlich sehen, aber sich nicbt mit Ueberzeugung für identisch mit ihnen erklären lassen, neu zu benennen, ist gewiss nicht zu missbilligen; er hätte aber jede Art mit der entsprecheuden europäischen vergleichen und die von ihm aufgefundenen Verschiedcnbeiten angeben sollen. Nit ihm nebme ich an, dass die Identität mancher euroläischen und americanischen Teras-Arten sich erweisen werde; denn da fast alle als Schmetterlinge überwintêrn, so ist tine Verpflanzung aus Europa nach Nordamerica bei ihnen so leicht ausführbar wie bei den Depressarien.

Die Arten, welche auf den Vdfl. Schuppenhöcker oder den Vdrd. von der Wurzel aus durch horizontal he1vorstehende Scbuppen rauh haben (HerrichSchäffer's Charakter für Teras), sind leicht als zu Teras gehörig zu eskennen (wobei nur hinsichtlich der zur Abtheilung Platynota gehörigen Tortrices die nöthige Vorsicht zu ûben ist). Wo beides fehlt, geben die verläugerten Fransen des Analwinkels der Htfl. (die bei Robinson nur selten in der richtigen Länge dargestellt sind), meist ein gutes Uuterscheidungszeichen gegen Tortrix (z. B. Teras Lipsiana). Auch die Kürze der Taster, welche nur sehr selten die

1) Dieses Wort als Fem. zu behandeln, ist so wenig genügender Grnud rorhanden, wie bei Exartema oder Anthrax; doch ūberlasse ich die Eiufūhrung der für die Species nothwendigen Endungen Andern. Vgl. Marshall im Eutomologit.'s Annual for 187t, p. 117 unter Dryoteras. 
doppelte Kopflänge haben, in der Regel aber nur wenig über die Stirn herausreichen, und der durchgängige Mangel eines Vdrd.-Umschlages an den männlichen Vdfl. geben einen guten Unterschied von vielen Tortrix-Arten. Das sicherste Merkmal soll nach Heinemann der Verlauf der Ader 7 anf den Vdf. bilden, indem diese bei Teras über der Spitze in den Vdrd., bei Tortrix unter der Spitze in den Htrd. ausläuft. Ob dieser feine Unterschied, nach welchem Heinemann Holmiana allerdings mit Recht zu Teras zieht, während sonst kaum weiter etwas dazu räth, ein generischer ist, möchte ich bezweifeln. In Lederer's Fig. 4 (Rhacodia = Teras) mündet Ader 7 so gut in den Htrid. wie in Fig. 5, 6 (Tortrix).

\section{Abth. Rhacodia,}

\section{Teras peculiana n. sp. Taf. VIII, Fig. 1.}

Alis ant. (costa jrofundius cmarginata) ulbis, munctis fuscis asperis adspersis, macula triangula brunea enarginationem amlectente, nebula dilutiore ex ejus apice ad dorsum usque producta. ㅇ.

Sehr ähnlich der Boscana F. und Deflectana Pbs., von ihnen zu unterscheiden durch die ziemlich tiefe Ausrandung des Vdrdes. und deu sie umfassenden, gleichmässig gelbbraunen, nicht zusammengesetzten Fleck, aus dessen Spitze ein lichterer, breiter Nebelstreifen bis zum Innenrand herabläuft. Ich glaube nicht, dass diese Art sehr abändert; höchstens wird der Nebelstreifen unterlochen oder verloschen sein.

P. und K. weiss. Taster un die halbe Kopflänge über die Stirn hervorstehend, weiss, am verdickten ziveiten Gliede aussen gebräunt: Endglied sehr kurz, knospenförmig. Beine hellbräunlich, die hinteren nit helleren Schienendornen.

Vdfl. $3^{\prime \prime}$ lang, etwas gestreckt, mit zugerundeter Spitze und convexem Htrd., an Vdrd. nit ziemlich tiefer Ausbuchtung, welche ohne abrupten Uebergang vor der Mitte anfängt und mit ebenso sanftem Uebergang in den Vdrd. bei $5 / 6$ endigt; die Schuppen au ihrem Anfang sind ein wenig rauh. Die Grundfarbe ist weiss und durch sehr verloschene graue, mehr oder weniger schräge und unterbrochene Querstreifen, die vor dem Htrd. reichlicher und zusammenhängender sind, nicht oder wenig getrübt. Einzelne punktförmige, rauhe Schuppenhäufchen sind schwarz. An der Ausbuchtung liegt ein von ihrem Anfang bis zum Ende reichendes, cinfarbig gelbbraunes Dreieck mit gestutzter Spitze, welche auf der Basalseite einen schwarzen Punkt trägt; unter diesem Punkt fängt der licht gelbbraune, breite Nebelstreif an, der schräg querüber zieht, an seiner Hälfte basalwärts eine Ecke mit einem dunkelu Punkt bildet und vor den Fransen des Inuenrandes endigt, ohne ihn jedoch zu berühren; in der Falte enthält dieser Nebel vorn und hinten ein schwärzliches Pünktchen. Die Frausen sind lehmiggran angelaufen. 
Hth. ziemlich dunkelgran, gegen die Wurzel heller, auf den helleren Fransen mit einer sehr verloschenen, gelblichen Linie umzogen, die die Flïgelspitze deutlich hervortreten lässt.

Unterseite der Vdfl. brännlichgıau mit undeutlichen, dunklern, sehrägen Querlinien. Am Anfang der Ausbuchtung ist eine weisse Stelle, und hinter derselben entlıalten die Vdrd.-Fransen zwej kleinere, weisse Wische. Htru.Fransen mit weisslicher Wurzel. Htfl. weisslicligran, weisslich gefranst, in der Flügelspitze dunkelgrau querfleckig.

Vaterland: Texas (Boll). Ein gut erhaltenes $Q$ im Museum Cambridge.

\section{Abth. Teras.}

\section{2. 'Ter. deftectaru Rbs.}

Parva; al. ant. apice obtuso albis, triangulo costae posticae brmmeofusco maculis tribus composito, lituris ante marginem posticum transtersis brunneis, cilies fuscescentibus. ơ $Q$.

- Robinson Trans. Am. Eunt. Soc. II (1868), p. 283, tab. 7, F. 71. Q.

Sehr ähnlich der europäischen Bosena. Die zwej vorliegenden Fx. sind bedeutend kleiner als mein kleinstes der Boscana (Vafl. 23/4-3"“ gegen 31/4 bis $\left.3^{3}{ }_{4}{ }^{\prime \prime \prime}\right)$, haben aber gleiche Flïgelgestalt, nur lass die Vdf. etwas gestreckter" und an der Spitze abgerundet sind. Das gelbbranne Costaldreieck besteht aus drei Flecken, deren unterster einen dicken, dunkeln Längsstrich bildet, der bein O mit dem ersten Costalfleck zu einem Streifen mit sehr schrïgem Basalrand zusammenfliesst. Unter dem Ende des zweiten Costalfiecks geht ein gelbbraunes, schwarzfleckiges Gewölk, worin sich besonders ein breiter Schrägstreifen auszeichnet, gegen den Inmenwinkel herab. (Bei Boscana sind blos grane und schwarze, zu Querlinien zusammenfliessende Querstrichelchen vorhanden, die gerade gegen den Innenwinkel am schwächsten nnd spärlichsten auftreten). Fransen gelbbraun, gegen den Innenwinkel am dunkelsten (bei Boscana ganz weiss), am Vdul. weiss mit dunkeln Flecken.

Hth. gegen die Wurzel heller grau als im Apicalraum (Boscamu einfarbig wie die etwas helleren Fransen); die Fransen grau, um den dnalwinkel und am Innenrand weiss.

Ich bezweifle nicht, die richtige Deflectana vor mir zu haben. Robinson hatte offenbar nur $1 \mathrm{Ex}$. (aus Pemsylvanien) zur Verfügung. In der Abbildung ist es grösser als die mir vorliegenden und mit schärfer gespirzten Vdh., was ich beides für Fehler des Zeichners halte. Dass das als ziemlich einfarbig abgebildete Costaldreieck nicht ganz richtig ist. zeigen die Worte: dark brown, except in the center, where it is pales. Die two brown lots near the base (des Vdrds.) in der Beschreibung wollen nichts sagen. Wichtiger ist, dass in Bild und Beschreibung gegen den Htrd. Keine dunklen Stellen erwähnt werden; aber dass nicht etwa Boscana dargestellt worden ist, gebt daraus hervor, dass bei dieser das dunkle Costaldreieck auf drei stark getrennten 
Fleckchen besteht, von denen das untere weiter gogen die Flïgeluitte hin erweitert ist. Robiuson's Ex. wird kein unversehrtes gewesen sein.

Ein ziemlich gut erhaltenes Paar ans Texas (Boll) im Cambridger Museum.

\section{Teras ferrugana S. V.}

- Heinemann, Wickler S. 25.

Fin schön erlıaltenes $\sigma^{7}$ dieser höchst veränderlichen Art, das noch am hesten der (zu grossen) Fig. $k$ auf Taf. 23 der F. R.'schen Beiträge entspricht, halte ich ohne allen $\%$ weifel für Ferugana. Die Grundfarbe des Vorderkörpers und der Vdfl. ist ein lichtes Grauchergelb. Die Gestalt der letzteren ist kaum cin wenig gestreckter als in der Regel. Schwarze, rauhe Punkte sind ohne Ordnung und nicht zahlreich ausgestreut. Am Vdrd. liegt an der gewöhnlichen Stelle ein verloschenes, dunkles, mit schwarzen Punkten bestreutes Dreieck, das sehr undeutlich ans drei Flecken zusammengesetzt und im Innern längs des Vdrdes. hohl ist.

Die Htfl. sind, wie oft, lichtgrau und am Rande, besonders in der Spitze mit dunkelgrauen Fleckchen bestreut; Fransen noch beller grau.

Da Ferrugana in Menge überwintert, so ist es sehr wahrscheinlich, dass sie erst durch die Schifffahrt in Nordamerica eingeführt ist. Auch wird sie dort wohl in so veränderlicher Färbung auftreten wie bei uns.

Das Ex. ist aus Ohio (Schläger).

Robinson's Ter. semiannula (aus Pennsylvanien) Fig. 70, S. 282 mag nur Ferrugana sein. Sie ist aber nicht so gut abgebildet (wohl auch zu gross) and beschrieben, dass nicht zu einem sicheren Urtheil die Ansicht eines Originals nöthig sein sollte.

\section{Ter. variolana n. sp.}

Parra; al. ant. ferrugineo-ochraceis, ferrugineo-pulveratis, pulvere posterius in strigas undulatas congesto, striola disci medii fusca; post. albidoochraceis. ठ․

Am besten mit Quercinana zu vergleichen, da die Grundfarbe anch etwas Geglättetes hat. Ader 7 mündet dicht über der Spitze; 2 entspringt weit vor der Hälfte der Medianıder.

Die gespitzten Taster, der Kopf und das Pückenschild sind hell rostfarbig.

Vdfl. 3"' lang, lä'ıgticher als die von Quercinana, von der Gestalt der Fermgana, nur an der Endhälfte des Vdrdes. und nur sehr schwach rauhschuppig, hell ochergelb, etwas geglättet, sehr reichlich mit grobeu, rostfarbenen Schuppen bestrent. Diese fliessen melur oder weniger zusammen und bilden auf der Endhälfte des Flïgels mehr oder weniger deutlich von einander getrennte, schräge, wellige Querlinien, welche durch die Adern in Punktfleckchen geschnitten werden. Im Ende der Mittelzelle liegt auf einer schwach eingedrückten Stelle ein verloschenes, braunes Längsstrichelchen. Fransen blass rostfarbig. 
Htfl. weisslich ochergelb, an Htrd. und in der Spitze grau gemischt. Fransen noch heller als die Flïgelfläche.

Unterseite einfarbig weisslichgelb ohne Querstrichelchen.

Vaterland: Texas (Boll). Ein o im Museum Cambridge.

\section{Ter. maculidorsana Clem.}

Alis ant. (costa vix scal)ra, postice subrecta) cinereis, laevigatis, punctis nigris scabris adspersis, macula plicae ante medium majuscula fusca, fascia media obliqua obscura nebulosa, in medio ferruginea. $\sigma^{\pi}$ ․

Cnephasia (?) Clem. Proc. Ent. Suc. Philad. III (1864), 1). 514.

Teras Robinson 1. c., p. 281, tab. 7, Fig. 64.

Recht gut bei Rbs. abgebildet, nur zu gross und mit zu breiten Vdff. Die Art gehört sicher nicht zu Hastiana, für deren mögliche Varietät Rbs. sie erklärt. Der auf den hintersten $2 / 3$ gerade Vdrd. der Vdfl. ohne Einbiegung, der fast gänzliche Mangel rauher Costalschuppen, die abgerundete Flügelspitze, die glatte, wenn auch mit einigen rauhen Schuppen bekleidete Fläche - das Alles verweist sie in die Nähe von Maccana.

Rbs. vervollständigt Clemens' gute Beschreibung. Die Sclıägbinde, bei meinem 오 sehr verloschen, enthält in der Flügelmitte eine roströthliche Stelle, die beim $q$ kleiner und verloschener ist als beim $\sigma$.

Mein Pärchen erhielt ich, wie Clemens das seinige, von Dr. Packard aus Maine oder Massachusetts. Rbs. kennt auch Pennsylvanien als Vaterland.

\section{Ter. Mastiana Linn.}

Var (?) ptychogrammos Z. alis ant. cinereis, linea plicae longa lineaque disci medii nigris, triangulo costali ferrugineo-fusco. ơ.

Unter 175 Ex. der Hastiana, die ich zum Vergleich habe, ist kein einziges, das mit dem vorliegenden übereinstimmt. Die Var. psorana Fröl. hat zwar die gekrümmte Linie des Mittelraumes, oft sogar schärfer, wenn sie auch nicht so weit nach hinten reicht; die Var. radiana Hbn. zeigt zwar öfters in der Falte eine Längslinie, ist aber sonst ganz anders, namentlich ohne das Costaldreieck. Da aber das americanische Ex. in Flügelban und Beschuppung, auch des Vdrdes, mit Hastiana stimmt, und da selbst Ribs. eine ihm unzweifelhafte Hastiana in der Var. livisana als nordamericanisch vorstellt, so ist es mir nur wenig zweifelhaft, dass ich eine blosse Varietät der Hastiana vor mir habe. - Hastiana überwintert wie Ferrugana sehr häufig, kann also ohne Schaden an ihrer Fortpflanzungsfähigkeit die Fahrt nach Nordamerica mitmachen, und so ist kein Grund denkbar, warum ihre dortigen Nachkommen nicht in so verschiedenen und selbst noch etwas modificirtem Gewande auftreten wie ihre europäischen Verwandten. 
Das Ex. ist nur so gross wie eine durch Hunger verkleinerte Hastiana. Vorderkörper und die $3^{1} /_{4}^{\prime \prime \prime}$ langen Vdfl. grau, letztere hier und da mit verloschenen schwäralichen Querstrichelchen. In der Faite zieht eine feine, schwarze Linie, welche bei $3 / 4$ verdinnt endigt. Aus der Schulter kommt (doch nur auf dem linken Flägel deutlich vorhanden) ein kurzer, dicker, schwarzer Strich. Von der Mitte des Vdrdes. an liegt ein verloschenes, rothbräunliches Costahreieck, das auf der Basalseite von einer schrägen, welligen, rauhen, dünnen, schwarzen Linie begrenzt wird, die hinter dem Ende der Faltenlinie auf dem Innenrande endigt; der Vdrd. zeigt in diesem Dreieck vier durch weisslichgraue Räume getrennte braune Fleckchen, und vor der Flügelspitze liegt noch eins. Unterhalb der gerade abgeschnittenen Spitze des Dreiecks und schon riel früher anfangend zeigt sich eine schwarze, nicht recht scharfe, feine Längslinie, welche im Mittelraum hinzieht, sich hinter dem Dreieck etwas hebt und vor $3 / 4$ des Ittrdes. verschwindet. Der Htrd. ist durch undeutliche, zusammenfliessende, lunkelgraue Flecke von den grauen Fransen geschieden. HtA. sehr lichtgrau, in der Spitze braungrau. Die hintere Hälfte des Htrdes. ist von einer braungrauen limie eingefasst. Anf der Unterseite sind in der Spitze nnd am Vdrd. branngraue Querstrichelchen ziemlich reichlich.

Vaterland: Texas (Boll). 1 o im Mus. Cambridge.

\section{Ter. tristann H.}

Vur. famula Z. alis ant. mfo-cinereis, punctis asperis atris adspersis, litura costae posticue fuscescenti obliterutu. o".

Von der veränderlichen Tristana H. (Heinemann S. 17) gibt es dunkle, ziemlich einfarbige Varietäten, die sich von der H. S.'schen (zu kurzflüglig abgebildeten) Erutuna Fig. 9 durch das ganz verloschene, nur als dunkler Wisch erscheinende Costaldreieck unterscheiden, und die völlig mit den 4 vorliegenden americanischen Männchen übereinstimmen. Ich glaubte einen specifischen Unterschied im Geäler der Hth. aufgefunden zu haben: bei Tristuna-Erutana die Adern 3 und 4 nur an der Wurzel vereinigt, bei den Americanern beide eine Gabel mit kurzem Stiel bildend. Aber dieses ändert bei jenen so ab, dass sogar einzelne Ex. vorkommen, welche anf ler linken Seite jene, auf der rechten diese Verbindung aufweisen. Selbst bei den Americanern lässt sich ein Mebr oder Weniger erkennen. So bleibt nicht einmal die Bezeichnung der Varietät als americanisch möglich. Es versteht sich, dass die americ. Ex. nicht haargenau nit einander stimmen. Eins ist am meisten mit rauhen, schwarzen Punkten bestreut. Anch der grissere Punkt in der Falte, den Heinemann als wichtig hervorhebt, ist bei ilnen zu bemerken.

Meine schön erhaltenen Fx. schickte mir Dr. Hagen ans der Gegend von Cambridge.

Anmerkung. Es scheint nir leicht möglich, dass Ter. viburnana Cl. Rbs. Fig. 66 nur eine Varietït der Tristana ist; auch Heinemann führt Viburmum als Nahrungspflanze der Tristana auf; doch würde sie nur zu 
Var. erutana gestellt werden künnen. Die Ansicht mehrerer americ. Ex. wird die Entscheidung sowohl über diesen Punkt wie darüber geben, ob nicht noch 1 oder 2 Robinson'sche Namen einzuziehen sind.

Tortrix (Iinn). Jederer, Heinemann.

Diese Gattung ist eine unnatiirliche, die nothwendig in melrere aufgelüst werden muss, wozu sich auch Merkmale, wenn schon uur nach dem männlichen Geschlecht, hinreichend finden. Ich legnüge mich, den mir in der Natur bekannten nordamericanischen Arten ihre Abtheilungen der Gattung Tortrix, wie wir sie bei Heinemann aufgestellt sehen, zuzuweisen. Nur eine darin nieht vorkommende crlaube ich mir sofort als eigenes Genns Cenopis zu trennen.

\section{Ahth. Cacoecia H. (Led.) Heinemann S. 32.}

\section{Tortr. (Cacoec.) rosaceama Haris.}

Alis ant. (margine postico convexo, or revolucro a basi remoto, fusco, † alae apice acutangulo), pallide luteis, fascin media obliqua maculaque costae antearjiculi brumescemlitus; post. O' canescontilus, Q pallide ochraceis, o $q$ interius cincrcis.

Tortr. rosaceana Rob. 1. c. p. 262. Fig. 3 万, 1, 2 9.

Sie steht der exropäischen Decretana Tr. so nahe, dass Schläger mir ein $\{$ unter diesem Namen sehickte. Bei Decretana ơ fängt der Vorderrandumschlag der Vdfl. an dex Flügelwurzel an und ist nicht viel dunkler als die Grundfarbe; Rosaceana hat einen kürzeren, der ziemlich weit von der Flügelwurzel wie ein dreieckiger Zipfel von branner Farbe herübergeschlagen ist.

Bei Decretuna ơ liegt nicht weit von der Basis unterhalb der Falte ein rostbrauner Fleck, welcher so wie die schimmernde Stelle hinter ihm bei Rosaceana $\sigma^{\nearrow}$ fehlt. Die Htfl. sind bei letzterer in grösserer Ausdehnung anf der Apicalbälfte weisslichgelb (in Robinson's Abbildung sind sie fälschlich ganz einfarbig weisslichgelb). - Beide Geschlechter von Rosaceana haben unter der einfarbigen hellen Spitze der Vdfl. eine schwache Eimbiegung des Htrdes., während diese bei Decretana beträchtlicher ist und die Spitze mehr hervortreten lässt, welche letztere auch dicht an den Fransen eine schwarze Stelle enthält. Die Htfl. der Rosaceana $Q$ sind in viel grösserer Ausdehnung blass ochergelb als bei Decretana $q$ und gegen den Innenwinkel schwach gran angelaufen, statt hier in mehr als halber Flïgelbreite braungrau, gewöhnlich recht dunkel, zu sein.

Meine Ex. sind aus Massachusetts, Maine, New-York and Ohio. Ein ? aus Texas (Boll) ist im Mus. Cambridge.

\section{Tortr. (Creoer.) murpmrama Cl.}

Alis ant. On (costa ante medium revoluta, margine postico valde conrero), rufescenti-luteis, violacco-nitirlulis, fascia media obliquer subintcrupta 
maculaque costae antenpicali bnunescentibus utrimque fusco-marginatis; post. canescentibus, interius late fusco-cinereis, margine costali prope basim albido.

q Al. ant. costa ante apicem prominentem profunde impressa, margine postico infra apicem excacato.

on Tortr. purpurena Rob. 1. c. p. 263, tab. 1, k. 4.

Q - grergitana Rob. 1. c. p. 263, tab. 4, F. 16.

Beide Geschlechter sind selı kenntlich abgebildet; nur sollte der Htri. der Vdfl. voch stärker convex sein und beim of dadurch die Spitze noch weiter zuıïcktreten. So auffallend iersclieden das $q$ in seiner Färbung von $\sigma^{\pi}$ ist, so zweifle ich doch eben wegen dieser sonlerbaren Hitrd.-Krünnung durchans nicht an ihrem 7usammengehören. Beile Geschlechter stimmen auch darin überein, dass anf den Htfl. der dunkle, grane Raum von der Medianader und ihrem zweiten Ast (Aler 3) begrenzt wird. (Robinson's Abbildung entbehrt der dunktln Färbung).

Das in der Färbung und Zeichnnng ziemlich veränderliche o hat am Vdrd. nicht eigentlich einen Umsclılag, sondern der Vdrd. fängt nicht weit von der Basis an, sich aufwärts zu biegen, und krümmt sich erst weiterbin, in der Gegend des Anfangs der Binde, etwas gegen die Flügelfläche. Dies, dann die Convexität des Htrdes., die violettliche Beimischung in die Farbe der Vdfl. und die Begrenzung des Grauen auf den Httl. - bilden die specifischen Merkmale. Die Grundfarbe der Vdfl. ist mebr oder weniger getrübt und, wenn sie stark verdunkelt ist, fast ohne Zeichnung. Die mikroskopisch-pubeccirenden ơ Fühler haben über dem rerdickten Wurzelgliede keinen Ausschnitt.

Meine Ex. sind aus Maine (Packard) und New-York (Speyer).

\section{Tortr. (Cacoec.) infumatana n. sp.}

Alis ant. (margine postico valde convexo, ot revolucro basali, appresso) nitidutis, fisco-luteis, area basali, fascia mediu introrsus dilatata strigaque anteapicali introrsus attenuata nigro-fuscis; post. fuscis totis. $\sigma^{7} \mathrm{Q}$.

Der Purpurana dadurch verwandt, dass der Htrd. der Vdf. auch unzierlich convex ist und die Flügelspitze sehr zurücktreten lässt; aber der Vdrd. des $\sigma^{7}$ ist nicht, wie bei Purpurana, blos ungebogen, sondern bat einen fest anliegenden Umschlag, der von der Basis bis an die Mittelbinde reicht. Durch ihre geglättete, ein wenig glänzende Vdfl.-Fläche und deren sebr dunkle Färbung, sowie durch die eiufarbigen, dunkelbraunen Htfl. ist Infumatana vor allen bekannten Tortrix-Arten ausgezeichnet. In der Grösse steht sie hinter Purpurana merklich zuritick.

$R$. dunkelbraun, $K$. heller. Taster lehmgelb ( $Q$ heller), von $1 \frac{1}{2}$ Kopflänge, nicht sehr stark, zusammengedrückt, mit hervorstebendem dünneren Endgliede. Saugrüssel vorhanden. Mittel- und Hinterbrust seidenglänzend grau. Beine lehmgelb, die vorderen an Schiene und Fuss braun mit hellen Enden der Glieder. Hinterleib bellbraun, beim $\sigma^{7}$ an den Seiten scbwarzbraun. 
Vdfl. $\sigma^{\prime \prime} 4^{\prime \prime \prime}$, ? 5"“ lang. länglicl, mit stark convexem, vor der Spitze nur schwarh eingebogenem Vdrd., sehr convexem Htrd. (der unter der Spitze beim 9 nur ein wenig mehr eingedrückt ist als beim $\sigma^{7}$ ), so dass die Spitze stumpfwinklig nnol wenig bemerkbar wird: di grösste Convexität des Htrdes. ist unter der Mitte. Der ganz fest auflingende Umschlag des $\sigma^{\pi}$ reicht ron der Schulter bis zum Anfang der Mittelbinde. Die Flügelfläche ist geglättet nnd hat einen schwachen Fettglanz. Die Gimulfarbe ist dunkel lehmgelb, aber zwischen der Zeichning durch Violettgran nehr oder weniger verdecht, so dass sie mur am Vdrd. und als Randlinien ler Zeichnung rein bleibt. Die sehr dunklen, fast schwarzbraunen Zeichnungen sind folgende: das breite Basalfeld ist hinten zugerunlet. Nach einent binlenfürmigen Paum, der beim ơ schmäler ist als beim , fulgt die breite, gar nicht durchbrochene, schrïge Mittellinde; sie ist am Vird. am schmälsten, erweitert sich schnell sehr stark und endigt etwas verengert am Innenwinkel; ihr Imnenrand bildet ungleiche, grosse Wellen und wird durch eine mehr oder weniger vollständige Linie der Grundfarbe ziemlich scharf abgegrenzt, während ihr Aussenrand, ausser am Anfange, wenig solche Begrenzung hat, wesshalb sie mit der verdunkelten und grau gemischten Grundfarbe zusammenfliesst. Vor der Flügelspitze geht vom Vdrd. ein fleckartig anfangender, beim $q$ schmälerer als bein $\sigma$, auf beiden Seiten lehmgelb eingefasster, schräger Streifen herab. der sich allmälig verdünnt und an untersten Drittel des Htrdes. endigt. Fransen lehngelb, an der Flügelspitze mit einem kurzen, schwarzbraunen Strichelehen.

Htfl. einfarbig dunkel schwärzlichbraun, beim 오 heller, Fransen einfarbig, etwas lichter als die Flügelfäche.

Die ganze Unterseite einfarbig graubraun, beim $q$ etwas lichter, der Vdrd. der Tdfl. schmal, beim $q$ ein wenig breiter. lehmgelb, durch braune Querstrichelchen unterbrochen.

Vaterland: Missouri. Zwei Paare, wahrscheinlich erzogen, erhielt ich von Riley mit der Nummer 325.

\section{Tortr. (Cacoec.) errasirorana Fitch.}

Majuscula, atis ant. latioribus, obtusis, saturite ferrugineis, squamis lilacinis nitidulis copiosis punctisque fuscis raris adspersis, maculis 2 costae fuscis minoribus; post. laete ochraceis, fuscescenti-suffusis $ᄋ$.

Tortr. cerasivorana Pob. 1. c. p. 275, tab. 6, Fig. 47. $\sigma^{7}$.

Das $\sigma^{7}$. welches Robinson abbildet, seheint in der Flügelgestalt und Grösse ziemlich verschieden vom $Q$ zu sein; es ist daher fraglich, ob ich die Art hier richtig anfüge.

Sie ist durch ihre fast rostfarbigen Htfl. der gleich grossen Rileyana ähnlich, aber doch leicht von ihr zu unterscheiden, da eben diese Flügel bei ihr ansser am breiten Vdrd. bräunlich angelaufen, und die Vdfl. sehr reichlich mit schimmernden lilafarbenen Schuppenanhäufungen. welche unregelmässige Querstreifen bilden, bestrent sind. 
Vaterland des einen Ex. meirer Sammlung Massachusetts (Beverly 22. Juli : Burgess), des anderen Maine (Packard). Nach Fitch, dessen Beschreibung ich nicht vergleichen kann, lebt die Art anch in Staate New-York.

\section{Tortr. (Cacoec.) Iaevigana S. V.}

Tortr. rosana Heinem. Wickler S. 34. Oxyacanthana H. Fig. 117.

Die 2 vorliegenden Ex. kann ich durchaus nur für Laevigana $q$ mittlerer Grösse ansehen. Sie haben genan deren Flïgelgestalt, nur dass der Htrd. der Vdf. kaum merklich weniger convex ist als bei den meisten europäischen Ex. Ihrer dunkeln Färbung nach gehören sie zn Oxyacanthana H., deren Htf.-Spitze in beträchtlicher Ausdehnung tiefgelb und bräunlich punktirt abgebildet ist, statt dass sie sich bei den 2 Americanerimmen, wie bei manchen europäischen Ex., nur auf einem kleinen Ram zu einem gelblichen Ton lichtet. Der Art angemessen ist bei dieseu Americanerinnen auf der Unterseite hier das Gelbe lebhafter und breiter als auf der Oberseite. Auf den trïb graubrannen Viff. tritt die Zeichnung, mit Ausnahme der braunen Querstriche, sehr wenig hervor. Das Gelbliche der Unterseite ist nicht lebhaft, aber in der Ausdehnung wie bei unserer Laevigana.

Ich vermuthe daher, dass die $\sigma^{7}$ ebensowenig specifische Unterschiede zeigen werden wie diese 2 aus New-York stammenden $q$. Bei Robinson finde ich keine der Laevigana entsprechende Abbildung.

Anmerkung. So wohl in Hübn. Fig. 302 wie in F. v. R.'s Taf. 11 haben die $q$ Htfl. einen so ausgedehnten gelben Raum, wie er in der Natur nie vorkommt; bei Hübn. nehmen sogar die Fransen an dieser Färbung Theil! Bei F. R. haben sie - ein fast bei allen Wieklern seines Werkes vorkommender Fehler - eine ganz falsche Gestalt. Auch bei Dnponchel's Oxyacanthana pl. 238, F. 10 ist die Htfl.-Gestalt, nur in anderer Hinsicht, verfehlt.

Da über den Namen Laevigana kein Zweifel stattfindet, so wähle ich ihn zur Bezeichnung der Art. Wie man Linnë's Worte: "Alce omnes griseae sere dilute testaceae tam supra quam infra, ut et totum animal" auf sie anwenden will, sehe ich nicht ein, und wenn etwa Linné's Museum ein Ex. der Laevigana unter dem Namen Rosana enthält, so bestreite ich dessen Beweiskraft. Wie gern ich auch Linnéische Namen annehme, so verbietet es sich mir in diesem Fall, wo die Worte der Beschreibung so entschieden widersprechen. Auch Werneburg's Beweis (I, S. 266), dass Linnés Americana zı Laevigana gehöre, erkläre ich für ganz verfehlt.

\section{Abth. Loxotaenia (H. S.) Led. Heinem. S. 35.}

Diese Abtheilung ist meiner Ansicht nach nicht von Cacoecia verschieden. Das schon zweifelhafte Geknicktsein (auf der Querader) der Vdfl. ist ein Merkmal, das beim Spannen völlig verschwindet. Es bleibt als Unterschied nur die weniger vortretende Flügelspitze, eine Folge davon, dass der Htrd, unter ihr 
eine Einbiegung hat oder nicht. Sie fehlt allerdings bei Dumicoluna, Histrionana, Muscaluna etc. Aber bei Semialbana (die Heinem. zu Cacoecia stellt) hat nur das $q$ sie; bei Unifasciuna (bei Heinem. in Loxotaenia) ist sie, wenn auch sclıwach, in beiden Geschlechtern vorlıandeı. Dieses Merkmal würde die verwandtesten Arten auseinander reissen.

\section{Tortr. (Loxot.) furecuna Rob.}

Majuscula, alis ant. (margine postico simpliciter cunvexo) ochraceis, fusco-fervugineo dense irroratis, maculis costatitus (una revolucro ó adjacente, nna majore media subquadrangula, una rarva apicali) allido-fluris, nitidutis. ơ 9 .

Tortrix - Robinson 1. c. p. 265, tal. 1, Fig. 9.

Sie ist in der guten Abbildung sogleich zu erkennen; dafür macht die Beschreibung sie kaum kenntlich, weil hier die 3 oder vielınehr 2 charakteristischen weisslichgelben Costalflecke, welche sich nur noch bei Flaccidana vorfinden, gar nicht hervorgehoben werden. Diese Flecke sind übrigens von veränderlicher Gestalt und Grösse. Der erste ist dreieckig, schief nach hinten gelegt und unten zngespitzt, und wird an seinem Anfange bein 0 durch den Unuschlag verdeckt. Der zweite, an der Flügelmitte befindliche, ist gewöhnlich auch schief nach hinten gelegt, dabei rhombisch oder trapezoidisch oder selbst dreieckig; unterhalb seines unteren Eudes ist ein schwarzer P'nnkt meist recht deutlich. Der dritte Fleck, der sich an der Flügelspitze befindet, ist der kleinste uud verfliesst oft in die läugs des Htrues. gelichtete Grundfarbe. - Schimnernde Schuppen zeigen sich zahlreich in der Flügelfläche zwischen deu schwer kenntlichen Bindenzeichnungen.

Diese Art ist sehr verbreitet. Ich habe sie aus Missouri, Ohio, Illinois (durch Lederer, der sie als eine Ptycholoma su. bestimmte), New-York, Massachusetts (wo Burgess die $\sigma$ frisch und verfogen Mitte Juli fing) und durch den verstorbenen Lieutenant v. Müller (weun seiner Angabe zu trauen ist) aus Californien. Boll brachte 1 q aus Texas.

\section{Tortr. (Loxot.) Haccillune Rob.}

Majuscula, alis ant. (margine postico simpliciter convexo) ochraceis, opacis, maculis costulibus (una revolucro o adjacente, una media triangulari, una apicali ter dissectu) albidis nitidulis, secunda in strigum angulatam proeluctu. ठ․

Tortr. - Robinson, l. c. p. 277, tab. 6, Fig. 53.

Sie kommt der Furvana so nahe, dass ich sie, zumal da ich meine Ex. vermischt mit ihr erhielt, für eine verblasste Varietät derselben drt hielt. Robinson hat sie mit Recht von ihr getrennt, obglich sie ganz dieselbe Grösse und den Flügelbau hat. Die Vdfl. sind ein wenig breiter. Die Grund- 
farbe ist ein gleichförmiges, mehr oder weniger gesättigtes, mattes Ochergelb, ganz ohne alle Marmorirung. Die Costalflecke sind weisslich, nur auf dem Vdrd. selbst matt, sonst schimmernd; die 2 ersten kleiner als bei Furvana, der zweite spitz dreieckig. Vom ersten gehen zwei mehr oder weniger deutliche, dirergirende, silbergrauc, glänzende Strcifen bis zur Faite lierab. Vom zweiten geht ein zweinal winklig gebrochener, sehr deutlicher, solcher Streifen bis in den Innenwinkel. Der dritte ist vor der Flügelspitze, undeutlich dreieckig, durch Querstriche in drei Stïcke zerschuitten, von deren erstem eine kurze, glänzende Linie bis zur Htrd.-Mitte reicht. Ein Ex. hat unterhalb der Spitze des Mitteiflecks auf der Querader ein schwarzes Strichelchen. Die Fransen sind sehr hell ochergelblich.

Unterseite heller als bei Furvana; die Htfl. auf einem grösseren Raum verdunkelt. - Das $ᄋ$ ist mir unbekannt.

Vaterland: Texas (Robinson, Boll), Illinois (Lederer).

\section{Tortr. (Loxot.) sescuplana n. sp.}

Parva, alis ant. acutis, dilute griseo-ochraceis, obscurius strigulosis, (revolucro ơ basali brunneo-luteo), macula costae mediae parva trianguloque costae postico cinereo-fuscis; posticis acutis, dilute cinereis. $\sigma^{\nearrow} \mathrm{Q}$.

Verwandt mit Unifasciana und Semialbana, viel kleiner, spitz Hlïgliger, besonders in den Htfl. Die grössere Peritana sieht ihr ähnlich, hat aber weniger gespitzte Flügel, und auf den Vdfl. gelbere Grundfarbe, ausserdem eine vollständige Mittelbinde und eine vom Costaldreieck herabgehende lehmgelbe Linie.

K. und R. wie die Vdfl. sehr hell grau ochergelblich. Fühler heller, gleichsam fein geringelt, beim $\sigma^{7}$ mikroskopisch pubescirend. Taster fast um Kopfläuge hervorstehend, aussen dunkel angelaufen, mit herrorragendem, dünnem Endgliede. Saugrüssel vorhanden. Beine blass. Rücken der 4 Vorderbeine an Schiene und Fuss braun, mit hellen Eiden der Glieder. Hinterleib lichtgrau; Analbusch des $\sigma^{\top}$ stark, so lang wie 3 Segmente, sehr blass gelblich; der des \& ärmlich und kurz.

Vdf. 3-2 $\frac{1}{2}$ " lang, länglich mit spitzem Vorderwinkel; der convexe Vdrd. läuft von der Hälfte an fast gerade und ist nur vor der Spitze schwach concav; der Htrd. ziemlich gerade, unter der Spitze kaum merklich eingebogen. Grundfarbe wie angegeben, reichlich mit bräunlichen oder schwärzlichen, nach hinten deutlicheren Querstrichelchen bestrent. Der Umschlag des o reicht von Aer Wurzel bis nahe an den Costalfleck und ist bräunlich oder röthlich lehnfarben, verloschen braun gefleckt. Vor der Mitte des Vdrdes. liegt ein schräges, blaungranes Fleckchen, vorn und binten dunkel eingefasst; es ist der Anfang der Mittelbinde, von ter sich gewöhnlich keine Spur entdecken lässt; bei zwei ganz unversehrten $\sigma^{\top}$ zeigt sich die schattenhafte Andeutung einer nach unten erweiterten, an ihrem Innentaude ziemlich geradlinigen Binde, die auf dem Dorsalrande des Fiügels in Hinterwinkel, wo sie endigt, mit ein paar dunkel- 
grauen Fleckchen bezeichnet ist. Nach diesem Costalfleckchen folgt ein mehr als doppelt so langes, braungranes, schmales Dreieck, das anf der Innenseite schwarz gerandet, ausserdem mit 2-3 schwarzen Costalfeckchen gezeichnet ist; ans seiner Spitze zieht keine Linie herab, und so ist auch der Htril. durch keine dunkle Linie oder Flecke vou den hellen Fransen geschieden.

Htfl. mit etwas verlängerter Spitze, sehr hell gran; von der noch lielleren Unterseite scheinen die zerstreuten dunkelgrauen, verdickten Querstrichelchen hindurch.

Die Vdfl. sind auf der Unterseite grau, am Vdrd. und noch breiter am Htrd. bleich ochergelb und auf dieser Farbe mit dunkelgranen Querstrichelchen bestreut.

Vaterland: Maine (Packard), Tesas (Boll, Belfrage - ein Paar lier am 17. September gefangen).

Anmerkung. Ein ungespanntes $q$ aus Texas (Boll) hat die Grösse der kleinsten Sescuplana. Die Vdfl. scheinen weniger scharfspitzig, und sicher haben sie einen convexer verlaufenden Vdrd. Grundfarbe ohne graue Beimischung, also sehr blass ochergelb, mit dunkel braungelben Querstrichelchen bestreut. Die Mittelbinde ist vollständig, im nittleren Drittel lichter, am Anfang und Ende gleich dunkel, wesshalb der verdunkelte Costaltheil weiter nach innen reicht als der Costalfleck der gewöhnlichen Sescuplana; der Inneurand dieser Binde ist fast gerade, verdunkelt und von einer bellen Linie der Grundfarbe begleitet. Statt des Costaldreiecks ist ein grösserer, halbeifürmiger, an den Rändern schwarz gefleckter Costalfleck, von dessen Mitte eine braungelbe, wenig auffallende Linie nach dem untersten Drittel des Htrdes. herabgeht. So vielfach dieses Ex. von den mir vorliegenden 9 Sescuplanc abweicht, so glaube ich doch, dass erst der Vergleich einer grösseren Zalıl entscheilet, ob es eine eigene Art oder nur eine auffallende Varietät der Sescuplana ist. Zu Tortr. peritana Rob. Fig. 52, p. 277 gehört es nicht. Diese hat (nach meinem am 29. Juni bei Beverly gefangenen q) entschieden weniger gespitzte Flügel, auf den vorderen sowie auf $\mathrm{P}$. und $K$. eine gesättigtere Ocherfínbe und eine dentliche, vom hinteren Drittel des Costaldreiecks in den Htrd. dicht über dem Innenwinkel herabgehende rostbraune Linie. Auch siud die ganzen Zeichnungen stark mit Rostfarbe gemischt. (Wie der Vdrd. der $\sigma^{7}$ Vdf. beschaffen ist, zeigt Robinson nicht an).

\section{Torts. (Loxot.) Rileyana Grote.}

Majusculu, alis ant. obtusis (costa postice subconcava, revolucro o' longiore), rufescenti-ochraceis, maculis 2 costae, ma disci strigulaque unte marginem posticum medium obscure cinnamomeis; post. subsericeis, dilute ferrugineis. of 0 .

Tortr. - Grote. Transact. Am. Ent. Soc. 1868 (Sept.), p. 121.

- - Robinson 1. c. p. 271, tab. 4, Fig. 28 ․

- Piley: Nox Ins. I (1869), pl. 2, Fig. 4, 5, p. 153.

Robinson's Abbildung des $q$ ist sehr gut. 
Die ochergelbe Grundfarbe der Vdfl. ist mehr oder weniger röthlich angehaucht. Bei dem viel kleineren of reicht der verdickte, etwas schmale Umschlag von der Schulter bis zum ersten Costalfleck und niment also über 1/3 des Vdrdes, ein. Der duukel zimmtbraume Fleck liegt an der Medianader zwischen ihrem ersten und zweiten Ast und hat gewöhnlich einen solchen Punkt über und unter sich. Dic schräge zinmtbramne Querlinie ror dem Htrd. besteht aus $3-5$ an einander gereihten Punlffleckchen, ist mit ihrem oberen Anfang gegen das Ende des zweiten Costalflecks gerichtet und endigt am Htrd. nicht weit vom Innenwinkel.

Die Htfl. sind ganz rein hellrostfarben, seidenschimmernd, mit gleichfarbigen Fransen.

Das Geäder zeigt dic Merkwürdigkeit, dass beim $\sigma^{7}-$ wenigstens dem meiner Sammlung - auf den Vdf. die Adern 7 und 8 zu einer Gabel verwachsen sind, deren Stiel 1/4 so lang wie das Ganze ist, während sie bei den Q sich an der Wurzel kauın berühren oder auch zu einern kaum 1/8 der Länge betragenden Stiel vereinigt sind.

Meine 6 Ex. erhielt ich durch Riley aus Missouri.

Abth. Idiographis Led. Heinem. S. 31.

Ich beschreibe hier eine sehr ausgezeichnete, als neuseeländisch erhaltene Art, die nach Led.-Hum.'scher Vertheilung zu Idiographis gehören würde, also mit Centrana H. S. (= Inopiana Haw.) zusammengestellt werden müsste. Meine Amplexana lebt ohne allen Zweifel wie die anderen TortrixArten nicht in der Erde und in Wnrzeln, wie Inopiana (s. Nolcken's Fauna v. Fstl., Livl. nnd Curland S. 359) - die also schon darum aus dem Genus Tortrix entfernt werden muss. So bliebe meine Amplexana, um diesen Abtheilungsbegriff: Ader 7 und 8 getrennt, Umschlag der $\sigma^{7}$ Vdfl. vorhanden. Taster wie bei der Abth. Capua nngewöhnlich verlängert, zu repräsentiren.

17. Tortr. (Irliogr.) amplexana n. sp. VIII, Fig. 2.

Palpis elongatis, albidis, exterius brunneis; alis ant. acutis, albidis, fusco-strigulosis, angulo revolucrum amplectente lituraque dorsi medii transversa ustulato-fuscis, trianguto costae posticae fuscescenti, nigro-striguluto. o.

Sehr kenntlich an dem brandigbraunen Winkelstreifen, der auf den weisslichen oder grauweissen V rdfl. den Basalumschlag einfasst, und den brandigbraunen, nach hinten gran beschatteten Querwisch der Innenrandmitte.

Kleiner als Costania. R. und Kopf hellgrau. Taster von dreifacher Kopflänge, zusammengedrückt, weissgrau, abwärts gelbbrauı; Endglied kurz und geneigt. Saugrüssel kurz, aufgerollt. Fühler grau, kurz pubescirend. Die 4 vorderen Beine mit weissgranen Enden der Glieder; die Mittelschiene mit weisslichem Bändchen unterlalb der Mitte; Hinterbeine einfarbig gelblichgran. 
Hinterleib lehmgrau, an den hintersten Segmenten mit rauhen seitlichen Schuppen; Analbusch länger als das letzte Segment, gran.

Vdfl. 41/2" lang, länglicher als bei Costana, mit graderem Vdrd. an der hinteren Hälfte und tieferer Einbiegung unterhalb der Spitze, die daher stärker hervorsteht. Der Umschlag befindet sich nahe der Basis, jiegt fest an und ist mehr oder weniger dunkelbräunlich angelaufen. Grundfarbe weisslich, grüsstentheils etwas durch Gran getrübt und reichlich mit braungrauen, welligen Querstrichelchen bestreut. Aus der Schulter geht ein kurzer, brandigbrauner Strich nach der Falte, wo sich ihm ein schräg aufsteigender, bis zum Vdrd. reichender, viel dickerer, in seiner Mitte mehr oder weniger verdünnter anschliesst; der dadurch gebildete rechtwinklige Haken umfasst den Umschlag und ein Stückchen der Flügelfläche unterhalb desselben. Vor der Mitte erhebt sich vom Innenrande, schräg einwärts geneigt, ein dicker, brandigbranner, zweiwelliger Strich bis iber die halbe Flügelbreite; auf der hinteren Seite geht er in einen doppelt so breiten, violettgrauen Schatten ïber. Wenig hinter seiner Spitze fängt das brännliche, mit schwarzen, schrägen Querstrichen durchzogene, einwärts nicht scharf begrenzte Costaldreieck an, welches bis kurz vor die mit einem schwarzen Punkt bezeichnete Flügelspitze reicht. Vor der Nitte des Htrdes. liegt eine schräge, mehr oder weniger kurze, schwarze, aus Schüppchen zusammengesetzte, hinten grau schattirte Querlinie. Eine schwarze, ebenso zusammengesetzte und mehr oder weniger weit herabreichende Htrd.-Linie zieht vor den Fransen, deren grössere obere Hälfte auswärts gebräunt ist.

Htfl. mit deutlicher Spitze, weisslichgrau mit gelblicher Beimischung und ziemlich reichlich mit verloschenen, braungrauen, von der Unterseite durchscheinenden Querstrichelchen bestrcut.

Unterseite der Vdfl. röthlich branngrau; der Vdrd. an der Wurzel, so weit der Umschlag reicht, graubraun, von da ab schmal grauweisslich und braun gefleckt. Fransen stärker verdunkelt als auf der Oberseite. Htfl. mit mehr gelblicher Beimischung und deutlichern Querstrichen als oben. Die Htrd.-Linie düns, gelbbräunlich, auf dem Analwinkeldrittel fehlend.

4 , bis auf eins, gut erhaltene $\sigma^{-1}$ ans Neu-Seeland in meiner Sammlung.

Abth. Ptycholoma Stph. Heinem. S. 38.

Getrennte Adern 7 und 8. Starker Umschlag des $0^{7}$. Taster sehr kurz.

\section{Tortr. (Ptychol.) melaleucana Walker.}

Media, palpis minutis; alis ant. elongatis (vevolucro or ex basi longe ultra medium producto), albidis, nitidulis, dorso latissime ustulato-fusco, in medio subinterrupto, macula costae anteapicali fuscescente. o 9.

Tortrix - Robinson 1. c. p. 271, tab. 4, Fig. 29.

In Robinson's Abbildung gut zu erkennen, wenn auch die Flügel zu wenig gestreckt und in der Grundfarbe nicht hell genug sind. Die Art hat 
ausser don Abtheilungsmerkmalen nichts mit Lecheana und Magnificana gemein. Die o Fühler entbehren der feinen Zähnchen der Lecheana und sind einfach borstenförmig, sehr zart pulescirend gefranst. Der Umschlag der Vdf. reicht von der. Wurzel an bis $2 / 3$ des Vdrdes., und ist also länger als bei irgend einer bekannten Wirklerart; an seinem Basaldrittel ist er gelblich braungran. Der sehr breite, braune, gelbumfossene nud mit glänzend granen. geglätteten Schuppen bestreute Wisch, der sich am ganzen Innenrand hinzieht, mimmt mehr Raun ein als die gelblichweisse Grundfarbe und ist durch glänzend grane und rostbrïnnliche Beschuppung in zwei Flecke getrennt. - Das grössere $q$ hat einen convexen Vdrd. und reineres Weiss, das an der Basis nirht verdunkelt ist. Anch verbindet sich der Costalfleck mit dem Dorsalwisch unr durch gelbe Linieı, statt dass er beim $O$ dnrch glänzendgrane und gelbbrïnuliche Firbung damit zusammenlängt.

Meine $4 \mathrm{Fx}$. sind aus Ohio (Schläger).

Anmerkung. Ohne Zweifel hat Robinson sich den Namen aus dem British Musem geholt. Denn an albo-cinereus und alae vitta postica latissima cinereo-fusca wird Niemand die Art erkennen. In der Beschreibung wird diese vitta, unserer Art entsprechend, an den Innenrand verlegt; aber über den Costalfleck schweigen Diagnose und Beschreibung. - Clemen's Beschreibung (Proceed. E. S. Phil. 3, p. 518, wo anch das Geäder und der Kopf abgebildet ist) als Ptycholoma? semifuscanc ist äusserst genau.

Abth. Lophoderus (Stph.) Heinem. S. 41.

Vufl. ohne of Umschlag, mit'wenig convexem Vird, und getrennten Adern 7 und 8. Scutellum nit einem Schuppenhöcker. Taster kurz.

\section{Tortr. (Lophod.) Iutosana Clemens.}

Parva, alis ant. (costa leviter convexa, revolucro ol nullo) subochraceis, fascia media obliqua superius fusca, infra striolam nigram dilatata cinnamomea, triangulo costae posticae fusco cum macula super angulo dorsali posita conjuncto; post. obscure cinereis. ơ 9 .

Tortr. - Clemens Proc. E. S. Philad, V. (1865), p. 138.

- - Robinson 1. c. p. 279, tab. 6, Fig. 59.

Ich habe nur $2 \sigma^{7}$ und 1 sicheres $q$ vor mir; nach ihnen ist mir die specifische Verschiedenheit von Politana Haw. sehr zweifelhaft. Die $\sigma^{\text {乃 }}$ sind kleiner als meine Ex. von Politana und haben auf den Vdfl. eine gelblichere, hellere Grundfarbe als diese gewöhnlich; aber der Flügelbau und die Zeichnungsanlage ist ganz dieselbe. Die Binde geht ron der Mitte des Vdrdes. schräg nach dem Innenrand; sie erweitert sich auf den unteren $2 / 3$ so, dass ihr Htrd. bis in den Innenwinkel reicht; sie ist auf dem obersten Drittel dunkel gelbbraun bis zu einem tiefschwarzen, sie durchschneidenden Längsstreifen, der 
auf der Basalseite zahnförmig gebogen liervorstelit, über welchem die Binde verengert ist. wodurch der von Robinson bemerkte helle Fleck an ihrer Basalseite entsteht; unterhalb des schwarzen Iängsstreifens ist die Farbe lebhaft dunkel ocher- oder zimmtbraun. Ganz so sind deutlich gezeichnete Ex. der Politana, denen aber öfters der schwarze Läugsstreifen fehlt. Der Raum zwischen der Binde und dem Costaldreieck, welcher sich auch auf der Unterseite als weisslicher (bei Politana öfters getheilter) Fleck auszeichnet, bildet eine schinale, helle Binde, welcle die Mittelbinde auswärts einfasst und in ihrem Costalanfang besonders scharf ist.

Anf diesen Raum folgen bei deutschen Ex. der Politana gewöhnlich noch 3-4 hleinere weisse Fleckchen; sie fehlen bei englischen meist ganz; bei den XAm. sind sie verloschen und dunkler gefärbt. Dic untere Spitze des Costaldreiecks hängt durch einen Faden mit dem eiförmigen zimmtbraunen Fleck zusammen, der zwischen dem unteren Theil der Mittelbinde und dem Htrd. über dem Innenwinkel liegt. - So bleibt für Lutosana ausser der Kleinheit und helleren Grundfarbe gar keine Anszeichnung ror Politana.

Robinson bildet in Fig. 59 ein grosses $q$ ab, dem der Fleck über dem Innenwinkel fehit; aber er dentet ihn in der Beschreibung durch die Worte an: connected by a paler streak with internal angle, während Clemens darübẹr schweigt. Das vorliegende $Q$, das sicher hierher gehört, hat ihn sehr deutlich, aber verdünnt bis in den Inneuwinkel fortgesetzt, und so ist es bei der europäischen Politana.

Ich habe $2 q$ aus Texas (Boll) vor mir, beide etwas grösser und breitflïgliger als das besprochene, von denen das eine ziemlich genau als Incertana bei Robinson in Fig. 58 abgebildet scheint. Der Raum zwischen Basis und Mittelbinde ist gesättigter, röthlich ochergelb; das Schwarze an Innenrand tiefer und breiter. Anch ist die Mittelbinde ein wenig breiter und angenehmer braungelb an den unteren 2/3. Das Costaldreieck ist dunkler und ein wenig grösser, und der schmale bindenförmige Streifen zwischen seiner Spitze und der Mittellinde ist schwärzlich bestäubt. Dieses Ex. hat, wie Fig. 58 es zeigt uud wie Robinson und Clemens ès beschreiben, den eirunden Fleck über dem Innenwinkel. - Die Zeichnungen haben aber alle die Lage wie bei der echten Lutosana ․ so dass nur die beträchtlichere Grösse und die schönere und gesättigtere Färbung als'ungenügender Unterschied übrig bleibt.

Das zweite abgeflogene Ex. ist offenbar dieselbe Art, nur mit blässerer, röthlicher Ocherfarbe und mit mehr gleichmässigem Schwärzlichbraun der Mittelbinde und des Costaldreiecks. Robinson's Fig. 57 Incertana $\sigma^{-}$ stimmt mit diesem Ex.; das Bild ist schmalflügliger und zeigt - offenbar in Folge ungenauer, durch den verdunhelten schmalen Trennungsranm veranlasster Darstellung - die Mittelbinde mit dem Costaldreieck zusammengeflossen. Robinson gibt dem Endgliede der Taster eine schwärzliche Farbe, was ein Versehen, jedenfalls nichts Beständiges ist. 
Meiner Ansicht nach ist daher Incertana Cl. Rob. p. 278 nicht specifisch von Lutosana, und beide zusammen nicht specifisch von Politana verschieden Vaterland meiner $2 \sigma^{7}$ New-York, der 3 q Texas (Boll).

A umerkung. Politana Haw. ist eine etwas veränderliche Art, nach Wilkinson (p. 271) sogar "sehr veränderlich, sowohl in der Färbung wie in der Intensität ihrer Zeichnnngen". Sie ist nur in der englischen Varietät, die auch Heinemann S. 41 beschreibt, bei H. S. als Lepidana gut und kenntlich abgebildet. F. v. R.'s. Sylvanu, die icl von ihm selbst unter diesem Namen erhielt, ist die deutsche, gelblichere, weniger scharf gezeichnete Varietät und bei ihm Taf. 22, Fig. 4 ganz unkenntlich dargestellt. Wenn H. S. IV, S. 162 sagt, die 2 schwarzen Punkte der Abbildung seien "selten" vorhanden, so heisst das nichts Anders, als an seinen Ex. seien keine zu sehen. Meine 12 deutschen und 9 englischen Ex. zeigen sie ebensowenig.

Ich selbst fing bisher bei Glogau in einer Kiefernschonung am 13. Mai $2 \sigma^{\nearrow}$ und bezweifle die Richtigkeit der bei Treitschke zu lesenden (wohl von C. v. Tischer ihm gemeldeten) doppelten Generation.

Abth. Argyrotoxa ${ }^{1}$ ) Heinem. S. 48.

R. glatt. Vdrd. der Vdfl. schwach convex oder auf der hinteren Hälfte gradlinig, ohne Umschlag des $\sigma^{7}$. Ader 7 und 8 getrenut.

\section{Tortr. (Argyrot.) trifurculana n. sp.}

Alis ant. oblongis (revolucro o mullo), pallide flavis, obsolete ochraceoreticulatis, strigis 3 subangulatis, obliquis, ochraceis (una ante medium, una postica utrimque furcata, una ante apicem); post. niveis totis. $\sigma^{7} \mathrm{Q}$.

Aehulich in Färbung und Zeichnung der folgenden Furcatana, bei welcher aber die Adern 7 und 8 eine Gabel bilden, wäbrend sie bei Trifurculana bis zur Wurzel getrennt bleiben.

R. und K. blassgelb, wie das Wurzelglied der beim $\sigma^{7}$ zart pubescirend gefransten Fühler. Taster blass ochergelb, beim $q$ von doppelter Kopflänge, beim $\sigma^{\pi}$ kürzer, am Ende des zweiten Gliedes stark verdickt; das Endglied kurz. Saugrüssel sehr kurz (oder fellend?). Beine weisslich, die vorderen aussen ochergelblich angelaufen; Hinterschienen weiss. Hinterleib gelblichweiss mit schwachem Analbusch.

Vdfl. $\sigma^{\pi} 3^{3} / 4^{\prime \prime \prime}$, $q 41 / 2^{\prime \prime \prime}$ lang, länglich mit sanft convexem, au der hillteren Hälfte ziemlich geradem Vdrd,, dentlicher Spitze und sanft convexem Htrd. ohue Eindruck unter der Spitze. Die blassgelbe Grundfarbe ist reichlich mit blass ochergelben Fleckchen oder groben Pnnkten bestreut, welche, beim $q$

1) Argyrotoza ist, sowie Lozotaenia, als ein Memento, das Stephens ohne dio griechischen Buchstaben zu kennen, griechische Wörter gubildet hat, zu verwerfon. 
deutlicher getrennt als beim ऽ, wellige Querlinien bilden. Vor der Mitte geht eine starke, schwachwellige, hier und da verdickte, ocherbranne Querlinie vom Vdrd. bis hinter die Mitte des Innenrandes. Ihr parallel ist die zweite Querlinie, von hinter der Mitte des Vdrdes. bis zum Htrd. dicht über dem abgerundeten Innenwinkel; an ihren Anfang und Ende bildet sie eine kurze Gabel, und über ihrer Hälfte sendet sie einen Ast nach der dritten Querlinie. Diese ist kurz, da sie vom Vdrd. nur bis zur Mitte des Htrdes. reicht; sie ist beim Q etwas zerrissen und am Vdrd. gleichfalls in eine kurze Gabel gespalten. Den Ftrd. umzielıt eine ocherbräunliche, gegen die weisslich gelben Fransen scharf abstechende Linie.

Htfl. rein weiss, etwas seidenglänzend, mit gleichen Fransen.

Unterseite weiss, beim $\sigma^{\nearrow}$ besonders am Vdrd. der Vufl, und gegen die Wurzel sehr blass ochergelb angelaufen. Ader 7 und 8 kommen einander an der Wurzel sebr nahe, uhne sich iloch zu vereinigen, und Ader 8 endigt entschieden ïber der Flügelspitze in den Costalfransen.

Das $\sigma^{\lambda}$ meiner Sammlung ist ans New-York (Speyer), das sehr schöne des Museum Cambrilge ans 'Texas (Boll).

\section{Tortr. (Arygrot.) robicomana Clemens.}

Parva; alis ant. breniusculis (revolucro o nullo, costa convexa), pallide citrinis, strigis 3-4 obliquis, arenatis, lilacinis, nitidulis, saepe ferrugineofusco marginatis; post. albis, saepe ad marginem posticum cinerascentibus. $\sigma^{\top} \mathrm{O}$.

Tortr. - Robinson 1. e. tab. 5, F. 41.

Var. b) al. ant. basi et margine postico pallide citrinis, ceterum fuscoferrugineis, in medio fermgineis, macula parva vence transversae albida, strigis litacinis dilatatis; post. cinereis. $\sigma^{7}$ ㅇ.

Xanthosetia - Clem. Proc. E. S. Philad. V. (1865), p. 137.

Tortr. - Robinson 1. c. p. 273, tab. 5, F. 42.

Robinson vergleicht sie richtig mit Bergmanniana; jedoch ist bei dieser die Spitze der Vdfl. etwas deutlicher, und Ader 7 geht etwas tiefer unterhalb der Spitze in den Htrd. Die einfachste Färbung (Fig. 41) scheint er darum weiter nicht zu erwähnen, weil Clemens sie beschrieben hat.

Beide Geschlechter dieser schönel Art konmen in beiden Färbungen vor; mir hat Var. b) wohl ohne Ansnahme dunkelgraue Htfl.

Die Art scheint sehr verbreitet und stellenweise häufig zu sein. Burgess fing $\sigma^{\lambda}$ der Var. a) bei Beverly am 21. Juli.

22. Tortr. (Avgyrot.) conigerana n. sp. Taf. VIII, Fig. 3.

Alis ant. (costa leviter convexa, revolucro o" basali, appresso) saturate rufo-ferrugineis, postice brunneo purpureoque mixtis, macula costae trianguluri vel trapezoidali nivea. of 
Nach den schneeweissen Costaldreieck der Vdfl. scheint diese schüne Art mit der viel kleineren Teras Holmiana I. verwandt; aber bei ihr gebt Ader 7 deutlich unterhalb der Flügelspitze in den Htrd., und das $\sigma^{\nearrow}$ hat einen ziemlich langen Umschlag. Es fällt mir sehr auf, dass ich, obgleich die Art nicht selten sein kann, bei Clemens keine auf sie passende Beschreibung finde. Robinson mag sie für ein anderes Genus, an dessen Bearbeitung ihn der Tod gebindert hat, aufgespart haben. Da sie aber nicht neben Holmiana gestellt werden darf, so findet sie wohl den geeignetsten Platz bei Unifasciana.

Etwas grösser als Loeflingiana. R. und K. röthlich rostfarben, beim $\sigma^{7}$ weniger lebhaft. Taster ziemlich diinn, um wenig mehr als die halbe Kopflänge rorstehend. Saugrüssel klein. Fühler des $\sigma^{\top}$ borstenfürmig, mit gedrängten Gliedern, inikroskopisch pubescirend; graubräunlich, mit gelblichem Wurzelgliede. Die 4 vorderen Beine bräunlich mit helleren Enden der Glieder; die Hinterbeine gran mit verdunkeltem Rücken der Wurzel der Fussglieder. Hinterleib grau, an den Hinterrändern der letzten Segmente schuppenhaarig gefranst. Analbusch des $\sigma^{\nearrow}$ stark, grangelblich, des $q$ ärmlich, bleichgelb.

Vdfl. 4" lang, länglich mit von der Wurzel stärker, dann sehwach convexem, beim $Q$ fast geradlinigem Vdrd, und sehr schwach convexem Htrd. Grundfarbe gesättigt rostroth, bei $1 / 3$ des Innenrandes mit einem braunen Fleckchen. Der Umsehlag reicht von der Basis bis zum weissen Dreieck und ist mit einigen dunkelgrauen Fleckchen bestreut. An der Mitte des Vdrdes., von der Basis etwas weiter entfernt bleibend als von der Flügelspitze und kaum 1/3 der Flügelbreite einnehmend, liegt ein schneeweisses Dreieck; beim $\subseteq$ ist seine Spitze abgeschnitten, wodurch es ein Trapez wird.

Eine sehr dunkel rostbraune, nach unten gebräunte Binde, die das Dreieck von der Basalseite begrenzt, läuft sehräg zum Innenrand; hinter ihr ist der Grund gelichtet und hell purpurfarbig gemischt. Am Htrd. ist eine bell rostbraune, gelblich bestäubte (oder gelbliche, rostbraun fleckige) Binde, welche an ihrer Mitte mehr oder weniger stark eckig nach innen erweitert und auf der Basalseite von einem breiten, braun rostfarbigen Streifen eingefasst ist, wodureh ihr Raum um so scbärfer bezeichnet wird. Fransen heller rostfarbig als die Grundfarbe.

Htfl. grau, gegen die Wurzel und den Vdrd. gelichtet.

Unterseite der VdA. hellgrau; das Costaldreieck scheint in gelblichweisser, die Htrd.-Binde in gelblicher Farbe velloschen durch; Fransen rostbräunlich. Httl. weissgrau, am Vdrd, und in der Spitze weisslich.

Ieine Sammlung entbält $1 \sigma^{\nearrow}$ aus Maine (Packard), 3 O aus Massachusetts (mit dem Datum 26. Juni) und 1 ㅇ aus New-York (Spejer).

Abth. Oenectra Gn., Heinem. S. 50.

Taster von dreimaliger Kopflänge. Vdrd. der Vdfl. des $\sigma^{\nearrow}$ ohne Umschlag. Ader 7 und 8 zu einer Gabel zusammengeflossen. 
An Pilleriana, der einzigen Art, auf welche Guené e und L ederer die Abtheilung Oenectra gründen, bemerke ich einen ganz kleinen Umschlag an der Wurzel des Vdrdes, und von ihm ans den Raud selbst fast bis zur Binde aufgebogen; der Umschlag scheint zwar nicht ans Haut, sondern nur aus vergrösserten Schuppen zu bestehen. - Bei Exustana Z. (Ent. Ztg. 1860, S. 144), die ich darauf hin nicht untersuchen kann, weil ich nur $1 q$ besitze (nicht $1 \sigma^{7}$, wie dort gedruckt ist), ist der Stiel der durch Ader 7 und 8 gebildeten Gabel viermal so lang wie die beiden Gabeläste. - Die folgende Art hat in sonstigem Bau und Färbung so wenig Aehnlichkeit mit den beiden anderen Oenectra-Arten, wie diese unter sich.

\section{Tortr. (Oenect.) violaceance Robs.}

Mediocris, palpis longis; al. ant. subacutis, (costa leviter convera, revolucro ot mullo), fusco-violaceis, basi late aurea nitidula, maryine postico ciliisque ochraceis; post. obscure cinereis, subtus canis, $\sigma^{7}$.

Tortr. - Robinson 1. c. p. 271, tab. 5, Fig. 31.

Die Fühler sind borstenförmig, kaum gegen die Spitze schwach gekerbt, mikroskopisch pubescirend. Die spitzen Vdfl. habeı einen schwach gekrümmten Vdrd. und einen solchen Htrd., so dass die Spitze nicht sonderlich scharf ist. Von einem Umschlag ist nicht die geringste Spur zu entdecken. - Eine Aehnlichkeit mit Ministrana, die Robinson sieht, ist der Art abzusprechen. Auch sehe ich bei ihr auf dem Scutellum keine Spur eines Haarschuppenhöckers.

Meine 4 Ex. sind, wie die Robinson's, aus den Staaten New-York und Massachusetts.

Abth. Dichelia Led., Heinem., S. 50.

'Taster kaum von doppelter Kopflänge. $\sigma^{\nearrow}$ Fühler nur pubescirend gcfraust. Vdfl. ohne Umschlag. Ader 7 und 8 bilden eine Gabel.

\section{Tortr. (Dichel.) puritune Robins.}

Alis ant. elonyatis (costa sine revolucro), aureis, fasciu perolliquu, sulangulata, maculu costae posticue lituraque sub urice rufo-ferrugineis, lilacinoconspersis; posticis cinereis, $Q$ dilntioribus.

Tortrix - Robiuson 1. c. p. 271, tab. 5, Fig. 30.

Sie hat einige Aehnlichkeit mit der europäischen Strigana, aber eine schöner gelbe Grundfarbe. Die Taster, die bei meinem Paar abgebrochen sind, beschreibt Robinson als lang und rüsselförmig, wonach die Art sogar zu Oenectra gehören und ein noch bunteres Artengemisch hervorbringen würde.

Das $\sigma^{\pi}$ hat an den Fühlern etwas Besonderes, indem die Geissel rom Wurzelgliede abgeschnürt, dann iı 10-12 Gliedern etwas zusammengedrückt 
convex, an beiden Seitenrändern sägezähnig und borstig gefranst, von da ab einfach borstenförmig, gezähnelt unıl flaumhaarig ist.

Die Binde der Vuff. geht ron 1/4 les Vdrdes. nach dem Anfang des letzten Innenranddrittels hin, an dem sie sich zu einem bis in den Innenwinkel reichenden Streifen erweitert, was sie anch in der Falte thut, wodurch sie eine eckige Gestalt exhält. Der Stiel iler Gabel von 7 und 8 hat kaum 1/3 der Länge des Ganzen.

Taterland meiner Ex. wahrscheinlich Naine. Robinson gibt fiir die seinigen Massachusetts un! Illinois an.

A nmerkung. Croesia? unifasciana Clemens (Proc. E. S. Phil. 3, p. 516). welche Rohinson für seine Art hält, kann kaum lierhergehören, wenn sie nicht sehr abänlert. Die Zeichnung der Flïgelspitze stimmt; aber von der Binde, dic er als über der Falto unterbrochen beschreibt, soll darlurch das mntere Ende als ein Fleck auf len mnemram ein wenig hinter der Mitte äbrig bleiben, statt lass sie, wie ich beschrieben habe, mu wie Robinson abbillet. sich von $2 / 3$ des Innenrandes bis in len Inuenwinkel fortsetzt. Robinson's Figur balte ich für die des $\sigma^{7}$; sie hat aber blass gelbliche Htfl., blässer als bei meinem $Q$. Clemens gibt kein Geschlecht an und bezeichnet sie als blass braungelb. Diese Elïgel mögen eine veränderliche Fürbnng haben.

\section{Torty. (Dirhel.) sulfureana (lem.}

Parva, palpis prominentibus; al. ant. (sine or revolucro) aureis, nitidulis, fermgineo-reticulatis, fascia obliqua ex margine dorsali ramum emittente adversus marginem posticum directum et cum macula marginali connexum, puncto dorsi ante medium maculaque costre posticae lilacino-brumeis; al. post. obscurc cinereis. of 9 .

Torts: - Robinson, p. 273, t. 5, Fig. 38 (zu gross), 39.

Croesia? - Clem. Proc. Ac. Nat. Se. Philad., 1860, p. $35 \%$.

- ? virgineana Clem. Proc. E. S. Philad. 1864, p. 517.

Robinson, der 100 Ex. zum Vergleich hatte, mag mit der Behauptung Recht haben, dass diese Art sehr veränderlich sei. Ich habe nur 5 sicher zu einer Art gehörige Ex. und zwei grössere o , die ich nicht mit Bestimmtheit damit vereinigen kann. Jene $\left(3 \sigma^{\top}, 2\right.$ ㅇ stimmen mit Clemens' Beschreibung seiner Sulfurerna, nur nicht in der der Htfl, die nach ihm whitish sein sollen, während sie bei meinen Ex. dunkel braungrau, beträchtlich dunkler sind als bei den 2 grösseren, in Anmerkung 1 erwähnten, und nicht in dem stripe along the inner margin (der Vdfl.), von dem meine Ex. so wenig zeigen wie Robinson's Figuren. In Rbs.' Fig. 39 nimmt ein dunkelrother Streifen fast den ganzen Htrd. ein.

Meine Ex. sehen folgendermassen aus. Auf den Vdfl. ist die Grundfarbe ein schönes, schimmerndes Goldgelb, mit rostrothen Gitterstrichen reichlich ïberzogen, die gegen die Basis hin ziemlich verloschen, gegen den Htrd, hin 
um so deutlicher ausgedrückt sind; hier treten besonders die Adern iu dieser Farbe scharf hervor. Eine violettlichbraune Binde fängt auf $1 / 3$ des Vdrdes. einfach oder zu einem Fleck erweitert an und geht schräg und ziemlich gerade bis zum Innenrand hinter der Mitte, wo sie sich zu einem grösseren Fleck erweitert: ron dessen hinterem Ende steigt schräg aufwärts ein starker Arm auf, der sich oberhalb der halbeu Flügelbreite ganz nach hinten wendet und sich durch verstärkte Adern mit einem Hinterrandfleck von verschiedener Länge und Deutlichkeit vereinigt. Am Innenrand liegt vor ${ }_{1 / 3}$ ein starker, gleichfarbiger Punkt und am Vdrd. vor der Spitze ein ebenso gefärbter dreieckiger Fleck. Die Fransen sind hellgelb.

Die $Q$ sind etwas grösser als die $\sigma^{7}$, mit schmäleren, spitzeren Vdfl., deren Vdrd. hinter der Mitte bis vor die Spitze sanft eingedrückt ist. Das Costaldreieck ist schmäler als beim $\sigma^{7}$, der Htrd.-Fleck kleiuer und vom Htrd. abgerückt, so dass hinter ihm die rostfarbenen Adern deutlich hervortreten.

Die Htfl. haben in beiden Geschlechtern in den Fransen dasselbe Dunkelgrau wie auf der ganzen Flügelfläehe. Rbs. bildet sie gelblich ab, lässt aber aus der Beschreibung errathen, dass sie von der Flügelfläche nicht abweichen. Der Stiel der Gabel, welche auf den Vdfl. die Adern 7 und 8 bilden, ist halb so lang wie das Ganze. - Die 2 haben dicke, lange, dunkelgraue Hinterleiber; der kleine Analbusch des einen ist gelblich; aber die dunkelgrauen Deckhaare mögen abgerieben sein.

Nach der Länge der Taster, die um etwas mehr als die Kiopflänge hervorstehen, würde diese Art auch zu Oenectra zu stellen sein; sie sind dreieckig verdickt, dann schnell verdünnt, mit dünnem, abwärts gerichtetem Eudgliede.

Meine Ex. sind aus Massachusetts (o 29. Jnni und o 16. Sept., Burgess), Missouri (Riley) und Texas (Boll).

Anmerkung 1. Die zwei grösseren $\sigma^{7}$ Ex. (1 so gross wie die eben beschriebenen 9 , das andere noch grösser, beide jedoch kleiner als Purituna) haben zwar unter einander gleiche Flügelgestalt, nämlich die Vdfl. ein wenig länger als bei den beschriebenen Sulfureana $\sigma^{\nearrow}$, sind aber ia der Färbung unter einander etwas verschieden. Bei beiden stimmt die goldgelbe, schimmernde Fläche ganz mit der von Sulfureana; es fehlt aber alle Gitterzeichnung, und die übrige Zeichnung ist rostbraun, mit violettlich schimmernden Schuppen überdeckt, so dass das Rostbraun nur schmal an den Rändern zum Vorschein kommt. Die Binde ist in 3 Flecke aufgelöst, von denen der mittelste weiter vom Dorsalfleck absteht als vom Costalfleck; der Dorsalfleck, der grösste, streckt gegen den Mittelfeck eine Spitze hervor und sendet hinten einen Arm schräg in die Höhe, der sich auf der Querader zu einem Fleck verdickt und hier endigt. Hiuter und über diesem Fleck ist bei dem kleineren Ex. der Grund ganz reingelb; bei diesem zieht dicht vor dem Htrd, ihn nicht berührend, aus der Flügelspitze ein breites Band herab, das sich unten verdünnt und durch einen dünnen Randstreifen mit dem Dorsalfleck verbindet. Ebenso ist auch der dunkle Dorsalpunkt auf dem Inneurande durch rostgelbe Schuppen mit dem Dorsalfleck verbunden. Das Costaldreieck, welches ror dem Quer- 
aderfleck anfängt, ist nach hinten sehr verengert und gelichtet und hängt nicht mit der Flügelspitze zusammen. Bei dem grösseren Ex. erreicht es aber nicht nur die Flügelspitze, sondern fliesst auch mit dem Bande des Htrdes. zusammen; zwischen diesem nnd dem Queraderfleck ist noch ein Querfleck vorhanden, der mit diesem. sowie mit dem Mittelbande durcl lichtere Rostfarbe wischartig verbunden ist. Die Gabelader ist wie bei Sulfureana. Die Fransen sind nur gelblich. Die Htfl, sind lichtgrau mit helleren, doch nicht gelblichen Fransen.

Was also diese Ex. (das kleinere aus Texas [Packard], das grössere aus Maine oder Massachusetts [gleichfalls von Packard]) von meiner Sulfureana unterscheidet, ist die beträchtlichere Grösse, der Mangel der Gitterzeichnung, die in Flecke aufgelöste Binde, der Queraderfleck, das Htrd.-Band und die helleren Htfl. - Auf das kleinere passt Rbs. Fig. $40^{\circ}$ gut, und ich würde sie für eine Darstellung desselben erklären können, wenn sie nicht eine vollständige Binde zeigte.

Anmerkung 2. Ich habe $3 \sigma^{x}, 1$ 오 von Belfrage aus Texas (die $\sigma^{\top}$ am 20. Juli nnd 1. August, das $q$ am 30. Juli gefangen). Sie sind zum Theil sehr abgeflogen; nur das eine $\sigma^{2}$ hat vollständige Fransen, woher sich mit Wahrscheinlichkeit aunehmen lässt, dass auch die Flügelfärbung bei ihm nicht durch Abreibung verändert ist. Sie sind noch kleiner als meine Sulfureanc, mit etwas längeren Vdfl., wie bei den in Anm. 1 beschriebenen. Die Grundfarbe ist ein helles Goldgelb mit cinigem Schimmer, und nur bei dem unabgeflogenen $\sigma^{7}$ in der Gegend des Innenwinkeis mit einiger Spur von Gitterung. Die Farbe der Zeichnungen und der Schulterdecken ist rostroth, schwach lilaschimmernd. Die Binde ist in 3 getrennte Flecke aufgelöst; bei einem $\sigma^{7}$ hängt jedoch der zweite mit dem grossen Dorsalfleck genau zusammen. Der grosse Queraderfleck ist mehr oder weniger weit vom Dorsalfeck entfernt: jedoch bei demselben $\sigma^{7}$ mit ihm durch einen dünnen Hals verbunden. Der Costalfleck ist klein und völlig frei. Der Htrd.-Streifen, der sich dem Htrd. über dem Innenwinkel melrr nähert als oben, ist nach unten sehr verdünnt. Der Dorsalpunkt vor der Binde ist gross und dreieckig. Auch die Basis des Vdrdes. ist fleckartig rostroth und durch solche Schuppen mit der Binde verbunden. Die Gabelader wie bei Sulfureana.

Htfl. selir hellgrau, auf der Unterseite fast gelblich. Hinterleib blass gelbgrau.

Diese kleine Form nenne ich als Varietät oder als Art, falls sie sich als solche erweisen sollte, Belfrageana.

\section{Tortr. (Dichel.) furcatamu Walker.}

Alis ant. acutis (revolucro or mullo?), pallide flavis, subreticulatis, fascia media inferius furcatu, ramo altero cum macula dorsali conjuncto, strigaque postica bisinuata in angulo interno cum macula dorsali conjuncta fuscoferrugineis; post. albis. 9 .

Dichelia - Walcker Brit. Mus. 28, p. 319.

Tortr. - Robinson 1. c. p. 270, tab. 4, Fig. 27. 
Meine 2 Ex. sind grösser als die folgende Reticulatana und haben keine Taster; nach Walker sind diese kurz, während Robinson über ilure luänge schweigt. Der Vdrd. der Vdfl, ist vor der scharfen Spitze sanft eingedrückt, der Htrd. fast gerade, kaum ein wenig convex, ganz ohne Eindruck unterhall, der Spitze. Die Gabel der Adern 7 und 8 ist länger als der Stiel.

Was diese Art besonders charakterisirt, ist der rostbraune Dorsalfleck, der von $2 / 3$ des Innenrandes, wo er den einen Arm der beiden, in die sich die Binde spaltet, aufnimmt, bis in den Innenwinkel hinein reicht. In Robinson's Bild ist er nicht ausgedriickt. - Die Art hat eine äussere Aehnlichkeit mit Trifurculana, bei welcher aber die Adern 7 und 8 der Vdfl. getrennt bleiben.

Meine zwei Ex. sind aus den Staaten New-Tork und Ohio.

Abth. Batodes Guen., Heinemann S. 4!!.

Vdrd. der Vdfl. mit kurzem Umschlag; Ader 7 und 8 bilden rine Gabel. Taster bis zu doppelter Kopflänge.

\section{Tortrix (Bat.) reticulatama. Clemens.}

Alis ant. acutis (revolucro or yarro), pallide aureis, fermgineorecti-

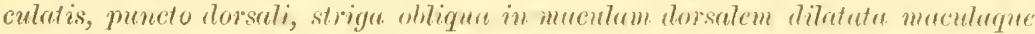
costue posticae fureum in maculam dorsulem et in angulum intermm demittente violuceo-fuscescentibus; post. allis net allivitis, in o ad maryinis interni busim eallosis. on

Croesia? - Clemens Proc. Acad. Nat. Sc. Philad. 1860, 1. 353.

Tortrix - Robinson 1. c. r. 272, tal. 5, Fig. 33-35.

?Var. b) mesosprila \%. al. unt. strigu unte metlium maculuque costali mullis, mucula dorsuli magna. 9 .

Mit liecht nennt Robinson liese Art selır veränderlieh. 1)as of wird aber wohl immer an der Beselaffenheit der Htf. zn erkemen seiu. An diesen ist nimlich der Innenrand aufallend kurz und wulstig verdickt, und weiter einwärts zicht in der etwas vertieften Fläche ein kurzer Wulststreifen herab. Die ganze Stelle ist blass ochergelb. Ausserdem ist der Flügel entweder so weiss wie beim $Q$, oder gelblichweiss, in der Flügelspitze grau angelaufen. Die Taster reichen un wenig mehr als Kopflänge über die Stirı hinaus. Der Umschlag des $\sigma^{7}$ liegt dicht an und ist ziemlich leicht zu übersehen; or reicht bis in den erweiterten Anfang des mebr oder weniger bindenförmigen Querstreifens. Das Costaldreicek ist hell und dunkel gegittert, und ron seinem unteren Ende geht ein stiel, der sich schnell in '2 gebogene Arne theilt, von denen der innere zu der dreieckigen Dorsalerweiterung des Querstreifens, der andere in den lnnenwinkel reicht; beide ändern in der Dentlichkeit ab, und es fehlt bisweilen der eine oder auch beide. 
Varietat b) unterscheidet sieh durch die breiteren Vifl., die anch unterhalb der spitze gar keine Finbiegung haben, wie sie loeh bei den drei anderen Ex., wenu auch sehr sehwaeh, vorhanten ist. Der erste Querstreifen fehlt; doch ist der Anfang, wenn auch undeutlich, zu erkennen. Dafiûr ist der halbeifürmige Dorsalfleck desto grösser und dunkler und durch Sehujpen auf dem Innenrand mit dem Innenrandpuukt verbunden. Auch das Costaldreieek fehlt und ist kaum durch verloschene Querstrichelchen angedeutet; wo sein Anfang sein sollte, geht eine dunkle, gebogene Querlinie in gleicher Richtung, wie bei den anderen Ex., in den Innenwinkel; die zum Dorsalfleck gerichtete fehlt völlig, wie auch die vor dem Htrd., welche sonst bei o' und $q$ vom Vdrd. sehräg zum Htrd. geht und ihı über den Innenwinkel erreicht. Die Gabel der Adern 7 und 8 hat einen kürzeren Stiel als bei den 3 anderen Ex., bei denen er $1 / 3$ des Ganzen beträgt. Es ist also möglich, dass das Ex. (dem die Taster fehlen) wegen der Breite der Vifl., des uneingebogenen Htrdes., der etwas anderen Zeichnung und der Gabelader zu einer verschiedenen Art gehört.

Vaterland: Texas (I $\left.\sigma^{\top}\right)$, Maine oder Massachusetts ( $\sigma^{7}$ 우), New-York (Var. b).

Anmerkung 1. Robius on's Fig. 36 seheint ein $\sigma^{\nearrow}$ darzustellen, dem die dünnen Querlinien nnd die Gitterung wie in Fig. 35 fehlen. Beide Figuren sind sicher nach Ex. mit weggewischtem Dorsalpunkt gemaeht. In Fig. 36 ist das Dorsaldreieck sehr klein und gegen die Wurzel zu nicht so weit verlüngert wie bei den anderen Ex., wesshalb seine Lage weiter gegen den Inneuwinkel gerüekt erscheint. Icb stimme Robinson bei, der beide Figuren als Varietäten hierherzieht.

A nmerkung 2. Der Name Reticulatana verträgt sich mit Reticulana If. und Reticulata Stt. in demselben Genus schlecht, da Verweehslungen nieht ausbleiben können. Ich würde daher Walker's Benennung Subauratana (Teras - 40, p. 28:9) vorziehen, deren Besehreibung ungewöhnlich sorgfältig ist und, wenu man weiss, dass diese Art gemeint sei, zutrifft.

\section{Abth. Amphisa ${ }^{1}$ ) Curt. Coelostatluna Clemens.}

Taster wenig länger als der Kopf. ó Fühler kammzähnig. Vdfl. des o’ ohne Unsehlag. Ader 7 und 8 bilden eine Gabel.

\section{Tortrix (Amph.) discopmencuma Clem.}

Parva, antennis o breviter pectinatis; ulis ant. ucutis (costa convexa,

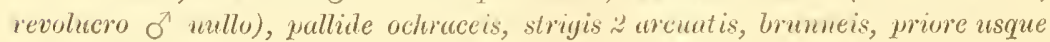

1) Nicht Amphysa, wie Lederer, If einewann und Audere schreiben. S. curtis Pritish Entomolegy, $V$ (IK2x), p. 2099. Stephens wihlte daliur in den lllustrations IV (1S31), p. 81 Philedone. 
al punetum renae transwersue nigrum, posteriore usque al marginem posticum fascine inster colore brameseenti adumbratis; post. whidis. of.

Coelostutluma - Clem. Proc. E. S. Philad. 1860, p. 355.

Tortrix - Robinson 1. c. p. 276, tab. 6. Fig. 51.

Der Stiel der aus 7 und 8 gebildeten Gabel ist lualb so lang wie das Ganze. Anf der Unterseite sind die Vdfl. blassgelb, gegen die Wurzel hin granschattig, der Vdrd. schmal weissgelblich und gegen die Wurzel lin mit bräunlichen und hinter der Mitte bis zur Spitze mit 4 starken, braunen Punkten gezeichnet, ans deren zweitem eine Querlinie bis in den Innenwinkel zieht. Der Qneraderpunkt ist braun nnd nicht so deutlich wie anf der Oberseite. Cambridge.

Fin $\sigma^{7}$, kleiner als Robinson's Abbildung, aus Texas (Boll) im Museum

Ein eben solches aus Dr. Rössler's Sammlung.

Abth. Platynota Clemens.

'T'aster von 2-3facher Kopflänge, vorgestreckt. Fühler einfaclı. Vdfl. mit rauhen Qnerlinien und Schuppenhanfen. Umschlag des o vorhanden. Ader 7 und 8 zu einer Gabel verwachsen.

Diese durch ilıre rauhen Vdfl. ausgezeichnete Abtheilung, die Clemens schr genan charakterisirt, ist nicht melır mo nicht weniger als die anderen Tortrix-Abtheilungen berechtight, eine eigene Gattnng zu bilden. Sie hat nicht blus in der Beschuppung, sondern anch in der Flügelgestalt mit den raubschuppigen Terrs-Arten Achnlichkeit. Nach T,ederer's und Heinemann's Anordnung würde sie am besten hinter Capua zu stehen kommen.

\section{Tortr. (Platyn.) sentana Clem.}

Alis ant. acutis, (revoluero ol breni), obscure fusecsecnti-griscis, strigis obliquis asperis nigris, striga media otslique nigra erterins fasciae insta fuescescenti-adumbrutu, tringulo costue posticue obsoleto fuscescente. puncto venue trunstersue uspero atro; post. fuser-einereis, on basi eanescente. Oे 9.

Platyote - Clemens Proc. Ac. Nat. Se. Philar. 1860, p. 348.

Tortrix - Robinson 1. c. P. 277, tals. 6, Fig. 54 ○.

Sie ist veränderlich in der Grösse (doch das lileinste ó so gross wiu Fluvedana (), desgleichen in der Länge der Taster (bei dem einen grösseren రౌ nicht un die sanze Kopflänge, bei dem kleineren ơ um die volle Kopfläuge, beim $q$ on die doppelte über die Stim hinausragend) mo in der Farbe der letzteren (bei den lileineren $\sigma^{-7}$ uben dunkelgrau, bei den 2 anderen Ex. hell staubgrau). Nach den vorliegenden Ex., deren Htfl-Farbe dunkel braungran ist, ändert liese woh] nie so ab, dass sie eine gelbliche Beimischung erlaalt. Clemens nennt sie freilich yellowish fuscons, nnd da er die Möglich- 
keit ammimmt, dass Flavedana mu Varietät der Senlana sei, so möchte seine Art gar nicht mit der liobinson'schen einerlei zu sein schcinen; dafür beschreibt "r die Vdfl. so treflend, dass ich gegen das r/nsammengehören der Clemens'schen, Robinson'schen und meiner Sentann keinen Zweifel habe.

Das wichtigste Unterscheidungszcichen, das weder Clemens, noch liobinson angibt, ist der Umschlag des $\sigma^{7}$; er reicht bei Sentanc nicht bis zimn Anfang der Binde und hat somit 1/5 oder 1/6 der Vdrd.-Länge; labei ist er ziemlich schmal; bei Flaveduna reicht er bis über die Hälfte des Vdrdes. und hat eine angemessene Breite. Einen anteren wichtigen Unterschied gibt die Färbung der $\sigma^{\nearrow}$ Htfl.; bei Sentuna ist nämlich von der Wurzel ans ein am Innenrand hinziehender, anffallend heller, dreieckiger Raum, der sich anf der Grundfarbe wie eine abgewischte Stelle ausnimmt.

Auf den Vdfl. zeigt sich ein starker, tiefschwarzer Schuppenbusch auf der Querader als hintere Grenze der Binde, die gerade hier am hellsten und von zwei schwarzen, rauhen Längslinien durchzogen ist. Der Dorsaltheil der Binde ist am breitesten und bildet cinen grossen, röthlich gemischten Wischfleck. Wie die Binde, so ist auch das verloschene, von schwarzen Querstreifen durchzogene Costaldreieck anf ler sehr schiefen Basalseite durch eine ranhe, schwarze Linie begrenzt.

Auf der Unterseite sind dic Vulf. brännlichgran, ringshertm hellgrau mit verloschenen, dunkleren Qnerstrichen; die Iftf. ganz hellgrau und sehr reichlich mit zu unvollständigen Querlinieu zusammenfliessendeu branngrauen Querstrichelchen bestrent.

Clenens beschreibt die an Viburnum prunifolimm lebende lianpe; den Schmetterling erhielt er daraus zeitig im Juli.

Robinson, dessen kenntliche Abbildung die schwarzen Quedinien nicht genug hervortreten lässt, kemnt als Vaterland: Massachusetis, New-York und Pennsylvanien. Aus den beiden ersten Staaten habe ich $\sigma^{-1}$ und $q$; ein $\sigma^{\lambda}$ im Mnsemu Cambridge stammt aus Texas (Boll).

\section{Tortr. (IMatym.) tareduma Clem.}

I'vrea; alis post. fuscescenti-luteis; ant. scabris, on, (revolucro longissimo) in basi anguste, ul morginem posticum latius lutescentibus, ceterum. fuseo nigroque mixtis; f lutescentibus, fasciu mediu obliqua, superines unystiore trianguloque costae postieue hruneseentibus, fusco transcerse scubris.

Platynotr - Clemens. Proe. Ac. Nat. Se. Phil. 1860, p. 318.

Tortrix - Robinson 1. e. p. 278, tab. 6, Fig. 55 ot.

- lateranu Rob. 1. ¿ \% 278, tab. 6, Fig. 56 ?.

Von dex vorhergehenden nnd den folgenden durch den ungewöhnlich langen Umschlag des of nnd ausser anderen Farbenverschiedenheiten durch die bräunlich lehmfarbenen Htfl. schr sicher zu nnterscheiden. Die beiden Geschlechter weichen dabej so sehr von einauder ab, dass Cle me $1 \mathrm{~s}$ ungewiss ist, 
ob das of wirklich zu dem vorher als Flavedana beschriebenen $q$ gehört, un liobiuson sie als zwei verschiedene Arten aufstellt, vou denen er sonderbarer Weise die eine, das Q, nen benennt und der anderen, den für Clemens zweifelhaften $\sigma$, den Namen Flavedana lässt. Robinson's Bilder machen die Art sehr kenntlich; nur sind sie, gegen die mir vorliegenden $3 \sigma^{\nearrow}, 3$, zu gross, und keins der $\Omega$ hat, obgleich sie in der Fürbung etwas veründerlich sind, so lebhaft gelbe Htf. wie Fig. 56; er nennt sie, wie anch die ganze Unterseite, tiefrostfarbig, Clemens sogar röthlich safranfarbig. Auch zeigen die Htfl. der Fig. 55 die Basalhälfte nicht heller gefärbt als den Rest, wie sie doch wach der Beschreibung und nach der Natur sein sollten.

Auch bei dieser Art sind die \& Taster länger als die männlichen; jene ragen um die doppelte, diese kamn um die anderthalbualige Kopflänge üluer die Stirn hinaus. Der bis über die Hälfte des Vdrdes. reichende Umschlag hat dunkelbraune Farbe, ist aber auf seiner Unterseite wie der dadurch verdeckte Flügeltheil blasslehmfarbig.

Die Htfl. des $\sigma^{\nearrow}$ sind lehmgelbbraun mit röthlicher Beimischung, an der Wurzel sehr gelichtet, wie verloschen; auf der Unterscite sind sie heller und einfarbig, aber auf der Costalhälfte und um die Flügelspitze mit brännliehen Querstrichelchen bestreut, die jednch auch verlöschen können. Beim $q$ sind beide Seiten gleichfarbig, gewöhnlieh viel heller als beim ó, und anf der Unterseite verloschener und spärlicher, oder gar nicht gestrichelt.

Vaterland der wir vorliegenden Ex.: Texas (Boll), Washington (OstenSacken), Massaehusetts, wo Burgess 2 gut erhaltene of bei Beverly an 15. und 18. Juli fing.

\section{Tortr. (Hotym.) labiosatma 11. sp.}

Parea; alis omnibus fermgineo-ochraceis, ant. bronneo-seabris (revoluero o brevi), maeula castali initium fusciue mentue referente, triungito costae posticae striaque trunseersa ante-marginuli brunnescentibus, puncto venae tronsversue scalbro atro; post. dilutioribus, mieoloribus. of f.

Von der vorigen verselieden durch den kurzen Umschlag, die lielle rostgelbliche Ocherfurbe aller Flügel, die in beiden Geschlechtern gleiche Zeichnung der vorderen, durch die unr in ihrem Anfange vorlandene Binde, und durch die an der Wurzel nieht gelichtete Farbe der ơ Htfl.

Grösse der Flaveluna, das \& nur wenig grösser und breitfiügliger als das Männchen. Farbe auf R. und Flügelı ein rostgelb gemischtes Oehergelb, auf K., Hinterleib und Htfl. nur heller. Taster un nuehr als Kopflänge schuabelfürmig über die Stim hervorstehend, an den Sciten gelbbraun, Endglied länglieh, kegelfüımig. Fühler zart sägezähnig mit feinen Fransenhaaren. Beinc ziemlich einfarbig, die 4 vorderen kaum nach unten verlosehen heller punktirt. Analbusch nieht stark.

Vdf. 3-3y/2" lang, ziemlich gestreckt, in der Gestalt wohl wenig von denen der Flavedana abweichend (worüber sich, da alle Franson abgeflogen 
sind, nicht sicher urtheilen lässt). Jer Umschlag, von der Wurzel bis zum Anfang des ersten Costalfleeks reichend und kaun 1/4 der Vdrd.-Länge betragend, liegt fest an. Der Costalfleck. der vor der Vdrd.-Mitte anfängt, ist brann oder gelbbrämmlich und dunkler begrenzt, selräg nach hinten gelegt, fast rhombisch, schon weit ïber der Falte gänzlich verschwindend. I) as hintere, gleichfarbige Costaldreieck ist dureh die Breite des Costaldreiecks von diesem getrenut und erreicht nicht die Flügelspitze; es ist auf der Basalseite dunkel begrenzt, und unter dem unteren Ende dieser Grenzlinie liegt auf der Querader ein dnukelbrauner Punkt. Das Dreieck ist hinter seiner Hälfte von einer braunen Sehräglinic durchschnitten, die sich in einer melr oder weniger deutlichen linie ranher Punlite gegen den Innenwinkel hin fortsetzt. Am Htrd. liegt eiu dnukler Streifen, der weiter als bei Flavedana nach dem Imnenwinkel hin reicht und sich nach unten verdünnt. Die dunkeln Querlimien sind wahrscheinlich bei muversehrten Ex. alle rauh, mo anch im Mittelraum werden sich ranlie, doch helltarbige Punkte finden.

Htfl. einfarbig, in beiden Geschlechtern gleich, mit helleren Fransen. So jst anch die Unterscite, wo jedoch der Vdrd. der Vafl. einige dunkle Fleckchen und P'unkte zeigt.

Vaterland: Texas (Belfrage). Die $30^{-1}$ meiner Sammlnng wurden am 25. Juni, 1. und 25. Juli, das ? am 2. Juli gefangen.

\section{Tortr. (IYlalyu.) exclsperalame 11. sp.}

Prarva; alis ant. (revoluero of trevi) ochracen, fuseo wigroque mixtis, dorso busali maryineque postieo pallidis, litum costre ante medium maenlaque quatrongula costae mediae pallidis (I allielis); prost. cinereis, of alversus basim alluilis. of ? .

Die hellgelblichen und sehr reichlich bram gemischten und mit schwarzen Schuppenhäufchen bestreuten Viff. haben an der Mitte des Vdrdes. einen, besonders beim $q$ reinen und scharfen, weissen, vicreckigrn Fleck, der dic Art sehr anszeichuct.

Grösse der Labrosana K. Gelbgrawweisslich mit bräunlicher Vorterlälfto der Schulterdecken. K. und Taster noch heller als das R., bei einom ó weisislich. 'T'aster mach aussen verdunkelt, un Kopfläıse hervorstelıend, zugespitat. mit geneigtem kndgliede. Beine wejssgrau, an len Fïssen, dic vorderen auch an den Sehienen, dunkler gran nit hellen Enden der Glieder. Hinterleib des б’ hellgran mit sehmalem, ziemlich langem, hellem Analbuseh; das \& ganz ochergelblichgrau, an Banch schwärzlich gran, mit sehr kleinem. ärmlichem, uranen Anallyasel.

Vifl. o' $3 "$, f $31 / 4^{\prime \prime \prime}$ lang, mit sanft convexem Vird. und noch schwärler convexem lltrd., von schmutzigem Ausselen: der blassochergelbe Grund ist dicht mit brammem, zusammengeflossenem fewölk ïberzogen, nnd dieses mit zahlreichen, schwarzen Schmpenlö̈ckern bestrent. Die Grundfarbe bleibt trei: in einem grossen Fleck an do Wuryel des Innenrandes, einem kleinen, ver- 
loschcnen Vdrd.-Fleck gleich hinter dem kurzen Umschlag, einem grösseren, viereckigen an der Mitte des Vdrdes. mnd in ziemlicher Breite längs des Htrifes. Der viereckige Costaltleck zeichnet sich beim $q$ dnrch seine Grösse und reinweisse Farbe aus: seine untere hintere Ecke ist nach hinten in rine Spitze verlängert. Vor der Mitte des Htrdes. liegt ein runder, verwischter, schwarzbrauner Fleck. Fransen heller als die Grundfarbe.

Htfl. grau, beim $q$ einfarbig, beim $O^{\prime}$ an der Wnrzelhillfte ohne scharfe Begrenzung weisslich.

Unterseite grau; die Vifl. dunkler, an schmal weisslichen Vird. der ganzen Länge nach mit braunen Querstrichen; an ler Nitte desselben ist cin kleiner, weisshcher, durchschnittener Fleck. Htf. hellgrau, mit verloschenen, dunkeln Querstrichelchen bestreut.

Vaterland: Texas (Boll) nnd New-York (Spreyer). of $o$ in meiner. o $Q$ in der Cambridger S'anmlung.

\author{
Cenopis 11. gु.

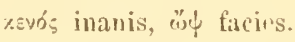

Frons ó profunde excavatu (Q integra??)

Palpi labiales capite duplo longiores, aticuln terminnli acuminuto.

Haustellum of brevissimum vel, sulmullum.

Fasciculus analis lreris, exilis.

Alae latae; anteriores oblongue, aculue, costu et margine postico leviter. convexis, venis 7 et $S$ in furcum conjunctis, vens s in upieem exmute; posteriores ô subtus cullo prope marginem internum decurvente, cilis anguli analis reliquis poulo longioribus.

Mir ist ansser der Sedenia biundulata weiter kein Schmetterling bekannt, bei dem die Stirn so tief und zu einem so regelmässigen Loch eingedrückt wäre wie bei den rorliegenden zwei Wicklern; es ist, ats ob den Mänuchen nach Herausnahme des Gehirns die Hirnschale umgekebrt eingesetzt oder wegen des Fehlens der sonst darunter liegenden Masse eingesunken ist. Die ? werden, wie ich nicht bezweifle, mit ausgefüllter, vollständiger Stirn versehen sein, wie bei anderen Schmetterlingen, als ob ihnen das Denken für beide Geschlechter übertragen ist. Ausser diesem Merkmal haben die ó anf den Httl. noch eine Auszeichnung. Anf der Oberseite zieht von der Basis neben dem etwas ungeschlagenen Innenrand eine furchenartige Vertiefung, welche aul' der Unterseite als eine wurmförmig gekrümmte, nach unten verdünnte Beule hervortritt. Der Bau dieser Flügel wird daher eigenthümlich sein; er lässt sich aber ohne Abschuppung nicht deutlich erkennen, wesshalb er küuttig genauer angegeben werden muss. Das $Q$ scheint sich auch darin von den echten Tortrices nicht zu unterscheiden.

In Uebrigen haben die Arten einigermassen das Anssehen der cinfarbigen Tortrix-Abtheilung Heterognomon; ihre Taster simd jedoch lïnger, und die 
Adern 7 und 8 der Vafl. sind nieht gesondert wie dort, sondern bilden eine langgestielte Gabel. - Der Jusschlag ist ganz kurz und schmal und daher leicht zin ïhersehen.

\section{Cen. Pettituna Robins.}

Major; alis post. niveis; ant. $\sigma^{\pi}$ sulpluneis, humero trunneo, striga ex costa ante medium lutescente ad plieam evaneseente; S albis, sericeo transverse umbulatis.

Tortvix - Robinson 1. c. p. 269, tab. 4, Fig. 21 o', 22 q.

Mein einzelnes of stimut, mit Ausnahme der Farbe der Vafl. genau mit Robinson's Fig. 22, mein einzelnes $\sigma^{\prime}$ mit Fig. 21, ausser dass es auf seinen, allerdings sehr abgeriebenen Vdfl. keine Spmr des zweiten Costalflechs zeigt; hiernach kommt es mehr mit Fig. 2\% überein; aber dieses Bild hat kürzere Taster, und der Querstreif der Vdfl. liegt der Wurzel näher, so dass ich von dem Zusannmengehören der in Fig. 21 und 22 abgebildeten Arten lange nicht so überzeugt bin wie Robinson. Merkwiirlig ist es, dass er die so auffallende Stirnbildung des $\sigma^{\nearrow}$ gar nicht bemerkt hat.

Der hellgelbe $K$. des $\sigma^{\prime}$ ist von hinten nach vorn erhöht und daum hinter der Mitte der Augen ziemlich senkrecht abgeschnitten, in dem abgesehnittenen Theil aber mit einer grossen und tiefen querelliptischen, von einem Ange zum anderen reichenden Höhle versehen, durch welche aber das dunkle Obergesicht nicht verengert wird.

Die Taster, etwas länger als beim $\mathcal{Q}$, stehen um mehr als Kopflänge hervor, sind ziemlich sehlank, znsammengedrückt, vor dem Ende des zweiten Gliedes verdickt, und das geneigte dritte Glied hat kaum 1/4 Länge des zweiten: sie sind auswärts rostbraun angelaufen bis vor das Ende des zweiten Gliedes, welches wie das dritte hellgelb ist. Vom Saugrüssel ist kaum eine Spur zu erkennen. Fühler borstenförmig, gezähnelt, kurzborstig gefranst, mit verlängertem Fudgliede.

Die hell schwefelgelben, wach hinten noch helleren Vdfl. sind am Vdrd. von der Schulter aus nicht völlig bis zam Querstreifen sehr schmal rostbram. Der Querstreifen geht von $1 / 4$ des Vdrdes. schräg nach hinten abwärts; er ist erst wie ein schmales Band, das sich bald fleekartig erweitert; dann wird er düun und verloschen und hört an der Falte ganz auf. Der Htrd. verläuft sehr schwach convex, fast geradlinig und ohne Einbiegung unter der Spitze bis zam abgerundeten Innenwinkel herab.

1)as $Q$ (das ich wenigstens für das meiner Pettituna halte) ist betrïcht-

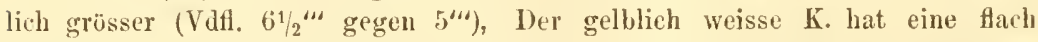
convexe Stirn ohne Auszeichnung. Die 'l'aster, nur nm Kopflinge hervorstehend, sind answärts ocherbräunlich angelanfen. Der Saugrüssel ist dünn, aufgerollt, etwa von Rückenschildlänge. Beine weiss, die vorderen auf der Lichtseite veherfarbig. - Die weissen Vafl. sind am Vdrd. vor der Mitte convexer als 
beim ơ, am Htrd. unter der Spitze sehr sanft eingebogen, an Iunenwinkel noch stärker abgerundet als beim $\delta$. Die schimmernden, sehr reichlichen Querwellen sind dentlicher als beim ơ. Auf der Querader ist wie bei diesem eine beulenartig aufgetriebene Stelle. An der Gabel lat der Stiel die halbe Länge des Ganzen, beim $\sigma^{\nearrow}$ aber volle drei Viertel.

Das $\sigma^{\prime}$ erhielt ich aus Missouri (Riley) mit der Angabe: „Raupe auf Eicheu", das $q$ aus New-York (Speyer).

\section{Cen. testuland n. sp.}

Alis ant. rufescenti-ochraceis, lituris 3 parvis, obsoletis, obscurioribus; post. flavescenti-albidis. $\sigma^{\top}$.

Sehr verschieden von der vorigeu durch gestreckteren Flügelbau, auch dadurch, dass das Loch in der Stirn kleiner, weiter nach vorn gerückt ist und damit das Obergesicht sehr verengert.

R., K. und Vdfl. röthlich ochergelb. Der Oberkopf ist sanft gewölbt und zeigt, von oben gesehen, das Locb gar nicht, weil es sich ganz vorne befindet; es ist kreisrund, viel kleiner als bei Pettitana und stelit daher weiter von den Augen ab; an der oberen Hälfte hat es einen schmalen, weisslichen Rand. Die auswärts gebräunten Taster stehen unı Kopflänge hervor, sind aber am Ende stark niedergebogen; das zweite Glied ist zusammengedrückt, an der Endhälfte stark erweitert, das dritte Glied deutlich. Saugrüssel kaum von Kopflänge. Fühler sehr kurz gezähnelt. Beine hell ochergelb, die vorderen dunkel gerüthet. Hinterleib blass ochergelb mit schwachem Analbuscb.

Vdfl. $3^{3}{ }^{\prime \prime \prime}$ lang, länglicher als bei Pettitana $\sigma^{7}$. am Htrd. und Innenwiukel nehr zugerundet, ohne Glanz und ohne Beule der Querader. Umschlag dicht an der Wurzel, klein, dicht auliegend, daber leicht zu übersehen. Die Fläche ist ziemlich reichlich mit kurzen, bräunlichen, sehr verloschenen Querstrichelchen bestrent, welche nur vor dem Htrd. sich zu etwa 3 vollständigeren welligen Querlinien vereinigen. Unterhalb des Anfangs der sonstigen Binde ist ein dreieckiges, bräurliches Wischchen, und an der Mitte des Innenrandes eine bis über die Falte reichende, gekrüımte, kurze Querlinie; beide sind offenbar die spärlichen Ueberreste der gewöhulichen Binde, die vielleicht bei anderen Ex. vollständiger vorhanden ist. Ein gleichfarbiger Wisch liegt auf der Querader, welcher, wie gesagt, die beulige Auftreibung fehlt. Fransen heller als die Grundfarbe.

Htfl. schmäler und spitzer als bei Pettitana, schmutzig gelblichweiss, gegen dic Wurzel weisshicher.

Unterseite der Vdfl. sehr blass röthlich ochergelb, anf dem Vdrd. verloschen dunkler gestrichelt. Htfl. unrein weisslich, läugs des Vdrdes. blassröthlich.

Vaterland: Texas (Boll). Ein $\sigma^{\top}$ im Musemu Cambrilge. 


\section{Comehylis Tr.}

Ohne Zweifel ist diese Gattung in Aneriea nicht weniger artenreich als in Europ'a, nnd eine Menge Arten werden ebenso sehwer zu unterscheiden sein. $\mathrm{Zu}$ der besonders schwierigen Gruppe der in den Stengeln des Alisma plantago lebenden Griseana werden Robinson's Lepidana, Interrupto-fasciatu, ete. gehören, die wohl alle nach wenigen und mittelmässig conservirten Ex. aufgestellt sind und daher schwer wieder zu erkennen sein werden. Ich enthalte mich daher der Charakteristik einer kleinen Art aus Texas, obgleich ich sie in 6 Ex. vor mir liabe, von denen 3, wie gewöhnlich zugerichtet, zu Ende Juni und Anfang Juli durch Belfrage gesammelt wurder. Sie ist so klein wie die zu derseiben Zeit auf unseren T'orfwiesen zwischen Triglochin palustre schwärmenden Ex., von denen moch nicht fest steht, ob sie einerlei mit Griseuna oder eigene Art sind. Mit ihnen haben die 6 T'exaner grosse Aehnlichkeit. Soll aber Sicherheit ïber die specifischen Rechte gewonnen werden, so müssen durchaus unversehrte, zahlreiche, wo möglich aus der Raupe erhaltene Fx. zur Verfïgung stehen

Dass es in Nordamerica Arten gibt, die der Gruppe der Latoniana und Parreyssiuna angehören, zeigen Robinson's Fig. 75-77.

Ein ơ aus New-York, von der Grösse der Bammanniana, stimunt in der Zeiehmunsanlage mit Vulneratana mo deren Var. Exsulana; seine Kleinheit und andere förloung mögen individuell sein; aber nach einem einzelnen schlecht conservirten Ex. lässt sich hier nichts Sicheres sagen.

\section{Conch. argentilimitana Robins.}

Minor; alis ant. elongatis, exalbidis, playa basali, fascia media fracta fusciaque marginis postici cum mucula costae josticae cohaerente vitellinis, argenteo-marginatis. $0^{7}$.

C. - Rubinson 1. c. p. 287, tab. S, Fig. 82.

Sie und die folgende Art, mit der sie nicht verwechselt werden darf, gehören wegen der silbergläuzenden Einfassung der Zeichnungen in die Nähe der europäischen Amiantana. Wenn sie auch nicht inmer grösser sein mag, als Vitellinuna, so hat sie doch auf den Vdfl. eine sehr helle, gelblichweisse Grundfarbe - nicht eine schön reingelbe; ihre Mittelbinde steht senkrecht und ist in der Mitte fast rechtwinklig gebrochen; ihre hintere Binde zieht dicht am Htrd. und bildet mit dem Costalfleck einen starken Winkel, statt eine Fortsetzung dieses Flecks zu sein und fern vom Htrd. zu laufen.

Statt des Basalfeldes zeigt sich bei genauer Betrachtung in geringer Entfernung von der Basis eine stark gebrochene, auf beiden Seiten silberglänzend eingefasste Binde, deren unterer, längerer Arm weiter gegen die Basis \%urückgeht, als der obere, kürzere; der Vdrd. ist bis zu letzteren von der Wurzel aus dottergelb mit schwärzlicher Costalschneide. 
Robinson's Abbildung macht die Art wenig kenutlich, da die Zeichnungen zu bräunlich sind und der silbernen Einfassung entbehren. Die Beschreibung hebt aber jeden Zweifel.

Vaterland: Texas (Boll), $2 \sigma^{\top}$ im Cambridger Museum.

\section{Conch. vitellinama n. $\mathrm{sp}$.}

Minor; alis ant. angustulis, laete flavis, fascia media subobliqua, incurva, fasciaque postica recta vitellinis, argenteo-marginatis. $\sigma^{7}$.

Nur ein $\sigma^{7}$, das aber an den in der Diagnose und bei Argentilimitance angegebenen Merkmalen zu erkennen sein wird.

Kleiner als Aøgentilimitana; alle Flügel schmäler, die vorderı mit weniger scharfer Spitze.

P. hellgelb, K. mehr ins Weissliche. 'Taster ziemlich dick mit kurzem Endglied, gelblichweiss. Beiue weisslich. Hinterleib ochergelblichgrau mit hell ochergelbem, schmalem Analbusch.

Vdfl. $23 / 4$ " lang, schmal, ohne scharfe Spitze, mit convexem Htrd., reingelb, an der Wurzel kaum verdunkelt; vom Innenrand nahe der Wurzel geht ein bräunlicher Nebelstreif schräg aufwärts bis über die Falte. Die dottergelbe, auf beiden Seiten silberglänzend gesäumte Mittelbinde ist auf dem Vdrd. näher der Basis als auf dem Innenrand; sie erweitert sich allmälig nach unten und ist in der Mitte sclıwach gebogen. Die hintere, gleichfarbige Binde fängt an der Stelle des sonstigen Costaldreiecks an, ist grade, schmäler als die Mittelbiucle, nur auf der verdunkelten Basalseite silberglänzend gesäumt, und endigt auf dem Htrd. ̈̈ber dem Innenwinkel. Auch die Flügelspitze ist in einem kleinen Fleck dottergelb und einwärts mit silberglänzenden Schuppen begrenzt. Fransen beller als die Grundfarbe.

Htfl. spitz, einfarbig dunkelgrau wie dic ganze Unterseite, wo aber der Vdrd. der Vdfl, gegen die Spitze weisslich ist; Fransen der Vdf. wie auf der Oberseite.

Vaterland; Maine oder Massachusetts. Ein von Packard erhaltenes Ex. in meiner Sammlung.

\section{Conch. bimaculana Robins.}

Minor; alis ant. elongatis, pallide grisco-ochraceis, macula disci curvatoovali, adscendente maculaque flexa ante marginem posticum jacente lacte cinnamomeis. $\sigma^{\top}$ ?

Conch. - Robinson 1. c. p. 285, tab. 8, Fig. 78 .

Leicht zu erkennen. In der Zeichnung mit keiner europäischen Art übereinstimmend, doch aber wohl zur Verwandtschaft der Jucundanu zu rechnen.

Der schräg aufgerichtete, gekrümmt eiförmige Fleck im Mittelraum reicht mit seinem untersten Drittel über die Falte herunter. Der grössere Fleck vor dem Htrd. fängt verdïnnt unterlalb der Spitze an, kriimmt sich einwärts und 
ist auf seiner concaven, gebrïunten Basalseite schimmernd weissheh eingefasst. Dic hellen, am Eude braunen Fransen sind vor der Mitte mit einer feinen. sclıwärzlichen Linie durchzogen.

Htfl. dunkelgrau, auf der Unterseite hell mit verloschenen dunkleren Querstrichelchen. Fransen bell, nahe der Wurzel mit dunkelgraner Linic durchzogen.

Ein $\sigma^{7}$ (Vdfl. nur $2^{\prime \prime}$ lang) ist kleiner, mit feineren Zeichmungen als die 3 anderen.

Vaterland: Texas (Boll). In meiner Sammlung und in Cambridger Museum.

\section{Comch. seriatana n. sp.}

Minor; alis ant. elongatis, acutis, exalbidis, linea obliqua prope basim, areu ex costa media demisso maculaque inferius posita cinnumomeis, nigrosquamulatis, serie lineolarum fuscarum marginis postici; post. canis. $\sigma^{\prime}$.

Nur ein $\sigma^{7}$, das jedoch, wenn es auch zu einer veränderlichen Art gehören sollte, sicher wieder erkannt zu werden scheint. Den schrägen Längsstrich in der Nähe der Wurzel, der hoffentlich ein beständiges Merkmal ist, sehe ich nur bei einzelnen Ex. der Smeathmanniana durch einen ganz verloschenen Nebelstreif angedeutet.

Grüsse der Kindermanniana; die Flügel aber viel spitzer. Vorderkörper und Vdfl. fast weiss, mit sehr schwacher gelblicher Beimischung. Taster dick, um die halbe Kopflänge hervorragend, weiss, mit kurzem Endgliede. Vorderbeine gelbbraun; Hinterbeine weisslich. Hinterleib gelbgran mit ansehnlichem zugespitztem, weisslichem Analbusch.

Vdfl. fast 3"' lang, gestreckt, langgespitzt; Htrd. sehr schräg zurïckgehend, schwach convex. Breit von der Basis getrenut zieht in Mittelfelde cin grader, dünner, zimmtbrauner Längsstrich sehräg äber die F’alte hinweg, die sie uın 1/3 ihrer Länge überragt, und hinter der sie in gleichem Abstaude vom Vorder- und Innenrand mit einem dunkelu Punkt endigt. Von der Mitte des Vdrdes. geht ein zimmtbrauner, schwarzbestäubter, nach aussen concaver Bogen schräg herab bis zur Querader, unter welcher, mehr gegen die Basis zu, an der Falte ein eckiges, ebenso gelbes, schrarzbestäubtes Fleckchon liegt; beide Zeichnungen stellen die gewöhnliche, gebrochene Mittelbinde vor. Den Htrd. säumt eine Linie aus 4 schwarzschuppigen, gelblich beschatteten Strichelchen gebildet, deren oberstes bis an die Flügelspitzc reicht.

Htfl. unterhalb der Spitze recht merklich eingedrückt, weissgrau, etwas seidenschimmernd, weissfransig.

Unterseite der Vdfl. braungrau; Fransen weisslich; die des Vdrdes. bilden eine bis vor die Flügelhälfte reichende, nach hinten erweiterte, weisse Linie. Htfl. noch heller als auf der Oberseite.

Vaterland: Texas (Boll). Ein Ex. in Cambridger Museum. 


\section{Conch. glaucofuscenue n. sp.}

Parva; alis ant. pallide flavis, costa fusco-strigulata, fascia cx dorso medio obliqua fuseu, atro-clisseetr, limbo latissime fusco, qlaneo nigroque mixto, ciliis glanco-fuscescentilus. O.

Sie gehört in die Verwandtschaft der Posterana, hat aber eine dumklerc Färbung und dic des Htrdes der Vdfl. noch mehr verbreitert, so dass zwischen ihr und dem schräg nach aussen gelegten Mittelband ein schmaler Costalfleck die Grundfarbe behält und dadurch eine Uebereinstimmung mit Schveibersiana entstelit.

R. dunkel gelbbräunlich (verwischt); die Schulterdecken so wie die Oberseite des Kopfes und dic Taster schmutzig hellgelb; letztere zugespitzt nit kurzem Endgliede und an der Seite gebräunt. Beine weisslichgelb. Hinterleib braungrau mit weisslichgelbem Analbusch und hervorstehendem Legestachel.

Vdfl. 21/2"' lans, länglich, mit wenig vortretender, abgerundeter Spitze. Die schmutzig gelbliche (sehr hell ochergelbliche) Grundfarbe nimmt kaum einen so grossen Raum ein wie die dunkle Zeichnung. Der Vdrd. ist mit senkrechten, schwarzbraunen Qnerstrichelchen gezcichnct, zwischen denen dicht an der Basis, danu bei $1 / 4$ der Länge und hinter der Mitte je ein gelbbräunlicher Fleck liegt; der dritte, als sehr verdünnter Anfang der Nittelbinde, ist grüsser und dunkler als die beiden vorhergehenden. Von der Wurzel des Innenrandes aus ist ein breiter, aufwärts gebogener, bis unter das zweite Costalfleckchen reichender, ochergelblicher Streifen, ähnlich einem Oelstreifen. Die breite, braune, dunkel marmorirte Binde fängt vor der Mitte des Innenrandes an und steigt schräg nach aussen aufwärts; bei $2 / 3$ ihrer Höhe endigt sie tiefschwarz, indem sie hier mit dem Costalfleck, der ihr sehr verengertes oberstes Ende bildet, kaum in Verbindung steht. Ein eckiger Costalfleck der Grundfarbe, der zugespitzt bis zur Hälfte der Flügelbreite herabreicht, folgt dieser Binde. Alles Uebrigc bis zum Htrd. ist braun, mit Schwarz und noch mehr mit Violettgrau gemischt. Nur vor dem Innenwinkel liegen auf den Innenrande ein paar Fleckchen der Grundfarbe als Begrenzung der Binde. Man kann also die grössere hinterc Flïgelhälfte als dunkel betrachten mit einem grossen, bellgelben Costalfleck und 2-3 solchen Dorsalfleckchen. Fransen dunkelbräunlich, violettschimmernd.

Htfl. braungrau. - Unterseite der Vdfl. braungrau; der Vdrd. an der Endhälfte schmal hellgelb mit schwarzen Querstrichelchen; die Flügclspitze bis zum halben Htrd. herunter mit hellgelben Fleckchen. Htfl. hellgrau mit ziemlich reichlichen braunen Querstrichelchen.

Vaterland: Texas (Boll). Ein in den Htfl. beschädigtes $\Omega$ im Museum Cambridge.

\section{Conch. Bunterna Rbs.?}

Parva; al. ant. in triente bresali pallide fermgincis, cetem roseis, fascia media ochreo-nigricante in costam eoarctata, playa anguli ilorsulis rotundata, superius fusca. $Q$.

? - Robinson 1. c. p. 288, tab. 8, F. 86 . 
Robinson's Besehreibung mit ihrem outer third of the wing prominently tinged with pink (wovon jedoch die Figur gar nichts zeigt) und large patch (welcher aber irregulär sein soll) of dull brown scales scheint gut auf die vorliegende Art zu passen; aber aus der Abbildung ist sie nicht zu erkennen. Vielleicht ändert sie ab.

Sie ist verwandt mit der gleich grossen Mussehliana, der Alisma-Griseana, Notulana; $u$ r hat sie etwas gestrecktere und hinten mehr erweiterte Vdf. Sie würde dnrch die schöne Posenfarbe der VdAl, welche durch die braune, auswäıts braun ochergelbe Mittelbinde gegen die hell rostgelbe Farbe des Basaldrittels sehr scharf abgegrenzt ist, leieht uud unverkennbar charakterisirt sein, wemn sie nicht abändert.

R., K. und Oberseite der Taster weissgelblich. Vorderbeine braun; Mittelbeine heller mit weisslichen Enden der Fussglieder; Hinterbeine bleich gelbgran. (Hinterleib fehlt.)

Vdf. 21/2"' lang, nael linten etwas erweitert; das Basaldrittel hell dot. tergelb, auf dem Vdrd. mit verloschenen bräunlichen Querstrichelchen. Die folgende sehräge Binde ist gesättigt oeherbraun, mit schwarzen Schuppen bestreut, besonders basalwärts, und verengert sich in den Vdrd., den sie in der Mitte erreicht; sie fliesst hiuten von der Nitte an gegen den Innenrand ans und umschliesst damit ein rosenfarbiges Dorsalfleckchen, welches ebenso wie sie schwärzliche Dorsalpunkte, deren hinterster der stärkste ist, enthält. Vor der Flügelspitze geht vom Vdrd. ein ocherbrauner, etwas schwarz gesäumter Streifen gegen den Htrd. herab, den er mit seinem versehmälerten Ende an der Nitte erreicht. Zwischen diesem Streifen und der Mittelbinde liegt im Innenwinkel ein grosser, gernndeter, ocherbraumer Fleck, der bis zu $2 / 3$ der Fliigelbreite heraufreicht und hier schwarzbraun gefärbt ist, während er sich nach unten lichtet und von dem ansgeflossenen Theil der Mittelbinde kaum getrennt bleibt; in ihm liat der Dorsalrand keine schwarzen Punkte. Der ganze, nieht von diesen Zeichnungen eingenommene Raun ist lebhaft rosenfarbig, mit schwarzen oder braunen ungleichen Punkten bestrent. Anch der Vdrd. enthält hier ungleiche, braune Fleckchen, besonders vor der Flügelspitze. Franseu ocherbräunlich.

Htfl. braungran; die Fransen lichter mit gelblicher Basallinie.

Unterseite der Vufl. dunkel braungrau; die Endhälfte des Vdrdes. init gelblichen, durch die Grundfarbe getlieilten Fleckchen. Fransen dunkler als oben. Htfl. heller, doch in der Spitze dunkel und mit einigen dunkleren Querstrichelehen.

Vaterland: Nordameriea. Ein in den Fï̈gehn schün erhaltenes $f$ in Dr. Rüssler's Sammlung.

Bactra Stph. Aplielia Heinem. S. 136.

li. glatt. Vdfl. ohne Umschlag, schnnal, spitz ohne Sichelspitze und ohne augenförmige Apicalzeichnung, mit fast graden Vdrul. und sehr schrägem, wenig convexem oder gradem Htrd. Htfl. mit Ader, 3, 4 und 5 aus einem Punkt. 


\section{Buctra Iunceolama Hbn.}

Var. verutana, alis ant. pallide coriaceis, costa subtititer oblique nigro-strigulata, dorso nigro-pmetato, signo fusco infra venam transversam obsoleto, linea marginati nigra. ơ $\subsetneq$.

Drei $\sigma^{\nearrow}$ und zwei $ᄋ$, unter einander in der Grösse und Färbung gleich, kommen den kleinsten Ex. der höchst veränderlichen Lanceolana so nahe, dass ich sie für nichts weiter als für Varietät davon halten kann. Jhre Vdfl. haben eine etwas stumpfere Spitze, indem der Htrd. unterhalb derselben gar nicht eiugebogen ist. Die Grundfarbe ist ein blasses Ledergelb (wie oft bei Lanceolana), am lichtesten in der Mittelzelle. Der Vdrd. luat feine, schwarze, schräg selegte Strichelchen, die sich auf der Basalhälfte allmälig in Punkte verwandeln (so schwarz, kurz und fein sehe ich sie bei keinem meiner vielen Ianceolana ơ 9). Der Innenrand ist mit ziemlich groben, schwarzen Punkten, die sich leicht verwischen, gezeichnet. Den Htrd. fasst eine, nur anf den Aderenden unterbrochene, grade, ganz schwarze Linje ein. (Bei mancher Lanceolana ist der Imnemrand auch schwarz punhtint, und bisweilen setzt sich die Punktirnng aus dem lnnenwinkel am Htrl. anfwärts fort, aber nie bis zur Hälfte desselben, geschweige dass sie zu einer Jinie vereinigt bis zur Flügelspitze gehen sollte, und ausserdem scheint sie sich etwas vom Hurd. zu entfernen). Fransen auswärts gebräunt.

Auf der Unterseite haben die Vdfl, mur die hintere IÏ̈lfte les V'drdes. gelblichweiss kleinfleckig (wie oft Lanceolana auch).

Die sehwarze Htrd.-Linie der Vifl. machte mich anfangs geneigt, in diesen 5 Ex. eine eigene Art anzuerkennen. Aber ein $\sigma^{\lambda}$, das offenbar zn keiner anderen Art als die übrigen gehört, gibt den Beweis, dass sie alle nur Lanceolana sind; es liat 2war dieselbe helle Grundfarbe wie die anderen; aber es fehlt ihm die schwarze Htrd.-Linie völlig, und der Vdrd. ist wie gewöhnlich unit hellbräunlichen Schrägstrichelehen bezeichuet. Daher geniigt 's, lie Varietät mit einem eigenen Namen zu versehen.

Vaterland: Texas (Boll, Belfrage). Die 2 ziemlich gut conservirten $f$ meiner Sammlung wurden an 31. Juli und 16. August gefangen.

\section{Buctre furfurence Haw.}

Aphelia - Heinem., S. 135. scirpana HS., S. 243. Pauperana Fig. 302.

Phoxopteris lamana Z. Isis, 1846, S. 257.

Ein $\sigma^{7}$, drei $\circ$, welche mit einander in der hellen Färbung ziemlich übereinstimmen, wurden von Burgess in Massachusetts bei Beverly voun 19. Juni bis 8. Juli gefangen. Sie gleichen den hellsten deutschen Ex., sind also von beträchtlich hellerer Grundfarbe als HS.' Figur und sowohl kleiner als viel lichtex als die englischen Fx. Weder Flïgelhildung noelı Yeichmmgsanlage 
erlaubt, in den americanischen Ex, eine verschiedene Art anzuerkennen. Da Furfurana auf sumpfigen Wiesen lebt md ihre Raupe sich von kleineren Binsenarten nährt, so lässt sich nur annehmen, dass sie in Nordanerica eine. nrsprüuglich einheimische Art ist.

\section{Phoxopteris Tr.}

\section{Anchylopera Stph., Clem.}

Taster knrz, durch Schmppenhaare verdickt, mit sehr kurzem Endgliede, R. glatt. Vdfl, ohne Umschlag, mit verlängerter sichelförmiger Spitze, unter welcher der Htrd. mehr oder weniger eingebogen und auf den Fransen mit 2 weissen Längsstrichen gezeichuet ist. Die stets verdunkelte Flügelspitze hat weissliche Costahäkchen, ohne dadurch ein ocellenähuliches Anselien zu erhalten. Der Spiegelfleck ist nicht völlig ausgebildet.

Mit Recht nennt Wilkinson diese Gattung eine sehr natürliche. Heineman n kennt in Htfl.-Geäder der dentschen Arten keine Verschiedenheit (Wickler, S. 100.) Clemens untersebeidet (Proc. Ent. Soc. Philad. III., 1864), S. 510 die ihm bekannten NAm.-Arten in Gruppen, je nachdem die Medianader der Htfl. sich in 3 oder 4 Aeste auflöst. Er behauptet von seiner Anch. striatana, dass bei ihr eiue Theilung bald in 3, bald in 4 Aeste stattfinde. - Gewöhnlich ist die Beschaffenheit der Medianader leicht und sicher auf der Unterseite zu erkennen; ob aber die Mittelzelle der Vdfl. eine Nebenzelle besitzt (l. c. S. 509. Fig. 3 b), kann ich nur durch Abreibung der Schuppen erkemmen, und es seheint mir zur Unterscheidung der Arten viel zu schwierig nnd darum wenig brauchbar zu sein.

Die Gattung ist offenbar in NAm. artenreich. Unter den mir vorliegenden 10 finde ich nur für 2 die Namen aus den $16 \mathrm{Clemens}$ 'schen mit Sicherlseit heraus; einige der letztem erklärt der Autor selbst für vermuthlich nicht gut begründet; auch werden sie sich theilweise wegen ungenügender Beschreibung sehwer wieder erkennen lassen.

\section{Phox. mediofusciane Cl. Taf. VIII, Fig. 4.}

Magna; al. ant. caesio-cinereis, fusco-marmoratis, costa late nivea, nigro punctata, trabe fusca media ex costa oblique porrecta, angulo dorsali albidonebuloso. o $\rightarrow$.

Anch. -- Clemens Ent. Soc. Philad. III, p. 511. (p. 509, Fig. 3.)

Von der Grösse der europ. Unguicella, breitflügehger, sehr kenntlich an der schiefergrauen Grundfarbe der Vdt1. mit breit reinweisscm, einmal dunkelbraun schief durchschnittenem Vird.

Da die Mittelzelle der Viff. deutlich eine Nebenzelle hat, mnd auf den Htfl. die Medianader in eine Gabel - von verïnderlicher Grisse - auslïuft, 
so gehört die Art in Clemens' dritte Grupue, und da sein Ex. nach seiner Angabe ${ }_{n}$ in sehlechtem Zustande* war, so lalte ich das Alweichende und Ungenügende in seiner Beschreibung für eine Fulge dieses Zustandes, nicht für ciu Zeichen von specifischer Verschiedcnheit.

Die $4^{\prime \prime \prime}$ langen Vdfl haken zur Hauptfarbe ein dunkles, bläuliches, verloschen bräunliches Schiefergrau, aber läugs des ganzen Virdes. einen schneewe.isen Streifen, der weniger als $1 / 3$ der Flïgelbreite einnehmend, gegen das Schiefergrau nicht seharf abgegrenzt und auf den Vdru. selbst nit schwarzen, vor der Flügelspitze vergrösserten Punkten bestreut ist. Von der Mitte des Vurdes. kommt ein schräg nach aussen gelegtes, gegen den Innenwirkel geriehtetes, braunes Band, das sich iu der schiefergrauen Farbe verliert. Fast in der Mitte zwischen dem untersten Theile dieses Bandes und der Flügelbasis ist in der dunkeln Partie in der Falte ein starker, tiefschwarzer, nach hinten weisslich eingtfasster Punht. Der Raum des Innenwinkels ist in beträchtlieher Ausdehuang weisslich mit hell bläulichgraueın Gewölk. Die etwas braunrüthlich gemischte Flïgelspitze enthält ein tiefschwarzes, nach hinten zugespitztes, dickes Strichelchen, unterhalb dessen die Fransen eine schneeweisse Iängslinie und darunter einen solchen Punbt zeigen. Tiefer abwärts sind die Frauseu weiss, auswärts braun, aber urn den Innewwinkel ganz reinweiss.

Httl. hell bräunlichgrau, von den helleren Franseu durch eine feine bräunliche Randlinie geschieden und in der spitze mit 1 - 2 bräunlichen Quersehatten. Auf der Unterseite besonders deutich, bildet Ader 3 am Ende eine längere oder kürzere Gabel; bei einem o ist sie ganz einfach. 14. Mai.

Vaterland meiner Ex. New-Yulk (Speyer): das eine o' trägt das Datun:

\section{Phox. mubeculama Cl. Taf. Vill, Fig. 5.}

Media; alis ant. allis, dorso ex basi late fusco, jostice cum margine posticu caesio-nebuloso, costa in medio striyula caesia obliqua notuta, postice cinereo-striguluta, apice ipso obscure ferrugineo. c 9 .

Anchyl. - Clem. Proc. Ateal. Nat. sc. Yhilal. 1860, p. 349.

Sie hat Aehnlıclikeit mit der gewohulich etwas grosseren Harpana H., bei welcher aber die braune Farbe des Inmenrandes von der Wurzel aus breiter nnd mit weissen Gewölk gemischt, dagegen nach dem Innenwiukel, wo Nubeculana ein helles, nit Weiss genischtes Grau hat, verdnukelt ist. Das bläulichgraue Gewilk des Innenwinkels und der schwache, hellgraue Querstreifen des Tdıdes. unterscheiden Nubeculana sogleich rou den andesen mir belianuteı Arten mit wcisser Grundfarbe.

R. hinten braun, vorn weiss wie die Schulterdecken und das Schildchon. K. hell oder röthlichbraun; Stirn und Taster weissuehaart. Beiue blass lehmgelblichgrau; Fñsse hell and dunkel punktirt. Hiuterleib lehrngelbgrau nit blass ochergelbem Analbasch des $\delta$. 
Vath. $3-3 \frac{1}{1} 2^{\prime \prime \prime}$ lang, weiss. Der Imenrand ist braun mit hellen, verloschenen Querflecken von der Wurzel ans bis über die Mitte hinweg; daun folgt schiefergraues Gewill, welches nit einem unregelınässig gerundeten, verdunkelten Fleck über die Ealte hinwegreicht, zuletzt aber sich verengert und vor dem Inneuwinhel dureh die weisse Grundfarbe begrenzt wird; der bei den folgenden Arten so scharfe Dorsalfleck ist also eigentlich anch vorhanden, nur durch das angehängte Gewölk indeutlich und von unregelmässigerer Gestalt. Von der Mitte des Vdrdes. geht schief nach hinten, in der Richtnng gegen den Innenwinkel, ein schmales, kurzes, granes, nur an seinem Anfange gebräuntes Bändehen herab. Unter seiner spitze liegen bis in den Inuenwinkel hellschiefergralie Wolken, getrennt durch unregelmässige, weisse, limienförnige Räume, die jeduch am Htrd, gegen die Spitze hinauf an wenigsten vorhanden sind, von denen aber der nach dem Innewwinkel herabziehtnde gewöhnlich der breiteste ist. Hinter dem Mittelbändchen ist der Vdrd. mit schiefen grauen Strichelchen gezeichnet, die nach der Flügelspitze hiı ruthbräunlich nud kürzer werden. Unterhalb derselben ist in granen Gewolk ein hurzes, tiefschwarzes Längs. strichelchen von wechselnder Länge und Dentlichkeit. Die Flügelspitze ist braun, wie die über ihr befindlichen Fransen; unter ihr enthalten die Fransen eine scharfe, weisse Längslinie und unter dieser eine weniger scharfe. Die Htrd.Fransen sind weiss, an reinsten an ilırer Wurzel; in der Concavität unterhalb der Flügelspitze sind sie in wechsehuler Ansdehunng auswärts grau.

Htfl. hellgran, gegen die Wurzel ein wenig heller, bein $q$ dunkler und überall gleichfarbig. Die anf der Untersite sehr deuthichen Adern zeigen bei keinem meiner 6 Ex. eine Gabelung.

Vaterland wohl aller Ex. Maine, welches wenigsteus bei dem einen angegeben ist; ich urhielt sie von Packard.

Annerkung. Clemens' Angabe: "in the middle of the wing bencath it the oblique central fascia) is a grayish brown round spot" bezicht sieh anf eine länglichrunde Wolke (wie das exterior to which is a short blachisl dash lehrt), die nicht immer durch weissliche Räume abgesondert ist und also nicht verdient hervorgehoben zn werden. Da das Gewölk ent chieden eine bläulichhellgraue Farbe hat, so nennt er es wohl mit Unrecht grayish brown and brownish. Ich zweifle nicht an der Richtigheit meiner Bestimmung. Mehr als ein Ex. wird Clemens schwerlich gehabt haben.

3. Phox. semiovama n. sp. Taf. VIII, Fig. 6.

Nedia; alis ant. niveis, macula dorsali semiovata obscure brunnea, trabe costae nediae obliqna brunnea cum parte alue postica cinnamomeo-finsca coalescente, striga trabi posterius adjacente nivea inferius ampliata et truncala, cosla postice ulbo-strigulata. $\sigma^{\top}$.

Eine sehr schüne Art, zu denen nit scharfbegrenztem braunén Dorsalfleck gehürig, von ihnen unterschieden durch beträ chtlichere Grösse, rein weisse Grundiarbe der Vift. und besunders dnreh den weissen hinter den braunen 
Mittelband folgenden Schrägstreifen, der sich nach unten erweitert und hier nach hinten zuspitzt.

Si gross wie die grössten Ex. der Derasana H. und Nubeculana $\mathrm{Cl}$. R. gelbbraun, voru und auf den Sthildehen weiss; Schulterdecken weiss, am Ende hellbramn. Die gesträubte, reichliche Kopfbtharung ist anf der Stirn wejss, auf dem Hinterkopf weisslich mit gelbbräunlichen Spitzen, auf dem Scheitel braun. Taster ganz rein weiss, znsammengedrickt dreiechig mit kaum hervorstehendem Endglied. Beine weisslich gelbgrau, die vordern auf der Lichtseite brann, die mittlern nur an der Schiene; die 4 hintern Füsse braun mit weisslichen Enden der Glieder. Hinterleib gelblichgrau mit reichlichem, weisslich ochergelbem Aualbusch.

Vdfl. $3 \frac{1}{3}{ }^{\prime \prime}$ lang, mit rein weissor Grundfarbe, die jedoc's einen geringereu laum einnimnt als das Branne. Anf den Innenrand liegt, von der Basis bis wenig binter der Hitte ein halb ovaler, kaffeebrauler Fleek, der nur hinten gesättigter, sonst eintönig ist; er reicht sehnell übor die Falte hinweg und ist am hintern zugerundeten Ende in der Mitte sehr schwach eingedrückt. Den Rest des Flügels kann man als dunkel zimmtbraun, heller als den Halbovalfleek, gefärbt ansehen, nur dass er von diesem Fleck durch einen schmalen, weissen, linienförmigen Raum getrennt ist, anf welehen schwarzbraune Bestäubıng auf weissem Grunde folgt. Der Costaltheil dieses zimmtbraunen Ranmes wird durch einen ziemlich sehmalen, streifenfürmigen, schrägen, scharfbegreuzten, verdunkelten Balken gebildet, der auswärts seiner ganzen Länge nach dureh einen anfangs schmalen, dann nach unten erweiterten und hier nach hinten ausgezogenen Streifen begleitet wird, unter dessen grade abgeschnittenem Enile zwei schwarze, nicht sebr auffallende Längslinien liegcu. Der Vird. trägt hinter diesen weissen Querstreifen 7 weisse, durcl braune Linien getrennte Hïkchen, unter denen der Grund etwas gelichtet ist. Die Flügelspitze ist dunkler; die Fransen darïber ebenso, nur an der Wurzel lichter; die darunter sind weiss nit einer schwarzen Längslinie. Die übrigen Htrd-Fransen sind glänzend weissgrau, am Ende gebräunt; an ihrer Wurzel ist der Htrd. in den untern zwci Dritteln ganz sehmal reinweiss mit ein paar schwarzen Pinktchen.

Htfl. ziemlich hellgran, nur um die Spitze mit einer dunkleren Linje eingefasst. Die helleren Fransen werden durch eine weissliche Basallinic von der Flügelfäche gitrennt. Auf der helleren Unterseite treten die Adern scharf hervor; die dritte ist ganz einfach.

Vaterland: New-York (Speyer). Ein sehïn erhaltenes ơ in meiner Sammlung.

Anmerkung. Bei diesem Ex. ist der halb ovale Fleck nicht reddish brown, und der weisse Streifen hinter der oblique fascia, die of the same hue sein soll, ist zu auffallenl, als dass er - wemn er constant ist - unerwälnt bleiben künnte. Ohne diese Abweichnngen, die jeduch vielleicht veränderlich sind, würde ich meine Art für Chemens' Spireaefoliana halten, aber den Namen in Spiracifoliana verwandeln, weil Clemens die Raupen auf einer Spiraea fand. 


\section{Phox. Burgessiuma n. sp. Taf. VIIl, Fig. 7.}

Merlia; alis ant. albis, maculn dorseli semiovata lnumen, fuscia costac mellire obliqua frsco-fermginea eum parte alde postica rufo-fermeginer coulescente et exterius allido-marginata, costa postiee albido fuseoque striguluta. ol ㅇ.

Von der etwas grösseren Semiovana sogleich durch dic rostrothe, nicht zimmtbraune Hinterhälfte der Vdfl. zu unterscheiden. Ausserdem ist ihr Weiss nicht so rein; statt des Balkens hat sie eine wirkliche Binde, und diese ist hinterwärts, statt nit einem auffallenden schneeweissen Streifen, nur mit einer weisslichen. nach unten bleifarbigen Linje gesiumt; der Vdrd. hinter derselben hat abwechselnd breite, braune und ganz kurze, dünne, weissliche Strichelchen; die Htru.-Fransen sind röthlich; die Htfl. dunkler braungrau. - Die folgende Laciniana hat gleichfalls als augenfälligsten Untersehied eine mehr zimmibrame, wenn auch mit etwas Rostgelb gemischte Endhälfte der Vdfi.; dazu ist das Weiss schon mit ein wenig Gelb versetzt und von geringerer Breite zwischen dem Vdrd. und dem halbovalen Fleck. Ferner ist die Schrägbinde schunäler und hat als äussere Einfassung einen Streifen fast von der Breite wie bei Semiovana, jedoch schmutzig weisslich. - Burgessiana hat anch grosse Achulichkeit mit der europäischen Lundana, bei der die Enihälfte der Vdfl. noch mehr mit Rostfarbe gemiseht ist als bei Burgessiana; bei Lundana ist statt der weisslichen Grundfarbe ein selır verblasstes Oehergelb; der helle Raum zwischen Vdrd. und Halbeifleck schmäler; die Schrägbinde beträchtlich schmäler, eiu bInsser Streifen, answärts mit ciner feinen Bleilinie cingefasst, welche hinter den 2 schwarzen Längslinien sich in einen sehr spitzen Winkel bricht mod dann erweitert bis in den Innenwinkel zieht. Die Costalbäkchen auf der Eudhälfte des Flügels sind weisslich und wechseln mit breiten, sehwarzen.

Grösse der Lumlana. R gelbbrann; Schulterdecken nchergelblichweiss. K. gelbbraun oder rostbraun; Gesicht weisslicb. Taster weiss, scheibenförmig zosammengedrïckt mit kurzem Endglied. Beine hell stanhgrau; Füsse aul' dem Rücken braun mit feinen weissen Enden der Glieder. Hinterleib dunkelgrau, Aualbusch des ơ stark, des \& sehwach, bleich ochergelb.

Vdf. $314^{\prime \prime \prime}$ lang, auf der hinteren Hälfte lebhaft rostroth, auf der Wurzelhälfte weiss, doch nicht ganz rein, welche Farbe einen geringeren Raum cinnimmt als der einfarbig gelbbraune oder braune Halbeifleck des Innenrandes. Dieser Fleck fängt von der Flïgelhasis an, reicht üher die Falte worg nnd endigt, nicht bei allen Ex. gleichförmig abgrondet, hinter der Hälfte des Innenrandes. Um sein Ende zicht sich das Weisse in einer ftinen Linie, hinter weleher bis zur Rostfarbe der Grund mit schwarzgranen Schuppen dieht bestrent ist. Die verdunkelto, schiof nach anssen gelegte Mitiellinde velfliesst in die Rostfarbe und ist answärts von einer röthlichweissen Linie begleitet; unterhalb ihres nach aussen gebogenen Endes liegen, wie bei Semiovana, zwei tiefschwarze, aber deutlichere luangslinien. Die röthlichweisse Linie ist ihrer- 
seits auswärts von einer feinen Bleilinie gesäunt, wclche um das hinterc Ende der zwei schwarzen Linien in einem scharfen Winkel herum und dann abwärts zicht, um an einem kleinen, dieken, tiefsehwarzen Längsstrichelehen (las bei dem schlecht erhaltenen $\sigma$ fehlt, vielleicht abgewischt ist) uberhalb des Innenwinkels zu endigen. Vor der Flügelspitze trägt der Vdrd. 4-5 rostbraune, stärkere, mit feinen, weisslichen wecbselnde Häkchen. Die Flügelspitze ist dunkel rostbrann, die Fransen darbiber etwas heller, die darnnter mit zwei reinweissen, durch eine schwarze Linie getrennten Wischen. Die übrigen Htrd.Fransen sind schwach schimmernd hell röthlichgrau; eine weisse, schwarzpunktirte Linie scheidet sie von der Flügelfäche.

Htfl. einfarbig braungrau; Fransen hellgrau, den Htrd. wit feiner, gelblicher Wurzellinie umziehend. Ader 3 ist ganz einfach.

Vaterland: Massachusetts. $1 \sigma^{\top}, 1 q$, von Burgess bei Beverly am 18. Juni und 3. Juli gefangen, 1 f von Packard erbalten, in meiner Sammlung.

Anmerkung. Anch. fuscociliuna Clem. (Proc. Ent. Soc. Philad. III [1864]. p. 512) kann nicht diese Art sein. Die Worte: the apical half of the costa, from the middle to the tip of the wing, is occupied by a dark ferruginous semioval pateh lassen sich gar nicht auf sie anwenden, sondern denten anf eine der Derasana nahe stehende Art. Es fehlen auch der Burgessiana lie dull leaden hued streaks zwisehen den weissen Costalhiikehen, und ihre Htrd.-Fransen sind nielst whitish.

\section{Phox. laciniuna n. sp. Taf. VIII, Fig. 8.}

Meatia; alis aut. albis, macule dorsali semiovate brunea, trube custae mediac obliqua brunnea cum purte alue posticu lutea coulescente, striga trati

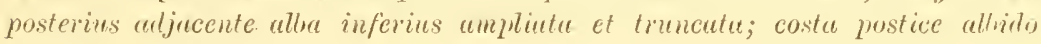
fuscoque strigulatu. 万’.

Ihre Verseliedenheit von Burgessiance ist schon bei dieser angezeigt. Vor den folgenden, b.i denen die bintere Costalpartie nicht wic bei Derasune ein dunkles, am Vdrd. hängendes Dreieck bildet, sondern die ganze hintere Flügelhälfte zienlich gleichförnig verdumkelt ist, zeichnet sie sieh dureh ihre beträchtlichere Grösse aus (nur vicht vor dan $\sigma^{7}$ der Subuequana), dann dureh die Dentlichkeit des sehrägen Querbalkens, der den Vdrd mit der dumkel lehmgelben Partis verbindet, und dureb den ihn hinterwärts begleitenden weisslichen. nach unten erweiterten mnd hier nach hinten zngespitzten Streifen. A veh ist der dorsale Halbeifleck bei Laciniane hinten sanft, zugerundrt.

Grösse dir Burgessiana. P. vorn wie die Schnlterdeeken schmutzig gelblichweiss, hinten bram. K. ubenanf verdunkelt, vorn weisslich. Taster viel weniger erweitert als bei Burgessinnu, schnntrigweiss. Hinterbeine weissgran. verlosehen braun punktirt. Hinterleif brangrau mii blass ochere. bibern Analbusch; die männlicheł Haltzangen seheibenfirmig, behaart, fast weissli.h.

Vdfl. $33_{4}-3 \frac{1}{2}$ " lang, nit weisser Grundfarbe, die aber eine gelbliche, nach hinten verstärkte Beimischung hat. Der Dorsalfleck, von der Flügelbasis 
bis übor die Hälfte des Innenrandes reichend, crhelot sich gerunclet über die Falte und ist einfarbig gelbbraun, an abgerundeten Hinterende durel einen schmalen, nach linten schlecht begrenzten Streifen der Grundfarbe gesäumt. Der weissliche Raum zwischen ihm und dem Vold. ist schmäler als bei $B$ urgessiana. Von der Mitze des Vdrdes. geht der schmale, balkenartige Bindenstreifen, der anf dem Vdrd. selbst an dunkelsten gelbbraun ist, schräg in der Richtung gegen den Innenwinkel und verliert sich in der Lehmfarbe der hinteren Flïgelpartie; ihn begleitet linterwärts ein wie bei Semiovana gestalteter Streifen, der aber schmutzigweiss ist, und unter dessen gerade abgeschnittenem Ende 2 deutliche, tiefschwarze Längslinien liegen; um deren hinteres Ende biegt sich öfters eine linienförmige, helle Fortsetzung des weisslichen Streifens nach innen $\mathrm{zu}$, die weit vor dem Innenrande versehwindet. Der Vdrd. ist hinter der Mittelbinde mit 6 abwechselnd starken und seliwachen gelbbraunen Schrässtrichelchen gezeichnet, zwischen denen der Grund als weisse Sirichelchen erscheint. Die Flïgelspitze ist verlunkelt, die Fransen darüber etwas heller, zimmtbraun, die darunter nit zwei reinweissen, durch eine schwarze Lüngslinie getrennten Wischen. Die übrigen Htrd.-Fransen schmutzig gelblichweiss, an der IVurzel reiner weiss.

Htfl. hollgrau, gegen die Basis heller, wie die Fransen. Die dritte Ader ist anf der lichteren Unterseite schr dentlich, einfach.

Ein $\sigma^{7}$ (von Beverly) ist cin wenig grösser, mit noch weniger reinem Weiss, das schon bei der etwas breituren Mittelbinde ganz gelblich wird; der sie begleitende weissliche Streifen ist viel dümer, nur eine unterwärts erweiterte Linie. Unterhalb der Flügelspitze liegen 2 weisse Längsstriche, indenn die tiefschwarze Zwischenlinie stärker ist. Htfl. viel dunkler, braungrau, ganz einfarbig. - Ieh halte das Ex. nur lïir Varjetät.

Vaterliud: Missachusetts, von wo 3 ó durch Packard, 1 f durch Burgess in meiner Sammlung.

Anmerkung. Aneh. dubiana Clemens (Proc. E. Soc. Philad. III [1E61], 1. 5[2), in weleher der Verfasser eine Varietät seiner Spirenefoliana vermuthet, ist nicht so genau beschrieben, dass ich meine Art mit ibr vereinigen könııte.

6. Phox. subuequaur и. sp. T'af. VIII, Fig. 9.

I'arve vel modia; alis ant. ochracco-allidis, postice obscuribibus, macula dorsali tiongula brunnca, superius fuscr, maculu costae mediae parva. fuscr, macula disci post erm lutea, atro-trilineato, costa postice allido fusconque strigulutu, apice fusco. ơ $\mathrm{O}$.

Sie hat zum Unterschiede von den 3 vorigen schon eine entschieden ochergelblich weisse Grundfarbe der Vdfl, die anf der hinteren Hilfte nur verdunkelt und onit Grau gemischt ist, so dass nur ein schwacher Gegensatz gegen die Basalhälfte entsteht. Unter den europäischen Arten konmt ihr Myrtillana am nächsten, indem bei dieser auch der gelbbraune Dursalfleck in seinem 
hintersten Theil sieh erhöht und so ein stmmpfes Dreieck bildet, dessen Basis auf dem Innenrand ruht.

Bei Myrtillana ist eine entsehiedene Costalbinde vorhanden, die sich in der dunkeln hinteren Flïgelpartie verliert, gegen welche sich im Inn'nwinkel ein grosser, eiförıniger, grauer sjiegelfeek abrrenzt; bri Subcequana ist statt der Binde nur ein angefangenes, schmales, braunes Sehräystruifchen vorhanden, das mit dem weiter nacb hinten liegenden, lehmgelblichen, drei schwarze Striche enthaltenden Querfleck nieht in Verbindung steht. - Die kleinere Angulifasciana, deren auch gauz gelbliche Vdfl. auf der Enilhälfte röthlich zimntbraun sind, zeigt den Dorsalfleck lalbeiförmig und ausserdem nicht nur eine vollstäudige Binde, sondern diese setzt sich auch, erweitert und über der Flügelmitte nach aussen eine scharfe Ecke bildend und answärts von einer hellen Linie gesäumt, beinahe ïber die ganze Flïgelbreite fort.

Das o ist (vielleicht nieht immer) so gross wie Burgessiana, das $q$ beträchtlich kleiner, so gross wie Angulifasciana. Taster, Kopf, Vordertheil des hellbraunen R. ochergelhlichweiss. Beine grau; Fussglieder sehwarz nit weissen Enden. Hinterleib bräunlich grau, mit hell ochergelblichem, beim $0^{x}$ kurzem Analbuseh.

Vdfl. o $3 \frac{1}{2}$, $\& 22^{3} / 4^{\prime \prime}$ lang, von schmutzig oehergelbweisshicher Grundfarbe, die sich, wenig verdınkelt, fast bis zur Fln̈gelspitze verbreitet Der gelbbraune Dorsalfleck, von der Flügelbasis bis zur Hälfte des Innenrandes oder wenig darüber reichend, ist mehr dreieckig als bei den vorigen Arten, indem er sich mit seinem Enddrittel in einem stumpfen Zahn, in welehen die Farbe aucb verdunkelt ist, stark über die Falte erhebt und dahinter (beim $O$ steiler als beiın $\sigma^{\top}$ ) gegen den Innenrand alfällt. Statt der gewöhulichen Binde zeigt sich nur ein kurzes, schräg nach aussen gerichtetes, brames Streifehen, das sehr sehuell anfhört. Der Vdrd. trägt vor ihm 2 sehr kleiue, braune, dahinter bis zur Spitze 7 längere, abwechselnd feine uud starke, alle dureh Weiss getrenute Strichelchen. Die Farbe tiefer abwärts zwischen Dorsaldreieck, Htrd. und Innenwinkel ist gelblichgrau nebelig; von ihr wird das Dorsaldreieck dureh eine feine, weisslichere Linie geschieden. In dieser nebeligen Partie liegt ein gelbbrännlicher, hinten concaver und durch eine weissliche, schimmernde Linie seharf begrenzter Fleck, der oberwärts $2 \frac{1}{2}$ tiefsehwarze Längslinien enthält und unteıwärts verlöscht, unter sich aber in Innenwinkel ein bıäuıliches Fleckchen hat. In der Flügelspitze bildet die tieforaune Farbe ein scharf begrenztes, längliches Fleckchen, das durch die weissen Costalhäkchen und unterhalb durch zwei weisse, fein schwarz getrennte Wische in den Fransen noch mehr gehoben wird. Die übrigen Htrd.-Fransen sind reinweiss, aber nuterhalb der 2 Wische auf der dussenbälfte mit einer breiten dunkelgrauen Stelle, welehe anf der Unterseite woch auffallender hervortritt.

Htfl. hell braungrau, einfarbig; Ader 3 einfach.

Vaterland: Maine odler Massachusetts; 2 б, 1 Q, von Packard erhalten, in meiner Sammlnng. 
7. Hho.r. angulifascirma n. sp. Taf. VIII, Fig. 10.

Parva; alis anl. ochraceo-rllbilis, postice subeinnamomeis, macula dorsuli semionata lnumea, fascia costne mediae angnsta brumea in maculam postice angulatam exterius linea alba maryinatam prodneta, costa post eam albids monneaque strigulata. of $\mathrm{Q}$.

Nuch etwas kleiner als Subaequana. Ausser len bei dirser angezeigten Vessehiedenheiten hat sie in den Htrd. Fransen unterhalb ter weissen Begrenzung der Spitze nur tinen kleinen oder gar keinen dunkelgranen Fleck. Von Comptana unterselieilet sie sich sofort dureh den Vird., der zwischen Basis und Mittelbinde rein bleibt, bei jener dagegen mit schwarzbramen QneTstrichelehen-gezeichnet ist. Auch ist bei Comptana der Raum zwischen Vild. und Dorsalfleck viel schmäler, und des letzteren obere Seite ohne alle scharfe Abgrelızung.

R. hinten gelbbraun, voru sowie die Sebulterdecken und d $\mathrm{r}$ K. röthlieh weissgrau. Taster ziemlieh stark behaart, zusammengedrücht, reiner weisslich, gegen die Spitze etwas gebräunt. Beine hell braungrau; die hinteren hellgran; alle Füsse braungrau mit weissliehen Enden der Glieder. Hinterleib dunkelgran mit gelblich weissem Banch und kurzern, blass ocherfarbenen Analbusch.

Vdfl. $2 \frac{1}{2}{ }^{\prime \prime}$ lang, trüb ochergelbweisslich, welche Farlee den Dorsalfleck hinten als eine feine weissliche Linie einfasst, worauf der Grund allnälig ochergelb und dann zimmtbraun wird. Der von der Flïgelbasis bis zur Innenrandmitte reichende halbeifürmige Dorsalfleck ist gelbbraun, in der über die Falte hinwegreichenden, nicht zahnfürmigen Partie und hinten verlunkelt und überhaupt gegen die Grundfarbe seharf abgegrenzt. Die sehräg nach anssen gelegte streifenfürmige Binde der Costalmitte ist mehr oder weniger lebhaft gelbbraun und setzt sich in gleieler Farbe erweitert bis unter die Flïgellälfte fort, wo sie hinterwärts einen scharfen Winkel bildet, in welehem nicht immer zwei sehwarze Längsstriche zu erkennen siud; sie wird auswärts von einer dïnnen, weisslichen, etwas glänzenden Linie als scharfer Begrenzung eingefasst, welche unterhalb des Winkels eine bleiglänzende Färbung annint und sich bisweilen erweitert.

Der Innenrand hat hinter dem Dorsalfleck auf weisslichem Grunde zwei braune Querstrichelchen und in Inneuwinkel einen braunen, sehltcht begrenzten Fleek. Der Vdrd. trägt vor der Binde keine Querstriche, aber hinter derselben bis zur Spitze 5-7 braune Strichelchen, von denen drei verdickt, alle aber durch weissliche Strichelchen getrennt sind; unterhalb derselben ist die Grundfarbe hell oehergelblich. Die Flïgelspitze ist dunkel zimntbraun, unterwärts durch einen reinweisshehen Fransenwiscb hervorgehoben, wehem unter einer schwarzen Linie ein breiterer, weisser folgt. Die Htrd.-Fransen sind gelblichweiss, an der Aussenhälfte schwach glänzend, mit einem grauen Fleckchen, das bisweilen fehlt, unterhalb der Ansraudung. 
Htfl. einfarbig dunkelgrau; die helleren, beim $\sigma^{7}$ bisweilen weissgranen Fransen mit feiner, gelblicher Wurzellinie. Ader 3 selı dentlich, einfach.

Vaterland: Ohio (Schläger), Massachusutts (Burgess). Vier ơ, ein $O$ in meiner Sammlung.

\section{Phox. rommtama Frölich.}

Parva: ulis ant. cincreis, jostice lutescentilus, costa tota fusco-strigulatu, macula dorsali lutu, triangula, brunea, superius exolescente, parte speculari cinerea maculam ex dorso adscendentem luteam continente.

Tortrix - Frölich Tortr. Würtenb. p. 99.

Phoxopterys - Herrich Sch. IV, 1) 280, Fig. 310.

Gropholitha - Heinemann 'Tortr.. p. 225.

Anchyloperu - Wilkinson Turtr., p. 141. Stainton Man. II, p. 225.

Fragariae Walsh. Riley First report nox. Ins. of Missouri (1869), p. 142, Fig. 81) und tab. 2, F. 26, 27. ef. Entom. Zeitung 1871, S. 178.

Veränderlich in der Grösse, in der sie meist über Angulifasciana steht, nnd in der Helligkeit und Dunkelheit der Vdfl.-Färbung und 7eichnung.

Der gelbbranne Dorsalfleck der Vdfl. reicht weit hinauf gegen den Vdrd. und verengert die Grundfarbe mehr als bei allen vorhergehenden Arten; er ist gegen diese nicht so scharf abgegrenat, ja wenn diese recht dunkel grau ist, fliesst er sogar mit ilır zusammen; nach hinten verdunkelt er sich und wird lurch eine dünne, hellgrane. ihn sänmende Linie noch mehr hervorgehoben. Dieser Linie folgt ein graner, bandförmiger Streifen, der bis zum Imnenrand heruntergeht, sich hier erweitert und sich dann über dem Inneuwinkel als Spiegelfleck erhebt. In diesem Spiegelfleck liegt dicht vor den Innenwinkel ein schräg nach hinten anfgerichteter, gerundeter, lchmgelber Fleck, der öfters oben mit der lehmgelben Partie zusammenhängt; zwischen ihm und dem unteren, erweiterten Ende der Binde ist der verengerte Raun gewöhnlich weisslich und von einer brangranen Linie durchzogen. Der Vard. ist fast von der Wurzel aus mit schwarzbraunen Schrägstrichelchen gezeichnet - eine Auszeichnung, die unserer Myrtillana nur einigermassen zukommt, und welche Subaequana in sofern theilt, als sie vor dem Mittelstreifchen doch 2 solche Strichelchen aufweist. Comptana hat gleichfalls an der Nitte des Vdrdes. ein gelbbramues, mehr oder weniger schmales Schrägband, das sich nach unten erweitert und aussen von einer hellen Linie begleitet wird. Hintor ihm ist der Vdrd. unt 7 abwechselnd dünnen und dicken bramen strichelchen versehen, mit einem weisslichen zwischen je zwei braunen. Die gelbbraune Flügelspitze hat unter sich in den Fransen 2 reinweisse, durch eine tiefschwarze Linie getrennte Wische oder Linien. Die darunter folgenden Htrd.-Fransen sind heller oder dunkler grau, einwärts an bellsten.

Die Htfl.-Fransen des $\sigma^{\nearrow}$ sind oft ganz so cinkel wie die des $O$. Ader 3 spaltet sich ganz deutlich in eine Gabel nit $1 / 3$ so langem sitiel. Die Vatt. haben ganz sicher keine Nebenzełle. 
Eine sehr verbreitete Art, dic in Livland von Hrı. v. Nolcken beobaclitet wurde und in Deutschland ïberall in der Fläche wie auf den Höhen vorkommt. In südlichen Ençland, wo sie an vielen Stellen lebt, fing ich selbst sie bei Micklehan und auf den Graubündner Alpen über $4000^{4}$ hoch. Ain südlichsten in Europa sclseint sie durch Mann in Toscana, am üstlichsten durch Christoph bei Sarepta beobachtet zu sein. - In Nordanerica hat sie gleichfalls eine grosse Verbreitung. Riley gibt Nord-Illinois, Indiana und Canada au. Boll brachte $1 \mathrm{Ex}$. (ein helles $\mathrm{O}^{\top}$ ) aus Texas. Aus Massachusetts erhielt ich sie von Burgess, und die von Packard erhaltenen mögen aus Maine stamnen.

Die Flugzeit ist zuerst, selbst in Norddentschland, zu Eude April und Anfang Mai (in Livland zu Ende Mai und im Juni); danu im Juli (nach Wilkinson erst im August; ich fing die Art aber in England selbst in Juli). In den Alpeu seheint nur eine jährliche Generatien stattzufinden, da die Art mir dort nur im Juli vorkam. Ihr Wohnort sind sonnige, trockene, blumige Waldstellen. Die Futterpflanze der Raupe ist auf Sandboden wohl vorzugsweise Potentille argentea, an der ich sie gezogen habe, vielleicht auf Kalk die von Stainton erwähnte Pot. verna, zu welcher er noch Poterium sanguisorba und Dryas actopetala fügt. Nach Riley lebt sie aber auf Fragaria und ist für die Exdbeerbeete sehr schädlich. Da sie sich in solcher Hinsicht bei uns nie bemerklich gemacht hat und nicht eimmal als Bewohnerin der Erdbeere bekannt ist, so scheint sie nicht zu den in America eingewanderten Arten zu gehören. Riley gibt, so viel ich weiss, die erste Besclıreibung der Ranpe, deren zweite Brut im Puppenstande überwintert.

\section{Phox. Horiduma n. sp.}

Parva; al. ant. area basali fasciuque postica fracta inferius dilatata lacte fusco-ferngineis, fascia interjectu maculaque speculavi plumbeis, costa fere ex basi strigulula, strigulis posticis allis; post. fusco-cinereis. $\sigma^{\top}$.

Von der folgenden etwas kleineren Art ist sie verschieden durch die deutlich verlängerte spitze ihrer Vatl., durch die schön rostbraune Hauptfarbe derselben und durch die nacb hinten an Länge zunehmenden weissen Strichelchen auf der Endhälfte des Vdrdes. - Auf Florilana folgt naturgemäss unsere viel grüssere Mitterpacheriana, die anch lebhaft rostfarbene Vith. hat, aber ohne Schimner, ohne bleiglänzende Mittelbinde und ohne solchen Spiegelfleck.

Grösse eines grösseren $0^{7}$ der Comptana. K. und Vorderrücken ochergelb, Hinterrücken gelbbraun; Stirn blass ochergelb. Taster gelblichweiss. Beine weissgrau; Hinterfüsse dunkelgrau mit weissen Enden der Glieder. (Hinterleib fehlt.)

Vdfl. $2 \frac{1}{2}$ " lang, länglich, weniger gestreckt als bei Comptana. Statt des Dorsalflecks ist eiu Basalfeld, dessen eckiger Htrd. auf der nnteren Hälfte durch eine grade, einwärts gerichtete Linie gebildet wird; es ist in der Dorsalgegend lebhaft rostfarben, an seinem Htrd. und noch breiter gegen den Vdrd. in Gelbbraum übergehend. Der Vdrd. ist an ihm bis zur Subcostalader 
so schimmernd schiefer- oder bleigran wio bis zmr rosthrannen Binde, unil dieses Gran zieht sich als schmale Binde $\mathrm{mm}$ das Basalfeld herum, also nach aussen einen Winkel bildend bis zum Innenrand. Die darauf folgende, besonders in der Mitte lebhaft rostfarbene, nach unten verdunkelte, auf dem Vdrd. rostbraune Binde ist an ihrem obersten Viertel viel schmäler als weiter abwärts, wo sie fast 3 mal so breit ist wie die vorhergehenile schimmernd graue Binde: sie ist auf $1 / 3 \mathrm{zu}$ einem Winkel gebrochen $n$ it fast grarlen Schenkeln, von denen der obere vom Vdrd. ans hinten von einer diinnen Bleilinie begleitet wird. Diese Bleilinie erweitert sich unten in einen dieken, bis zum Innenwinkel reichenden Streifen, hinter welchem der schmale Raum bis zum Htrd. hellrostgelb ist. Der Winkel der Postbinde enthält ein paar schwarze, kurze Längslinien. Vor ihr zeigt der Vdrd. zwei Paar weissliche Querstrichelchen, hinter ilır vier Paar weisse, die an Länge und Schärfe bis vor die Flïgelspitze zınehmen: sie sind dnrch abwechselnd dünnere und dickere branne Striche getrennt. Unterhalb derselben ist der Grund zwischen Binde und Htru. ziemlich hell rostfarbig, an Htrd. unterhalb der Spitze durch Braun verdunkelt. Die Flügelspitze ist rostfarbig und wird oherhalb durch die zwei letzten weissen Costalluäkchen, unterwärts durch einen weissen Fransenwisch hervorgehoben, dem abwärts ein schwarzer Längsstrich und noch ein weisser folgt. Tiefer abwärts sind die Ftrd.-Fransen grau mit Bleischimmer.

Htfl. dunkelbraungrau, gegen die Wurzel wenig, die Fransen viel heller. Anf der hellen Unterseite ist die dritte Ader sehr dentlich in eine kurzstielige Gabel gespalten.

Vaterland: Ohio (Schläger). Ein $\sigma^{\nearrow}$ in meiner Sammlung.

\section{Phox. Amblygona II. sp.}

Parv; al. ant. apice obtuso, cinnamomeis, aren basali fusco-ferruginea postice per strigam albidam terminata, parte speculari cinerea maculam brunneam ex dorso alscendentem continente, costa inde a basi oblique nigrostriguluta. Q.

Dadurch, dass die Vdfl.-Spitze fast gar nicht hervortritt, ist sie von allen vorhergehenden Arten verschieden, dagegen der europäischen Obtusana sehr ähnlich, anch nach der rostbraunen Färbung. Wie diese, stimmt sie mit Comptana darin. dass der Vdrd. von der Flügelspitze an fast bis zur Basis schwarzbrann gestrichelt ist. Aher bei Obtusana bilden die weissen Costalstriche zwischen der Binde und der Flügelspitze vier Faare und sind sehr deutlich, und auch diesseits der Binde sind die 7wischenräume der schwarzhraunen Strichelchen weiss; bei Amblygona lassen sich keine Paare unterseheiden, sondern nur dunkle Strichelchen mit fein linienförmigen Zwischenräumen von der gelichteten Grundfarbe. Ferner entsteht bei Obtusana, als der einzigen mir bekannten Phoxopteris, durch die Abrundung der Flïgelspitze ein wirklicher Apical-Ocellus, indem das letzte weisse Costalstrichelchen sich im Bogen gegen den FItrd. herumzieht und sich an den einzelnen, ziemlich langen, reinweissen 
Längsstrich der HItrd-Fransen anschliesst; anch sind die Apicalfransen weisslich, nur oberwärts und auswärts braun. Bei Amblygona dagegen ist zwar ein sehr kurzes, weissliches Costalstrichelchen als letztes vor der Spitze vorhanden; es reicht aber bei weitem nicht bis zn dem sehr kurzen, weissen Doppelstrich der Htrd.-Fransen, und die Fransen um die Spitze sind ganz braun, so dass also kin abgerundeter, einwärts umschriebener Augenfleck gebildet werden kann. Endlich sind auch die Htrd.-Fransen bei Obtuscunc auswärts hell ochergelb, selbst gelblichweiss, und nur unterhalb des weissen Striches dunkelgrau: bei Amblygour sind sic einfarbig gran.

Kleiner als Obtuscunr. K. und Vorderriicken hell ochergelh. Taster viel heller, länglich, auswendig und am Ende verdunkelt. Beine hell braungrau: Füsse braun mit weisslichen Fnden der Glieder. Hinterleib zugespitzt, braungran.

Vdfl. wenig über $2^{\prime \prime \prime}$ lang, mit wenig vortretender Spitze und schwach eingedrücktem Htrd. unter derselben. Grundfarbe rüthlich zimmtfarben. Der gewöhnliche Dorsalfleck ist viel gesättigter, röthlicher und nach hinten verdunkelt, gegen den Vdrd. zu gar nicht abgegrenzt und lässt sich daher als verdunkeltes, auf dem Vdrd.-Drittel gelichtetes Basalfeld ansehen, das hinten sehr schräg abgeschnitten ist und den Immenrand hinter der Mitte erreicht; es ist an seinem verdunkelten Ende mit einer feinen weissen, vom Inneurand bis zur Subcostalader hinaufreichenden Linie eingefasst. Hinter ihr ist der Innenrand, wie bei Comptana, breit gran, welche Farbe sich am Innenwinkel zu dem grossen, grauen Spiegelraum ausdehnt. In diesem crhebt sich aus dem Innenwinkel ein oben nach aussen geneigter, schmaler, oben abgermndeter, gelbbranner Streifen, den oberwärts eine feine, weissgrane Linie umzieht. Der Spiegelraum selbst ist oben ebenso hell weissgran gesännt und sticht dadurch von der Grmndfarbe sehr ab. Von der Wurzel aus bis zu der sonstigen Mittelbinde hat der Vdrd. kleine, sehr schräge, schwarze Strichelchen; hinter dem schwachen und schmalen, dunkeln Anfang der Binde zieht ans dem Vdrd. eine selı feine, helle, auswärts schmärzlich gesäumte Linie schräg gegen den Htrd., verschwindet aher vor den zwei weissen Htrd.-Strichen. Auf diese Linie folgen bis zur Flïgelspitze nicht recht dentliche, braune, nit hellen der Grundfarbe abwechselnde Strichelchen. Unterhalb der verdunkelten zimmtbrannen Spitze enthalten die Htrd.-Fransen zwei sehr kleine, weisse, durch eine schwarze Linie getrennte Längsstrichelchen, unterhalb deren die Fransen grau sind.

Htfl. einfarbig braungrau; die wenig helleren Fransen mit sehr feiner heller Linie an der Wurzel. Die Adern sind nicht deutlich zu erkennen, scheinen aber mit denen der Obtusana übereinzustimnen, bei welcher die dritte Ader in eine fast his zu ihrem Aufang reichende Gabel gespalten ist. funden hat.

Vaterland: Washington, wo Baron Osten-Sacken mein einzelnes 9 gre-

\section{Phox. mareidama 11. sp.}

Mellia; al. ant. prellide rufo-fermgineis, al costrom lative crullidis, fusciu angusta ex costa strigulisque post eam costrulibus obsolete ferrugineis, 
striolis 2 nigris ante murginis postici trientem supremum; post. pallide ochracco-grisescentibus. ơ 9 .

Sie sieht wie ein Albino ans und würde, wenn sic einen scharf umschricbenen Dorsalfleck hätte, wegen der schmalen, weisslichen hinteren Finfissung der Mittelbinde gleich hinter Lraciniana zu stehen kommen. Die verloschene, hell roströthliche Färbung ihrer Vdfl., die gegen den Vird. ins Gelbhichweisse übergeht, und worin die Adern als dunklere Linien hervortreten, und die sehr hell graugelblichen Htfl. zeichnen die Art vor den mir bekanuten ans.

R., K, und Fühler von der hell ochergelblichweissen Farbe des Vdrdes. der Vdf. Taster und Beine noch weisslicher, nur die Vorderbeine mit Grau gemisclit, ungefleckt. Hinterleib hell ochergelb, beim $Q$ noch heller.

$V d f$, von der Gestalt und wechselnden Grösse der Laciniana. Grundfarbe hell röthlich rostfarben, ohne sichere Grenze in die ochergelblichweisse Farbe des Costaldrittels übergehend, am dunkelsten am Htrd. Das Dorsaldreieck ist dadurch wenigstens angedeutet, dass sich die Farbe hinter der Flügelmitte lichtet, um sich gegen den Htrd. wieder zu verdunkeln. Die Adern bilden wenig deutliche, dünne, etwas verdunkelte Lüngslinien. Von der Mitte des Vdrdes. geht eine schmale, rostfarbene Binde sehr schief nach hinten und verliert sich in der Grundfarbe; wo sie sonst ihre untere Ecke hat, der Einbuchtung des Htrdes. gegenüber, sind zwei wenig deutliche, tiefschwarze Längs streifchen neben einander; als hintere Einfassung dieser Binde lässt sich blos ein schmaler, weisslicher Streifen erkennen.

Bis zu der dunkelrostrothen Flügelspitze ist der Vdrd. mit 6-7 Schrägstrichelchen, die die Grundfarbe haben, bezeichnet. Fransen hell roströthlich, unterhalb der Spitze mit zwei verloschenen, weissen Längsstrichelchen.

Htf. sehr hell ochergelblichgrau, in der Spitze mehr ochergelblich, Fransen lichter. Medianader dreiästig; erster Ast weit vom zweiten entfernt, und dieser nit dem dritten aus einem Punkt an der Spitze der Mittelzelle.

Die ganze Unterseite lıeller als die Htfl. obeu. Die Spitze der Vdfl. braunrostfarben, die Fransen etwas heller.

Vaterland: Nordamerica. Ein kleineres $\sigma^{7}$ aus Texas (Boll) im Museum Cambridge; ein grösseres Paar aus nicht angezcigter Localität in Dr. Riössler's Sammlung.

Euchromia Stph. Grapholitha Heinemann, Wickler S. 100.

1. Euchr. hemidesma n. sp. Taf. VIII, Fig. 11.

Media; alis ant. latis, fuscis, postice fuscescenti-mubiginosis, fuscin media migro-fusca, infcrius flavido temitcr marginuta; post. fuscis. \&.

Der Färlung nach verwandt mit Mygindana; doch kann ich nicht erkennen, ob Ader 3 nnd 4 der Htfl. genan aus der Ecke der Nittelzelle entspringen oder, wie es fast scheint, einen kurzen gemeinschaftlichen Stiel haben. Die Fliigel, die vorderen ohne Einknickung, sind auffalleud breit; die braunrothe 
Farbe in der Endhälfte der vorderen nud die wenigstens an der nuteren Hälfte fein gelblich gesäưnte dunkelbranne, schmale Binde zeichnen die Art vor den nir bekannten aus.

Grösse einer mittleren Mygindana. R. glatt, von der Farbe ler Vdfl.Basis. K. mehr grau. Taster nu Kopflänge hervorstehenl, nach roru verdickt, zusammengedriickt, vorn sehrüg abgeschnitten, lunkelgrau, am Ende, sowie das stmmpfe Endglied braun. Beine phump, lehmig gran; Mittelsehienen aussen ziemlich dicht auliegend behaart: Hinterschienen mit langen, starken Dornen, auf der Innenseite, sowie die Füsse hell gelblichgrau. Hinterleib braungrau, am Bauch hell; der Legestachel versteckt.

Vdf. 4" lang, breit, mit stark convexem Vdrd., abgestumpfter Spitze und selwwach convexem Htrd. Grundfarbe auf der Basalbälfte röthlieh brann, hinter der Binde ziemlich hell braumroth, welche Farbe sich in der Flïgelspitze loräunt. Von der Mitte des Vdrdes. geht eine schwarzbraune, etwas schmale Binde nach $2 / 3$ des Innenrandes. Sie ist an mehr als der unteren Hälfte (ich vermuthe, bei manchen Ex. noch weiter hinanf) anf beiden Seiten mit einer scharfbegrenzten gelblichen Linie gesäumt; die innere bildet zwei Ecken: in der Falte und an der Subdorsalader; die äussere macht in der Mitte, wo die Binde einen Vorsprung hat, eine nach aussen convexe Krümmung, unterhalb welclier sie schwach convex verläuft. Sonstige Zeichnungen sind nicht vorhauden, wenn man nicht ganz verloschene dunklere Costalstrichelchen, die von der Flïgelbasis bis hinter lie Binde reichen, als Zeichnung ansehen will. Fransen einfarbig braun.

Htf. braungrau, gegen die Basis heller. Fransen hell gelblichgran, von einer starken dunkelgrauen Linie durchzogen.

Unterseite dunkelbraun, anf den Htfl. etwas heller. Besonders auf diesen treten die Adern stark hervor, doch nicht so, dass sich der Ursprung der Adern 3, 4, 5 bestimut erkennen liesse. Fransen einfarbig brangrau.

Vaterland: Massachusetts. Ein $Q$, vou Burgess bei Beverly mit mehreren am 3. Juli gefangen, in meiner Sammlıug.

Penthina Tr. Antithesia Stph. Clem.

1. Albeolrma n. sp. Taf. VIII, Fig. 12.

Alis ant. obtusioribus, albis, a basi ultre medium einereo-nebulosis, praesertim juxta dorsum, macula eostae melicue adhaerente obscuriore infra per lineam nigram terminata, apice alae cinereo-liturata. ठ’.

Ein einzelnes $\sigma^{7}$, so rein weiss und so wenig grau nebelig, wie Hartmanniana bei uns nie vorkommt. Das Auffallendste ist aber der Fleck der Costalnitte; er ist kleiner als hei jener Art und basalwärts nicht sclıäg, sondern fast senkreeht begrenzt, inden der soustige dunkle Theil des Flecks blos durch wenige dunkelgrane Punkte auf weissen Grunde vertreten ist; der Fleek wird wie bei Hartmanniana an der Medianander durch eine kurze, tiefschwarze Lïngslinie abgeschuitten. Hinter deren Ende zeigt sich auch das schwarze, 
schräge Strichelchen, das am Aussemrande des granen Gewölks liegt. Unterbalb der schwarzen Längslinie folgt nach einem weissen Zwischenraum allmäliy graues Gewölk bis zum Innenrande, das aber nicht so dunkel ist wie der Costaltleck (was bei Hartmanniana gewöhnlich der Fall ist, nur nicht in Hübner's Fig. 110 [Scriptunu], welcher also Albeolana am besten entspricht). In dem reinweissen Endtheil des Flügels liegen vor der abgerundeten Spitze zwei lichtgraue, gebogene Querstreifen, deren oberster bei Hartmaniana fehlt, Vdrd. auf der Endhälfte mit ein paar grauen Fleckchen bestreut. Fransen weiss, gegen die Flügelspitze grau, durch eine scharfe graue Htrd.-Linie von der Flügelfläche gesondert, die jedoch den Inneuwinkel nicht erreicht.

Htfl. grau, einwärts gelichtet; Fransen weisslich mit grauer Schattenlinie nahe der Wurzel.

Unterseite wie bei Hartmanniana, auf den Vdfl. an der Basis und längs des ganzen Vdrdes. weiss und letzterer mit grauen Fleckchen bestreut.

Wenn Albeolana nicht abändert und sich nicht durch Uebergänge mit Hartmanniana verbindet, so sind ihre Hauptmerkmale die gerundete spitze urd las viel reinere Weiss der Vdfl.

Vaterland: Massachusetts, wo B n rgess das ziemlich gut erhaltene ठ meiner Sammlung mit mehreren an 15. August fing.

Anmerkung. Es ist mir nicht klar, warum man Linnés Worte: Alis cinereis, superioribus linea nigra alloe adnata auf H übner's Scriptana (die zwar auch in Schweden vorkommt) und nicht lieber auf Haworth's Semifasciana anwendet. Fischer v. Föslerstam m, von dessen Urtheil T reits chke sich vielfach leiten liess, besass lange Zeit nur Semifasciana und hielt Scriptana H. für Varietät, bis er im Jahre 1834 in meiner Sammlung eine Anzahl echter Scriptana sah, deren Artrechte er sofort anerkannte. Charpentier scheint umgekehrt Semifasciana nicht gekannt und daher Seriptana für Linné's Hurtmanniana erklärt zu laben. Es mag also eine stillschweigende auf keiner Ueberzeugung beruhende Annahme sein, nach welcher alle Autoren der Hübuer'schen Scriptana die Benenung Hartmanniana L, geben, ohne an der linea nigra albae adnuta, die eigentlich keine der beiden Arten besitzt, Austoss zu nebmen.

Heinemann ertheilt der Hartmanniana (Scriptana), S. 106, August und September als Flugzeit. Die Wahrheit ist, dass der Wickler von len letzten Tagen des Juni an bis in den Anfang des August auf der Rinde der Weidenstämme sitzt.

\section{Penth. nimbatana Clem. Taf. VIII, Fig. 13.}

Media; alis ant. breviovibus, costa convexu, a basi ad tertium trientem usque fuscis, nigro-marmoratis, fuscedine urcutim lerminuta, postice albis vel exulbidis, unte apicem rotundutum vix cinerascentibus. $\sigma^{7}$ ㅇ․

Antithesiu - Clem. Proceed. Ac. Nat. S'c. Plilad. 1860, 1. 346. 
Eine sehr nahe Verwandte der Pruniana, doch weiter von ihr entfernt als Pruneticolana (deren Artrechte etwas zweifelhaft sind), aber verschieden von beilen durch abgerundetere Vafl., an deren Spitze die gelblichweisse Grundfarbe kanm grau getrübt ist, und durch den Mangel des schwarcen Punktflecks, der bei Pruniana mo Pruneticolana an der Mitte des hinteren Randes des Braunen sehr dentlich hervortritt. Ochroleucanu, welche Clemens in der Nimbalunu vermuthet, ist gewöhnlich grösser, immer nit gestreckteren, spitzeren, gesaittigter gelben Vaf., deren Fransen, ansser gegen den Innenwiıkel, grau oder doch graufleckig sind.

1. (bei Pruniana einfarbig Annkelbraun. bei Pruneticolana ein wenig heller) weissgrau mit braungrauem Kragen, dunklem Querschatten über die Mitte und dunkel gelbbrannem Scutellnmshöcker. Mittelbeine wie bei Pruniana dunkelgrau mit schmutzig weisslichbandirter Schiene und braungrauen, an Ende weisslichen Fussgliedern. Hinterbeine trïl, gelblichweiss; Schiene stark zusammengedrückt, auf der Basis aler Rïckenschneide mit einem abstehenden, bleichen Haarbïsehchen.

Vdfl. $33_{4}$ "' lang, ziemlich breit, an Vdrd. etwas convexer als bei Prunianu, mit etwas zugernudeter Spitze, von der Basis an auf $2 / 3$ ein Gemisch von Gelbbraun, schwarzen Fleckchen und violettlichem Grau, mit ein paar trüb weisslichen Stellen. Unter der Subdorsalader liegen fast in der Hälfte dieser dunkelı Farbe zwei weisse Punkte hinter einander, die sich auch vergrössern und zusammenfliessen und daun sich zu einem hellen Fleck bis an den Innenrand ausdehmen. Der Htrd. des Braunen ist convex, doch vicht scharf begrenzt und reicht vom Anfang der Innenrandfransen bis zur Mitte des Vdrdes.; aus ihm steht gar kein schwarzer Punktfleck (wie bei den zwei Verwandten) hervor, wenn auch an der Stelle ein schwarzes Querstrichelchen den Rand des Dunkeln bildet. Von da an ist die Grundfarbe gelbliehweiss. In ihr ist der Vdrd. bis zur Spitze mit kleinen, verloschenen, grauen Flecken oder Punkten bezeichnet. Dicht vor der Flügelspitze liegen ein paar graue, verloschene Querstreifchen an Htrd. herunter, weleher an seiner Apicalhälfte mit einer grauen Linie eingefasst ist. Fransen weiss, ungefleckt.

Htfl. lichtgrau, beim $q$ dumkler; die Fransen weisslich mit grauer Schattenlinie nahe der gelblichen Wurzel.

Unterseite der Vafl. dunkelgrau, am Vard. olne helle und dunkle Flecke, längs des Innenrandes weissliclı wie die Htfl.

Vaterland nach Clemens: Massachusetts, Pennsylvanien, Illinois. Meine Ex. wurden von Burgess bei Beverly in der ersten Hälfte des Juli an verschiedenen Tagen gefangen.

Die Raupe lebt nach Clemens zwischen zusammengezogenen Blättern der Rosensträncher.

A nmerkung. Clemens vermuthete in seiner Nimbalana die Hübner'sche Ochroleucana hauptsächlich woh\} wegen der Raupennahrung. Grade diese ist der beste Grund, warum sie nicht Varietït der Prmiana sein kann, inden Pruniana nnr an Schlehen und Pflaumen lebt. Prunianu fängt zu Fnde 
Mai zu fliegen an und findet sich ganz ausnahmsweise und verflogen noch Anfang Juli. Dieser Monat, den Heinemann neben dem Juni als Flugzeit aufführt, gilt kaum vou Gebirgsgegenden. Nimbatana scheint ibre beste Zeit zu Ende Juni und in den allerersten Julitagen zu haben.

\section{3. (Penth.?) Chionosema n. sp.}

Alis ant. obscure schistaceis, transverse nigro-undatis, macula costae posticae semiovata nivea. ㅇ.

Sehr nahe verwandt mit der europäischen Schreberiana, kleiner, mit weniger dunklen Vdfl, deren schneeweisser Costalfleck weniger weit in die Flügelfläche hineinreicht.

Grösse wie von Exart. albofasciatum. R. (beschädigt) dunkel schiefergrau; der Schuppenhöcker des Scutellums viel kleiner als bei Schreberiana. K. oben und vorn röthlich hellbraun. Taster keulenförmig, zusammengedrückt, etwas über die Stirne hervorstehend, inwendig hell braunröthlich, aussen braun, mit hellem Bande vor der Spitze; Endglied knospenförmig. Beine innen sehr hell staubfarbig: die vorderen und mittleren aussen braun, bellfleckig. Hinterbeine einfarbig; die Schienen verdickt, zusammengedrückt, auf der Rückenschneide mit etwas flach liegenden Haarschuppen obne Flocke (also wie bei Schreberiana). ${ }^{1)}$ Hinterleib fehlt.

Vdfl. 31/4" lang, länglich, wie bei Schreberiana gestaltet, aber mit convexerem Htrd. Grundfarbe dunkel schiefergrau, schwarz quermarnorirt. Ein stumpfwinkeliges Querband bildet die Grenze des fleckigen Basalfeldes. Hinter der Mitte hängז am Vdrd. ein halbeifürmiger, nach hinten gespitzter schneeweisser Fleck, der nicht ganz bis $2 / 3$ der Flügelbreite herabreicht und auf dem Vdrd. mit 6-7 abwechselnd ungleichen, tiefschwarzen Punkten bezeichnet ist; gegen die Flügelfläche ist er breit schwarz eingefasst. Von dem Anfang dieser Einfassung geht durch die Flügelhälfte ein schwarzer Streifen zum Innenrand, und von dem hinteren Ende erst ein schwärzlicher, schwarzgesäumter bis vor den Innenwinkel und dann ein anderer bis zur Mitte des Htrdes., an dem er sich zugespitzt herabzieht. Der von den letzteren z.wei Streifen eingeschlossene graue Raum bildet einen aus dem Innenwinkel aufsteigenden bandförmigen Streifen, der bis über $2 / 3$ der Flügelbreite reicht, am Ende zugerundet ist und ziemlich grade Ränder hat. (Bei Schreberiana ist er liürzer, unregelınässig und wie zerrissen.) Zwischen der schwarzen Flïgelspitze und dem schneeweissen Costalfleck trägt der Vdrd. ein weisses Doppelhäkchen. Htru.-Linie schwarz. Fransen dunkelgrau, am Inneuwiukel bräunlich.

1) Schreberiana $\sigma^{7}$ hat an der Wurzel der Rūckenschneide eine abstehende, gekrūmmte Haarflocke von ${ }^{1 / 3}$ der Schienenlānge (Lederer, Taf. ₹, Fig. 14); aber' in der Seite fehlt die kinne und der darin rulende Haarbusch (wie Heinemann Tortr. S. 103 richtig angibt); sie gehōrt daher und wegen sonstiger Beschaffenheit nicht zu Penthina $\mathrm{Tr}$. 
Htfl. mit abgerundeter Spitze und unter dieser schwach eingedrüclitem Htrd., braungran, in der Spitze am dunkelsten; Vdrd. unter den Vdf. weisslich. Fransen weisslich mit dunkelgrauer Linie nahe der Wurzel durchzogen.

Unterseite der Vdfl, einfarbig schwarzgrau. Der helle Costalfleck sehr scharf, ochergelblich. (Bei Schreberiana schimmert er von der Oberseite verloschen durch, und nur der Vdrd. ist in einer gefleckten Linie ochergelblich.) Htfl. grau, am Vdrd. heller.

Vaterland: Nordamerica. Ein Weibchen in Dr. Rössler's Sammlung.

\section{Eedytolopha n. g.}

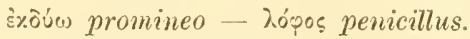

Antennae breves, simplices, setaceae.

Palpi breves, compresso-cylindrici, squamati, articulo terminali brevissimo. Haustellum breve

Pedum posticorum femora ac tibiae compressae, hae robustae, pilis appressis, apicem versus productis vestitae.

Scutellum tuberculo squamoso instructum.

Fasciculus o analis tumidus, rotundatus.

Alae anteriores angustae, subobtusae, sine revolucro $\sigma^{\top}$, macula obscura triangula anguli interni pictae, speculo nullo; venis apicalibus separatis.

Alae posteriores latae, vena mediana trifida, rami tertii basi a venae quartae origine distante; supcrne penicillo ex sulco juxta venae medianae basim eminente.

Das wesentliche, aber sicher nur dem ơ eigenthümliche Merkmal besteht in dem gelblichen Pinsel, der auswärts an der Wurzel der Medianader aus einer Furche hervorragt und nicht mit der anders gefärbten Behaarung der Medianader verwechselt werden darf; an dieser Stelle sind auch die Adern gleichsam etwas verkrüppelt, weshalb der Flügel hier Längsfalten wirft.

Der Schuppenwalst auf dem Scutellum, der Mangel eines Umschlags und die Färbung der Vdfl.: von der Basis aus dunkel, am Ende hell, mit einem schrägen, dunklen Strich am Htrd. unterhalb der Flügelspitze - weisen diese Gattung in die Verwandtschaft von Penthina Tr.

Erd. insiticiana n. sp. Taf. VIII. Fig. 20.

Magna; alae ant. angustae, fuscae, postice albidae, fuscedinis termino oblique ex dorso medio extrorsus adversus costam adscendente, albedine nitidule transverse undulata, macula parva triangula fusca anguli dorsalis. o’.

In der Flügelgestalt, selbst in der Zeichnung des Endtheils der Vdfl. hat diese Art einige Aehnlichkeit mit der gegen sie zwerghaften Tmet. ocellana; sie weicht aber von ihr sowie von allen Penthinen ab durch die scluräg answärts vom Innenrand nach dem Vdrd. aufsteigende Grenze des braunen Wurzelfeldes.

Viel grösser als die grösste Penth. salicella. R. und K. braun. Taster wenig über die Stirn hervorragend, aussen braun, innen hell. Wulst des Scutellums dunkelbraun. Hinterleib bräunlich staubgrau, ziemlich schlank, nach 
binten besonders an den Seiten lockerschuppig; der helle Analbusch stark, abgernndet, breiter als lang. Beine staubgrau; Mittelschienen aussen dunkel mit hellem Mittelbändchen und solchem Ende; Füsse an den vier Eudgliedern etwas verdunkelt, mit verloschenen, hellen Spitzen.

Vdfl. 5-6 $6^{\prime \prime}$ lang, sehmal, nach hinten erweitert; Vdrd. fast grade; Spitze zugerundet; Htrd. schwach convex, wenig zurückgehend. Grundfarbe auf mehr als der Basalhälfte braun, dunkler marmorirt, grob- und lockerschuppig; diese Farbe hat eine von der Mitte des Innenrandes schräg nach $2 / 3$ des Vdrdes. gehende Grenze und verlängert sich hier schmal bis in die Flügelspitze, vor welcher ein braunes, tiefschwarz gesäumtes Streifchen, das nicht immer vollständig ist, bis zur Mitte des Htrdes. herabgeht. Der Vdrd. ist undeutlich heller und dunkler gestrichelt. Die übrige Farbe des Flügels ist schmutzig weisslich oder hellgrau, mit helleren, etwas schimmernden, unregelmässigen Querwellen, welche ans grösseren und lockerer liegenden Schuppen bestehen als der matte Grund. Im Innenwinkel ist auf dem Innenrand ein kleiner, nach oben gespitzter, brauner, mehr oder weniger tiefschwarz verdunkelter Fleck. Fransen an der Flügelspitze braun, tiefer abwärts dunkelgrau, undeutlich gefleekt, an der unteren Hälfte weisslich oder lichtgrau, wie der angrenzende Flügeltheil.

Htfl. braungran, gegen die Basis wenig gelichtet. Der Haarpinsel sehr hellgelb. Fransen weissgrau, nalie an ihrer gelblichen Wurzel mit einer dunkelgrauen Schattenlinie durchzogen.

Unterseite der Vdfl. dunkelgrau, auf der Endhälfte des Vdrdes. mit braunen Fleckehen in gleichen Entfernungen: Htrd. lell mit braunen, verloschenen, schräg gegen ihn herabgehenden Querlinien. - Htfl. lichtgrau, am Vdr.- und Htrd. mit verlosehenen braunen Strichelchen. Ader 5 entspringt, weit von der Medianader getrennt, aus der sehr feinen oder vielleicht nicht vorhandenen Querader und steht von 4 und 6 fast gleichweit ab.

Vaterland: Massachusetts (Burgess). Die 5 o meiner Sammlung wurden zwischen 16. Juni und 18. Juli gefangen, und scheinen keiner sehr seltenen Art anzugehören; jedoch erhielt ich kein ․

\section{Tmetocera Lederer.}

Der Ausschnitt des $\sigma^{7}$ Fühlers ïber dem Wurzelgliede ist schwach und nur in gewisser Riehtung gut sichtbar; sein oberes Ende wird durch ein Knötchen bezeichnet.

Ocellıma Fabr. Heinemann S. 206. Wilkinson p. 118.

Grapholitha oculana Canadian Entomologist 3, p. 13, Fig. 9.

Zn den besten Merkmalen der in der Färbung des hellen Vdfl.-Theiles veränderlichen Art gehört das kleine, braune, schwarzfleckige, an seiner Spitze tiefschwarze Dreieck dicht vor dem Innenwinkel und die 3 oder $3 \frac{1}{2}$ tiefschwarzen Längsstriche auf dunklem Grunde vor und unterhalb der Flügelspitze. 
Die zwei vorliegenden $\sigma^{7}$ sind klein und gehören zu der hellen gewöhnlichen Färbung; nur ist das eine auf der Costallälfte des Weissen graugewölkt. Ich erhielt letzteres von Speyer aus New-York, das andere von Packard mit der Angabe: Salem, 1. Juli.

Ich bezweifle nicht, dass die Art in Nordamerica eingewandert ist und dort ebenso abändert wie bei uns. Der Holzschnitt im Canad. Ent. stellt die gewöhnliche Färbung recht kenntlich dar. Nach der hier von W. Saunders gegebenen Auskunft ist die Raupe, die in Aussehen und Lebensweise ganz mit der europäischen übereinstimmt, in Canada in den kleinen Gärten dem Obst sehr verderblich.

Der Name Gr. oculana scheint aus irgend einer mir nicht bekannten (Garten?) Schrift genommen zu sein.

\section{Exartema Clem. Eccopsis Led. $\left.{ }^{1}\right)$}

Schildchen mit schwachem Schuppenwulst. Vdfl. ohne Uinschlag, mit der Zeichnung von Sericoris. Htfl. des $\sigma^{\nearrow}$ an der Wurzel des Innenrandes mit linienförmigem Hautanhang.

Diese Gattung, die bei uns nur mit einer, oder wenn mit Lederer S. 374 seine Cymolomia Hartigiana dazu gezogen wird, mit zwei Arten vertreten ist, kann in Nordamerica nicht arm an Arten sein. Dass Clemens das Genus Exartema später einzog, mag weniger daher kommen, dass er den Werth des Hauptmerkmals verkannte, als weil er bei Wilkinson keine entsprechend charaterisirte Gattung fand. ${ }^{2}$ )

Auffallend ist mir, dass, während ich sieben nordamericanische Arten kenne, mir nicht eine aus Texas vorliegt.

Exartema erfordert nach den Sprachregeln die Speciesnamen im sächlichen Geschlecht.

1. Exart. quadrifidum n. sp. Taf. VIII, Fig. 14.

Alis ant. acutis, margine postico infra apicem subimpresso, griseo-fuscescentibus, dorso lituraque costae mediae obscuratis, vena mediana exalbida in ramos 4 tenues albos fissa, stria marginali obliqua fuscescenti obsoleta. $\delta$.

Die grösste mir bekannte Art, kenntlich an der verstärkten, schmutzig weisslichen Medianader der Vdfl, deren vier sehr feine Aeste mehr oder weniger deutlich und gleichfalls hell sind.

1) Wickler in d. Wien. Zeitschr. 1859, S. 288. Meine Gattung Eccopsis (Micropt. Caftr., p. 79) kann es nicht sein, wenn ihr wirklich der Hautanhang fehlt; ich habe keinen bemerkt, und da ich Irein Es. der africanischon Art besitze, so wird das Stockholmer IIuseum am ersten entscheiden kōnneu, ob ich ihn übersehen, oder mit Recht unerwähnt gelassen habe.

$\left.{ }^{2}\right)$ So ühergenau auch Wilkinson die Länge der Tasterglieder mass und das Flügelgeäder untersuchte, nm die schlechten Gu $\theta$ né'schen Generi zu begründen, so hat er doch an der ihm ganz wohl bekannten Latifasciana den Hautanhang nicht gesehen. 
R. und K. gelbbräunlich, Gesicht heller. Taster von doppelter Kopflänge, anfgebogen und bis zur Höhe der struppigen Scheitelhaare heraufreichend, cylindrisch, zusammengedrückt, schmutzig gelblichweiss; Endglied etwas hervorstehend. Beine von der Farbe der Taster; die vier vorderen auswärts braungrau, an den Enden der Glieder und in einem Mittelbändchen der Schienen weisslich. Hinterbeine unverdunkelt; die Scbienen stark zusammengedrückt, auf der Rückenschneide mit langen, locker aufliegenden Haaren ziemlich reichlich bekleidet, auf der Innenseite in einer Furche mit langem, schwärzlichem Haarpinsel. Hinterleib dünn, grau; Analbusch bleich ochergelb, fast doppelt so lang wie breit, nach hinten erweitert.

Vdfl. über 4" lang, etwas gestreckt, nach hinten erweitert, am Vdrd. schwach convex, mit ziemlich scharfer Spitze, unter ihr an dem ziemlich graden und steilen Htrd. schwach eingedrückt, mit wenig deutlichem Innenwinkel. Gruudfarbe graugelbbraun, mit hellen Schuppen überstreut und dadurch hell erscheinend; am Innenrand bis zur Falte fehlen die Schuppen, und so ist die Farbe hier dunkel gelbbraun, nach hinten ins Helle übergehend. Ein grosser Wischfleck, eigentlich die wegen der lichten Schuppen bis zur Medianader reichende Mittelbinde, nur nach hinten erweitert, hat dieselbe gelbbraune Färbung. Die Medianader erscheint als ein heller, schmutzig gelblichweisser Längsstreifen, der von der Schulter anfängt und sich in vier feine, weniger helle Aeste auflöst; von diesen Aesten sind die zwei untersten die deutlichsten und etwas abwärts gekrümmit der oberste ist der kürzeste, undeutlichste und wie der zweite grade; keiner erreicht den Htrd. Der gelbbraune Querstreifen, der bis unter die Mitte des Htrles. herabreicht, ist durch die dichte, ihm aufliegende Beschuppung sehr verloschen. Der Vdrd. ist von der Wurzel aus, doch bis zur Mitte undeutlich, mit allmälig längeren, gelbbraunen Querstrichelchen gezeichnet, zwischen welchen der Vdrd. selbst blass gelblich ist. Die Flügelspitze enthält einen uudeutlichen braunen Fleck, der auswärts auf den Fransen etwas röthlich schimmert. Fransen hell, nahe der gelblichen Wurzel mit einer graueu Linie durchzogen und an der Endhälfte noch dunkler grau; im Innenwinkel sind diese Färbungell ganz verloschen, und ihre Farbe daher hell.

Ftfl. hell braungrau, gegen die Wurzel allmälig hellgrau. Das Anbängsel ist streifenförmig, hell, gefranst; das anliegende kleine Feld des Flügels mit duukelgrauen Schüppchen belegt. Fransen weissgrau, dicht an der gelblichen Wurzel mit grauer Schattenlinie durchzogen.

Unterseite der Vdfl. dunkelgrau, an der Endhälfte des Vdrdes. ziemlich breit bleichgelb mit dünnen, dunkelgrauel Querstrichelchen. Htfl. einfarbig weissgrau.

Vaterland: Massachusetts. Burgess fing am 6. Juli mehrere, von denen das beschriebene $\sigma^{\top}$ in meiner Sammlung ist. 


\section{Exurt. exoletum n. sp.}

Alis ant. acutis, margine posticn infra apicem non impresso, pallide fuscescenti-griseis, crebrius fuscescenti-strigulatis, puncto apicis rotundato nigro, litura fusca ex dorso ante medium oblique adscendente. $\sigma^{7}$.

Ich hin nicht sicher, ob dies nicht eine blosse dbänderung des Exart. quadrifidum ist, von dem es sich hauptsächlich durch den Mangel der hellen Adern auf den Vdfl. unterscheidet.

Ex. exoletum ist bedeutend kleiner als Quadrifudum. Die Vdf. sind nämlich nur 31/2"“ lang, im Bau zwar sonst gleich; nur ist der Htrd. gänzlich ohne Einbiegung unterhalb der Spitze, also gleichrässig schwach convex. Die Grundfarbe der Vdf. ist heller, licht bräunlich staubgrau, reichlich mit braunen Querstrichelchen wellig überzogen (jedoch bei dem einen Ex. blässer und weniger gedrängt, als bei dem zweiten). Die Adern entbehren gänzlich der helleren Färbung. Ader 3 hat zwar deutlich die Krümmung wie bei Quadrifudum, ist aber am Ursprung von Ader 4 völlig getrennt, also nicht wie dort mit ihr an der Wurzel zusammengeflossen. Voin Innenrand, nahe der Basis, erhebt sich, schräg gegen die Mitte des Vdrdes. gerichtet, ein bindenförmiger, brauner Wisch, der bis über die Falte hinwegreicht und sich dem dunklen, doch verloschenen Nebel der Costalmitte anschliesst. In der Flügelspitze liegt ein starker, schwarzer Punktfleck, und vor ihm trägt der Vdrd, einige wechselnd breitere und schmälere Querstrichelchen. Von dem Querstreifen, der von der Htrd.-Mitte schräg zum Vdru. zieht, lässt sich nur bei dem weniger dunkel gestrichelten Ex. eine Spur entdecken. Fransen hellgrau, über der Nitte an der Aussenhälfte fleckartig braun.

Htfl. auffallend spitzer als bei Quadrifidum, dunkler branngrau und gegen die Basis weniger gelichtet. Fransen nicht verschieden. Anf der Unterseite sind diese Flügel dunkler grau.

Vaterland des von Packard erhaltenen Ex. Massachusetts; das des anderen, in Dr. Rössler's Sammlung befiudlichen, ist mir unbekannt.

\section{Fxart. nitidunum Clem. Taf. VIII, Fig. 15.}

Alis ant. dilute cinereo-purpureis, macula dorsi ante medium, fascia media postice tridentata striaque obliqua ovata ante marginem posticum medium nigro-bunneis, pallide tenuiter marginatis. O’.

Exartema nitidana Cl. Proceed. Ac. Nat. Sc. Philad. 1860, p. 356.

Sericoris - Cl. Proceed. Ent. Soc. Philad. 1865, p. 133.

Obgleich ich nicht zweifeln darf, dass mein Ex. mit dem Clemensschen zu einerlei Art gehört, so finde ich es doch, da kleine Abweichungen obwalten, rathsam, selbst eine Beschreibung zu verfassen. Grade die hell purpurrothe Grundfarbe ist für die Art "sehr charakteristisch; Clemens bezeichnet sie 1860 passend dull sordid crimson, dagegen 1865 reddish brown, als ob er nicht mehr dieselbe Art vor sich gehabt laätte. 
Nitidanum ist kleiner als Quadrifidum, mit gleichfalls etwas gestreckten, aber nach hinten weniger erweiterten und stumpferen Vdfl., ganz obne linbiegung des Htrdes.

Die Grundfarbe ist ein angenehmes, blasses Purpur- oder Karminroth, etwas mit violettlichem Grau, am reichlichsten auf der Basalhälfte gemischt. Die Zeichnungen sind tief gelbbraun. Näher der Mittelbinde als der Basis trägt der Innenrand einen bis zur Medianader reichenden, oben nach hinten gebogenen, auf der hinteren Seite seicht ausgehöhlten Fleck. (Von einem gleichfarbigen Streifen [streak] über demselben zeigt mein unverwischtes Ex. keine Spur). Die Mittelbinde ist in den oberen $2 / 3$ ziemlich schmal, im untersten Drittel doppelt so breit und in der Mitte durch eine gelblichweisse Längslinie fast zerschnitten; ihr Basalrand ist wellig, tief ausgebuchtet, am tiefsten an der Stelle, wo die gelblichweisse Linie in sie hineintritt; auf der abgewendeten Seite zeigt sie bei $1 / 3$ einen scharfen Zahn, an der Mitte einen grüsseren, schlecht abgerundeten (unter welchem sie einen tiefen Einschnitt hat) und nahe am Innenrande einen breiten, zugespitzten. Der schräge Keilstreifen erweitert sich stark, ist mit einem Costalfleck durch eine feine Linie verbunden und berührt mit seinem unteren, verschmälerten und gelichteten Ende den Htrd. unter der Mitte. Diese drei Zeichnungen sind, doch theilweise undeutlich oder wirklich nnterbrochen, mit einer feinen, hellen Linie eingefasst. Vor dem Innenwinkel ist ein kleines, belles, leicht zu übersehendes Dreieck. Der Vdrd. ist von der Wurzel bis zur Mitte etwas undentlich gelbbräunlich gestrichelt, hinter der Mitte bis zu dem nicht recht scharfen Apicalfleckchen deutlicher; zwischen diesen Strichelchen liegen in gleichen Abständen drei gelbbraune, dreieckige Fleckchen, etwas schräg nach hinten gerichtet; das erste ist dasjenige, welches mit dem Keilstreifen zusammenhängt. Eine gelbbraune Linie, die unterhalb des Keilstreifens verschwindet, fast den Htrd. ein. Die Fransen sind röthlichgrau, am hellsten am Innenrande; an der Flügelspitze und dem Keilstreifen gegenüber braun, ausser an der Wurzel.

Htfl. (nach Cl. dark fuscons) ziemlich hell braungran, gegen die Wurzel heller, an der Wurzelhälfte des Vdrdes. grauweiss. Fransen an der Flügelspitze dunkelgrau, sonst weissgrau, mit einer grauen Linie nahe der gelblichen Basis durchzogen. Das behaarte Anhängsel ragt bis ans Ende der Fransen des kleinen angrenzenden Flïgelfeldes. Ader 5 entspringt ziemlich nahe an 4, doch etwas höher, aus der Querader.

Unterseite der Vdf. dunkelgrau; Vdrd. streifenartig bleichgelblich, von feinen, braunen Querstrichelchen durchschnitten und mit vier grösseren braunen Flecken, deren grösster auf der Mitte liegt.

Die Hinterschiene scheint auf dem Rücken auch eine Furche mit schwärzlichem Haarbusch zu baben.

Vaterland: Maine oder Massachusetts (Packard). Ein gut erhaltenes $\sigma^{\pi}$ in meiner Sammlung. 


\section{Exart. albofasciatum n. sp.}

Alis ant. albis, area basali fasciaque lata media fusco, nigro plumbeoque mixtis, costa postice alba, nigro-strigulata, stria marginali obliqua fuscolutea. $0^{7}$.

In der Färbung und Zeichnung schon ganz wie die gewöhnlichsten Sericoris-Arten, von dieseu, so wie von den anderen Exartema-Arten durch die als weisse Binde vor der Mitte hervortretende Grundfarbe und die weiss und schwarzwechselnde Vdrd.-Zeichnung zu unterscheiden.

Grösse der Seric. cespitana. R. und K. schwarzbraun, ersteres weisslich gefleckt. Taster um eine halbe Kopflänge hervorstehend, länglich, zusammengedrückt, mit abstehender Behaarung, weiss, obenauf graugetrübt; Endglied dünn, stumpf, hervorstehend. Beine unrein gelblichweiss; die vier vorderen und alle Füsse aussen schwärzlich, weissgefleckt; die Hinterschienen zusammengedrückt, durch die reichlichen, langen, locker liegenden Haare auf der Rückenschneide erweitert, auf dem Rücken mit schwarzer Längsfurche. Hinterleib grau, an den Enden der Seginente locker haarschuppig; Analbusch mässig, bleich ochergelblich.

Vdfl. 3-31/2" lang, länglich, wenig nach hinten erweitert, am Vdrd. mässig convex, am Htrd. mit schwacher Concavität. Die weisse Gruudfarbe nimmt kaum $1 / 3$ des Flügelraumes ein und zeigt sich vorzüglich als Band vor der Mitte. Das Basalfeld ist klein, von etwa $1 / 5$ der Flügellänge, braun, mehr oder weniger mit bleigrauen und schwarzen Flecken querdurchzogen und (nicht immer) mit gelblichen Haarschuppen bestreut; der Htrd. dieses Feldes ist unregelmässig convex. Die folgende weisse Binde ist ebenso breit oder schmäler, oben am breitesten, mit 2-3 schwarzen Costalpunkten und ein paar schwärzlichen, unregelmässigen Punkten in der Mitte. Auf sie folgt die breite, braune, schwarzfleckige und mit Bleistreifen durchzogene und mehr oder weniger mit lehmgelben Haarschuppen bestreute Mittelbinde; bei genauer Betrachtung ist sie am Vdrd. schmal wie gewöhnlich und scheint nur so breit, weil Bleigran sie hinten oberwärts bis zu den Costalflecken säumt und diese als einen Theil der Binde erscheinen lässt; eben so erscheint der halbeiförmige, aufrechte, schwarzbraune, gelbbestreute Dorsalfleck vor dem Innenwinkel, weil er nur durch einen dünnen Bleistreifen von der Binde geschieden ist, als ein Theil der letzteren. Der schräge Keilstreifen ruht mit seinem verbreiterten Untertheil anf dem Htrd. unter der Mitte und ist braun, mit lehmgelben Schuppen theilweise verdeckt. Zwischen ihm und dem Halbeifleck des Innenrandes bildet die Grundfarbe einen aus dem Innenwinkel aufsteigenden, schrägen, zugespitzten Streifen, der in der Mitte durch bleigrau getrübt ist. Vdrd. bis zur Spitze weiss mit abwechselnd schmalen und breiten, schwarzen Schrägstrichen. In der Flügelspitze ist ein schwarzes, gerundetes Fleckchen an der braunen, unterwärts verlöschenden Htrd.-Linie. Fransen weiss, an der Flügelspitze braun, tiefer abwärts mit einem solchen Fleckchen und am Keilstreifen breit schwarzbraun; tiefer bleibt die Farbe bis zum Halbeifleck rein. 
Htfl. braungrau, nur an der Basalhälfte des Vdrdes. weisslich. Fransen weisslich, mit einer deutlichen grauen Linie nahe an der gelblichen Wurzel durchzogen. Das behaarte, weissgraue Anhängsel reicht bis über das Ende der Fransen. Ader 5 entspringt fast dicht an 4.

Unterseite der Vdfl. braungrau, im Dorsalfelde weisslich; der Vdrd. schmal weisslich gefleckt, die Flecke durch Braun getrennt und jeder durch einen braunen Querstrich durchschnitten. Httl. weissgrau; die Fransen heller, ohne dunkle Linie.

Vaterland: Ohio (Schläger); Illinois (Lederer). Drei $\sigma^{\top}$ in meiner Sammlung.

Anmerkung. Exart. fasciatana Clem. (Proc. Acad. Pbilad. 1860, p. 357) kann nicht wohl meine Art sein, welche kein silvery white band hat (nur im Sonnenschein schimmert das weisse Band, so wie auch die Fransen und noch mehr die Bleistellen), und bei welcher der Keilstreifen nicht bis zam Vdrd. reicht, sondern von dem Costalstrich, gegen den er gerichtet ist, deutlich getrennt bleibt oder höchstens mit ihm durch eine feine Linie verbunden wird.

\section{Exart. permundanum $\mathrm{Cl}$.}

Alis ant. area basali, fascia media postice tridentata, macula semiovata anguli dorsalis striaque marginali obliqua luteo-brunneis, pallide marginatis, spatiis interjectis angustis, plumbeis. $\sigma^{\top}$ 오.

Exartema permundana Clem. Proc. Ac. Philad. 1860, p. 356.

? Sericoris - Clem. Proc. Ent. Soc. Philad. 1865, p. 134.

Dadurch, dass alle dunkle Zeichnungen der $\nabla$ dfl. hell gesäunt sind, hat diese Art eine gewisse Aehnlichkeit mit Sericoris rivulana (conchana H.), und sie unterscheiden sie von den anderen Exartema-Arten. Nur bei dem auch sonst nicht ähnlichen, hell purpurfarbenen Nitidanum hat die Mittelbinde drei Zähne; bei dem näher rerwandten Appendiceum sind die trüben, verflossenen Zeichnungen nicht hell gesäumt.

Etwas grösser als Albofasciatum, in der Färbung etwas veränderlich; wenigstens ist mein einzelnes $q$ bedeutend dunkler, wofür die hellen Einfassumgen der Zeichnungeu desto reiner hervortreten.

K. mit etwas aufgerichteten Haaren, heller als das gelblichbraune R., im Gesicht noch heller. Taster hellgelblich, fast um Kopfläng $\theta$ hervorstehend, beim $ᄋ$ dünner als beim $\sigma^{\nearrow}$, besonders unten behaart; die Endhaare des zweiten Gliedes mit bräunlicher Spitze; das hervorstehende Endglied dunkelbraun. Vorderbeine gelbbraun, hell gefleckt; Mittelschienen verloschen braun und hell gezeichnet; Hinterschienen zusammengedrückt, grau, auf der Rückenschneide dicht mit langen, etwas aufgerichteten Borstenhaaren gefranst; Hinterfüsse dunkler grau mit hellen Enden der Glieder. Hinterleib dunkelgrau mit hellerem, länglichem, reichlichem Analbusch des $\sigma^{x}$; beim $\$$ ist er kurz, von der braungrauen Farbe des Hinterleibes und hat am vorletzten Segment zu jeder Seite ein hellgelbes Büschchen. 
Vdfl. $33^{3} "$ lang, wie bei Albofasciatum gestaltet. Als Grundfarbe, die zwischen den Zeichnungen selır eiıgeengt ist, muss man die hellen Sänme derselben und die von ihnen eingesclilossene schwach glänzende Bleifarbe ansehen. Die Zeichnungen sind gelbbrann, beim $\sigma^{\pi}$ theilweise mit lehmgelben Haarschuppen verdeckt, beim $q$ rein, mit braunen scharfen Rändern, so dass bei ihm ihre Gestalt recht deutlich ausgedrückt ist. Der Htrd. des Wurzelfeldes ist in der Mitte eckig, bein $q$ etwas unregelmässig. Der bindenförmige Raum der Grundfarbe zwischen ihm und der Mittelbinde ist schmal, am Vdrd. über das Basalfeld lin gegen die Wurzel erweitert. Die Mittelbinde ist auf der Basalseite wellig, saumwärts über der Mitte mit zwei starken, spitzen Zähnen; unterhalb des zweiten ist sie sehr zusammengezogen, dann wieder erweitert und mit einem. kurzen breiten Zahn auf der Subdorsalader versehen. Der halbeiförmige Fleck des Innenwinkels reicht ziemlich nahe an die Mittelbinde heran und lässt auch zwischen sich and dem Mittelzahn derselben and ebenso zwischen sich und dem Keilstreifen uur einen schmalen Raum. Der schräge Keilstreifen, der unterhalb der Mitte auf der braunen Htrd.-Linie ruht, erweitert sich nach oben etwas und steht beim $\sigma^{7}$ durch einen dünnen Hals, beim $q$ nur durch einen hellen Faden mit dem ersten der drei gelbbraunen Costalfleckchen in Verbindung. Die Costalfleckchen, welche zwischen sich helle Ocherfarbe mit dünnem, brannen Querstrich haben, spitzen sich nach unten und linten zu. Alle Räume zwischen den gelblichgesäumten Zähnen und Flecken sind, wie schon angegeben, mit Bleifarbe ausgefüllt. In der Flügelspitze ist ein braunes, nicht scharfes Fleckchen, und an diesem die gelblichen Fransen schwarzbraun. Einen jedoch lichteren Fleck tragen die Fransen auch an Keilstreifen. Beim $q$ sind sie aber ganz braungrau, unr an Innenwinkel ein wenig heller.

$\mathrm{Httl}$. des $\sigma^{\nearrow}$ bräunlichgrau, gegen die Wurzel sehr gelichtet; beim 오 einfarbig graubraun. Fransen weisslich, beim $q$ grau, an der gelblichen Wurzel mit einer dunkelgrauen Linie durchzogen. Das Anhängsel des $\sigma^{\gamma}$ reicht bis ans Ende der Fransen des Innenwinkels. Beim $Q$ sind die Felder der freien Innenrandadern gar nicht ungewöhnlich verkürzt. Ader 5 entspringt nahe an 4 .

Unterseite der $V d \theta$. braungrau, am $V$ drd. des $\sigma$ mit 6 , des $q$ mit 4 gelblichen, von je einem brannen Querstrich durchschnittenen Fleckchen. Htt. heller als auf der Oberseite.

Vaterland: Missouri (Riley), Washington (Osten-Sacken). $\sigma^{\pi}$ und $q$ in meiner Sammlnng.

Anmerkung 1. Ein $\sigma^{\nearrow}$ aus Illinois unterscheidet sich wahrscheinlich als eigene Art durch Folgendes: Alle Flügel sind breiter, die hinteren einfarbig hell graubraun, die vorderen lieller und von gelblicherem Ton' als bei der beschriebenen Art. Die helle Binde hinter dem Bisalfelde ist am Vorder- und Innenrand erweitert, enthält gar keine Bleifarbe und ist hell ochergelb, gar nicht vorn und hinten durch scharfe, hellere Linien begrenzt. Auch sind die Zeichnungen im hinteren Flügelraum ıur undeutlich hell gesäumt, so dass die Zwischenräume breiter scheinen. Der Keilstreifen ist oben plützlicher erweitert. Der Anaibusch ist länger nud bleichgelblich. 
Anmerkung ?. Clemens gibt an der zweiten Stelle eine Diagnose, die nicht zu der Beschreibung an der ersten stimmt: "Vdrd. an der Basis ocherweisslich, ohne scharfe helle Räume hinter deın Basalfleck (das sinnlose fascal wohl Druckfehler für basal) und hinter der Mittelbinde". Ich besitze ein schlecht erhaltenes $\sigma^{\nearrow}$ aus Ohio, auf welches diese Bezeichnung ziemlich gut passt; es ist sicher von Permundanum verschieden, aber zur Beschreibung nicht gut genug.

Anmerkung 3. Als Synonym zu Sericoris permundana Cl. führt Grote Walker's Sciaphila Meanderana (!) XXVIII, p. 341 auf (Trans. Am. Ent. Soc. 1868). Aus der Beschreibung lässt sich, nm fon Anderem zu schweigen, die Angabe: Forewings with transverse black streaklets nicht auf die rorliegende Art anwenden.

\section{Exart. appendiceum n. sp.}

Alis ant. area basali, fascia media superius nigro-fusca, macula semiovata anguli dorsalis striaque marginali obliqua fuscescentibus squamisque lutescentibus obtectis, fascia ante medium angusta, pallida, fuscescenti-strigulata, spatio anguli dorsalis albido, nitidulo, puncto apicali nigro. o 9 .

Eine unscheinbare Art, von oberflächlichem Aussehen der Sericoris lacunana oder noch mehr der Lucivagana. Sie mag dadurch etwas abändern, dass sich die gelben Schuppen abreiben, wodurch dann die Zeichnungen in schwarzbrauner Färbung hervortreten. Bein $\sigma^{7}$ (wenigstens dem einzelnen Ex., das ich besitze) zeichnet sich das Anhängsel der Htfl. durch seine Länge aus, indem es über die Fransen des Aualwinkels hervorsteht und das Aussehen eines verkümmerten Beines hat. Auf den Vdfl. hat die Art das auffallende, schwarze, gerundete Fleckchen in der Spitze mit Albofasciatum gemein; die Binde hinter dem Basalfelde ist schmal, hellgrau, mit braunen Querstrichelchen bestrent; am weissesten and etwas schimmernd ist der zugespitzte Streifen, der sich, ans dem Innenwinkel schräg aufwärts steigend, allmälig zuspitzt.

Kleiner als Permundanum, von derselben Gestalt der Flügel, nur die hinteren ein wenig spitzer. R. und K. trüb graubraun, blassgelblich gemischt; Gesicht des $\sigma^{7}$ weisslich. Taster um die halbe Kópflänge hervorstehend, länglich, unten und am Ende behaart, weisslich, beim $Q$ dunkler; das Endglied bervorstehend, nicht dunkler. Vorderbeine brann, hellfleckig. Hinterbeine bell, staubgrau, ziemlich kräftig, zusammengedrückt, beim $Q$ auf der Rückenschneide mit reichlichen, sehr geneigten Haaren, beim $\sigma^{\top}$ auf der Innenseite mit einer Längsfurche, die einen langen, schwärzlichen Haarbusch einschliesst; die vier letzten Fussglieder grau mit hellen Enden. Analbusch des 9 kurz und braungrau, des $\sigma^{\nearrow}$ länglich, bleichgelblich, au der Wurzel obenauf grau.

VdA. $3 \%_{4}^{\prime \prime ~ l a n g, ~ i n ~ d e r ~ G e s t a l t ~ w i e ~ b e i ~ P e r m u n d a n u m, ~ t r u ̈ b ~ g r a u g e l b-~}$ bräunlich, auf den sebr beschränkten lichten Stellen ins schutuigweissliche. Das Wurzelfeld ist durch braune Querstriche marmorirt und hinten in der Mitte eckig begrenzt. Die schmale, darauf folgende, helle Binde. beim $\sigma^{\nearrow}$ deutlicher braun quergestrichelt als beim $q$, erweitert sich am Vorder- und Innen- 
rande. Die Mittelbinde liegt in ihrem ersten Drittel schräg; dann ist sie am breitesten und hat eine fast senkrechte Richtung, worauf sie sich am untersten Drittel wieder verengt: in der obersten Hälfte ist sie dunkelbraun, dann wie die zwei folgenden Zeichnungen - durch gelbliche Schuppen verdeckt, und an der hintersten Ecke der breitesten Stelle befindet sich ein undeutlicher, schwarzer Punkt. Der Halbeifleck des Innenwinkels ist breit, von der Mittelbinde durch einen schmalen hellen Streifen getrennt. Der schräge Keilstreifen ist breit, nach oben etwas verengert, mit der breiten Basis auf dem Ende der feinen, schwarzbraunen Htrd.-Linie aufliegend. Beide Flecke schliessen einen weisslichen, etwas schimmernden, länglich dreieckigen, auf dem Innenwinkel ruhenden Streifen ein, an welchem auch die Fransen am hellsten sind, während sie darüber die Farbe des Keilstreifens haben und an der Flügelspitze am dunkelsten sind. Der Vdrd. ist von der Wurzel aus braun gestrichelt, hinter der Mitte auf hellem Grunde; hier liegen drej dreieckige Fleckchen, mit je einem braunen Strichelchen zwischen sich. In der Flügelspitze ist ein schwarzer, nicht recht scharf begrenzter Punkt.

Htel. braungrau, gegen die Wurzel gelichtet. Fransen weisslich, von einer scharfen, graven Linie an der gelblichen Wurzel durchzogen. Ader 5 entspringt etwas höher und gesondert von 4. Der freie Hautstreifen reicht bis über die Fransen des Analwinkels hervor.

Unterseite der Vdfl. braungrau; der Vdrd. mit fünf hellen, braun unterbrochenen Streifchen.

Vaterland: Massachusetts. Ein $\sigma^{\top}$, ein $q$, von Burgess bei Beverly am 10. Juli gefangen, in meiner Sammlung.

\section{Phaceasiophora Grote.}

Diese, durch die beim $\sigma^{x}$ dichtwolligen, wie in einen Schimmelpelz gehüllten Hinterschienen ausgezeichnete Gattung gehört, wie Clemens richtig erkannte, zu den Sericoriden, weil die Vdfl. drei dunkle Costalfleckchen vor der Spitze und ein Basalfeld, eine Mittelbinde, einen Keilstreifen am Htrd. und einen Halbeifleck (auf dem Innenrand dicht vor dem Innenwinkel) haben. Da das $\$$ gewöhnlich gebildete schienen hat, so sind die beiden Geschlechtern gemeinschaftlichen Merkmale: aufsteigende, dem Gesicht anliegende, dicht beschuppte Taster mit deutlichem Endglied - Schildchen mit Schuppenwulst Hinterleib stark und weit über die Htfl. hinausreichend. - Der Keilstreifen der Vdfl. den Htrd. mit zwei Spitzen berühlend. (Dass das Wurzelfeld und die Mittelbinde vom Innenrande scharf getrennt bleiben, und der Halbeifleck sehr nach innen geneigt ist, mag vielleicht nicht generisch sein.)

Phaec. mutabilana Clem.

Sericoris mutabilana Cl. Proc. Ent. Soc. Philad. 1865, p. 135.

Phaecasiophora - Grote: Bulletin of the Buffalo Soc. of Nat. Sc. I (1873), p. 90 , t. 2, Fig. 4-6. 
Aus Clemens' Worten bätte ich diese Art sicher nicht erkannt. Das Basalfeld der Vdfl. ist nur am Enddrittel dunkel und gegen den Innenrand fein hellgesäumt und dadurch scharf begrenzt. Dass die Mittelbinde unterhalb der Falte abgeschnitten und weisslich gesäumt ist, übersieht $\mathrm{Clcmens,} \mathrm{und} \mathrm{auf}$ das whitish discal dot legt er ein zu grosses Gewicht. Der Keilstreifen, den er als vollständige Binde behandelt. ist nur ungewöhnlich breit und nur bis nahe an das erste und zweite Costalffeckchen verlängert, ohne sich mit ihnen zu verbinden; er theilt sich unten in zwei Enden, deren oberes wie gewöhnlich auf dem Htrd. aufsitzt, während das untere ihn mit einer Spitze berührt. - Der Analbusch des $\sigma^{7}$ ist dunkler graubräunlich als der Hinterleib, der des 오 hellochergelb.

Bei Grote ist das $q$ kenntlich abgebildet. Ich erhielt von ibm beide Geschlechter.

Vaterland: New-York, Pennsylvanien, Virginien (Grote).

Anmerkung. Grote's zweite Art, Phaec. niveiguttana l. c. p. 91, Fig. 15, stimmt wenigstens in der Eigenthümlichkeit des Keilstreifens mit Mutabilana; ob auch die Mittelbinde vor dem Innenrande abbricht, ist aus dem Bilde nicht wohl ersichtlich.

\section{Sericoris $\mathrm{Tr}$.}

Schildchen mit schwachem Schuppenwulst. Vdfl, ohne Umschlag, mit dunklem Wurzelfeld, solcher Mittelbinde und einem Keilstreifen der Htrd.-Mitte, der sich bisweilen als schräge Binde bis zum Vdrd. verlängert, selten ganz fehlt; im Innenwinkel ist ein halbeiförmiger oder kurz kegelförmiger Fleck, der oft mit der Mittelbinde zusammenfliesst. Die Fransen ohne die gedrängte Atomenreihe von Semasia. Htfl. ohne den streifenförmigen Anbang von Exartema. Hinterschienen des $\delta^{7}$ mit langen, anliegenden Haaren und oft mit langem Haarbusch in einer Längsrinne.

A) Vdfl. mit Metallpunkten oder Metallstreifen; der Keilstreifen in eine Binde verwandelt oder ganz fehlend.

\section{Seric. aryyrö̈lana n. sp.}

Alis ant. subangustis, pallide ochraceis, cinereo-ciliatis, area basali fasciaque media nigro-sparsis, plumbeo-punctatis, fascia postica plumbeo-marginata, costa subtiliter nigro-punctata, strigula anteapicali plumbea; poster. fuscis, cinereo-ciliatis. $\sigma^{7}$.

Ganz nahe verwaudt mit unserer hochalpinen Metalliferana, welche aber auf dem Vdrd. grobe, schwarze, nach hinten weisslich wechselnde Fleckchen hat (bei Argyroëlana sind ganz feine Querstrichelchen, die gegen die Flügelspitze hin nur etwas lichtere Grundfarbe zwischen sich haben) und des Bleistreifchens der Argyroëluna vor der Flügelspitze entbehrt; auch ist bei ihr die hintere Binde breiter und geht grader bis in den Innenwinkel herab, und endlich sind ihre Beine sehr dunkel. -- Die folgende Coruscana steht der Argyroëlana 
dadurch etwas ferner, dass ihre Vdfl. spitzer sind; ausserdem unterscheidet sie die helle, fast weissliche Farbe aller Fransen, der helle Analbusch und die bellen Beine am leichtesten von Argyroëlana.

Etwas kleiser als die fulgeude. R. und K. bleich ochergelb, ersterer schwarz gefleckt und punktirt. Fühler stark, bräunlich. Taster um eine halbe Kopflänge hervorstehend, zusammengedrückt, unteu reichlich behaart und nach hinten verstärkt, aussen vor der Spitze mit einem schwärzlichen Punkt; Endglied kurz, vorstehend, hell, mit schwarzem Fleckchen vor der Spitze. Beine bleichgelb, die vorderen vorn braun, hell punktirt; an den mittleren und hinteren die Schienen vor der Spitze mit verloschenem, grauem Bäudchen; alle Fussglieder obenauf schwarz mit weisslicher Spitze; die Hinterschiene scheint keinen Haarpinsel zu haben. Hinterleib dunkelgrau; Analbusch an der Wurzel ebenso, an der Endhälfte trüb ochergelblich.

VdA. $3^{1 / 2}{ }^{\prime \prime \prime}$ lang, etwas gestreckt, nach hinten erweitert, an der Spitze abgerundet, von blass ochergelber, aber sehr beschränkter Grundfarbe. Das Basalfeld ist nur durch zerstreute tiefschwarze Stäubchen angedeutet und unordentlich mit groben, lebhaft bläulich bleiglänzenden Flecken oder Punkten bezeichnet. Diese lassen das darauf folgende schmale Feld der Grundfarbe nur an der Costalhälfte rein erscheinen. Die Mittelbinde ist wie das Basalfeld, nur reichlicher, schwarz bestäubt; mit ihr fliesst der schlecht ausgedrückte Halbeifleck des Innenwinkels so zusammen, dass nur am Inuenrande ein schmaler, kurzer Streifen der Grundfarbe zu erkennen ist. Der Keilstreifen ist in eine breite, nach oben einwärts gebogene, vorn und hinten durch eine Bleilinie scharf begrenzte Binde verwandelt, in welcher unter den ochergelblichen Haarschuppen durch Abreibung schwarze Stäubchen mehr oder weniger hervortreten; sie reicht bis an den Vdrd., wo zwei schwarze Costalpunkte in ihr liegen; die innere Bleilinie reicht bis in den Innenwinkel herab und begrenzt dessen helle Grundfarbe so, als ob diese den unteren Theil der Bivde bildete. Hinter der Binde ist ein schmaler, nach oben erweiterter Streifen der Grundfarbe, in welchem vor der Flügelspitze ein bleigläyzendes Querstreifchen liegt. Der Vdrd. ist ein wenig heller als die Grundfarbe, von der Wurzel aus mit schwarzen, kleinen, kaum gebogenen Querstrichelchen gezeichnet. Eine Htrd.-Linie fehlt. Fransen braungrau, am Innenwinkel heller.

Htfl. dunkel braungrau, an der Basalhälfte des Vdrdes. weissgrau. Fransen dunkelgrau mit weisslicher Basallinie.

Unterseite dunkelgrau. Vdfl. im Dorsalfelde bis zur Falte hell; der Vdrd. als ein schmaler Streifen hellgelblich, mit schwarzen Querstrichen ziemlich weitläuftig durchschnitten. Fransen an der Wurzel hellgelblich, sowie ein sebr schmaler Streifen vor dem Htrd. Htfl. einfarbig grau, uur am Vdrd. gelblich und grau besprengt.

Vaterland: New-York. Zwei von Dr. Speyer erhaltene $\sigma^{\lambda}$ in meiner Sammlung. 


\section{Seric. comscana Clem. (?)}

Alis ant. subangustis, acutis, pallide ochraceis, exalbido-ciliatis, area basali fasciaque media nigro-sparsis, plumbeo-punctatis, fascia postica plumbeomarginata, costa nigro-strignlata, strigula plumbea anteapicali; post. fuscis, albido-ciliatis. $\sigma^{\pi}$.

\section{? Antithesia coruscana Clem. Proc. Ac. Nat. Sc. Philad. 1860, p. 346.}

? Sericoris - Clem. Proc. Ent. Soc. Philad. 1865, p. 134.

Es ist rein willkürlich, die Clemens'sche Benennung auf diese Art anzuwenden, da die Beschreibung ebensogut auf die vorige Art passt; ich nehme aber den Namen an, weil ich zwei so bezeichnete Ex. von Grote erhielt, der sich vielleicht von der Identität in der Clemens'schen Sammlung überzeugt hatte. Die Beschreibung lässt sich sogar mit ihren hindwings dark brown ganz bequem auf Constellatana anwenden, da die Grösse nicht angezeigt ist.

Die Hauptverschiedenheiten zwischen dieser Coruscana und Argyroëlana sind bei letzterer angezeigt.

Coruscana ist etwas grösser. Die Fühler sind gegen das Ende merklich verdünnt, auf dem Rücken von der Wurzel aus bleichgelblich. Taster an der Spitze des zweiten Gliedes verdunkelt, sonst wie bei Avgyroëlana. Beine mit breiteren hellen Stellen. Die vier hinteren Schienen und Füsse sehr bleichgelblich, fast weisslich; die Hinterschienen oben und unteu locker langhaarig; die Hinterfussglieder nur ganz an der Wurzel obenauf schwarz. Hinterleib dunkelgrau, an den Hinterrändern der Segmente locker weisslichschuppig und am Bauch weisslich. Analbusch hell, nur am Basaldrittel obenauf dunkelgrau, daber länger scheinend als bei Argyroëlana.

Vdfl. mit sehr deutlicher, nicht abgerundeter Spitze und graderem Htrd. als dort. Grundfarbe und Zeichnung wie bei jener. Wurzelfeld und Mittelbinde reichlicher schwarz bestäubt, besonders in der Mitte. Der Vdrd. ist an der Endhälfte heller, die Querstrichelchen aber ebenso klein. Fransen fast gelblichweiss, nur an der Flügelspitze und unter der Mitte fleckartig grau.

Htfl. so dunkel wie dort. Fransen wie der ganze Vdrd. gelblichweiss, nahe der Wurzel von einer braungrauen Linie durchzogen.

Unterseite der VdA. dunkelgrau; der Vdrd. als eine breitere, nach hinten erweiterte Linie gelblich, schwarz gestrichelt. Die gelblichweissen Fransen an der Flügelspitze fleckartig grau und unterhalb der Mitte an den Enden schwärzlich. Htfl. hellgrau, an der Endhälfte zwischen den gelblichen Adern staubig dunklergrau; Fransen einfarbig weisslich.

Vaterland: Wahrscheinlich New-York. Zwei $\sigma^{\prime}$ in meiner Sammlung.

\section{Seric. constellatana n. sp.}

Magna; alis ant.latis, subobtusis ( $Q$ angustioribus, acutioribus), pallide ochraceis, nigro-punctulatis, area basali fasciaque media nigro-sparsis, plumbeo- 
punctulatis, fascia postica plumbco-marginata, in costae punctum nigrum desinente, strigula anteapicali plumbea. $\sigma^{7} \bigcirc$.

Grösser und breit- und stumpfflügliger als Metallicana, bei welcher die hellen Stcllen der Grundfarbe bedeutend breiter und ganz rein bleiben, and die Bleifleckchen der Mittelbinde fast nur auf die Ränder beschränkt sind. Sie stimmt in der Flügelzeichnung sehr mit den zwei vorigen überein, ist aber viel grösser und in allen Flügєln viel breiter und kürzer, und die hintere Binde rundet sich obeu so dicht vor dem Vdrd. ab, dass nur ein braunes Fleckchen desselben sie berührt.

Fühler bräunlich. Taster um Kopflänge herrorstehend, buschig, zusammengedrückt, sehr bleich, am Ende gebräunt; das dritte Glied macht sich in den dunklen Haaren als helles Pünktchen bemerklich. Hinterleib wie bei Coruscuna; der Analbusch des $\sigma^{\pi}$ ganz hell, der des $q$ am Basaldrittel obenauf dunkelgrau.

Vdfl. 41/4" lang, beim of ansehnlich breit, nach hinten erweitert, an der Spitze abgerundet, am Htrd. sanft convex, beim $\$$ schmäler, doch verhältnissmässig nicht so schmal wie bei Coruscana, am Htrd. grader und daher mit mehr hervortretender Spitze. Grundfarbe ein bleiches Ochergelb, welches durch die Zeichnungen sehr eingeengt und durch melır oder weniger zahlreiche schwarze Pünktcheu verunreinigt wird. Der schmale Raum zwischen dem Basalfelde und der Mittelbinde wird dadurch und durch Bleifleckchen so verdeckt, dass sich nur am Vdrd. eine Stelle als dazu gehörig deutlich erkennen lässt, und dass es den Anschein hat, als ob die ganze Fläche von der Wurzel an bis weit hinter der Mitte auf bleichem Grunde reichlich schwarz quergestrichelt (am meisten in der Mittelbinde) und mit groben, recht glänzenden Bleifleckchen unregelnaässig bestreut ist; in diesen Raum ist auch der Halbeifleck des Innenrandes mit aufgenommen. Die hinterste Binde ist schwarzbestäubt und auf jeder Seite mit einer Bleilinie gesäumt; sie reicht vom untersten Drittel des Htrdes. (den keine schwarze Linie einfasst), etwas gekrümmt und nach oben schwach erweitert, mit ihrem abgerundeten Ende bis an die schwarzen Costalpunkte, von denen ein starker die Mitte dieses abgerundeten Endes einnimmt. Die Flügelspitze ist ein bleiglänzender Querstrich wie bei Coruscana. Der Vdrd. ist in einer dünnen Linie gelblich und von der Basis aus mit schwarzen, fast querstrichförmigen Punkten bestreut, unter denen die hintersten sich wenig durch Stärke auszeichnen. Fransen fast weisslich, vor der gelblichen Wurzel beim 오 mehr als beim $\sigma^{7}$ mit einer bräunlichen Linie, die von der Flügelspitze anfängt, aber wohl nie bis zum Innenwinkel reicht; an der Flügelspitze sind sie braun angelaufen und auch oberhalb des Innenwinkels an ihrer Spitze streifenartig verdunkelt.

Htfl. breit und ziemlich abgestumpft, beim $q$ ziemlich dunkel braungrau, beim $\sigma^{\top}$ hell.

Unterseite der Vdf. braungrau, beim $\sigma^{\top}$ von der Querader einwärts heller. Vdrd. breiter gelblich und schärfer schwärzlich gefleckt und punktirt als oben. 
Auch die Fransen mit lebhafter braunen und breiteren Stelleu. Htf. des $\sigma^{\nearrow}$ weissgrau, an der Apicalhälfte mit dunkeln Querstrichelchen auf gelblicherem Grunde, des $q$ dunkler grau, am Vdrd. und in der Spitze mit bleichgelben Querstrichelchen. Fransen ohne Schattenlinie.

Vaterland: Ohio (Schläger), New-York (Speyer). Die Art scheint gar nicht selten zu sein, da ich sechs $\sigma^{\circ}$, zwei zur Verfügung habe.

\section{Seric. astrologana n. sp.}

Magna; alis ant. latis, subobtusis, ochraceis, nigro-pulvereis, praesertim in medio, munctis majusculis nitide plumbeis copiosis inordinate sparsis, ciliis dilutis; post, fuscescenti-cinereis, exalbido-citiatis. $\sigma^{\top}$.

Sie weicht darin von der Regel bei Sericoris ganz ab, dass auf den Vde. alle sonstige Bindenzeichnung fehlt; doch ist sie als Sericoris nicht wohl zu verkennen.

R. und K. ochergelb, ersterer schwarz gefleckt und punktirt; Scutellumsbusch klein, ungefleckt; Gesicht mit vier verwischten scbwarzen Punktfleckchen. Taster um Kopflänge hervorstebend, stark, buschig, zusammengediückt, am Ende abgerundet, hell ochergelb, aussen mit einem schwarzen Punkt vor den schwärzlichen Endhaaren des zweiten Gliedes, aus denen das dünne, ziemlich lange, helle Endglied hervorragt. Fühler mikioskopisch gefraust, obenauf ochergelblich; Basalglied vorn mit tinem schwarzen Fleck. (Beine und Hinterleib fehlen).

Vdfl, $4 \frac{1}{2}{ }^{\prime \prime}$ lang, breit, doch nicht so sehr wie bei Constellatana, auch liicht ganz so stumpf und mit weniger convexem Htsd, nach hinten erweitert. Grundfarbe röthlich ochergelb, gegen die Sjitze etwas beller und weniger röthlich, auf den ersten zwei Dritteln sehr reichlich mit schwarzen Stäubchen bestreut, welche in der Flügelmitte zu einer giossen Querwolke angthäuft sind und am meisten längs des Innenrandes zu Querstrichelchen zusammentreten. Von der Wurel aus liegen über die ganze Fläche hin bleiglänzende Punkte and runde Fleckchen sehr zahlreich $(50-60)$ ohne bestimmte Ordnung, ausser dass sie gegen die Flügelspitze hin beinahe Quereilıen bilden. Den Vard. nimmt vou der Wurzel aus eine selur feine, nach liuten ein wenig erweiterte, blass ochergelbe Linie ein, die wengstens auf der Endhälfte nur unterwärts von schwarzen Pünktchen begrenzt ist, also auch der gewöhnlichen Costalzeichnung von Sericoris gänzlich entbehrt. Fransen fast gelblichweiss, dicht an der Wurzel ochergelbich, nur oberhalb des Innenwinkels an ihren Enden ein wenig verdurkelt, dagegen um die Flügelspitze so hell wie am Innenwiukel.

Htt. nicht ganz so breit wie bei Constellatana, braungrau, an der Wurzelhälfte gelichtet. Fransen gelblichweiss, uahe der Wurzel mit starker, dunkelgrauer Schatteilinie.

Unterseite der Vdf. dunkelgrau. Vdrd.-Strieme ziemlich breit bell ochergelb, nit nicht sehr reichlichen schwarzen Querstrichelchen, die auf der End- 
hälfte sie nicht ganz durchschneiden; ebenso gelb ist eine sehr schmale Htrd.Linie, vor welcher hellgelbe Stäubchen gestreut sind. Fransen sehr hell, an ihren Spitzei ins Grane. Htfl, weissgrau, in der Spitze und längs des Vdrdes. dunliler, und an diesem nit gelblichen Stäubchen bestreut; der Htrd. mit einer so feinen gelblicheu Linie umzogen wie die Vdfl.; die Fransen olue Schattenlinie.

Vaterland: Texas (Boll). Ein Ex. in meiner Sammlung; mehrere ganz gleiche befinden sich nach Hagen's Angabe im. Cambridger Museum.

B) Vdfl. ohne Metallzeichnung; der vom Htrd. unterhalb der Mitte ausgehende Kieilstreifen völlig ausgebildet.

\section{Seric. poana n. sp.}

Parva; palporum apice fusco; al. ant. subelongatis, pallide ochraceis, fusco-strigulosis, area basali, fascia mcdia superne coarctata strigaque marginis postici obliqua cimeata fusco-brunneis, linea marginis postici superioris tenuissime exalbida, ciliis fuscescentibus. ơ 오.

Die zehn mir vorliegenden Ex. sind den kleinsten der Cespitana so ähnlich, dass sie leicht als kleine, dunkle Form derselben angesehen werden können, für welche Dr. Rössler sie auch erklärte.

Gestalt der 3-31/4" langen VdAl. wie bei Cespitana. Die Grundfarbe, die im Raum hinter dem Basalfelde am reinsten hervortritt und etwas weisslicher ist, lässt die zahlreicheren, feineren und schwärzeren Querstrichelchen deutlicher zum Vorschein kommen. Das Wurzelfeld, die Mittelbinde, der Keilstreifen und ein aus dem Apicalfleck herabziehender Streifen, der mit dem Keilstreifen verschmilzt, sind schwärzlichbraun, fast ohne gelbliche Beimischung, und durch diese Farbe fallen die Ex. am meisten auf. Der Keilstreifen hat eine veränderlich $\Theta$ Gestalt, indem er sich nicht immer nach oben verengert, sondern auch bisweilen erweitert, und nimmt die Richtung gegen das erste starke Costalhäkchen, bleibt aber etwas weiter von demselben getrennt als bei Cespitana. (Bei dieser, wie bei Flavipalpana und Poana zieht über dem Keilstreifen dicht an der dunkelbraunen Htrd,-Linie eine feine hellgelbliche Linie, welche die schwarzbraune Flügelspitze nicht erreicht). Fransen dunkelgrau, am Keilstreifen und um die Flügelspitze braun oder doch verdunkelt.

Htfl. und ganze Unterseite braungrau, nur die Vdfl. am Vdrd. mehr oder weniger reichlich mit gelblichen, einmal durchschnittenen Fleckchen, deren Zwischeuräume braun sind, bezeichnet.

Vaterland: Ohio (Schläger). Massachusetts, wo Burgess die Art wahrscheinlich nicht selten bei Beverly vom 16. Juni bis 3. Juli sammelte.

6. Seric. campestrana n. sp. Taf. VIII, Fig. 17.

Parva; palpis pallidis, exterins griseis; al. ant. subelongatis, albidis, area basali, fascia medic superne angustata strigaque marginis postici obliqua cuneata brunneis, linea marginis postici superioris subinterrupta albida, ciliis maculatis. 우 오. 
Etwas grösser als Poana, mit gestreckteren Vdfl., weisserer Grundfarbe und heller gelbbraunen, schärfer hervortretenden Zeichnungen; die weissliche Htrd-Linie zwischen Flïgelspitze und Keilstreifen ist breiter nnd bis zur. Füugelspitze verlängert. Von Fuscalbana ist sie durch meist geringere Grösse, durch weniger reines Weiss der Grundfarbe und durch Schmalheit der Mittelbinde (welche nicbt den ersten der drei Costalflecke mit umfasst) leicht zu unterscheiden.

P. gelbbraun, hell gefleckt. Gesicht staubgrau. Taster um mehr als anderthalb Kopflängen hervorstehend, stark behaart, zusammengedrückt, bleichgelblich, aussen melır oder weniger grau angelaufen; Endglied deutlich hervorstehend, bleichgelb. Mittelschienen braungrau mit blassem Mittelbändchen; Mittelfüsse obenauf dunkelbraun mit bleichgelben Enden der Glieder. Hinterbeine staubgrau, an den letzten Fussgliedern verloschen gefleckt: Schienen stark, zusammengedrückt, auf beiden Schneiden etwas abstehend behaart, auf der Imnenseite oberwärts mit schwarzem, in einer Furche verstecktem Pinsel. Hinterleib grau mit länglichem, bleichgelbem Analbusch.

Vdfl, bis $3 \frac{1}{2}{ }^{\prime \prime}$ lang, etwas gestreckt, mit deutlicherer Spitze als bei Poana. Grundfarbe unrein gelblichweiss, sehr schwach schimmernd, von dor Farbe der gelbbramen Zeichunugen stark abstechend; sie bildet zwischen dem Basalfelde und der Mittelbiade eine ziemlich schmale, von einer welligen unterbrochnen Mittellinie durchzogene Binde, deren Basalrand winkliger ist als der der Mittelbinde zngekehrte Rand; letzterer ist veränderlich, bisweilen fast grade, wohl meistens in der Mlitte mit einer ausspringenden Ecke. Die Mittelbinde ist am Vdrd. verengert (weniger als bei Poana), hierauf, indem sie den halbeiformigen Fleck des Innenrandes in sich aufgenommen lat, allmälig stark erweitert; ibr unregelmässiger Htrd. zeigt über dem Ende des Halbeiflecks einen unregelmässigen Einschnitt, über welchem eine verdunkelte, öfters schwarzbraune, zugerundete Ecke, die sich bisweilen punktförmig absondert, hervorsteht; diese Binde und besonders das Basalfeld sind dunkel marmorirt. Der breite Keilstreifen ist nicht immer nach oben erweitert und abgerundet; er ist nit deın dunkelbraunen Fleck der Flügelspitze durch einen bräunlichen Nebel verbunden, doch nicht so, dass beicle nicht sollten $z u$ unterscheiden sein. Zwischen ihm und der Flügelspitze zieht längs dor braunen Htrd.-Linie eine weissliche Linie, stärker als bei Poana und fast bis zur Spitze hinaufreichend, abwärts bisweilen schwach unterbrochen. Das Weisse zwischen Mittelbinde und Keilstreifen enthält einzelne bräunliche Querstriche. Vor der Flügelspitze sind drei schwarzbraune Costalfleckchen, mit solchen Strichelchen abwechselnd. Fransen hell, über der Flügelspitze und am Keilstreifen brüunlich.

Htfl, einfarbig grau; Fransen weisslich, mit grauer Schattenlinje durchzogen. Unterseite der Vdfl. braungrau, auf dem Vdrd. mit verloschen weisslichen, braun durchschuittenen Fleckchen. Htfl. weisslich grau.

Das $q$ ist kleiner, schmallügliger und schärfer gezeichnet als das $\sigma^{\top}$. Vaterland: Maine oder Massachusetts (Packard). 
7. Serir. fusculbuma n. sp. Taf. VIII, Fig. 18.

Parva; palpis fuscescentibus; al. ant. albis, area basali, fascia media (punctum nigrum in margine suo medio postico continente) strigulaque marginis postici medii cuneata brunne-fuscis, linea marginis postici superioris alba interrupta, ciliis albo fuscoque maculatis. $\sigma^{7}$.

Von der vorigen sogleich durch die den ersten Costalfleck mit umfassende, also oben breitere Mittelbinde der Vdf. zu unterscheiden, kommt sie der europäischen Bipunctana (Heinemann S. 129) am nächsten; sie ist aber kleiner, mit lichterem Schwarzbraun der Zeichnungen, in der Nittelbinde ohne die Ausbuchtung des hintern Randes hinter dem weissen Pünktchen (wodurch diese Binde bei Bipunctana gewölnnlich eingeschnürt erscheint), dafür aber mit einem starken, tiefschwarzes Punkt in diesem Rande. Die weisse Linie am Htrd. zwisclıen dem schärferen Keilstreifen und der Flügelspitze reicht fast bis zu dieser hinauf, statt dass bei Bipunctana nur kurze Bruchstücke, bisweilen auch nichts davon vorhanden ist. Bei Tiedemanniana ist das Schwarz gleichfalls dunkler als bei Fuscalbana, und die zwei Binden, welche von der weissen Grundfarbe gebildet werden, sind beträchtlich schmäler. Bei Sieversiana ist die erste Binde in der Mitte unterbrochen, und die ganze Flügelspitze dunkel.

Grösse der vorigen. R., K. und Taster braun, letztere bisweileu auf der Innenseite hell. Beine bunt; die hinteren staubgrau, mit brannem, bis über die Hälfte reichendem Furchenpinsel der Schiene; die vier Endglieder des Fusses an der Wurzel etwas verdunkelt.

Vdfl. $31 / 2$ " lang, von der Gestalt wie bei Bipunctana, weiss, mit schwärzlichen Zeichnungen, die hier und da mit gelblichen Schuppen belegt sind. Das Basalfeld ist an seinem Htrd. schräg zugerundet und wellig, unter der Falte mit einiger Ausbuchtung. Die Mittelbinde ist, weil sie das erste der drei Costalfleckchen mit umfasst (was bei einem Ex. jedoch nicht der Fall ist, weshalb sie hier nur so breit wie bei Campestrana ist), am Vdrde. breit, über rler Medianader an ihrem Basalrande gewöhnlich mit einem Ausschnitt verselıen und am untersten Drittel, weil der Halbeifleck ganz mit ihr zusammengeflossen ist, besonders breit; sie enthält auf dem Vdrd. ein weisses, querdurchschnittenes Fleckchen und auf der Verästelung der Querader, hinter einer weisslichen, verloschenen Stelle einen tiefschwarzen, ein wenig aus dem Htrd. hervorst henden, gerundeten Punktfeck. Der Keilstreiten ist breit, nicht immer nach oben erweitert, abgerundet oder auch zugespitzt, durch eine Verdunkelung oder ein Gitterwerk init dein schwarzen gerubdeten Apicalpunkt verbumlen, von welchem aus bis zun Keilstreifen längs der schwarzen Htrd.-Linie eine weisse, dünne, etwas unterbُochene Linie läuft. Zwischen dem Apicalpunkt und der Mittelbinde trägt der Vdrd. zwei schwarze, mit Hähchen wechselude Fleckchen. Der weisse, bindenförmige Raum vor der Mittelbinde ist schmäler als das Basalfeld und mehr oder weniger vollständig in der Mitte von einer braunen Querlinie durchzogen. Fransen weisslich, an der Flügelspitze und am Keilstreifen auf ihrer Endhälfte bräunlich. 
HtAl. ziemlich hellgrau, einfarbig. Fransen weissgrau mit dunklerer Scbattenlinie.

Unterseite der Vdfl. branngrau, auf der Endlälfte des Vdrdes. mit vier verlosehenen, weisslichen, querdurchschnittenen Fleckehen. Htfl. weissgrau.

Vaterland: Ohio (Schläger). - Maine oder Massachusetts (Packard).

8. Seric. caesialbanre n. sp. Taf. VIII, Fig. 19.

Media; al. ant. latiusculis, albidis, area basali fasciaque media lata (in margine suo mellio postico punctum majus nigrum continente) caesio fuscoque mixtis, strigula marginis postici medii cuneata cinerea obsoleta: alis post. cinereis canisve. $\sigma^{\top}$.

Grösser als Fuscalbana und von ihr, sowie von der gleichgrossen Bipunctana aufallend durch breitere, stumpfere Flügel verschieden; auf den vorderen tritt das Weisse mehr hervor, besouders in der Endpartie, wo der Keilstreifen verloschen und brucbstiickweise erscheint; die schwarze Zeichnung dagegen ist blässer, weil in ihr das Schiefer- oder bläuliche Gran vorherrscht.

R. und K. schwärzlichbraun. Taster uın etwas über halbe Kopflänge bervorragend, buschig, länglichrusd, zusammengedrückt, braun, nur ganz im Innern hellgrau; Endglied versteckt. Die vier vorderen Beine auswendig braun, nit weisshichen Spitzen der Fussglieder; Mittelschiene mit verloschenem hellen Bändchen. Hinterbeine sehr hell staubgran; die Schienen anf der Rückenschueide reichlich behaart, nur mit hellem kurzem Pinsel. Hinterleib grau, nach hinten heller und ins Bleichgelbliche; Analbusch breit, abgestutzt, bleichgelblich.

Vdfl. 4" lang (bei einem Ex. nur 31/2"), breit mit zugerundeter Spitze und schwach convexem Htrd. Grundfarbe weiss, etwas schimmerud; die Zeichnungen dunkel schiefergrau, mit schwaren Querstrichen uuregelmässig durchzogen. Das Basalfeld hat hinten in der Mitte eine hervorstehende Ecke. Der folgende weisse Raun bilket eine halb so breite Binde, welche auf den Gegenrändern einige deutliche, im Innern ein paar verwischte, dunkelgrane Querstrichelchen enthält. Die Mittelbinde ist doppelt so breit, am Innenrande. wo der Halbeifleck völlig in sie aufgenommen ist, etwas breiter als am Vdrd., wo das erste Costalfleckchen gewöhnlich mit ilı zusammengeflossen ist, wodurch die vor diesem befindliclien zwei weissen Costalpunkte innerhalb der Binde erscheinen; sie ist über der Nitte nerklich verengert und an dieser Stelle auf weisslichen Grunde mit einem schwarzen Mittelpunkt gezeichnet; in ihrem hinteren Rande trăgt sie einen starken, schwarzen, etwas aus ilı hervorragenden, gerundeten Punktfleck. Hinter ihr folgen bis zur Flügelspitze zwei dunkelgraue, mit je einem Querstrichelchen abwechselnde Costalfleckchen. Die Flïgelspitze enthält ein solches Fleckchen, das mit hellerem Nebel ungeben ist, der sich bis zu dem verloschenea Keilstreifen verbreitet. Dieser ist an Ende fleckartig erweitert und bisweilen von seinem untersten Ende getrenut, das dann als Nebelfleck vor dem obersten Drittel des Htrdes. daliegt. Unter ihm ist die weisse Grundfarbe am reinsten. Fransen weiss, um die Flügelspitze am dunkelsten 
braungrau, tiefer abwärts mit zwei mehr oder weniger breiten verduıkelten Stellen, um den Innenwinkel ganz weiss.

Htfl. breit stumpfer als bei Fuscalbana und Bipunctana, hellgrau und einfarbig, oder weisslich und in der Spitze dunkelgrau angelaufen. Fransen weisslich, mit grauer, starker Schattenlinie an der Apicalbälfte des Flügels.

Unterseite der Vdfl. dunkelgrau, auf dem Varde. wie bei Fuscalbana, uur verloschener, weissfleckig. Htfl. weissgrau oder weisslich; die Fransen der Flïgelspitze auswärts grau, oder auch hier wie ïberall einfarbig weisslich.

Vaterland: Massachusetts (Burgess). Fin Fx. wurde nebst melireren am 14. Juni gefangen.

\section{Grapholitha Tr.}

Es wäre mir lieb, wenn Herr C. G. Barrett, unter den Engländern gegenwärtig der beste Kenner der Tortricinen, sich ausfïhrlicher über den Werth der jetzigen Wicklereintheilungen ansgesprochen hätte. Er begnügt sich im Montluly Magazine IX, S. 124 zu sagen: „Dr. Wocke's newe Anordnung zu befolgen, hindert mich die Schwierigkeit, die ich empfinde, ein solches Genus wie Penthina anzunehmen, welches mit unserer Paedisca jrofundana anhebt und unsere Brachytaenien, eigentlichen Penthinen, Euchromien, Orthotaelien, Mixodien, Roxanen, die grösseren Artell von Sericoris und die Siderien umfasst".

Die Arten, die ich hier als Grapholitha aufführe, haben nur das Gemeinschaftliche, dass sie nicht zu einer der vorhergehenden Gattungen gehören, aber, wie diese, mit Ausnahme einiger Tortrix-Abtheilungen, im männlichen Geschlecht keinen Costalumschlag besitzen.

Die ersten fünf Arten sind sowohl unter einander als auch mit der zweiten Abtheilung von Paedisca verwandt.

\section{Graph. Vestaliana n. sp. Taf. VIII, Fig. 21.}

Media; al. ant. (sine on revolucro?) margine postico infra apicem subconcavo, niveis, puncto venae transversae, strigulis costalibus posticis lineaque marginis postici atris. $Q$.

Eine schöne, sehr ausgezeichnete Art, durch die einfache Vdfl.-Farbe und Zeichnung: rein weiss und tiefschwarz, leicht zu erkennen, aber schwer einer europäischen Art anzuschliessen, da sie keine Andeutung eines Spiegelflecks zeigt.

Vorderkörper weiss. Taster um die halbe Kopflänge hervorstehend, Beine weiss; Füsse auf dem Rücken des ersten Gliedes bis vor die Spitze grau; die folgenden Glieder schwarz mit weissen Enden; Hinterschienen spindelförmig, etwas verdickt, nur an der Spitze mit einigen über dieselbe hervorstehenden Haaren. Hinterleib weissgrau, am Banch weiss wie der starke, grade abgeschnittene Analbusch, in welchem der Legestachel ganz velborgen ist. Vdfl. 41/2"' lang, ziemlich gestreckt, mit gradem, nur an der Basis sehr wenig convexem Vdrd., deutlicher Spitze und unterhalb derselben sanft ein- 
gedrücktem Htrd, und stark abgerundetem Innenwinkel. $\mathrm{Ob}$ das $\sigma^{7}$ einen Costalumschlag hat, ist noch zu erforschen. Grundfarbe schneeweiss mit tiefschwarzer Zeichnung. Auf der Endhälfte des Vdrdes. liegen vier länglich dreieckige Punkte und vor der Flügelspitze zwei Häkchen, das zweite doppelt so lang wie das erste; von dem dritten Punkt geht eine dünne, zweimal unterbrochene Linie schräg nach der Einbiegung des Htrdes. Die feine Htrd.-Linie fängt in den Apicalfransen an, folgt der Krümmung des Htrdes. und verlöscht in der Nähe des Inneurandes. Am Ende der Falte im Innenwinkel ist ein kleiner Punkt; ein grösserer auf der Querader unterhalb des Zwischenraumes des zweiten und dritten Costalpunktes. Fransen weiss, etwas schimmernd, an ihrer Wurzel in einer Linie reinweiss, in der Krümmung, dem Ende der Querlinie gegenüber, mit einem dunkelgrauen Längswisch auf der Aussenhälfte.

Htfl. länglich und spitz, aus der weisslichen Basalhälfte in entschiedeneres, in der Flügelspitze verdunkeltes Bräunlichgrau übergehend, mit weissen Fransen.

Unterseite der Vdfl. dunkelgran; das Enddrittel des Vdrdes. schmal weiss; die Apicalfransen mit dem braungrauen Anfang der nicht hervortretenden Htrd.-Linie. and ein solches Häkchen in den weissen Costalfransen; der dunkle Wisch in den weissen Htrd.-Fransen grösser als auf der Oberseite. Htfl. weiss, am Vdrd. bis zur Subcostalader braungrau.

Die Medianader 4 ästig; Ader 3 und 4 ziemlich nahe bei einander und an der Wurzel fast zu einem Stiel vereinigt; Ader 2 ilınen ein wenig näher als der Flügelwurzel; alle drei grade; Ader 5 etwas gebogen, mit der Concavität gegen 4.

Vaterland: Texas (Boll). Ein $q$ (auf den Vdfl. etwas fettfleckig) im Cambridger Museum.

\section{Graph. trivittana n. sp. Taf. IX, Fig. 22.}

Media; al. ant. (revolucro of nullo, margine postico infra apicem vix concavo) albis, trabe longitudinali infra costam vittaque infra plicam dimidia luteo-griseis (aut al. ant. luteo-griseis, vitta costali ac trabe longitudinali supra medium albis), costa postice strigis luteo-brunneis dissecta, speculo albo, atrobilineato. $0^{7}$ ㅇ․

Bei dieser Art hat auf den Vdfl. entweder das Weisse die Oberhand, und das Gelblichgrau bildet die Zeichnung, oder es ist umgekehrt; in beiden Fällen bildet das Weisse eine mehr oder weniger breite Costalstrieme und einen nach hinten erweiterten und bis an den Spiegel verlängerten Balken. Eben dieser Balken gibt, wenn das Gelblichgrau die Grundfarbe ist, das sicherste Unterscheidungszeichen von Spiculana, die bei der Veränderlichkeit der Trivittana leicht als Varietät davou angesehen werden könnte; er lehnt sich mit meist gespaltenem Ende an die Falte, welche hier eine schwarzbraune, bis an den Htrd. reichende Linie enthält. Bei Spiculana ist statt dieses Balkens eine scharf zugespitzte, sich von der Falte weit entfernende schneeweisse Vitta. 
Ausserdem enthält bei Trivittana die Costalstrieme schräge, gelblichgraue, vom Vdrd. selbst ausgehende Querlinien, während sie bei Spiculana sich unterwärts verästelt und vor der Flügelspitze ein gelbgraues Costalstreifehen trägt.

In der Grösse etwas unter der ähnlichen europäischen Albidulana (die aber einen Costalumschlag hat), am nächsten verwandt mit Wimmerana. K. und Vorderrïcken reinweiss; hinter dem Kragen siud bei einem $\sigma$, zwei $q$ schwarze Punkte (die bei den anderen durch Verölung verschwunden sein mögen); die Schulterdecken am Ende und einwärts lehmgran. Taster zusammengedrückt mit kurzem, schwarzen Endglied. Beine weiss; die vier Endglieder der Füsse obenauf schwarz mit weissen Spitzen; die Hinterschienen schmutzigweiss, kräftig, zusammengedrückt, auf der ganzen Rückensehneide etwas abstehend behaart. Hinterleib grau, Analbusch klein und weiss.

Vdfl. $3^{1 / 2-4 " ' ~ l a n g, ~ l a ̈ n g l i c h, ~ z i e n ı l i c h ~ s p i t z ~(b e i n ~} \bigcirc$ spitzer) mit schwach convexem Vdrd. und unterhalb der Spitze schwach eingedrücktem, in den ganz abgerundeten Innenwinkel zuräckgehendem Htrd. Als Grundfarbe wird, auch wenn das Weisse die Oberhand hat, wohl richtig die helle Lehmfarbe angenommen, welche tiber und unter dem Spiegel mit schwarzen Atomen dicht bestreut ist und etwas oder gar nicht schimmert. Den Vdrd. bildet eine weisse, sich bis zur Spitze erweiternde Strieme, welche auf ihrer Endhälfte mit drei sehr schräg nach hinten gelegten und zuletzt mit zwei kürzeren fast seukrechten Querlinien der Grundfarbe durchschnitten ist. Diese Querlinien ändern in der Stärke ab; bei einem $\sigma^{7}$ sind sie fein und verlöschen schnell, so dass nur die erste das Weisse völlig durchschneidet; beim 오 liegt zwischen den drei ersten noch je ein kurzes Strichelchen, das mit der vorhergehenden Linie ein y bildet. Die mittlere, breitere Strieme zieht dicht am oberen Rand der Falte hin, welche weit hinter ihrer Fälfte eire braune Linie enthält; die Strieme, nach hinten erweitert, zeigt vor ihrem Ende zwei oder einen lehmiggrauen Längsstrich, wodurch sie, wenn ein Querstreifen der Grundfarbe sie vom Spiegel trennt, wie drei- oder zweispaltig erscheint. Der Spiegel wird von zwei etwas glänzeuden Linien eingefasst, ist weiss, hüher als breit, und $\epsilon$ thält zwei tiefschwarze Längslinien. Der Raum zwischen Falte und Innenrand ist entweder von der Gruidfarbe, am lichtesten in der Nitte und an der Basis des Inuenrandes rein weiss; oder er ist weiss, im Mittelranm mit einer lichten Längswolke der Grundfarbe, und mit einer Strieme der Grundfarbe, welche aus der Basis, sich etwas verengernd, bis zur Flïgelhälfte reicht. Die Flügelspitze ist bis zur Htrd.-Hälfte lehmiggrau und gegen die weisse Costalstrieme durch einen schwarzen Strich scharf geschieden. Htrd.-Fransen weiss, mit schwarzen, gegen die Flügelspitze verdichteten Atomen bestreut.

Htfl. grau, am Inneurand hell. Fransen weiss, dicht bei ihrer Wurzel mit einer lichtgrauen Linie durchzogen.

Unterseite der Viff. dunkelgrau, anf der hinteren Costalhälfte mit dunklern Fleckchen auf schmutzig hellgelblichem Grunde. Frausen weiss, gegen die Flügelspitze hin immer reichlicher mit schwarzen Atomen. - Htfl. weisslich, auf der Subcostalader grauschattig; oder sie sind auch ganz lichtgrau. Ader 3 
und 4 bilden eine sehr enge Gabel mit kïrzerem Stiel; Ader 5 ist am Ursprung von diesen getrennt. Beim $Q$ ist die Gabel kürzer, aber viel weiter auseinander gesperrt. Bei einem $\sigma^{7}$ aus Massachusetts, das ich doch durchaus nicht als eigene Art anerkennen kann, ist gar keine Gabel da, sondern die Medianader ist nur dreiästig.

Vaterland: Texas (Boll). Ein o daher in meiner Sammlung, mehrere genau stimmende im Museum Cambridge. Illinois (ein $q$ von Lederer erhalten). Massachusetts, wo Burgess mehrere Ex. am 16. Juli bei Beverly fing, ron denen ich eins erhiclt.

Anmerkung. Clemens gibt von seiner Anchylopera striatana (Acad. Nat. Scienc. Philad. 1860, p. 349) eine Beschreibung in Fabricischer Manier; aber unmöglich hätte er, wenn er meine Art vor sich hatte, diese für eine Anchylopera (Phoxopteris) ansehen können. Rei dieser Striatana liaben die Htfl. eine zweiästige Medianader und einen medio-discalen Ast, d. h. die Medianader ist dreiästig wie bei dem obenerwähnten Ex. aus Massachusetts.

\section{Grap) spiculana n. sp. 'Taf. IX, Fig. 23.}

Minor; al. ant. (sine of revolucro) angustulis, acutis, luteo-griseis, vitta nivea costali postice ramosa, striam griseam costalcm continente, vittaque nivea media acuminata, ultra medium producta, speculo albido lineolis duabus nigris dissecto. $Q$.

Ihre auffallendsten Unterschiede von Trivittana sind bei dieser angezeigt.

Etwas kleiner als Trivittana. Vorderrücken und Kopf cinfarbig hellgrau; die zusammengedrückten, länglich dreieckigen Taster auf der Innenseite weisslich. Beine schmutzig gelblichweiss, an den Füssen kaum dnukler. Hinterschienen ziemlich dünn und cylindrisch, ohne abstehende Haare. Hinterleib hell bräunlichgrau; Analbusch klein, weisslicb, abgestumpft kegelförmig mit etwas hervorstehendem Legestachel.

Vdfl. $3^{1 / 4}{ }^{\prime \prime \prime}$ lang, ziemlich schmal mit verlängerter Spitze, noch weniger convexem Vdrd. und an schräger nach hinten gehenden Htrd., wie es schejut, etwas tiefer concav. Grundfarbe lehmgelb, auf dem Enddrittel und am breiten Innenrand hellgrau mit sehr dichten, schwarzen Atomen. Die schneeweisse Vdrd.-Strieme zicmlich schmal, am Enddrittel unterwärts mit zwei sehr schrägen, einander parallelen, durch lehngelbe Farbe getrennten Aesten; über dem zweiten fängt auf dem Vdrd. selbst ein nach hinten erweitertes Streifchen der Grundfarbe an, wodurch ein dritter Ast entsteht, der sich aber vor der Flügelspitze erweitert. Die Mittelstrieme ist an ihrem Anfang etwas dỉm, erweitert sich dann und läuft unterhalb des ersten Astes der Costalstrieme sehr spitz zu; sie wird unterwärts durch dnnkelbraune Farbe grell gesäunt. Der Raum zwischen ihr und der Costalstrieme ist hell lehmgelb, fast ochergelb; ebenso der Raum unter ihr bis über die Falte. Der Spiegel ist schmal, vorn und hinten durch je eine dicke, etwas matt glänzende, weissliche Linie begrenzt und enthält zwei feine, an jedem Ende zu einem Punkt verdickte, schwarze Linien. Die Flügel- 
spitze hat die Grundfarbe, sticht aber dureh einen schwarzen Strich gegen das reinweisse Ende der Costalstriemen scharf ab. Dic (beschädigten) Fransen sind wenigstens an ihrer Wurzel mit schwarzen Atomen dicht bestreut.

Htfl. spitz, dunkelgrau. Fransen weiss mit gelblicher Basallinic.

Unterseite der Vdfl. branngrau mit weissem Costalfleck vor der Spitze. Fransen weiss, am meisten an der Flügelspitze mit schwarzen Atomen. Htfl. branweiss, Die dritte Ader ist einfach.

Vaterland: Texas (Boll). Ein 우 im Muscum Cambridge.

\section{Graph. stercoreana n. sp.}

Itedia; alis ant. acutis (revolucro of mullo), luteis, litura obliqua dorsali obscuriore, costa postice brumeo nitideque albido-strigulata, speculo distincto, lineis $2-3$ atris signato, linea citionum basali cinerea rel mulla; post. olscure cinereo-fuscis. of 9 .

Nächst verwandt mit Aspridiscana und wie diese alme Umschlag und dałurch sofort von Hohenwortiana zu untersehciden. Die ïberall glänzenden weisslichen Costalstriche, die Feinheit oder der gänzliche Mangel der schwarzen Atomenlinie anf der Wurzel der Htrd.-Fransen, worin sie der Hohenwartiane nahe kommt, und die dnukelbrannen, weisslich gefransten Htfl. tremnen Stercoreane sicher von Aspridiscana.

Grösse der grössten Aspidiscana. R. und K. Jehmfarben. Taster 110 Kopflänge hervorstehend, zusammengedrickt, ein breites und stumpfwinkliges Dreieck bildend, vorn mit cinem spitzen Trinkel, aussen grau. Beine gelblichgrauweiss; die vier letzten Fussglieder obenauf dunkel mit weisslichen Enden; die Hintersehienen kräftig, wenig zusammengedrüclit, anf den Schmeiden locker behaart. Hinterleib brännlich; der hell ochergelbliche Analbusch beim ơ reichlich, abgestutzt.

Vdfl. 4-41/2"' lang mit sanft convexem Vdrd., deutlicher Spitze und schr schwach eonvexem Htrd. Grundfarbe lelmgell, bis zur Nitte mit groben, haarähnlichen Schupıen. Bei $1 / 3$ ist ein verdunkelter, oben nach hinten ïberhängender, dunkel zimmtbranner Querwisch; hinter ilm his zu der bindenartigen Verdunklung ist die Farbe gelichtet und bildet einen oben moollständig begrenzten Dorsalfleck, dessen Farbe auch die Costallälfte des Flïgels bis zur Jasis zigt. Von der Mitte des Vdrdes. kommt ein schräg nach hinten gelegtes dunkles Band herab, von dessen unterem Fnde, bei ${ }_{1 / 3}^{1 / 3}$ der Flïgclbreite, der Raum bis zum Spirgel und senkrecht herab bis zum Innenrand brcit dunkel ist. Von dem Nittelbande an bis zur Flügelspitze trägt der Vdrd. abwechselnd dunkle und sehr selıräg nach hinten verlängerte weissliche, metallglänzende Querstrichelchen; das letzte ist bei einem o reiner weiss und auswärts dunke] gesäunt; bei allen geht es lis dicht vor den Htril. und schliesst sich der bleiglänzenden hintern Grenzlinie des Spiegels an. Diese hiegt sich ïber dem Innenwinkel nach voln und verbindet sich mit dessen vorderer Grenzlinie, welche dirker und mondsichelförmig ist. Der Spiegel ist höler als breit, ochergelb mit 
zwei schwarzen Längslinien und unterhalb des Längskniff's mit dem Anfang einer solchen. Fransen hell, beim $q$ durch eine zimmtbraune Linie von der Bleilinie getrennt; bein or fehlt sie, mod dafür zieht anf $\downarrow n$ Fransen wahe ihrer Wurzel eine nach oben erweiterte Linie dichtgestruter schwarzer Atome.

Htfl. dunkel grimbraun, einwärts naeh und nach lichter. Fransen weisslich, dicht an der gelblichen Wurzel mit starker, dunkelgrauer Linie durelizogen.

Unterseite der Vdfl. dunkelgrau, auf dem Enddrittel des Vilrdes. mit ab. wechselnden, verloschenen, gelblichweissen nnd zimmtbraunen oder dunkelgrauen Querstrichelchen. Fransen an der Wurzel weisslich, allnällig dunkler lehngelblich. - Htfl. hellgrau, auf der Costalhälfte dunkler; beim ? sind sie einfarbig dunkelgrau. Ader drei ist in eine gesperte Gabel gespalten, welche kürzer ist als ihr Stiel.

Vaterland: Maine oder Massachusetts; drei $\sigma^{-1}$ ein $ᄋ$ durch Dr. Packard erhalten, in meiner Sanmlung.

A n merkung. Nit ihr verwandt, aber viel kleiner und angenehuer gefärbt ist $S$. corculana Z. von der Vancouver-Insel. (Diese Verhandlung. 1874, Bd. XXIV, p. 433).

5. Graph. Roessleri n. sp. Taf. IX, Fig. 24.

Magnu; al. ant. (sine $\sigma^{\pi}$ revolucro) clongatis, infru apicem impressis, sordide abidis, inferius, wacsertim ante maculum speculurem punctis \pm nigris notutam, luteo-obscuratis, costa fusco-punctuta; post. obscure firscis, basim versus dilutioribus, cono-ciliatis, subtus totis exalbidis. $\sigma^{\top}$.

Noch grüsser als Paed. monogrammanu, besonders durch die auf der Oberseite dunkelbrannen, anf der Unterseite einfarbig schmutzig gelblichweissen Htfl. ausgezeichnet. R. und K. hellbräunlich grau. Fühler borstenfümig, nnbehaart, grau. Taster buschig, zusammengedrückt, mit sehr kurzem Endgliede. Sauger klein, gelblich. Vorder- und Mittelbeine hellgran, lehmgelblich angreflogen (Hinterbeine fehlen). Hinterleib bräunlich mit zum Theil hellgrauschuppigen Segmenten, weissgrauem Bauch und gespreiztem, gelblichem Analbusch.

Vdfl. fast 7"“ lang, sehr gestreckt mit vortretender Spitze, weil der Htrd. unter ihr recht merklich eingedriickt ist. Grundfarbe lehmgelblichweiss, längs des Vrdrdes. am hellsten, sonst lehmgelb nebelig, besonders längs des Innenrandes, wo der Grund durch verlängerte, gelbbraune Schuppen verdunkelt ist; die duukelste Stelle, ein grosser Nebelfleck, befindet sich vor dem Spiegelfleck. Dieser ist gerundet, ohne scharfe Begrenzung ausser dnrch die Htrd.-Linie, hell wie die Costalpartie, und gegen den dunkeln Nebelfleck durch einen breiten Bleistreifen abgegrenzt; ausserhalb desselben liegen zwei tiefschwarze Punkte übereinander, und zwei innerhalb; diese vier Punkte sind weit von einander getrennt und bilden die Ecken eines Quadrats. Der Vdrd. ist fast von der Basis an braun punktirt; die Punkte nehuren in Grösse nud Dunkelheit gegen die rostbraune Flügelspitze zu nnd werden zuletzt dreieckige Costalstriche. Eine weissliche Linie geht schräg fom viertletaten Costalstrich nach der eingedrückten Htrd.-Stelle, wo die Fransen auch weisslich sind; ein eben solches Strichelchen 
kommt dicht vor der Flügelspitze aus dem Vdrd. herab. Zwischen der Flügelspitze and dem Ende der weissen Querlinie, und in einem Fleck unterhalb der letztern sind die übrigens weisslichen Eransen schwärzlich.

Htfl. etwas gegen die Spitze verlängert, schwarzbraun gegen die Basis gelichtet, am Innenrand lell bräunlichgrau. Fransen weissgrau, gegen die Flügelspitze weisslich, an der Wurzel mit einer braungrauen Linie durchzogen.

Unterseite der Vdfl. dunkelbraun; der verloscheu punktirte Vdrd. ist in einem schmalen Streifen weissgeblich; die Fransen ebenso, an der Aussemhälfte wie auf der Oberseite gezeichnet. Htfl. einfarbig schmutzig weissgelblich; die Fransen um den Innenwinkel hellgrau, gegen die Flügelspitze weiss. Ader 3 und 4 bilden eine Gabel, deren kürzerer Stiel mit Ader 5 fast aus einem Punkt kommt.

Vaterland: Nordamerica. Ein schön erhaltenes $\sigma^{\pi}$ in Dr. R ös sler's Sammlung.

6. Graphol. (Poecilochroma) malachitana n. sp. Taf. IX, Fig. 25.

Minor, fronte palpisque exalbidis: al. ant. (sine revolucro $\sigma^{\text {T) }}$ purpureo-cinereis, plaga maxima, media, rotundata, virescente, albo-marginata, adversus costam canescente, arcu postico longitudinali nigro, superius albomarginato. $\sigma^{7} Q$.

Keiner mir bekannten Art ähnlich, an dem grossen, runden, bräunlichgrünen Fleck der Vdfl.-Mitte leicht kenntlich.

R. purpurgrau. Hinterkopf grau, Vorderkopf weissgelblich wie die Taster. Diese stehen um die halbe Kopflänge hervor und sind etwas gekrïmmt, zusammengedriickt keulenförmig; das kurze Endglied ist frei und auf der Oberseite grau. Saugrüssel kaurn vorhanden. Fühler ziemlich dick, loraun nit hellgelblichem Wurzelglied. Brust weiss, seidenglänzend. Vorderbeine braungrau. Mittelbeine an den Schenkeln grau, seidenglänzend; ihre Schienen zusammengedriickt, durch die reichliche, anliegende Behaarung länglich dreieckig, braun; Füsse branngrau, seidenglänzend, mit hellen Spitzen der Glieder. Hinterbeine grau mit Seidenglanz; Schienen nur unterwärts etwas behaart; die vier letzten Fussglieder dunkelgrau mit hellen Enden. Hinterleib ziemlich schlank, dunkelgrau mit blassgelblichem Aualbusch des $\sigma^{x}$; das weibliche Analglied kegelförmig mit verstecktem Legestachel.

Vdfl. 3-31/4" lang, länglich, mit schwach convexem Vdrd. und noch schwächer convexen Htrd. Grundfarbe anf der Basalhälfte schiefergrau, schwärzlich gefleckt, auf der Endhälfte purpurgrau und mit schwarzen Strichelcheu und Punkten bestrent. Ein sehr grosser, fast bis zum Inuenrand ruchender, gerundeter, basalwärts etwas gespitzter, bräumlichgrïner Fleck nimmt den ganzen Mittelrauın ein; er ist fein weisslich gesäunt und geht gegen den Vdrd. in weissliche Farbe über. Anf dem Innenrand vor dem Innenwinkel liegt ein kleines, schwarzes Dreieck, basalwärts weisslich yesäuınt und von dern grossen, grünen Fleck durch einen schwarz bestäubten Raum getrennt. Von der Mitte 
des Htrdes. reicht ein schwarzer, gegen den Vdrd. convexer und oberwärts weissgesäumter Streifen bis nahe an den grünen Fleck. Vdrd. auf den beiden Enddritteln mit schwarzen, sehr schrägen Querstrichelchen gezeichnet. Fransen einfarbig purpurgrau.

Htfl. ziemlich schmal und spitz, braungrau, am Htrd. und in der Spitze am dunkelsten, die Adern braun. Fransen grau mit dunkler Linie nabe der Wurzel.

Unterseite der Vdfl. dunkelbraungrau, am Innenrand hell, auf der Endhälfte des Vdrdes. schmal blass mit braunen Flecken. Htfl. heller.

Vaterland: Missouri, von wo Riley mir ein Pärchen schickte; ein $\sigma^{\text {T }}$ erhielt ich von Professor Hering mit der Angabe: Südamerica.

\section{Graphol. (Poecilochr.?) usticana n. sp. Taf. IX, Fig. 26.}

Alis ant. (sine revolucro $\delta^{7}$ ?) oblongis, obtusis, cinereis, obscurius strigulatis, area basali brevi, truncata, plaga costae posticae magna in marginem posticum medium coarctata punctoque apicali badio-fuscis. 9 .

Von der Grösse und Gestalt der Achatana SV., sehr ausgezeichnet durch das scharf abgeschnittene rothbraune Basalfeld, den grossen, ebenso gefärbten Costalfleck und den Mangel eines Spiegelflecks.

R. rothbraun, K. heller, Gesicht ins Gelbgrane. Taster bell gelbgrau, stark zusammengedrückt; das Endglied dünn, stumpf, deutlich hervorragend. Sauger kurz. Beine sehr hell staubgrau, die vorderen mit braunen, hell geringten Scbienen und Füssen (die Mittelbeine fehlen); die Hinterbeine mit ziemlich verdickten Schienen, einfarbig. Hiuterleib bräunlichgrau mit weisslichem Bauch und kaum hervorragendem Legestachel.

Vdfl. fast $4^{\prime \prime \prime}$ lang, ziemlich breit mit abgerundeter rechtwinkliger Spitze und darunter convex hervortretendem Htrd. Grundfarbe hellgrau, mit bräunlichen Querstrichelchen, welche auf Vorder- und Innenrand dunkle Punkte bilden, wellig durchzogen. Das sehr kurze, hinten scharf und ziemlich grade und senkrecht abgeschnittene Basalfeld ist rothbraun, mit dunkleren Querstrichelchen bestreut. Hinter der Mitte hängt am Vdrd. ein rothbrauner, grosser, etwas trapezoidaler Fleck, der in einen schmalew Arm bis an die Mitte des Htrdes. ausgezogen ist und auf dem Vdrd. in der Mitte in einer wenig bemerkbaren grauen Stelle drei schwarze Querstrichelchen enthält. Hinter ihm trägt der Vdrd. zwei verstärkte, rothbraune Striche, welche mit feinen abwechseln, und anf welche der gerundete rothbraune Apicalpunkt folgt. Die Stelle des Spiegelflecks ist wenigstens basalwärts dnrch eine verloschene, weissgraue, einwärts dunkel beschattete Querlinie abgegrenzt. Htrd.-Linie braun. Fransen hellgrau, am Apicalpunkt und am Ende des brannrothen Arms des Costalflecks braun.

Htfl, schwärzlichbraun. Fransen weissgrau mit schwärzlichgrauer Basallinie.

Unterseite der Vdfl. schwarzgrau, am Vdrd. schmal ochergelblich und auf diesem Grunde abwechselnd mit schwarzgrauen Fleckchen und schwarzen Querstrichelchen gezeichnet. Fransen blässer gefleckt als auf der Oberseite. - Htfl. 
hell gelblichgrau, in der Spitze hell und davor dnnkler bestäubt. Eine dunkle Stelle befindet sich an Htrd. zwischen Ader $1 \mathrm{~b}$ und 2. Ader 3, 4 und 5 kommen fast aus derselben Stelle und stehen am Ende gleich weit von einander ab.

Vaterland: Nurlamerica. Ein gut erhaltenes $q$ in Dr. Rössler's Sammlung.

\section{Graph. subnisana n. sp.}

Capite palpisquc canescentibus, al. ant. cinereis, obscurius pulverosis, costa grossins fuscescenti-strigulata, apice ocellari, macula dorsali fusca ante spatium dorsi medii canescens, macula anguli interni triangula transversa brunnea nigro-bilineolata. ơ 9 .

Aeusserst ähulich den ganz hellen, auf dem Innenrand der Vdfl. nur mit gelichteter Grundfarbe versehenen Ex. der Paedisca nisella L., aber oberhalb des Spiegelfeldes ohne dunkeln, mit schwarzen Längsstrichen gezeichneten Fleck, und beim $\sigma^{7}$ ganz ohne Umschlag, wesshalb die Art nicht einmal mit Nisellu nahe verwandt ist, sondern etwa in die Nähe der Graph. corticana gehört. Sie hat auch nicht geringe Aehnlichkeit mit Paed. tephrinana und der etwas grösseren Paed. tetraquetrana, bei welchen beiden der Umschlag sehr sichtbar ist, und die schmäleren Vdf. gegen die Spitze eine lehmgelbliche Beimischung und ein glänzend eingefasstes spiegelfeld haben.

So gross wie kleine Paed. visella oder tephrinana. R. weissgrau mit dunklerer Bestäubung; K. und 'Taster ohne dieselbe. Taster' obenanf noch weisslicher, auswärts dunkler ausser am Ende des zweiten Gliedes; sie ragen mit dem kurzen Endgliede um die halbe Kopflänge über die Stirn hervor. Beine weisslich; die vier vorderen Füsse aussen braun mit weissen Enden der Glieder; Mittelschienen breitgedrückt, auswärts brauugrau mit weisslichem Mittelband und solcher Spitze. Hinterleib hell staubgrau, am Bauch weisslich; Analbusch blass, beim $\sigma^{\text {t }}$ länglichrund, beim $Q$ abgestumpft.

Vdfl. $3 \frac{1}{4}{ }^{\prime \prime}$ lang, in cler Gestalt wie bei Nisella, nämlich etwas gestreckt, nach hinten kaum erweitert, mit schwach convexem Vdrd. und solchem, unterhalb der zugerundeten Spitze eingedrücktem Htrd. Grundfarbe weissgrau, reichlich dunkler grau bestäubt und unregelmässig mit kleinen Flecken bestreut. Das Basalfeld ist nur bei $1 / 3$ durch einen vom Innenrand schräg auswärts aufsteigenden und bis über die balbe Flügelbreite reichenden, mehr oder weniger dicken, bräunlichgraueu, aussen schmal weissgrau gesäumten Querstreifen angedeutet. Der ganze Vdrd. ist mit etwa acht schwärzlichbraunen, dreieckigen, schrägen Querstrichen bezeichnet, welche nach hinten grösser werden und je eine feine, gleichfarbige Querlinie zwischen sich haben. Vor dem nur durch etwas hellere Färbung ausgezeichneten Spiegelrauın liegt ein gelbbräunlicher, mehr oder weniger deutlicher, dreieckiger Dorsalfleck, dessen Spitze eine kurze und darunter eine etwas längere, tiefschwarze Längslinie enthält. Die Flügelspitze ist ocellenartig braun, durch zwei weissliche Costalläkchen abgegrenzt, die sich zu einem weisslichen Strich, der den Htrủ. in der Krümmung erreicht, 
verlängern. Htrd.-Linie braun, dureh den weisshehen Strich an der Krïmmung nnterbrochen und nur bis zur Hälfte des Htrdes, herabreichend. Fransen bräunlichgrau, an Spiegel hellgrau.

Htfl. ziemlich hellgran, an Immenrand noch heller. Fransen wcisslieh, nahe der Wurzel mit einer grauen Schattenlinie durehzogen, die den Analwinkel nicht erreicht.

Unterseite der Vdfl. braungrau, das Innenrandfeld hell; Vird. bram und weisslich weehselnd gefleckt. Htfl. noch heller als oben.

Vaterland: Massachusetts oder Maine. Zwei $\sigma^{7}$, ein $q$, die ich von Packard erhielt, in meiner Sammlung.

9. Graphol. (Hedya) rellukance 1. sp. Taf. IX, Fig. 27.

Minor; atis ant. elongatis (sine revoluero ol) pallidissime carneis $s$. oetwaceis, lilacino-submicuntibus, spisse fuscescenti transwerse strigulosis, lituru costae posticae fuscescente, speculo interius striga plumbea marginato, nigrolineato. o o.

Eine nahe Verwandte der meist etwas grösseren, europäischen Minutana, doch ausser vielem Anderen von ihr dadurch verschieden, dass sich bei ilır auf den Vdfl. kein Basalfeld absondert, dass dagegen am Vdrd. linter der Mitte cin verdunkelter Wischfleck lıängt, der sich durchaus nicht zu einer Binde fortsetzt, und dass der Spiegel basalwärts mit einer Bleilinie eingefasst ist.

R. und K. sehr blass ochergelb, gelbbrïunlich gefleckt; Gesicht bisweilen fast weisslieh. Taster klein, kaum über den K. liervorstehend, zusammengedrïckt kenlenfïrmig, blass, answärts bis gegen die Spitze gebräunt; Endglied lurz, bräunlich. Sangrüssel kurz. Beine blass; die vier vorderen auf den Schienen auswärts braun geflerkt, und die vier letzten Fussglieder auswärts brann mit weisslichen Enden. Hinterleil grau, am Bauch weissgelblich; Analbuseh bleich, beim on stark.

Vdfl. 3-31/4" lang, ziemlieh gestreekt mit sehr sehwach convexem Vidrd. und convexem, unterhalb der Spitze eingedrücktem Htrd. Grundfarbe mit schwachem Lilasehiller, sehr hlass ochergelbröthlich, nach hinten mehr röthlieh, reichlich mit hellbraunen Querstrichen, die sich hier und da za Qnerlinien vereinigen und auf den Gegenrändern oft punktförmig verdunkeln, wellig durehzogen. Hinter der Mitte hängt am Vdrd. cin bräunlicher, dunkler Wisch, ron dessen Anfang bis zur Flïgelspitze der Vdrd. auf verdunkeltem Grunde mit abwechselnd feinen weisslichen und breiteren, längeren, braunen Querstrichelch n gezeichnet ist. Der Spiegel wird basalwärts ron einer starken, unregelmässig gekrümmten Bleilinie begrenzt, ist hell und glanzlos und enthält ein paar Bleiwölkchen und eine Querreihe sehwarzer, nach oben zu Punkten verminderten Jängsstriclıen. HItrd.-Linie brännlich, am Eindruck durch eine helle Stelle unterbrochen und weit vor dem Innenwinkel aufhörend. Die blass ochergellen Fransen, welche nahe der Wurzel vol einer verloschenen grauen, mit 
der Htrd.-Linie aufhörenden Iinie durchzogen sind, tragen unterhalb des Eindrucks auswärts einen braunen Fleck.

Htfl. hellgrau, gegen den Htrd. verdunkelt, bein $Q$ ganz dunkelgrau. Fransen weisslich.

Unterseite der Vdfl. braungrau, zwischen Medianader und Innenrand weisslich. Endhälfte des Vdrdes. schmal blassgelblich mit 4-5 breiten, braunen Querstriclien, die mit ebeuso vielen schmalen wechsein. Htrd. blassgelblich gefleckt. Htfl. heller als oben. Ader 3 und 4 bilden eine Gabel, die kürzer ist als ihr Stiel, und deren Aeste näher an einander stelıen als der erste (oder Ader 3) von Ader 2.

Vaterland: Texas (Boll, Belfrage), wo ein $Q$ am 26. Juli gefangen wurde; Massachusetts, wo Burgess bei Beverly ein abgeflogenes $\sigma^{7}$ am 9. Juli fing; New-York, wo Tengström die Art sammelte. Ex. davon in meiner Sammlung und im Museum Cambridge.

\section{Graph. (Ephipp.) interstinctana Clem. Taf. IX, Fig. 28.}

Parva, palpis albidis: alis ant. ex basi cinerascenti nigris, strigulis costae 8 subaequaliter distantibus, subobliquis, niveis, alternatim caerulescentiterminatis, lunula geminata dorsi medii alba, strigula incrassata violascente speculari; post. fuscis, allido-ciliatis. ơ 9 .

Stigmonota - Clem. Proceed. 1860, p. 351.

Graphol. distema Grote, Bull. Buff. I (1873) p. 92.

Unserer Coronillana gattungsverwandt und höchst ähulich, von ihr nicht immer durch weissliche Htfl.-Fransen verschieden (denu diese sind bei Coronillana öfters eben so hell), sondern am sichersten durch die gelichtete, ins Graue gelıende Farbe der Vdfl. an der Basis (bei Coronillana ist die ganze Fläche gleich dunkel), durch das von der Basis weiter abgerückte und den folgenden weissen Costalbäkchen mehr genäherte Häkchenpaar und durch das weissliche, nicht graue Gesicht. Aehnlich, doch leichter zu unterscheiden ist die etwas grössere Pallifrontana; bei ilır ist das erste Häkchenpaar noch weiter abgerückt und wie der gradere und aufgerichtetere Doppelstrich des Innenrandes gelblicher, und das Gesicht gelblich statt weiss. Mit Compositella ist Interstinctana haum zu vergleichen, da sie jenen vierfachen Dorsalmond und halbweisse Htfl. hat. Eher möchte Internana zu erwähnen sein, deren $Q$ schwarzbraune, weissgefranste Htfl. hat; bei ihr ist das Gesicht braun, und das erste Costalhäkchenpaar wie bei Coronillana abgerückt, und die $\sigma^{\top}$ Htfl. sehneeweiss.

Vou Coronitlana habe ich das Geäder blosgelegt und es mit den Clemens'schen Angaben über seine Stigmonata übereinstimmend gefunden. l)ie Vdf.-Zelle enthält ziemlicl nahe an der Subcostalader eine Ader, die eine sehr schmale Nebenzelle abschliesst, und wird ausserdem durch eine Falte ziemlich nahe der Medianader durchschuitten. Dass Guenée von dieser Beschaffenheit der Zelle nichts wusste, ist sicher; er hat sein Genus Stigmonata auf nichts 
als die Zeichnung gegründet, und so hat sich erst Wilkinson, dann Clemens vergebens abgemüht, Gattungsmerkmale dafür herauszubringen.

Gewöhnlich kleiner als Coronillana. Gesicht und Vorderseite des Wurzelgliedes der Fühler schmutzig weisslich. Taster ziemlich dünn, fein zugespitzt, horizontal, weisslich. Beine dunkelgrau, schimmernd. Hinterschienen flach, an der Spitze hell, die Dormen weiss; erstes Fussglied dunkelgrau mit weisslicher Spitze, die folgenden weisslich mit dunkler Wurzel. Rücken und Hinterleib schwarzgrau, letzterer an den Seitenrändern der hintern Segmente weisslich; Bauch mit breiten, weissen ader weisslichen Hinterändern; Analbusch klein, beim $\sigma^{\nearrow}$ an der Seite weisslicl.

Vdfl. 13/4-2"“ lang, länglich, beim $\sigma^{7}$ etwas schmäler als beim $Q$, schwarzbraun, an der Basis, besonders am Vdrd. bis zu den Costalliäkchen ins Graue, ohne irgend scharfe Begrenzung. Der Vdrd. trägt ron $1 / 3$ an bis vor die Spitze acht fast rein weisse, ziemlich hurze Querstrichelchen; die zwei ersten Paare sind schräger nach hinten gelegt, als die zwei letzten, und das erste Paar steht rom zweiten ein wenig weiter ab, als die übrigen unter sich; die zwei letzten Strichelchen sind senkrecht; 1, 3, 5 und 8 haben eine etwas glänzende, blaue Verlängerung. Auf der Mitte des Innenrandes liegen zwei durch eine feine schwarze Linie getrennte, weisse, doch ein wenig mit Gelblich rersetzte, nach aussen gekrümmte Querlinien, welche die halbe Flügelbreite erreichen, sich dort zuspitzen und meist eine blaue Farbe annelımen. Ein ziemlich dicker, glänzend blaner oder rötblicher, gebogener Strich liegt im Spiegelfelde; sein oberes Ende nähert sich der blauen Fortsetzung des dritten Costalstrichs; sein unteres ruht auf dem Innenwinkel, wohl meist als ein weisses Pünktchen. Den Htrd. fasst eine schwarze Linie ein, welche unterhalb der Flügelspitze gewǒnnlich von einem kurzen, weissen Längsstrichelchen durchschnitten wird. Fransen schimınernd dunkelgran, über der Flügelspitze weisslich schimmernd.

Htfl. einfarbig dunkel braungrau. Fransen weisslich, gegen die Flügelspitze ins Hellgrane.

Unterseite schwärzlich, unit bläulichem oder gelblichem Schiller. Nur die sechs hinteren Costalhäkchın deutlich und scharf. Fransen der Htfl. heller grau als die der Vdfl.

Vaterland meiner sieben Ex. Massachusetts, wo Burgess sie vom 1. bis 12. Juni bei Beverly fing. Ein Ex. erhielt ich von Grote als sein Distema mit der Nachricht, dass die Raupe in Kleesaat lebt.

A nmerkung. Ich halte diese Art für einerlei mit der Clemens'schen, ungeachtet einiger Differenzen: Die Gesichtsfarbe wird verschwiegen, da das head dark brown offenbar nur auf die Oberseite des K. geht; der dorsale Doppelmond soll etwas Glanz haben (somewhat silvery) - der Specularstrich, der violettlich oder bläulich ist, soll silvery sein; die Costalstriche werden nicht so angegeben, wie ich sie beschreibe, sondern als yellowish white, slightly silvery hued; ron der Farbe der Htfl.-Fransen geschieht keine Erwälnung. Grote, der seine $G r$. distema ziemlich kurz beschreibt, meldet mir, dass er 
sic hauptsächlich darum nicht für die Clemens'sche Art ansehe, weil bei dieser die Vafl. brown sein sollen.

11. Grap). (Ephip).) ectipsana n. sp. Taf. IX, Fig. 29.

Parva, palpis canis; al. ant. ex basi cinerca fuscis, strigulis costalibus aequaliter distantibus, niveis, caenlescenti-terminatis, primis duabus elongatis, perobliquis, speculo strigis duabus aureis incluso; post. niveis, apice fusco. $\sigma^{7}$.

Bei genauer Betrachtung erkenne ich am Innenrand der Vdfl. des einzigen vorliegenden Ex. zwei Sichellinien in der Gestalt wie bei Interstinctana; sie sind aber so undentlich, dass sie als nicht vorhanden gelten können, jedoch die Vemuthung erregen, dass sie bei anderen Ex., namentlich heim $q$, deutlicher auftreten und in die Diagnose anfgenommen werden müssen. Das lange, sehr schräge erste Paar der Costalstriche, der von zwei goldglänzenden Querstreifen eingefasste Spiegel, die weissen, an der Spitze breit geschwärzten Htfl. machen die Art, wenigstens das $\sigma^{\pi}$, leicht kenntlich.

Etwas grösser als Intcrstinctana. R. hell bräunlichgrau; $\mathrm{K}$. heller, im Gesicht weissgrau. Taster cylindrisch, zusammengedrïckt, von etwas mehr als Kopflänge, horizontal, weissgrau; Endglied dünn, hervorstelıend, etwas abwärts geneigt. Beine gran; Mittelfüsse verloschen heller und dunkler geringelt (Hinterbeine und Hinterleib fehlen).

Vdf. 21/4"' lang, länglich, nach hinten allmälig erweitert. Aus der hellgrauen Wurzel sind sie nach und nach dunkler und zuletzt braun, init gelblichem Schimmer, besonders gegen den Vdrd., am dunkelsten vor dem Spiegel und in der Flügelspitze. Der Vdrd. trägt acht weisse, durch dunkelbraune Querlinien getrennte Querstriche; nur das erste Paar, das viel grösser und scliräger als die folgenden ist, steht etwas weiter ron dem anderen ab, als diese unter sich; der erste Querstrich befindet sich bei 1/5 der Vdfl.-Länge und ist sowie der dritte, basalwärts dunkler gesäumt; die sechs hintersten nelmen eine immer weniger schräge Richtung an, bis der letzte mit dem Htrd. parallel läuft; die meisten schimmern an ihrem nnteren Ende bläulich. Auf der Mitte des Imnenrandes sind die zwei oben erwähnten Mondlinien, deren Anwesenheit nur, wenn man sich genau danach umsieht, erkannt wird. Der schmale Spiegel ist gelblich, von einer tiefschwarzen Querlinie durchzogen und von zwei röthlichen, glänzenden Streifen eingefasst, deren imnerer, breiterer auf dem Innenwinkel ruht. Die schwarze Htrd.-Iinie ist unterhalb der Flügelspitze von einem feinen, weissen Längsstreifchen durchschnitten. Fransen grau, heller schimmernd, am Innenwinkel verdunkelt.

Htfl. weiss, in der Spitze breit graubraun. Fransen des Htrdes. grau, mit dunklerer Linie nahe der Wurzel; gegen den Innenwinkel hin sind sie einfarbig reinweiss; die Vdrd.-Fransen sind dicht an der Flügelspitze fleckartig schneeweiss.

Unterseite der Vdfl. braungrau, reifartig schimmernd; von den weissen Costalhäkchen sind die sechs hintersten rein, die zwei ersten sehr verloschen. 
Htfl. weiss, in der Spitze in geringerer Ausdehnung braun als oben; der Vdrd. braunfleckig, die Flecke an der Flügelspitze auf schneeweissem Grunde.

Vaterland: Texas (Boll). Ein $\sigma^{\nearrow}$ im Cambridger Museum.

12. Graphol. perfluane n. sp., Taf. IX, Eig. 30.

Parva; alis ant. subelongatis, costa recta, plumbeo-cinereis, brunnescentistrigatis, striga media angulata, brunnea, inferius dilatata, macula dorsali post eam canescente, linea marginis postici incrassata atra. 9.

Einigermassen verwandt mit Strobilella, Vacciniana, Corollana, und wobl am besten bei Strobilella einzuorduen; vor ihr und den anderen sogleich durch den graden Vdrd. der nach hinten erweiterten Vdfl. ausgezeichnet und besonders charakterisirt durch die starke, tiefschwarze, aus zusammenfliessenden Flecken gebildete Linie des ziemlich graden Htrdes.

Grösse einer kleinen Vacciniana. R. und K. dunkelgrau. Taster weissgrau, zusammengedrückt, vorn abgerundet, um die halbe Kopflänge hervorstebend. Beine aussen grau; die Enden der Fussglieder weiss; die Hinterschienen zusammengedrückt, vor der weisslichen Spitze schwarzbraun. Hinterleib graubraun mit weisslichen Analschuppen; Bauch mit weissen Segmenträuder»u.

Vdfl. $2 \frac{1}{2}{ }^{\prime \prime}$ lang, etwas gestreckt, nach hinten sanft esweitert, mit ganz gradem Vdrd, abgerundeter Spitze und fast gradem, einwärts gehendem Htrd. Die Grundfarbe ist bis zn der brannen Binde, also bis un die Mitte, ein schwach schimmerndes Schiefergrau, mit einigen dicken, kurzen Querstrichen und Costalpunkten bestrent; hinter der Binde gewinnt ein lehmgelbliches Braun die Oberhand, und das allmälig immer melr gläuzende Bleigran erscheint darin als Querlinien von verschiedener Gestalt und Länge. In der Mitte ist eine stumpfwinklig gebrochene, dunkelbraume Binde, deren oberer Arm kürzer und weiter gegen die Wurzel geneigt ist, während der untere den Innenrand halbirt; diese Binde ist auswärts scharf begrenzt, einwärts ohne scharfe Greuze und gegen den Vdrd. hin schmäler und streifenartig; der untere Arm wirl von einem schmalen, oben verengten, weissgramen, hinten nicht scharf abgesetzten Fleck begrenzt, welchen verloschene, dunklere Querstreifen durchziehen.

Vom Vdrd. gehen bis zur Flügelspitze sieben bleiglünzende Querlinien aus, die vier ersten parallel mit dem oberen Arm der Binde, die drei folgenden mehr senkrecht; die drei ersten sind ziemlich kurz; die vierte reicht, zweinal gebrochen, bis zum Innenwinkel; die fünfte ist ganz kurz, sechs und sieben wenig länger und weiss. Von der Flügelspitze zieht am Htrd. eine dicke, tiefschwarze, sich nach unten verdïnnende Linie bis unter die Hälfte luerab; sie ist durch feine Trennungslinien in. fünf Punkte zerschnitten, am deutlichsten unterhalb der Flügelspitze, wo der Htrd. ein wenig eingezogen ist. Fransen glänzend hellgrau, am Ende dunkler.

Htfl. dunkelgrau, gegen die Basis hell; die schwärzliche Htrd.-Linie ist an der abgerundeten Flügelspitze am schärfsten ausgedrü kt. Fransen heller grau. 
Unterseite der Vdfl. schwarzgrau; der Vdrd. von $1 / 3$ bis vor die Spitze mit sieben weisslichen, durch Schwarz getrennten, an Länge und Schärfe zunehmenden Häkchen; die ersten sehr verloschen und halbirt, die zwei letzten ganz weiss. Die tiefschwarze Htrd.-Linie der Oberseite ist hier sehr deutlich in fünf gerundete Punkte aufgelöst, von denen die zwei stärksten obersten durch einen weissen Strich von den drei anderen abgesondert sind. - Htfl. hellgrau, schillernd; der Htrd. vor der schwärzlichen Randlinie mit einer weisslichen, gegen den Innenwinkel verlöschenden Linie umzogen.

Vaterland: Texas (Boll). Ein gut erhaltenes $q$ im Ifusenm Cambridge.

13. Graphol. Packardi n. sp. Taf. IX, Fig. 31.

Parva; al. ant. cinereis, obscurius transverse undulatis, fascia media fusco-cinerea, costa obsolete fusco-strigulata, spatio speculari vix nigro-signato; post. dilute cinereis, postice obscuratis. ( $Q$ ?)

Eine sehr nahe Verwandte der europäischen Funebrana Tr., noch kleiner als die kleinsten Ex. dieser Art, mit hellerer Grundfarbe der Vdfl. und sehr deutlicher, dunkler, fast senkrechter Mittelbinde.

R. und Kopftheile ziemlich dunkelgrau. Taster etwas aufgebogen, wenig über die Stirn hervorstehend, mit kurzem Eudgliede. Beine grau; Füsse hell, die Glieder obenauf am Ende dunkelgrau; Hinterschenkel und Hinterschienen weisslichgrau, einfarbig. (Hinterleib fehlt).

Vdfl. wenig über $2^{\prime \prime}$ lang, länglich, von der Gestalt der Funebrana \& (deren Vdrd. convexer ist als der des $\sigma^{7}$ ), am Htrd. unterhalb der Spitze haum merklich eingedrückt. Grundfarbe glanzlos grau, heller als bei Funebruna, auf der Basalhälfte deutlich dunkelgrau querwellig; die Wellenlinien etwas verflossen, nehr oder weniger vollständig, hie und da verstärkt, meist oberwärts nach binten geneigt. In der Flügelmitte folgt eine ziemlich breite, fast senkrechte, dunkle Binde (bei Funebrana ist gewöhnlich eine bindenförmige Verdunkelung zu erkennen, die aber vou der Costalınitte schräg nach dem Innenwinkei geht), am Innenrand verengert. Auf sie folgt im Innenwinkel ein ziemlich deutliches, kleines, dunkelgraues Dorsaldreieck. Der Spiegelraum ist nur hell, etwas nebelig, in der Hitte mit Spuren von ein paar schwarzen Längsstrichelchen. Die Flügelspitze ist etwas verdunkelt. Die braunen oder schwärzlichen, dreieckigen Costalstrichelchen sind sehr undeutlich, weil sie auf dunklem Gruncle liegen. Htrd.-Linie fein, braun. Fransen dunkelgrau.

Htfl. sehr hellgrau, an Htrd. und breiter in der Flügelspitze etwas verdunkelt; auch die Adern sind durch ihre dunkle Färbung kenntlich. Fransen grau, an der Wurzel mit dunkler Linie fast bis zum Analwinkel.

Unterseite der Vdfl. ziemlich hellgrau, vor der Htrd.-Linie und auf der Endhälfte des Vdrdes. schmal weisslich, wodureh die dreieckigen, braunen Costalhäkchen recht deutlich werden. HtH. heller und am Rando viel weniger verdunkelt als oben. Die Adern sind selnr dentlich; 5 steht von 4 etwas weiter ab, als diese von 3 , und soweit wie 2 von 3 . 
Vaterland: Texas (Boll). Ein wahrscheinlich weibliches Ex. im Museum Cambridge. Ich habe diese unscheiubare Art dem Herren Dr. Packard jun., dew ich so viele Beiträge zu meinen Arbeiten über die nordamericanischen Micropteren verdanke, zu Ehren benannt, weil sie olne Zweifel wie ihre Verwandte, welche die Früchte der Pflaumen (und Schlehen) verdirbt, ein ökollomisch wichtiges Thier ist. Wie der Schmetterling von Funebrana sehr selten im Freien gesehen wird, so wirl es auch mit Graph. Funebrana sein, und meine Vermuthung, dass sie in NAn. eine bisher ungeahnte Verbreitung hat, wird sich wahrscheinlich bestätigen.

\section{Paedisea Tr.}

Vdf. länglich, beim $\sigma^{7}$ mit Vdrd.-Umschlag an der Basis. Spiegel unvollständig, bisweilen etwas glänzend, ohne Einfassung durch glänzende Linien. Halbeifleck am Innenwinkel meist vorhanden. An der Nitte des Innenrandes ein heller, gegen die Flügelbasis hin durch einen dunkeln Fleck begrenzter, mehr oder weniger gegen den Vilrd, verlängerter Fleck. Apicalfleckchen oft ocellenähnlich.

A) Fransen ohne einen dunkeln Atomenstreifen an der Basis.

\section{Peed. inclinand n. sp. Taf. IX, Fig. 32.}

Media; alis ant. subangustis, violuceo-fuscis, macula dorsi medii alba angustu, angulata, inclinatu, maculu speculuri albida ulversus eam dentem porrigente. of 9 .

Verwandt mit Paed. foenella L., bei welcher aber der weisse Dòrsalfleck weiter gegen den Vdrd. hinaufreicht und der Specularfleck nie eine zahnartige, gegen den Dorsalfleck gerichtete Verlängerung hat; auch ist ihre Grundfarbe nie dunkel violettbraun.

Grösse einer kleineren Foenella. R. und K. chocoladenfarbig, Gesicht heller. Fühler stark, einfach borstenfürmig, Taster von mehr als Kopflänge, zusanmengedrückt; zweites Glied keulentörmig, innen hell; Endglied knospenförmig hervorstehend. Beine hell, an den Füssen etwas dunkler ausser an den Euden der Glieder; Hinterschienen stark, zusammengedrückt, anf dem Rücken mit niederliegender Beharung. Hiuterleib des $\sigma^{\nearrow}$ dünn, des 9 kräftig, staubgrau. Aualbusch schwach, ins Hellgelbliche.

Vdfl. 4-41/2"' lang, ziemlich schmal mit deutlicher Spitze und schwach convexen Htrd, violettbraun, hie und da dunkel. Umschlag des $\sigma^{7}$ dicht anliegend, von $1 / 3$ Länge des Vildes. Dieser von der Mitte an mit gedrängten, schrägen, nach hinten an Länge zunehmenden, dunkelzimmtbraunen Strichen; vor dem tiefbraunen, ocellenähulichen Apicalfleckchen ist ein sehr deutliches, weissliches Costaldreieck, welches vor seiner vorderen Ecke einen braunen Querstrich hat. Auf der Mitte des Innenrandes liegt ein bis über die Falte reichender, nach hinten überhängender, fast reinweisser Fleck von wechselnder Gestalt, 
der aber wohl immer gegen den Vdrd. hin zugespitzt ist und hinten oberhalb eine spitze Ecke führt. Der grosse Spiegelfleck reicht bis in den Innenwinkel hinein, ist schmutzig weisslich, über der Falte mit einem starken, abwärts gerichteten Zahn versehen, dessen Farbe in der ihn einfassenden, verdunkelten, gelbbraunen Grundfarbe grell hervortritt; oberhalb enthält der Spiegelfleck, wo er durch Grau wolkig wird, 2-3 sehwarze sehr knrze Längsstriche; sein oberes Ende verliert sich in die Grundfarbe und wird dureh einen tiefgelbbraunen Fleck gegen das weissliche Costaldreieek abgegrenzt. Fransen brännlich, an der Basalhälfte violettgrau bestäubt, am Innenwinkel um den Spiegelfleek weisslich.

Htfl. dunkel braungrau, an der Basis kaum heller. Fransen hellgrau, gegen den Innenwinkel ins Weissliehe, nahe der Wurzel von einer verloschenen, graven Sehattenlinie durelizogen.

Unterseite der Vdfl. dunkelbraungrau, auf der Eudhälfte mit vier verlosehenen, nach hinten deutlicheren und grösseren, zerschnittenen weisslichen Costalfleckehen. Htfl, etwas heller, am lichtesten an der Wurzel und am Innenrand. Ader 3 und 4 bilden eine Gabel, deren Stiel etwas weniger als die Hälfte des Ganzen beträgt.

Vaterland: New-York (Speyer), Texas (Boll). Ein $\sigma^{7}$, ein $q$ in meiner Sammlung, ein $\sigma^{x}$ im Cambridger Museum.

\section{Paed. bimaculana Don.}

Media; thorace et capite fuscescenti-ochraceis, alis ant. fusco ferrngineoque mixtis, macula dorsi medii lata, angulata, alba, macula speculari magna albida, nitidula, dentem postice deorsus porrigente. $\sigma^{\top} q^{\prime}$.

Grapholitha - Heinem. Wiekler S. 145.

Paedisca dissimilana Tr., Fr. R. Beitr. S. 170, Taf. 62, Fig. 2.

Mit der bei uns im Spätsommer als vorletzte Paedisca auftretenden Bimaculana stimmen drei dureh $\mathrm{Boll}$ bei Cambridge gefangene Weibchen so genau überein, dass ich sie nieht als eigene Art ansehen kann.

Ihre Abweichungen sind folgende: Sie sind etwas kleiner, auf P. und K. lichter grauochergelb, fast ins Rostfarbene ziehend, die Htfl. heller grau. Hiernach könnten sie als Var. $b$ elarakterisirt werden: minor, thorace et capite griseo-ochraceis, alis post. dilnte cinereis. Ob die Männchen damit übereinstimınen, und ob die Art eine ursprünglieh americanische ist, bleibt noch zu entscheiden.

Bei Bimacnlana hat der Htrd. der Vdfl. an der Mitte, etwas unter dem obereu Ende des SpecularHecks einen sehr sanften Eindruck. Der etwas glänzende Specularfleck wird in seiner Mitte von oben nach unten dureh einen glanzlosen, blass ochergelben Streifen durelizogen, der aber nicht bis in den Innenwinkel reicht. Ader 3 und 4 bilden eine Gabel, deren Stiel 1/3 des Ganzen beträgt. In dem allen stimmen die americ. Ex. mit den europäiselien. 
3. Paed. clarana Schläg. in lit. Taf. IX, Fig. 33.

Media; palpis longioribus; alis ant. acutis, rufescenti-cinereis, macula ante dorsum medium semiovata, fascia postica inferius attenuata, in plica constricta strigaque lata obliqua marginis posticibrunneis, cano-marginat is. $\sigma^{7}$ 을.

Diese ziemlich grosse Art steht trotz ihrer sonstigen grossen Verschiedenheit am besten bei Hübneriana nnd Junctana. ") Sie ist durch die breite, schräge hintere Binde sehr auffallend gezeichnet, welche sich nach unten verengert und auf der Falte beim $q$ eingeschmürt, beim $\sigma^{\top}$ wirklich durchschnitten ist.

Von der Grösse der grössten Hübneriana, mit scharfer Vdfl.-Spitze. R. und K. rötblichgrau, letzterer mit etwas gesträubten Haaren und weissgrauem Gesicht. Taster fast $\mathrm{nm}$ doppelte Kopflänge hervorstehend, horizontal oder geneigt, stark, zusammengedrückt, weit vor dem Ende am breitesten, aussen röthlichgran, innen hellgrau; Endglied kurz, haarig, stumpf. Fühler des o mikroskopisch gezähnelt, mit gedrängten Gliedern. Beine röthlichgrau; Hinterbeine sehr hellgrau, ungefleckt; die Schiene ziemlich dünn, ohne Haarpinsel, auf der Rückenschneide mit geneigten Borstenhaaren dicht besetzt. Hinterleib grau, ziemlich dünn; Analbusch schwach, kaum heller.

Vdfl. $4^{1 / 2}-5^{\prime \prime \prime}$ lang, ziemlich schmal, nach hinten etwas erweitert, scharfspitzig, am schwach convexen Htrd. unterhalb der Spitze ein wenig eingedrückt, röthlichgrau, gegen den Innenrand heller und ohne Roth, sonst mit spärlichen, verloschenen, dunkleren Querstrichelchen. Umschlag des $\sigma^{7}$ von 1/3 Iänge des Vdrdes. Am Innenrand vor der Mitte liegt ein halbeiförmiger, nach oben rerdünnter und hier etwas nach hinten geneigter, ein wenig über die Falte hinwegreichender, dunkel braunröthlicher Fleck, dessen hintere Seite etwas concav, und der überall mit einer weissgrauen Linie umzogen ist. Von der Mitte des Vdrdes. kommt eine erst verloschen, dann immer lebhafter braunröthliche Binde schräg herab, welche sich gegen die Falte zusammenzieht und beim mit dem kleinen, braunröthlichen Innenwinkeldreieck zusammenhängt, so dass sie als in der Falte zusammengeschnïrt gelten kann, während sie beim $\sigma^{\nearrow}$ hier zugespitzt endigt und von dem Innenwinkeldreieck getrennt bleibt; sie ist auf beiden Seiten mit einer weissgranen Linie gesäumt. Vom Htrd., oberhalb des Inmenwinkels, geht ein nach oben erweiterter, breiter Kieilstreifen bis nahe an den Vdrd.; er ist blässer als die Binde, besonders beim $\sigma^{\top}$, und auf beiden Seiten hell gesäunit. Zwischen der Binde und dem röthlichbraunen, einwärts hell gesäunten Apicalfleckchen sind nur zwei etwas hellere Costalfleckchen, bis an welche der Keilstreifen heranreiclit. Fransen grau, an der Wurzel in einer undeutlichen Linie schwärzlich.

Htfl. grau, beim $\sigma^{7}$ heller als beim $Q$; Fransen noch heller, von einer grauen Schattenlinie durchzogen.

1) Die ich wegen ihres Aufonthalts zwischen Pinsen an sumpfigen Ufern Juncetana getauft hatte, welches Wort HS, zu einem so nichtssagenden verdorben hat. Einer gleichen Verderbung verdankt Scoria selectata ihren Namen; ich hatte sie als Sc. sceletala mus. Z. an Guenée geschickt. 
Unterseite der Vdfl. braungran, einfarbig; die Htfl. heller, besonders auf der Innenrandhälfte. Ader 3 und 4 bilden eine Gabel, deren Stiel kaum $1 / 3$ der ganzen Länge liat.

Vaterland: Ohio (Schläger). New-York (Speyer). Massachusetts, wo Boll bei Cambridge mehrere Ex. fing.

4. Paed. quintana n. sp. Taf. IX, Fig. $34,35$.

Parva, capite allido, alis ant. angustis, griseo-luteis, fasciis duabus superius abruptis, maculis 2 costae posticae maculaque anguli dorsalis magnis allis. $0^{7}$.

Var. b) fasciis superius conjunctis. o $^{7}$ (Fig. 34).

Von der dritten Grösse der Paedisken, sehr kenntlich an den fünf grossen scharfbegrenzten, weissen Zeichnungen der dunkel graulehmfarbenen Vdfl.

R. von der Farbe der Vdfl, die Schulterdecken an der Endhälfte weiss. K. und Wurzelglied der Fühler weisslich. Taster um melır als die halbe Kopflänge hervorragend, zusammengedrückt, erweitert, vorn dünner, oben und innen weiss, auswärts staubgrau. Beine staubgrau, die vier vorderen an den Fussgliedern obenauf braun mit weissen Enden; Hinterbeine einfarbig mit dünnen, glatten Schienbeinen. Hinterleib dünn, ziemlich lang, glatt, staubgrau mit weisslichem Analbusch.

Vdfl. $3 \frac{1}{3} 3^{\prime \prime}$ lang, ziemlich schmal, nach hinten wenig erweitert, mit deutlicher Flügelspitze und wenig convexem Htrd. Der Umschlag von $1 / 3$ Länge des Vdrdes. Grundfarbe dunkel graulehmfarbig, etwas braun bestäubt. Auf dem Innenrand liegen bei $1 / 4$ und $1 / 2$ zwei weisse, scharf abgegrenzte Binden, die den Vdrd. nicht erreicheı und die bei Var. b) oberwärts zusammenfliessen. Die erste ist oben erweitert und abgerundet; die zweite etwas breiter, unterhalb der Falte hinten zahnartig erweitert, oben nach innen geneigt und dem Vdrd. mehr genähert. Bei der Varietät, bei welcher sie sich vereinigen, schliessen sie ein dunkel lehmfarbenes Dorsaldreieck ab, das bis oberhalb der Falte reicht und hier durch schwarze Schuppen sehr verdunkelt ist. Auf der Endhälfte des Vdrdes. liegen zwei grosse, weisse, schwärzlich eingefasste Flecke, jeder in der Mitte mit einem braunen Costalpunkt; der erste Fleck ist schräg nach aussen gelegt, halb elliptisch; der kleinere zweite ist halbkreisförmig. Im Innenwinkel liegt ein grosser, ebenso gefärbter und gesäumter Fleck, welcher oberwärts eingeschuitten ist und dem ersten Costalfleck näher kommt als dem zweiten. Der Vdrd. hat nur über der ersten Binde einige verloschene, bräunliche Costalstrichelchen auf hellem Grunde; die Flügelspitze ist nicbt ocellenartig verduukelt. Fransen grau (beschädigt; sie scheinen aber auf der Wurzel eine dunkle Atomenlinie zu haben).

Htf. einfarbig bräunlichgrau, heller gefranst.

Unterseite der Vdfl. wie dif Htfl. oben; am Vdrd. scheinen die zwei Costalflecke, aber verloschen und sehr verkleinert, durch. Htfl. heller. Die Adern 3 und 4 sind blos an ihrem Ursprunge vereinigt. 
Vaterlaud: Texas (Boll). Zivei in den Fransen mehr oder minder beselıädigte $\sigma^{\lambda}$, das eine in meiner Sammlung, das andere (Var. b) im Cambridger Museum.

5. Paed. (?) constrictana 1. sp. Taf. IX, Fig. 36.

Minor; al. ant. ollongis, costa convexa (cum o' revolucro?), lutescentibus, dorso medio late exalbido, area basali postice fusco-lutea, macula anguli dorsalis transversa fusco-lutea, albido-marginata, superius constricta, spatio speculari exallido, ocello apicali fusco. $\sigma$.

Kenntlich an dem quer verlängerten und oberwärts eingeschnürten Dorsalfleck.

P. lehmgelbbräunlich, Schulterdecken hinten ganz hell. Oberkopf hell lehmfarbig, Stirn gelblichweiss wie die Taster; diese wenig über die Stim hervorstehend, kurz dreieckig, zusammengedrückt; Endglied kurz, frei, braun. Vorderbeine lehmgelblichbraun mit bleichen Enden der Fussglieder; Hinterbeine einfarbig hell staubgrau. Hinterleib weit über die Htfl. hinausragend, gelbbraungrau, hinten ins Bleichgelbliche übergehend; Bauch bleichgelblieh; Analbuseb kuiz, abgestutzt.

Vdfl. $3^{\prime \prime \prime}$ lang, länglich; der Vdrd. im ersten Drittel grade, danu auffallend conrex; die spitze deutlich hervortretend durch den sanften Eindruck des convexen Hitres. Einen Umschlag, der so weit reichen sollte, wie der Vdrd. gradlinig ist, und dessen stelle auch abgegrenzt erscheint, finde ieh so wenig wie den Haarpinsel, der sonst gewöhnlich unter den Unschlag verborgen liegt; es ist also nicht sicher, ob die Art, wie es ihre Zeichnung audeutet, in Paedisca ihren riehtigen Platz hat. Grundfarbe bräunlich lehmfarben. Das Basalfeld ist braun querstrichig, gegen ùie Wurzel hell, an Ende dunkel lehmgelbbraun, und zwar an der Innenıandhälfte am breitesten; seime hintere Grenzlinie bildet in der Mitte einen stumpfen Winkel und wird dureh eine geiblichweisse Linie gesäumt, die gegen das folgende Inneuraudfeld nicht absticht. Dieses gelblichweisse Innenrandfeld reicht oben bis an die Falte, linten an den Dorsalkegel und stellt ein Trapez dar. Der dunkel bräunlieh lehmfarbene Kegelfleck des Innenrandes vor dem Innenwiukel ist nach oben verlängert und in der Falte stark eingeschnürt; der über der Einschü̈rung liegende Theil ist oben, wo er sich in die Gruudfarbe rerliert, abgerusdet und trägt in der Gegend der Querader ein schwarzes Längsstrichelchen. Vorn uud hinten ist dieser Fleck mit einer feiuen, gelblichweissen Linie gesüunt, die am feinsten und vollständigsten auf der dem Spiegelfteck zugekelurten seite ist. Der Spitgelfleck ist gelblichweiss, gegen den liegelfleck grauschattig und sonst ohne Zeichnung. Der Vdrd. ist auf der Evdhälfte auf weisslichem Gruade wit starken, gellbraunen, schrägen, zugespitzten Querstrichen gezeichnet, die zwisehen sich je ein schwarzes Querstrichelchen haben. Die Flügelspitze ist zu einem braunen Ucellus verdunkelt, der durch ein weisses Costalhäkchen und unterwärts durch ein gebo- 
genes, weisses Längsstrichelchen abgegrenzt wird. Fransen grau mit dunklerer Wurzel; (um die Flügelspitze sind sie abgestossen).

Htfl. hellbraun. Fransen grau mit verloschener duskler Linie nahe der Wurzel durchzogen.

Unterseite braungrau. Vdfl. auf dem Vdrd. wie oben gezeichnet; der Apicalocellus schwarz. Htfl. etwas heller, um die Spitze und am Vdrd. mit braunen, groben Punkten spärlich bestreut.

Vaterland: Texas (Boll). Ein ơ im Museum Cambridge.

\section{Paed. desertana n. sp. Taf. IX, Fig. 37.}

Minor, palpis intus canis, exterius griseis; alis ant. area basali nigricante, oblique terminata, ceterum sordide albidis, macula anguli dorsalis obsolete cinerea, ciliis praeter angulum dorsalem fuscis. o’.

Nächst verwandt mit den europäischen Arten Roborana und Incarnatana, von verloschenem Aussehen, auf den Vdfl. ausser dem Basalfelde schmutzig weisslich, ohne die graue Fortsetzung des Basalfeliles auf dem Vdrd. und obne die braunrothe, schwarz bezeichnete Stelle in der Flügelspitze.

Grösse ciner inittleren Roborana, von gleicher Färbung des R., des K. und der Taster.

Vdf. 4" lang, von der Gestalt der Roborana, doclı ein wenig stumpfer und am Htrd., wenn auch nur sehr schwach, convex. Die Grundfarbe ist ein schmutziges, fast unnerklich zum Röthlichen neigendes Weiss, olne das bleigraue Gewölk der beiden Verwandteu. Das Wurzelfeld ist schwärzlichgrau, uuterbalb der Falte mit der Grundfarbe gemischt und ruit vielen dunkelu, groben Querstrichen durchzogen; es reicht am Vdri. weiter als am Inneurande und etwas mehr gegen das Ende des Umschlags als bei Roborana; es hat über der Falte eine stumpfe Ecke und darunter eiue seichte Concavität. Der Vdrd. ist bis zur Flügelspitze mit etwa 12 verloschenen, grauen, abwechselnd feineren und stärkeren, etwäs schrägen Querstrichen bezeichnet, von deaen die hintersten sich zum Theil als verloschene Querlinien bis zum Htrd. fortsetzen, ohne die Flügelspitze dadurch dunkler erscheinen zu lassen. Der dunkle Fleck iı Innenwinkel ist mit weisslichen Schuppen überdeckt, durch welche nur einige dunkle Querstriche lindurchscheinen; die schwarze Spitze, welche dieser Fleck bei Roborana, Incarnatana, Suffusana stets zeigt, fehlt hier gänzlich. Ebenso fehlt in der Flügelspitze der rothbraune Augenfleck und die schwarzen Punkte in braunrothen Streifchen darunter. Nur dicht am Htrd. selbst licgt ein schmaler, schwer kenntlicher, etwas unterbrochener, bräuulicher Streifen läug der braunen Fransen, so weit diese eine solche Farbe haben; am Innenwiukel sind die Fransen von der Grundfarbe des Flügels.

Htfl. dunkler braungrau als bei Roborana.

Unterseite der Vdfl. braungran, auf dem Vdrd. sehr verloschen weisslich quergestrichelt. Htfl. weissgrau, an Vdrd. dunkel bestäubt und mit verloschenen 
solchen Querstrichelchen. Der Stiel der Gabel, welche Ader 3 und 4 bilden, ist ein wenig kürzer als bei Roborana.

Vaterland: Texas (Boll), wo die Art vermuthlich auf Rosen lebt. Ein $\sigma^{\pi}$ im Musenm Cambridge.

\section{Pred. affusanu n. sp. Taf. IX, Fig. 38.}

Minor, palpis intus exalbidis, exterius fuscis; al. ant. subelongatis, albis, area basali nigricante, brevi, oblique truncata, costa nubeque ante spatium speculare cinereo-nebulosis, speculo atro-punctato, margine postico infra apicem ferrugineo. 오.

Von der vorigen sogleich zu unterscheiden durch das gar nicht weisslich gemischte, am Vdrd. verlängerte Basalfeld. Die sehr schief vom Vdrd. zum Innenrand gezogene Grenze dieses Feldes unterscheidet sich auch von allen ähnlichen europäischen Arten; ausserden fehlt der Affusana, wie der verwandten Roborana, die Giuppe der drei tiefschwarzen Längsstrichelchen, welche die kleinere Suffusana vor lem oberen Ende des Spiegelflecks immer besitzt. Im sonstigen Aușsehen nähert sie sich am meisten den verdunkelten Ex. der Roborana, deren grössten Ex. sie gleichkommt.

R. und K. schwarzbraun. Taster schwarzbraun, innen am zweiten Gliede gelblichweiss. Fühler braun. Vorderbeine braun (die anderen Beine fehlen). Hinterleib grau mit dunklerem Analbusch und gelbweisslichem Bauch.

Vdfl. 5" lang, etwas gestreckt, hinten kauns erweitert, mit ziemlich gradem Vdrd. und ohne Einbiegung des Htrdes, unterhalb der rechtwinkligen Spitze. Grundfarbe weiss. Das schmale Basalfeld schwärzlich, dunkler gefleckt, auf dem Vdrd. um die Hälfte weiter reichend als auf dem Innenrand; seine hintere Grenze geht also vom Vdrd. aus sehr schräg einwärts in ziemlich grader Richtung, doch etwas wellig. Der ganze Vdrd. ist von da an bläulichgrau nebelig mit dunkleren Costalhäkchen; eine solche Wolke mit kleinen weisslichen Stellen zieht breit vor dem Spiegelraum bis zum Innenrand herab und enthält oberhalb der Falte einen grösseren eckigen, in der Falte unter ihm einen kleineren tiefschwarzen Punkt; vor beiden zieht eine feine, schwarze, wellige, oben gegabelte Querlinie herab. Der weisse Raum zwischen der Wolke und dem Basalfelde ist oberwärts mit wenigen grauen Fleckchen und auf dem Innenrand mit drei Querstrichelchen bestreut. Der Spiegelraum ist weiss, hinteıwärts mit einer herabgehenden Reihe grauer Fleckchen und im oberen Theile mit zwei ungleichen, tiefschwarzen Punkten bezeichnet. Vor der Flügelspitze ist ein weissliches, grau quergestricheltes Costaldreieck, und unterhalb der Flügelspitze am Htrd. eine schlecht begrenzte, rostbraune, schmale Mondsichel, zwischen welcher und dem spiegelraum von der Mitte des Htrdes. eine feine rostbraune Linie schräg aufwärts geht. Fransen braun, gegen den Innenrand heller, um denselben weisslich.

Htfl. dunkelgrau. gegen die weissliche Basis gelichtet. Fransen hellgrau mit dunkler Wurzellinie. Die Gabel, welche Ader 3 und 4 bilden ist länger als ihr Stiel. 
Unterseite der Vdf. dunkelgrau, auf dem Vdrd. in einer nach hinten erweiterten Linie weisslich und grau querstrichig. Htfl. weisslich, am Vdrd., ausser gegen die Basis, und in der Spitze mit groben, fleckartigen, grauen Querstrichelchen bestreut. Sammlung.

Vaterland: Nordamerica. Ein gut erhaltenes $Q$ in Dr. Rössler's

\section{Paed. tripartitana n. sp. Tat. IX, Fig. 39.}

Minor; al. ant. infra apicem retusis, costa strigulata, area basali fusca, recta truncata, fascia media latissima exalbida, triente apicali fuscescente, nigro-consperso, speculo indistincto; post. fusco-cinereis. $q$.

Sie sieht den gewöhnlichen, in der Mitte der Vdf. hellen Ex. der Tmet. ocellana etwas ähnlich, ist aber viel grösser, auf den Vdfl. mit kürzerem, grade abgeschnittenem Basalfelde und scharf begrenztem dunklen Apicaldrittel. Auch mit Olindia ulmana. 9 hat sie eine oberflächliche Aehnlichkeit; abcr ihre am Htrd. über der Mitte eingedrückten $V$ df. haben ein viel breiteres gelblichweisses Mittelfeld, und da auf den Htf. der Tripartitana Ader 6 und 7 aus einem Punkt kommen, so kann sie nicht in das Genus Olindia gesetzt werden. Weniger Aehnlichkeit hat sie mit Roborana, weil ihre Vdf. an der Mitte des Ydrdes. gar nicht verdunkelt, dagegen auf dem ganzen Enddrittel so verdunkelt sind, dass das Innenranddreieck, nicht zu erkennen ist. Doch mag die Art zu der Gruppe der Tripunctana, Roborana, Amoenana, Suffusana und Rosaecolana und folglich in die Verwandtschaft der Affusana gehören, wenn auch ibr Tasterbau etwas abweicht.

Grösse der kleinsten Roborana. R. und K. dunkelgelbbraun. Taster heller, von wenig über Kopflänge, fast cylindrisch, mit wenig lockerer Behaırung und gegen das Ende nicht erweitert; das Endglied kurz, kaum abgesondert. Beine schmutzig hellgrau; die vier vordern Schienen und Füsse auf der Lichtseite brann und hell punktirt. Hinterleib gran mit weissem Bauch.

Vdfl. 31/2"' lang, etwas gestreckt, hinten sanft erweitert, am Vdrd. sanft convex, an convexen Htrd. nnterhalb der Spitze schwach eingedrüclit. Das Basalfeld ist kurz, hraun, hinten fast senkrecht abgeschnitten. Das folvende, um die Hälfte breitere Feld ist gelblichweiss und nur auf dem Vdrd. init etwa sechs selır kurzen, schwarzen Schägstrichelchen gezeichnet; seine hintere Grenze geht convex schräg bis vor den Innenwinkel, so dass es am Innenrand bedeutend breiter ist als an Vdrd Der wenig schmälere Flingelrest ist schiefergrau nud mit sclıwarzen Punkten und Fleckchen unregelnässig bestreut. In der hellern Iartie des Spiegelflecks liegen drei schwarze, ungleiche Längsstrichelchen. Der Vdru. dieses Endfeldes ist auf weisslichern Grunde abwechselnd schmäler und breiter braun gestrichelt, und die Spitze selbst ist bräunlich. Den Htrd. umzieht eine feine, braune Linie mit länglicher Verdickung unterhalb des Eindrucks, und diese Verdickung wird gegen den Spiegelfleck durch 
eine weisse, bis in den Innenwinkel reichende Linie abgegrenzt. Fransen (unvollständig) am Innenwinkel weisslich, darüber bis zum Eindruck dunkelgrau.

Htfl. bräunlichgrau, gegen die Wurzel hell. Fransen weisslich, an der Wurzel mit einer braunen Iinie nmzegen.

Unterseite der Vdfl. braungrau, zwischen Falte und Innenrand weisslich. Vdrd. schmal weisslich und fast von der Wurzel an bis zur Spitze schwarzbraun gestrichelt, die Strichelchen vor der Spitze wechselnd breiter und schmäler. Htfl. weisslichgrau, auf dem Costalviertel dunkelgrau mit bräunlicben Querfleckchen.

Vaterland: Texas (Boll.). 1 @ im Cambridger Museum.

Die beinfarbige Raupe lebt in einer länglichen Auftreibung des Stengels (ähnlich der von Conch. hilarana in Artemisia) von Gutiereza microcephala Hooker, in der sie überwintert; 1 Fx. kam in Europa Ende Juni aus.

\section{Paed. tephrinama n. sp.}

Parva abdomine sericeo-cano; alis ant. angustis, infra apicem impressis, griseis, fuscescenti-marmoratis, area basali obscuriore, triangulo dorsali (ante spatium speculare utrimque striga plumbea inclusum) luteo, superius nigro; post. canescentibus, apice obscuriore. o $\sigma^{\top}$.

Sehr ähnlich unserer so gemeinen Tetraquetrana Haw. (Frutetana H. 293, 294), aber specifisch verschieden. Sie ist kleiner und hat gestrecktere Vuff. und gespitztere Htfl.; letztere sind weissgrau, in der Spitze etwas verdunkelt, iiberhaupt heller als bei jener Art; dafür ist die Linie, welche anf den weisslichen Fransen nalıe der Wurzel hinzieht, aber vor dem Analwinkel aufhört, dunkler und schärfer ansgedrückt. Die Vdfl. (fast $3^{\prime \prime \prime}$ lang gegen $3^{1} / 3$ ), deren Umschlag noch etwas länger als bei Tetraquetrana ist, sind von weniger dunkler Färbung; der helle Inuenrandraum zwischen dem verdunkelten Ende des Basalfeldes und dem gelbbraunen Dreieck des Inneuwinkels tritt weniger durch Helligkeit als die gewöhnliche Paediskenzeichnung hervor. (Die Spitze dieses Dreiecks ist wie bei Tetraq. mit einem schwarzen Punktfleckchen oder kurzen Längsstrich bezeichnet). Der Spiegelraum macht sich nicht durch besondere H-lligkeit bemerklich; doch wird in ihm deutlicher als dort ein Spiegel abgegrenzt durch zwei mattglänzend? Bleilinien, die, einander parallel, gegen den Htrd. divergiren und sich bis an die hellen Costalstriche verlïngern; sie schliessen einen hell gelbbrännlichen Raum ohne Zeichnung ein. (Die schwarze Htrd-Linie ist fast schärfer als bei Tetraq.). Der Apicalpunkt ist nicht wie bei Tetraq. zu einem Ocellus verdunkelt.

Der Hinterleib ist riel heller als dort, beim $\sigma^{7}$ weissgrau mit etwas Seidenglanz. Auch Kopf und Taster sind bell. was bei Tctraq. nur ausnahmsweise der Fall.

Vaterland: Massachusetts oder Maine, wo die Flugzeit wahrscheinlich dieselbe (Mai und Juni) ist wie bei der europäischen nächsten Verwandten. 4 ơ 1 ㅇ, von Packard erhalten, in meiner Sammlung. 
10. Prerl. vertummana n. sp.

Purva; alis longins ciliatis, anterioribus elongatis, margine postico perobliquo, non impresso, cinereo-fuscescentibus, vulde variabilibus, ciliorum linea hic illic interrupta fusca.

Var. a) al. ant. subunicolorbus, obscuris, dorso late dilutiore. $\sigma^{7}$.

Var. b) ut a) sed dorso concolure, cosla postice fusco-strigulatu $Q$.

Var. c) al. ant. totis cinereo-fuscis, lineola ante spatium speculare nigre $\mathrm{Q}$.

Var. d) al. ant. cinereis, trabe atra incequaliter incrassata, in medio interrupta, ex basi ad apicem usque perilucta. $q$.

Var. e) al. ant. dilutioribus, striga abbreviata ex dorso ante medium lineolaque vel striola plicae ante spatium speculare nigris. $\sigma^{7}$..

Var. f) ut e) sed costa fusco-striguluta, plica fere tota late fusca. $\sigma^{7}$ 오.

Eine kleine, sehr veränderliche Paedisca, die in einzelnen Varietäten mancher verwandten (unbeschriebenen ?) Art sehr ähnlich sieht, aber wohl immer durch feste Merkmale zu unterscheiden. Als solche Merkmale haben zu gelten: Die gestreckten Vdfl, deren Vdrd. kaum convex ist, und deren Htrd. keinen Eindruck unterhalb der Spitze zeigt, und sehr schwach convex, sehr schief rückwärts läuft; ferner die verhältnissmässig ungewöhnlich langen Fransen aller Flügel; endlich die schwarzbranne, in Stücke anfgelöste Linie nahe an der Wurzel der Vdel.-Fransen.

Vorderkörper dunkel graubräunlich; Kopfhaare bei 'mancheı Ex., besonders Var. c) ins Weissgraue, Taster etwas länger als der Kopf, zusammengedrückt, dreieckig, mit abwärts gerichtetem Endgliede. Beine dunkel, die hintern licht staubgrau. Hinterleib des $\sigma^{7}$ sehlank, dunkelstaubgrau mit bleichgelblichem, etwas gesträubtem, abgestutatem Analbusch; beim $q$ ist der Hinterleib ziemlich stark, mehr ochergelblichgrau, mit zugespitztem Analgliede, ohne hervorstehenden Legestachel.

Vdfl. 3-31/4" lang, beim 9 kürzer als beim $\sigma^{7}$, ziemlich gestreckt mit sehr wenig gebogenem Vdrd., abgerundeter Spitze und sehr schräg zurückgehendem, schwach convexem, uneingtdrücktem Htrd. Der Umschlag hat $1 / 3$ der Länge des Vdrdes, und verdeckt einen eben so langen, bleichgelben Haarpinsel. Grundfarbe dunkel graubräunlich bis ins Weissgraue. Ersteres bei der am einfachsten gefärbten Var. a). Bei dieser ist nur der Innenrand bis zur Falte herauf gelichtet; die Falte enthält in einiger Enfernung von der Basis einen schwarzbraunen Längswisch. Der Vdrd. ist auf der Endhälfte mit einigen ganz verloschenen, nach hinten verstärkten, braunen Fleckchen gezeichnet. Auf den verlängerten grauen Fransen zieht nahe der Wurzel eine schwarzbranne, hie und da unterbrochene, starke Linie. - Bei Var. b) einem 9 , ist der Innenrand nicht gelichtet; aber der ganze Vdrd. anf etwas hellerem Grunde mit deutlichen, kleinen, dunkelbraunen Querfleckchen bezeichnet. - Var. c) ein $\$$, hat die ganze Fläche sehr dunkel und einfarbig, fast olıne jede Spur von Costalzeichnung, dagegen hinten in der Falte eine feine, schwarze, doch wenig 
hervorstehende, gukrümmte Längslinie. - Bei Var. d) einem etwas heller braungrauen $Q$, fängt von der Schulter eine sehr dicke, tiefschwarze, unregelmässige Längslinie an, welche iu der Falte bis vor die Flügelhälfte reicht; sie ist auf dem rechten Flügel eine starke, einfache Linie, erweitert sich aber auf dem linken allmälig zu mehr als dem doppelten Umfang, so dass sie ein über die Falte lıerabreichendes Dreieck bildet, das in eine Spitze ausläuft. Ueber dem Ende dieser Linie fängt eine zweite, etwas wellige Linie an, die sich erst auf der Querader, daın vor der Flügelspitze knotenartig verdickt und mit dem schwarzen Apicalfleckchen zusammenfliesst. - Die Ex. mit hellgrauer Grundfarbe (Var. e) sind gleichfalls im Innenrandfelde am hellsten, über demselben in mehr oder weniger Breite, am breitesten gegen die Flügelspitze bräunlich wolkig, auf dem Vdrd. fast von der Basis ans auf hellem Grunde braunfleckig, mit Flecken, die in der Gestalt sehr nach dem Ex. wechseln, immer aber nacl hinten dunkler und grösser werden. Vor der Fiügelmitte geht aus dem Innenrand ein nach hinten concaver, brauner Querstreifen bis über die Falte und basalwärts heller schattirt, also die Andeutung eines Basalfeldes. Oicht über der Falte, etwas näler gegen den Htrd. als gegen den eben beschriebenen Bogen ist ein kurzer, schwarzer Längsstrich, der bisweilen oberwärts dunkler schattirt ist. (Bei einem $Q$ fehlen beide Zeichnungen.) - Bei Var. f) befindet sich in der Falte ein von der Basis anfangender, dicker schwarzer Längsstreifen, der bis an den braunen Querstreifen reicht oder sich auch bis zu dem schwarzen Längsstrich fortsetzt. Die zerstückelte schwarze oder schwarzbraune Linie nahe der hellen Wurzel der gramen Fransen ist bei allen Varietäten vorhanden und reicht von der Flügelspitze bis zum Innenwiukel.

Htfl. beim $\$$ gespitzter als beim $\sigma^{\lambda}$, gran, auf den langen, hellern Fransen an der Wurzel mit einer verloschenen, dunkelgrauen Linie durchzogen.

Unterseite dunkelgrau, auf den Htfl. heller. Ader 3 und 4 bilden eine kleine Gabel, die kürzer ist als ihr Stiel; das Ende der Ader 5 steht wenig weiter von $4 \mathrm{ab}$, als 4 von 3 .

Vaterland: Texas (Boll.), wo die Art läufig zu sein scheint. Ein $\sigma^{7}$ der Var. a) erhielt ich durch Speyer aus New-York.

B) Mit dem Atomenstreifen an der Wuzel der Hinterrandfranseu der Vorderflügel.

\section{Faed. dodecruna n. sp. Taf. IX, Fig. 40.}

Media; al. ant. (revolucro of appresso, margine postico subconvexo) griseis, densissime nigro-atomosis, parte apicali ochracea, glomere punctorum 12 atrorum ter stanneo-dissecto super angulo interno. $\sigma^{7}$ ㅇ․

Nach ihrer Zeichnung. welche auf den Vdfl. keinen eigentlichen Spiegel bildet, hat sie eine gewisse Aehulichkeit nit Arcuana L., doch auch mit Gr. pupillana, welche einen vollständigen Spiegel besitzt. Vor beiden ist sie durch das Vorhandensein eines Unschlages ausgezeichnet. 
Von wechselnder Grösse, ungeführ wie Arcuana, doch auch bisweilen bedeutend darüber, mit länger gestreckten Vdfl.

Vorderkörper hell gelblichstanbgrau. Taster, um weniger als Kopflänge hervorstehend, zusammengedrückt dreieckig, einwärts heller. Beine noch heller, an den vier letzten Fussgliedern obenauf schwäılich nit puuktförmig weisslichen Enden. Hinterschienen stark zusammengedrückt, auf der Rückenschneide etwas locker liaarig, auf der Unterseite nur bis zum trsten Dornenpaar behaart. Hinterleib dunkler staubgrau, Analbusch hell, zicmlich kurz, abgerundet zugespiizt. Legestachel des $q$ kaum sichtbar.

Vdfl. $3 \frac{1}{2}{ }^{\prime \prime}$ lang, bei einem $O 31 / 4$, bei zwei anderen $4 \frac{1}{4}$, ziemlich gestreckt; der grade Vdrd. uur an der Wurzel sehr schwach convex, die Spitze zugerundet, der Htrd. schwach convex, in den abgerundeten Innenwinkel zurückgehend; der sehr dicht anliegende Umschlag von etwas über $1 / 4$ der Vdrd.Länge. Grundfarbe ein helles Staubgrau, aber äusserst dicht mit schwarzen Atomen bestrcut. Nur der Apicalraum voll etwa halber Flügellänge ist bleich ochergelb, olnne Atome, und eine schmutzig gelblichwcisse, schwach nach oben gebogene Längslinie, die aber of auf der Basalhilfte verloschen ist, ziẹt von der Basis am Unschlage her, danu, die obere Grenze des tiefschwarzen Punktconglomerats bildend, bis ans Ende des letzteren. Bisweilen euthält auch die Falte eine ganz feine weisslichgelbe Linie von der Basis aus bis unter die schwarzen Punkte. Das hell ochergelbe Feld wird von vier bleiglänzenden Limien in gleichen Abständen quer lurchzogen; die vierte ist die längste; die zwei mittleren endigen an einem nach hinten ausgebreiteten Büschel von fünf Strahlen, die aus tiefschwarzen Pünktchen bestehen; die Bleilinien fangen mit mehr oder weniger deutlichen weisslichen Costalpunkten an; bisweilen ist vor der ersten noch eine zu erkennen. Die tiefschwarzen, ungleichen, viereckigen Punkte, ungefähr 12-14, liegen in drei Längsreihen iiber dem Ende der Falte auf weissgelblichem Grunde und sind von zwei Bleilinien quer durchschnitten and von einer dritten, gleichsam der Fortsetzung der dritten Costallinie, hinten begrenzt. Vor der Mitte ist uuterhalb der Falte ein verloschenes, schwarzgraues Fieckchen, und zuweilen weiter gegen die Basis ein zweites auf dem Innenrand. Htrd.-Fransen grau, mit Reihen schwarzer Atome querdurchzogen.

Hifl. hellgrau, in der ziemlich scharfen Spitze am dunkelsten. Fransen schmutzig weiss, an der Wurzel init feiner, gelblicher Linie.

Unterseite der Vdfl. gran, auf der Basalhälfte des Innenrandes hell. Vdrd. auf der Endhälfte mit mehr oder weniger dentlichen weisslichen Punkten. Fransen wcissgrau mit dunkleren Enden. Htfl. viel heller als oben. Die Medianader vieüatig; Ast 3 und 4 bilden eine Gabel, die fast so lang wie ihr Stiel ist.

Vaterland: Ttxas (Boll, Belfrage), wo die auch in weiblichen Geschlecht leicht verülende Art häufig zu sein scheint. Zwei or wurden von Belfrage am 24. und 29. Mai gefangen. 
12. Pred. monogrummana n. sp. Taf. IX, Fig. 41.

Magna; al. ant. (revolucro of longiore, margine postico superius subconcavo) albidis, punctis griseis crebrius adspersis, strigulis postisis subargenteis, speculo strigis duabus argenteis formato lineam atram unam continente. $\sigma^{7}$.

Diese grosse Art scheint leicht erkennbar zu sein. Ihre gelblichweissen Vdfl. haben einen vollständigen Spiegel mit nur einer tiefschwarzen Längslinie und sind mit staubgrauen Punkten reichlich bestrent. Sonst hat sie eine gewisse Aehnlichkeit mit der südenropäischen Albuncana.

Körper mit seinen 'Theilen unrein weiss. Taster um die halbe Kopflänge hervorstehend, vor der Stirn stark erweitert, zusammengedrückt und abgeruudet. Sauger fehlt. Die vier letzten Fussglieder obenauf grau, an den Euden weisslich. Analbusch kurz, vielhaarig; die Haltzangen in der hitte verengert, am Ende schräg zugerundet. (Der Hinterleib scheint leicht zu verölen).

Vdfl. fast 6" lang, ziemlich gestreckt; der Viril. sehr schwach convex, der Htrd. unterhalb der Spitze sehr sanft eingezogen, dann schwach convex und in den abgerundeten Innenwinkel zurückgehend; der Unschlag reicht über $1 / 3$ des Vdrdes. hin. Grundfarbe ein gelbliches, umreines Weiss, reichlich mit verloschenen, bräuulich staubgrauen Punkten von ungleicher Grösse bestrent und wie bestäubt. Vor der Flügelspitze bilden einige derselben verloschene Querstriche, zwischen denen silberne Querstriche, und unter diesen ein paar solche Längsstrichelchen liegen. Der Spiegel wird durch silherne, etwas unregelmässige und nicht völlig zusammenhängende Querlinieu eingefasst, die nach unten convexer gegen einander laufen, oben sich durch eine zerstïckite Längslinie vereinigen, so dass der Spiegel eine ungefähr birnfürmige Gestalt erhält; in der Mitte wird er von einer feinen, tiefschwarzen Längsinie durchschnitten. An seiner oberen Grenze zeigen sich noch ein paar Längsreihen schwärzlicher Stäubchen, die es möglich erscheinen lassen, dass bei mancben Ex. noch eine oder die andere kürzere schwarze Längslinie vorlıanden ist. Fransen weisslich, vom Htrd. durch sehr feine, doch nicht reichliche, tiefschwarze Atome getrennt.

Htfl. weisslichgrau, in der Spitze und längs des Htrdes. grau, ohne scharfe Abgrenzung nach innen. Fransen weiss mit gelblicher Wurzellinie.

Unterseite der Vdfl. dunkelgrau, am Innenrand weissgrau. Vdrd, auf den binteren $2 / 3$ weisslich, wit braunen, nicht scharfen Punkten an der Grenze des dunklen Grundes. Fransen reiu weiss. Htfl. weiss, gegen den Vdrd. hellgrau beschattet. Mediauader vierästig, indem Ast 3 und 4 eine Gabel bildeu, lie halb so lang wie ihr Stiel ist.

Vaterland: Texas (Boll). Ein schönes $\sigma^{\top}$ in meiner Sammlung, mehrere nach Dr. Hagen's Angabe im Museum Cambridge.

\section{Paed. albignttama 13. sp.}

Parva; al. ant. (cum revolucro ó, maryine postico leviter convexo), pallidissime ochraceis, costa tota strigulis strigisque albidis griseo-disseptis 
notata, guttulis disci sparsis allitis, speculo flavido, atro-bitincato, ciliis marginis postici dimidiis nigro-atomusis. 0 .

Aus der Verwandtschaft der Decolorana, Griseolana, Modestuna, Caccimaculana, also wie sie im männlichen Geschlecht mit dem Costalumschlag, dazu auf dem ganzen Vdrd. mit hellen, schrägen Querstrichen und insbesondere auf dem Basaldrittel der Htrd.-Fransen dicht mit schwarzen Atomen bestreut. Aru nächsten ist sie der grösseren, dunkleren Hornigiana zu stellen, aber von ihr, sowie von allen anderen, durch die weisslichen, dunkel eingefassten Tröpfchen zn unterscheiden, welche, 10-12 an der Zahl, zwischen der Falte und den Costalstrichen unregelmässig ausgestreut sind.

Grösse der Decolorana. K. ziemlich glatt, bleich staubfarbig behaart; Gesicht weiss wie die länglich dreieckigen Taster, an denen das Endglied nicht hervorsteht. R. hell staubgrau. Beine weisslich: Hinterschienen schwach verdickt, zusammengedrückt, auf den Schneiden mit etwas lockeren Haaren; an allen Füssen die vier letzten Glieder obenauf halb schwarz, halb weiss. Hinterleib weisslicher als das R. Analbusch weiss, mässig stark, länger als breit.

Vdf. $3^{\prime \prime \prime ~ l a n g, ~ z i e m l i c h ~ g e s t r e c k t ; ~ V i r d . ~ s e h r ~ s c h w a c h ~ c o n v e x, ~ S p i t z e ~}$ fast rechtwinklig, doch etwas abgestnmpft, Htrd. fast grade, Inneuwinkel abgerundet; der Umschlag von mehr als 1/4 Länge des Vdrdes. Grnndfarbe gleichmässig blass ochergelb. Der Vdrd. ist von der Basis aus mit graubraunen, starken Punkten bezeichnet, welche auf weisshichen Grunde liegen; von der Mitte an wechseln längere und kürzere, hinterwärts dunkel beschattete Querstrichelchen. Zwei dieser weisslichen Querstriche bilden sehr schräge, nach hinten gebogene Linien, deren erste aus der Costalmitte kommt und die Richtung nach dem Spiegel nimmt, die zweite, über dem Anfang des Spiegels ans dem Vdrd. herabkommt und gekrümmt und unterwärts glänzend über dem Spiegel bis an den Htrd. und an diesem herunter zieht. Das letzte Costalhäkchen, vor der mit einem weissen Punktfleckchen gezeichneten Flügelspitze, ist anch verlängert, steht viel senkrechter, glänzt unterwärts etwas und reicht bis zu 1/3 des Htriles. In dem Raum zwischen der weissen Costalzeichumng und der Falte liegen etwa 12 runde, weissliche, dnukel umzogene Trüpfchen näher oder entfernter von einander. Zwischen Falte und Inuenrand sind zerstrente grössere graue Punkte, von denen einzelne einen weisslichen Kern haben. Der spregel wird vorn und hinten dureh zwei parallele, grade, zinnglänzemie, ungleich lange Querlinien eingeschlussen, ist blassgelb uml wird von zwei schwarzen Längslinien durchschmitten. Fransen weisslich; auf ihrem basaldrittel bilden dichte, schwarze Atonie einen Streifen, der sich um den Innenwinkel herum bis in den Innenrand verlängert.

Htfl. grauweissheh, weiss gefranst.

Unterseite der Vdfl. schattengrau; der Vird. in dẹ Fndhälfte weisslich, mit sechs ziemlich dicken, schwargrauen, nach hinten gerichteten Qnerstrichen, die aber ilen Vird. selbst nicht berühren. Fransen weisslich, an Ende ge- 
bräunt. Htfl. wie oben. Ader 3 bildet eine Gabel, die etwas länger als ihr Stiel ist.

Vaterland: Texas (Boll). Ein gnt erhaltenes or in meiner Sammlung, mehrere im Museun Caınbridge.

\section{I4. Paed. orcipitana n. sp.}

Parra; capillis supra hirsutis, pallide griseis; al. ant. (cum revolucro o ) pallide griseis, dense brunnescenti-marmoratis, costu tota fisco-strigulosa, speculo obsoleto, interius nigro-terminato, citiis marginis postici tlimidis nigroatomosis. 0 .

Mit der vorigen gar nicht zu verwechseln, desto leichter mit der folgenden, für welche ich sie anfangs hielt. Der sicherste Unterschied besteht darin, dass Comatulana längs des Virdes. der Vdfl. in anschnlicher Breite weisslich, dass ihre übrige Grundfarbe oeherfarl,ig, und lass ihr Spiegel gut ausgebildet und von zwei schwarzen Längstinien durchschnitten ist - während bei Occipitana die Grundfarbe überall schmutrig gelblichweiss ist, unu ihr unausgebildeter Spiegel nur ein paar schwarze Strichelchen enthält.

Grösse der vorigen. R. sehr hell gelblichstaubfarhig. Kopfhaare von gleicher Farbe, vom Nacken bis zu den gleichfarbigen Fühlern aufgerichtet und aus einander gespert, auf der Stirn fast gelblichweiss und locker. Taster hell, länglich dreicckig, znsammengelrückt, mit verborgenem Enlylicle.

Beine gleichfalls ganz hell; alle Füsse an iten vier letzten Gliedern obenauf brann mit weisslichen Enden; die Vorderschienen vorn gelbbraun mit lellen Punkten, die Mittelichienen graubraun mit schrägem, hellem Mittelband, hellem Ende und solchen Dornen; die Hinterschienen wenig verdickt, zusammengedrïckt, auf der Rückenschneide auf $2 / 3$ locker behaart. Hinterleib ochergelbgran mit gleichfarbigem, kurzem, grade abgeschnittenem Analbusch.

Vdfl. 3"' lang; Vdril. fast grade, Spitze deutlich, Htrd. schwach convex; der Umschlag dicht anliegend, von ${ }^{1 / 3}$ Länge des Vdrdes. Grundfarbe bleichgelb, zwischen den sehr reichlichen, vielfach zusammenfliessenden, bräunlichen Marmorfleckchen hervortretend. Vur der Mitte liegt auf der Falte ein grösserer, schwärzlich bestänbter, nach hinten gespitzter, unterwärts hell begreuzter Fleck; unter ihm ist am Immenrande, doch weiter basalwäts, ein gleiclufarbiger, niclit gespitzter: beide sind die getreunten Stiicke des bei Modestume, Modicana ete. vorhandenen, vom Inneurande ausgehenden Bandstreifens. Der Vilrd. ist mit vielen nieht scharfen, gelbbraunen Qnerstreifchen bezeichnet, am undentlichsten auf den rerdmukelten Umschlag. Der spiegel ist ganz unausgebildet; ein schwachglänzeniler, weisslicher Querfleck, unf der Basalseite durch eine undeutliche schwarze Limie begrenzt, brzeichnet seine basale Begrenzung, eine solche Querlinie vor dem Htril die änssere; in dem schmalen, dunkleren Zwischenraun liegen oberwärts zwei schwärzliche, sehr kurze, verflossene Längsstreifchen. Die (grösstentlueils abgestussenten) Fransen zeigen an der Wurtel die dichte, schwarze Bestämbung der vorigen und der folgenden Art. 
Htfl. grau, gegen die Basis und den Innenrand heller, gleich den Fransen.

Unterseite der Vdfl. dunkelgran; der Vdrd. vom Umschlag an auf bleichgelblichem Grunde mit braunen, an Länge nach hinten zunehmenden und schrägeren Querstrichen, die mit schwarzen Atomen bestrent sind. Htfl. weisslichgran, am Vild. gegen die Flügelspitze mit bräunlichen Punktflecken. Ader 3 ist auf dem rechten Hth. ganz cinfach, auf dem linken aber in eine ziemlich enge Gabel getheilt, welche so lang wie ihr Stiel ist.

Vaterland: Texas (Belfrage). Ein $\sigma^{\pi}$, am 24. Juni gefangen, in meiner Sammlung.

\section{Paed. comatulana n. sp.}

Parva; capillis comosis, pallide ochraceis; al. ant. latius juxta costam ulbidis, costa fuscescenti-strigulatu, ceterum, ochraceis, olsolete nigricanti-pustulatis, speculo atro-bilineato, ciliis marginis postici dimidiis nigro-atomosis. ㅇ․

Ihre Hauptverschiedenheiten ron Occipituna sind bei dieser angeztigt. Sie ist auch ein wenig grösser und breitflügliger.

R. hell ochergelb; Kragen und Schulterdecken weisslich gerandet und in der Mitte mit weisslichen Stellen. K. bleich ochurgelb behaart; die Haarschupen im Nacken niellergelegt, anf dem Scheitel timen starken, aufrechtstehenden Schopf bildend, der sich bis tief ins Gesicht zieht.

Taster stark behaärt, zusannmengedrückt, am Ende scheibenförmig, inwendig weisslich. Peine gelbweisslich; Schienen und Füsse wie bei Occipitana gezejchnet, doch nmr blassbraun; die znsammengedrückten Hinterschimen auf der Rïekenschneide in der Mitte und am Ende mit verlängerten Haaren. (Hinterleib fehlt).

Vdfl. 31/3" lang, breiter und stumpfer als bei Occipituna, an Htrd. unterhalb der Spitze ein wenig eingebogen. Grmulfarbe hell ochergelb, längs des Vdries. in 1/4 der Flügelbreite, jedoch nach hinten sehnäler, ohne scharfe trenze gegen innen, gelblichweiss, vou der Basis ans mit kurzen, nach hinten ein wenig längeren, gelbbräunlichen, schrägen Querstrichelchen; das in der Mitte ist aus zweien znsammengeflossen; drei andere, mit feinen abwechselnd, folgeu bis zur Flügelspitze; alle vier sind mit tiefschwarzen Atomen dicht bestrent. In dem achergelben Grunde liegen sehr kleine verloschene, weissliche Tröpfchen, und in mehr oder weniger weiten Zwischenräumen zeigen sich Anhïnfungen von schwarzen Atomeu, welche Anhäufungen sich dem blossen Auge als sehwärzliche Pusteln darstellen. Der Spiegel ist weisslich, an seinen Ränlerm (uur nicht au oberen) etwas glänzem, reicht bis zum Ende der Falte herab md esthält in seiner oheren Hälfte zwei scharfe, tiefschwarze Längslinien. Frausen schr hell, gelblichweiss, auf der Wruthälfte nit einem Streifen tiefschwarzer Atonne, welcher sich versehmälert bis in den Innenrand zieht.

Itfl. hellgran; Fransen weisslich, nahe der gelblichen Basis mit grauer schattenlinie. 
Unterseite der Vdfl. hellgrau; Vdrd, sthmal weisslich, mit braungrauen, rerloschenen Querstrichelchen, unter denen vier durch ihre Dicke ausgezeichnet siud, alle mit schwarzen Atomen bestrent. Solche Atome haben auch die weisslichen Fransen gegen die Wurzel. HtH. granweiss. Die dritte Ader bildet eine auseinander gesperrte Gahel, welche viel kürzer als ihr Stiel ist. Sammlung.

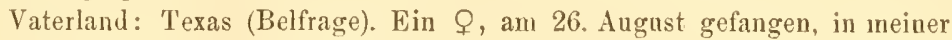

\section{Pued. mumerosana n. sp.}

Parva; al. ant. acutis (cum revolucro o), albidis, confertim fuscopulvereis, fuscedine praesertim cunte speculum confluente, costu totu albo fuscoque oblique strigulosa, strigula majore alla arte apicem, speculo alivido striolam. nigricantem continente, ciliis dense nigro-atomosis. $0^{7}$.

Auch aus der Verwandtschaft der Modicana, Modestuna, Caecimaculana, aber mit dunkelbrauner Bestäubung anf weisslichem Grunde. Sie hat die Grösse der Comatulara, ist aber noch etwas breitflügliger.

li. auf weisslichem Grunde braun bestäubt. Oberkop! reichlich nnd lorker behaart, gelblichstanbfaıbig. Gesicht und Taster weisslich; ersteres in der Mitte mit einem braunen, schlecht urugrenzten Fleck; letztere eiförmig, zusanmengedrückt, mit braunem, kaum hervorstehendem Sndgliede. Beine (verölt), die vier letzten Fussglieder der Hinterbeine obenauf schwarz mit weissen Enden. Analbuseh hell stanbgrau, ziemlich reichlich, grade abgeschnitten.

Vdfl. 31/4" lang, ziemlich breit, mit etwas convexem Vdri., dentlicher Spitze und schwach convexen, unterhalb der Spitze sehr seicht concaven Htrd. Grundfarbe woisslich, sehr reichlich nit schwarabraunen Punkten und Querstrichelchen bestreut, un den Spiegel in unregelmässiger Breite dunkelgran mit gedrüngten schwarzen Atomen. Unter der Falte längt vor cler Mitte ein unregelmässiger, sehwarz gesïnmter, doch nicht sehr auffallender Fleck. Daher tritt in dem Raum zwischeu diesem und der dem Spiegel vorhergehenden Verdunkelung die Grundfarbe an meisten hervor, und die Lichtung zicht sich anf dem Inneurand noch unter und über dem Fleck etwas gegen die Basis. Der Vdrd. ist von der Basis aus, doch an dunkelsten auf dem Unıschlag, uit schmalen, schrägen, schwarzbraunen und weissen Querstrichen, die etwa bis zur Subcostalader reichen, bezeichnet. Vor der etwas verdunkelten Fiïgelspitze ist ein senkrecht herabhängendes, weisses, mit einer schwärzliehen Qnerlinie durchschuittenes Dreieck recht auffallend; unterhalb der Spitze desselben zieht eine sehr feine, verloschene, unregelmässig geschlängelte, weissliche Linie vom Htrd. bis gegen die Flügelhälfte. Der Spiegel, der oberhalb des Innenwinkels liegt und deu Htrd. berührt, ist recht auffallend, unregelnı̈ssig gernndet, breiter als hoch, weisslich, einwärts etwas zinnfarbig, an oberen Rande mit eineu schwarzen Längsstricheichen und im Innern unterhalb seiner Mitte init einem ebenso kurzen. Frausen grau, ausser an ihren Enden dicht mit schwarzen Atomen bis an den Innentwinkel bestrent. 
IItf. dunkel branngran, mit liehtgraten Fransen.

Unterseite der Vdfl. griu, auf dem Vird., ansser in der Gegend des Unschlages weisslich nnd mit kurzen, braunen Querstrichelchen. Flügelspitze braun, das Costaldreieck davor deutlich. An der Mitte des Htrdes. ist eine helle Stelle. Fransen heller als oben. Htfl. hellgrau mit noch helleren Franseu. Ader 3 bildet eine Gabel, die die Länge ihres stieles hat.

Vaterland: Texas (Boll). Ein or (auf der lechten Seite verölt) im Cambridger Museum.

\section{Graph. suberersana n. sp.}

Parva; al. ant. angustulis (verolucro ơ lonyiore), fusco-cinereis, costae dimidio postico oblique fusco-strigulato, strigula albidu costali ante apicem, speculo albido angulum internum atlingente, cilis marginis postici superius nigro-atomosis, ad arigulum internum albidis. $\sigma^{7}$ 오.

Auf den ersten Blick sieht sie wie eine vergrösserte Phoxopt. curvana oder verkleinerte Tineana aus; mit den vorher besehriebenen Grapholithen ist sie also gar nicht zu verweehselı.

Grösse der Albiguttına. R. braungrau; $\mathbf{K}$. überall nur wenig heller. Tister länglich, weisslieh, nur unterwärts nit abstelienden IIaren. Beine schmutzig gelbliehweiss; nur die vier vorderen Fussghieder oben gebräunt mit weisshichen Enden. Hintersehienen wenig verdiekt und ohne abstehende Haare. Analbusch kaum leller als ter Hinterleib.

Vafl. $3^{\prime \prime}$ lang, ziemlich sehmal, mit sehr sehwach convexem Vdrd., dentlieher Spitze und sehwacher Einbiegung des wenig eonvexen Htreles. Grundlarbe braungrau, nach hinten durch reichliche schwarze Atome, welche durch Schüppchen nit weisslielien Spitzen gubildet werden, etwas verdunkelt. Der sehr sichtbare Umschlag reicht fast bis zur Hälfte des Vdrdes. und von da an ist dieser mit vier I'aaren schräger, schwarzbranner, nach hinten etwas verlängerter Schrägstrichelchen bezeichnet, jedes Paar von dem anderen lureh einen hellen, aber nicht weissen $/$ wisehenraum gesonilert; hinter dem letzten folgt vor aler Flügelspitze ein fast weisses, answärts duuklbraun gesäuntes, senkreclit gestelltes Häkehen. Der weissliche, vorn und hinten matt schimmernde Spiegel reicht von der Mitte des Htrdes. bis in den Innenwinkel, ist basalwärts mit schwarzen, gediugten Sehuppen umzogen und trägt an seinem oberen Rande eine» sehwarzen, beim Q lakenfürmigen füngsstrieh, etwas über seiner Nitte cine feine solche Längslinie und tiefer ein paar verloscheno Punkte. Die Fransen sind an unteren Ende des Spiegels weisslich, häher hinauf äberall, ausser an den äussersten Enden, mit schwarzen Atnuen bestänbt.

Htfl lell bräunlichgrau init granen Fransen.

Unterseite der Vifl. grau, am Inuenrand breit b]eich. Die Costalbäkchen sehr undentlich, die Fransen vor der Spitze und un dieselben weissschimmernd. Htfl. weisslichgran. Ailer 3 bildet eine aufgesperrte Gabel, die laalb so kurz wie ihr Stiel ist. 
Vaterland: Texas (Boll). Massachusetts bei Beverly (Burgess) wo zwei 우 am 27. Juni und 3. Juli gefangen wurlen. Ein $\sigma^{\lambda}$, ein $q$ im Museun Cambridge, ein $q$ in meiner Sammlung.

\section{Dichrorampha aurisignana n. sp.}

Alis ant. ollongis (cum revolucro ठ), lnteo-fuscesecntibus, postiec ferrugineo-mixtis, maenla dorsi meaii magna, semiovata, pallide ferrugineu, frostice evanescente, munet is 3 atris in spato fermgineo ante marginem prostieum. 0 .

Nächst verwandt mit Petiverella, alpinana, politana, von ihnen verschieden durch den Dorsalfleck der Vdfl., der binten nicht ausgehöhlt und scharf begrenzt (also mondsichelförmig), sondern haibeiförmig ist und ganz allmälig in die Grundfarbe übergeht. Dadurch hat sie mehr Uebereinstimnuึng mit Heegeriana (welche Heinemann mit Unrecht aus dieser Verwandtschaft zu entfernen scheint); allein ihr Fleck ist gar nicht von Querlinien durchschnitten.

Grösse einer mittleren Petiverella. Vorderkörper von der Farbe der Vdfl. Taster weissgrau, an Ende verdunkelt. Hinterbeine schmutzig hellgelblich, an den Füssen gebräunt, mit blassen Spitzen der Glieder.

Vdfl. fast $3^{\prime \prime}$ lang, in der Gestalt wie bei Petiverella, an Htru. unterhalb der Spitze sebr schwach eingezogen, lehmig gelbbraun, hinten rostfarbig gemischt. Der deutliche Umschlag von $1 / 4$ der Länge des Vdrdes. Der blass rostgelbe, fast goldfarbene, halbeiförmige Dorsalfleck fängt etwas weiter gegen die Nitte and hinter dem Fude des Umschlags an als bei den anderen Arten; er ist etwas höher als breit, basalwärts convex und scharf begrenzt, reicht bis zur halben Flügelbreite hinauf und ist auf seinem Enddrittel dunkel bestäubt, so dass er auf dieser Seite in der gelbgemischten Grundfarbe verschwindet. Ueber seinem oberen Ende liegen in der gelbgemischten Grundfarbe einige sehr feine, tiefschwarze Längsstriche. Die matt bleifarbenen Costalstriche, welche verschiedene Länge haben, ziehen auf rostfarbenem Grunde schräg nach aussen; der eine verlängert sich, zu eimen spitzen Winkel gebrochen, bis zum Innenwinkel und fasst anf der Basalseite den schmalen Spiegelfleck ein, weleher von einer schwarzen, gebogenen Linie von oben nach unten durchzogen ist. "Wwischen der linteren bleifarbnen Linie des Spiegels und dem Htrd. ist der Grund in einem schmalen Streifen rostfarben und mit drei starken, tiefschwarzen Punkten und darïber mit einem feinen Längsstrichelchen gezeichnet. Aurh die gerundete Flügelspitze ist rostfarben. Fransen glänzend grau, an den Enden dunkel.

Htfl. braungrau. Fransen hellgrau, an der Wurzel mit einer starken, dunkelbrannen Linie durchzogen.

Unterscite der Vdfl. braungrau, am Vdril. vor cler Spitze etwas gelhlich und dunkel gestrichelt, auf der Mitte des Innenrandes mit einem kleinem, schmutzig weisslichen Dreieck. - Htfl, viel heller als oben, an dunkelsten in Costalviertel. 
Vaterland wahrscheiulich die Gegend von Washington. Ein von OstenSacken gefangenes $\sigma^{\top}$ in meiner Sammlung.

\section{Cloreutina Hunn.}

Choreutis pretiosana Dup.

Xylopoda - Dup. Suppl. IV, p. 182, tab. 65, Fig. 9.

Chorentis - Stand. Horae Soc. Eut. Ross. 1870, S. 272.

Choreutis vibrana var. australis Z. Isis 1847, S. 643.

Diese überall um das Mittehmeer lebende Art unterscheidet sich von Bjerliandrella Thbg. (Vibrana H.) durch nichts als durch ihre Kleiuheit und lichtere Färbung; die Zeichnung ist ganz.gleich, und die Vdfl. der Bjerkandrellu haben nicht immer einen weniger convexen Htrd. Dabei wechselt Pretiosana doch etwas in der Grösse, und das $q$ ist etwas kleiner als das $0^{7}$.

Die sieben mir vorliegenden nordamericanischen Ex. sind noch kleiner, als die $q$ der europäischen Pretiosana. Bei den vier aus Texas stammenden sind die zwei hellen, durch runde, sehr kenntliche Schuppen hervorgebrachten Binden (die erste, ziemlich grade vor der Mitte, die zweite, gebogene und über der Mitte stark erweiterte bei $2 / 3$ ) hellgrau, bei den drei aus Ohio ( $\sigma^{7}$ Q $)$, die auch Schläger als Australis bestimmte, reinweiss, so dass die Schüppchen sich unter der einfachen Lupe nur auf der hinteren Binde undeutlich nnterscheiden lassen. (Sie könnten, wenn die weisse Farbe beständig sein sollte, als Var. Ohiensis abgesondert werden). Ein weniger rein weissbindiges, sonst übereinstimmendes $q$ habe ich bei Syrakus gefangen.

Da die specifische Identität zwischen den americanischen und den europäischen Ex. sicher und an keine Einwanderung zu denken ist, so kann Pretiosana nur zu den beiden Erdtheilen ursprünglich gemeinschaftlichen drten gezählt werden.

A nmerkung. Zu beobachten bleilut (was ich in Italien versäumt habe), ab Pretiosana, beim Sitzen auf Blumen, die Flügel so sonderbar verbogen trägt wie Bjerlandrella. Ietztere Art oder Form, für deren Raupe Heinemann als Nahrungspflanzen Inula salicina und Helenimm kennt, lebt gewiss auch auf Carlina acaulis, auf deren Blättern ich die Raupen an trockenen, sonnigen Stellen bei Bergïn und Raibl (wo ich sie für die einer Depressarie hielt, zool.-bot. Ges. Schriften 1868, S. 609) beobachtete; sie fressen, so viel ich mich erimere, die Epidernis stellenweise ab und lassen dadurch die Blätter fleckig erscheinen. Bjerkandrella kommt an den Bergen von Jena vor, bei Bergün über 4000 Fuss hoch; wahrscheinlich ist sie überall einheimisch, wo Carlina acaulis wächst, also immer in einiger Höhe über dem Meere, während Pretiosana sogar uahe am Meeresufer fliegt. Dass ich in Paibl Bjerkandrella auch von einer Veronica (wahrscheinhich alpina) gezogen habe, erwähnte ich 1. c. S. 619. Jedenfalls ist ihre Raupenuahrung mannigfaltig, wenn auch nur unontan oder alpin. 
Simaethis rimulatis n. sp.

Palpis exalbidis, nigro-fasciatis, antennis albo nigroque annulatis; alis tuteo-bumeis, anterioribus ochraceo-squamulatis, striga ante medium posita pallida, fascia angusta marginali rubra, utrimque nigro-marginata; ciliis cinereis, nitidis. ${ }^{\circ}$.

Selur kenntlich an dem schmalen, rothen Streifen, der am Htrd. der hell gelbbraunen Vdf. bindenartig hinzieht, und der feinen, weisslichen Querlinie vor der Mitte.

Grüsse einer mittleren Nemorana. Oberseite des Körpers gelbbraun. Im Gesicht ist ïber dem Mnude ein gelbliches Bändchen. Taster dïnn, aufgebogen, üher das Gesicht etwas heranfreichend, ohne Borsten, weisslichgelb, auswärts am zweiten Gliede nit zwri, am ziemlich kurzen, stumpfen Endgliede nit einem schwarzen Bündchen. Fühler fein. weiss und schwarz geringelt. Die vier Itinterheine ziemlich schlank, hell ochergelb; die Mittelschienen an der Wurzel schwarz. und mit sclswarzer Binde in der Mitte mud vor der Spitze; die dünnen, unbehaarten, gelbdornigen Hinterschienen nur auswärts braun gezeichnet; die Füsse schwarz mit blassgelben Enden der Glieder. Am Hinterleib sinu die Segmente dunkelbraun mit bindenfürmig hellgelben Hinterrändern; Analbusch hellbraun.

Vdf. 31/2 "“ lang, nach hinten stark erweitert, mit convexem Vdrd. und fast graden, wenig einwärts gericbtetem Htrd. Die Grundfarbe dunkelbraum, aber durch die sehr reichlich aufgestreuten ochergelben, runden Schüppchen viel heller anssehend. Vor der Mitte geht eine dünne, schwach nach aussen gebogene Querlinie schräg herab; sie ist am Vdrd. weiss, im weiteren Verlauf gelblich getrübt und wird auf der Basalseite durch die dunkle, hier nicht gelblich bescluppte Grundfarbe bindenartig beschattet. An der tiefschwarzen Htrd.Linie zieht ein schmaler, bindenförmiger, ziegelrother Streifen an der Flügelspitze vorbei und zugespitzt bis zum Vdrd.; er ist abwärts ebenso zugespitzt und erreicht den Innenwinkel nicht; gegen die Flügelfläche säumt ihn eine ftine schwarze Linie. Fransen metallglänzend grau.

Htfl. dunkel gelbbraun; von der Basis ans zieht auf der Medianader ein schmaler. hell ochergelber Streifen, der an der Verästelung mit einer Erweiterung anfhört. Fransen an der Flïgelspitze hellgelb, sonst braungrau, mit lsellgelber Wurzellinie, welche aber weit vor dem Analwinkel aufhört.

Unterseite der Vdfl. braun, ausser am Vorder- und Htrd., röthlich gemischt; von der Flügelspitze zieht ein hellgraner Staubstreifen sich verdünnend längs der schwärzlichen Htrd.-Iinie herab. Fransen schwärzlich, fast ohne Glanz. Htfl. dunkelgelbbraun. Die Median- und die Querader sind hellröthlich. Fransen braun, an der Flügelspitze und in der Wurzellinie unrein hellröthlich.

Vaterland: Die westindische Insel St. Thomas. Ein Ex. aus dem Berliner Museum in meiner Sammlung. 


\section{Simathis virnrialis n. sp.}

Palpis piloso-squamatis, articulo terminali setoso; alis ant. brunneis, nebulis albidis fascius duas (alterum angustam ante, alteram latam post medium) formantibus, ciliis fuscis supra et infra medium albidis; post. subtus albido-nebulosis. + .

Von der Grösse und Flügelbreite der Pariana, aber ohne die zwei Einbuehtungen in den Vdfl.-Fransen; ihr Platz ist daher zwischen Pariana und Diana, obgleich ihr Aussehen mehr an Fabriciana erinnert.

Körper braun, K. weisslich gemischt. Taster etwas dick, schwach aufgebogen, über die Stirn hervorragend, weisslich beschuppt nud behaart; das zweite Glied vor der Spitze hellbraun; das Endglied hellbraun, stumpf, mit nach voru gerichteten, kurzen Borsten bekleidet. Fühler sehr fein, bräunlich, ungeringelt. Beine weisslich, schwarzbraun bandirt und gefleckt; Hinterschienen kurz und durch anliegende Behaarung verdickt. Bauch weisslich mit hell bräunlicher Bestäubung. Analbusch hellbraun.

Vdfl. fast $3^{\prime \prime \prime}$ lang, ziemlich breit, nach hinten allmälig erweitert, mit sanft convexem Vdrd. und fast gradlinigem Htrd., gelbbraun, ain dunkelsten, und zwar bindenförmig, hinter der zweiten weisslichen Binde. Vor der Mitte ist eine ziemlich schmale, weissliche, nach aussen bogenförmige Binde (oder breiter, Querstreif), auf dem Vdrd. reinweiss anfangend (die hier verwischten Flügel lassen ihren Verlauf nicht genau erkennen). Die zweite Binde ist viel breiter und anf dem Vdrd. auch rein weiss; sie ist über ihrer Hälfte stumpfwinklig gebrochen, darunter erweitert, mit cinem zalunartigen Vorsprung auf der Basalseite unterhalb der Falte; in ihrem hinteren Drittel zieht eine am Anfang nnd Ende deutlichste dunkelbraune Linie herab, durch welche sie wie ans einer Binde mnd einem sie begleitenden Querstreifen zusammengesetzt erscheint. In dem Winkel dicht an ihr ist auf der Querader ein sehr kleines, weisses Möndchen. Die Fransen, durch eine starke, schwarze Linie von der Flügelfläche getrenut, sind hellbraun, unterhalb der Spitze und oberhalb des Innenwinkels mit einer breiten weisslichen Stelle.

Htfl. heller und gelblicher braun als die Vdfl., in nach aussen zunehmender Dunkelheit. Fransen weisslich, nit starker, schwarzer Basallinie und verloschen grauer Linie vor der Spitze; an der Flügelspitze sind sie schwärzlich angelaufen.

Unterseite der Vdfl. braun, einwärts hell; wo die zwei Nebelbinden anf der Oberseite anfangen, ist auf dem Vilrd. erst ein reinweisser Punkt, dann ein solcher Nebelfleck. Fransen wie oben, nur mit hellerer Linie an der Wurzel. Htfl. weisslich, am Vorder- und Htrd. braun bestänbt und mit einem bramen Staubstreifen quer durch die Mitte, wodurch gleichsam eine breite, weissliche, schlecht begrenzte Binde auf den Enddrittel gebildet wird.

Vaterland: Maine oder Massachusetts; das einzelne $Q$ meiner Sammlung worde mir durch Dr. Packard mitgetheilt. 
Brenthia pavonacella Clem.

Tarsorum apice nigro, palpis tenuibus; alis obtusis, longius ciliatis, cervinis, anterioribus diffuse albido-squamatis, ammlo oblongo venae transversae albido, fascia marginali atra, nitidissime lilacino-squamata; posterioribus macula ante medium rotundatu allida, squamulis nitide lilacinis ad. angulum apicalem. ơ 오.

Brentlia pavonacella Clem. ed Stainton, p. 134.

Auffallend durch die in dieser Familie ganz ungewöhnlich langen Fransen, gehört sie, obgleich sie dünu gespitzte Taster hat, doch nicht zu der folgenden Gattung Setiostoma, weil sie gar keine Aehnlichkeit mit der Wicklerabtheilung Ephippiphora, dagegen die breite Choreutidenform und anf der Unterseite scharf gezeichnete Htfl. hat. Schon ihre langen Fransen nöthigen zur Beibehaltung eines eigeneu Genus.

Die Art ist durch die fast metallglänzenden Lilaschuppen auf dem tiefschwarzen Itrd.-Bande der abgerundeten Vdfl. und an der Spitze der Htfl. auf der Oberseite und an mehreren Stellen der Unterseite und durch die grösstentheils weissliche Unterseite aller Flügel sehr ausgezeichnet.

Grösse der Pretiosana. Körper gelbbraun, auf der Unterseitc weiss. Gesicht allnülig ins Weissliche übergehend. Fühler nicht so fein, wie bei den anderen bekannten Arten, bräunlich, sehr undeutlich geringelt, beim o mikroskopisch pubescirend. Taster von 11/2 Kopflänge, horizontal, sehr wenig aufgebogen, ziemlieh dünn, nur am Wurzelgliede mit etwas abstehenden Haaren, weiss, am zweiten Gliede mit einem verloschenen, braunen Fleckchen; das halb so lange Eudylied an der Wurzel und Spitze braun. Beine kurz und stark, weiss, die vorderen schwarzfleckig; die vier hinteren Schienen durch lockere Behaarung verdickt; an allen Füssen ist die Spitze des ersten and dic drei letzten Glicder schwarz.

Vdfl. des $\sigma^{\prime \prime} 2^{\prime \prime \prime}$, des ㅇ $2^{1 / 2} 2^{\prime \prime}$ lang, länglich, nach hinten sehr erweitert und an den Winkeln abgerundet, lunkel rehbraun mit helleren und trüberen, weisslich beschuppten Stellen und Linien. Nicht weit von der Wurzel ist eiue helle, verloschene, gebogene Querlinie. Von der Falte gehen nach dem Innenrand drei schräge, weissliche Linien herab, die erste bei $1 / 3$, die zweite von der Querader, die dritte an Innenwinkel. Auf der Querader liegt ein nicht recht leicht bemerkbarer, quergezogener, fast nierenförmiger Ring. Noch gibt es ein paar linienförmige weissliche Striche und einen solchen Costalpunkt vor dem Anfang des tiefschwarzen, längs des Htrdes. herabziehenden Streifens. Auf dem hinteren Theil dieses Streifens bilden metallschimmerude Lilaschuppen eine unterbrochene Querlinie. Die langen Fransen sind hinter der gelbbräunlichen Wurzel von einer starken dunkelbraunen Linie durchzogen, hinter derselben braungrau, um die Flügelspitze weisslich.

Htfl. gleichfalls ungewöhnlich abgestumpft, braun, vor der Nitte mit einem länglich runden, weissel Fleck und einem kleineren am Vdrd. gegen die Flügelspitze. Von dieser zieht an Htrd, bis zur Flügelhälfte eine blasslila- 
farbige, gleichfalls glänzende Linie, von deren Ende eine weisse, kurze, lie und da etwas glänzende Linie schräg aufwärts gegen den Vdrd. gerichtet ist. Die langen Fransen sind an der Wurzel wie bei den Vdfl. gezeiclnet, dahinter weiss, an der Mitte und vor cler Flügelspitze weiss.

Unterseite der Vdfl. weiss, beim ol mit grüsseren braunen Flecken als beim $q$, nit breiter, brauner Htrd.-Binde, in welcher eine violettglänzende Querlinie vor ciner durch dic hellen Adern zerschnittenen ticfschwarzen linie zicht. Htfl. schwärzlieh; die Basis nimmt ein grosser weisser Fleck cin, dem in Mittelraun ein etwas kleinerer, kreisrunder folgt. Ein eckiger Costallleck liegt vor der Flügelspitze, als dessen Fortsetzung die weisse Querlinie der Oberseite gelten kann; darüber gegen den Innenwinkel zu ist noeh ein weisser Punkt. Er, sowie ein Fleck darüber, der Anfang und das Ende der Querlinie, das innere Ende des Costalflecks und ein Htrd.-Streifen vor der Flügelspitze baben die schon erwähnte Lilabeschuppung.

Vaterland: Texas (Boll), von wo das schön erhaltene $q$ des Museums Cambridge, und Brasilien, woher das kleine $\sigma^{7}$ meiner Sammlung stammt. Nach Clemen s' Angabe ist die Flugzeit im Juli und August.

Anmerkung. Die Clemens'sche Beschreibung stimmt zwar nicht genau, enthält aber doch die Merkmale der mir vorliegenden Ex. Wahrscheinlich ändert die Art etwas ab. Ob die zwei anderen Clemen'schen Arten in den Gattungsnierkmalen genau uit Pavonacella stimmen, nuss die Ansicht natürlicher Ex. lehren.

\section{Setiostoma H. 8 .}

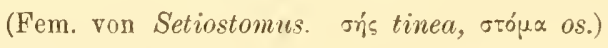

Caput breve, fronte perpendiculari.

Palpi labiales reflexi, squamat $i$, non setosi, articulo terminali longiore, attenuata, subulato.

Haustellum breve, convolutum.

Tibiae 4 posteriores in medio et apice setis inerassatae.

Corpus breve, robustum.

Alae mediocriter ciliatae, posteriores elonyato-rotundatae, margine postico toto convexo, subtus unicolores.

Ganz von der Gestalt einer kleinen Lederer'sehen Phthoroblastis oder Ephippiphora - nur mit tropischer ganz abweichender Färbung - aber mit gelechienartiger Bildung der aufgekrümmten Taster, also sicher nicht zu den Wieklern gehörig. Die Kürze der Fransen erlaubt durchaus nicht, sie zu den Gelechiden zu zählen. Dagegen entspricht der kräftige Kürperban und die an der Mitte und Spitze durch Borsten etwas verdickten Schienen den Choreutiden, während der Mangel von Borsten an den Tastern und von Zeichnung auf der Unterseite der Htfl. wenigstens nicht den europäischen Arten gemäss ist. Vielleicht gibt das Geäder, das sich ohne Abschuppung nicht genau erkenucn lässt, eine sichere Auskunft. 
1. Set. xatheobresis n. sp. Taf. IX, Fig. 42.

Capite scapulisque citrinis; al. ant. triente basuli citrino, ad costem et dorsum nigro, striga caerulea terminato, ceterun vigris, nitide violaceo-rivulosis; post. nigris, nigro-ciliatis. $\sigma^{\prime}$.

Grösse einer mittleren Coronillana. Körper schwarz. Schulterdecken und K., ausser im Nacken, citronengelb. (42a) Fühler von $3 / 4$ Länge der Vdf., kräftig, gegen das Ende verdünnt, braun nit feiner, gelblicher, in den Gelenken unterbrochener Fückenlinie. Taster anliegend, ziemlich dünn, zusanmengedrïckt, bis ein wenig über die Stim reichend, blassgelb; das Endglied nicht abgesetzt, fein zugespitzt. Vorderbeine innen grau, anssen schwarz; Mittelbeine innen metallglänzend grau, sonst schwarz, an den Fussgliedern mit weissen Spitzen; Hinterbeine am Knie weiss, an den Schienen imen so wie die Dornen glänzend weiss, aussen in der Mitte und an der Spitze durch schneeweisse Borsten verdickt: Fussglieder schwarz mit glänzend weissen Spitzen. Hinterleib mit glänzend weissen Htrdn. der hinteren Segmente; Analbusch dümı.

Vdfl. 21/2"' lang, auf dem gradlinigen, wenig schräg abgeschnittenen Basaldrittel citronengelb; in diesem an der Schulter mit einem tiefschwarzen Fleck und einem längeren längs des Innenrandes. Als Begrenzung dieses gelben Feldes folgt auf tiefschwarzem Grunde eine dunkelblaue, breite, grade, vollständige Querlinie. Der Rest des Flügels ist tiefschwarz. Vor der Mitte des Vdrdes., zwischen dem gelben Felde und der Flügelspitze ist ein weisser, verloschener Punkt, von welchem blaue Beschuppung schräg abwärts nach hinten geht. Vor der Flügelspitze liegt ein unregelmässiger, breiter, glänzend violetter Querstreifen, der sich in hellerer Färbung und dünner am Htrd. herabreicht. Fransen schwarzbraun mit grauem Schimmer.

Htfl. an Htrd. ganz ohne Eindruck unterhalb der Spitze, einfärbig schwarz; die Fransen wie au den Vdfl.

Unterseite schwärzlichbrauı. Die Vdfl. haben am Vdrd. zwei weissiiche, verwischte Punkte an den Stellen, wo auf der Oberseite der weisse Punkt liegt und der violette Streifen anfängt. Eine sehr feine weissliche Linie trennt die Flügelfläche von den Fransen.

Vaterland: Texas (Boll). Ein ơ im Cambridger Museum.

\section{Set. chlorobasis n. sj.}

Thorace et capite viridi-flanis; al. ant. dimidio basali virili-flam, linea atra terminato, ceterum fuscis, uitide violacco-rivulosis; post. fuscis, cinereociliatis. $\uparrow$

Etwas kleiner als die vorige. R. und $\mathrm{K}$. grünlichgelb. Fühler fein, hellbräunlich. Taster dünn, über die Stirn lıeraufrejchend, mit pfriemenförmigem, feinspitzigem Endgliede. Beine braun: Fussglieder schwarz, an den Enden silberweiss; die Verdickungen viel weniger auffallend als bei $X$ unthobasis; die Dornen der Hinterschienen fein und weiss. Hinterleib braungrau, hinten heller, am Bauch 
mit bellen Htrdn. der Segmente. Der abgestutzte, flache, gelbe Legestachel steht hervor.

Vdfl. $2^{1} / 4^{\prime \prime \prime}$ lang, auf der kleineren Wurzelbälfte einfärbig grüngelb, binten durclı eine feine, vollständige, tiefschwarze Querlinie fast senkrecht abgeschnitten. Der Rest ist dunkelbraun und mit metallglänzendem Purpurviolett durchzogen, welches einen breiten, bandförmigen Querstreifen hinter der schwarzen Querlinie, einen vom Vdrd. herabziehesden und nach hinten gebogenen Haken und ein mehr bläulich schimmerndes Htrd.-Band bildet. Fransen braun mit schwarzer Wurzellinie.

Htfl. braun, am Vdrd. auf der vom Vdfl. verdeckten Stelle weisslich. Fransen grau, gegen die Flïgclspitze dunkler, nahe der Wurzel von einer bräunlichen Linie durchzogen.

Unterseite braun, auf den Htfl. dunkler. Alle Fransen braungran, durch eine feine, verloschene, weissliche Linie von der Flügelfläche getrennt.

Vaterland: Brasilien. Ein vielleicht von Bates gefangenes Q, erhielt ich mit der Angabe: Marannon.

\section{Berichtigungen und Nachträge}

zu den Aufsätzen von 1872 nud 1873.

Nola malana. Taf. X, Fig. 44 a.b.

Verh. d. zool.-bot. Gesellsch. XXII, 1872, S. 484 (Sep. 8.).

Nolaphana Grote Bull. Buftalu Soc. II (1874), p. 126.

Gleich nach Durchlesnug des gedruckten Artikels meldete mir Dr. Speyer ich müsse ein dünnleibiges $\subsetneq$ für cin $\sigma^{\top}$ angesehen baben, weil das $\sigma^{-1}$ in der Wirklichkeit kammzähnige Fïhler besitze. Da ich dies bestritt, überzeugte er unich von der Pichtigkeit sciner Behauptung durch Zusendung des $\sigma^{7}$; ich sah aber zugleich, dass ich mit manchen ancricamischen Lepidopteristen in gleichem Irrthum befangen gevesen war, das $\sigma^{7}$ init borstenförmigen Fühlern für dieselbe Art mit dem, welches haumzähnige hat, zu halten. Grote, dem ich dieses mittheilte, verfolgte die Sache weiter und benannte die Art nit hammzähnigen männlichen Fühlern - und das ist die Fitch'sche, wie das von nir unbeachtet gelassene: the antennae in the males are pectinated with two rows of short robust branches beweist. - Nolaphana malana, und die mit ungezähnteu mänulichen Fühlern Nolophana Zelleri; endlich entdeckte sein Scharfblick bei beiden Arten Ocellen, weshalb er sie ganz aus der Nähe von Nola entfernte und zu den Noctuiden hinter Adipsophanes stellte.

Dass zwei Arten vorliegen, leidet keinen Zweifel. Ich habe seit 1872 noch kein unversehrtes Ex. erhalten, glaube aber duch, für beide Geschlechter einer jeden derselben, also abgesehen von den mämnlichen Füblern, die jeden Zweifel heben, als Merkuale angeben zu können, dass Malana Ftch, eine ziem. 
lich deutliche weisse, nach hinten verschwindende Costalvitta hat, und dass die dritte schwarze, vom Vdrd. ausgehende Querlinie in ihrem sehr zackigen Verlauf meist vollständig bis zum Innenrand verfolgt werden kann, wälrend Zelleri längs des Vdrdes. kaum ein wenig heller ist als auf der übrigen Flăche, und die dritte schwarze Querlinie bald verschwindet, um erst gegen den Inuenrand wieder zu erscheinen, wofür die schwarzen Aderu un so stärker hervortreten. Bei Malana $\sigma^{7}$ sind die Htfl. hellgrau, gegen den Htrd. etwas verdunkelt, bei Zelleri auf der ganzen Fläche gleichfürnig dunkel staubgrau. Ob das 오 rou Zelleri auch auf den Htfl. noch dunkler braungran ist als das von Malana, ist mir unbekanut.

Um zu erfahren, ob beide Arten ausser durch das Vorhandensein von Ocellen und durch den Mangel von Schuppenbeulen anf deu Vdfl, sich noch durch Anderes von den gewühniichen Nola-Arten unterscheiden, habe ich die Flügel der $\sigma^{\nearrow}$ abgeschuppt. Mit Erstaunen sah ich, dass auf den vorderen sich am oberen Ende der Mittelzelle eine schmale Nebenzell e befindet, von welcher bei Nola keine Spur vorhanden ist; auch gehen dort von der Subcostalader drei Aeste (der dritte als Gabel) in den Vdrd., bei Nola nur zwei (der zweite als Gabel); ${ }^{1}$ ) ausserdem geht dort ein Ast mehr in den Htrd., der dicht an der Spitze endigt.

Somit scheint Grote Recht zu haben, wenn er seine Nolaphana zu den Noctuinen ordnet. Dem entspricht wahrscheinlich auch die Zahl der Beine bei der Raupe, welche nicht die von Nola sein wird, und ebenso wird die Verwandlung wohl nicht in dem so charakteristischen kahnfürmigen Gehäuse von Nola, sondern nach nicht ungewöhnlicher Noctuen-Weise in kunstiosem Gewebe zwischen Blättern vor sich gehen.

Da der Name Brachytaenia, für sehr verschiedene Thiere gebildet, der Gattung nicht bleiben kann, so hat Grote mit Recht einen neuen geschaffen.

Nach ihm kommen beide Arten in den östlichen und mittleren Vereinsstaaten vor.

Zum Vergleich des Flügelgeäders der Gattung Nolaphana habe ich das der Nola confusalis in Fig. 43 a. b. abgebildet.

\section{Agrophila truncatula $\mathrm{Z}$.}

Verh. d. zool.-bot. Ges. XXIII (1873), S. 203 (Sep. 3.).

Da das $\sigma$ sehr verschieden vom $q$ aussieht, so muss die Diagnose, $1 m$ beide Geschlechter zu bezeichnen, geändert werden.

Capite et thorace rufo-ferrugineis; al. ant. in basi abrupte rufo-ferrugineis, ceterum or flavidis, litura ciliorum mediorum brunnea, q nigris squamisque filiformibus sulphureis obtectis, apice abrupte exalbido; post. o' flavidogriseis, postice obscuratis, $q$ obscure cinereis.

Das $\sigma^{\nearrow}$ ist kleiner als das $Q$, mit merklich schunäleren Vufl. und spitzeren Htfl. Jene sind anf der ganzen Fläche so weisslichgelb, wie beim $q$ die

1) Wenigstens bei Confusalis, Centonalis und Cucullatella. 
Flügelspitze und die Begronzung des braunrostfarbenen Basalflecks, also sehr hell, ganz ohne Schwarz nud ohne die anfgestreuten schmalen, schwefelgelben Schmpjen; nur der Vdrd. ist in einer dümnen, bis zur Flügelspitze reichenden Linie, und die Flügelnitte iı einem Längsschatten bis zum Htrd. blassrostgelblich oder ochergelblicl. Der braunrostfarbene Basalfleck hört am Innenrand etwas eher auf. Die Htrd.-Fransen sind gegen die Flügelspitze wie die Grundfarbe, aber auf der grösseren nnteren Hälfte braungran, was sich am Innenwinkel selır lichtet; am oberen Anfange der dunkelı Fransenpartie liegt ein kurzes, rostbraunes Htrd.-Strichelchen. Die viel weniger umfangreichen, stark zugespitzten Htfl. sind hellgran, am Htrd. dunkelgrau; die Fransen weissgran.

Unterseite der Vafl. hellgran, am Innenranddrittel weissgelb; ebenso der Vdrd. in einer vor der Flügelspitze erweiterten Linie. Htfl. gelblichweiss, in der Spitze und an Vdrd. schmal hellgrau.

Der schlanke Hinterleib ist grau ochergelb mit weisslichem Banch und starkem, gesträubtem, ocherfarbenem Analbusch.

Walurscheinlich ist die Art in der Fürbung sehr veränderlich, so dass diese so anffallende Geschlechtsverschiedenheit durch Bindeglierler ausgeglichen wird.

Iclı erhielt das männliche Ex. von Dr. Rössler mit der richtigen, offenbar durch die Abbildung des $q$ (die doch der Kupfersteclier an der Vdfl.-Basis zu hell gegeben hat) veranlassten Benennung und mit der Angabe: Aus Central-America.

\section{Sudariophora Z.}

Verh. d. zool.-bot. Ges. XXII (1872), S. 490 (Sep. 44), Taf. 2, Fig. 11.

Phyprosopus callitrichoides, Grote, Transact. Am. Soc. IV (1872), p. 90. Sudariophora callitrichoides, Grote, Bullet. Buffalo Soc. II (1874), p. 29.

Bei dieser so ganz spannerähnlichen Gattung fiel mir nicht ein, nach Ocellen zu sucheu. Sie hat sie aber wirlich und gehört daher nicht zu den Geometriden, falls sich nicht die Raupe als echte Spannerraupe, d. h. mit blos einem Paar Bauchfïsse versehen erweist. Das generische Merkmal, das ich gefunden zu haben glaubte, beruht auf einem Irrthum: die zwèi Anhängsel unter dem Kinn sind weiter nichts als die Vorderlüften, an denen der Rest des Beines abgebrochen ist, und deren Anheftungspunkt nur so weit nach vorn geschoben ist, dass er durch die etwas verlängerten Haarschuppen des Kinus verdeckt wird. Hieraus ergibt sich, dass die Abbildung falsch ist.

Grote, der nichts von der dichten Behaarung der Vorderhüften sagt, beschreibt in den Aneric. Transact. das Flïgelgeäder. Die zwei abgeschuppten Flügel, die ich von ihm erhielt, bezeugen die Genauigkeit seiner Angaben. Welches die charakteristischen Merkmale der Gattung sind, gibt er nicht an. Er weist ilır eine Stelle zwischen Calpe (thatictri) und Hypsoropha an, welche letztere Gattung ich nicht keme und nicht eimmal in der Abbildung vergleichen kann. 
Im systenatischen Verzeichniss nimmt er meine Gattungsbenennung auf, vielleicht wegen der sprachlich falsehen Bildung von Phyprosopus. Da sich aber für Sucturiophora die Priorität kaum nachweisen lässt, so vermuthe ich stark, dass man die Species kinftig als Phyprosopus acutalis verzeichnet sehen wird.

Nach Grote lebt die Art ausser in Texas auch in staate New-Yurk.

\section{Colobochila saligna Z.}

Verh. d. zool.-bot. Ges. XXII (1872), S. 464 (Sep. 16).

Mudopa interpuncta Grote 'Trausact. Am. Ent. Soc. IV, S'ept. 1872.

Grote Bull. Buff. Soc. Ul (Mai 1874), p. 49.

So gut wie bei Sudariophora hat Grote's specifische Benennung den Vorzug vor der meinigen. Wenigstens glaube ich, dass das Heft der Wiener Schrifteu später als in September ausgegeben wurde. ${ }^{1}$ )

\section{Hypena laciniosa Z.}

Verb. d. zool.-bot. Ges. XXII (1872), s. 464 (Sep. 18.), Taf. II, Fig. 8.

Hypena benignalis Wkr. Cat. Pyr., p. 32 (1858).

- baltimoralis (Guen. Gr. Transact. Am. Ent. Soc. IV, Sept. 1872.

- $\quad$ - Gr. Bull. Buti. Soc. II (1874), p. 51.

Walker's Benignalis (die Grote citirt) ist ausnahmsweise gut und kenntlich beschrieben. Er gibt auch nach vier Ex. die Diagnose einer Hypena, die er für identisch mit der Guenée'schen Baltimoralis Gn. ansieht, die aber wohl Niemand nach seinen Worten dafür anerkennen wird. Da Grote die Gründe nicht anzeigt, aus welchen gerade Laciniosa, und nicht neine Pallialis gleich Baltimoralis Gn. sein nuss, so sehe ich für jetzt kein Hinderniss, Walker's Benennung als die berechtigtere anzunehnen.

Nach Grote bewohnt diese Art Canada und die westlichen und mittleren Staaten als ganz gemein.

\section{Hypena pallialis $\mathrm{Z}$.}

Verb. d. zool.-bot. Ges. XXII (1872), S. 466 (Sep. 20.), Taf. 2, Fig. 9.

Hypena bijugulis Wkr. Cat. Pyr. p. 32 (1858).

(Wkr.) Gr. Transact. Am. Eint. Suc. IV, (Sept. 1872), p. 103, pl. 1, Fig. 93 ㅇ.

Bomolacha - (Wkr.) Gr. Bull. Buff. Soc. II (1874), p. 51.

Wenn auch Walker's Beschreibung etwas dunkel ist, so bezweitle ich doch nicht, das Grote hecht hat, und ziehe meine Benennung als symonym ein.

Diese Art bewohnt nach Grote die üstlichen, mittleren und südlichen Staaten Nordamericas.

1) Die Arbeit wurde schun im März vorgelegt. ging aber verluren, su duss ich sie noch einmal ins Reine schreiben wusste. 


\section{IIypena achatimalis Z.}

Verl. d. zool.-bot. Ges. XXIl (1872), S. 468 (Sep. 22), Taf. II, Fig. 7.

Hypena malefactalis Gr. 'Pransact. Am. Soc. IV (1872), p. 108.

Bomolocha achatinalis Gr. Bull. Buff. Soc. 11 1874, p. 74.

Ein etwas kleineres $Q$ aus Dr. Rössler's Sammlung weielt dariu ab, dass auf' den Vdfl. das dunklere Basalfeld nicht durch eine helle Liuie begrenzt wird, dass sich aber auf dem Vdrd. dicht an diesem Felde ein heller, ochergelber Wisch: das obere Ende jener Begrenzungslinie sehr bemerklich macht. Die sichel auf der Querader ist verwischt und in einen schwarzen, schlecht umgrenzten Fleck verwandelt. Der Rest des Flïgels ist mit weniger Gran versehen, dafür mchr mit Ochergelb gernischt. Die in einiger Entfernung vor dem Htrd. herziehende blasse Wellenlinie ist sehr unkenntlich und mehr durch ihre inuere dunkle Beschattung angedeutet. Statt des lichtgrauen Costaldreiecks vor der Flügelspitze ist ein licht vchergelbes vorhanden, das noch grösser ist als der vorhergehende Costalwisch. Auf der Unterseite der Htfl. zieht eine bräunliche Schattenlinie hiuter dem Queraderwiseh querüber.

\section{Mararial galbineata Z.}

Verh. d. zool.-bot. Ges. XXII (1872), S. 484 (Sep. 38).

Dr. Speyer meldete mir, dass Mac. quadrisignata Wkr. (Cat. Suppl. 35, 5. p. 1655) dieselbe Art sei. Aus Walker's Beschreibung widerspricht: palpi fusci, palpi brown, dem bei Galbineata sind sie so bleichgelb wie ler K.: antennae sulsetosae, antennae setose (wozu wohl auch minutely gehört) - demn bei Galbineata or sind sie mikroskopiseh kurz pubeseirend; alae posticae margine exteriove subangulato, hiud wings with the exterior border slightly angular in the middle - deun bei Gall. ist die Ecke der Htfl. sehr merklich, wenn auch weniger fein zugespitzt als bei Notata. Auf die kleinere Abweichung. dass die Vdf. der quadrisignata schwärzliche Binden haben solles, ist weniger Gewicht zu legen, weil diese Abänderung eigen sein kann; aber jene drei Abweichungen sind viel zu bedeutend, als dass man sie als unerheblich ansehen dünfte. Ist also der Name aus dem British Museum geholt, so ist er eiu Beispiel daron, dass die Namen der Gegenstande sich dort nicht immer in Uebereiustimmung mit den Catalogsbeschreibungen finden. Uebrigens scheint der Name Quadrisignata Wkr. für Galbineata in Nordamerica als giltig angenommen zu sein. In Lintner's Entomological Contributions wird sie ohne Weiteres S. 64 und S. 182 (mit den Flugzeiten Juli 4 und 25) aufgeführt.

Iı 33. 'Theil, Suppl. 3, p. 974 des Walker'schen Catalogs gibt es noch eine Daddala (hernach Daddata) quadrisignata; diese gehört aber zu deu Noctuinen. 


\section{Fidonia halessmia Z.}

Verh. d. zool.-bot. Ges. XXII (1872), S. 488 (Sep. 42).

Fidonia fimetaria Grote Transact. Am. Ent. Soc. 1870, p. 182, pl. 2, Fig. 84-86.

Grote's Benennung hat dic Priorität. Belfrage zeigt bei ihm den Monat August als Flugzeit an. Es ist mir aber gar nicht zweifelhaft, dass es, wie bei Fasciolaria, eine erste diesjährige Erscheinung in Frühjahr gibt.

Oectoperic n. g. Taf. X, Fig. 45, a, b. c.

(olys!y öffnen - rípx Tasche.)

Ocelli mulli.

Palpi labiales thoracis longitudine, pilosi, compressi, adscendentes, articulo terminali secundo breviore.

Haustellum convolutum, squamatum.

Alae anteriores latae, acutae, costa in medio late emarginata, bis incisa, ó costa inde a basi solenis instar ante emarginationem aperti inflata; subtus in disco medio striola excavata instructae.

Alae posteriores rotundatae, renae medianae basi muda.

Abdomen gracile.

Pedes mediocres; mediorum tibiae spisse piloso-squamatae, pilis in mare fasciculos duos formantibus.

Eine sehr ausgezeichnete Gattung, anscheinend neben Amblyura und Cordylopeza gebörig, gleich ihnen ohne behaarte Wurzel der Htfl.-Medianader, aber mit abgerundeten Htfl, also ohne die stumpfe Ecke des Htrdes. von Amblyurc. Ihre zwei Hauptauszeichnungen sind:

1. die Gestaltung des Vdrdes. der scharfspitzigen Vdfl. Er hat in der Mitte eine breite, beim $\sigma^{7}$ tiefere dusrandung als beim $q$, in welcher der Rand noch zuerst einen tieferen und dann einen seichteren Einschnitt zeigt. Zwischen der Ausrandung und der Fliigelbasis ist der Vdrd. des o stark convex, sonst ohne Auszeichnung. Beim $\sigma^{7}$ ist er aber zu einer kurzen, weiten, an der Schulter zugespitzten und geschlossenen, vor der Ausrandung weit geöffneten Röbre mit schräger Oeffnung erweitert. Bei schräger Haltung sieht man in ihrem Innern sprungfederartig gebogene Borsten, durch welche die Röhre ausgespannt wird. Die Röhrenwände scbeinen aus Flügelmembran, welche mit Schuppen bekleidet ist, zu bestehen. Der Vdrd. des Flügels bildet längs der ganzen Röhre einen scharfen Kiel. - Auf der Unterseite des Flïgels liegt am Ende der Mittelzelle ein länglicher, ausgehöhlter Streifen von honiggelber Farbe; auf der Oberseite des Flügels ist die Membran über ihm nnmerklich erhöht und ohne alle Auszeichnung. - Das Geäder und der eigentliche Ban der Flügel bleiben noch zu erforschen.

2. Die Beine sind von mässiger Länge, die vorderen dünn, und, wie die dickeren, zusammengedrückten hinteren, anliegend beschmppt. Die Mittelbeine 
sind an der Unterseite des Sebenkels durch einen Streifen verlängerter Haarschuppen geflügelt; die Schiene ist, gleichfalls an der Unterseite, mit sehr reichlichen Haarschuppen bekleidet, welche zuerst einen kleineren. dann gegen das Ende einen viel grösseren und stärkeren Busch bilden. Die Hinterbeine haben zwei Paar Dornen, das längere erste hinter der Mitte.

Der Hinterleib ragt wenig über die Htfl. binaus und ist ziemlich schlank, glatt, beim $\sigma^{\nearrow}$ mit einem länglichen Analbusch, beim $q$ mit einem kurzen, aus spärlichen Haaren bervorstehenden Legestachel.

\section{Oect, sincera n. sp.}

Alae ant. latae, peracutae, ferrugineo-cinereae, striga angulato-undata. obscuriore obsoleta post medium posita; post. grisene, subtus striga media albida, nigricanti-marginata notatae. ot $Q$.

Grösse der Cordylopeza. Körper einfarbig staubgrau. Taster um mehr als K.-Länge hervorstehend. Fühler dünn, borstenförmig, unbehaart. weisslich, braun geringelt (dem $Q$ fehlt der K.). Die vorderen Beine sind grau mit schwärzlicher Bestäubung; die Haarschuppen der mittleren schwärzlich.

Vdfl. 31/4" lang, sehr breit, sehr scharfspitzig; der convexe Htrd. unterhalb der Spitze sanft eingebogen. Grundfarbe am hellsten gegen die Wurzel, rostgelblichgrau, bei $ᄋ$ mit weniger Rostgelb, beim $\sigma^{\top}$ am lebhaftesten rostgelb am Vdrd. zwischen der Ausbuchtung und der Flügelspitze. Die Costalröhre ist innen hell ochergelblich, aussen dunkelgrau. Vor der Mitte geht beim $\sigma$ ein ganz verloschener, dunklerer Querstreifen bis zum Innenrand. Ein beim $\sigma^{\prime}$ viel deutlicherer und breiterer als beim $q$ gelit hinter der Mitte vom Innenrand etwas wellig, mit starker Concavität nach aussen, hinauf gegen das hintere Ende der Aushuchtung, macht aber unterhalb derselben einen starken Winkel und endigt im vordern Ende ler Ausbuchtung. Die Fransen sind an der Fligelspitze dunkelgrau. unterhalb derselben an ihrer Endhälfte weiss, tiefer abwärts grau und dunkler querwellig.

Htfl. zugerundet, doch gegen die Spitze etwas verengert, staubgrau, gegen die Basis gelichtet. Fransen weisslich mit dunkelgraner Schattenlinie, welche vor dem Analwinkel verschwindet.

Unterseite der Vdfl. grau, beim $q$ vom Vdrd. aus braunbestäubt; beim $\sigma^{\nearrow}$ am ersten Costaldrittel dunkelbraun bcstäubt, dann hellgrau, gegen den Innemrand am hellsten. Htrd.-Linie schwärzlich, eine feine Reihe weisslicher Punkte enthaltend. Htfl. weisslichgrau. auf der Costalhälfte und in einer Htrd.Linie braunbestäubt. Mitten zwischen dem starken, braunen Queraderpunkt und dem Htrd. ist eine weissliche Querlinie, welche auf beiden Seiten, aber am breitesten und dunkelsten anf der inneren, schwarzbrann gesäumt ist: beim $?$ ist sie sehr verloschen, ihre innere Einfassung am deutlichsten.

Vaterland: Texas (Boll). Ein gut erhaltenes $\sigma$ und ein abgeflogenes, beschädigtes $Q$ im Cambridger Museum. 


\section{Perisposta n. g.}

Frans rotundata.

Antennae mediocres, simplices, setacene.

Ocelli distincti.

Palpi labiales pitosi, compressi, acuminati.

Haustellum distinctum, convolutum.

Pedes graciles, mediocres, simplices.

Alae anterioris acutae, costa valde convexa, margine postico infru apicem sinuato, macula hyatina post venam transversam instrnctae, ramis venae medianae infra eam congestis et flexis, plica super vena mediana profunde impressa.

\section{Alae posteriores rotundatae (vena subcostali trifida?)}

Diese Gattnng kann nicht mit Crocidophora vereinigt werden, weil ihr deren starke Haarflocke auf der Unterseite der Vdfl. fehlt, und nicht mit Marasmin, welche einen ziemlich gralen Vdrd. der Vdfl. hat, und weil auf den Htf. vor der gegabelten Subcostalader eine sehr lange, scheinbar nahe ihrer Wurzel entspringende Ader herlänft. Die Medianader der Vdfl. scheint bei Perispasta einen von beiden Gattungen abweichenden Verlauf zu haben; die Aeste sind an ihrem Ursprung, unterhalb des Glasflecks, zusammengedrängt, sind hier etwas gebogen und gehen strahlenförmig auseinander; die krümmste Linie bildet die erste. Diclit oberhalb der Medianader zieht auf der Unterseite der Vifl. eine tiefe Furche, welche durch ein Einkniffen der Membran entstanden scheint. Auch die Subcostalader scheintEigentlümlichkeiten zu haben. Damit aber der Aderverlauf genan beschrieben werden kann, wird die Abschuppung der Flügel erforderlich sein.

Per. creculritis n. sp. Taf. X, Fig. 46. a. b.

Alae fusco-cinereae, striga postica flexusa fusca; anteriores mucula magna hyalina instructae, cilies nigris, infra apicem exterius longe allis. ot.

Die Art, und folglich auch die Gattung, ist an ihrem noch mehr als bei Crocid. pustuliferalis Led. (tab. 12, Fig. 11) convexen Vdrd. der Vdfl. und der schneeweissen Stelle in den schwarzen Frausen kenntlich.

R. und K. graugelbbraun. Fühler stielrund, unbehaart, hellgrau. Taster fast $1 \mathrm{~m}$ K.-Länge über die Stirn hervorstehend, unten und am Ende locker beschuppt, sehr zusammengedrückt, zugespitzt, an der oberen Hälfte gelbbraun, an der unteren schneeweiss. Saugrïssel weiss beschuppt. Beine schlank und von mässiger Länge, ohne Auszeichnnng: Schenkel und Vorderschienen gebräunt. (Hinterleib fehlt.)

Vdfl. $3 \frac{1}{2}{ }^{\prime \prime \prime}$ lang, länglich, mit sehr stark nach aussen gebogenem Vdrd. und unterhalb der scharfen Spitze concavem, hierauf convexem Htrd. Grundfarbe ziemlich dunkel braungrau. Unmittelbar binter der Querader ist ein grosser, viereckiger, mit einer Ecke fast an den Vdrd. reichenden Glasfleck; seine hinterste Seite wird durch eine braune wellige Querlinie gebildet, die vor dem Enddrittel des Vdrdes. schräg herabkommt, sich dem Htrd. nähert, gebogen 
gegen die Falte zurückweicht, hier eine Ecke bildet und dann schräg einwärts und verdünnt und verloschen zum Innenrand zieht. Die feine Htrd.-Linie ist braun. Die schwarzen Fransen sind an ihrer Aussenhälfte in einem Streifen schneeweiss, der von unterhalb der Flügelspitze bis zur Hälfte des Htráes, reicht und die dadurch um so bemerkbarere Concavität desselben ausfüllt.

Htfl. etwas heller, am Costalviertel ins Weissliche. Die braune Querlinie der Vdfl. sctzt sich, dnrch das Weissliche unterbrochen, auf der Hinterhälfte des Flügels fort, indem sie einen nach aussen convexen Bogen bildet und dann unter einem Winkel mehr einwärts zum Innenrand zieht. Fransen an der innern Hälfte schwarz, an der äussern schneeweiss.

Unterseite heller als die Oberseite, besonders anf den Htfl. Die Querlinie ist nur auf den Vdfl. in ihrer oberen Hälfte vorhanden.

Vaterland: Texas (Boll). Ein etwas bescluädigtes ơ im Miuseum Cambridge.

\section{Botis Thesentis.}

Verh. d. zool.-bot. Ges. XXII (1872), S. 514 (Sep. 68).

Meine Sammlung hat sich mit einem Pärchen meiner Thesealis ans New-York ( $\sigma^{7}$ verflogen 10. Juli, \& frisch 4. Sept.), einem $Q$ der Bot. magistralis Grote (ohne Fühler und Hinterleib), und, was mir das wichtigste ist, einem typischen $\sigma^{7}$ der Bot. Thesealis Lederer aus dem kaiserlichen Museum bereichert.

Meine Thesealis kann ich nicht mehr von Lederer's Pertextalis getrennt halten. Die dunkelen Längslinien, welche die zweite Querlinie mit dem z.weiten, nierenförmigen Ringe verbinden, sind beim verflogenen $\sigma^{\top}-$ und verflogene Ex. aus Nordamerica un erhalten ist die Pegel, von welcher die Lederer'schen $\sigma^{\top}$ keine Ausnahme gemacht zu haben scheinen - nicht zu erkennen. Dass in der Abbildung die dritte, zickzackförmige Querlinie auf den Vdfl. zu nahe an der zweiten läuft, halte ich jetzt für einen Fehler, den sich der Zeichner zu Schulden kommen liess, und der aus Lederer's kurzer Beschreibung nicht erkannt werden kann. Wenn Lederer sagt: "leicht mit Multitinealis zu rerwechseln", so ist das von geringem Gewicht, da es wenigstens eine noch näher stehende Art gibt, die er nicht kannte, und die noch leichter mit Pertextalis zu verwechseln ist.

Der Pertextalis sehr ähnlich ist Grote's Bot. magistralis. Mein cinzelnes $Q$ ist grösser und von so gestalteten Flügeln wie bei Pertextalis $\subseteq$ (also breiter und kürzer als beim $\sigma^{\nearrow}$ derselben). Der Raum zwischen Vdrd. und Suhcostalader ist von der Basis aus bis zu der zweiten Querlinie sattochergelb, das Uebrige weisslich, fast glasartig und opalisirend. Die Zeichnnngen sind viel gröber und dunkler, und was die Art besonders kenntlich macht, die sägezähnige, weiter als bei Pertextalis vom Htrd. abstehende Querlinie ist auf ihrer hinteren Seite breit dunkelbraun schattirt. Ausserdem ist der Htrd. der Vdfl, mit dicken, dunkelbraunen Punkten gezeichnet. Wo diese Art beschrieben ist, weiss ich nicht. 
Bot. Thesealis mus. Led. (Fig. 47) ist kleiner als die zwei eben besprochenen Arten und gehört mit den zwei noch zu erwälınenden in Guenée's Gruppe IX. Sie kamm nicht einmal Walker's Theseusalis nahe stehen, da sie entschieden nicht mit Verticalis S. V. (Kuralis Scop.) verwandt ist, keine abdominis segmenta albido-marginata, keine wings iridescent, keine browu marginal points besitzt, auch in den orbicular and reniform marks keine paler disks zeigt.

Die Flügelgestalt und die Lage und Gestalt der Querlinien und Mittelzeichen zeigt die Figur. Von den beiden Mittelzeichen der Vdf. ist das erste klein, fast punktförmig und viel näher an die erste Querlinie gerückt als an den ziemlich dicken Strich der Querader. Die zweite Querlinie ist an oberen Drittel auswärts blass gerandet. Der Htrd. ist mit einer feinen, ununterbruchenen, bräunlichen Linie umzogen. Der Hinterleib ist einfarbig, hell ochergelblich.

Ich besitze ein schönes $q$ (von Burgess bei Beverly am 3. Juli gefangen), das in den Zeichmungen auf das genaueste mit dem $\sigma^{7}$ der Thesealis Led. überejnstimmt, nur dass sie alle dunkler und schärfer sind. Aber die Grundfarbe ist, statt wie bei der Thesealis ein ziemlich gleichmässiges, blasses Ochergrau zu sein, ein recht angenehmes helles Ochergelb, und die hintere Querlinie ist auf den Htfl., nur nicht an dem feinen, einwärts ziehenden Theil, auswärts mit gelichteter Grundfarbe eingefasst. Obgleich die Flügel auftalleud breit, kurz und weniger gespitzt sind (in höheren Grade als bei Pertextalis 9 ), so vermuthe ich doch, dass dieses $Q$ und Lederer's Thesealis $\sigma$ eine und dieselbe Art bildet.

Der Thesealis nächst verwandt ist die africanische Bot. aegrotalis Z. Caffr., p. 38 (Fig. 48). Das beste Unterscheidungszeichen würden die puncta abdominis duo fusca der Diagnose sein, -. wenn sie nur standhaft wären! Aber mein von Bohemau uach Rückgabe der beschriebenen Arten erhaltenes, sehr gut conservirtes $\sigma^{7}$ zeigt keine Spur davon, und die specifischen Unterschiede sind daher anderwärts zu suchen. Die Grundfarbe aller Flügel ist eiu reineres Gelblich, ohne grane Beinischung; ausserdem sind die vorderen spitzer und länger. Auf diesen steht der erste Punkt weiter von der ersteu Querlinie ab, also viel näher dem Queraderfleck, der nicht ein Querstrich, sondern ein an beiden Enden etwas verdickter Fleck ist. Die zweite Querlinie bildet auf beiden Flügeln über der Hitte einen eckigeren, breiteren Vorsprung, dessen hintere Linie also länger und dabei grader als bei Thesealis ist, und ihr Costaltheil biegt sich zu einem stärkeren Winkel. Die Htrd.-Linie der Vdfl. ist fein, gran, mit sieben Punkten gezeichnet, die aber wohl bisweilen ganz undeutlich sind, da ich in der Beschreibung nichts von ihnen erwähnt habe. Auf den Htfl. ist die Htrd.-Linie aus Stückchen zusammengesetzt und verschwindet gegen den Analwinkel. Der Hinterleib ist wie bei der vorigen und der folgenden Art.

Weil selbst der scharfsichtige Lederer sich irrte, so erwälne ich noch eine sehr ähnliche Art von der Grösse der Aegrotalis (Fig. 49) mit ein wenig 
breiteren und nicht ganz so blassen Flügeln. Ihr Hauptmerkmal - nur gegen die zwei besprochenen Arten, nicht gegen andere nordamericauische - bildet die zweite Querlinie, welche auf beiden Flügeln an ilnem Vorsprunge mit drei recht scharfen Sägezähnen versehen ist. Der erste Punktfleck steht weuiger weit von der ersten Querlinic ab als bei degrotalis, aber weiter als bei Thesealis. Die Htrd.-Linie der Vdfl. ist sehr fein, oder vielmehr fehlt sie: anf den Htfl. ist sie deutlich, etwas breiter als bei Thesealis, und wie bei Aegrotalis vor dem Analwinkel verloschen. Diese, aus dem Staat Georgien stamnende Botis bestimmte mir Guené e als "Verminalis?", welche africanische Art sie offenbar nicht sein kann. Ich schickte sie mit dieser Bestimmung zugleich mit meinem Aegrotalis-Ex. an Lederer, von dem ich sie mit der Notiz: "gleich Ihrer Aegrotalis. Vaterland richtig??" zurückerhielt. Wegen seines Zweifels an der Richtigkeit der Vaterlandsangabe zeigte er im Pyraliden-Katalog nur Africa für Aegrotalis an.

Welchen Namen die Art etwa bei Walker tragen nnag, nnterlasse ich zu erforschen, da ich doch sehr wahrscheinlich nicht den richtigen treffen würde.

Keine der drei vorstehenden Arten kann Walker's Theseusalis sein, da die oben für Thesealis angegebenen Abweichungen auch von den zwei auderen gelten. Die Worte: the orbicular and reniform marks rather large, not excavated, their disks paler werden wohl richtig so verstanden, dass beide Flecke vollständige, nirgends unterbrochene Ringe bilden. Diese Theseusalis behält also vor der Hand ihren Namen so gut wie ilıre gleich schlecht benannten Kameraden Siriusalis, Mysippusalis, Thymetusalis.

\section{Zophodia Bollii Z.}

Verh. d. zool.-bot. Ges. XXII (1872), S. 550 (Sep. 104).

Die Nachricht über ilıre Flugzeit ist ans der Verwechslung der Art mit einer Spinnerart entstanden. Wie mir Dr. Hageu meldet und Boll bestätigt, sind die Ex. wirklich aus Raupen gezogen, welche in Agaveblätteru minirend lebten.

\section{Ephestia.}

\section{Eph. interpunctella $\mathrm{H}$.}

- Heinemanu Pyr. S. 202.

Tinea zeae, Indian mealmoth, Fitch Noxious Insects (1868), p. 320, pl. 4, Fig. 1.

Einen Schuppenkegel auf der Stirn, den Heineu. angibt, hat diese Art nicht, sondern die Schuppen des schwachgewölbten Gesichts verlängern sich nur nach unten zu einer auf den Tastern liegenden spitze.

Obgleich die Bezeichnung: dull gray or blackish with the basal third of the forewings whitish sehr schlecht passt, so lässt doch die ausführliche Beschreibnng keinen Zweifel, dass Fitch diese Art, dereu Naturgeschichte er mittheilt, gemeint hat. Auch schickte mir Burgess ein ơ als Tinea zeae Fitch. 
Ausser aus Massachusetts erbielt ich dieses sehr verbreitete Hausthier aus 'Texas, wo Boll es mehrfach in Dallas County sammelte, und Belfrage ein sehr kleines $\sigma^{7}$ ohne Fransen am 24. August und ein gutes. gewöhnliches q am 28. April fing. Dass Intevpunctella noch riel südlicher lebt, beweist ein Q aus der Westindischen Insel St. Thomas. Ein wohl erhaltenes $Q$ fing ich hier in Grünhof am 13. Juli 1874 in meiner Stube.

\section{Eph. ochrifrontella n. sp.}

Parva, palpis fronte collarique ochraceis; atis ant. usque ad medium, rufescenti-luteis deinde fusco-cinereis, strigis duabus appropinguatis pallidis, opposite fusco-murginatis. $0^{7}$.

Ungeachtet der lehmgelben Basalhälfte ihrer VdH. steht sie doch mit Interpunctella in keiner nahen Verwandtschaft. Ihre K.- und Tasterfarbe, und die einander genäherten Querlinien der VdH., deren erste in der Flügelmitte steht, machen sie sehr kenntlich.

Etwas grüsser als gewöhnlich die folgende Hospitella. K. und Halskragen ochergelb; letzterer an der Seite von der Farbe des gelbbräunlichen R. Stirn schwach gewölbt. Taster an ihr heraufgebogen und sie mit dem langen, spitzen Endgliede überragend, bell ochergelb; das zweite Glied auswärts gelbbräunlich. Beine braun; nur die Hinterschienen anf den ersten $2 / 3$ hellgrau. Hinterleib hellgrau, am Ende bleich ochergelblich; der Analbusch als Bekleidung der zwei oberen, horizontalen Genitalklappen zweilappig mit abgerundeten Lappen, unter welchen eine dunkle, fast dreieckige Höhle in den Hinterleib führt.

Vdfl. $23 / 4^{\prime \prime}$ lang, in der Basalhälfte schmal, dann stark erweitert. Die Basalhälfte ist braun röthlichgelb mit etwas Kupferschimmer, hierauf dunkel braungrau. Die Grenze beider Färbungen wird durch eine helle, nach aussen convexe, etwas wellige Querlinie gebildet, welche am Dorsalrand am hellsten und auf der binteren Seite schwarzbraun schmal beschattet ist. Die zweite gelbliche Querlinie ist der ersten ungewöhnlich nahe, weil diese die Flügelhälfte abschliesst; sie ist dünner, wenig gebogen, dem Htrd. ziemlich parallel; ihre braune Einfassung ist auf der Basalseite dunller und schmäler, als auf der hinteren Seite. Der ron beiden Linien eingeschlossene Raum ist viel dunkler, als das Htrd.-Feld. Eine Queraderzeichnung ist kaum durch einen ganz verloschenen dunklen Punkt angedentet. Eine linienförmige Verdunkelung trennt den Htrd. von den brännlichgrauen Fransen.

Htfl. grau, an Rande dunkler. Fransen hell, nahe der Wurzel von einer dunkelgrauen Schattenlinie, die gegen den Innenwinkel verschwindet, durchzogen.

Unterseite der VdH. bräunlichgrau wit deutlich von den Fransen abgesondertem Htrd. Htfl. hellgrau.

Vaterlani: Texas (Boll). Ein gut erhaltenes of im Cambridger Nuseum. 


\section{Eph. elutella H.}

- Z. Isis, 1848, S. 592. Heinemann Pyr. S. 201.

Obgleich die gewöhnlich am Inneurand mehr oder weniger lebhaft gerötheten Vdfl. die Art meistens kenntlich machen, so ist doch das sicherste Artmerkinal der starke, bleichgelbe Haarpinsel an der Wurzel der männlichen Htfl.

Gewiss ist dies in Europa gemeine Hansthier auch in Nordamerica sehr verbreitet: dennoch habe ich nur ein $q$ durch Speyer aus New-York. Es gehört zu den kleineren Ex. und ist auf dem Vorderkörper und den Vdfl. dunkelgrau, an Inwenrand kaunı ein wenig röthlich gemischt. Da dies bei mancher enropäischen Elutella ebenso der Fall ist, so bat das Ex, vor den unseren nur das voraus, dass auch die HtH. ihren verhältnissmässigen Antheil an der Verdunkelung nehmen, wodurch die Gabel, welche Ader 3 und 4 bilden, recht sichtbar wird.

\section{Eph. hospitella n. sp.}

Parva; al. ant. cinereis, strigis 2 dilutis, latiusculis, late distantibus, opposite nigricanti-udumbratis, posteriore undulata, exterius nigricanti-adumbrata, panctis 2 venae transversae nigris; post. canis vel dilute cinereis. $\sigma^{\top} Q$.

Mit der Färbung und Zeichuung dieser Art ist gar manche Phycidee versehen; daher ist, obgleich ihre Kleinbeit sie sehr auszeichnet, vor allen Dingen anf das Gattungsmerkmal - die einfache Gabel der Subcostalader der Htfl. zu achten. Aber auch unter den Ephestien gibt es beschriebene nnd unbeschriebene älnnliche Arten. Elutella ist fast immer erheblich grösser und am Innenrand der Vdfl. gewölnnlich geröthet, während bei Hospitella der Innenrand gar nicht geröthet und zwischen den Querlinien bisweilen geschwärzt ist. Die hellen Querlinien der Elutella sind dünner und an den Gegenrändern nicht so dunkel gesänmt; die erste ist der Basis näher gerückt und die zweite, weil sie feiner ist, weiter vom Htrd. entfernt; die Queraderpunkte, die gewöhnlich fehlen, sind nie so schwarz und scharf ausgedrückt, wie bei Hospitella in den allermeisten Fällen. Elutella $\sigma^{7}$ hat auf der Htfl-Basis den schon erwälnten Haarpinsel; die Flitgelspitze ist in diesem Geschlecht mehr abgerundet als beim $Q$; endlich hat Elutella $\sigma^{\nearrow}$ einen länglichen, abgerundeten Analbusch, während bei $\mathrm{Ho}$ spitella o' der untere Theil des Analgliedes weit nnter dem abgestutzten Haarbusch hervorsteht. - Die mit Ficella verwaniten Arten sind noch grösser als Elutella und haben viel gestreektere Vdfl. ohne auffallend dunkle Einfassung der Querlinien; eine Art hat auch durchscheinende Htfl., und bei keiner hat der männliche Analbusch die Anszeichumg der Hospitella. - Die grössere, auf den Vdt. sehr verloschen gezeichnete Milleri hat einfarbig weissliche Htfl, einen Analbnsch ohne Auszeichnnng, dagegen an deu männlichen Füblern eine Krümmung, die keine bisher bekannte Art besitzt.

Vorderkörper ziemlich dunkelgrau. Gesicht gerundet, glatt. Taster an ihı anfgekrümmt und über die Stirn hinaufreichend, anssen brännlich an- 
gelauf́cu, zugespitzt. Fühler einfach borstenfơmig, grau, mit abgesetzten Gliederı, daher bisweilen scheinbar duntler geringelt. Beine bräullich grau, Fussgliederspitzen weisslich. Hinterleib staubgrau, beim $f$ nit gespitztem Analgliede. Beim $\sigma^{7}$ ist der Analbusch hell, flach, abgestutzt; die untere Genitalklappe reicht nnter ihm hervor und ist kielfürnig zusammengedrückt mit einer End spitze; zwischen ihr und dem Analbusch bleibt dadurch ein leerer, dunkler Raum.

Vdf. $2 \frac{1}{2}-3^{\prime \prime \prime}$ lang, ziemlich schmal, nach hinten erweitert, heller oder dunkler gruu. Bei $1 / 3$ ist ein breiter, heller, etwas schräger Querstreifen, auf seiner welligen hinteren Seite mit einem eben so breiten schwärzlichen Raude und gegen diesen scharf abgegränt, während er auf der Basalseite gegen den grauen Grund wenig absticht. Der zweite helle Querstreifen liegt bei $3 / 4$, ist weniger lreit, als der erste, meist schärfer gezähnt und auf der Basalscite weniger breit schwarz beschattet: auf dem Vdrd. steht er weiter vom ersten ab, als auf dem Innenrand, wo er sich etwas erweitert; auf der Hinterseite ist er mehr oder weniger breit beschattet. Zwischen bciden Querstreifen ist der Innenrand öfters schwärzlich angelanfen. Die zwei Punkte der Qucrader sind schwarz, scharf, doch etwas in eimander fliessend (bei einem $ᄋ$ fehlen sie ganz!); sie sind dem zweiten Querstreifen meln als doppelt so nahe, wie dem ersten, und beriihren fast den Schatten des zweiten. Der Htrd. lat eine unvollständige Reihe schwarzer Punkte, bisweilen gar keine, so dass die gelichtete Farbe des Htrdes. in dic fast ebenso helle der Fransen olme Grenze verläuft.

Htfl. des $\sigma^{7}$ fast so spitz, wie die des 9 , dunkler oder heller grau, selbst weisslich ausser dicht am Rande. Fransen wenig heller. dunkelt.

Unterseite der Vdf. dunkelgrau; Htfl. Lellgrau, gegen den Vdrd. ver-

Vaterland: Texas (Boll, Belfrage). Sie scheint dort in zwei Generationen zul fliegen, da ein $q$ am 17. Mai, drei $\subseteq$ am 20. Juli und 16. August gefangen wurden.

\section{Eiphest. Milleri $11 . \mathrm{sp}$.}

Antennis or supra basim leviter arcuatis; alis ant. dilute cinereis, strigis duabus late distantibus, dilutis, olsoletis, opposite cinereo-marginatis, puncto venae transversae obscuro, obsoleto; post. albidis. $0^{7}$ ㅇ.

In der unscheinbaren Färbung und Zeichung mit mancher Phycidee übereinstimmend, ist sie eine eclite Ephestia, aber mit der wichtigen Auszeichnung, dass die männlichen Fühler über dem Wurzelgliede eine schwache lírümmung und vor deren Anfaug eine kleine Verdickung haben. Von der gleich grossen Elutella unterscheidet sie sich ausserdem durch schmälere Vdfl. ohne gerötheten Innenrand und durch weissere Htfl. mit mebr vortretendem Analwinkel und weisslichem Basalpinsel. Hospitella ist viel kleiner mit breiteren, nach hinten mehr erweiterten VdH., auf denen die Querstreifen einander viel näher stehen und eine scharfe, dunklere Einfassung haben etc.

R. und K. ein wenig dunkler grau als die Vdfl. Fühler grau, borstenförmig; beim $\delta$ oberhalb des Wurzelgliedes mit einer schwachen Krïmınung 
ıud vor dem Anfang rerselben auf dem Rücken mit einer beulenartigen Verdickung, die, schwächer werdend, sich bis zum Wurzelgliede hinzieht und den Fühlerstiel etwas rerdickt erscheinen lässt. Taster an del convexen Stirn aufgekrümmt und sie mit dem länglichen, spitzen Endgliede ïberragend. Saugriissel ziemlich lang. Fussglieder an den Enden weisslich; Hinterschienen breit, zusammeng'edrückt, am Ende oberwärts in einen spitzen Haarbusch endigend. Hinterleib staubgrau; Analbusch heller, zugerundet, beim $\sigma^{-1}$ auf der Unterseite mit einer Längsspalte, beim ㅇ mit eingezogenem Legestachel.

Vdfl. 4" lang, schmal, nach hinten sehr wenig erweitert, an Vdrd. nach hinten convex; Grundfarbe gran, durch weisse Stäubchen gelichtet. Zwei verloschene, weissliche Querstreifen stehen sehr weit von einander ab; der erste bei $1 / 4$, wenig schräg, schwach wellig, hinten verloschen und ziemlich duukelgrau gesäunt; der zweite hinter $3 / 4$, dem Htrd. parallel, also gegen den ersten unterwärts stark divergirend, geschlängelt, basalwärts schmal-, saumwärts breiter grau gerandet. Ihm näher als dem ersten liegt auf der Querader ein manchmal ganz verloschener, dunkelgrauer Punkt und über diesem zuweilen ein kleinerer. Auf dem Htrd. ist eine Reihe grober, dunkler Punkte. Fransen einfarbig, heller als die Grundfarbe.

Htfl. stark zugespitzt, am Htrd. weniger abgerundet als bei Elutella, wodurch der Analwinkel meh" hervortritt und die Flügelgestalt schärfer dreieckig wird. Grundfarbe weisslich nit schwach verdunkelter Htrd.-Linie. Fransen weisslich.

Unterseite der Vdf. hell bräunlichgrau. Der durch Schnppen gebildete Unschlag an der Wurzel des Vdrdes, reicht fast bis zum zweiten Drittel desselben. Htfl. wie oben, am Vdrd. striemenförmig staubgrau. Die durch Ader 3 und 4 gebildete Gabel ist länger, als bei Elutella; iln Stiel ist halb so lang, wie das Stiick der Medianader von Ader 2 an bis zur Flügelbasis.

Vaterland wahrscheinlich Mittelamerica. So viel ich mich erimere, fing Herr Hermann Miller diese Art anf einem direct von dorther gekommenen Schiffe. Ich benenne diese, wenn auch unscheinbare Art, nach dem Entdecker, um das Andenken an den fleissigen, wissenschaftlichen Lepidopterologen auch in der Familie der Phycideen zu erhalten. (Vgl. Entomol. Zeitung, 1874, S. 320).

\section{Tegeticula alba Z.}

Verl. d. zool.-bot. Ges. XXIII (1873), S. 232 (Sep. 32).

Diese Alt hat eine etwas ältere Benennung, die eintreten muss, nämlich Pronuba Yuccasella Riley. ${ }^{1)}$

Pronuba Yuccasella Riley, Trans. of the St. Louis Ac. of science $187 \%$.

- Fifth Feport on the Insects of Missonri 1873 , p. 150 , Fig. 74,75 .

- Sixth Report etc., p. 131, Fig. 38 (Puppe).

Sie gehört nicht, wie ich, durch ihre sonstige Uebereinstimmung und durch Uebersehen ihrer langen Maxillartaster verleitet, anuahm, zu den Hyponomeu-

1) Vịlleicht mit einer kleinen Abänderung in Yuccaclella, da Fuccasella eine gegen die Kegeln der lateinischen Worthildung streitende Ableitung von Yucca ist. 
tiden, sondern zu den Tineiden, unter denen sie wegen des Tasterbaues nicht bei Amydria und Anaphora stehen kann, sondern ihren besten I'latz vor Blobophanes, wenn auch in weiter Entfernung, zu finden scheint.

Zufolge der Riley'schen, sehr genauen Beobachtungen, wird die Bcfruchtung der Yucca-Arten : angustifolia, rupicola, Whipplei, flaccida, mubrula, glauca, die in verschiedenen Südstaaten wachsen, einzig und allein durch die Weibchen dieser Motte bewirkt. Sobald es befruchtet ist, kriecht es zwischen den Staubgefässen abwärts, bohrt mit dem feingespitzten Legestachel in das weiche Fleisch des Fruchtknotens und legt ein Ei hinein; darauf klettert es anf eine Anthere, sammelt mit ihren Maxillartastern (tentacles) den Stanb und schiebt ihn in die Oeffnung des Stigma. Dies geschieht gewöhnlich nach jedem Ablegen eines Eis, so dass, wo 10-12 Eier eiuem einzigen Pistill übergeben werden, das Stigna ebenso vielmal mit Samenstaub versehen wird. Die Samen, welche ron dem am vierten oder fünften Tage ausgekrochenen Räupchen ausgefressen werden, schwellen an und verrathen grade durch ihre Geschwuist die Anwesenbeit des ganz jungen Thieres, das man sonst iibersehen würde. In einzelnen Kapseln zählte Riley 21 Raupen: doch in der Regel sind nur zwei in einer. In letzterem Falle bleiben, da 12-15 Samen für eine Raupe bis zur Verpuppung ausreichen, von den mehr als 200, die oft eine Kapsel enthält, genug fruchtbare Samen übrig; bei den Yuccas mit kleinen Kapseln wird jedoch zuweilen jeder Same zerstërt. Die Raupe ist olne Bauchfüsse und Nachschieber (?), weiss, erwachsen fleiscbfarbig; der K. lropalfarbig. Ausgewachsen bolurt sie sich hervor und verfertigt unter der Erde ein eifürmiges, immen mit Seide ausgefüttertes Gehäuse. Darin bleibt sie unverwandelt bis gegen die Blïthezeit der Yucca (5. Juni bis 5. Juli); auch lässt sie sich durch Stubenwärme nur wenig treiben. Bei der Verpuppung wird nicht die Raupenhaut nach hinten abgestreift, sondern die Puppe arbeitet sich durch eine Rückenspalte der Raupenhant hervor, so dass die letztere beinahe ihre ursprüngliche Länge behält. (Ich kenne keine Schmetterlingsranpe, die sich anf diese Weise verpuppt; nur von den Zygänen-Raupen weiss ich, dass sie so ihre Bäutungen vollziehen). Die Puppe hat einen kurzen Stirndorn; ihre HinterleibsSegmente, besonders das erste, sind anf dem Rücken mit kräftigen Dornen bewaffnet. Mit dieser Ausrüstung durchbohrt sie nicht allein ihr Gehäuse, sondern arbeitet sich anch durch wirbelnde Drebungen aus der Erde hervor.

Diese so merkwürdige Motte hat in Louisiana, Californien, Colorado, Siid-Carolina eine weite Verbreitung.

Das 9 , das ich ron Grote erhielt, ist etwas grösser als die zwei von mir gesehenen $\sigma^{\pi}$, und lat breitere Vdfl.; der Hinterleib ist an der Endhälfte zusammengedrückt, kahl, hornbraun, zugespiłzt; aus der Spitze ragt eiu feiner, $2^{\prime \prime \prime}$ langer Stachel hervor. Das Merkwürdigste an dem Ex. ist der grosse, hellgelbe, wachsähnliche, anscheinend solide, nicht aus Körnchen zusammengesetzte Klumpen, welcher zwischen der Wurzel des Saugrüssels und den Vorderhüften fest angeklebt ist; anf ihm liegen, wie der Länge nach angeklebt, die zwei hellbraunen Maxillartaster, und zwischen ihnen, also auch auf der oberen Seite, 
reicht der hell honiggelbe Saugrïssel frei und gebogen bis etwa zur Hälfte des Klumpens, während die Lippentaster gar nicht sichtbar, sondern wahrscheinlich unter die Masse verklebt sind. Dic Erklärung, welche Riley von đer Ansammlung der Fig. 74 richtig dargestellten Pollenmasse gibt (V, p. 154) will mir nicht genügen, da ich die Maxillartaster nicht für brauchbar zu dem Zweck halte. Der kräftige Saugrüssel scheint mir dazn allein brauchbar; aber wie durch allmäliges Ansammeln des Staubes eine solide, wie zusammengeschmolzene Masse entsteht, bleibt noch genauer zu untersuchen. Meines Erachtens hat Riley bei seiner höchst interessanten Entdeckung noch nicht Alles gesehen, und noch andere Beobachter werden erforderlich sein, um die sonderbaren Vorgänge bei der Fortpflanzung der Motte ganz genügend zu erklären.

\section{Timea dorsistrigella Clem.}

Verh. d. zool.-bot. Ges. XXIII, 1873, S. 220 (Sep. S. 20).

Baron v. Nolcken erkennt Mendicella H. 179, die ich für eine verdorbene, abgeblasste Ferruginella erklärte, in einer Art wieder, welche er mit Tin. corticella aus Banmschwämmen erzogen hatte. Das o Ex., das er in seiner musterhaften "Lepidopt.-Fauna von Estland, Livland und Kurland, Abth. 2 (1870), S. 478 (oder Heft III der neuen Folge der Arbeiten des Naturforschervereines zu Riga) als Tin. mendicella auffüht und nit Hübner's Fig. 179 und Fermginella genau vergleicht, habe ich durch die Güte des Eigenthümers vor mir. Dass es nicht mit Ferruginella verbunden werden kann, ist, wie . Nolcken richtig bemerkt, unzweifelhaft; ihm fehlt der durehsichtige Vdfl.Punkt, so dass es gar nicht einmal zu Blabophanes gelıört. Mit Mendicella $\mathrm{H}$. stimmt es darin überein, dass sein $\mathrm{R}$. braun ist, und in meinem Ex. des Hübner'schen Werkes ist auch das Schwarze auf dem linken Vdfl. gegen deu Innenrand verlängert, also dem Nolcken'schen Ex. einigermassen entsprechend; dieses hat auch einen weisslichen Punkt auf dem Vdrd. der Vdfl. vor der Mitte (wofür jedoch Häbner's Bild auf dem rechten Vdfl. zwei weit getrennte, auf dem linken nur einen dicht am Mittelfleck zeigt). - Was mich hindert, der Nolcken'schen Ansicht beizustimmen, ist der schmale, schwarze K. der Mendicella H., der breite, hellgelbwollige der Mendicella Nolck. und der grosse, wenn auch dunkel besprengte Costalfleck vor der Flügelspitze der letzteren, wofür Mendicella $\mathrm{H}$. links drei, rechts nur zwei kleine Costalstriche aufweist. Selbst wenn die livländische Art so abändern sollte, dass sie der Mendicella $\mathrm{H}$. in der Flügelzeichnung ähnlicher sehen sollte, als es jetzt der Fall ist, so wird ihr Kopf doch nie schwarz sein, und daher scheint es mir das Richtigste, ihr als einer neuen Art einen Namen zu geben.

Adela trigrapha ч. sp. Taf. X, Fig. 50.

Capite palpisque hirsutissimis, antennis $\sigma^{7}$ longis, $q$ brevibus, albis, inferius nigro-subannulatis; al. ant. atris, strigis tribus albis; post. nigris, puncto anguli analis albo or 9 .

Var. b) $\sigma^{\top}$ striga tertia in medio interrupta. 
Eine aurch die tiefschwarzen Vdfl. mit drei weissen Querlinien und den weissen Punkt der Htfl. sehr ausgezeichnete Art, die der grösseren Cuprella verwandt ist.

Grösse der Rufimitrella. Körper tiefschwarz. K. des $\sigma^{\top}$ oben und auf der Stirn lang- und unordentlich behaart; Taster kaum von R.-Länge, an der unteren Seite mit noch längeren Haaren reichlich bekleidet; das vorgestreckte Endglied kahl. Sangrüssel an der Wurzel behaart. Beim $q$ ist der K. selır beschädigt und zeigt nur noch im Nacken und auf der Stirn kurze, rostrothe Haare; auch die Taster fehlen ihı. Das $\sigma^{\gamma}$ ist an Schenkeln und Schienen langhaarig; die Schienen und Füsse sind auf einer Seite weisslich oder doch sehr hell; an den Hinterbeinen sind die Schienen innen kupferig schimmernd, die Füsse weisslich, ausser am ersten Gliede. Beim $ᄋ$ sind die Beine spärlich behaart; die Füsse gelbfleckig, die Hinterschienendornen gelblich. Der Hinterleib des $\sigma^{7}$ ist kurz und schlank, des ㅇ viel länger mit gelber, stachelförmiger Legeröhre.

VdAl. O $2^{1} / 2$, ㅇ $2 \frac{1}{4} 4^{\prime \prime}$ lang, länglich mit abgerundetem Htrd. und sølcher Spitze, tiefschwarz, beim $Q$ auf der Endhälfte von der zweiten Querlinie an grünschimmernd, während beim $\sigma^{\top}$ der Vdrd. von der zweiten Querlinie an bis zur Spitze schmal violett schimmert. Die drei weissen vollständigen Querlinien liegen nicht bei allen Ex. in denselben Entfernungen von einander: die erste ungefähr bei $3 / 4$, die zweite in der Mitte, die dritte näher der Flügelspitze als der zweiten. Die erste ist die feinste und ganz grade; die zweite krümmt sich ein wenig nach aussen, die dritte, welche unter der Mitte des Htrdes. verdünnt endigt, zieht sich auf dem Vdrde. ein wenig gegen die Spitze hin. Bei Var. $b$ ist sie in der Mitte so durchbrochen, dass das untere Stück die halbe Länge des oberen hat. Fransen schimmernd gelbbräunlich, gegen den Innenwinkel verdunkelt, um die Flügelspitze auswärts grau oder fast weisslich.

Htfl. viel heller schwarz als die Vdfl., nur längs des Innenrandes in einem breiten Streifen dunkler. In diesem verdunkelten Theil liegt im Analwinkel ein in der Grösse wechselnder weisser Punkt. Fransen dunkelgrau, gelblich schimmernd.

Unterseite der Vdfl. schwärzlich: die zwei hinteren Querlinien scheinen verloschen durch. Htf. schwärzlich, violettschimmernd, an den Rändern, am breitesten in der Flügelspitze, mit goldfarbenen Schuppen bestreut.

Meine drei Ex. sind ans Nordamerica, wahrscheinlich aus Californien, woher die Var. $b$ und ein gewöhnliches $\sigma$ der Rössler'schen Sammlung sicher stamnen.

C'ryptolechia rtrojicte n. sp. Taf. X, Fig. 51.

Palpis reflexis, albis, basi nigra; pedibus fusco-nigris; al. ant. exalbidis, pulvere brunnescenti et punctis nigris varius conspersis, macula humeruli. parva magnaque costae post medium subangulatu alris; post. dilute cinereis. ㅇ. 
Kleiner als $C r$. ustimacula, so gross wie Albicilla, durch den kleinen, tiefschwarzen Schulterfleck und den ebenso gefärbten Costalfleck hinter der Mitte der gelblichweissen Vdfl. sehr ausgezeichnet.

R. und K. von der Farbe der Vdf.; Schildchen braun. Fühler borstenfürmig, an der Wurzel weiss. Saugrüssel aufgerollt, braun. Taster von R.-Läng̨,, zurückgekrümnt, weiss; ziveites Glied zusammengedrücht, glatt mit anliegender Behaarung, aussen am Basaldrittel schwarz; Endglied ebenso lang, dünu, fein gespitzt, etwas braun bestäubt. Beine sämmtlich schwarzbraun; nur die Vorderhüften vorn weisslich mit dichter, brauner Bestäubung. Hinterleib (verült) grau, ziemlich stark, mit kurzem, ziemlich dünnem Legestachel.

Vdfl. etwas über $4^{\prime \prime \prime}$ lang, schmal, am Vdrd. hinter der Vitte, wo der tiefschwarze Fleck liegt, ein wenig eingebogen; die Spitze deutlich. doch nicht scharf; der Htrd. sanft convex. Grundfarbe gelblichweiss, hie und da, besonders anf der Innenrandhälfte und unter dem grossen schwarzen Fleck bräunlich bestäubt. Die Schulter trägt einen kleinen, tiefschwarzen Fleck. Hinter der Mitte hängt am Vdrd. ein ebenso gefärbter, eckiger Fleck herab, an dessen Ende sich der tiefschwarze Queraderpunkt anschliesst. Ihm räher als dem Schulterfleck liegt in der Mittelzelle ein schwarzer Punkt, und hinter dem Costalfleck, dem Htrd. weit uäher, zieht auf den untereu $2 / 3$ der Flïgelbreite ein Bogen aneinander stossender tiefschwarzer Punkte. Der Htrd. ist von den weissen Fransen nur durch bräunliche Stäubchen abgesetzt.

Htfl. von der Breite der Vdfl., an der Spitze etwas verengert und abgerundet, hellgrau wie die Fransen.

Unterseite hellgrau. Die Vdfl. an der Stelle des Costalflecks verdunkelt, dahinter bis vor die Flügelspitze fast weisslich. Der Htrd. scharf abgesetzt gegen die weisslichen, in der Mitte von einem granen Nebel durchzogenen Fransen.

Vaterland: Nordamerica. Ein 우 in Dr. Rössler's Sammlung.

\section{Encemiar $\mathrm{z}$}

Verh. d. zool.-bot. Ges. XXIII (1873), S. 562 (Sep. S. 116).

Diese so echte Tineinen-Gattunghh - denn, dass sie zu den Tineinen gehört, zeigt schon die verhältnissmässige Kürze des Inueurandes der Htfl. lintes den Lithosien zu suchen. war mir nicht eingefallen. Nun ist es wohl möglich, dass man, wie das Walker'sche Geuus Atteva, auch die nahe verwandte Gattung Trichostibas Z. unter den Bombyciden vorfinden werde. Liune stellte die Lithosien unter die Tineen, Walker kehrte die Sache theilweise um; aber Grote hätte Walker's Vorgange nicht folgen solleu. Ob der Gattungsnane Eustixis Hbn., welchen Grote vorzieht, oder Mieza Wkr., oder keiner von beiden der berechtigte ist, kamn ich in Ermangelung des $\mathrm{H}$ ïb nejschen Werkes nicht beurtheilen. 


\section{Eu. psammitis Z.}

Eustixis subfervens (Wkr.) Grote Bull. Buffalo Soc. II (Sejt. 1874), p. 152. Miezu - Wlir. List. Bomb. II, 528.

Walker beschreibt meine Psammitis; ich hätte dies aber obme Grote's Synonymie nicht erkannt, da ich die Farbe des K., des Thorax und der Vdf. nicht, wie Wkr., weiss, sondern grau sehe und ans dem Schweigen über die Htf.-Farbe eher auf Weiss als auf Roth geschlossen bätte. Vie Walker'sche Speciesbenemung hat also die Priorität vor der meinigen.

\section{En. crassivenellı Z.}

Verh. d. zool.-hot. Ges. XXIII (1873), S. 563 (Sep. 117).

Mieza igninix Wkr. List. Bomb. 527.

Eustix. pupula Grote 1. c. p. 152.

Dass Wkr. die vorliegende Art meinte, leidet wenig Zweifel, obgleich hinsiclıtlich der von ihm als weiss bezeichneten Kör]ertheile um der Htfl.Farbe dasselbe gilt wie bei der vorigen. Seine Weise zu zählen ist aber schwer verständlich; er sagt: thorax albus sexmaculatus und thorax white with six black spots: one on the disk, two on each side, and one on the scutellum. Es könnte scheinen, als ob er die lage der zwei noch zu den sechs fehlenden verschwiegen habe; aber ich sehe an dem Ex. des Cambridger Museums nur drei fleckähnliche Verdunkelungen!

Als dritte Art seiner Mieza führt Walker noch Hübner's Pupula auf, die nacb Grote glejch meiner Crassivenella ist. Die Worte: Mieza? pирияа (p. 528), aurantiaca; thorax albus; alae anticae supru nigro notatae, pallicle virides, apices versus subrosecie passen auf meine Art bis auf das nichtssagende nigro notatae nicht in allermindesten. Ehe ich über Hübuel's Art, von welcher. Walker nur die Abbildung kannte, nichts Bestinunteres weiss, selıe ich nicht ein, wie Grote sie zu Crassivenella stellen komte.

\section{Blastobasis mubilella $\mathrm{Z}$.}

Verh. d. zool.-bot. Ges. XXIII. (1873) S. 297 (Sep. 97).

Diese Art ist mit grösster Wahrscheinlichkeit einerlei nit Holcocera gland ulella Piley Report. IV (1872) S. 145, natürlich bloss nach der Beschreibung, da das Bild mit seinen fast keulenförmigen Fülılern und den in der Dunkelheit verschwindencken Vdfl.-Punkten nur die Darstellung einer Blastobasis in Allgemeinen gibt. 
Riley sagt, die Art ändere ab, was ich gern glaube. Es ist mir nicht ganz klar, ob er mit den Worten: this [dark] shade generally extends from the elbow [of the pale stripel to the costa above the discal spots, forming a more or less distinct triangular shade in the anterior middle portion of the wing das Dreieck hezeichnet, das bei meiner Sciaphilella Fig. 34 so deutlich ist. dass es mir specifische Rechte anzudenten schien. Da nächstverwandte tepidopternSpecies nicht so durcheinander vorzukommen pflegen, so wird Riley beim Vergleich seiner gezogenen Ex. der Glaudulella mit meinen Beschreibungen und Bildern recht sicher beurtheilen können, ob ich nacb den mir vorliegenden Ex., ïber deren I,ebensweise mir gar nichts vorlag. Varietäten, und welche ich zu dem Range von Species erhoben habe.

Riley erzog seine Glandulella aus Eicheln, die hauptsäcblich durch den Frass des Rüsselkäfers Balaninus rectus beschädigt und zum Abfallen gebracht waren. Auffallend ist die lange Dauer des Auskriechens der Motte: von Ende April bis September. Von unserer Phycidella und Roscidella, welche allein ich lebend heobachtete, fliegt die erstere in der Endhälfte des Mai und den Juni hindurch, letztere in den ersten zwei Dritteln des August. Riley's Beobachtnngen, geben einen Fingerzeig sowohl hinsichtlich der Lebensweise wie der Artrechte dieser zwei Blastobasis. Da Phycidella nur im Kieferngehölz lebt, so wird die Raupe in den abgefallenen Kieferzapfen, Roscidella, die ich nur im Eichen- und Kastaniengehölz, in dem es kein Nadelgebölz gab, beobachtete, in den Früchten einer dieser Baumarten leben. Hein stiller Verdacht, dass Roscidella am Ende doch nur eine zwerghafte, blasse Phycidella sein möge, ist dadurch völlig gehoben.

\section{Lithocolletis}

1. Quercetorum Frey. Taf. X, Fig 52.

Ent. Zeitung 1873, S. 207.

Auch in Texas, wie schon Frey hemerkt. $2 \sigma^{\top}$, von Boll dort gesammelt, wovon 1 in meiner. 1 in der Cambridger Sammlung.

\section{Conglomeratella n. sp.}

A7. ant. subopacis, croceis, linea basali nulla, strigntis costae tribus (secundae apice atomis nigris cireumdato) dorsoque toto lincae instar albidis, nuhe marginis postici atomis nigris composita. $\sigma^{7}$.

Etwa in der Nähe der Corylifoliella aufustellen, von allen nahen und fernen Verwandten durch den gänzlichen Mangel der Basallinie ausgezeichnet, wozu noch die Kürze der Costalhälichen und die an Frölichiella erinnernde Anbänfung schwarzer Schüppchen komınt. 
R., wic es scheint, eiufarbig safrangelb; K. heller mit weisslicher Stirn und solchen Tastem. Fühler fein braun geringelt, gegen die Basis verloschen. Vorder- und Mittelfüsse weiss, schwarz punktirt; Hinterfüsse rein weiss.

Grösse der gewöhnlichen Quercifoliella. Vdfl. matt safrangelb. Auf dem Vdrd. liegen zwei selrr kurze Schrägstrichelchen und ein Punkt bei 1/3, 1/2 und $2 / 3$ der Länge, alle 3 weiss ohne Glanz; die beiden ersteren sind hinten schwärzlich gerandet, das zweite, längere um sein verloschenes Ende mit einem Gewölk aus schwarzen Schuppen umgeben. Der Innenrand ist in einer dünnen Linie weiss; diese versteckt sich ein wenig dem ersten Costalhäkchen gegenüber, verlöscht dann fast völlig, worauf sie sich mit einer Verstärkung. zwischen dem zweiten Costalstrich und dem Costajpunkt, erhebt und in einem nach aussen convexen Bogen, sich verdünnend, als innere Begrenzung der schwarzen Atomenwolke bis in die Nähe der Flügelspitze zieht. So ist es aber nur bei den einen Ex.; bei dem zweiten hört sie nach der Verstärkung, die ein kurzes Häkchen bildet, gänzlich auf, und als Andeutung ihrer Fortsetzung lässt sich noch ein verloschener Punkt oberhalb der Atomenwolke, etwas hinter dem Costalpunkt ansehen. Gegen die Htrd.-Fransen und zum Theil auf diesen ist ein breiter Querstreifen, eine Wolke schwarzer Atome bildend, von dem Gewölk des zweiten Costalstrichs durch einen schmalen Raum getrenut. Fransen gelblichgrau, an der Atomenwolke ochergelblich, ohne jeden Lilaschimmer.

Htfl. grau, heller gefranst. Auf der granen Unterseite der Vdfl. scheint nichts ron den Zeichnungen durch.

Ein kleines $\sigma$ hat fast ungeringelte Fühler. Auf den Vdfl. sind die Costalzcichnungen wie angegeben: nur die Strichelchen sind ein wenig länger, und um die Spitze der zweiten liegen sehr wenig Atome, wie denn ihr Htrd. auch nur verdunkelt, nicht schwärzlich ist. Die Innenrandlinie ist ganz wie bei dem zweiten Ex. Aber die Atomenwolke ist zu einer Atomeulinie verengert, welche von der Spitze der häkchenartigen Erweiterung im Innenwinkel gegen die Flügelspitze gerichtet ist und sich in diescr etwas versteckt. Eine eigene Art kann ich hier nicht erkennen, wozu ich anfangs geneigt war, sonderu ich nehme an, dass Conglomeratella variirt oder sich die Atome leicht abfliegt.

Vaterland: Texas (Boll). Das kleinere Ex. sowie das mit der verlängerten Dorsallinie im Museum Cambridge, das dritte in meiner Sammlung.

\section{Ornatella Frey.}

Ent. Zeitung 1873, S. 217.

Von dieser schönen, auch durch clen Mangel eines Apicalpunktes der Vdfl. ausgezeichncten, schwarzschopfigen Art, die ich durch Prof. Frey selbst erhielt, wurden unir durch Burgess vier urverflogene, bei Beverly gefangene Ex. mit den Daten: 17. Juni, 23. Juni und 7. Juli geschickt. Ich schliesse hieraus auf eine zweite, sehr zeitig auftretende Generation. 
4. Robimiella Clem. Taf. X, Fig. 53.

Capillis nigro cinereoque mixtis, antennis fuscis unicoloribus; alis ant. aureis, dorso fusco-pulvereo, linea basali alba nulla, strigis costue 4, dorsi 3 ulbis, lineola plicae posticae punctoque apicis magno atris. $0^{7}$.

- Cleın. ed Stainton p. 8, p. 16 (Flügelgeäder) und p. 66.

- Proc. Ac. Nat. Sc. Plilad. 1859, p. 319.

Clemens lat diese Art recht genau beschrieben (man hat jedoch für behind the apical spot zu lesen beforc, wie anderwärts), sie aber in der Tabelle S. 64 durch die Worte: sometimes rather silvery, die jch gar nicht anzuwenden, anch aus der Beschreibung nicht zu erklären weiss, unkenntlich gemacht.

Es ist eine echte Lithocolletis, die man schwerlich zu einer neuen Gattung erheben wird; daher bat Parectopa Robiniella Clem., die mir übrigens unbekannt ist, mit ihr nichts zu schaffen.

Da ich von ihr die folgende Tcxanella unterscheiden zu müssen glaube, so beschreibe ich sie vollständig. Sie hat breitere Flügel, als Texanella, dazu weniger silberglänzende Costalstriche, keine Basallinie und keinen glänzendweissen Dorsalstrich bei $1 / 3$ der Flügellänge.

Grösse der Ornatella Fr. R. goldbraun, ohne Zeichnung. K. mit reichlichem, schwärzlichem Schopf, dessen Haare an den Enden grau sind. Gesicht uıd Taster glänzend weiss. Fühler einfarbig schwärzlichbraun. Beine answendig schwarz und weiss bandirt. Hinterleib dunkelgrau mit weisslichem Bauch.

Vdf. oberhalb der Falte und hinten goldfarbig, etwas glänzend, unterhalb der Falte ron der Wurzel bis zum ersten Dorsalstrich mit Andeutung eines schwarzell, abgekürzten Querstreifens. Eine weisse Basallinie feblt gänzlich. Aus dem Vdrd. kommen vier reinweisse Querstriche (ungefähr bei 1/3, 1/2,3/4 und 4/5). Die zwei ersten laufen parallel, sind sehr schräg nach hinten gelegt, auf beiden Seiten schwarz eingefasst und reichen etwa bis zur halben Flügelbreite; der erste ist etwas breiter, als der zweite. Der dritte und vierte (welcher letztere öfters mit dem dritten Dorsalhäkchen zusammenfliesst) sind kürzer, weniger schräg und nur einwärts schwärzlich gesäumt. Das in der Hälfte liegende weisse, bisweilen getrübte Dorsalhäkchen ist schräg nach aussen gelegt, schmal, spitz und berührt mit seiner Spitze die starke, tiefschwarze Faltenlinie, welche ihrerseits die Spitze des dem dritten Costalstrich gegenüber befindlichen und fast senkrechten Dorsalhäkchens berührt. In dem Raum vor und hinter diesen zwei Dorsalhäkchen, besonders zwischen beiden, ist der gelichtete Grund mit groben, tiefschwarzen Schuppen bestrent. Dem zweiten Dorsalhäkchen nahe und dem vierten Costalhäkchen zngewendet, ist das dritte Dorsalbäkchen, das eigentlich dem Htrd. angebört. In der Flügelspitze ist ein starker, tiefschwarzer, runder Punkt, welchen eine tiefschwarze Bogenlinie auswärts umzieht. Fransen grau, um die schwarze Bogenlinie weisslich schimmernd. 
Htfl. ziemlich dunkelgrau mit gleichfarbigen Fransen. Auf der dunkelgrauen Unterseite der Vdfl. liegen vor der Spitze zwei weisse, einwärts gerichtetc Costalstriche, von denen der zweite länger ist, als der erste.

Vaterland meiner als Robiniella erhaltenen Ex. Massachusetts. Zwei tragen das Datum: 23. nnd 31. October. Burgess schickte mir ein trockenes, buckelig zusammengezogenes Foliolum der Robinia pseudac., dessen untere Epidermis ganz weiss ist. Zwisclsen den beiden Häuten befinden sich drei verhältnissmässig sehr grosse, länglich elliptische, etwas flache, reinweisse Gespimste, mit ihren Enden über einauder liegend; aus zweien haben sich die Puppen, nach der Sitte ihrer Gattung, aus den Enden her vorgedrängt. Hiernach scheint also ein Fiederblatt sogar drei Raupen enthalten zu können. - Sehr ausführlich landelt über die Lebensweise dieser Art Clemens in seinen Briefen an Stainton S. $8 \mathrm{ff}$.

\section{Texamella u. sp. Taf. X, Fig. 54.}

Capillis nigro cinereoque mixtis, untennis fuscis, unicoloribus; al. unt. aureis, dorso late fusco, linea basuli temai alba, strigulis costae 1 , dorsi 3 niveis nitidissimis, lineola plicae posticae punctoque upicis magno atris. of $f$.

Clem ens erwälnt 1. c. S. 67 einer an Amphicurpuea monoicu minirenden Art, die er nur für Robiniella var. erklärt. Er beschreibt sie nicht so genan, wie er gethan hätte, wenı el sie für eigene Art hielt. Sie stimnıt in nanchem mit meiner Texanella, scheint aber der weissen Basallinie zu ermangeln, da, wenn sie an ihr vorlanden war, Clemens sie schwerlich übersehen hätte.

Texanella kommt der Roliniella so nahe, insbesondere in der so cliarakteristischen schwarzen Faltenlinie, dass es wirklich möglich scheiut, dass sie Joeh nur eine Varietät davon ist; aber keine meiner zwölf Robiniella hat eine Spur der weissen Basallinie, keine den Glanz der Costalhäkchen oder das reinweisse Dorsalhäkchen bei $1 / 3$ des Innenrandes. Ich grbe nur die Unterschiede an.

Texanella hat die Grüsse der kleinsten Robiniella. Beine nur weiss and graubunt, also besonders auffallend blass an den Hinterfüssen.

Vdfl. bedeutend schmäler. Die Randhäkchen reinweiss, lebhaft silberglänzend. Von den Costalhäkchen ist das erste kürzer und verhältnissmässig nicht so breit, wie bei Robiniella; das zweite läuft mit ihm nicht parallel, sondern convergirt und vereinigt sich mit dem zweiten Dorsalhäkchen $z u$ einen nach aussen convexen Bogen oder doch sehr stumpfen Winkel (bei Robiniella reicht seine Spitze weit über dieses Dorsalhäkchen, das bei ihr als ersies zu gelten hat, hinaus und bildet wit ihm einen recht scharfen, spitzen Winkel). Auf dem Innenrand liegt bei $1 / 3$, etwas vor dem Anfang des ersten Costalhäkchens, ein senkrechter, bis zur Falte reichender und hier abgestutater glänzendweisser Strich (er ist bei mancher Robiniella duıch eine lichte Stelle angedeutet). Der zweite, den ersten bei der Robiniella darstellend, glänzt lebbaft und hat 
hinter sich in der Falte die schwarze linie wie Robiniella. In der Falte komnt aus der Flügelbasis eine feine, sich nach hinten verdünnende, weisse linie, welche die Spitze des ersten Dorsalhäkchens berïhrt und hinter derselben verselıwindet. Der Raum unter ihr, zwischen Basis und erstem Dorsalstrich, bilket ein längliches, einfarbig dunlielbraunes Viercek; der Raum zwischen dem ersten und zweiten Dorsalhäkchen ein längeres, schmäleres und helleres; der mnterhalb der schwarzen Faltenlinie ist grau (vielleicht verwischt). Die Zeichnung der Flügelspitze liat nichts Abweichendes.

Auf der Unterseite der Tdfl. sind dic zwei weissen Costalfleckehen wie bei Robiniella; ausserdem sind aber auch die zwei vorhergehenden Costalhäkchen und die entsprechenden Dorsalhäkchen durch weissliche Punkte angedentet.

Vaterland: 'Texas (Boll). Ein o im Museum Cambridge.

\section{Atomariella n. sp.}

Capillis albidis; al. ant. latiusculis, albis, opacis, nigro-pulvereis, maculis costae 5, dorsi 3 obliquis luteis, postice nigricanti-marginatis (excepta secunda costali), in fascias angulatas confuentibus, lineola apicis atra. $\sigma^{\top}$.

In der Gruppe der Pastorella, Populifoliella, Tremulae, Comparella stimmt sie durch den weisslichen Haarschopf nur mit der gleich grosseu, schmalftïgligeren und anf den VdA. reiner weissen Comparella ïberein. (Ob Apparella HS. Fig. 804, 805, die ich nicht besitze, auch einen so weiss behaarten $K$. hat, ist nicht angegeben). Die weisse Grundfarbe der Vdfl. und die Kürze der schwarzen Apicallinie - Comparella hat eine längere - lässt sie der Atomariella am nächsten erscheinen; bei ihr fehlt aber, sowie bei Comparella, der grosse Htrd.-Fieck vor der Flïgelspitze (also ein vierter Dorsalfleck), den Atomariella besitzt.

Grösse der Populifoliella. R. und K. wciss: der Schopf in zwei divergirende Büsche getheilt, gleichfalls weisslich, bisweilen mit gebräunten Spitzen einzelner Haare. Fühler weiss, mehr oder weniger deutlich geringelt. An den Hinterfüssen ist das erste Glied weiss, am Enddrittel braungrau; die folgenden drei Glieder braungrau mit reinweisser Wurzel; das Endglied weisslich. Hinterleib dunkelgrau mit weisslichem Analglied.

Våf. in der Breite nicht ganz beständig, aber breiter als bei Comparella und schmäler als bei Populifoliella, ohne Glanz, reinweiss, mit schwarzen Stäubchen nicht sehr reichlich bestreut. Die Zeichuung besteht in angenehn lehmgelben oder dunkel ocherfarbigen, hinterwärts schwarz gesäumiten Flecken. Auf den Vdrd. vertheilen sich fünf, von denen die zwei ersten sehr schräg nach hinten liegen und sich scharf zuspitzen, und der erste sich auf dem Vdrd. bis zur Basis verlängert; der dritte ist weniger schräg, und die zwei folgenden, in 
der Grösse schr abnehmenden. fast senkrecht; der letzte, kleinste umschliesst, inden er sich bis zum Htrd. bogenförmig verlängert, den schwarzen Apicalstrich von unten ein. Unter der Falte liegt auf dem Innenrand nahe der Basis ein Fleckchen, das oft klein oder verwischt nnd selbst bisweilen vom Pande getrennt ist. Der folgende, als erster angesehene Dorsalfleck ist sehr schräg, spitzlreieckig, reicht mit der scharfen Spitze an den ersten Costalfleck und hildet mit ihm eine scharfwinklig gebrochene Binde. Der zweite, weit vom ersten getrennte Dorsalfleck ist länger und in der Grösse veränderlich und vereinigt sich mit dem dritten und vierten Costalfleck, und da der dritte, oben einwärts geneigte Dorsalfleck sich ihnelı auch anschliesst, so entsteht eine einigermassen $\mathrm{X}$-ähnliche Figur, deren Enden anf den Gegenrändern ruhen. Der schwarze Apicalstrich ist kurz und unten und hinten lehmgelb eingefasst, während über ihm die weisse Grundfarbe als Costalfleckchen (hinter dem fünften gelben Costalfleck) erscheint; auf den weisslichen Fransen ist er mit einer schwärzlichen, bis nahe an den dritten Dorsalfleck reichenden Bogenlinie umzogen.

Htfl. grau, lichter gefranst.

Unterseite der Vdfl. dunkelgrau, mit vier verloschenen weissen, an Grösse nach linten zunelımenden Costalfleckchen.

Vaterland: Massachusetts, bei Cambridge (Hagen), wo die Art nicht selten zu sein scheint.

\section{Alternatella n. sp.}

Capillis albis; al. ant. opacis, albis, fasciis duabus superius fractis maculaque costae posticae ochraceis, nigro-pulvereis, interjectis strigis e pulvere nigro, apice crebrius nigro-pulverato. $\sigma^{\top}$.

Wegen der glanzlosen (in der Sonne freilich schimmernden) und in der Spitze mit keinem schwarzen Strich oder Punkt, sondern (etwa wie bei Trifasciella) nur schwarzbestäubten Vdf. kann sie leicht für eine Argyresthia bei Austerella gehalten werden; aber ihre schmalen, gleichförmig zugespitzten Htfl. beweisen, dass sie wirklich zu Lithocolletis gehört. So unähnlich sie auch sonst der Trifasciella ist, so scheint doch der beste Platz für sie in der Nähe dieser Art, hinter den Verwandten der Pastorella, zn sein. Ihre weissen, schwarzbestäubten Vdfl. mit zwei gebrochenen, schwarz bestäubten Binden, welche schwarzstaubige Querlinien vor, zwischen und hinter sich haben, und die reichlichen schwarzen Stäubchen in der Spitze zeichnen sic vor allen Lithocolletiden aus.

Grösse der Trifasciella oder einer gewöhnlichen Pastorella. R. und K. ganz, weiss. Fühler weiss mit abgesetzten Gliedern, daher scheinbar dunkler geringelt. Beine weiss; die Mittelfüsse dunkel gefleckt; die Hinterschienen mit langen, auseinander gesperrten, steifen Haaren. Hinterleib hellgrau; Bauch und Analbusch weisslich. 
Vdfl. glanzlos, weiss, mit feinen, schwarzen Schuppen ziemlich reichlich bestreut, am meisten auf den zwei Binden und in der Flügelspitze. Die zwei Biuden sind ochergelb, ïber der Falte breit, larauf winklig gebrochen, worauf sie schr verschmälert nach dem Innenrand gehen; die erste ist dicht vor, die z.weite hinter der Fiïgelhälfte. Die schwarzen Atome bilden vor der ersten und hinter der zweiten eine, nnd zwar nur undeutlich, aber zwischen beiden eine ebenso wie diese gebrochene Querlinie. Hinter der zweiten Binde ist ein gelber, unter den stäubchen versteckter, bindenförmiger Costalfleck. Die schwarze Atomenanhäufung der Flïgelspizze wird dadurch vergrössert, dass ausserhalb dieser Spitze die Fransen noch drei scliwarze Atomenlinien tragen, welche nur bis zur Hälfte der trüb gelblichweissen Fransen herabreichen.

Htfl. lichtgrau; Fransen gelblichweiss.

Unterseite der Vdfl, gelblichgrau, am Viri. dunkler uni vor der Spitze mit zwei verlosclienen weissen Flecken.

Vaterland: Texas (Boll). Eill gut erlualtenes ơ (aber ohne Vorderfüsse) im Cambridger Museum.

\section{Tischeria}

\section{Quercitella Clen.}

- Clem, ed. Stainton, p. 221. - Frey, Entom. Zeitung 1873, S. 221.

Mit Frey halte ich diese Art fïr die Clemens'sche, nngeachtet diese orange yellow Vdfl. haben soll, wälırend die unsere blass citronengelbe hat.Statt Quevcitella hatte Clemens doch wohl sicher Quercetella im Mannseript. Zwei Weibchen aus Texas (Boll) in Cambridger Museum.

\section{Concolor n. sp.}

Al. ant. luteo-ochraceis, unicoloribus, circa apicem fusco-pulvereis; post. angustis, albidis, exalbido-ciliatis. ㅇ.

Das einzelue Weibchen hat die Grösse der Quercitella, also die einer kleinen Complanella, und seine Vdil. sind etwas breiter als bei jener und etwas schmäler als bei dieser. Ausserdem unterscheidet sie sich von Quevcitella durch die ganz einfarbigen, dunkeln Vdfl., welche überall so dunkel sind wie bei Complanella an der Spitze. Die etwas glänzenden, weisslichen Htfl. geben gleichfalls einen Unterschied von beiden Arten, sowie von Zellerella Clem.

K., Fühler, Hinterleib (dessen Endglied abgestutzt kegelförmig ist) und Beine sehr bleich ochergelb (wie bei Quercitella); die Fühler zeigen am Wurzelglied deutlich das charakteristische Zöpfchen. R. von der Farbe der Vdfl. (bei Quercitella wie die ersten zwei Drittel der Vafl.).

Vdfl. einfarbig dunkel-, fast lehmfarbig ochergelb, nur in Endisittel mit äusserst feinen braunen Stäubchen bestreut, die jedoch die Spitze nicht dunkler erscheinen lassen. Fransen fast so hell wie an den Htfl. 
Htfl. schmal messerförmig, feiner zngespitzt als bei Complanella, etwas glänzend, weiss, kaum ins Graue gemischt; Fransen ebenso hell, gelblich schimmernd.

Unterseite der Vdfl. lell oehergelb, auf der Wnrzelhälfte dunkelgrau angelaufen.

Vaterland: Texas (Boll). Ein $Q$ im Museum Cambridge.

Anmerkung. Von Ti. Zellerella Frey (l. c. S. 220), die ich auch nur sebr zweifelhaft für die Clemens'sche lalte, empfing ich von Frey selbst ein $\sigma^{\lambda}$. Es übertrifft in der Grösse die grösste Complanella. Die Fühler haben zwar die den Tischerien eigene Belıaarung, aber keine Spur des Basalzöpfehens. Auf der Unterseite der Vdfl. bemerke ich niclits von dem bei Frey erwähnten dunkelbraunen Längsstrich. Das Merkwürdigste sind die Htfl. Diese haben eine für Tiscleria durchans abweichende Breite, nämlich etwa $2 / 3$ der Vafl., und spitzen sich sehr plötzlich fein zu; der ganze Vdrd. ist mit langen (so langen wie die Htf. breit sind), schräg nach aussen gerichteten, blass ochergelben Haaren bis zum Anfang des letaten Drittels besetzt; von da an sind die Haare plötzlich sehr kurz und werden es bis nahe an die, wie am Htrd., langhaarige Spitze noch mehr, so dass es anssieht, als ob hier eine beschädigte Stelle ist - was doeh bei der gänzlichen Uebereinstinmmung an bejden Flïgelı auffallend genug wäre.

\section{Bucculatrix}

\section{Pomifoliella Clem.}

Antennis pallide fusco-anmulatis, capillis ochraceo fuscoque mixtis; al. ant. pullidis, maculis costae 4 obliquis, ucuminatis, ochruceis, fusco-pmlvereis, una dorsi medii subovatr, punclo apicis rotundato atro, cxterius ureu nigro circumdato. ठ’.

- Clemens ed. Stainton, p. 146.

Ich glaube, die richtige Clemens'sche Art vor mir zu haben, obgleich bei dieser der Apicalpunkt nur als dark-brown statt tiefscliwarz angegeben wird. Keine der bisher bekannteu Arten aus der Gruppe der Ulmella, Vetulella, Crataegi hat ihn in dieser Schärfe.

Pomifoliella, deren Namen wegen der Lithocoll. pomifoliella Anstoss erregen wird, bat nach dem vorliegenden Ex. nur die Grösse der kleinsten Ulmella und sieht noch etwas blässer aus als die hiesigen Ex. dieser Art, also sehr unäbnlich den durch Dunkelheit ausgezeichneten englischen. Die Grundfarbe der Vdfl. ist also beller gelb als bei Ulmella, die Zeichnungen ziemlich hell ochergelb (doch zu dunkel, um nur pale yellowish heissen zu können) und mit dunkelbrauuen Atomen, die alle von einander getrennt bleiben und nirgends zusammenfliessen, reichlich bestreut. Der Innenrandfleck, der nicht viel duukler 
als der dritte Custalfleck ist, mag bei manchen Ex. so stark bestäubt sein, dass Clemens' dark-brown gerechtfertigrt ist (Clemens versteht offenbar unter opuosite denselben Fleck auf dem amderen Viff.). Auf dem Vdrd. liegen vier schrïg nach hinten gerichtete, deutlich getrenute, bandförmige solche Flecke, von denen der erste nur bis zur Falte reicht, der zweite wit dem Dorsalfleck an einem schrägen Querband verbunden ist, der dritte den Innenwinkel nur verunittelst einer uubestäubten Foutsetzung crreicht, der vierte bis zum Htrd. verlängert ist. Der tiefschwarze Apicalpunkt ist gurundet und sehr auffallend; die schwarze, ihn von aussen unziehende Bogenlinie liegt auf den Fransen.

Clemens beschreibt die im September auf Apfelblättern lebende Raupe, welche nichts von der Natur des Genus Abweichendes zu haben scheint. Der S'chmetterling fliegt Ende April und im Mai. - Das vorliegende $\sigma^{7}$ ist aus Texas (Boll) und befindet sich in Museum Cambridge.

Anmerkung. Riley gibt im vierten Annual Report Ins. Miss. 1872. 1. 49-51 Nachrichten von einer Bucculatrix, die or Bucc. pomifoliella Cl., the alple-leaf Bucculatrix, menut, und bildet Fig. 23 den Schnetterling in der Vergrösserung ab. Die Vufl. zeigen ausser dem schwarzen Apicaljunkt nur zwei lunkle Zeichnungen. Da eine Beschreibung fehlt, aus welcher sich ersehen liesse, ob die zwei sonstigen sclwächeren Zeichunngen nur aus Versehen oder nach mangelhaften Originalen weggelassen sind, so wage ich diese Buccul. pomifoliella niclit bei der meinigen zu citiren.

\section{Litigiosella n. sp.}

Autennis fuscescenti-unmulutis, cupillis ochraceis; al. ant. pallide ochroceis, maculis costae 4 (tertia listincliore) maque dorsi medii interius fusco-notatu saturationibus fusco-prulvereis, alae upice linea arenata nigra circumiato; al. 1rost. dilute cinereis. $\mathrm{O}^{\prime}$.

Die Clemens'sche Coronutella 1. c. p. 109, worin aber das Dunkle als Grundfarbe, das Helle als Zeichnung behandelt ist, scheint mir meiner Art sehr wahe zu kommen. Orange-chrome haben aber die Vdf. der Litiyiosella nicht; ihre Httl. sind ginz hellgrau (nicht dark-gray), und ihr Hinterleib ist nur hell stanbgran mit blass ochergelbem Bauch und Analbusch (nicht pale orangechrome with a dark brownish stripe along the dorsum varied with fulvous).

Ausserdem kommt Litigiosella der Ulmelle (Stainton Nat. Hist. VII. t. 2, f. 1.) so nahe, dass es mich nicht wundern würde, wenn sie sich uur als sehr helle Farbenvarietät derselben auswiese. Ibre Vafl.-Gestalt ist lieselbe, also breiter, als bei Pomifotiella, und cbenso die Zeichnung mit folgenden Abweichungen: sie sind viel lichter und spärlicher mit schwarzbrannen Atomen bestreut; der erste Costalfleck, bei Ulmella fast so bramn, wie der dritte, ist so hell und so wenig bestäubt, wie der zweite und verfliesst in die Dorsalfärbung; der dritte scheint etwas kürzer als bei Ulmella zu sein und ist, wenn anch dunkler, als die anderu, doch im Vergleich mit dem der Ulmella sehr letl; der vierte ist ganz blass, verflossen und bis zum Htrd. ausgedehnt. Der 
ovale, der Länge nach liegende lorsalflech ist an! der Basalceite selır dunkel bram, sonst so bell wie des dritte Costalfleck. Die Flügelspitze liat keinen selswarzen I'unkt, ist aber wie bei Pomifoliclla anf den spärlich mit brannen Atomen bestreuten Fransen mit einer seliwarzen Bogenlinie umzogen. Von dem schwarzen Längsstrich, den Vetustellu und Cruluegi (bei Stainton in Fig. 2 anf den zu sehmalen Vufl. mit zu gelber Grundfarbe) vielleieht immer zeigen, ist keine Spur zu sehen.

Htf. viel heller grau mit weissgelblich schimmerisden Fransen.

Vaterland: Texas (Boll). Zwei ठ

\section{Pterophorus momodactylus Linn.}

Pter. pergracilidactylus Packard. Annals of the Lycem of Nat. Hist. N. Y. X, 1873. 3. 265.

- cineridactylus Fitch, Nox. Ins. State of New. Vork 1) 144.

Ich erhielt ein aus Massachusetts stammendes Ex mit der Bezejchnnng: ${ }_{n}$ Cincridactylus Fitch $=$ Pergracilidactylus Pck".

Packard's Beschreibung eines einzeluen on als Pergracitiluctylus (!) passt recht genau auf die mehr graue Varietät des Monoductylus. Nur die Fühler sind (wie auch bei mir Isis 1841. S. 816 I'terodactylus: grau und verloschen, hellbraun geringelt) usriehtig angegebon als whitish ringed with brown. An frisch gefangenen Ex. sind sie ganz einfarbig weissgrau; erst durch Eintrocknen werden die Einschnitte tiefer, und dir darlurch entstehende Schatten bringt die Täuschung hervor, als seien zwei Farben vorhanden. - Packard erklärt seine californischen Ex für versehieden von Pterorluctylus H. Monodactylus Linn. und auch für verschiden von Cineridactylus Fitch. Theser Antor beselureibt seinen Cinerilactylus so: "Ueberall asclograu, an der Finst dunkler gefärbt. Vifl. mit schwärzlichbrannen Atumen besprengt, hanjtsïchlich gregran den Innemrand und die Basis. Fühler an jedem Gliede nit einem bellbrannen, auf der Unterseite breit moterbrochenen Bande. Füsse und Schien.n (ohanks) woisslich; die Hinterschienen mit einer schwachen, brännlichon Binde? an der spitze und einer anderen in ler Mitte. Flïgelspannung 0,75. Gefang n in ler ersten Hälfie des Juli in Gehöften mm dic Mäuses". Nach dinser Beschreihnng, in w lcher von dej: Flug lgestalt und den dunkeln Flerk an der Spalte der Vdf. nichts erwähnt wird, den Dionodactylus limn. zn erkennen, i,t numüglich; Aer Aufenthaltwort würde die drt fast am besten b. z: ichn'-11, voransgesetzt, lass, wie bei uns, auf den dortigen hartuffel- und Getreidefeldern unter andern Unkräutern auch Convolvulns wächst.

Packırd hält disen Cineridactylus für den ostlichen Stellrentreter seines I'ergracilidactylus. Er sagt: von Cinerilact. liabe er in bei salen a $s 26$. Sept. gefangenes Ex. grsehen; die hintere Abtheilung des Vdfl. sei mehr dreieckig, weniger scharf gespitzt, als bei der Cahfornischen drt, und die Zeichnungen (the markings on this division, wobei wohl dis an der spalte mitgomeint ist) seien ein w'nig anders. 
Nun ist aber nach dem nir zugegangenen Ex. und nach der Beschreibung Pergracilidactylus obne Zweifel Monodactylus, und so wird Cineridact. auch nichts anderes sein.

Dr. Speyer hat mich auf eine bisher unbeachtete Eigenheit des Monodactylus aufmerksam gemacht. Die Hintertarsen sind nämlich gleichsam geflügelt, indem die Schnppenhaare der Oberseite sehr dicht stehen und nach oben gerichtet sind und so eine recht auffallende Erweiterung der Tarsenglieder bilden, nur dass diese sich am langen Metatarsus bloss am Enddrittel zeigt. Bei manchen Ex. ist die Erweiterung stärker, als bei anderen, ohne dass sie vom Geschlecht oder vom längeren Fluge (der jedoch nicht ganz ohne Einfluss sein mag) abznhängen scheint. So zeigt sie wein Sareptaner Ex. am auffallendsten. Man sieht sie natürlich nur, wenn man den Fuss von der Seite betrachtet. Es versteht sich, dass die nordamericanischen Ex. (deren eins ich auch aus Ohio habe) diesc Auszeichnung vor den bekannten Pterophoriden auch besitzen. 


\section{Benennung der Figuren.}

\section{Taf. VIII.}

Fig. 1. Teras peculiana S. 210.

2. Tortr. amplexana S. 222.

3. - conigerana S. 227.

4. Phox. modiofasciena S. 248.

5. - mbecultura S. 249.

6. - semiovana S. 250.

7. - Burgessiana S. 252

8. - laciniana S. 253.

9. - subaequana S. 254.

10. - angulifasciana S. 256.

11. Euchrom. hemidesma S. 261.

12. Penth. albeolana S. 262.

13. - nimbatana S. 263.

14. Exart. quadrifidum S. 268.

15. - nitidanum S. 270.

16. albofasciatum S. 27 ?.

17. Scric. campestrana S. 282.

18. - fuscalbana S. 284.

19. - caesiallana S. 285.

20. Ecrlytol. insiticiuna S. 2636.

21. Graphol. Vestaliana S. 286.

\section{Taf. IX.}

Fig. 22. Graphol. trivittana S. 287.

$" 23$. - spiculana S. 289.

"24. - Roessleri S. 291.

25. - malechitana S. 292.

26. - usticana S. 293.
Fig. 27. Graphol. allutana S. 295.

"28. - interstinctena S. 296.

29. - cclipsana S. 298.

30. - perfluana S. 299.

31. - Paclardi S. 300.

32. Paed. inclinana S. 301.

33. - clavana S. 303.

34, 35. Paed. quintana S. 304.

36. Pued. constrictana S. 305.

37. - desertana S. 306.

38. - affusance S. 307.

39. - tripartitana S. 308.

40. - dodecuna s. 311.

41. - morogrammane s. 313.

42 a. Set. xanthobasis s. 325.

\section{Taf. $\mathrm{X}$.}

Fig. 43 a.b. Nola confusulis S. 327.

" 44 a.b. Nolaph. malence S. 321 .

"45a.b.c. Oect. sincera S. 331.

46 a.b. Perisp. caeculalis S. 333.

47. Bot. Thesealis S. 335.

48. - aegrotalis S. 335.

49. - spec. Am. sept. S. 335.

50. Ad. trigrapha S. 342.

51. Crypt. atropicta S. 343

52. Lith. quercetorum S. 346.

53. - robiniella S. 318.

54. - texanella S. 349. 


\section{Pegister.}

Achatinalis 7. (Hyp.). . . . $\begin{array}{r}\text { Seite } \\ 330\end{array}$ Aegrotalis Z. (Bot.). . . . . 335

Affusene n. sp. (Pued.) . . . 307

Albu Z. (Tegeticulu) . . . . 340

Albeoluna n. sp. (Penth.) . . 262

Albicomana Clem. (Tortr.) . . 227

Albiguttana n. sp. (Pued.) . . 313

Albofasciatum 11. sp). (Exat.) . 272

Allutanat n. sj). (Grailhol.) . . 295

Allernatella 11. sp. (Lithocoll.) . 351

Amblygone n. sp. (Phoxopt.) . 259

Amplexana n. sp. (Tortr.) . . 22⿺

Augulifasciana n.sp. (Phoxopt.) 256

Appendiceum n. :P. (Exav) . 275

Argontilimitana kbs. (Coneh.) . 242

Aryyroelana 11. sp. (Serie.) . 277

Astrologana n. sp. (Seric.) . . 281

Atomariella n. sp. (Lithoc.). . 350

Atropicla 1. sp. (Cryplol.) . . 343

Aurisignuma n. sp. (Dichror.) . 319

Bullimoralis Cir. (IIyp.) . . 329

Belfrageanu ॥. sp. (Tortr.) . . 23:

Benignolis Wkr. (Hyp.) . . . 329

Bijugrelis Wия. (Hy). . . . 329

Bimaculane libs. (Conch.) . . 243

Bimaculanu Don. (Pued.) . 302

Bollii \%. (Lophod.) . . . . . 336

Bunteunu Fibs. (Conchyl.) . . 245

Burgessiana n. sp. (Phoxipt.) . 252

Caeculalis 11. sp. (Perispasta) . 333

Cacsialbana 1. sp. (Serie.) . 285

Callitrichoides (irute (Phypr.) . 32s
Ceite

Campestrance n. sp. (Seric.) . 282

C'cuopsis 11. \%. . . . . . 239

Cerasivorana Fteh (Tortr.) . . 217

Clionosema n. \&p. (Penth.?) . 265

Chlorobasis n. sp. (Setiust.) . . 325

Cineridaetylus Ftch (Pterolh.). 355

Clavunu n. sp. (Paerl.) . . . 30:3

Comatulana n. sp). (Paed.) . . 316

Comptana Frül. (Phoxopt.) . . 257

Conchylis Tr. . . . . . 242

Concolor n. sf. (Tisch.) . . . 352

Conglomeratella n.sur. (t.ithocoll.) 34 if

Conigerana n. sp. (Torle) . . 227

Constellatara n. sp. (Seric.) . 279

Constrictana II. Sp. (Pacd.) . 305)

(oruscana Clem. (Soric.). . 275

Crossixcnelli Z. (Enacm.) . . \$15

Deflectana Ris. (Terus) . . 211

Ilesertana n. sp. (Pued.) . . . 306

Jrisesinuchun Clem. (Turtr.) . 2034

Dissimilanu Tr. (Pucrl.) . . . 502

Distema Gr. (Gruphol.) . . . 296

Dodeenna n. sp. (Pued.) . . . 311

Dursistrigella Clen. (Tin.) . . 342

Unbiana Clem. (Anchylop.) . . 25.1

Ecdytolopher n. y. . . . . 246

Eclipsana n. sp. (Grophol.) . . 298

Enaemia \%. . . . . . . 344

Elutella II. (Ephest.) . . . . 333

Exartema Clem. . . . . . 268

Exasperatena n. sp. (Tortr.) . 2:38

E.eoletum n. sp. (Exart.) . . 27i 
Famela (T'erus) -

Fasciulanu, (lem. (Hxart.) . . 273

Ferruguna S. V. (Tera.) . . . 212

Fimetaria Gr. (Fill.) . . . . 3331

Flaccidana Rbs. (Tortr.) . . . 219

Flavedana Clem. (Tortr.) . . 236

Floriclana n. sp. (Plooxopt.) . 258

Fragariae Walsi, (Anchylop.) . 257

Furcatana Wkr. (Tortr.) . . . 232

Furfurana Haw. (Bactra) . . 247

Furvana Ribs. (Tortr.) . . . 219

Fuscalliana n. sp. (Seric.) . . 284

Fuscociliana Clem. (Anchylop.) 253

Gallineata Z. (Micaria) . . . 330

Glundulellu Riley (Holcoc.) . . 345

Glaucofuscana (Conchyl.) . . 215

Grapholitha Tr. . . . . 286

Gurgitana Ribs. (Tortr.) . . 216

Halesaria Z. (Fidon.) . . . . 331

Hastima Linn. (Teras) . . . 213

Hemidesma n. sp. (Euchrom.) . 261

Hospitella n. sp. (Ephest.) . . 338

Idiographis Led. . . . . . 222

Igninix Wkr. (Mieza) . . . . 345

Incertana Ribs. (Tortr.) . . . 225

Inclinana n. sp. (Paed.) . . . 301

Infumatana n. sp. (Tortr.) . . 216

Insiticiana n. sp. (Ecdyt.) . . 266

Intermincta Gr. (Mad.) . . . 329

Interpunctella H. (Epluest.) . . \$36

Interstinctana Clem. (Graphol.) 290

Labiusanu n. sp. (Tortr.). . . 237

Laciriana n. sp. (Phoxopt.). . 25 is

Laciniosa 7. (Hyp.) . . . . $3 \div 9$

Laevigana S. V. (Tortr.) . . . 18

Lamana Z. (Phoxopt.) . . . 247

Lanceolana H. (Buctra) . . . 247

Laterana Rbs. (Tortr.) . . . 236

Lepidana F. R. (Tortr.) . . . 226

Litigiosellu n. sp. (Bucc.) . . 354

Loxotaenia Ld. . . . . 218

Lutosana Clem. (Tortr.) . . 224

Macutidorsana (Hem. (Teras) . 213
Maulefuctulis Gr. (Jiomol) Seite

Mayjistralis (Ar. (Bot.) . . . . 331

Malachitana n. sp. (Graph.) . 292

Mulama \%. (Nola) . . . . . 326

Marcidana n. sp. (Phoxolt.) . 260

Meanderana Wkr. (Sciarh.). . 275

Mediufasciana Clem. (Phoxopt.) 248

Melulencuna Wkr. (Tortr.) . . 223

Menticella H. (Tin.) . . . . 312

Mesospila n. sp. (Tortr.) . . . 233

Milleri n. sp. (Ephest.) . . . 339

Monodactylus Linn. (Ptcroph.) . 3:5

Monogrummana n. sp. (Puerl.) . $\$ 18$

Mutulitana Clem. (Phacc.) . . 276

Nimbutuna Clem. (Penth.) . . 2tis

Nitidanum Clem. (Exart.) . . 270

Nolaphanu Grote. . . . 326

Nulleculana Clem. (Phoxopt.) . 24!

Nubilellu \%. (Blastol.). . . . 345

Numerosuna n. sj. (Pacd.) . $\quad 317$

Occipituna n. sp. (Pued.) . . 315

Ocellamu F. (Tmetoc.) . . . . 267

Ochrifrontella n. sp. (Ephest.) . 337

Oculance (Graphol.) . . . . 267

Oertoperia n. \%. . . . . 381

Oenectra Gr. . . . . 228

Oinatella Frey (Lithoc.) . . . 347

Oxyacanthana H. (Tortr.) . . 218

Packardi n. sp. (Giraphol.) . . 800

Pullialis Z. (H!/p.) . . . . . 329

I'amperana H. S. (Aphel.) . . 247

Puronacelle Clen. (Brenthir) 323

Peculiana n. sp. (Teras) . . . 210

Perfluana n. sp. (Grathol.) . . 299

Pergracitidactylus Pack.(Pterojh.) 855

Terisplestu \%. \%. . . . . . 383

Peritanu Pbs. (Tortr.) . . . 221

Permandanum Clem. (Exart.) . 273

Pertextulis Led. (Bot.). . . . 334

Pettitana Rbs. (Cenop.). . . 240

Phaceasiophora Grute. . . 276

Phocopteris Tr. . . . . 245

Poana 11. sp. (Seric.) . . . 282 


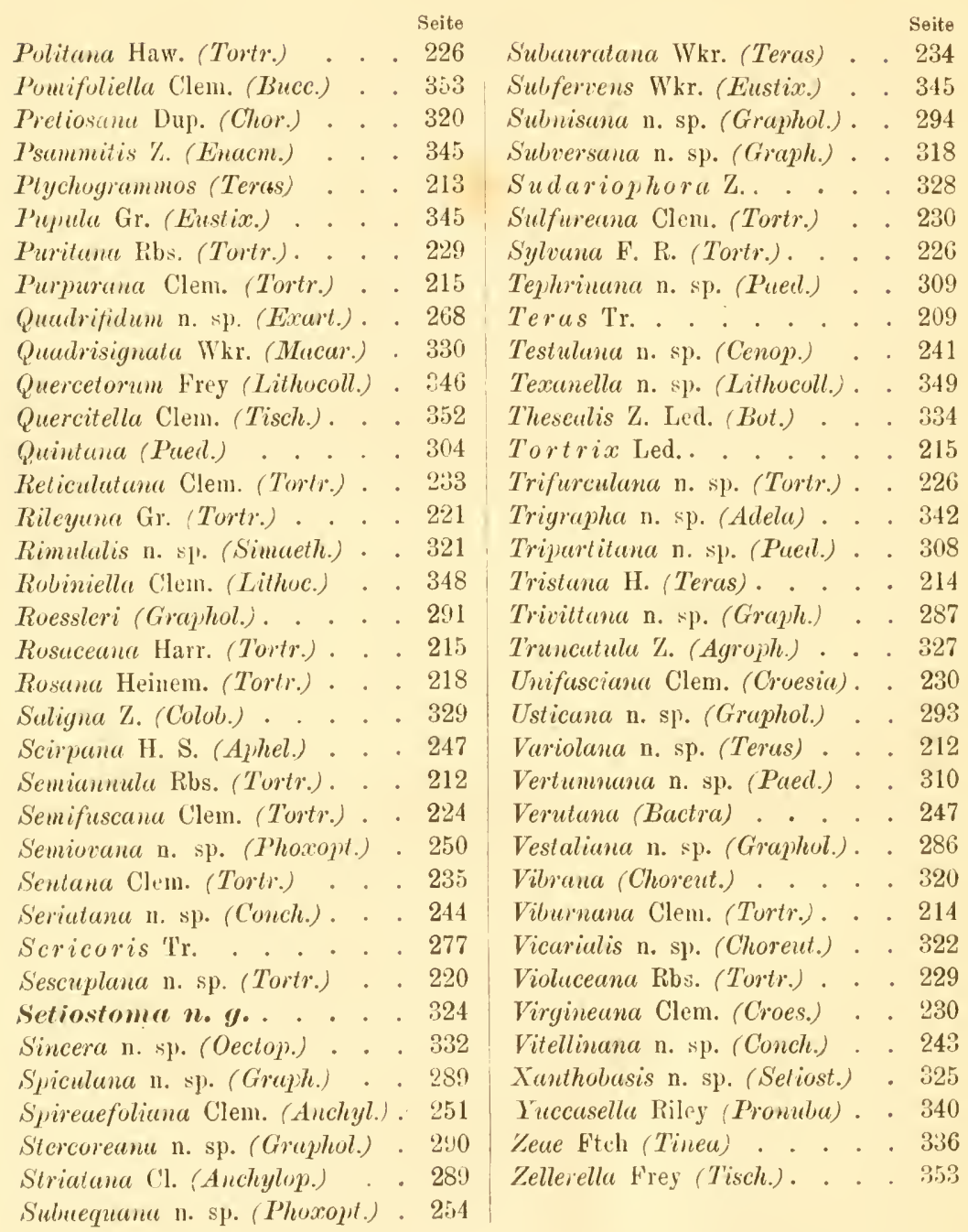



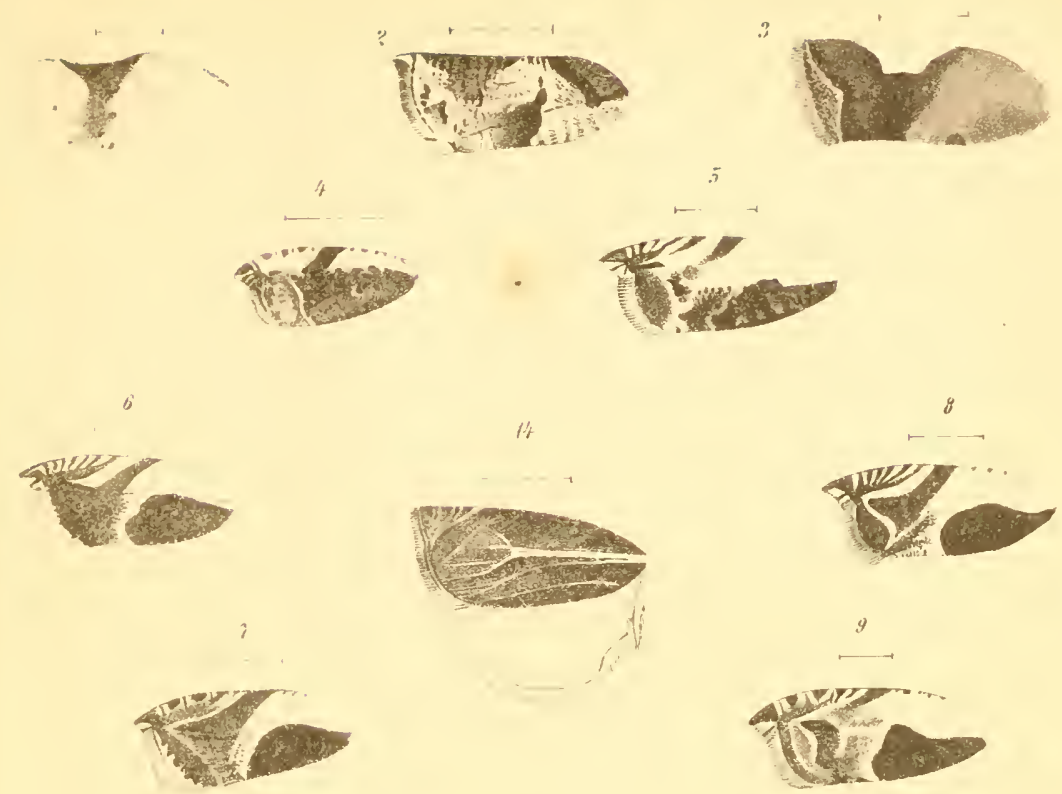

if
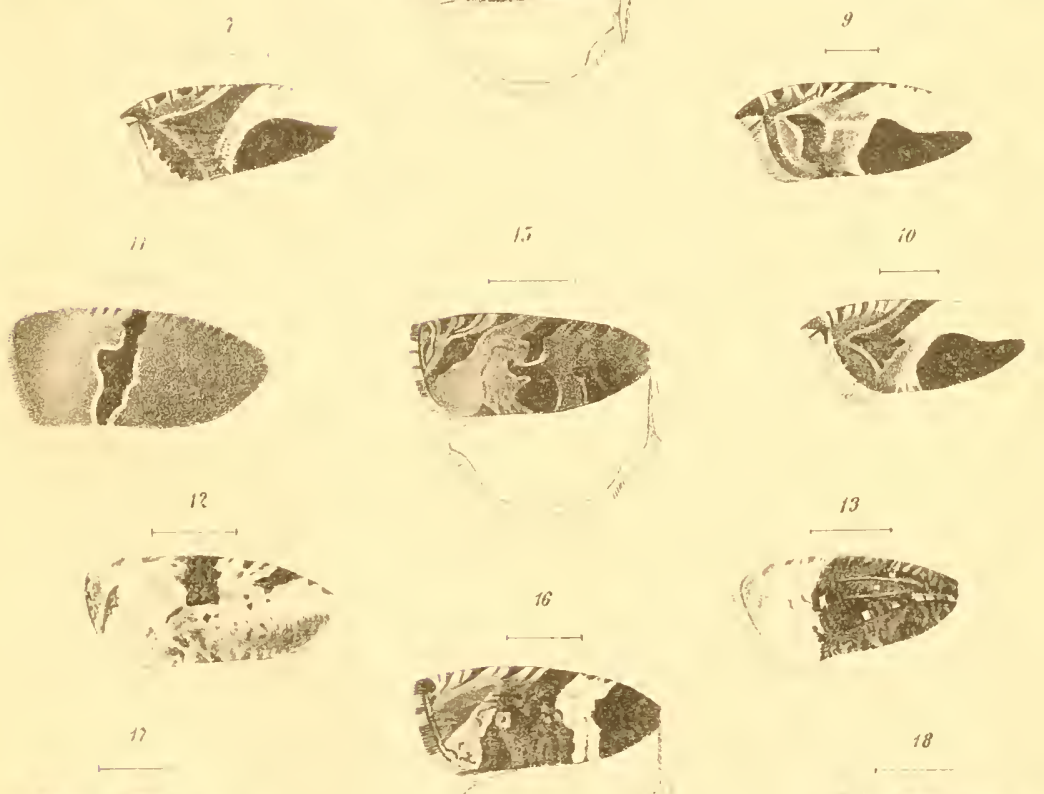

13
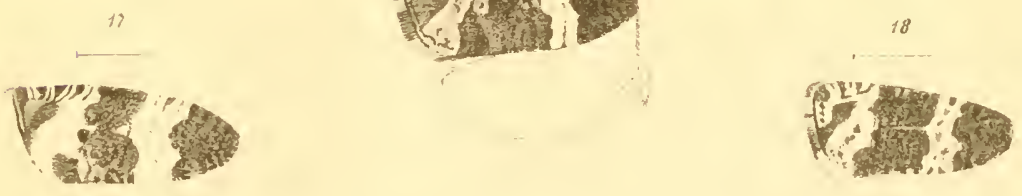

$\therefore 0$
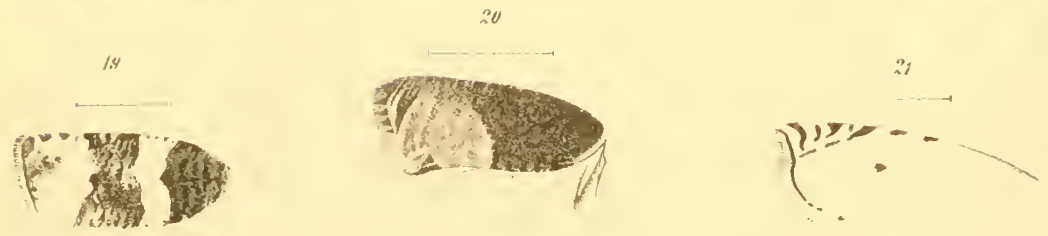


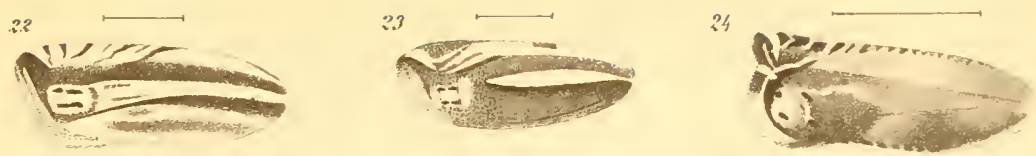

25

36

$? 7$

$1-\longrightarrow$
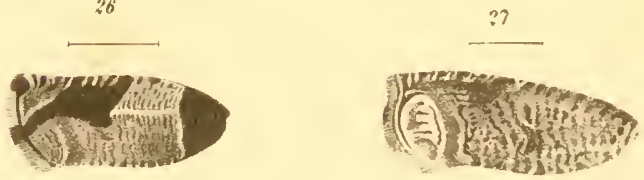

29

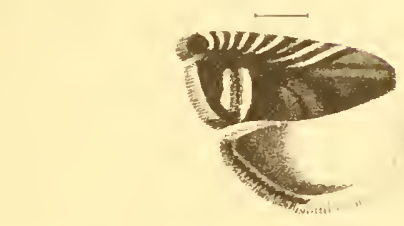

30
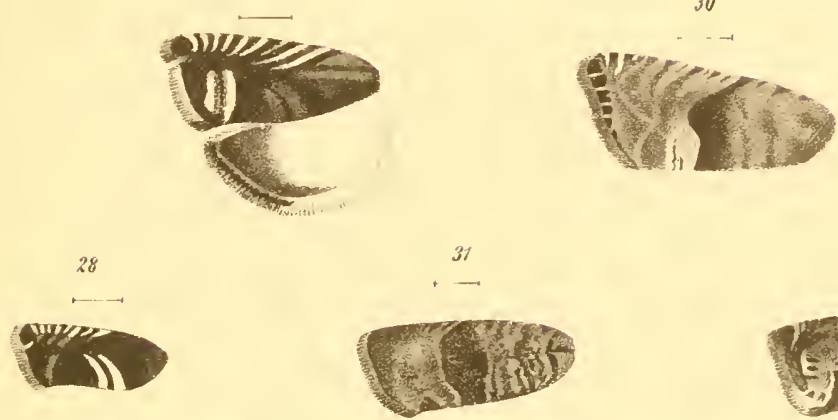

33

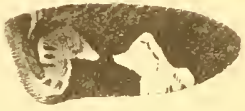

3 ;

(rove
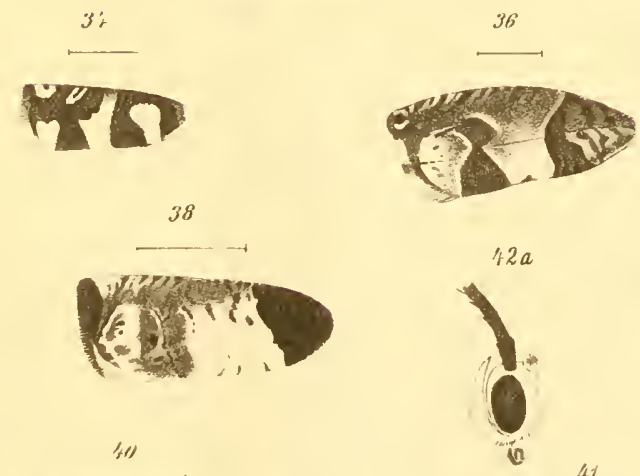

$3 i$
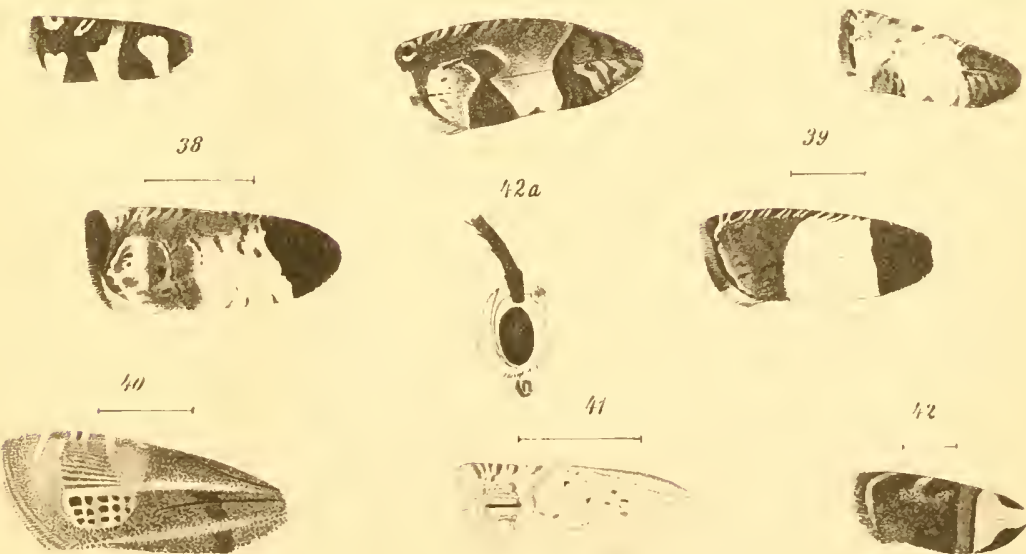

42

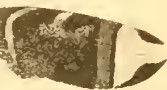




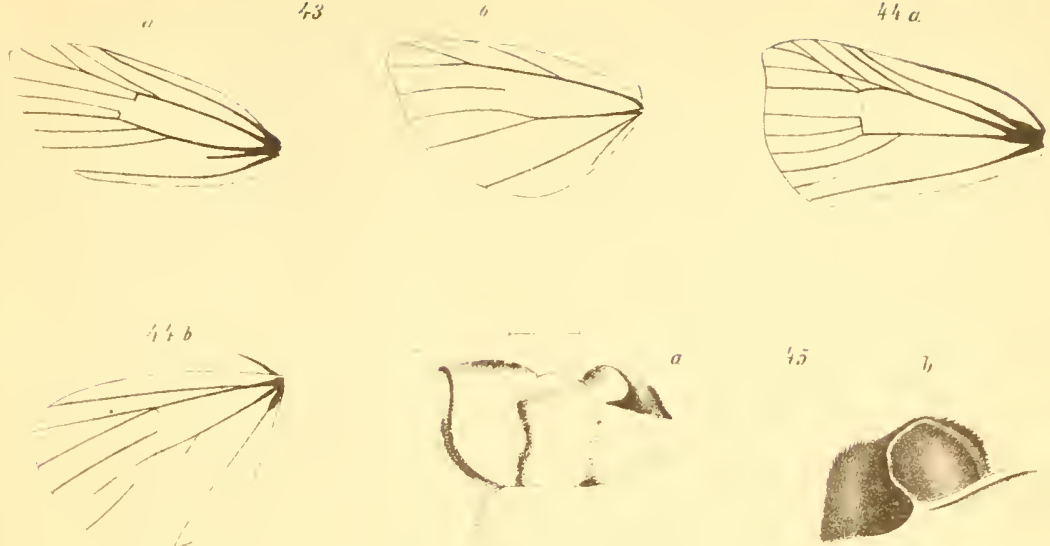

$$
\text { (1.20 }
$$
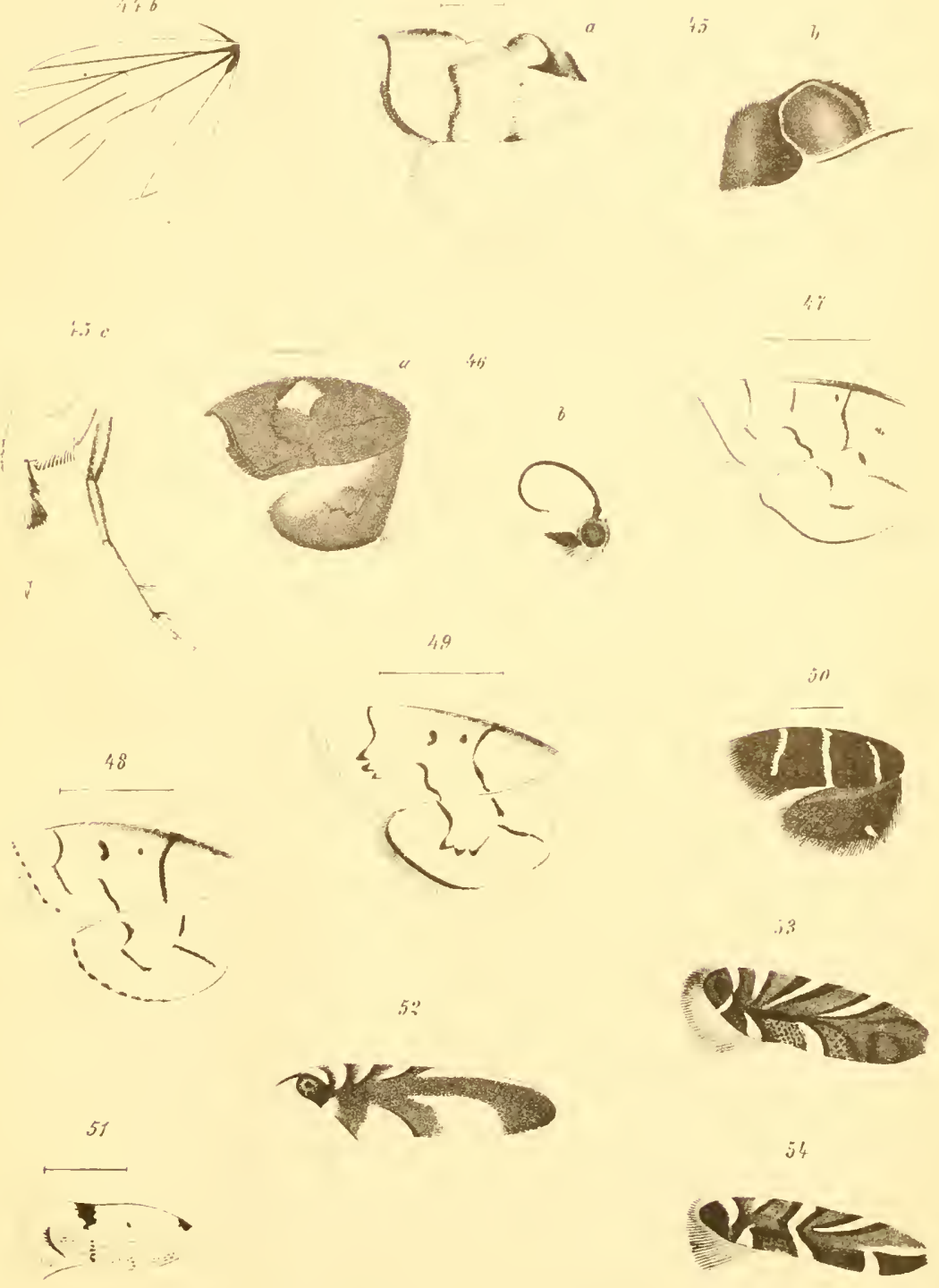







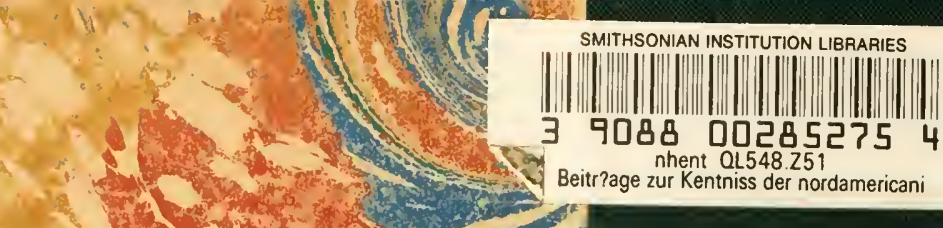

,

to

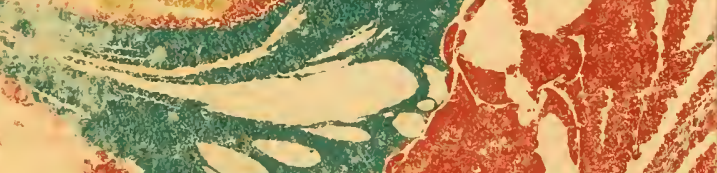

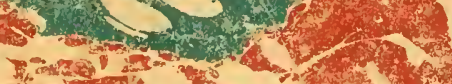

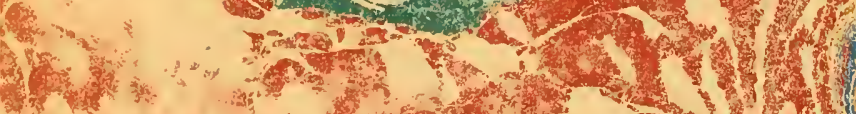

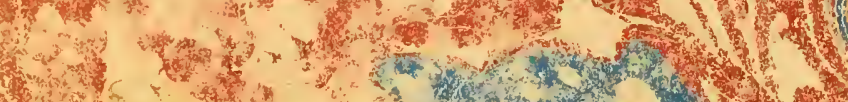
(1)

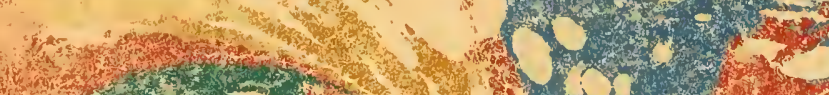
3
$y$

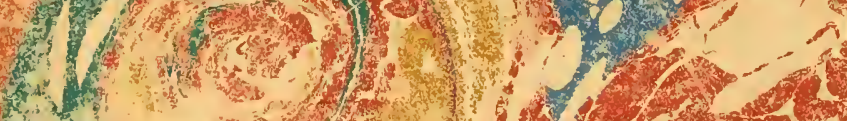

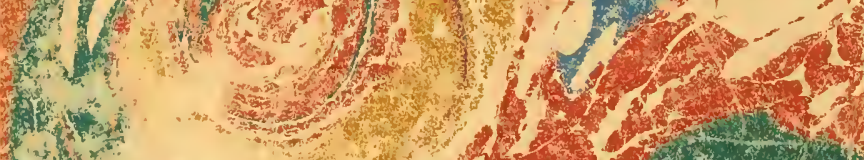

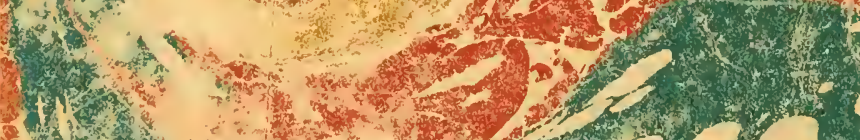

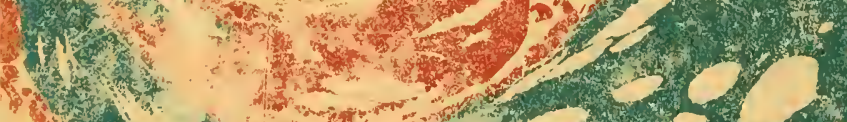
(x)

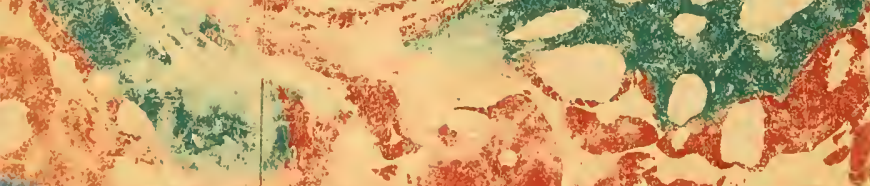
1.6o .

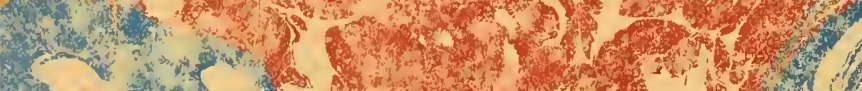

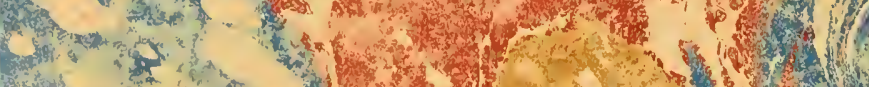
x $(x+5)=5$

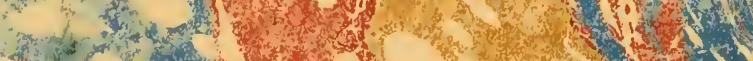

